\title{
Archeological Testing at 41TR170, along the Clear Fork of the Trinity River, Tarrant County, Texas
}

Christopher Lintz

Texas State University

Stephen A. Hall

Timothy G. Baugh

Tiffany Osburn

Follow this and additional works at: https://scholarworks.sfasu.edu/ita

Part of the American Material Culture Commons, Archaeological Anthropology Commons, Environmental Studies Commons, Other American Studies Commons, Other Arts and Humanities Commons, Other History of Art, Architecture, and Archaeology Commons, and the United States History Commons

Tell us how this article helped you.

This Article is brought to you for free and open access by the Center for Regional Heritage Research at SFA ScholarWorks. It has been accepted for inclusion in Index of Texas Archaeology: Open Access Gray Literature from the Lone Star State by an authorized editor of SFA ScholarWorks. For more information, please contact cdsscholarworks@sfasu.edu. 


\section{Archeological Testing at 41TR170, along the Clear Fork of the Trinity River, Tarrant County, Texas}

\section{Licensing Statement}

This is a work for hire produced for the Texas Department of Transportation (TxDOT), which owns all rights, title, and interest in and to all data and other information developed for this project under its contract with the report producer. The report may be cited and brief passages from this publication may be reproduced without permission provided that credit is given to TxDOT and the firm that produced it. Permission to reprint an entire chapter, section, figures or tables must be obtained in advance from the Supervisor of the Archeological Studies Branch, Environmental Affairs Division, Texas Department of Transportation, 125 East 11th Street, Austin, Texas, 78701. 


\section{ARCHEOLOGICAL TESTING AT 41TR170, ALONG THE CLEAR FORK OF THE TRINITY RIVER, TARRANT COUNTY, TEXAS}

by

Christopher Lintz

Stephen A. Hall

Timothy G. Baugh

Tiffany Osburn

for

Texas Department of Transportation

Austin, Texas

Texas Antiquities Permit No. 3699

MISCELLANEOUS REPORTS OF INVESTIGATIONS

NUMBER 348

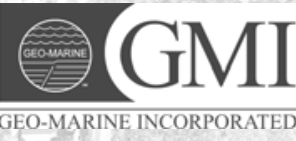

May 2008 



\title{
ARCHEOLOGICAL TESTING AT 41TR170, ALONG THE CLEAR FORK OF THE TRINITY RIVER, TARRANT COUNTY, TEXAS
}

\author{
by \\ Christopher Lintz \\ Stephen A. Hall \\ Timothy G. Baugh \\ Tiffany Osburn \\ Principal Investigator \\ Christopher Lintz \\ for \\ Texas Department of Transportation \\ Environmental Affairs Division \\ 125 E. 11 th Street \\ Austin, Texas 78701 \\ TeXas ANTIQUities PERMit No. 3699 \\ MISCELLANEOUS REPORTS OF INVESTIGATIONS \\ NUMBER 348 \\ Geo-Marine, Inc. \\ $2201 \mathrm{~K}$ Avenue, Suite A2 \\ Plano Texas 75074
}

May 2008 



\section{MANAGEMENT SUMMARY}

Archeologists from Geo-Marine, Inc., were subcontracted through Prewitt and Associates, Inc., of Austin to conduct National Register of Historic Places evaluative testing at archeological site 41TR170, located in Tarrant County, Texas. This work (Geo-Marine project number 30353.06.02) was conducted for the Environmental Affairs Division of the Texas Department of Transportation under contract/work authorization 57524SA006. The archeological remains are located on and in the alluvial terrace of the Clear Fork of the Trinity River, within the proposed 130-meter-wide right-of-way of State Highway 121 in southwestern Fort Worth. The work was conducted to comply with Section 106 of the National Historic Preservation Act of 1969, as amended (Public Law 89-665); the Department of Transportation Act of 1966 (Public Law 89670); and the Antiquities Code of Texas, as incorporated into Title 98, Chapter 191, of the Natural Resources Code of Texas of 1977, as amended. The work was conducted under Texas Antiquities Permit Number 3699 issued by the Texas Historical Commission.

A three-stage field tactic was used during the testing of the site. Stage 1, conducted between March 15 and 29, 2005, consisted of archeological monitoring of the mechanical excavation of 28 backhoe trenches, followed by geomorphological field studies of the trench profiles. Trenches were placed both north and south of a relic channel of the Clear Fork of the Trinity River; the present channel was formed in the late 1960 s by river-straightening channelization efforts. Efforts were made to ensure archeological sampling of all feature- and artifact-bearing areas previously identified in trenches dug during the 2000 archeological survey. The second stage, which occurred between March 21 and April 29, 2005, involved the manual excavation of 10 test units to depths of 2 meters below surface using standard 10-centimeter-thick levels. The purpose of this phase was to assess the reliability of the backhoe trench monitoring activities and to locate occupation zones worthy of further excavations. The third stage of field investigations was conducted between May 2 and June 3, 2005, and consisted of the mechanical stripping of the overburden above target occupation surfaces and the manual excavation of three block excavations, each 9 square meters, to a depth of 40 centimeters below surface. Upon completion of the fieldwork, a fourth stage comprised a limited analysis to document the nature of the recovered assemblage and to make National Register recommendations about the site, and a final stage was to design a plan for further study or analysis that would then be based on the results of an interim report. 
The geomorphic investigations, coupled with the processing of eight radiocarbon dates, ascertained that the upper 2 meters of the Clear Fork sediments date to the past 2,900 years. All trenches contained evidence of the regionally dominant West Fork paleosol that is buried under a thin layer of recent alluvium. Beneath the West Fork paleosol were grayish and yellowish clayey strata, and stringers of pea-sized gravels could be correlated to many of the trenches onsite. The substrate for a series of trenches dug into the south edge of the site encountered cemented gravels that likely date to the Pleistocene age. These gravels extend above the Holocene alluvial sediments onsite and provide some minor relief above the floodplain. Although some bioturbation has blurred boundaries between the West Fork paleosol and more recent sediments, the degree of sediment movement is not as pronounced as observed in many other parts of Texas.

The excavations generally documented a series of low-density, highly stratified occupations that could not be correlated with any great assurance. The site context and integrity of deposits are generally excellent. Nevertheless, the paucity of remains in most areas is generally insufficient to provide data necessary to address many regional research questions. Site 41 TR170 is not unique in this regard, because many sites within the Trinity River basin seem to be short-term specialized logistical extractive activity areas rather than campsites. Two areas of 41TR170, however, seem to be exceptions to low-density, brief occupations and contain a range of features unlike any previously encountered or recorded in the Clear Fork of the Trinity River.

In an area located about 60 meters north of the relic river channel, Block 2 exposed part of a deeply buried (180-220 centimeters below surface) ashy zone with abundant charcoal flecks and burned clay daub that occasionally retained impressions of sticks and small posts. Three burned rock features (small pits, scattered rocks, and rock dump concentrations) were found within this ashy zone, but they were not associated with the genesis of the ash. Bone preservation in this zone was good (numbering 121 specimens), but only one stone tool and four pieces of manufacture/maintenance debris were found. Based on the stratigraphic position and the recovery of one unclassified dart point, this feature is possibly Transitional Archaic in affiliation. Indeed, four radiocarbon dates from two features and the top and bottom of the ashy zone reaffirm that the occupation dates between A.D. 540 and 710 (two sigma dates, tree-ring calibrated), and relates to the Transitional Archaic period. The genesis of the thick ashy zone is problematic and not well understood. The radiocarbon dates suggest that the 40-centimeter-thick ashy zone did not develop instantaneously but rather apparently accumulated over a span of about 180 years (ca. 1,270 and 1,450 years ago). Even though a few rock features and some relatively high density of bone are preserved in this ashy sediment, the low density of remains suggests that the deposit cannot be considered an occupation midden. The age range also suggests that this is not a burned architectural structure. The formation process resulting in a 40-centimeter-thick ashy zone remains unknown.

In an area almost 150 meters south of the relic channel, an extensive area of burned rock covering at least 12-x-12 meters was encountered. Noncontiguous Blocks 1 and 3 were opened to explore the variability of burned rock features and ascertain the kinds of remains present. The recovery of two dart points (a Trinity and a Yarbrough) at comparable depths of 90 to 130 centimeters below surface suggests that this area along the edge of the Pleistocene gravel terrace was repeatedly occupied during the Late Archaic period. Among the burned rock features revealed in Block 3 was one large incipient burned rock oven with a pit measuring 2.54 meters in diameter surrounded by a discard ring of burned rocks that were only some 20 centimeters thick. Another cluster of burned rock more deeply buried in the sediments suggests multiple occupations. In adjacent Block 1 were two smaller (possible) pit ovens about 1 meter in diameter, an elongated 
pile of rock stored for reuse, a few rake-off piles or dumps, and one area of fitted burned rock that might have served as a large griddle-like feature. Tools and chipped stone debris were moderately abundant in Block 1, but rare in Block 3. Bone preservation in this area was very poor, although several hundred fragments of scattered freshwater mussel shell were present. Analysis of shell umbos or hinges indicates that about 59 shells were present in Block 1 and only 50 hinges in Block 3; none were concentrated into discrete discard features. The size, density, and morphological variability of the burned rock features are unlike anything previously seen in the Trinity River basin. Four radiocarbon dates from Blocks 1 and 3 suggest that the series of occupations date between A.D. 540 and 780 (2-sigma dates, tree-ring calibrated). Indeed the radiocarbon dates indicate that the activities resulting in the accumulation of dense burned rock features exposed in Blocks 1 and 3 are culturally contemporaneous with the activities occurring in the thick ashy zone located some 170 to 210 meters apart, even though they undoubtedly represent multiple reuse of the area. The two areas may not have been occupied simultaneously, for the low artifact density suggests that comparable groups of people from the Transitional Archaic period made the distinctly different occupational signatures in the two areas.

The testing phase of work at 41TR170 has documented considerable variability in feature forms during the Transitional Archaic period for the Trinity River basin. Test probes also strongly suggest that many more burned rock features occur parallel to the Pleistocene gravel terrace. In this regard, the testing has not exhausted the information potential related to the spatial patterning in activities by these people. However, the associated stone, shell, and bone artifact assemblages are relatively meager. Similarly, extensive flotation has failed to find any macrobotanical remains other than a single nutshell and small amounts of wood charcoal. Efforts to retrieve lipids samples from the burned rock feature proved to be successful, but the results were not very helpful in providing insight into the diversity of feature activities. Although examination of more burned rock features may stumble on examples of cooking accidents that preserve ancient foodstuff, the current robust level of testing suggests that the information content from the site is relatively limited. For this reason, even though the site is of considerable interest from a regional perspective, the site seemingly does not have the potential to make further contributions to the knowledge of the region. Thus, site 41TR170 fails to meet the standards of Criterion D or any other significance standard required for assessing National Register eligibility. Site 41TR170 is recommended as not eligible for National Register inclusion, and no further archeological investigations are recommended. 



\section{TABLE OF CONTENTS}

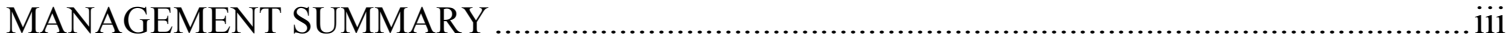

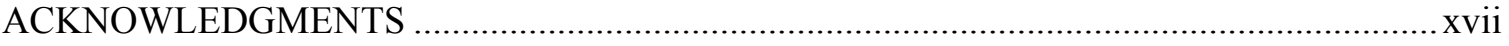

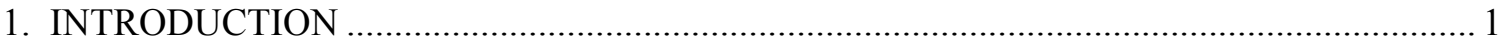

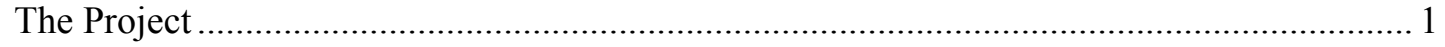

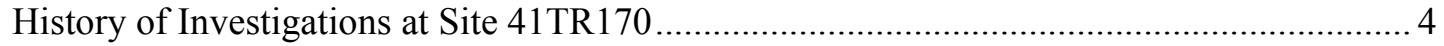

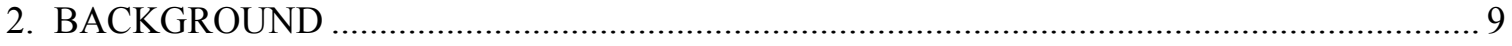

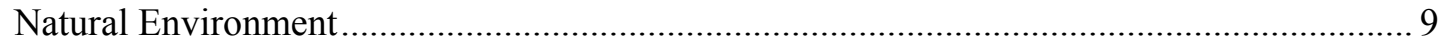

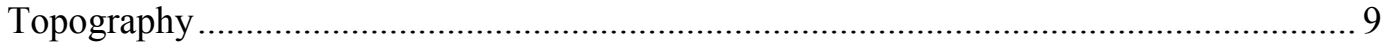

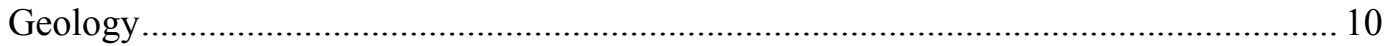

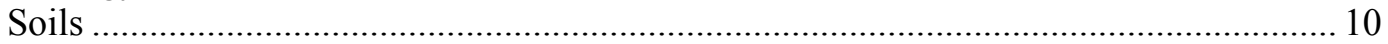

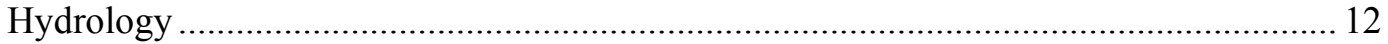

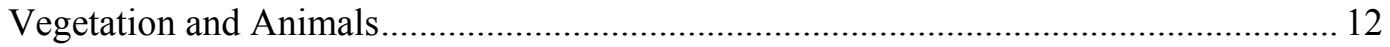

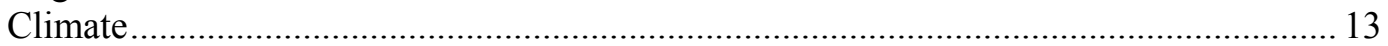

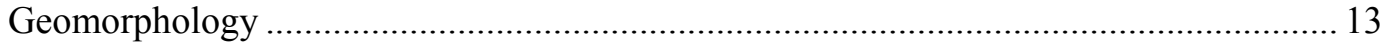

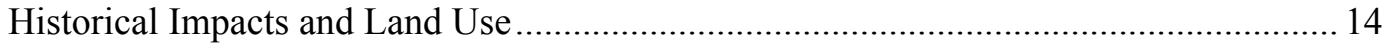

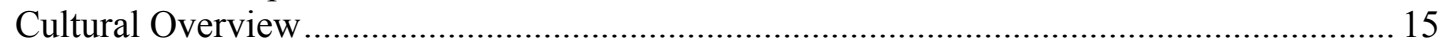

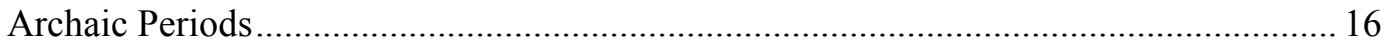

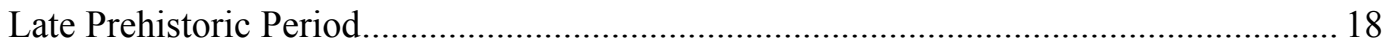

Protohistoric Period and Historic Native American Groups.......................................... 19

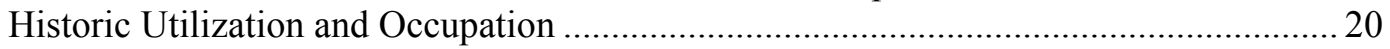

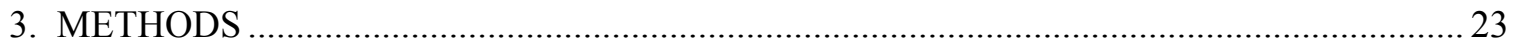

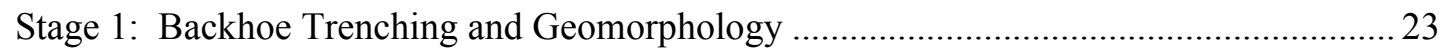

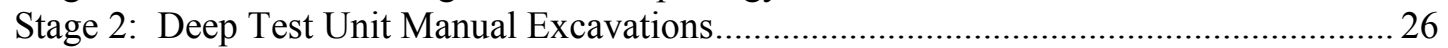

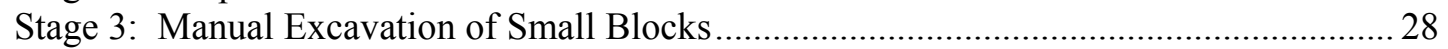

Stage 4: Initial Processing and Preparation of an Interim Report ............................................ 34

Stage 5: Subsequent Processing for the Revised Interim Report ........................................ 35

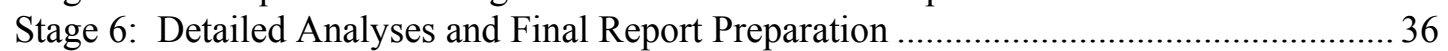

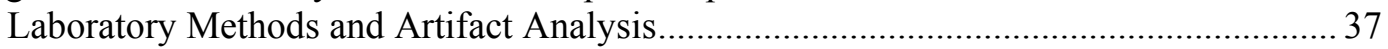

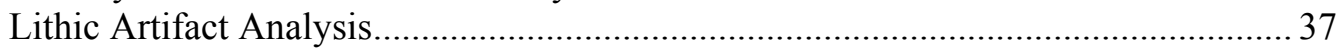

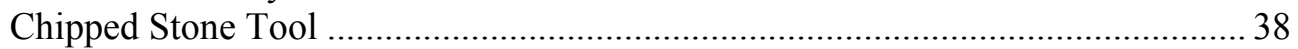


Table of Contents

(cont'd)

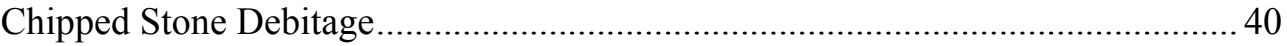

Core

Ground Stone and Cobble Artifact................................................................. 42

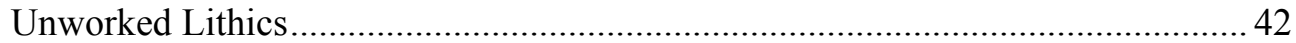

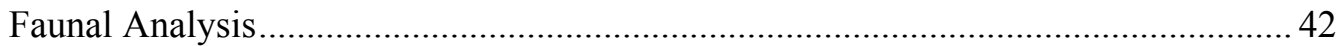

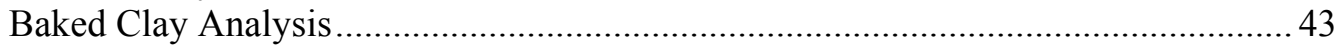

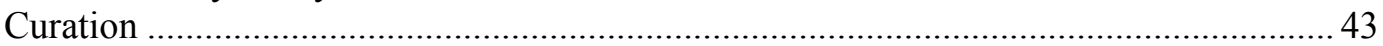

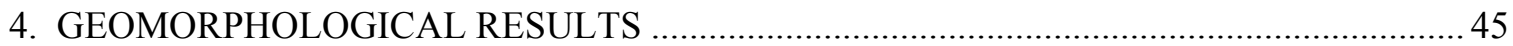

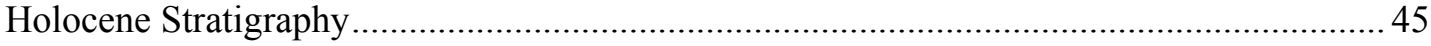

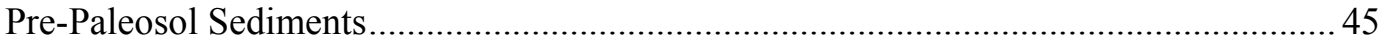

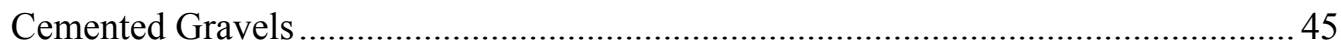

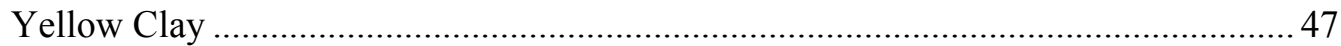

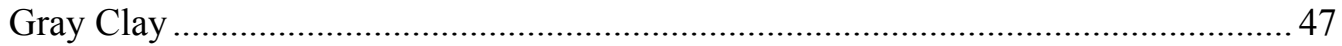

Floodplain Paleo-Topography and Cumulic Soil Development ...................................... 48

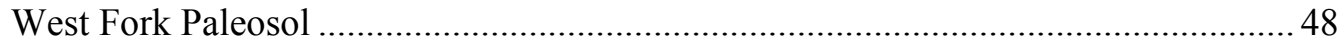

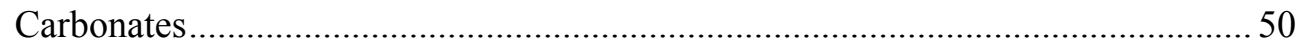

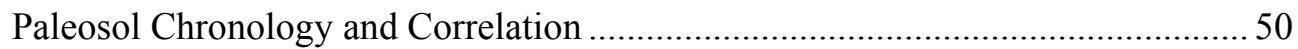

Absence of Evidence for Channel Cutting 1,000 Years Ago....................................... 50

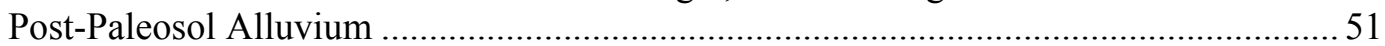

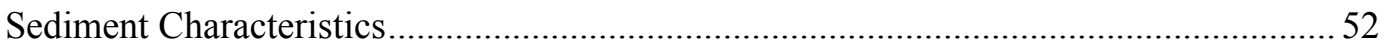

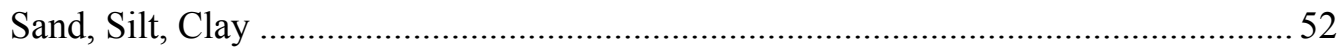

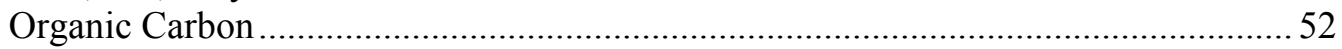

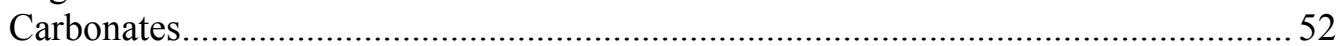

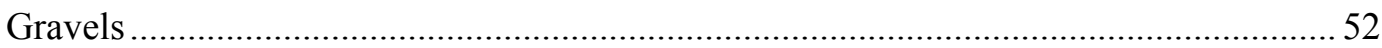

Gravels in the Late Holocene Alluvium................................................................ 52

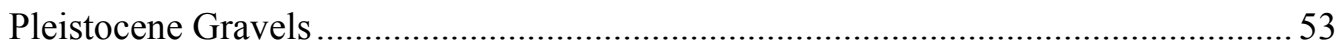

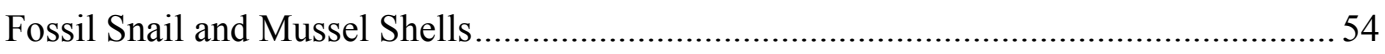

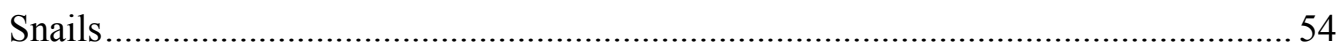

Freshwater Mussel Shells...................................................................................... 55

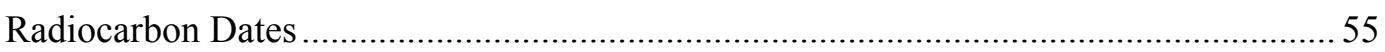

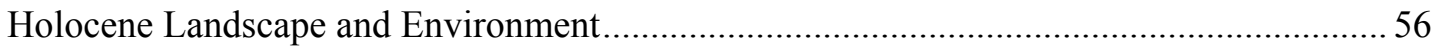

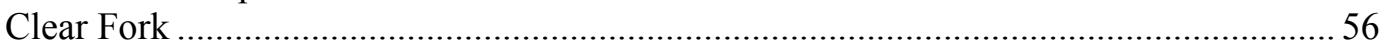

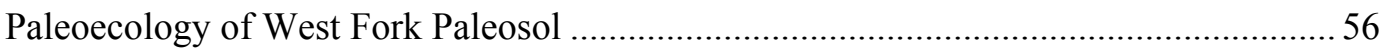

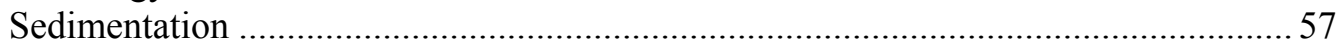

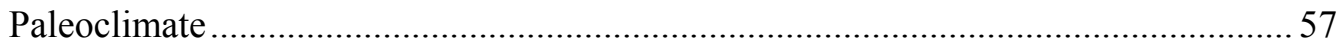

Carbon Isotopes and Late Holocene Vegetation........................................................... 58

Stable Carbon Isotopes and Paleoclimate at Site 41TR170 ...........................................5

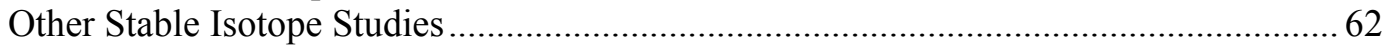

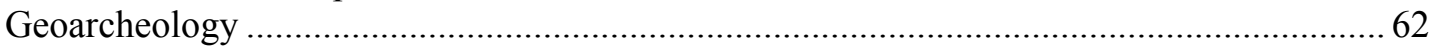

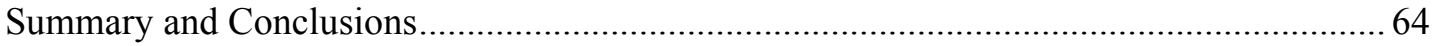


Table of Contents

(cont'd)

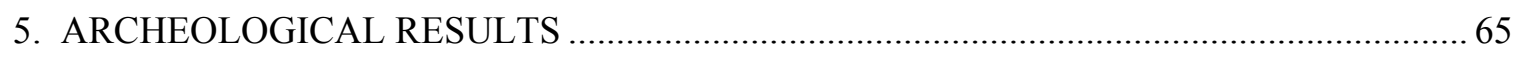

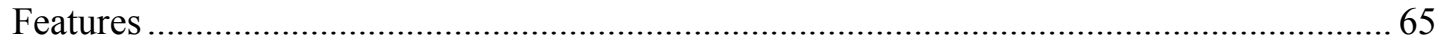

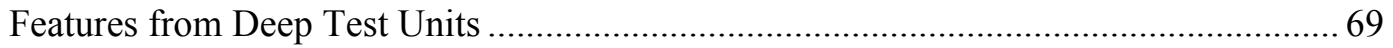

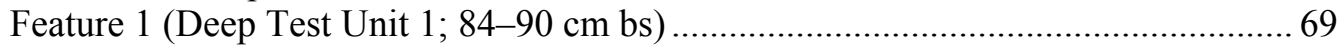

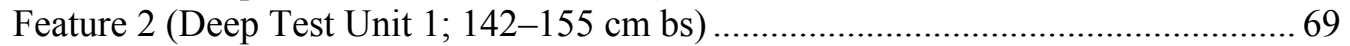

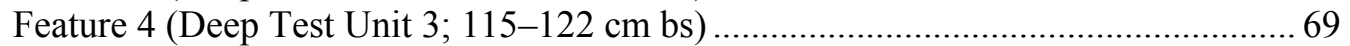

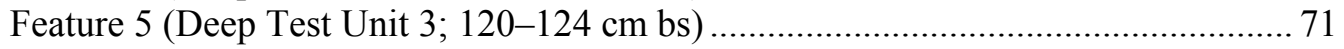

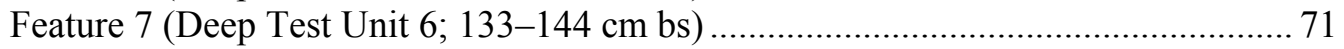

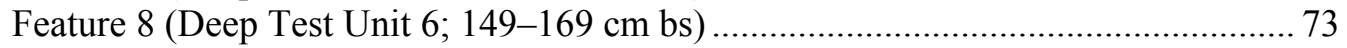

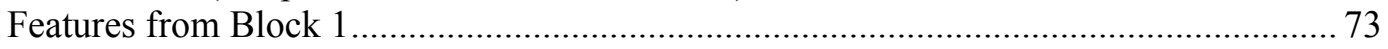

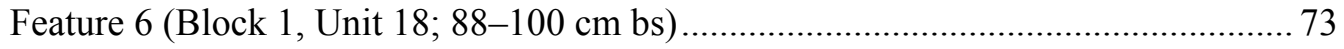

Feature 9 (Block 1, Units 2 and 13; 91-121 cm bs).............................................. 75

Feature 10 (Block 1, Units 12, 15, N19, N29; 88-100 cm bs)................................ 76

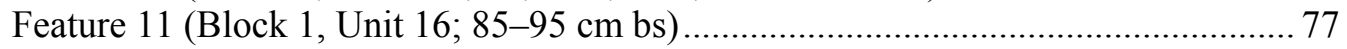

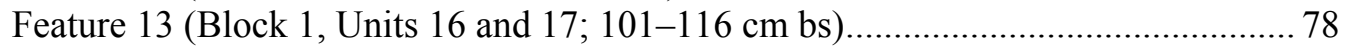

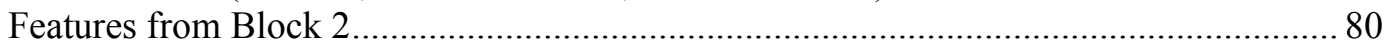

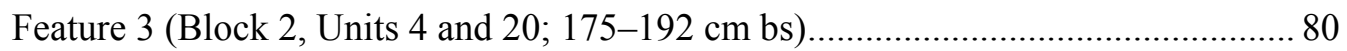

Feature 12 (Block 2, Unit 20; 182-198 cm bs) ....................................................... 81

Feature 20 (Block 2, Units 21, 22, 24, and 25; 196-204 cm bs)............................ 83

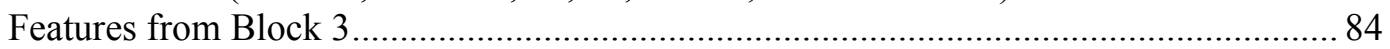

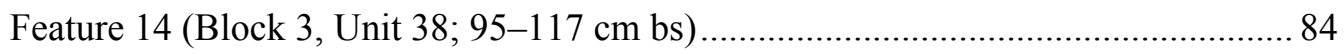

Feature 15 (Block 3, Units 33 and 38; 93-119 cm bs).......................................... 85

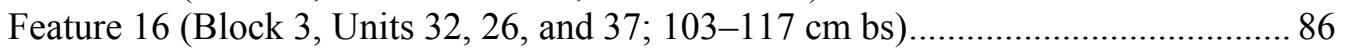

Feature 17 (Block 3, Units 34, 35, S30, S31, SW36, and W37; 108-129 cm bs) ....... 88

Feature 18 (Block 3, Units 30 and 38; 117-128 cm bs)....................................... 90

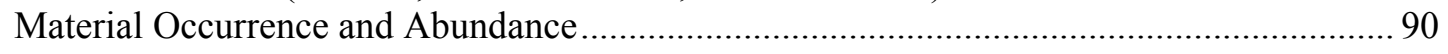

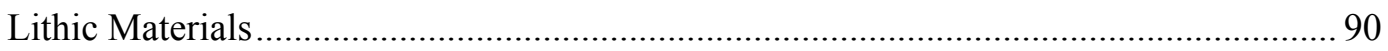

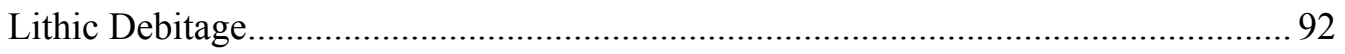

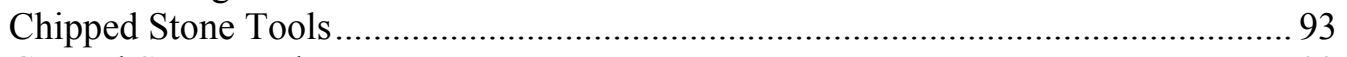

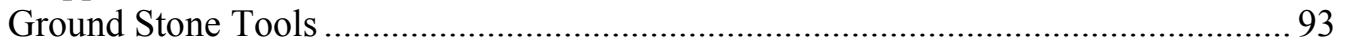

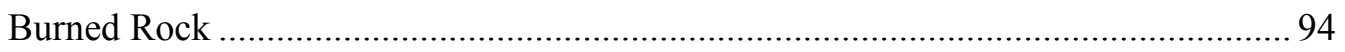

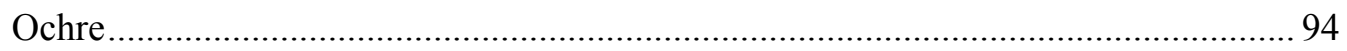

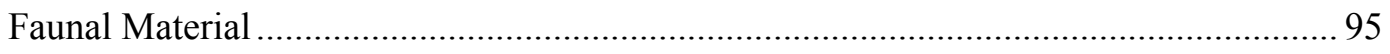

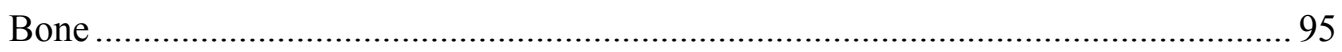

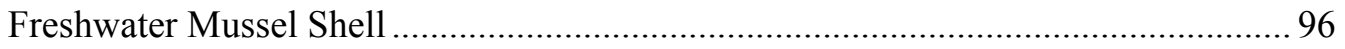

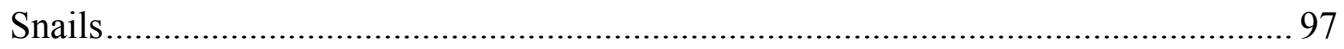

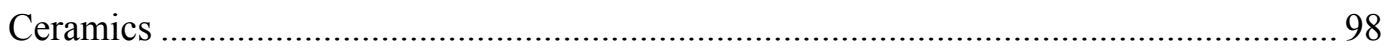

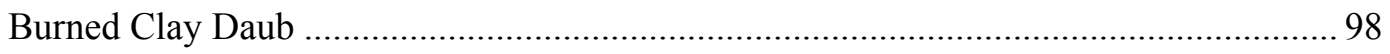

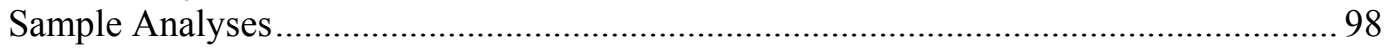

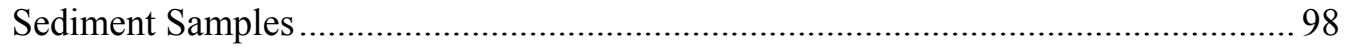

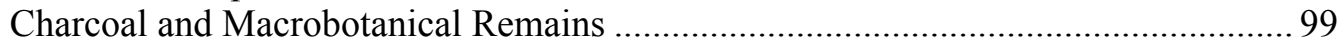

Radiocarbon Results from Cultural Contexts ............................................................ 99 
Table of Contents

(cont'd)

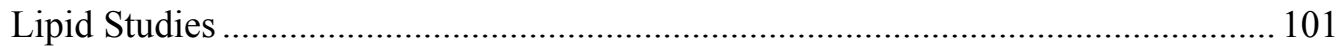

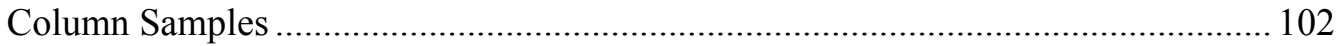

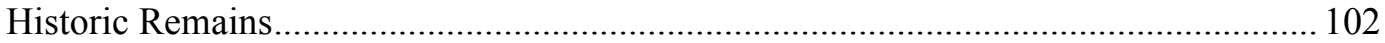

Material Distribution and Results from Trench Monitoring and Deep Test Units............... 103

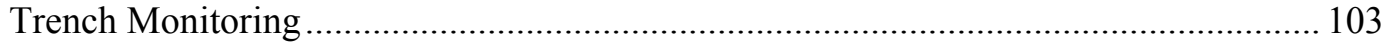

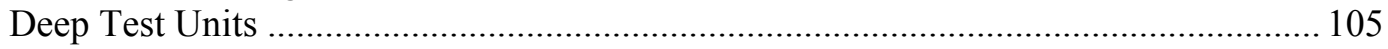

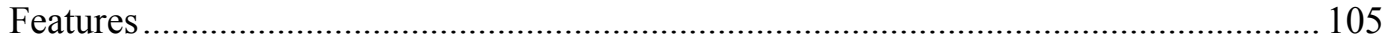

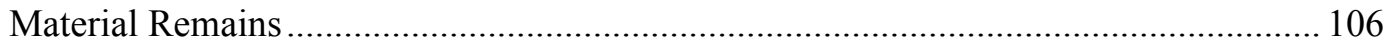

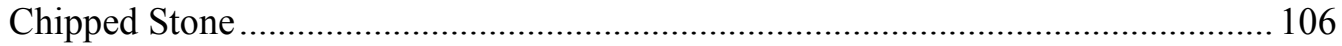

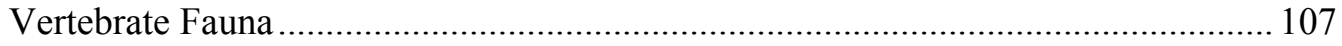

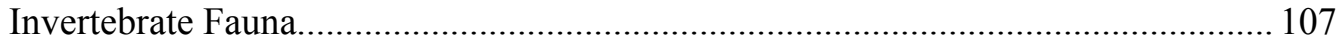

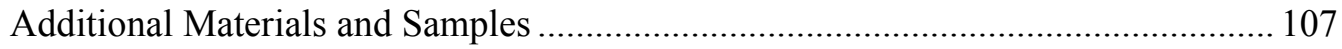

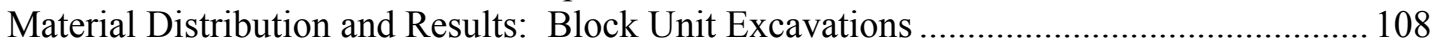

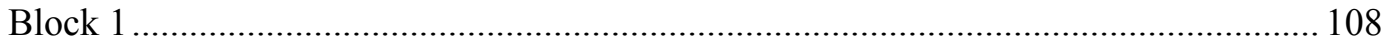

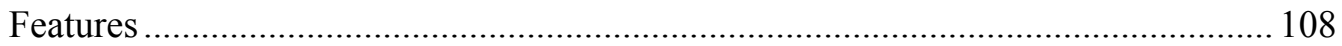

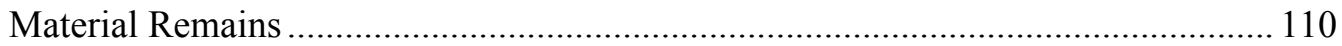

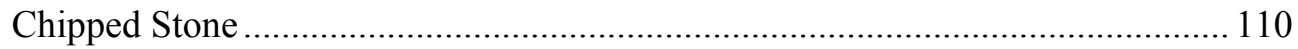

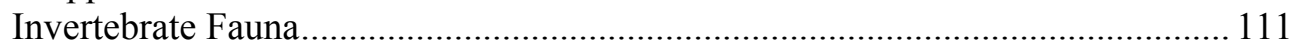

Additional Materials and Samples .............................................................. 112

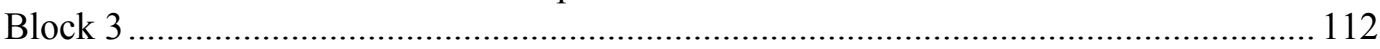

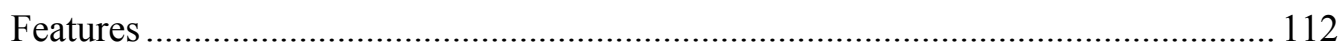

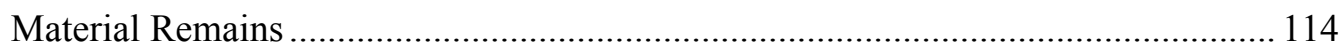

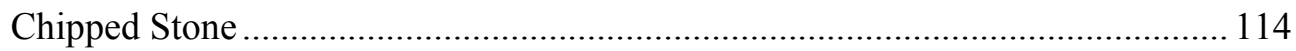

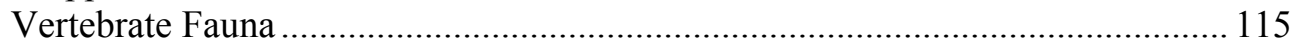

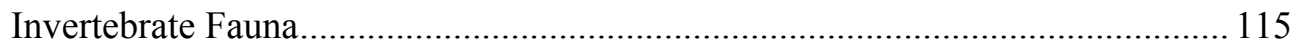

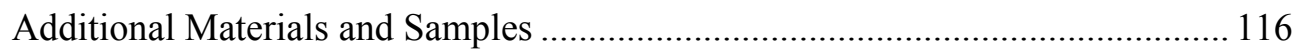

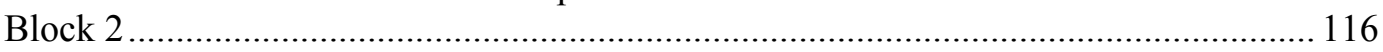

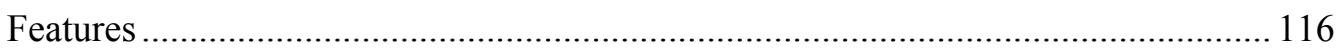

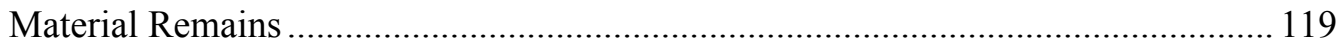

Chipped Stone

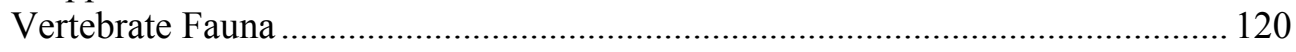

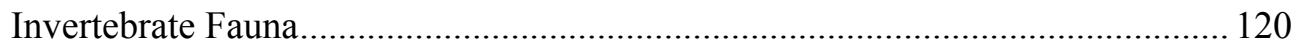

Additional Materials and Samples ................................................................. 120

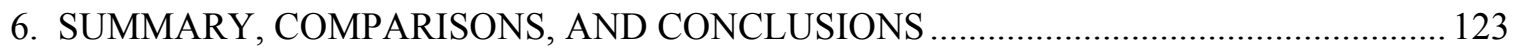

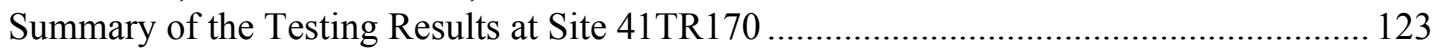

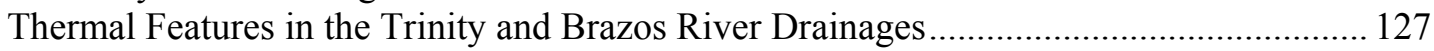

Distribution of Burned-Rock-Feature Sites in Northcentral Texas................................. 127

A Review of Trinity River Archeology Overview Studies .......................................... 129

A Review of Texas Burned-Rock-Midden Distribution Overviews ................................ 132

A Review of Thermal Features in the Texas Archeological Sites Atlas Database ......... 133

Summary of Burned Rock Feature Distributions......................................................... 138 
Table of Contents

(cont'd)

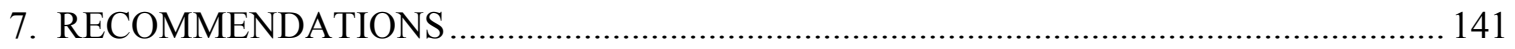

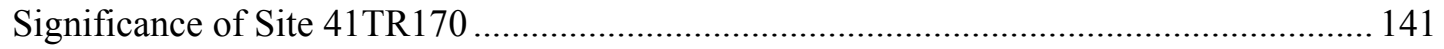

Potential for Site 41TR170 to Address Regional Research Domains ................................... 143

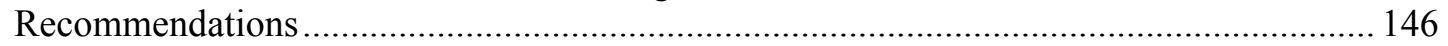

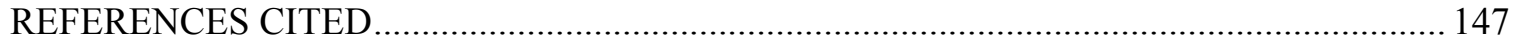

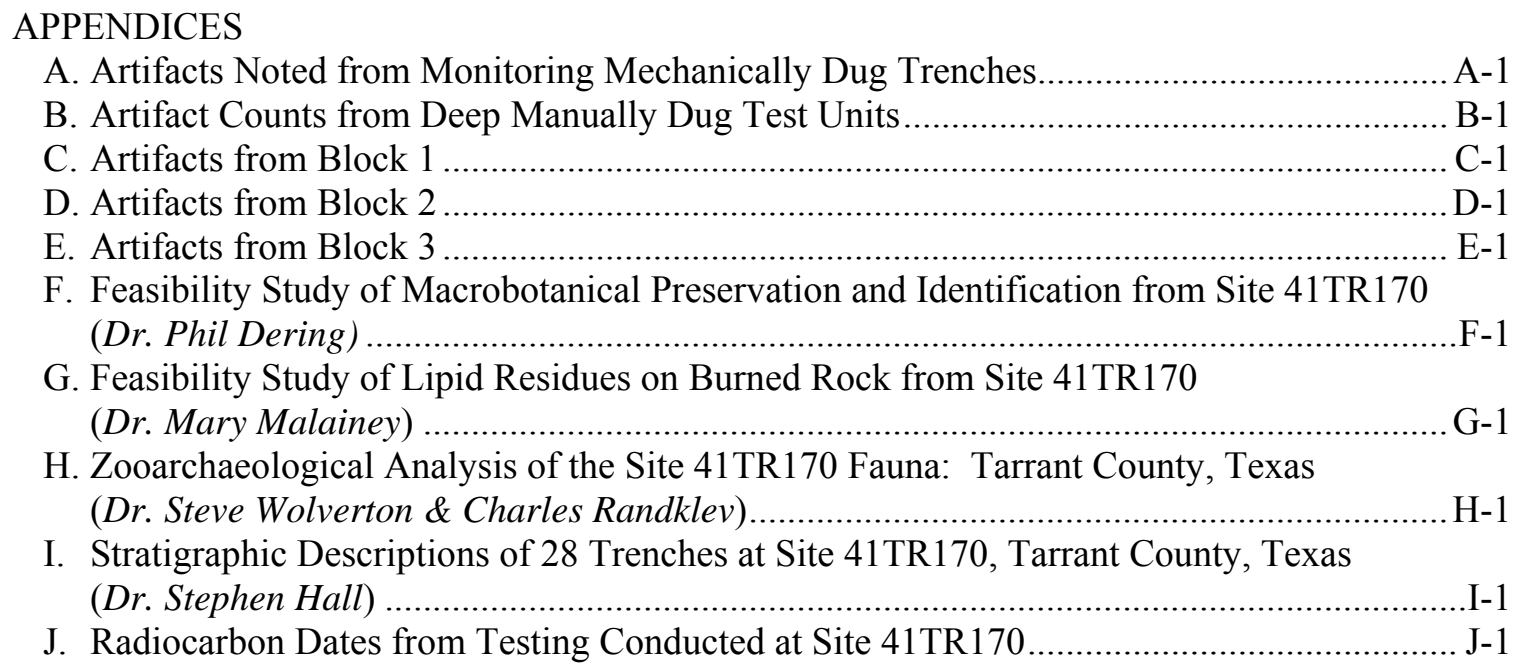





\section{LIST OF FIGURES}

1. General location of site 41TR170 near Fort Worth, Tarrant County, Texas ............................ 2

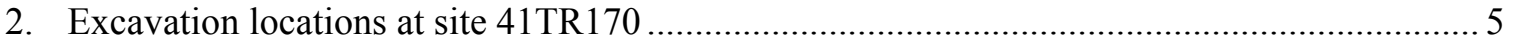

3. Soils map of the Clear Fork of the Trinity River floodplain at site 41TR170 ...................... 11

4. Distribution of burned rocks around Block 1 as determined by probes ................................... 30

5. Spatial relationship of Blocks 1 and 3 at the south end of site 41TR170 ............................. 31

6. Schematic showing test unit designations within Blocks 1, 2, and 3 at site 41TR170........... 32

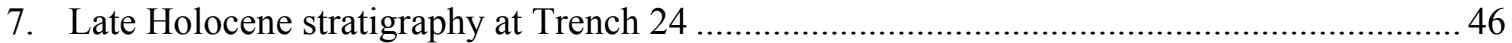

8. Correlation of stratigraphic sections with radiocarbon ages, site 41TR170 …....................... 48

9. Gradational contact between West Fork paleosol and overlying post-paleosol alluvium ........51

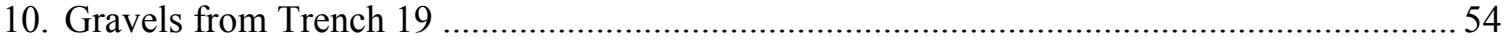

11. Cross section of the Clear Fork channel and floodplain at site 41TR170 prior to

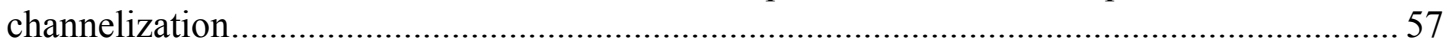

12. Distribution of $\delta^{13} \mathrm{C}$ values from late Holocene Clear Fork alluvium at site 41TR170.......... 59

13. Stratigraphic sequence of carbon isotopes in late Holocene alluvium at site 41TR170......... 61

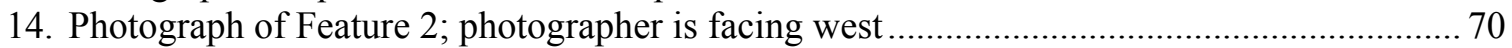

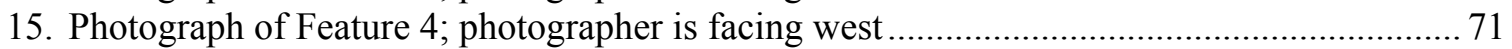

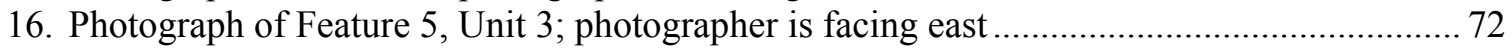

17. Photograph of Feature 7, Unit 6; photographer is facing west ............................................. 72

18. Photograph of Feature 8 in Unit 6; photographer is facing west ......................................... 74

19. Photograph of Features 6, 9, and 10 in Block 1; photographer is facing west ........................ 74

20. Photograph of Feature 11, Unit 16; photographer is facing east ........................................... 77

21. Photograph of Feature 13, Block 1; photographer is facing west .......................................... 78

22. Photograph of Feature 3, Block 2; photographer is facing south ......................................... 80

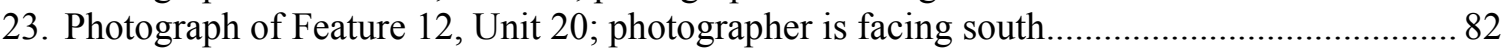

24. Photograph of Feature 20, Block 2; photographer is facing north ...................................... 83

25. Photograph of Feature 14, Unit 38; photographer is facing west .......................................... 85

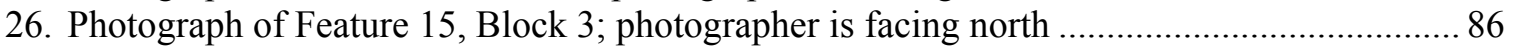

27. Photograph of Feature 16, Block 3; photographer is facing east............................................. 87

28. Photograph of Feature 17, Block 3; photographer is facing east............................................ 89

29. Photograph of Feature 18, Block 3; photographer is facing south ....................................... 91

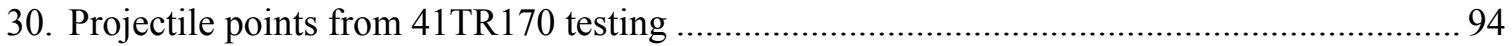

31. The relationship between fragment weight and NSP:NISP for sites in Texas ....................... 96 


\section{List of Figures}

(cont'd)

32. Distribution of features at Block 1

109

33. Pie chart depicting the proportion of chipped stone debitage classes identified in Block 1.. 111

34. Distribution of features at Block 3 113

35. Pie chart depicting the proportion of chipped stone debitage classes identified in Block 3.. 115

36. Distribution of features at Block 2 118

37. The distribution of scatter, small hearths, and ovens in counties near site 41TR170. 


\section{LIST OF TABLES}

1. Chronological Framework for the Upper Trinity River Basin ............................................ 16

2. Locations of Backhoe Trenches and Nonblock Test Units at Site 41TR170 ........................24

3. Test Units and Features Comprising Excavation Blocks 1, 2, and 3 at Site $41 \mathrm{TR} 170$........... 33

4. Sediment Data from Site 41TR170, Clear Fork of the Trinity River Floodplain, Tarrant County, Texas.

5. Radiocarbon Ages from Geomorphic Settings along the Clear Fork of the Trinity River, Site 41TR170, Tarrant County, Texas

6. Carbon and Nitrogen Isotope Values from Late Holocene Alluvium Including the West Fork Paleosol at Site 41TR170, Clear Fork of the Trinity River, Tarrant County, Texas

7. Features in Relation to Test Units, Trenches, and Blocks at Site 41TR170..........................66

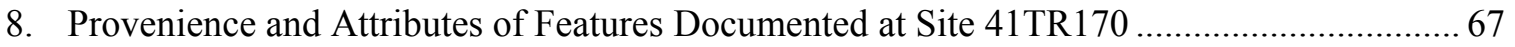

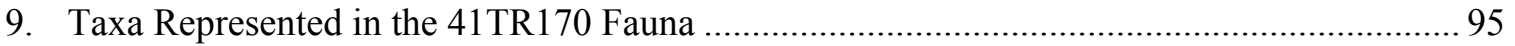

10. Faunal Fragmentation Data for Texas Sites, Including 41TR170 …................................... 97

11. Radiocarbon Ages from Feature Contexts at Site 41TR170, Tarrant County, Texas ........... 100

12. Artifacts Noted During Monitoring Mechanical Excavations of Trenches at 41TR170 ....... 104

13. Distribution of Chipped Stone Debitage Classes Recovered from Test Units ....................... 106

14. Representation of Invertebrate Fauna Recovered from Trenches and Deep Test Units........ 107

15. Distribution of Size and Cortex Among Biface Thinning Flakes and Core Flakes in

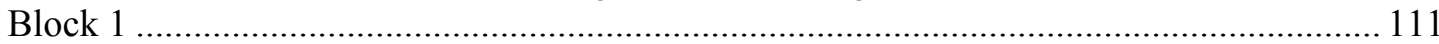

16. Representation of Invertebrate Fauna Recovered from Block 1 ........................................... 112

17. Representation of Invertebrate Fauna Recovered from Block 3 ......................................... 116

18. Representation of Invertebrate Fauna Recovered from Block 2 ....................................... 121

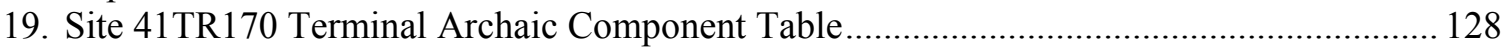

20. Frequency of Thermal Features for 15 Counties in Northcentral Texas Based on 1981 Data

21. Sites within 80-km Target Search Area, Their Drainage Basin, and Number of Recorded Sites...

22. Distribution of Thermal Feature Types by Drainage Basin

23. Data Sets Available to Address Research Design Issues 144 



\section{ACKNOWLEDGMENTS}

The authors would like to thank the following individuals for their involvement on this project. Foremost, the landowners, especially Mr. Scott Walker of Edwards Geren Limited, and the tenant, Mr. Tom Blackmon, helped in gaining access to the property and allowed the influx of strangers on their lands while they were running cattle and other concerns on the land. Thanks go to Dr. G. Lain Ellis, Dr. John Arnn, Dr. James Abbott, and Mr. Dennis Price of the Texas Department of Transportation, Environmental Affairs Division, and to Mr. Robert Hall, Environmental Coordinator for the Fort Worth District Office of the Texas Department of Transportation.

Dr. Stephen Hall conducted the geoarcheological studies on this project. Dr. Steve Wolverton conducted faunal analysis for the project. The archeological field crew was directed by Dr. Timothy G. Baugh and Mr. Caleb Johnson. The success of the project is due to their diligence in controlling the paperwork and making the moment-to-moment field decisions, addressing specific issues as necessary. The field crew consisted of Mr. Tom Collinwood, Mr. Adam Graves, Mr. Chris Kugler, Mr. Selwyn J. Nash, Ms. Lisa Shaddox, Mr. Mike Shannon, Mr. Nash Sherrod, and Ms. Fiona Vasbinder-Pemberton. Laboratory support was provided by Mr. Steven Hunt, director, and Mr. Michael Breneman, Mr. Jeff Cumonow, and Ms. Donna DeYoung. Ms. Michelle Wurtz and Mr. Jason Lyon provided graphic support. The report was edited by Ms. Sharlene Allday and produced by Ms. Denise Pemberton. 



\section{CHAPTER 1 INTRODUCTION}

\section{THE PROJECT}

On February 4, 2005, archeologists from Geo-Marine, Inc. (GMI), were subcontracted through Prewitt and Associates, Inc., of Austin to conduct National Register evaluative testing at archeological site 41TR170 in Tarrant County, Texas. This work (GMI project number 30353.06.02) was conducted for the Texas Department of Transportation (TxDOT) Environmental Affairs Division (ENV) under contract/work authorization 57524SA006. The archeological remains are located on and in the alluvial terrace of the Clear Fork of the Trinity River, within the proposed right-of-way (ROW) of State Highway (SH) 121 in southwestern Fort Worth (Figure 1). SH 121 is sponsored by the Fort Worth District of TxDOT, and cultural resources testing is required to comply with Section 106 of the National Historic Preservation Act (NHPA) of 1969, as amended (Public Law [PL] 89-665), the Department of Transportation Act of 1966 (P.L. 89-670), and the Antiquities Code of Texas, as incorporated into Title 98, Chapter 191, of the Natural Resources Code of Texas of 1977, as amended.

The project was conceived by TxDOT ENV staff to secure information about the alluvial depositional history and prehistoric cultural history of the site by examining its geomorphology, archeological content, and artifact and feature abundance and diversity. Through these means, an evaluation could be made regarding National Register of Historic Places (NRHP) eligibility of the site by assessing whether it contains the information potential to contribute significantly to local, regional, or national research issues. If information derived from artifacts, features, and other forms of material remains were regarded as significant, additional investigations must be undertaken to mitigate the effects of road construction on the cultural resources before the site is adversely affected. If no significant data were recovered, then the site would be considered not eligible for NRHP inclusion, and the proposed highway development could proceed without further cultural resources concerns.

Insofar as archeology is a discovery process, TxDOT ENV prefers to contract testing and data recovery investigations in three distinct phases: (1) development of the scope, budgets, and permits for the fieldwork portion of the project, (2) implementation of field excavations and development of an interim report and analysis plan, and (3) preparation of a detailed analysis and final report. This tactic is used to evaluate the artifact returns and allow the contract archeologists 


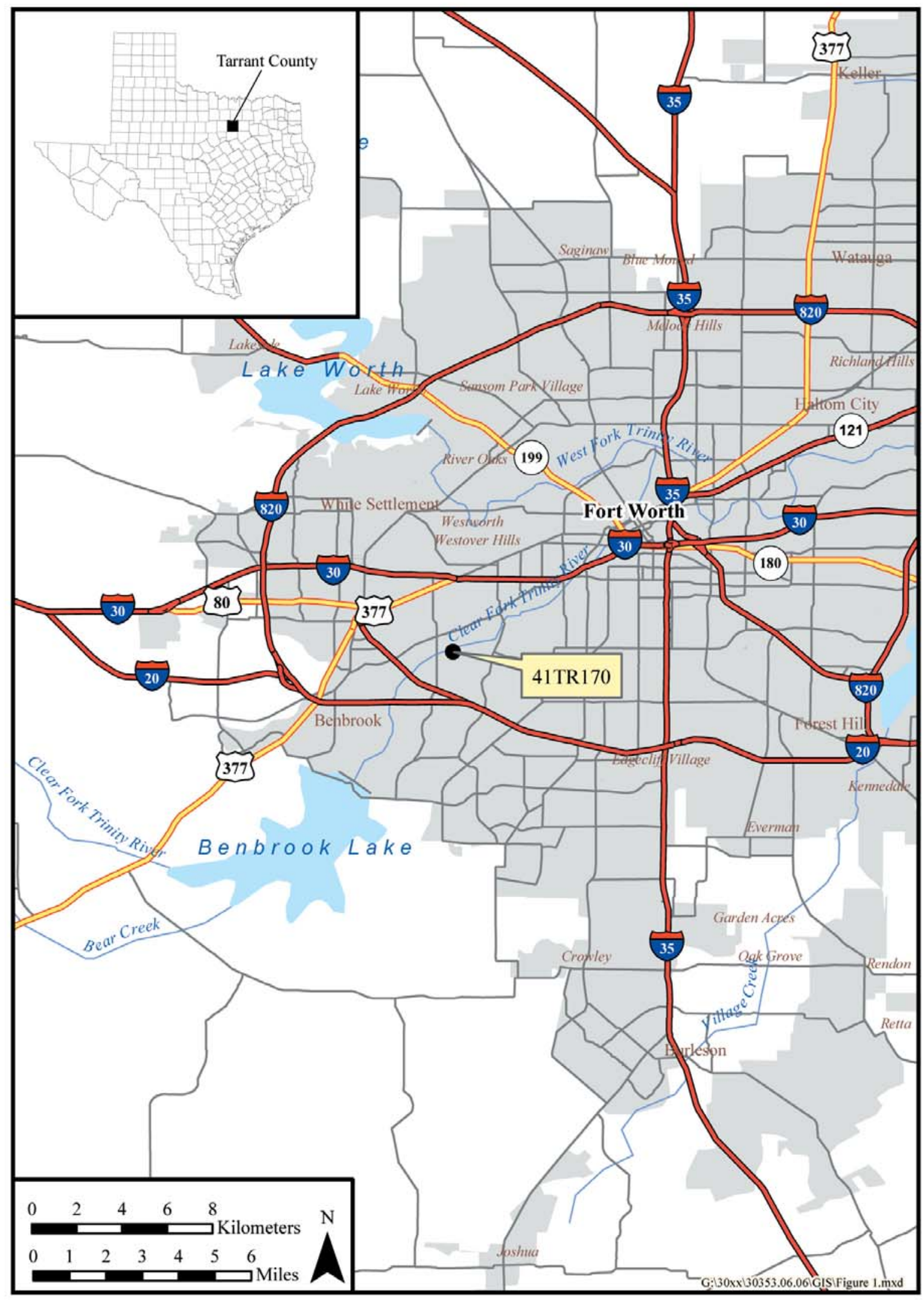

Figure 1. General location of site 41TR170 near Fort Worth, Tarrant County, Texas. 
to focus studies on the range of materials actually recovered from the site, rather than being based on optimistic expectations developed before the beginning of excavations. Initially, the portion of site 41TR170 within the proposed TxDOT ROW was thought to be about 7 acres in size; however, further examination of the aerial photographs ascertained that the site occurred within an 11.5-acre area. Accordingly, the stipulated level of effort at the site was expressed as a range in the numbers of backhoe trenches, test units, and block excavations. The field project archeologists were given latitude to use field judgment to determine the appropriate point for terminating the testing phase within the stipulated range of units placed, provided that the areas were adequately covered and afforded a true assessment of the site.

The first phase of the project was conducted between February 4 and March 11 and consisted of converting the contractual scope of work into a project scope, developing the field and interim report budgets, coordinating with Native American groups, and applying for the Texas Historical Commission permit. These efforts led to the issuance of Texas Antiquities Permit Number 3699 for conducting the testing phase investigations at site 41TR170.

The second phase of the testing project, as conceived by TxDOT ENV, consisted of three stages of fieldwork and the development of an interim report. Stage 1 called for the excavation of between 21 and 35 backhoe trenches and the description and interpretation of the sediments in each trench by a professional geomorphologist. Archeologists monitored the mechanical excavations of 28 trench holes and examined the corresponding backdirt, recording the presence of artifacts and bone/shell ecofacts for each mechanically dug trench. The geomorphologist described the trench profiles and collected samples for dating and sediment characterization. This fieldwork stage was conducted between March 15 and 29, 2005.

Stage 2 also called for 10 to 17 test units, placed adjacent to backhoe trenches, to be manually excavated in levels of 10 centimeters $(\mathrm{cm})$ to depths of 2 meters $(\mathrm{m})$ below surface $(\mathrm{bs})$. These units were a means of assessing the accuracy of the archeological monitoring of the mechanical trench excavations and of obtaining data on the depth, occurrence, and abundance of archeological remains. Most test units were required to be placed adjacent to positive trenches, but a few must also be next to negative trenches to test the reliability of trench monitoring. A total of 10 test units was excavated: nine next to trenches with positive artifact remains and one, Unit 9, next to a trench without artifacts (Figure 2). Fieldwork for these investigations of 10 test units took place between March 21 and April 29, 2005.

Stage 3 required the examination of between three and five targeted occupation zones, the mechanical stripping of overburden, and the manual excavation of nine adjacent square meters in each block to a depth of approximately $40 \mathrm{~cm}$. The purpose of this stage was to examine the occurrence of features and the density/diversity of archeological remains preserved in the site in order to assess the integrity and information content from specific components. Excavators examined three excavation blocks ranging from 90 to $180 \mathrm{~cm}$ bs during the period of May 2 to June 3, 2005.

An interim report provided an overview of the background, methods, and fieldwork, as well as an initial description of the features and preliminary tabulations and distributions of the recovered archeological remains. Subsequent sections evaluated the information content and made recommendations as to the kinds of analyses and specialized studies performed to understand the results of the testing phase. A recommendation of the NRHP eligibility of site 41TR170 was presented, justified by the kinds of information that could be extracted from this location to better understand the sites in the region. Appendices provided data for materials and samples collected from the testing phase of the project. 
Due to the nature and diversity of the many burned rock features found on the site, the initial interim report stipulated that the site was being recommended as eligible for the NRHP and that further excavations would be prudent to salvage more data from the feature areas. A TxDOT ENV review of the initial interim report determined that insufficient information about the features was developed and that some additional processing of the site information was needed before a concurrence decision could be made about the contractor's recommendation. The requested additional information included (1) the processing of a series of feature matrix flotation samples in order to extract macrobotanical preservation data, (2) the radiocarbon dating of these macrobotanical remains from several features to understand the age and chronology of the cultural occupations, (3) the processing of some of the feature burned rocks to ascertain the condition of prehistoric lipid remains, and (4) refinements in the counts of shells and bones to ascertain the minimum number of individuals, rather than the count of fragmentary specimens. In addition, TxDOT ENV requested that a regional overview of burned rock features be developed for portions of the Trinity and Brazos river basins so that the contextual uniqueness of these kinds of burned rock features could be interpreted. Information from these new kinds of data was also to be integrated into the recommendation and summary portions of this current report.

\section{HISTORY OF INVESTIGATIONS AT SITE $41 T R 170$}

Site 41TR170 was discovered in 2000 as one of two sites found during the surface and subsurface survey of the proposed SH 121 across the Clear Fork of the Trinity River floodplain (Seibel et al. 2000:43). The second site, 41TR171, is along a T-2 terrace remnant on the north edge of the Clear Fork floodplain and represents the remains of a historic ranch complex that contains mixed historic and modern materials, but lacked integrity; it was recommended as not eligible for the NRHP or for Texas State Archeological Landmark (SAL) designation.

During the initial survey, archeologists from Hicks and Company dug a total of 37 shovel tests and 17 backhoe trenches at 41TR170 along both sides of a natural meander channel of the Clear Fork that was bypassed by the historically dug channelization process. During the survey phase, numerous shovel tests were dug to depths of $100 \mathrm{~cm} \mathrm{bs}$, but at least one shovel test yielded burned rock at a depth of $130 \mathrm{~cm}$ bs. The 37 shovel tests recovered at least 24 pieces of burned rock, two flakes, 10 freshwater mussel shell fragments, five lots of charcoal, and one bone fragment, and identified three rock features (Features 4, 7, and 8).

Most of the 17 survey phase backhoe trenches were dug to depths of 190 to $200 \mathrm{~cm}$ bs, but two trenches recovered burned rocks from depths of 250 and $280 \mathrm{~cm}$ bs. These trenches recorded 26 lots of burned rock, six flakes, 22 lots of freshwater mussel shell (one lot had 35 shells with umbos and likely was a feature), 10 lots of charcoal, and six lots of bone.

Hicks and Company archeologists defined the northern edge of site 41TR170 as the south edge of the modern river channel and a hike-and-bike trail, and the southern edge of the site was delineated by disturbances erroneously attributed to gravel-quarrying activities. The overall site within the proposed ROW covers both sides of the old meander channel and reportedly measured about $385 \mathrm{~m}$ (1,263 feet [ft]) north-south, by $128 \mathrm{~m}$ (420 ft) east-west. However, as noted below, no gravel quarries are depicted on the 1981 aerial photographs, and the ranch manager (Scott Walker, personal communication 2005) knows of no such activities occurring on this part of the site. 


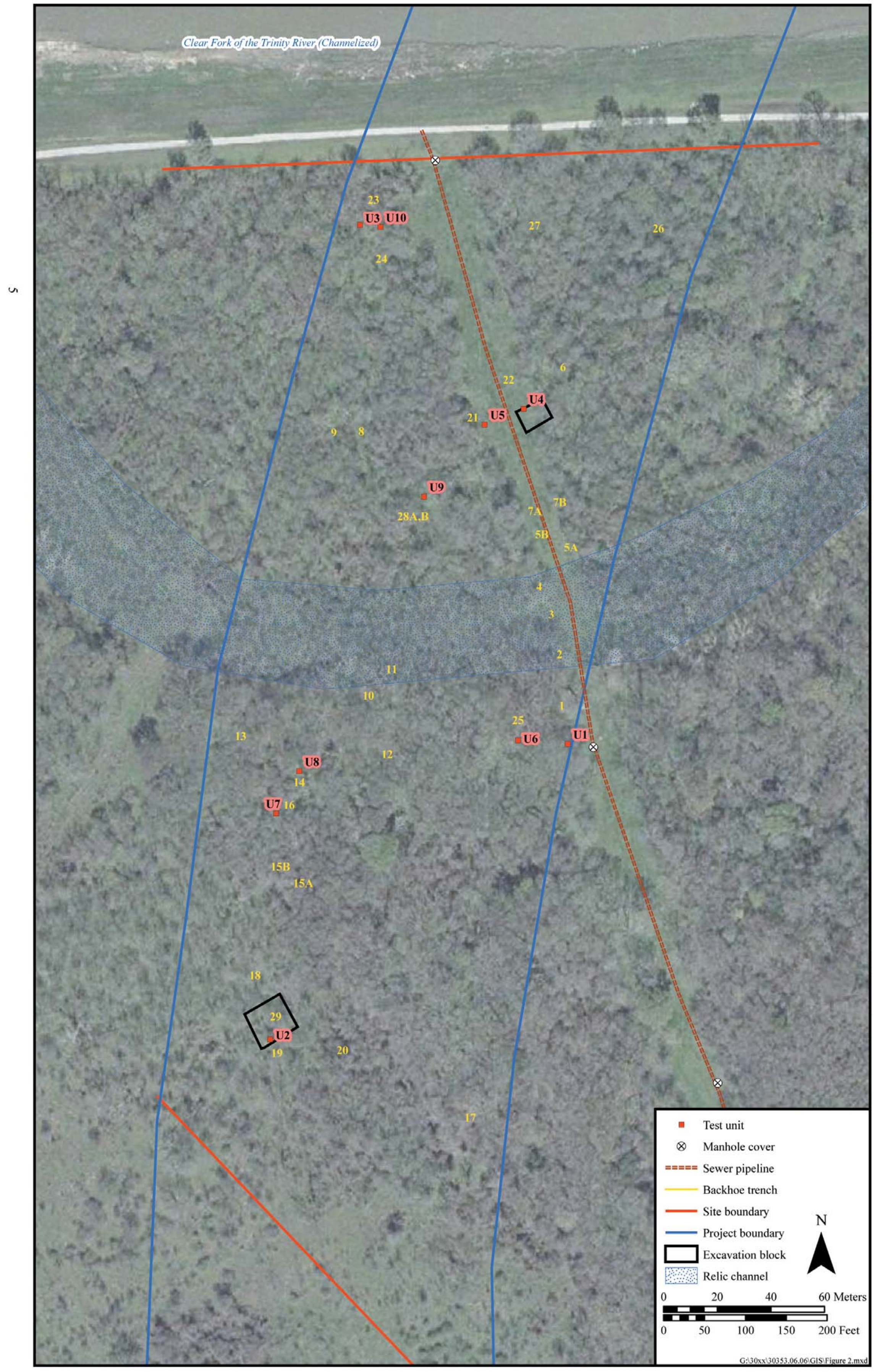

Figure 2. Excavation locations at site 41TR170. 
Overall, the survey assessed 41TR170 as a highly stratified, low-density multicomponent, special activity or brief campsite used by highly mobile peoples during the past two or more millennia. The cultural remains within the proposed highway ROW cover about 11.5 acres on both sides of the abandoned relic channel. Due to the presence of low-density archeological remains of lithics, bone, mussel and snail shell, and burned rock associated with features, Hicks and Company archeologists recommended that the site be tested to determine its eligibility for inclusion in the NRHP. That recommendation led to the present investigations at the site. 



\section{CHAPTER 2 BACKGROUND}

This section summarizes the modern environmental conditions at the site and then provides a brief overview of the cultural sequence known for the region. Particular attention is paid in the environmental section to the local geology and geomorphology, as well as historic impacts, since these have bearings on the overall site integrity and resource acquisition for the cultural features discussed in later chapters of this report.

\section{NATURAL ENVIRONMENT}

Site 41TR170 consists of features and artifacts occurring along both sides of a relict channel of the Clear Fork of the Trinity River in western Tarrant County. This area is in the Grand Prairie portion of the Central Texas section of the southern Great Plains of North America (Fenneman 1931:9-10, 54-57, 1938; Kier et al. 1977). The Grand Prairie tends to be a relatively flat landscape that slopes gently toward the southeast. Soils in this area are brown and lighter in color than those of the adjacent Blackland Prairie to the east.

\section{Topography}

Site 41TR170 is located on the floodplain of the Clear Fork branch of the Trinity River at an

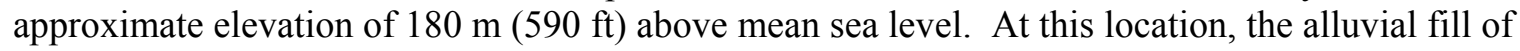
the Clear Fork valley is about $935-1,635 \mathrm{~m}(3,065-5,360 \mathrm{ft})$ wide and is flanked by relatively steep valley walls about $27.5 \mathrm{~m}(90 \mathrm{ft})$ in height before they transition into rolling upland hills.

The Clear Fork floodplain near the site drains from the southwest to the northeast in one of the rare northeast-trending portions of the river. The floodplain elevation drops an average of $2.9 \mathrm{~m}$ per kilometer $(\mathrm{km} ; 15 \mathrm{ft}$ per mile). Numbers of ridges intruding into the valley represent remnants of Pleistocene terraces; one prominent ridge is located just upstream from the site and

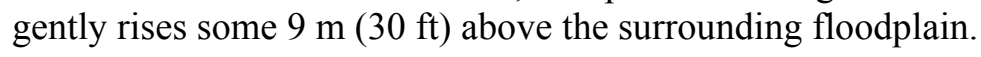


The archeological remains at 41TR170 occur on both sides of an incised relic river channel about

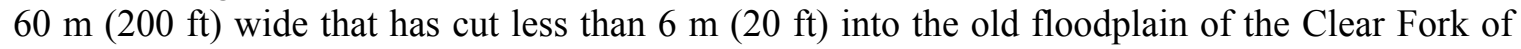
the Trinity River. The relic channel is currently dry, but the U.S. Geological Survey (USGS) Benbrook 7.5-minute topographic quadrangle indicates that the main channel of the Clear Fork was rerouted and straightened sometime between 1955 and 1981. Discussions with the property manager indicated that the mechanical channelization occurred around 1968-1969, but before then, the relic channel was the main river channel (Scott Walker, personal communication 2005).

\section{Geology}

The regional surface geology is composed of a series of Lower Cretaceous formations incised by the channel of the Clear Fork of the Trinity River and filled with Quaternary age sediments. Thus, within 2 miles of the project area, the earliest rock deposits consist of the Goodland Limestone, overlain by the Kiamichi Formation, and in turn by the Duck Creek Formation (on the west side of the valley) and the Fort Worth Limestone (on the east side of the valley). All of these Lower Cretaceous formations contain limestone, but the Kiamichi alone reportedly also yields sandstone (Barnes 1988). Potential bedrock exposures of these limestone resources range from $700 \mathrm{~m}(2,300 \mathrm{ft})$ to $1,400 \mathrm{~m}(4,600 \mathrm{ft})$ away from the center of 41TR170, with the sandstone resources potentially occurring about $700 \mathrm{~m}(2,300 \mathrm{ft})$ to the north and $1,160 \mathrm{~m}(3,800 \mathrm{ft})$ to the south.

The Quaternary sediments within the Clear Fork near 41TR170 are constrained within a valley 935-1,635 m (3,065-5,360 ft) wide. These consist of both remnant Pleistocene fluviate terrace deposits composed mostly of subangular limestone cobbles and Holocene fine alluvial sediments. An extensive remnant of Pleistocene gravels projects into the valley immediately upstream from the site. Undoubtedly, these gravels form the basis of the quarries reported by the Hicks archeologists that created the southwestern site boundary and the occurrence of gravels encountered in the lower deposits of the backhoe trenches placed along the southern edge of site 41TR170. Based on the size and angularity of the cobbles, and the fact that many of these rocks were cemented with caliche, these cobbles were not the primary source of the stone used in the burned rock features on the site.

\section{Soils}

The soils along the Clear Fork of the Trinity floodplain are classified as belonging to the FrioTrinity Association, a nearly level, deep clayey soil on floodplains (Ressel 1981). More specific to 41TR170, detailed mapping of the site shows it to be on the Frio silty clay that is occasionally flooded (Figure 3, areas marked 26). More technically, these constitute fine, mixed thermic, cumulic Haplustolls, which simply mean that they are relatively soft, thick, dark-colored, humicrich sediments that formed from the decomposition of organic residues in the presence of calcium-rich deposits under an arid moisture regime. The genesis of most of the organic matter is derived from grasses and forbs, as well as modern plant roots.

One interesting aspect of the soil map as depicted by Ressel (1981:Sheet 41) is the presence of small gravel quarries associated with Sunev soils that formed on the Pleistocene gravel remnant that extends onto the floodplain southwest of the site (see Figure 3, areas marked 43, 44, 78, and 79). These quarries, however, are between 760 and 1,190 $\mathrm{m}(2,493-3,904 \mathrm{ft})$ away from the 


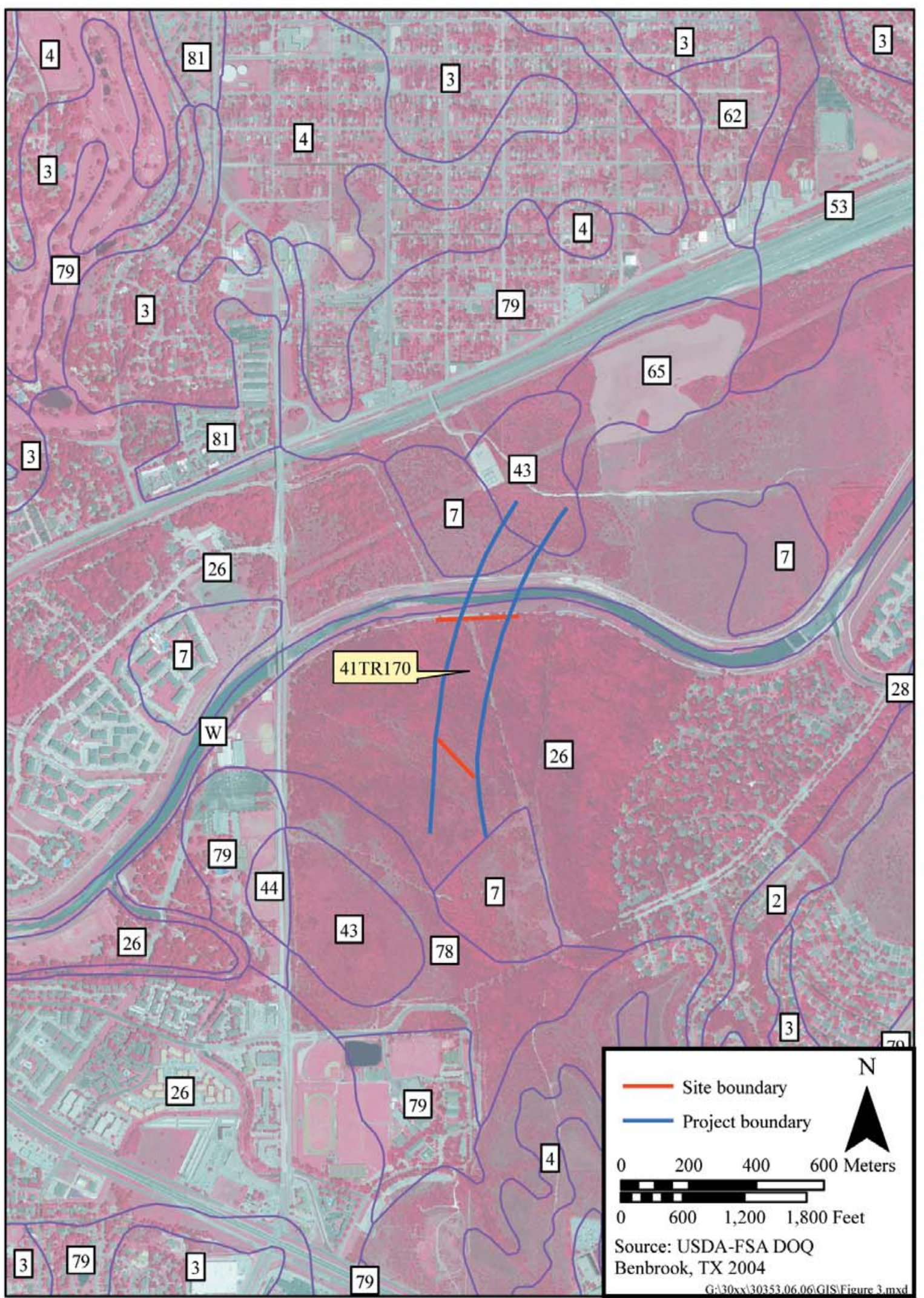

Figure 3. Soils map of the Clear Fork of the Trinity River floodplain at site 41TR170. Note Pleistocene gravel lens (Nos. 43,44, 78,79) southwest of the site (adapted from Bessel 1981). 
center of 41TR170 at the relic channel and do not encroach on the southwestern limits of the site, as suggested by Hicks and Company archeologists (Seibel et al. 2000). There is also a rather large area of Arent soil at least $460 \mathrm{~m}(1,500 \mathrm{ft})$ south of the relic river channel and the middle of site 41TR170 (see Figure 3, area marked 7). Arent soil deposits represent areas containing the overburden from excavated sand and gravel quarries (Ressel 1981). Based on the aerial photographs predating 1981 in the soil manual and discussions with the manager of the landowning company, no extensive gravel quarries have encroached upon the edge of 41TR170 (Scott Walker, personal communication 2005). Quite likely, some exploratory trenching to assess the quality of gravel deposits or trenching to control surface water flow may have occurred in the area of the site, but these disturbances have not delineated the boundary of the site as suggested by previous investigators (Seibel et al. 2000:18, Figures 4 and 5).

\section{Hydrology}

The Clear Fork is a main western branch of the West Fork that, along with the other two main tributaries - the Elm and East forks - make up the Trinity River basin that drains most of Northcentral Texas and empties into Trinity Bay at the Gulf of Mexico more than $560 \mathrm{~km}$ (350 miles) to the southeast. The Clear Fork heads in northwestern Parker County and flows southeastward for about $62 \mathrm{~km}$ (39 miles), before turning northeast and traversing another $24 \mathrm{~km}$ (15 miles) to the confluence with the West Fork of the Trinity River. The Clear Fork is the first main branch east of the Brazos River divide in the upper Trinity River basin. As the name implies, the Clear Fork historically has been regarded as being of good water quality with relatively low amounts of salts and other dissolved particles, and may have been a preferred place for settlements.

Much of the water from the Clear Fork derives from a combination of surface runoff and numerous springs (Brune 1981:352). As described in 1877, a pool of water at the headwaters of the Clear Fork was $200 \mathrm{~m}$ (656 ft) long at the site of Poolsville, Texas; unfortunately, poor land management decisions caused erosion of the Paluxy sands, and now this pool is completely filled in. Numerous springs occurred all along the Clear Fork throughout Parker and western Tarrant counties. Intense settlement of the region gradually lowered the aquifer levels and most springs are no longer active.

\section{Vegetation and Animals}

Northcentral Texas consists of a series of relatively narrow, north-south alternating vegetation bands of oak-hickory forests and open grasslands. From west to east, these are the Western Cross Timbers, the Grand Prairie, the Eastern Cross Timbers, and the Blackland Prairie. Archeological site 41TR170 occurs in the Grand Prairie portion of the region. Much of the native vegetation has been destroyed by urban sprawl, but the Clear Fork bottomlands are covered in a dense growth of oaks that represent the floodplain forests that once covered the region. The presence of thick paleosol deposits, however, also suggests that dense stands of grass covered the region.

The region is also assigned to the Texan Biotic Province, which is representative of its intermediate location between the grasslands of the Southern Plains to the west and the deciduous forests of the Southeast. There are no endemic vertebrate species in the Texas biotic province, but 49 species of mammals occur in the region. Important species that exist or once existed in the 
area include white-tailed deer, bison, bear, squirrel, rabbit, and raccoon. Along with a wide range of turtle, snake, frog, fish, freshwater mussel shell, and bird species, the region has a wide range of resources for supporting indigenous groups.

Site vegetation consists mostly of dense stands of mature oak-hickory forest, with a dense understory of greenbrier and acacia brush. Vegetation is especially thick where deep alluvial sediments occur in the valley. Conversely, in areas of dense gravels near the surface, especially along the southern margin of the site, aerial photographs show a marked decrease in the upperstory tree cover. Likely, this marked and drastic vegetation change led the previous archeologists to conclude erroneously that the southern boundary of the site had been quarried in the past.

\section{Climate}

The climate of Tarrant County is classified as subtropical with humid, hot summers and mild winters, except when "blue northers" blow in periodically. A wide range of annual temperature extremes characterizes the region. Periods of cold temperature are short-lived; temperatures falling to or below $20^{\circ} \mathrm{F}$ average only six days per year. For Tarrant County, the records for daily extremes reflect a low of $-8 \mathrm{oF}$ in February 1899 and a high of $113 \mathrm{oF}$ in June 1980. Typically, temperatures average $47.4 \mathrm{oF}$ in the winter season (December-February) and $83.3 \mathrm{oF}$ in the summer season (June-August) (Ressel 1981:Table 2).

The region has an average annual precipitation of $81.5 \mathrm{~cm}(32.1$ inches [in]); the greatest amount occurs in April and May, when slightly more than a quarter of the annual precipitation falls during the summer. Indeed, about 60 percent of the precipitation occurs during the six-month interval of April through September. Rainfall usually occurs at night with an average of about 44 rainfall events a year. The maximum historically recorded one-day rainfall amount on record is $24.3 \mathrm{~cm}$ (9.57 in), which happened in 1932. Only $7.4 \mathrm{~cm}$ (2.9 in) of precipitation fall on average as snow, and frozen precipitation occurs in three of four years. Hailstorms typically occur on two or three days a year. The region has on average 249 freeze-free periods.

The region receives sunshine about 76 percent of the time. The prevailing winds are usually from the south, and the highest speeds reach $22.5 \mathrm{~km}$ (14 miles) per hour in March and April.

\section{Geomorphology}

Studies elsewhere in the Trinity River basin have identified a series of Holocene-aged cut-and-fill alluvial sequences that seem to correlate across the river basin and indeed correlate with events identified in the Colorado and Brazos rivers. In addition, during periods of terrace construction, the vegetation cover (probably grasslands) contributed organic carbon at a rate faster than sediment deposition, resulting in a series of buried soils and the accumulation of soils as the terrace treads aggraded. These soils have been named and radiocarbon-dated at several locales across the Trinity River basin. The following is an overview of the geomorphic situation expected for the region. 
From studies elsewhere in the upper Trinity River basin, it is likely that as many as three alloformational stratigraphic units comprise the Holocene terrace (Ferring 2001:28-39). Each is marked by an erosional unconformity at the top and pedogenic or soil development. Along the Elm Fork, these consist of the Aubrey Alloformation, dating ca. 14,200 to perhaps 13,400 years ago, at the bottom; the Sanger Alloformation dating between 10,900 and 5,700 years ago; and capped by the Pilot Point Alloformation that dates from 4,525 to about 700 years ago (Ferring 1990a:47-48). The Arlington paleosol developed in the upper part of the Sanger Alloformation depositional unit, whereas the West Fork paleosol developed in the Pilot Point Alloformation. In

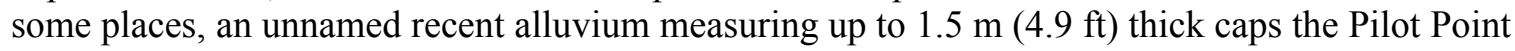
alluvium, and it too has developed a pronounced soil in some places.

Most of the mechanical excavations at 41TR170 were restricted to the upper $2 \mathrm{~m}(6.6 \mathrm{ft})$ of the deposits and primarily examined the recent sediments, the West Fork paleosol, and some of the underlying sediments. In this report, Ferring's terms for the allomorphic depositional packages (e.g., Pilot Point, Sanger, and Aubrey alluvium) are not used, in part due to the shallow depth of the mechanical trenching and in part due to the recent age of the radiocarbon dates (spanning only the past 3,000 years). Instead, material correlations are tied to the stratigraphic position relative to the prominent West Fork paleosol identified in all trenches onsite. Nonetheless, because of the extent of meso- and micro-scale bioturbation in the sediments at 41TR170, stratigraphic unconformities so easily observed elsewhere on the Southern Plains (including the top of the West Fork paleosol) are difficult to identify. All or nearly all of the sediments and the associated archeological remains exposed in the trench profiles likely relate to the Pilot Point and recent sediments. However, further contemplation of how the stratigraphy of 41TR170, especially involving the clays and dense gravel deposits along the southern edge of the site near Trenches 18 and 19 and Blocks 1 and 3, relates to Ferring's (1990) Trinity River regional stratigraphic model is under consideration. At this time, none of the cultural deposits from the site appears to be more than ca. 3,000 years old.

\section{Historical Impacts and Land Use}

Site 41TR170 occurs on relatively undeveloped lands owned by Edwards Geren Limited, which operated the area as a ranch since the area was settled. Overall, little development is evident relative to the housing and business developments that surround the remaining ranch lands. The property is still used as a ranch and is leased for raising cattle.

Aerial photographs show small gravel quarries on the Pleistocene terrace remnant that are located about $760 \mathrm{~m}(2,500 \mathrm{ft})$ south and $1,190 \mathrm{~m}(3900 \mathrm{ft})$ southeast of the relic channel at 41TR170 (Ressel 1981:Sheet 41). As discussed above, a large area of Ardent soils that represent overburden from quarry activities is located some $460 \mathrm{~m}(1,509 \mathrm{ft})$ to the south of the site. The source of this fill is unknown, but it may be possible that some quarrying has occurred in this area $460 \mathrm{~m}$ south of the relic channel. The date of these possible gravel-quarrying operations is unknown. However, none of these areas impact site 41TR170.

Despite the rural nature of the area, several recent changes have modified the land (Scott Walker, personal communication 2005). In 1963, a large sewer line was installed at a depth of about $6 \mathrm{~m}$ (20 ft) across the property and crosses 41TR170, and the SH 121 highway is proposed north of the relic channel. The sewer line was upgraded in the 1990s, and it currently has access manholes spaced along the route; the alignment serves as one of the main access routes through the wooded bottomlands. 
As mentioned above, in 1968 or 1969 the new channel of the Clear Fork of the Trinity River was excavated to a depth of more than $4 \mathrm{~m}(13 \mathrm{ft})$ and perhaps a width of $60 \mathrm{~m}(197 \mathrm{ft})$ into the floodplain to straighten and deepen the riverbed to reduce the risk of flooding. This channelization left the older channel dry. The original depth of the relic channel and the amount of historic infilling is unknown. Current attempts to trench the bottom of the relic channel along the edges of the sewer line ROW were completely thwarted in three trenches by the presence of massive ( $2+\mathrm{m}$ long by roughly $1 \mathrm{~m}$ thick) limestone blocks that seem to have been set or placed together and buried under about $0.5 \mathrm{~m}$ of sediment. Although it is possible that these blocks and the channel infilling occurred simultaneously with the channelization project, the effort to fit blocks together (if valid) in the relic channel seems at odds with the need to haul away quantities of fill from the major excavation effort. The placement of these blocks along the sewer line road and tens of meters west of the road in the channel bottom either might reflect early flood control/bank stabilization efforts or might possibly be related to the sewer line development. The date of the placement and the depth of fill added to the relict channel are unknown.

Shortly after the river was diverted, a second raw sewer line was installed from a private school located on the hills south of the Clear Fork. This second pipeline was placed in the ROW corridor of the first pipeline, but it is not marked on the surface, and the depth and precise location are not known.

During the early 1990s, a housing development was established on the floodplain east of the main ranch property. Although the deepened river channel was regarded as adequate to remove waters coming down the Clear Fork, concerns arose over secondary flooding from adjacent hillslope runoff. To diminish that possibility, a bulldozer informally recontoured the lands in 1990 or 1991. Some gullies were bulldozed to straighten or redirect surface runoff, and a large berm or earthen dike was built from the sewer line road, angling toward the northeast and stopping at the property edge of the public hike-and-bike trail. Other modifications may include various bulldozer cuts that, when coupled with the marked vegetation shifts over the dense gravel areas, may have been misconstrued as the edge of gravel quarry operations near the site.

The final modification of unknown age is the creation of a series of hike-and-bike trails, some in gravel and others in concrete, built on publicly owned property on both sides of the constructed river channel. Some branches of the trail east of the site cut down the embankment and cross the Clear Fork by means of a bridge. Periodically, benches have been placed along the trail to enhance public use. The trail and the adjacent property fence line constitute the northern edge of the site as defined during the initial survey.

\section{CULTURAL OVERVIEW}

Several major reports concerning the archeology of the upper Trinity River basin (Peter and McGregor 1988; Prikryl 1987, 1990; Yates and Ferring 1986) aptly summarize most of the history of archeological investigations within the upper Trinity River drainage and the culturalhistorical framework for the area. Although the combined efforts of professional and avocational archeologists have resulted in recording numerous sites, it is apparent that much research remains to be done. 
The chronological framework for the upper Trinity River basin is not well developed. Prikryl (1987) has presented a chronological sequence of six prehistoric periods based primarily on cross-dating diagnostic projectile point forms from mostly surface contexts, and the sequence based on Joe Pool Reservoir investigations adds a Protohistoric period (Table 1; Peter and McGregor 1988). For purposes of this report, in light of the radiocarbon dates on geomorphic contexts that indicate the deposits date to the past 2,900 years and based on the few diagnostic dart points recovered from site 41TR170, the following summarizes only the Archaic through historic sequences.

\begin{tabular}{lcr}
\hline & \multicolumn{2}{c}{ Table 1} \\
& Chronological Framework for the Upper Trinity River Basin \\
Cultural Period & Time Interval & Calendrical Date \\
\hline Paleo-Indian & Pre-8,500 B.P.* & pre-6550 B.C. \\
Early Archaic & $8,500-6,000$ B.P. & $6550-4050$ B.C. \\
Middle Archaic & $6,000-3,500$ B.P. & $4050-1550$ B.C. \\
Late Archaic & $3,500-1,250$ B.P. & 1550 B.C.-A.D. 700 \\
Late Prehistoric I & $1,250-750$ B.P. & A.D. $700-1200$ \\
Late Prehistoric II & $750-250$ B.P. & A.D. $1200-1700$ \\
Protohistoric & $350 / 250-150$ B.P. & A.D. $1600 / 1700-1800$ \\
\hline
\end{tabular}

* B.P. $=$ Years Before Present (1950)

Source: Peter and McGregor 1988; Prikryl 1990:48

\section{Archaic Periods}

The Archaic period in Northcentral Texas is tentatively dated between 6550 B.C. and A.D. 700 . As is true for many areas, a threefold division of the Archaic period, consisting of Early, Middle, and Late subperiods, has been applied in Northcentral Texas (Prikryl 1990). Thus, the Early Archaic has been dated from 6550 to 4050 B.C., the Middle Archaic from 4050 to 1550 B.C., and the Late Archaic from 1550 B.C. to A.D. 700. Archaic remains are usually found in upland settings and are frequently mixed with later material. In fact, the initial treatment of the Archaic period in Northcentral Texas (Crook and Harris 1952) that defined the Carrollton and Elam foci was based upon materials from such mixed terrace contexts. Consequently, these time-space constructs are no longer recognized as being acceptable for this area of Texas (Peter and McGregor 1988; Prikryl 1990; Yates and Ferring 1986). General trends that have been proposed as characterizing the Archaic period in Northcentral Texas include an increasing complexity of settlement systems, increasing population size and density, decreasing mobility, and the development of distinct group territories (Prikryl 1990; Story 1985:52).

During the Early Archaic (ca. 6550-4050 B.C.), in general, the occurrence of small and widely distributed sites has been suggested to reflect high group mobility within large and poorly defined territories, with a generalized hunting-and-gathering economy (Story 1985:35, 39). Unfortunately, Early Archaic occupations in Northcentral Texas are poorly documented, and no sites with isolated Early Archaic components in this area are known (Prikryl 1990). Based on 
surface collections, Prikryl (1990) hypothesizes a generalized hunting-and-gathering economy during this period, with high group mobility, a lack of regionalization, and "little in the way of recognized territorial boundaries" (Prikryl 1990:71). Projectile point forms that may be associated with the Early Archaic in Northcentral Texas include Early Split Stemmed and possibly Angostura points (Prikryl 1990; Story 1990b:Figure 31).

In comparison to the Early Archaic, the Middle Archaic period in Northcentral Texas (4050-1550 B.C.) is even less well known. Fewer sites are known with Middle Archaic components than for any other period, but the few surface collections available suggest the beginnings of regional cultural differences by the end of the period (Prikryl 1990). Diagnostic dart points that may be associated with the Middle Archaic include the Basal Notched group (which includes Calf Creek, Bell, and Andice), Wells, Dawson, Carrollton, and Bulverde (Prikryl 1990; Story 1990b:Figure 31). An intact Middle Archaic component was identified at the Calvert site (41DN102) at Lake Ray Roberts and is summarized by Ferring and Yates (1997:305):

Hearths, a burial, an unmixed assemblage of artifacts and fauna provide new evidence of adaptations to a drier middle Holocene landscape. Artifact types are similar to those from adjacent regions (Story 1990) suggesting broad cultural interactions. The foraging economy emphasized procurement of small game and deer. It is assumed that these people were quite mobile, as repeated occupations of the site during the Middle Archaic period are evident.

Population density may have reached a peak during the Late Archaic period in Northcentral Texas (ca. 1550 B.C.-A.D. 700), as indicated by an apparent increase in the number of sites, a greater distribution of sites over the landscape, and evidence of decreasing mobility (Prikryl 1990). At the same time, as group mobility may have become more limited, interregional contact may have diminished. If greater spatial dispersal of sites is not a result of sampling error due to unequal destruction or burial of earlier sites, it may reflect an economic system making increasing use of all available floral and faunal resources. Throughout Northcentral Texas, Late Archaic period occupation sites are relatively common in the uplands, and a relatively large number of shallow buried sites are known from the Trinity River floodplain (Ferring 1990a:51). Dart points that may be diagnostic of the Late Archaic include Castroville, Marshall, Edgewood, Ellis, Trinity, Palmillas, Yarbrough, Dallas, Godley, Elam, and Gary (Prikryl 1990; Story 1990b:Figure $31)$.

Investigations at Joe Pool Lake (Peter and McGregor 1988) and Lake Ray Roberts (Ferring and Yates 1997) indicate that remains of the Late Archaic period are characterized by assemblages apparently left by small bands of foraging hunters and gatherers who occupied a locality for a limited time and then moved to another locality. These sites were apparently reoccupied numerous times on a seasonal basis. Faunal remains indicate that Late Archaic populations exploited a mix of prairie, forest, and riparian species, with white-tailed deer, rabbit, turtle, and freshwater mussel shells being primary food resources (Ferring and Yates 1997:6). The results of investigations at numbers of Late Archaic sites at Lake Ray Roberts are summarized by Ferring and Yates (1997:305).

The most substantial occupations of the project area took place in the later part (post-3,000 yr b.p.) of the Late Archaic period. This is clearly a broad regional trend . . . although poor site exposure limits our understanding of earlier periods. Late Archaic sites here uniformly register mobile foragers that exploited all habitats available to them. Residential mobility ... is implied. Repeated occupations at multiple sites were characterized by use of rock-lined and unlined hearths. On stable surfaces these are recorded as rock middens. In aggrading environments, discrete hearth construction events are clear. 
Import and curation of chert tools is evident, and contrasts with core-biface curation in the Middle Archaic period. Chert was preferentially used for straight, expanding and corner-notched points, while local raw materials were reduced on-site and dominate the contracting-stemmed forms. Despite quite good resource availability, dietary stress is recorded from skeletal and dental analyses. ...

\section{Late Prehistoric Period}

The beginning of what is called the Late Prehistoric period in the upper Trinity River basin (ca. A.D. 700-1700) is marked by the initial appearance of arrow points. The A.D. 700 date for the start of this period is based upon dated contexts for similar material in the Brazos River drainage to the west. Both Lynott (1977) and Prikryl (1990) propose that the Late Prehistoric period be divided into an early and a late phase, with the early phase reflecting a continuation of the foraging subsistence system of the preceding Late Archaic period and the late phase reflecting Southern Plains influences. In this view, the early phase dates between A.D. 700 and 1200, and is characterized by sand- and grog-tempered ceramics and by Scallorn, Steiner, Catahoula, and Alba arrow points (Lynott 1977; Prikryl 1990). The late phase dates from A.D. 1200 to 1700 and is associated with the appearance of Nocona Plain ceramics of the Henrietta focus, various unstemmed triangular points (e.g., Maud, Fresno, Harrell, and Washita), and the Perdiz point (Lynott 1977; Prikryl 1990). Evidence of horticulture and bison procurement also appears in sites of this period.

Investigations at the Cobb-Pool site (41DL148) at Joe Pool Lake (Peter and McGregor 1988) have resulted in a reformulation of the Late Prehistoric period. The Cobb-Pool site has yielded house structures, roasting pits, Alba points, grog-tempered ceramics, and charred corn cupules. Radiocarbon dates from several features indicate the site was occupied during the late twelfth or early thirteenth century. Present evidence suggests that the site does not represent an intrusive Caddoan occupation; consequently, a significant adaptive change appears to have occurred, in at least some areas, during a middle phase of the Late Prehistoric period. It is also likely that ceramics were not introduced to the region before this time.

In regard to the Late Prehistoric components investigated at Lake Ray Roberts, Ferring and Yates (1997:305) summarize the results of that research:

There are no woodland-like sites in north central Texas, suggesting that Plains Woodland influence or contact did not characterize the transition to the Late Prehistoric period. No ceramics were found with LPI [Late Prehistoric I] assemblages, which have Scallorn, Alba and small Gary points. These appear to be short-term occupations that took place under conditions of reduced precipitation compared to the Late Archaic. Except for the replacement of darts with bow-arrow weaponry, these occupations are essentially similar to the Late Archaic. Regional exchange of technological information, rather than environmental change, probably is the factor behind the Late Archaic to Late Prehistoric shift.

Late Prehistoric II occupations are characterized by multiple, short-term use of probably logistic sites, which lack ceramics and architecture. The architectural remains at 41DN102 are the only ones in the project area. At best, this was a small hamlet, occupied ca. 500-650 yr b.p. No evidence of horticulture was recovered, and the LPII faunas indicate a foraging strategy that emphasized deer procurement, and occasionally bison as well. Transport and curation of chert raw materials was about as frequent as in the LA, and long-distance raw material acquisition (e.g., Edwards, Alibates) is not evidenced. Ceramic traditions are dominated by locally produced shell-tempered wares, which by this time were being produced in the Southern Plains region generally. As recorded by previous synthesis 
(Story 1990), little if any interaction with the Caddoan area is indicated. Thus, the Ray Roberts prehistoric data suggest that regional traditions emerged at the end of the LP period largely independent of the Plains or East Texas Woodlands.

In light of these results, the status of the Cobb-Pool site is even more striking. Whether the CobbPool site merely represents a local experiment or reflects a regional adaptive change separate from that emerging to the north remains to be fully documented; however, recent analysis of a Native American burial salvaged along Spring Creek (site 41DL373) in Dallas County also suggests maize consumption. The individual was a female around 50 years old. Radiocarbon dating indicates that this individual lived between A.D. 1155-1275; a carbon isotope ratio of $-17.7 \%$ suggests that maize was consumed, but it did not form a major part of her diet (Peter and Clow 1999). These indications of maize consumption contrast with a small grouping of disturbed human remains recovered from the Harbor Pointe site (41DL369) in Dallas County. This site, located on Rowlett Creek (a tributary of the East Fork of the Trinity River), yielded remains of at least four individuals, dated by tree-ring calibrated radiocarbon dates on bone collagen to cal A.D. 1010 (1035) 1165. No pottery was recovered with these remains, although shell beads and a shell gorget were present; a carbon isotope ratio of $-21.6 \%$ suggests that the group's diet was not high in maize (Cliff et al. 1996). Given the slightly earlier date of the Harbor Pointe burials compared to Cobb-Pool and 41DL373, it is possible that maize agriculture was introduced to the Dallas area ca. A.D. 1200; conversely, this same evidence may indicate that divergent subsistence patterns were practiced by groups in the Dallas area.

\section{Protohistoric Period and Historic Native American Groups}

Within Northcentral Texas, the time from A.D. 1600 to 1800 has been designated the Protohistoric period. Prior to the founding of New Mexico in 1598, European presence in the Southwest and on the Southern Plains had been sporadic at best (Coronado in 1540-1541, the RodriguezChamuscado party in 1581, Espejo in 1582-1583, etc.). However, after 1598, Spanish influence was never absent from the Southern Plains, although actual contact with Europeans continued to be limited and there are only brief records of journeys into or through the area. Despite this, it was not until the beginning of the nineteenth century that the physical presence of Europeans on the Southern Plains became commonplace - the result of increasingly peaceful relations between the Spanish in Texas and the Plains Indians to the north, and the acquisition of Louisiana by the United States in 1803. Prior to about 1725-1750, Apachean groups appear to have dominated the western portion of the Southern Plains, known as the High Plains, but after this time the area was increasingly controlled by the Comanche and Kiowa. On the eastern portion of the Southern Plains, within the area now known as the Lower Plains and Northcentral Texas, the Wichita tribes became dominant (Bell et al. 1967; Hofman 1989:91).

Unfortunately, since good historical documentation is very sparse for the upper Trinity River basin during the Protohistoric period, it is not clear which specific aboriginal groups were residing in the Dallas/Fort Worth area at the beginning of this period. What is clear is that the Protohistoric period in Northcentral Texas was a time of population fluctuation, movement, and amalgamation (see Newcomb 1993). Available data suggest that many, if not all, aboriginal occupants of the eastern margin of the Great Plains, including Northcentral Texas, were Caddoan language speakers, from the Arikara in the north to the Wichita and Kichai in the south. In this light, it is worth noting that it has also been suggested that the Socoatino, who were encountered by the survivors of the De Soto expedition in the sixteenth century, were Caddoan speakers and 
were the same group as the Canohatino identified by the French in the latter part of the seventeenth century. The latter group was apparently located at that time "on the Blackland Prairies between the Guadalupe and Trinity rivers to the east of present-day San Antonio, Austin, and Waco" (Newcomb 1993:24). If the prehistoric occupants of the eastern plains margin in Texas were indeed Caddoan speakers, then it would explain how these groups were absorbed very early into other Caddoan-speaking groups (such as the Yojuane, Kichai, Tawakoni, Taovayas, Iscani, and Wichita proper) who arrived in Northcentral Texas in the late seventeenth and early eighteenth centuries. Most of these groups, in turn, amalgamated to form the historicera Wichita Tribe, but some were probably absorbed by the united Caddo tribes, and some may even have joined amalgamations of a variety of groups, such as the Tonkawa, during the late eighteenth and early nineteenth centuries. Many of these groups along with the Comanche were called the Norteños by the Spanish, and the historic archeological remains of these peoples postdating ca. 1750 are designated the Norteño Focus for the region.

\section{Historic Utilization and Occupation}

The first presence of Europeans in Northcentral Texas may have occurred in 1542 when the remnants of the De Soto expedition, led by Luis de Moscoso de Alvarado, entered the area that would become present-day Texas in an effort to find a land route to New Spain. Some researchers believe that the expedition crossed Northcentral Texas (Lebo and Brown 1990:61), although others place the route much farther to the east and south (Bruseth and Kenmotsu 1991; Chipman 1992). A consistent European presence to the region did not occur until the early 1700s, when French traders from Louisiana began to move west along the Red River. French traders were residing among the fortified Wichita villages near Spanish Fort, Texas, and were probably partly responsible for inciting the raid against the Spanish missions.

The earliest recent history of Tarrant County is poorly documented. The first Euro-Americans to settle in the region were primarily from Arkansas Territory. In 1840, Capt. Jonathan Bird and a small group of settlers (commonly referred to as Peters Colonists) established a blockhouse called Bird's Fort along the West Fork of the Trinity River. The fort-consisting of three buildings surrounded by a stockade - was inadequately manned to be a significant defensive locale against roving Apache and Comanche and instead served as a trading station rather than a fort. Additional families joined the initial occupants of Bird's Fort in the fall of 1841, but the fort was entirely abandoned by the spring of 1842 .

In 1845, a trading post was established at Marrow Bone Springs (later named Mary Le Bone Springs) along Johnson Creek (formerly called Mill Creek). Although Werdman's (1969:10) account of its location suggests either a Rush Creek or Johnson Creek location, an 1872 map of Texas (Petermann 1872) places Marrow Bone Springs on Johnson Creek. Col. Middleton Tate Johnson and a company of Texas Rangers also established their headquarters at Marrow Bone Springs in 1847. Two years later, Colonel Johnson received a land grant for his services, and he established a plantation near Marrow Bone Springs. The community that grew around the colonel's plantation came to be known as Johnson Station.

Shortly after the establishment of Johnson Station, Camp Worth was established in 1849 at the junction of the Clear and West forks of the Trinity River in order to provide protection for settlers along the western frontier. In the same year, Colonel Johnson was instrumental in the political process of establishing Tarrant County. By 1860, the population of Fort Worth had grown 
sufficiently to cause the county seat to be moved from Birdville to Fort Worth. The coming of the railroad and the discovery of oil after 1900 significantly affected the economy and market accessibility of the area. 



\section{CHAPTER 3 METHODS}

The methods used for testing 41TR170 are based on the three field stages, as outlined in Chapter 1. This section reiterates and expands upon the methods used to test the site. All reported field investigations occur within the known footprint of the proposed roadway. In order to guarantee this claim, the aerial photographs used in the project's environmental assessment posted on the TxDOT website were downloaded, rectified to standard geo-coordinates. The Universal Transmercator (UTM) locations of the ROW margins were ascertained for the following points: (1) the east and west edges of the ROW along the fence line forming the northern boundary of the archeological site as defined by the archeologists from Hicks and Company; (2) the east and west boundaries of the ROW in the river channel meander, (3) the east boundary of the project ROW along the northwest-southeast "sewer line" road across the site, and (4) the east and west boundaries along the southern edge of the site as measured from the aerial map provided in the Hicks and Company report. The various points were plotted in the field and demarcated by flagging tape in lieu of any other engineering data. The TxDOT protocol for dealing with human remains was stipulated as part of the permit application; since no human remains were found, those procedures are not discussed in this report.

\section{STAGE 1: BACKHOE TRENCHING AND GEOMORPHOLOGY}

The first stage of fieldwork consisted of the excavation of standard backhoe trenches, which were monitored by archeologists and described by the project geomorphologist, Dr. Stephen Hall. The THC permit guidelines stipulated that the actual number of trenches to be dug (between 21 and 35) depended upon the frequency of trenches containing observed artifacts (burned rock and chipped stone tools) and ecofacts (bone, shell) and the adequacy of site sampling across all areas of the site within the proposed ROW. If backhoe trenches sampled all portions of the site within the ROW and artifact/ecofacts were found in at least 15 to 20 trenches with materials, then the total number of trenches could be scaled down below the maximum number of 35 . The placement of many of the trenches within the project ROW was based on the judgment of Dr. Hall to maximize the information retrieval for the geomorphological study of the Clear Fork of the Trinity River. Secondary consideration was to ensure that all areas identified by the Hicks and Company archeologists as containing artifacts and features were trenched. Some of the GMI trenches were placed to cover areas not intensely investigated during the survey. Based on the stipulations outlined above, an initial 28 backhoe trenches were dug at the site (Table 2). In most 
Table 2

Locations of Backhoe Trenches and Nonblock Test Units at Site 41 TR170

Stage 1: Backhoe Trench

\begin{tabular}{|c|c|c|c|c|c|c|c|c|}
\hline \multirow[b]{2}{*}{$\mathrm{BT}^{*} \#$} & \multirow[b]{2}{*}{$\begin{array}{l}\text { Length } \\
(\mathrm{m})\end{array}$} & \multirow{2}{*}{$\begin{array}{l}\text { Depth } \\
\text { (m) }\end{array}$} & \multirow[b]{2}{*}{$\begin{array}{l}\text { Location from } \\
\text { relic channel }\end{array}$} & \multicolumn{2}{|c|}{ Approx UTM } & \multirow[b]{2}{*}{ Test Unit \# } & \multirow[b]{2}{*}{ Feature \# } & \multirow[b]{2}{*}{ \# } \\
\hline & & & & $\begin{array}{l}\text { Northing } \\
\text { 3619xxx }\end{array}$ & $\begin{array}{l}\text { Easting } \\
649 \times x x\end{array}$ & & & \\
\hline \multicolumn{9}{|c|}{ Fence line north end of site } \\
\hline 23 & 7.30 & 2.68 & north & 765 & 405 & TU 3 & F4, F5 & \\
\hline 27 & 6.60 & 2.00 & north & 765 & 468 & & & \\
\hline 26 & 4.25 & 1.93 & north & 758 & 512 & & & \\
\hline 24 & 7.00 & 2.00 & north & 753 & 410 & TU 10 & & \\
\hline 6 & 5.10 & 2.00 & north & 705 & 480 & & & \\
\hline 22 & 5.70 & 1.90 & north & 697 & 463 & TU 4 & F3 & Block 2 \\
\hline 21 & 6.00 & 2.00 & north & 685 & 438 & TU 5 & & \\
\hline 8 & 6.20 & 1.95 & north & 677 & 405 & & & \\
\hline 9 & 6.90 & 2.00 & north & 677 & 390 & & & \\
\hline 28 & 6.90 & 2.00 & north & 660 & 428 & TU 9 & "sterile unit" & \\
\hline 7 & 3.55 & 2.14 & north & 653 & 472 & & & \\
\hline 5 & 11.10 & 1.80 & north & 643 & 478 & & & \\
\hline \multicolumn{9}{|c|}{ Relic Channel North Bank } \\
\hline 4 & ca. 5.00 & ca. $<1.0$ & inside & 625 & 471 & \multicolumn{3}{|c|}{ Stopped by limestone blocks } \\
\hline 3 & ca. 11.00 & ca. $<1.0$ & inside & 610 & 473 & \multicolumn{3}{|c|}{ Stopped by limestone blocks } \\
\hline 2 & ca. 9.00 & ca. $<1.0$ & inside & 600 & 475 & \multicolumn{3}{|c|}{ Stopped by limestone blocks } \\
\hline \multicolumn{9}{|c|}{ Relic Channel South Bank } \\
\hline 11 & 6.55 & 2.00 & south & 588 & 415 & & & \\
\hline 10 & 6.70 & 2.12 & south & 585 & 410 & & & \\
\hline 1 & 16.30 & 1.83 & south & 580 & 480 & TU 1 & $\mathrm{~F} 1, \mathrm{~F} 2$ & \\
\hline 13 & 5.30 & 2.07 & south & 572 & 355 & & & \\
\hline 25 & 7.00 & 1.96 & south & 570 & 462 & TU 6 & F7, F8 & \\
\hline 12 & 4.90 & 2.00 & south & 560 & 410 & & & \\
\hline 14 & 3.80 & 2.23 & south & 556 & 380 & TU 8 & & \\
\hline 16 & 5.80 & 2.00 & south & 543 & 373 & TU 7 & & \\
\hline 15 & 5.80 & 2.19 & south & 517 & 378 & & & \\
\hline 18 & 6.60 & 1.90 & south & 478 & 360 & & & \\
\hline 19 & 5.00 & 2.00 & south & 455 & 370 & TU 2 & F9 & Block 1 \\
\hline 29 & ca. 3.50 & ca. 1.00 & south & 457 & 372 & & & Block 3 \\
\hline 20 & 6.80 & 2.05 & south & 450 & 395 & & & \\
\hline 17 & 5.50 & 1.85 & south & 425 & 445 & & & \\
\hline
\end{tabular}

* BT=Backhoe Trench 
cases, considerable effort was spent in mechanically clearing small brush from the dense vegetation cover on the site, although every effort was made to honor the landowner's request not to knock down trees larger than $15 \mathrm{~cm}$ (6 in) in diameter. A few supplemental trenches (Trenches A-D) beyond the initial 28 were dug late in the testing program, especially near Blocks 1 and 3, to ascertain the extent of cultural burned rock or define the depths of deposits. Since these trenches were placed to refine the extent of materials, the project geomorphologist did not have the opportunity to see or document these latter trenches.

The backhoe trenches were demarcated by numbered pieces of flagging tape tied to adjacent brush, and the locations were recorded using a global positioning system (GPS). The backhoe trenches ranged from 3.8 to $16.3 \mathrm{~m}(12.5-53.5 \mathrm{ft})$ in length. Mechanical excavations were conducted with a toothed bucket to various depths, with an estimated average of 20-30-cm (7.911.8 in) intervals, to a depth of $200 \mathrm{~cm}$ (78.8 in) due to the density of roots in most areas of the site. Actual depths of mechanically dug trenches ranged from 1.80 to $2.68 \mathrm{~m}(5.9-8.8 \mathrm{ft})$, except for three trenches that were terminated when encountering limestone blocks placed in the old meander channel as an early bank stabilization effort.

Two archeological monitors were present during the trench excavations. The goal of monitoring mechanical excavations was to identify locations where artifact density was high enough to be readily detectable and, therefore, potentially exploitable for a data recovery excavation. These areas were to be verified by the manual excavations of the $1-\mathrm{x}-1-\mathrm{m}$ test units, and the importance of some areas was to be assessed through the excavation of the small blocks to obtain data on material abundance, diversity, and spatial distribution. Although the monitoring process was uneven at the outset of the program, the team of monitors developed a routine geared toward watching for and recording the occurrence of buried materials onsite. In principal, one monitor watched the excavation process to identify in situ materials, and to measure and record the general depth of the trench at each pass of the bucket; the second monitor watched the dumping of the back dirt, looking for bone, burned rock, freshwater mussel shell, or other materials showing up in the spoil pile. The second monitor also used a shovel to probe the back dirt to check for materials, but no effort was made to systematically screen samples of the back dirt. The removed fill was probed as a standard good faith effort to find artifacts that would likely be used by monitors on other projects. When artifacts were noticed, the monitors used a monitoring form to record their discoveries, along with the trench number and relative depth of the identified materials. Unless the objects were diagnostic implements, little attempt was made to collect fragments of burned rock, shell, and bone. In practice, the attempt to gather depth observations on artifacts was not as smoothly implemented as desired.

Even though microtopography is clearly evident on the landscape, no attempt was made to compile a topographic map of the alluvial terrace due to the dense vegetation cover over most of the site. Instead, the locations of the backhoe trenches were documented using a GPS device, and the results were imposed over the project area aerial photograph. The GPS data were also used to document trench locations sketched on 11-x-17-inch graph paper that was annotated and used as a guide for plotting observations throughout the field project. Additional data about the size and depth of each trench were manually recorded and retained.

Upon completion of the excavations, the project geomorphologist photographed and provided geomorphic descriptions of each trench. Typically, the machine-smeared wall was cleaned prior to making descriptions, and standard soil taxonomy methods were used to provide a measured description of a representative wall from each trench. The geomorphologist also collected a 
series of samples from each stratum that could be used to process radiocarbon samples and for texture and chemistry analyses. A preliminary series of eight sediment and charcoal samples was submitted for dating, and the results are integrated in the geomorphic descriptions below and in a report appendix. Information from the geomorphology and trench monitoring activities helped determine the placement of hand-dug test units.

\section{STAGE 2: DEEP TEST UNIT MANUAL EXCAVATIONS}

Simultaneously with the geomorphic investigations, a series of 10 hand-dug test units was placed at select exposures in order to sample the occurrence and diversity of materials relative to the kinds of items observed in mechanical trenching. The contract and permit called for the placement of most units on trenches yielding artifact evidence from the monitoring exercise, but at least one test unit was required next to a "culturally sterile" trench to evaluate the reliability of the trench monitoring activity. Due to the scarcity of materials observed during trench monitoring, only 10 test units were excavated. These units, measuring $1-\mathrm{x}-1 \mathrm{~m}(3.3-\mathrm{x}-3.3 \mathrm{ft})$, were excavated in 10-cm (4 in) arbitrary intervals from surface to a depth of $2.00 \mathrm{~m}(6.6 \mathrm{ft})$ or $2.10 \mathrm{~m}(6.9 \mathrm{ft})$ if cultural remains were found at the twentieth level. The ground surface served as the basis for measuring depths of levels. Fill from test units was screened through 0.625 millimeter ( $\mathrm{mm}$; .025 in) hardware cloth; all lithic debris, chipped and ground stone tools, bones, and freshwater mussel shells were collected, but only a sample of 10 Rabdotus snails per level and burned rock was kept. In many instances, the test units were placed near areas where artifacts or debris were noted during the monitoring activities. Only when concentrations of artifacts (burned rock) were encountered were sediments collected for later flotation.

As a result of Occupational Safety and Health Administration (OSHA) safety standards that require special stepped excavations if test excavations exceed 5 feet $(1.5 \mathrm{~m})$, GMI crews were required to mechanically strip off a $0.5-\mathrm{m}$-thick (1.6 ft) safety bench around the tops of all 1-x-1$\mathrm{m}$ units targeted for manual excavation before reaching the defined OSHA depth in order to accommodate safety requirements. The use of sloping sidewalls was rejected as impractical due to the goals of the excavations. The project geomorphologist was designated as the responsible party to assess the sediment safety from sidewall collapse. Thus, the test units were initially excavated to depths of between 0.5 and $1.2 \mathrm{~m}(1.6$ and $3.9 \mathrm{ft})$. Nails were inserted into the test unit wall to document the boundaries between levels as subsurface elevation data. The upper profiles of each unit were drawn and photographed. Then the backhoe mechanically stripped off a "safety collar" of at least $0.5 \mathrm{~m}(1.6 \mathrm{ft})$ thick. Crews manually cleaned the rubble from the holes, and the nail referencing elevation data were used to reestablish the test units. Manual excavations resumed to depths of 200 or $210 \mathrm{~cm}$ ( 79 or 83 in) bs without requiring OSHAregulated safety shoring or trench-stepping procedures. The field director and the principal investigator used the results from the various test units to evaluate the number and placement of occupation zones worthy of testing through formal 9-square- meter $\left(\mathrm{m}^{2}\right)$ areas.

In addition to the stratigraphic samples collected by the geomorphologist, the field archeologists collected a continuous set of samples $(10-\mathrm{x}-10 \mathrm{~cm}$ horizontally by $5 \mathrm{~cm}$ vertically [4-x-4-x-2 in]) from three columns of sediments from surface to a depth of $2.00 \mathrm{~m}(6.6 \mathrm{ft})$ next to Trenches 1, 19, and 22. These samples provide a continuous record of artifact density of materials such as snails, etc., that were sampled only during the excavation of the test units. The column samples also have the potential to provide data on magnetic susceptibility of the deposits and can supplement color, texture, and chemical samples collected from particular zones by the geomorphologist. 
Two of the three columns were collected from areas that served as a focus for block excavations, and the column samples have direct relevance for contributing further information about these block areas.

The dark sediments of the West Fork paleosol were found in all excavation trenches, and the enriched organic horizon was generally too dark or bioturbated to permit the recognition of prehistoric pits or posthole features and perhaps even some stratigraphic unconformities. During mechanical trenching, several areas contained amorphous charcoal and/or oxidized burned stains spanning $50 \mathrm{~cm}$ (20 in) or more of the profile and often angling at step inclines; these were regarded as tree burn events and were not treated as cultural features. Based on prior experience in excavations in the Trinity River alluvium at 41TR174 (Lintz et al. 2004), it was thought that freshwater mussel shell or bone concentrations might be encountered and these would warrant feature designation. However, such was not the case at 41TR170. The primary material classes designated as features were multiple pieces of burned rock in clusters, mounds, or depressions. Other concentrations of bones and soil discolorations beneath the paleosol had the potential to be designated as features but were rarely used. Only eight features were designated during the initial backhoe trenching and excavation of the deep test units. These consist of one area with concentrated charcoal flecking (Feature 5) and seven burned rock concentrations (Features 1-4, 7-9; Feature 6 was used in later block excavations).

The designation of rock clusters as features afforded greater documentation, and they were excavated differently from the standard levels. In general, rocks comprising a feature were exposed in plan view and were profiled. Each was mapped in plan view and profile, and each feature was photographed. Many rocks were assigned a specimen number, and the top and bottom elevations of the rocks were recorded. On some maps, the direction of the downward slope of the rocks was recorded. Initially, when few rocks were treated as features, each rock was bagged with the number corresponding to the plan view map and returned to the laboratory for further analysis regarding size, shape, and material type. However, later when large rock features were encountered, the rocks were documented in the field. Rock sizes were measured in 5-cm (2 in) intervals $(<5,5-10,10-15,15-20,20>$, etc.), sorted into size groups and material types (sandstone, limestone, or other), and weighed as a class grouping. Burned sandstone rocks were numbered on the site maps and individually collected to provide maximum context data on specimens for possible lipid residue analysis.

In an effort to recover minute charred plant remains from features, a series of sediment samples from feature fill was collected. These samples consisted of sediments from one or more bags each of a 12-liter galvanized bucket. In addition, the presence of rock features also signified the possibility of an associated occupation surface. Therefore, other sediment samples were collected from one corner of each level of test units containing a feature during the deep testing and during the subsequent block excavation phase of investigations. These samples were collected for waterscreening or flotation to recover minute artifacts that would be missed during conventional screening and macrobotanical remains for dating and subsistence analysis. Insofar as few of these samples have been processed to date, it is possible that the frequency of artifact counts reported in this report may increase, especially since these samples were from layers that likely represent cultural zones. 


\section{STAGE 3: MANUAL EXCAVATION OF SMALL BLOCKS}

The final phase of fieldwork called for archeologists to establish no fewer than three and no more than five $9-\mathrm{m}^{2}$ blocks next to trenches with the highest potential to contain archeologically exploitable deposits. Due to the paucity of cultural material found through deep testing, only three blocks were examined during the testing at 41TR170. The principal investigator and project archeologist chose the locations for the blocks based on the results of trenching and deep test unit excavations. One main source of information was the tabulation of artifacts (flakes, tools, bones, shell, burned rock, etc.) on individual level forms maintained during the manual excavation of the deep test units. These data were supplemented by stratigraphic observations of sediments and the distribution of features.

The shape of the blocks varied in configuration (i.e., 3-x-3 m, 1-x-9 m, or another layout) based on the presence of cultural zones, distribution of features, or other considerations, including the configuration of the stripped overburden above the target excavation area. The results from these block excavations serve as the basis for assessing the potential for the recovery of horizontally distributed cultural materials associated with single occupations or repeated occupation over relatively short time periods.

The scope of work called for the blocks to be excavated in layers no thicker than $40 \mathrm{~cm}$ (16 in), specifically targeting culturally dense occupation zones. Furthermore, the units comprising the excavation blocks were to be dug in incremental units no larger than 1-x-1 m (3.3-x-3.3 ft) in size and in levels no thicker than $10 \mathrm{~cm}$ (4 in). Identified features might cause deviation in these standard methods in order to maximize the understanding of the feature context and the associated materials. The fill overlying the targeted occupation zones was mechanically stripped, and for targeted zones deeper than $1.5 \mathrm{~m}(4.9 \mathrm{ft})$, a larger excavation hole or safety benches were mechanically stripped around the edge of the block in compliance with OSHA safety requirements.

The project scope stipulated that blocks be placed next to different trenches unless locations were not available in five different trenches or some other compelling reason (including absence of suitable cultural zones) existed to concentrate the blocks in fewer than three locations. Initial assessment of the artifact recovery identified two areas yielding burned rock features about $100 \mathrm{~cm}$ (39 in) deep near Trench 19 along the south edge of the site (Block 1) and massive ashy deposits with bone preservation and artifacts about $200 \mathrm{~cm}$ (79 in) deep at Trench 22 north of the relic river channel (Block 2).

The mechanical excavation of Trench 19 encountered an unusually high density of burned rock features. As a means of determining the configuration of the burned rock extent and to help plan the configuration of Block 1 and maximize the information recovery, a series of supplemental test trenches (designated A-E) was dug, and the overburden was stripped away to just above the burned rock in a fairly large area. This led to the recognition of concentrated burned rock over a sizable area measuring at least $12-\mathrm{x}-12 \mathrm{~m}(39-\mathrm{x}-39 \mathrm{ft})$. Discussions with regional archeologists ascertained that no comparable density or size of burned rock feature has been documented in the Trinity River basin (Duane Peter, Dan McGregor, Maynard Cliff, personal communications 2005). The density of features in this area contrasted with the overall very low occurrence of remains in other parts of the site within the TxDOT ROW. The principal investigator and the project archeologist decided that the investigation area of Block 1 was too small and inadequate to assess the size, shape, and diversity, as well as the significance, of large burned rock features in 
this large area. In order to enhance an understanding of the burned rock density and diversity in this amorphously stripped area, a 2-x-2-m (6.6-x-6.6 ft) grid oriented to that used for Block 1 was expanded over the stripped area, and the presence of burned rock was determined by probes placed at a series of $50-\mathrm{cm}$ (20 in) intervals along the grid (Figure 4). Consultation with TxDOT archeologists was conducted, and a second noncontiguous manually dug area (Block 3) was placed near a trench used to delineate the extent of burned rock (subsequently designated as Trench 29, although this trench was not documented by the project geomorphologist). Thus, noncontiguous Blocks 1 and 3 were placed over this occupation zone to increase an understanding of the diversity and complexity of features in this large burned rock area (Figure $5)$.

In addition to the standard photographic documentation of the feature areas, detailed mapping of burned rock and other feature information was compiled on plan maps that encompassed multiple excavation units of any particular block. Such maps were compiled for each level of an excavation block. The maps also document the spatial clustering of the rocks and help delineate the limit of discrete features.

As required by the scope of work, test units were excavated in series of $1-\mathrm{x}-1-\mathrm{m}(3.3-\mathrm{x}-3.3 \mathrm{ft})$ units that were assigned sequential numbers bearing no coordinates within the blocks. In Block 1, eight full 1-x-1-m (3.3-x-3.3 ft) units were excavated in a 3-x-3-m block configuration adjacent to deep Test Unit 2. In addition, the northern halves of two other test units were dug to capture the parts of a burned rock feature exposed in the sidewall of Trench 19. Thus, the test units comprising Block 1 were designated 2, 11-18, N19 (north half), and N29 (north half). The units for Block 2, placed north of the relic channel adjacent to Trench 22 and Test Unit 4, were designated Test Units 20-28, and excavated squares comprising Block 3, in proximity to Block 1, were designated Test Units 30-38. The distribution of test unit numbers in each of the three blocks is provided in Figure 6.

Following the scope of work guidelines, all units were excavated in 10-cm (4 in) intervals to a depth of $40 \mathrm{~cm}$ (16 in). However, excavation of Block 2, north of the relic channel, investigated a thick ashy zone containing abundant small, burned clay daub and charcoal, with bones, shells, and artifacts, which tended to be about $40 \mathrm{~cm}$ (16 in) thick but sloped slightly down toward the relic river channel. By the end of the excavation of the 40-cm-thick (16 in) occupation zone $(170-210 \mathrm{~cm}$ [67-83 in] bs), a number of test units along the south edge of the block still contained the ashy matrix. Investigators suspected that the matrix might reflect parts of a prehistoric house structure, but had yet to find conclusive evidence of postholes or hearth features at the basal contact of the excavation zone. In order to examine the basal contact of the ashy zone, excavators removed the ashy fill from Level 22 (below $210 \mathrm{~cm}$ [83 in] bs) as a natural level (to the basal contact with the nonashy substrate) from these test units to look for evidence of structural features; no evidence of architectural features was found.

Features excavated during Stage 3 were treated in the same manner as in the second stage of fieldwork. Features were exposed in plan view and cross-sectioned. A series of large-scale block maps was developed to show the spatial occurrence of features. At times, the surface slope of the rocks was indicated. Many rocks were assigned specific numbers on the base maps, and these were point-plotted with top and bottom elevations and collected for further studies; special emphasis was placed on saving sandstone rocks for possible lipid analysis. Several liters of feature sediment were collected for flotation and waterscreening. Specific feature forms were completed, and the features were photographed. When high densities of burned rock were 


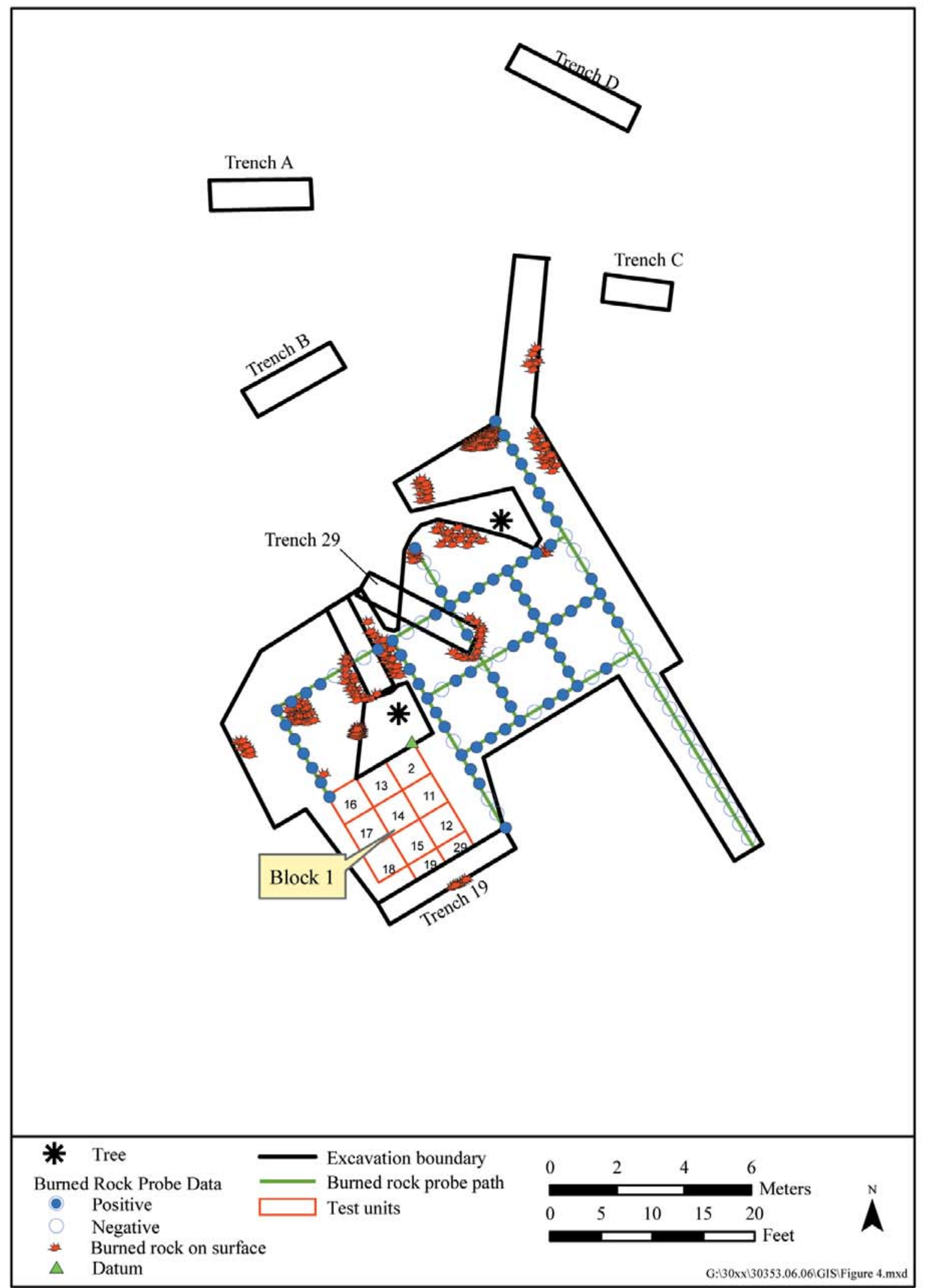

Figure 4. Distribution of burned rocks around Block 1 as determined by probes. 


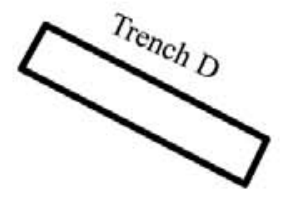

Trench A
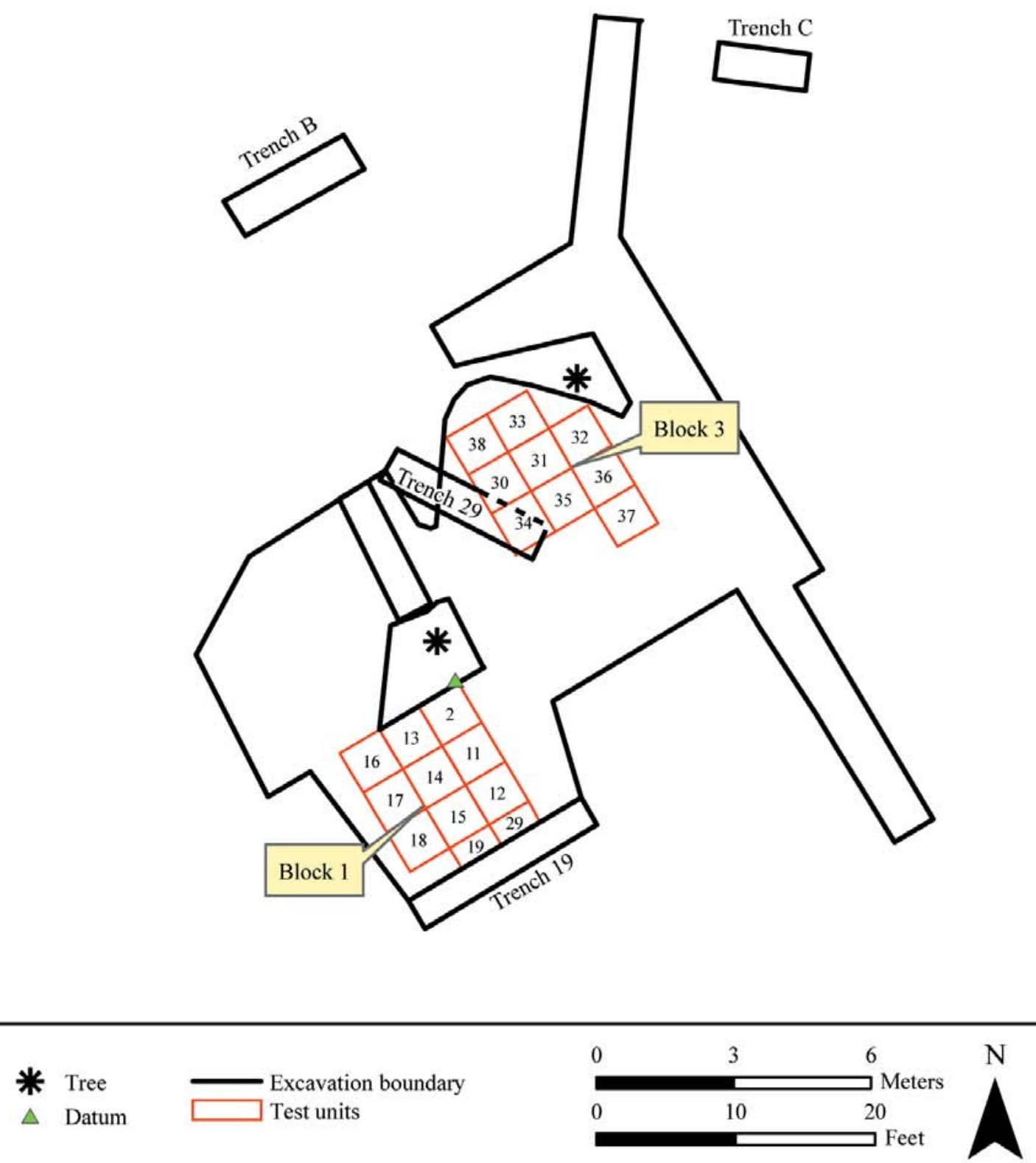

G:130xx\30353.06.06 GIS।Figure 5.mxd

Figure 5. Spatial relationships of Blocks 1 and 3 at the south end of site 41TR170. 


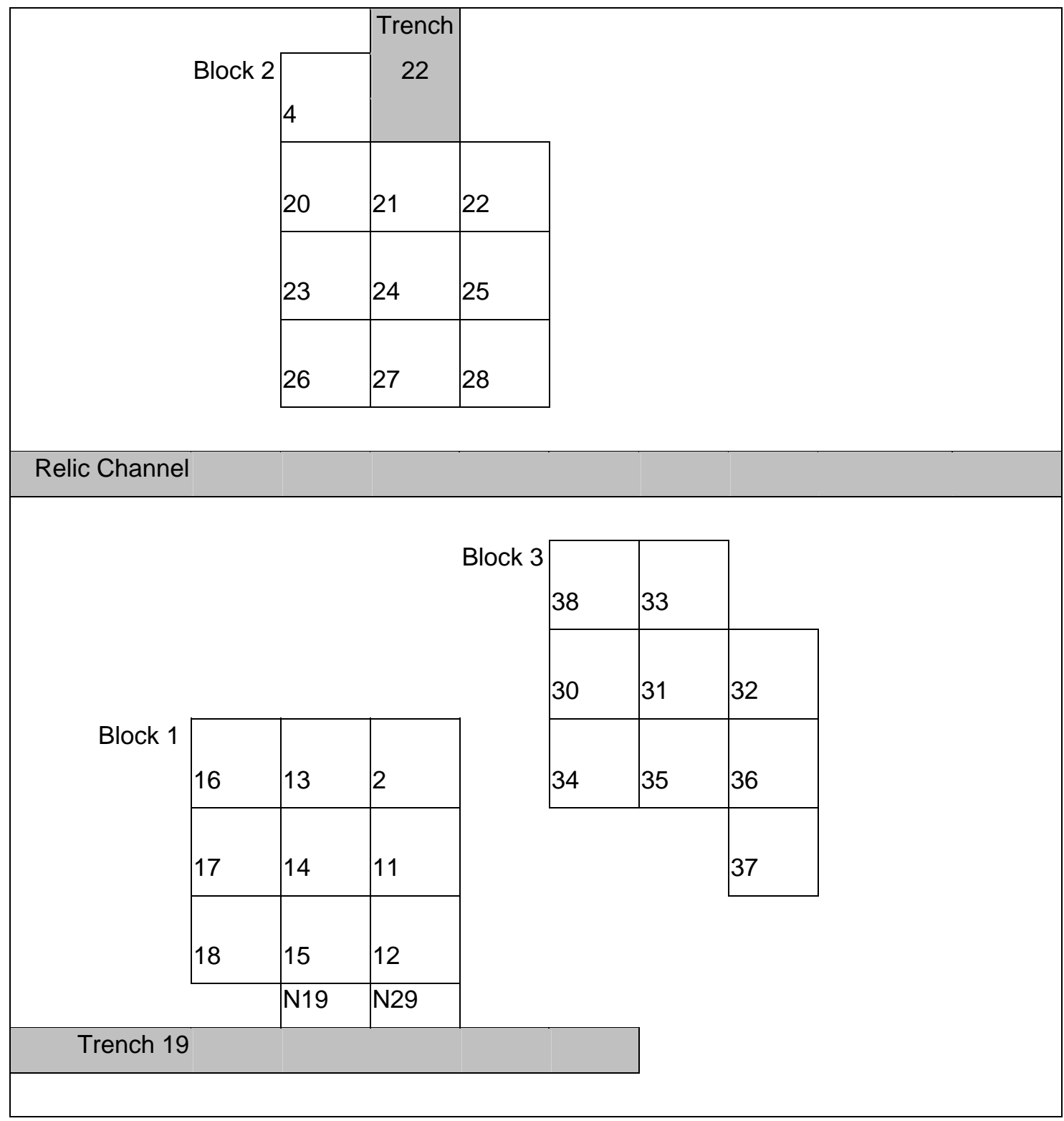

Figure 6. Schematic showing test unit designations within Blocks 1, 2, and 3 at site 41TR170.

encountered, the process of recording number, size grade, material type, and weight was completed in the field, and the rocks were left onsite. Altogether, five features each were documented in nearby Blocks 1 and 3 at the south end of the site, and three features were recorded in Block 2, located north of the relic channel (Table 3).

Upon completion of the excavation of the three blocks, all excavation units were mechanically backfilled. No further efforts to dig trenches to discern limits of the ash features in Block 2 were authorized or undertaken. The procedures used to backfill the site involved the placement of black plastic sheeting along the walls of the three excavation blocks and addition of about $30 \mathrm{~cm}$ (12 in) of backfill over the excavation area. Then, orange plastic trench protective webbing was 
Table 3

Test Units and Features Comprising Excavation Blocks 1, 2, and 3 at Site 41TR170

Block No. 1, South End of Site, Adjacent to North Side of Trench 19 Test Units Level 10 Level 11 Level 12 Level 13

\begin{tabular}{cccccl} 
Test Units & Level 10 & Level 11 & Level 12 Level 13 & Feature \# & Unit \# \\
\hline 2 & F*-9 & F-9 & & F-6 & 18 \\
11 & & & & F-9 & 2,13 \\
12 & F-10 & & & F-10 & 12,15, N19, N29 \\
13 & F-9 & F-9 & & F-11 & 16 \\
14 & & & & F-13 & 16,17 \\
15 & F-10 & & & & \\
16 & F-11 & F-13 & F-13 & & \\
17 & & F-13 & F-13 & & \\
18 & F-6 & & & & \\
N19 & F-10 & & & & \\
N29 & F-10 & & & & \\
\hline
\end{tabular}

Block No. 3, North of Block 1, Adjacent to North Side of Trench 29

Test Units Level 10 Level 11 Level 12 Level 13

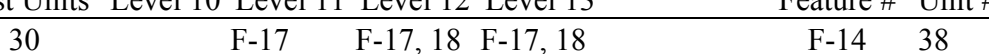

$\begin{array}{llllll}31 & \text { F-17 } & \text { F-17 } & \text { F-17 } & \text { F-15 } & 33\end{array}$

32 F-16, F-16 F-16 32, 36, 37

33 F-15 F-15 F-17 34, 35, S30, S31, SW 36, W37

$\begin{array}{llllll}34 & \text { F-17 } & \text { F-17 } & \text { F-17 } & \text { F-18 } & 30,38\end{array}$

$35 \quad$ F-17 $\quad$ F-17 $\quad$ F-17

$36 \quad$ F-16, 17 F-16, 17 F-17

37 F-16, 17 F-16, 17 F-17

$38 \quad$ F-14 F-14

Block No. 2, North of Relic Channel, Adjacent to South End of Trench 22 Test Units Level 18 Level 19 Level 20 Level 21 Level 22 Feature \# Unit \#

\begin{tabular}{lllllll}
\hline 4 & F-3 & F-3 & & F-3 & 4,20 \\
20 & F-3 & F-3 & F-12 & & F-12 & 20 \\
21 & & & & F-20 & F-20 & $21,22,24,25$ \\
22 & & & F-20 & \\
23 & & & & \\
24 & & F-20 & \\
25 & & F-20 & \\
26 & & & & \\
27 & & & & \\
28 & & & & \\
\hline
\end{tabular}

$* \mathrm{~F}-=$ Feature-\# 
placed over the excavation area as a warning marker to delineate the locations of the entire mechanically stripped areas that contained three excavation blocks. Should additional excavations be required in these areas, the webbing was to signal the approach of the target excavation areas, and the black plastic wrapping the walls of the 40-cm-block (16 in) limits should serve as an indication of where the controlled excavations stopped. After mechanical backfilling, the ground surface was restored to pre-excavation grade.

\section{STAGE 4: INITIAL PROCESSING AND PREPARATION OF AN INTERIM REPORT}

Simultaneously with fieldwork, laboratory staff began the process of cleaning and sorting the artifacts obtained from the excavations. The individually collected artifacts were washed and dried, then sorted and counted by material class within discrete bags. The cleaned artifacts were not labeled with site numbers, but maintained in bags assigned discrete numbers for each artifact provenience. The artifact counts for items such as bone and shell reflect the number of fragmentary specimens present and do not reflect the minimum number of individuals or minimum number of elements; thus, if one bone was broken into a dozen pieces, the entry recorded a dozen items of bone from the provenience lot. These data were used to establish an Access database that lists the Field Specimen (FS) number, the provenience of materials, the rough counts of artifacts, and the general artifact classes from the project. Coordination with the Texas Archeological Research Laboratory (TARL), which will ultimately curate the collections from 41TR170, indicates that catalog lot numbers for the testing phase of the project should start with \#76 and photographic prints should start with \#58, so that the artifact processing does not duplicate the lot numbers assigned during the survey phase from the site.

All photographs from the project have been processed, and the field photographic logs have been entered into an electronic database. Site records were organized and grouped by test units in file folders and notebooks. In addition, GPS data on backhoe trench, test units, and excavation block locations were plotted, rectified, and superimposed over aerial photographs that also depict the proposed ROW edge as published in the environmental assessment report posted on the TxDOT web site. Other graphics were developed from select field maps in both electronic and paper formats.

No detailed or formal analysis of the artifacts was undertaken for preparation of the initial interim report. However, the chipped stone debris was examined to identify the approximate number and general kinds of stone tools in the assemblage. Similar examinations were conducted on historic artifacts and ground stone tools. Bones and shell were checked to ascertain whether seemingly high counts of remains were real or the result of excavation damage.

Only 12 of the 149 collected sediment samples from feature and nonfeature (test unit) contexts were initially processed by GMI staff in order to identify the presence of organic material preservation. A 5-liter (5.3 quarts [qt]) subsample of each sediment bag was extracted for flotation recovery using $0.5-\mathrm{mm}(.02 \mathrm{in})$ and $6.25-\mathrm{mm}(.25 \mathrm{in})$ geological sieves to capture very fine and coarse particles. The remainder of the sample was processed using waterscreening methods through a $6.25-\mathrm{mm}(.25 \mathrm{in})$ screen and a pressure hose in order to retrieve artifacts comparable to that from the dry screening methods used in the field. The flotation was designed to obtain a minimally damaged assemblage of small charred remains from the specific provenience context. The heavy fraction component was also saved and dried. Only a cursory examination of these samples to look for the existence of organic remains was made during development of the initial interim report. 
Later, 15 other sediment samples were sent to Dr. Phil Dering for flotation recovery and macrobotanical identification. These samples ranged from 3 to 5 liters $(3.2-5.3 \mathrm{qt})$ each, but the submittal of multiple samples from the same feature was designed to examine the recovery of macrobotanical remains from up to 10-liters $(11 \mathrm{qt})$ of sediments from a single feature. Some of the identified charred botanical remains were then submitted for radiocarbon dating of specific features.

Eight bulk sediment and carbon samples collected by the geomorphologist were prepared and submitted through TxDOT ENV for radiocarbon dating to define the geomorphic context of the site. These samples were explicitly collected near stratigraphic boundary zones to provide information about the changing depositional regimes on site. During later stages of the analysis, eight other macrobotanical samples were submitted through TxDOT ENV in order to chronometrically date the cultural features and occupations from the three target excavation blocks.

The interim report was based primarily on information derived from the Access database. After data were entered, the database entries were proofed for typographical accuracies. Some rechecking of data occurred during this period. Specific material classes derived from this project consist of one continuous sediment column sample of alluvial terrace sediments and other sediment samples from features and occupation surfaces for flotation and fine screening. Also collected were burned sandstone samples for lipid studies, other burned rocks from feature and nonfeature contexts, organic/charcoal samples, burned clay or daub samples, lithic debris and lithic tools, ground stone tools, bones, freshwater mussel shells, land snails, and historic artifacts.

\section{STAGE 5: SUBSEQUENT PROCESSING FOR THE REVISED INTERIM REPORT}

Upon review of the initial interim report, TxDOT ENV staff directed GMI to conduct additional laboratory studies in order to further document the age of the important cultural components and further document the preservation conditions for the organic remains from the site. Additional literature review was also requested in order to provide a context for making recommendations and guiding further work if the site were to be deemed eligible for inclusion in the NRHP and future investigations were warranted. Information from these studies was to be integrated into the body of the report.

The freshwater mussel shells and bones were examined for this stage of investigation. For the freshwater shells, a count was made of the umbos or hinge segments as a means of quantifying the frequency of the number of individual specimens (NISP), as opposed to the raw count of total fragments or number of specimens (NSP) (Appendix H). This distinction becomes critical since freshwater mussel shells tend to readily fragment into many pieces, which provides a very misleading count of individuals.

One significant data gap in the initial interim report involved ascertaining the preservation of macrobotanical remains, especially from feature contexts. Since charred macrobotanical remains are rarely reported from sites in the Trinity River basin, such data have tremendous potential to provide information about prehistoric subsistence activities or regional habitat conditions. Accordingly, 15 sediment samples were selected from feature and nonfeature contexts from the three main excavation blocks and sent to Dr. Phil Dering. A consistent 5-liter (5.3 qt) sample of matrix from each feature was processed using a flotation device, and both the light and heavy 
fractions of these samples were identified. The macrobotanical data are integrated into this report and provided as an appendix at the end of the report. Similarly, Dr. Mary Malainey was sent a single burned rock from two features in each of the three blocks for the extraction and general identification of prehistoric lipid residues from the outside of the heated stones. Her results based on these six lipid samples are also summarized in the report and provided as an appendix to this report. In addition, a series of eight identified macrobotanical/charred wood samples from direct feature contexts as identified by Dr. Dering was submitted to Beta Analytic Radiocarbon Dating Laboratory (Beta Analytic) to chronometrically date the cultural features found in the three excavation blocks at the site. These results are also integrated into the body of the final report and included as an appendix. Note that the specific samples sent to outside consultants are referenced in this report by the original FS number, the TARL catalog lot number, and sometimes, with the lipid samples, a specific rock number. This cross-referencing ensures a cross-referenced procedure that maximizes the retention of provenience data.

Finally, in order to understand the importance of the burned rock features at 41TR170, a literature review was conducted to determine the prevalence of burned rock features in the region, as well as to provide some baseline data about the uniqueness of the kinds of burned rock features present at the site. The impression gained from many archeologists working in the Dallas-Fort Worth region is that, unlike Central Texas, burned rock features are relatively rare or, when encountered, tend to be small. Insofar as a relatively high density of burned rock features was found at specific settings at 41TR170, the popular perception was that the situation was a rather rare event. However, since the site is along the Clear Fork of the Trinity River and is only some $8 \mathrm{~km}(5 \mathrm{mi})$ from the Brazos River drainage divide, any regional summary must include data from both the upper Trinity and middle Brazos river basins.

In order to collect information about the occurrence of burned rock features in the region, an 80$\mathrm{km}$ (50-mile) radius around 41TR170 was selected as a target area. Information on isolated and feature-based burned rock from all 15 counties within this target radius was included in the study area. Data from the Trinity River basin were derived for Wise, Denton, Collin, Tarrant, Dallas, Ellis, and portions of Jack, Parker, Johnson, and Hill counties. Data from the Brazos River basin were derived for Palo Pinto, Erath, Hood, Somervell, Bosque, and portions of Jack, Parker, Johnson, and Hill counties. The initial sources for data about burned rock occurrences and feature types were the electronic Texas sites atlas maintained by the THC and TARL. Refinements in the nature of sites in the region were obtained by consulting regional overview studies. The results are presented in Chapter 6 .

\section{STAGE 6: DETAILED ANALYSES AND FINAL REPORT PREPARATION}

The final stage of investigation consisted of detailed analyses and the preparation of a final report. The tasks included in this phase of investigation include geomorphological analysis, inventory, screening and discard, detailed lithic and faunal analyses, and the preparation of a draft and final report, as well as the preparation of materials for curation. Due to the recovery of little to no macrobotanical remains, the washing and inventory of all materials collected during archeological testing included screening all of the sediment samples. All but one of the column samples taken during the testing phase were screened as well. One column sample from Trench 19 was retained for curation. 
Detailed geomorphological analyses include textural and chemical analyses of the geomorphic sediment samples collected during testing to better document the various depositional units in the Clear Fork terrace. These analyses will contribute important information about the paleoenvironmental sequence of the region since they are associated with dated sediments. The proposed analyses consist of the following: granulometric analyses of sand (1-phi), silt, clay, organic matter, and carbonates; and stable carbon isotope analysis of the organic matter from Trenches 6 and 14.

\section{Laboratory Methods and Artifact Analysis}

Initially, all artifacts were cleaned and placed in 4-mil plastic bags. Artifacts were rough-sorted into different bags based on material and artifact type within provenience. These bags, in turn, were placed in fresh 4-mil level bags, and each bag was labeled on the outside with its provenience with permanent marker. Information on the outside of bags included project number, site number, test unit number, level number and depth, collector's initials, and date.

All artifact analyses were conducted by the principal investigator, qualified project archeologists, and/or outside consultants demonstrating the necessary expertise. Laboratory technicians assisted in analyses.

\section{Lithic Artifact Analysis}

The goals of the lithic analysis were to provide information about site function, technology and production, lithic source procurement (exchange/interaction), and cultural affiliation based on the presence of diagnostic chipped stone tool types. In order to address these diverse issues, stone materials were initially separated into five main classes: (1) chipped stone tools, (2) chipped stone debitage, (3) cores, (4) ground, pecked, and battered stone artifacts, and (5) unworked lithics (fire-cracked/burned rock and manuports).

All artifacts were examined macroscopically, or occasionally with a $15 \mathrm{X}$ hand lens, to search for signs of use and wear. Only stone pieces with formal retouch, consistent incidental flake scars, or formal shaping were classified as tools; other materials were classified as manufacturing debitage, cores, or nonchipped-stone items. Without the use of a high-power microscope, it is difficult to differentiate purposeful edge modification from edge damage that occurs as a result of use or postdepositional disturbance.

Chipped stone lithic materials (tools, debitage, and cores) were sorted by class or implement type, stone tool material type (siltstone, chert, etc.), condition (proximal, medial, distal, indeterminate), percent of cortex present (100 percent, primary; 1-99 percent, secondary; or 0 percent, tertiary), size, and evidence of heat treatment as indicated by potlid, crazing, or discoloration. Counts and weights were collected for each sorted group.

Lithic material types were identified based on attributes of texture, color, luster, and rock classification. Many of the cherts were obviously river gravels from the San Antonio River. River gravels tended to have rounded edges and were stained to a yellow-brown color. Similarly, instances of thermal alteration were noted by the occurrence of heat treatment or damage as indicated by potlidded surfaces, crazing, or reddish discoloration. 
The primary distinction for chipped stone is between tools, which include any flaked stone artifacts that exhibit either use-wear or purposeful modification, and debitage, which is manufacturing debris, or flakes, that does not show any macroscopically obvious signs of retouch or edge damage. Chipped stone tools, at a minimum, include bifaces, projectile points, flake tools, and unifaces. By definition, a biface is any flaked stone tool that has substantially modified ventral and dorsal surfaces; bifacial flaking is not limited to the edge of the artifact. Relatively unrefined bifaces may be modified over less than 50 percent of either or both faces, but all later stage bifaces must be modified over at least 50 percent of both dorsal and ventral faces. A projectile point is (usually) a finished bifacial tool that appears to have been hafted on a spear, dart, or arrow and whose main function appears to have been penetrating the hide of prey. Any finished (i.e., finely worked) biface, regardless of size, with a formal sharpened tip or evidence of hafting is considered a projectile point. Some "unifacial" projectile points that do not fulfill the entire biface definition may still be considered projectile points because of their sharp tips and evidence of preparation for hafting.

Flake tools are those flakes that show purposeful retouch to one or more edges and include the forms that are traditionally known as side scrapers, end scrapers, spokeshaves, and other lessrefined forms. They are distinct from edge-modified flakes, which are flakes whose edges have been altered only through use or postdepositional damage. Without the use of a high-power microscope, it is difficult to differentiate between purposeful edge modification and edge damage that occurs as a result of use or postdepositional disturbance. Flakes with modified edges are only considered flake tools if the flake scars along the edge of the piece "invade" either the dorsal or ventral face of the tool more than $2 \mathrm{~mm}$. Although somewhat arbitrary, this is a standard measurement used in other studies. The distinction between flake tools and edge-modified flakes helps distinguish those artifacts in which a significant amount of effort was invested in their shaping from those that were used with less refinement.

Cores (also known as "objective pieces") are pieces of flaked stone used primarily as sources for flakes that were further reduced/manufactured into tools; occasionally, however, the core itself was used as a core/cobble tool. Cores are found in a variety of forms, but amorphous cores with multiple platforms and little deliberate shaping are probably the most common. Other forms include bipolar cores, which are created through use of a hammer and anvil, and unidirectional cores, which have a single platform.

\section{Chipped Stone Tool}

Chipped stone artifacts with formal symmetrical or asymmetrical shaping or exhibiting systematic unifacial or bifacial flake scars were regarded as tools, separate and distinct from cores or debitage. Chipped stone tools were separated into three classes: (1) projectile points or portions of projectile points (established as a distinct category because many are time and culturally diagnostic), (2) bifacial implements, and (3) unifacial implements. The size of individual pieces was measured using spreading calipers to the nearest tenth of a millimeter. Items were counted and weighed to the nearest tenth of a gram. Other observations included the amount of extant cortex, stone material type, and condition. Each tool was counted and specific attributes recorded. 
Projectile points were classified as haftable bifaces with a defined base, stem, and shoulders. The distinction between dart (large) and arrow (small) points was based on overall size. If sufficient amount of the point was present, it was compared to established named types (Turner and Hester 1999). These names form the basis for ascertaining the cultural affiliations and time periods present. In addition, measurements were taken for the maximum overall size, and the length and width of the stem element.

Projectile points are likely to be the only reliable indicators of relative site age during fieldwork and as such are of critical importance to the chronological research domain. Application of comparative type-variety analysis provides both refined temporal data and sociocultural group relationships in cases where specific varieties of a type have complementary distributions interpretable as sociocultural group boundaries. Identification of nonlocal raw material sources for projectile points, and their potentially derived thinning flakes, provides data on the locations of previously visited localities. Material source identification thus helps reconstruct part of any seasonal round of movement, trade, and/or areas exploited by extractive teams operating from the same base camp(s) as those present at the study area (Brown and Vierra 1983; Nance 1987; Stafford 1991, 1994). The utility of projectile point data is largely dependent on the overall sample size and the relative frequency of projectile points.

Bifacial implements refer to nonprojectile point implements. If a generalized biface, rather than an elaborate form, was represented, the specimen was classified according to the Callahan biface reduction or manufacturing stages (Callahan 1979). Callahan's Stage 1 was not used, since it refers to an unmodified and unshaped blank suitable for making a biface. The following are summaries of Callahan's Biface Stages 2 through 5:

- Stage 2 biface, also called a rough-out, generally has little emphasis on shape reduction or thinning, but instead has a few large flake scars removed to create an initial bifacial working edge around the circumference of the objective piece. These crude bifaces tend to be thick relative to width (a width-to-thickness ratio ranging from 2:1 to 3:1) and have very sinuous edges and no emphasis on reduction in the middle of the biface.

- Stage 3 biface, also called primary preform, exhibits initial stages of thinning and shaping. These specimens show the initial efforts to drive flakes entirely across the face of the implements and have lenticular cross sections and a centered biconvex edge. They tend to be somewhat thinner (width-to-thickness ratio ranging from 3:1 to 4:1) and have the beginning of a generalized geometric shape and slightly less sinuous edges.

- Stage 4 biface, also called secondary preform, demonstrates a focus on creating a symmetrical outline with a flattened, lenticular cross section and straighter, slightly sinuous, centered, bi-convex edges. The width-to-thickness ratio ranges from 4:1 to 5:1.

- Stage 5 biface, also called final or thinned preform, is symmetrical, with a relatively parallel-sided outline reminiscent of the final tool shape. These bifaces have a flattened, lenticular cross section and straight, nonsinuous edges. The width-to-thickness crosssection ratio ranges from roughly 5:1 to as thin as 10:1. 
Some bifacial implements were produced as other formal tools and were identified based on specialized shape and functional requirements. Bifacial implements were classified by function, such as knife, perforator/drill, graver, etc., or by Callahan production stage. Typology and terminology generally followed that provided by Turner and Hester (1999).

Unifacial tools referred to formally and informally shaped implements with edge modification and retouch solely on one face. Formal, shaped unifaces can include scrapers, Albany unifaces, etc. Scrapers were subdivided into categories of end scrapers, side scrapers, end/side scrapers, and scrapers with spurs based on the location of modification on the implement. Informally shaped unifaces included modified flakes, gravers, and notch/spokeshaves. Note that the term modified flake is used to describe visible edge modifications on edge-modified pieces rather than the term utilized flake, which is often based on judgmental opinion on a presumed cause of edge alteration.

Analysis of flake tools can address the technological activities research domain and, if specific types of tasks can be associated with specific locations, also the subsistence patterns domain. Examination of apparent working edges of flake tools attempted to provide insight into this area by identification of probable uses producing the observed wear characteristics, such as scraper use on hides vs. wood, when possible.

\section{Chipped Stone Debitage}

Debitage analysis was undertaken on each of the assemblages collected during the current project. Discarded remains from chipped stone tool manufacture were assigned to the category of chipped stone debitage. Material in this class was sorted into subgroups of flakes (core, biface thinning, blades, notching flakes, tool rejuvenation, and indeterminate fragments), shatter, or potlids. The focus of this analysis was to determine the types of lithic technologies represented at each site and to delineate the specific reduction stage or tool use that occurred. Analysis focused on three factors: (1) material type, (2) cortical stage of decortication flakes, and (3) reduction stage of postdecortication flakes. The cortical and reduction stages are defined as follows:

\begin{tabular}{|c|c|}
\hline CORTICAL STAGE & CRITERIA \\
\hline Primary & $99 \%$ or more cortex on dorsal surface \\
\hline Secondary & $1-99 \%$ cortex on dorsal surface \\
\hline Tertiary & No cortex on dorsal surface; includes interior flakes and biface thinning flakes \\
\hline REDUCTION STAGE & CRITERIA \\
\hline Shatter & Dorsal and ventral surfaces cannot be identified; can occur at any stage \\
\hline \multicolumn{2}{|c|}{ Core/Decortication Flake: } \\
\hline Early Core & Primary flake with planar platform and less than 3 dorsal ridges \\
\hline Late Core & Primary or secondary flake with planar platform and 3 or more dorsal ridges \\
\hline Interior Flake & Tertiary flake with planar platform \\
\hline \multicolumn{2}{|c|}{ Biface Thinning Flake: } \\
\hline Early Biface & $\begin{array}{l}\text { Secondary or tertiary flake with moderate longitudinal curvature, moderately } \\
\text { steep platform, and less than } 3 \text { dorsal ridges }\end{array}$ \\
\hline Late Biface & $\begin{array}{l}\text { Tertiary flake with moderate to strong longitudinal curvature, moderately steep to } \\
\text { steep platform, and } 3 \text { or more dorsal ridges }\end{array}$ \\
\hline
\end{tabular}


Pressure Retouch Elongated or teardrop-shaped flake, not more than $5 \mathrm{~mm}$ in thickness with nippleshaped platform

All debitage was sorted into the following size ranges:

$<6.4 \mathrm{~mm}(<1 / 4$ in $)$

6.4 to $12.7 \mathrm{~mm}(1 / 4$ to $1 / 2$ in $)$

12.7 to $19.0 \mathrm{~mm}(1 / 2$ to $3 / 4$ in $)$

19.0 to $25.4 \mathrm{~mm} \mathrm{(3/4}$ to $1 \mathrm{in})$

25.4 to $38.1 \mathrm{~mm}\left(1\right.$ to $1 \frac{1 / 2}{2}$ in $)$

38.1 to $50.8 \mathrm{~mm}\left(1 \frac{1 / 2}{2}\right.$ to $\left.2 \mathrm{in}\right)$

$>50.8 \mathrm{~mm}(>2$ in $)$

Source stone material type for all debitage was identified. Other recorded attributes included the amount of cortex present on the dorsal surface (100 percent, 1-99 percent, 0 percent, platform only, indeterminate) and presence/absence of heat treatment or thermal damage (none, discolored, potlidded, crazed, curved thermal spall).

"Flake" was defined as a sharp piece of stone with defined dorsal and ventral surfaces and, if the platform was present, a series of attributes that delineate the striking point that removed the flake from the core. In contrast to flakes, which can be oriented, the term "shatter" was applied to angular blocky chunks of stone, with or without cortex, that do not exhibit ripple marks or other indications that permit orientation of the specimen.

Whole and proximal flake portions that retain the striking platforms were subdivided into core or biface thinning flakes. The distinction was not based on a single attribute, but rather on an impression of a cluster of attributes. Core flakes tend to be thick, with salient bulbs, steep platform-to-dorsal surface angle, and no ridge crests across their platforms. In contrast, biface thinning flakes tend to be thin, with acute platform-to-dorsal surface angle, one or more ridges on the platform surface, and occasionally a lipped surface. The classification of core and biface thinning flakes indicate the range of reduction present onsite. Medial and distal flake fragments lacking a platform were classified as indeterminate.

Blades are special kinds of flakes that typically are twice as long as wide, but they also refer to a reduction strategy and the use of specific kinds of cores. Notching flakes are a relatively rare kind of small flake with a concave-convex platform. They are produced during the attempt to add notches to projectile points during initial manufacture. Tool rejuvenation flakes reflect a special kind of knapping in which a flake was struck along the margin of the working blade in order to remove a series of overhanging resharpening flake scars (Shafer 1970). Typically, they are narrow curving flakes that have distinctive flake scars along the dorsal ridge. The distinctive scars along the dorsal ridge can either be unifacial scars, many with step or hinge scars, or bifacial flake removals with comparable damage.

\section{Core}

Cores refer to raw nodules or reduced objective pieces that are used to make flakes to be fashioned into tools, or that represent the early reduction stages of a cobble itself on its way to becoming a cobble/core tool. No cores were recovered from site 41TR170. 


\section{Ground Stone and Cobble Artifact}

Ground stone tools consist of nonsiliceous/noncutting tools such as milling stones and hand stones, mortars and pestles, and axes/adzes/chisels. Other forms include pitted anvil stones, often with grinding wear on the faces and hammerstone usage on the edges, and shaft abraders identified by grooves worn in abrasive stone such as sandstone. Analysis of size and wear attributes of the ground stone artifacts potentially addressed the subsistence pattern, community structure, and technological activities research domains.

\section{Unworked Lithics}

This category included unworked lithics associated with human occupation such as fire-cracked rock, burned rock, and griddle stones that were used but not formally flaked or shaped (manuports, unaltered, nonindigenous stones brought onsite by the occupants, is also classified as unworked lithics). Burned rock was the main component remaining in cooking and heating features at this site. Burned rock recovered from test unit levels was weighed separately from rock recovered from feature contexts. Most of the burned rock was recorded by lithic material, weight, rough size, and description in the field and not collected.

Burned rock samples were collected for lipid analysis from several features. In addition, a great deal of burned rock was collected from particular features during excavation as well as included inadvertently as a part of the sediment samples. All of the rock collected was counted and weighed in the laboratory and was included with the field counts of burned rock in the excavation results before being discarded.

\section{Faunal Analysis}

Specimens are assigned to class, order, suborder, family, genus, and species according to their identifiability. Size classes are used to describe remains that bear no diagnostic features but are similar in size and shape to portions from a particular element from a species; the class "medium ungulate" is less diagnostic than "deer size" and tends to comprise long-bone midshaft fragments. Specimens assigned to medium ungulate are not included in the systematic paleontology. Given the low density of elements from the axial skeleton and the taxonomic overlap in morphological characteristics of rib fragments in particular, several fragments are considered "unidentified." When identifications of such elements are possible (including long-bone shaft fragments), they are offered in terms of size class, which is a conservative approach. A discussion of taphonomy of the fauna is covered. Freshwater bivalve remains are identified through comparison to modern specimens from the region and through use of published criteria. Specimens were counted using two quantitative units: NSP (number of specimens) and NISP (number of identified specimens) (Lyman 1994).

Fragmentary non-umbo freshwater mussel shells were discarded; umbos and fragments with evidence of hinges were retained. Approximately 2,000 snail shells (mostly Rabdotus and Helicina) were collected. Of these, 10 were retained for curation and the potential of future studies that may investigate sediment integrity via epimerization studies. The remainder of the snail shells were counted and discarded. 


\section{Baked Clay Analysis}

Baked clay (daub and burned clay) specimens are distinguished from vessel sherds by several indicators. Those pieces exhibiting impressions of vegetal fibers or other vegetal remains are indicative of architectural daub from wattle-and-daub structures. If, however, no impressions are present, the fragments are considered to be unimpressed burned clay, the nondiagnostic clay fragments of unknown origin that could represent the residue of hearths or other open-firing activities, the remains of burned clay cooking balls, or even possibly indistinguishable fragments of architectural daub. Baked clay specimens collected in the field were weighed, after determination of whether each piece was daub or burned clay.

\section{Curation}

All artifacts were catalogued, labeled, and bagged in compliance with standards, procedures, and guidelines set forth in 36 Code of Federal Regulations (CFR) 79, "Curation of Federally Owned and Administered Archeological Collections." All documentation and photographic records compiled during the investigations were catalogued in compliance with these standards. At the termination of this project, all cultural material and documentation generated during this investigation will be curated at TARL, the University of Texas, in accordance with TARL requirements. 



\section{CHAPTER 4 \\ GEOMORPHOLOGICAL RESULTS}

Archeological site 41TR170 occurs on an abandoned or stranded floodplain terrace of the Clear Fork of the Trinity River in Fort Worth, Tarrant County, Texas. An artificial channel of the Clear Fork was cut down more than $4 \mathrm{~m}$ into Cretaceous limestone during channelization, leaving the older natural channel and its floodplain terrace high and dry. The older channel is visible on the 1981 USGS Benbrook 7.5 minute quadrangle map. Site 41TR170 is located along a southturning bend of the old channel in the middle of the alluvial valley.

\section{HOLOCENE STRATIGRAPHY}

The valley fill deposits at site $41 \mathrm{TR} 170$ are not exposed in outcrops but instead have been inspected in a series of 28 2-m-deep backhoe trenches located throughout the site on both the north and south side of the old natural channel of the Clear Fork (stratigraphic sections in Appendix I). The overall stratigraphy shown in the trenches is fairly uniform from exposure to exposure and reflects the late Holocene floodplain environment of the Clear Fork at this locality (Figure 7). The dominant geologic feature of the floodplain is the West Fork paleosol. Its ubiquitous presence serves as a marker for correlation of archeological remains and features within the floodplain stratigraphic sequence.

\section{Pre-Paleosol Sediments}

Based on information from the basal sediments observed in trenches at site 41TR170, three prepaleosol units are present (oldest to youngest): cemented gravels (late Pleistocene), yellow clay (late Holocene), and gray clay (late Holocene).

\section{Cemented Gravels}

Carbonate-cemented, rounded limestone gravels occur at the base of Trenches 18 and 19; only the upper $30 \mathrm{~cm}$ of the gravel deposit are exposed. The gravels have a yellowish clay matrix. The gravels exhibit a moderate amount of sorting. Individual gravels are generally less than $20 \mathrm{~mm}$ in diameter although rare individual clasts are larger than $40 \mathrm{~mm}$ in diameter. The individual limestone clasts are white with a weak yellowish weathering rind about $2 \mathrm{~mm}$ thick. 


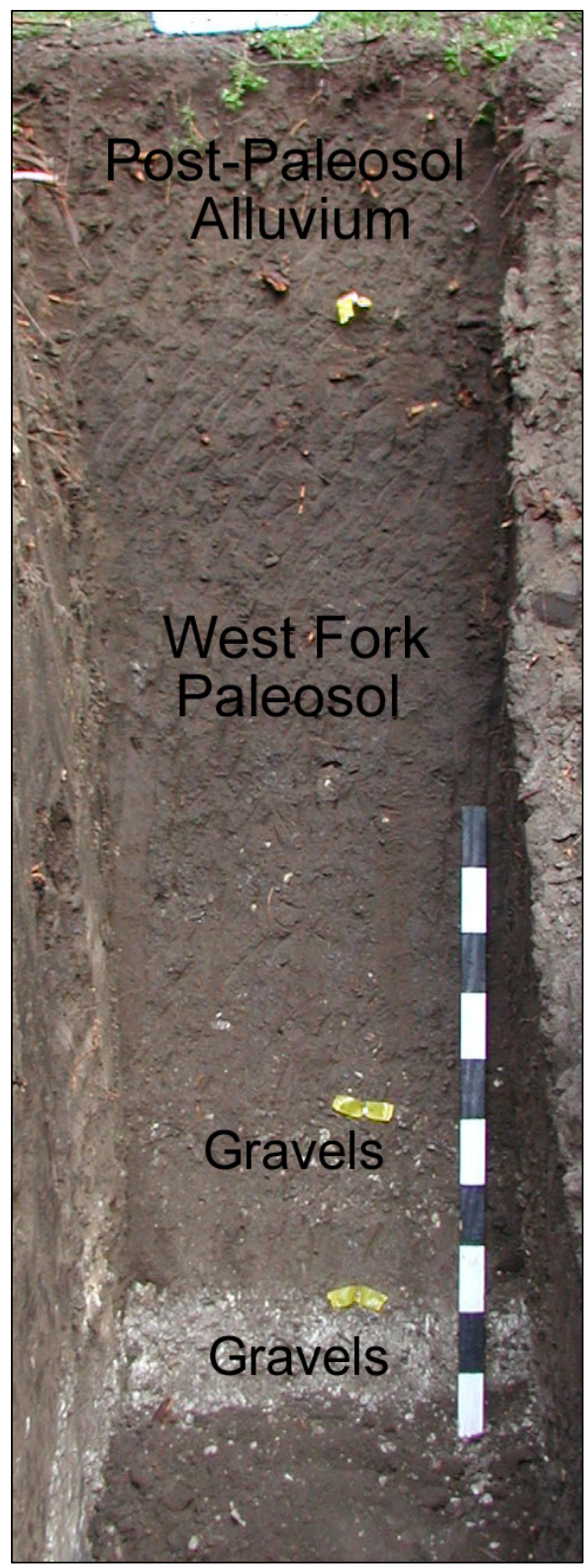

Figure 7. Late Holocene stratigraphy at Trench 24; the lowermost part of the West Fork paleosol in adjacent Trench 23 has a radiocarbon age of $2,300 \pm 50{ }^{14} \mathrm{C}$ years B.P.; two layers of gravels occur at the base of the paleosol; the dark material at the floor of the trench is clay that has been cleaned off of the exposure; yellow tags mark unit boundaries; 1 -m scale with 10 -cm intervals.

Carbonate coats on the gravels are thin, less than $0.5 \mathrm{~mm}$ in thickness. Carbonate cementation of the gravels occurs in subrounded lenses or masses; some gravel clasts are not cemented together. The secondary carbonate cementation is likely related to former higher water table positions in the alluvial valley during the late Pleistocene. The gravels probably represent the top edge of a late Pleistocene buried terrace deposit. An extensive Pleistocene terrace outcrops above the Holocene floodplain along the Clear Fork valley and is previously mapped (Bureau of Economic Geology 1972). The gravels may correlate with the late Wisconsinan Carrollton alluvium beneath a buried eroded margin of the Denton Creek terrace complex (Ferring 1990). 


\section{Yellow Clay}

The yellow clay unit (yellowish brown, 10YR 5/6) is about $1 \mathrm{~m}$ thick, is exposed in only Trenches 18 and 19, and rests directly on cemented gravels with which it has a sharp basal contact. It is silty and sandy, massive with no bedding, calcareous with faint carbonate filaments in the lower $30 \mathrm{~cm}$, and contains occasional small isolated rounded limestone pebbles. Bulk sediment from the lower $12 \mathrm{~cm}$ of the yellowish brown clay has a conventional radiocarbon age of $2,910 \pm 60{ }^{14} \mathrm{C}$ years B.P., the earliest radiocarbon age from site 41TR170.

The yellow clay may have been more extensive in the late Holocene local valley fill but now is eroded and missing from the base of most trenches, although remnants of it may occur at greater depth. Based on the radiocarbon ages of the yellow clay and overlying gray clay, the episode of erosion occurred ca. $2,500{ }^{14} \mathrm{C}$ years B.P. There is an outside possibility that the yellow clay is a weathered component of the gravel deposit and that its radiocarbon age is spurious. However, the clay-gravel basal contact is an erosional unconformity, and the bulk sediment was pretreated to remove carbonates before dating. Otherwise, stratigraphic position, the geography, and the radiocarbon age are consistent within the context of the small area studied at 41TR170.

At Trenches 18 and 19, a 16-26-cm-thick zone of limestone gravels overlies the yellow clay. The clay-gravel contact is sharp and represents the erosional episode ca. 2,500 ${ }^{14} \mathrm{C}$ years B.P. after which the gravels were deposited. The gray clay unit is missing at Trenches 18 and 19, never deposited in this small area, and the West Fork paleosol occurs directly on the thin zone of gravels.

\section{Gray Clay}

The basal alluvial sediment directly beneath the West Fork paleosol and exposed in most of the trenches at site 41TR170 is grayish brown (10YR 5/2) clayey silt and very fine sand. The alluvium is massive with no primary bedding features preserved. It is strongly calcareous and commonly includes numerous carbonate filaments along small root traces but does not include carbonate nodules. The carbonate filaments become less abundant in the upper part of the unit where it grades into the overlying paleosol; the secondary carbonate filaments are related to groundwater rather than downward-percolating water from precipitation.

The gray clay and the West Fork paleosol represent a single continuously deposited body of alluvium without a discernible unconformity. The primary difference between the two is sedimentation rate, the paleosol accumulating more slowly than the gray clay.

Two accelerator mass spectrometer (AMS) radiocarbon ages on isolated detrital charcoal from this unit are 2,360 \pm 40 and $1,630 \pm 40{ }^{14} \mathrm{C}$ years B.P.; the latter age may be a few hundred years too young. Although not directly observed, an erosional unconformity occurs between the older yellow and the younger gray clay; to reiterate, the episode of erosion occurred about $2,500{ }^{14} \mathrm{C}$ years B.P. 


\section{Floodplain Paleo-Topography and Cumulic Soil Development}

The yellow clay and gray clay units together form a surface on which the West Fork paleosol developed. The pre-paleosol floodplain surface topography in the study area is not flat; it has a relief of $93 \mathrm{~cm}$ (assuming the modern surface as the elevational datum; precise total station or high resolution GPS data are not available). Prior to the overbank or valley-wide flooding that produced the slowly accumulating paleosol, there were areas of topographic high as well as adjacent areas of topographic low, probably a result of erosion and floodplain scouring about 2,500 years ago. The locality of Trenches 18 and 19 was a topographic high, the deposits at that place composed of an erosional remnant of the yellow clay and underlying cemented-gravel units. During flooding events on the paleofloodplain, low areas would be flooded more frequently and, consequently, the cumulic West Fork paleosol will have accumulated first in these low areas and the resulting paleosol will be comparatively thick. Specifically, the early stage of cumulic soil development as illustrated by the 140-cm-thick paleosol in Trench 23 began by about 2,300 \pm 50 ${ }^{14} \mathrm{C}$ years B.P. (Figure 8). Topographic high areas have a cumulic paleosol that is less thick and that may have begun forming a few hundred years after paleosol accumulation in low areas.

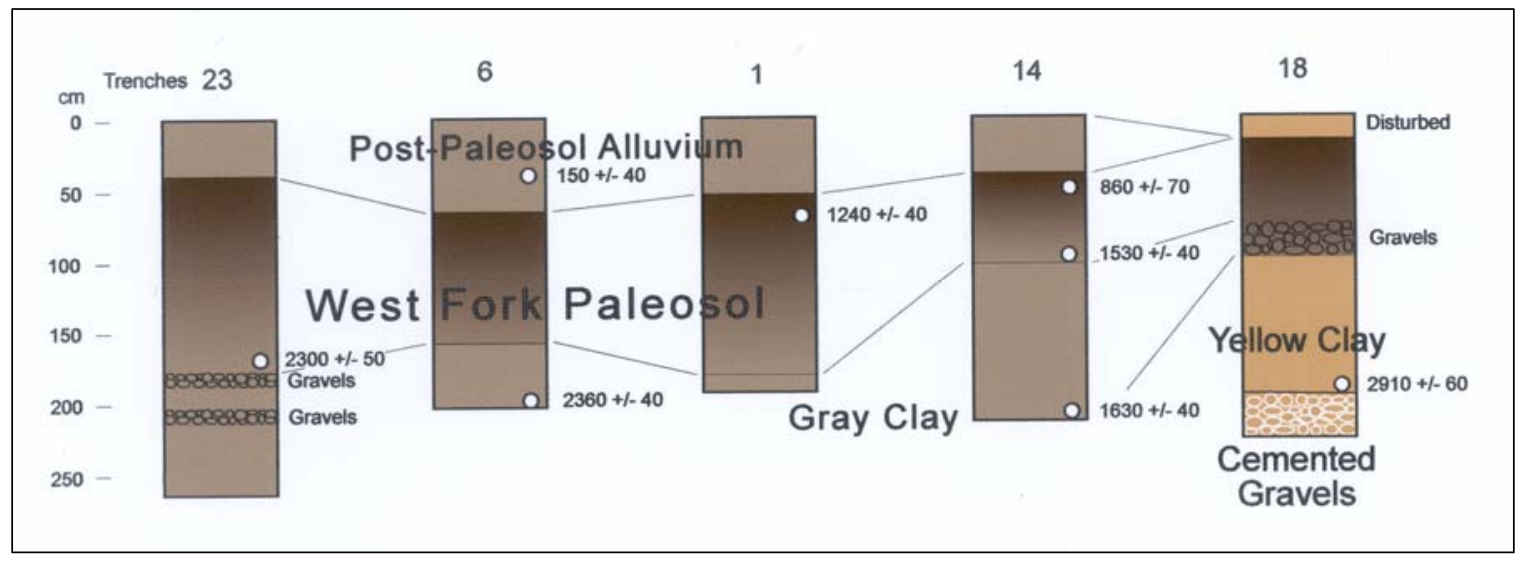

Figure 8. Correlation of stratigraphic sections with radiocarbon ages, site 41TR170, along the Clear Fork, Tarrant County, Texas.

\section{West Fork Paleosol}

The West Fork paleosol was named from floodplain bank exposures along the West Fork of the Trinity River, central Tarrant County, Texas (Ferring 1986:93). Subsequent studies along the Elm Fork of the Trinity River show that the West Fork paleosol is a prominent basin-wide soilgeomorphic feature (Ferring 1987:40). In the present investigation at site 41TR170 on the Clear Fork, the paleosol is also present and is a cumulic over-thickened A horizon soil, formed by slow fluvial aggradation on the floodplain over a comparatively long period of time. The cumulic soil is largely devoid of pedogenic features, such as clay skins or clay accumulation, blocky or ped structure, or secondary carbonates. The cumulic soil is called a "paleosol" instead of "soil" in this investigation. A paleosol is a soil that formed in the past under conditions of the physical landscape, geomorphology, vegetation, hydrology, and climate that no longer occur at that location, a situation that certainly applies specifically in this case along Clear Fork as well as throughout the Trinity River drainage basin and elsewhere in the southcentral United States. In other words, the environmental conditions that produced the West Fork paleosol no longer exist. 
The West Fork paleosol at site 41TR170 is dark grayish brown (10YR 4/2) clayey silt and very fine sand; its dark color distinguishes it from older and younger alluvium (Table 4). The thickness of the paleosol ranges from $59 \mathrm{~cm}$ (Trench 12) to $152 \mathrm{~cm}$ (Trench 21) and averages about $85 \mathrm{~cm}$ (these numbers excluded paleosol localities where historic activity may have resulted in the removal of the top part of the old soil; Trenches 13,15, 17, 18, 19, and 20). The fluvial sediments that make up the paleosol are all fine-grained sands, silt, and clay derived from Lower Cretaceous sedimentary rocks, mostly limestone, shales, marls, and sandstone, that outcrop in the Clear Fork drainage. The paleosol itself formed by very slow aggradation on the Clear Fork floodplain, an average sedimentation rate of perhaps no more than $1 \mathrm{~mm}$ per year. The soil is massive, lacking any evidence of primary bedding. The slow sedimentation rate coupled with bioturbation by burrowing insects, snails, and earthworms resulted in the obliteration of micro-sedimentary layers. To reiterate, the paleosol does not exhibit secondary pedogenic features at this locality.

Table 4

Sediment Data from Site 41TR170, Clear Fork of the Trinity River Floodplain, Tarrant County, Texas

\begin{tabular}{|c|c|c|c|c|c|c|c|c|c|c|c|}
\hline \multirow[b]{2}{*}{ Sample } & \multicolumn{5}{|c|}{ Sand (mm) } & \multicolumn{3}{|c|}{ Recalculated } & \multirow[b]{2}{*}{$\mathrm{OC}$} & \multirow[b]{2}{*}{$\mathrm{CaCO}_{2}$} & \multirow[b]{2}{*}{ Dry Color } \\
\hline & $\begin{array}{c}2.0-1.0 \\
\text { V. coarse }\end{array}$ & $\begin{array}{l}1.0-0.5 \\
\text { coarse }\end{array}$ & $\begin{array}{l}0.5-0.25 \\
\text { medium }\end{array}$ & $\begin{array}{c}0.25-0.125 \\
\text { fine }\end{array}$ & $\begin{array}{c}0.125-0.0625 \\
\text { very fine }\end{array}$ & Sand & Silt & $\begin{array}{c}\text { Clay } \\
<3.9 \mu \mathrm{m}\end{array}$ & & & \\
\hline \multicolumn{12}{|c|}{ Trench 14} \\
\hline $18-23 \mathrm{~cm}$ & $2.0 \%$ & 7.9 & 31.1 & 36.3 & 22.7 & 46 & 35 & 19 & 0.87 & 42.7 & $10 Y R 5 / 2$ \\
\hline $26-31$ & 3.8 & 10.1 & 31.1 & 33.6 & 21.4 & 46 & 35 & 19 & 0.70 & 43.4 & $10 Y R 5 / 2$ \\
\hline \multicolumn{12}{|c|}{ West Fork paleosol } \\
\hline $52-57$ & 0.2 & 2.1 & 14.8 & 38.4 & 44.5 & 31 & 44 & 25 & 1.07 & 35.1 & $10 Y R 3 / 2$ \\
\hline $70-75$ & 0.2 & 2.0 & 11.8 & 36.1 & 49.9 & 27 & 45 & 28 & 1.10 & 36.0 & $10 Y R 3 / 2$ \\
\hline $82-87$ & 0.5 & 3.5 & 14.7 & 38.0 & 43.3 & 31 & 42 & 27 & 0.95 & 38.3 & $10 Y R 3 / 2$ \\
\hline $102-107$ & 0.7 & 5.3 & 20.6 & 39.2 & 34.2 & 36 & 37 & 27 & 0.79 & 41.4 & $10 Y R 3 / 2$ \\
\hline \multicolumn{12}{|c|}{ Pre-paleosol alluvium } \\
\hline $133-138$ & 0.4 & 3.3 & 18.8 & 41.4 & 36.4 & 36 & 38 & 26 & 0.70 & 41.4 & $10 Y R 4 / 2$ \\
\hline $148-153$ & 0.2 & 1.6 & 12.1 & 41.9 & 44.2 & 33 & 40 & 27 & 0.77 & 39.0 & $10 \mathrm{YR} 4 / 2$ \\
\hline $160-165$ & 0.1 & 1.1 & 11.4 & 43.9 & 43.5 & 32 & 40 & 28 & 0.73 & 39.7 & $10 Y R 4 / 2$ \\
\hline $190-195$ & 0.1 & 0.7 & 7.2 & 43.0 & 49.0 & 26 & 43 & 31 & 0.78 & 38.1 & $10 \mathrm{YR} 4 / 2$ \\
\hline \multicolumn{12}{|l|}{ Trench 6} \\
\hline \multicolumn{12}{|c|}{ Post-paleosol alluvium } \\
\hline $20-25$ & 0.7 & 1.2 & 4.8 & 24.6 & 68.7 & 15 & 59 & 28 & 1.53 & 33.1 & $10 \mathrm{YR} 5 / 2$ \\
\hline $40-45$ & 0.6 & 1.2 & 4.7 & 24.4 & 69.1 & 13 & 59 & 28 & 1.43 & 34.6 & $10 Y R 5 / 2$ \\
\hline $55-60$ & 0.3 & 0.5 & 3.4 & 24.8 & 71.0 & 17 & 55 & 28 & 1.03 & 33.0 & $10 Y R 5 / 2$ \\
\hline \multicolumn{12}{|c|}{ West Fork paleosol } \\
\hline $75-80$ & 0.1 & 0.6 & 6.6 & 31.3 & 61.4 & 30 & 45 & 25 & 1.03 & 31.8 & $10 Y R 3 / 2$ \\
\hline $95-100$ & 0.3 & 1.0 & 10.4 & 37.0 & 51.3 & 30 & 44 & 26 & 1.08 & 34.1 & $10 \mathrm{YR} 3 / 2$ \\
\hline $115-120$ & 0.4 & 1.5 & 12.0 & 36.0 & 50.1 & 27 & 45 & 28 & 0.79 & 35.8 & $10 Y R 3 / 2$ \\
\hline $135-140$ & 0.3 & 1.7 & 13.1 & 38.6 & 46.3 & 28 & 44 & 28 & 0.84 & 36.8 & $10 Y R 3 / 2$ \\
\hline \multicolumn{12}{|c|}{ Pre-paleosol alluvium } \\
\hline $170-175$ & 0.1 & 0.3 & 5.4 & 33.3 & 60.9 & 21 & 79 & 30 & 0.82 & 36.1 & $10 \mathrm{YR} 4 / 2$ \\
\hline $185-190$ & 0.1 & 0.4 & 4.8 & 27.2 & 67.5 & 15 & 55 & 30 & 0.85 & 37.3 & $10 Y R 4 / 2$ \\
\hline $200-205$ & 0.2 & 0.7 & 6.5 & 27.0 & 65.6 & 15 & 54 & 31 & 0.88 & 38.5 & $10 Y R 4 / 3$ \\
\hline
\end{tabular}

$\mathrm{OC}=$ organic carbon, Walkley-Black; carbonates determined by chittick method; samples are in centimeters depth; numbers are percentages; Wentworth scale; Munsell Soil Color Chart; analyses by Milwaukee Soil Laboratory, Milwaukee, Wisconsin 


\section{Carbonates}

The paleosol sediments are all highly calcareous, ranging from 32 to 41 percent and probably representing calcite particles derived from limestone and marl bedrock in the watershed. Visible secondary carbonates in the form of filaments along root traces are rare in the sediment column of the paleosol but are generally abundant in the lower $15 \mathrm{~cm}$ of the paleosol and especially in the underlying alluvium. These secondary carbonates are probably derived from dissolution of detrital calcite clasts in the fine sediment and transported by groundwater in the more permeable alluvium beneath the less permeable clayey paleosol. Given the overall abundance of carbonates and the youthfulness of the paleosol, it would otherwise be difficult to account for the presence of secondary carbonates only at depths of $70 \mathrm{~cm}$ or more and the absence of filaments in the upper $70 \mathrm{~cm}$ of the paleosol. The carbonates at the base of the paleosol are not related to soil-forming processes but instead are a byproduct of water uptake and respiration by rootlets.

\section{Paleosol Chronology and Correlation}

A few radiocarbon ages from site $41 \mathrm{TR} 170$ indicate that the paleosol began to accumulate by about 2,300 $\pm 50{ }^{14} \mathrm{C}$ years B.P. and that paleosol accumulation ended after $1,240 \pm 40{ }^{14} \mathrm{C}$ years B.P. but perhaps continuing as late as $860 \pm 70{ }^{14} \mathrm{C}$ years B.P. Thus, the West Fork paleosol ranges from about 2,300 to roughly $1,000{ }^{14} \mathrm{C}$ years B.P.; additional radiocarbon ages would help refine the chronology.

A similar cumulic paleosol is reported from late Holocene floodplains throughout the Southern Plains. Its significance was first recognized and documented by Hall $(1977,1978,1979,1982$, 1988; Hall and Lintz 1984) where it is known as the Copan paleosol, named for the community of Copan, Washington Company, northeastern Oklahoma. Subsequently, the equivalent paleosol was recognized in Texas where it has been called the Navarro paleosol (Bruseth et al. 1987), Asa soil (Waters and Nordt 1995), and the West Fork paleosol (Ferring 1986). The Copan paleosol and its geomorphology, geochronology, and paleoecology, as well as its nomenclatural equivalents, were reviewed by Hall (1990).

\section{Absence of Evidence for Channel Cutting 1,000 Years Ago}

Many of the late Holocene alluvial sequences reported from the Southern Plains, beginning with early studies in Oklahoma and including more recent investigations in Texas, are dominated by the cumulic A horizon Copan paleosol and its equivalent. The formation of this paleosol is terminated by down-cutting of floodplains in river basin after river basin across the broad subcontinent region about $1,000{ }^{14} \mathrm{C}$ years B.P. (Blum and Valastro 1994; Hall 1990). Alluvial sequences that exhibit 1,000-year B.P. channeling also generally exhibit a sharp erosional boundary between the Copan paleosol and overlying alluvium. At site 41TR170, no evidence for the post-paleosol channel trenching was observed, and the boundary between the West Fork paleosol and overlying alluvium is gradational, obscured by bioturbation (Figure 9). The small project area may simply not be large enough to incorporate a post-paleosol channel fill. 


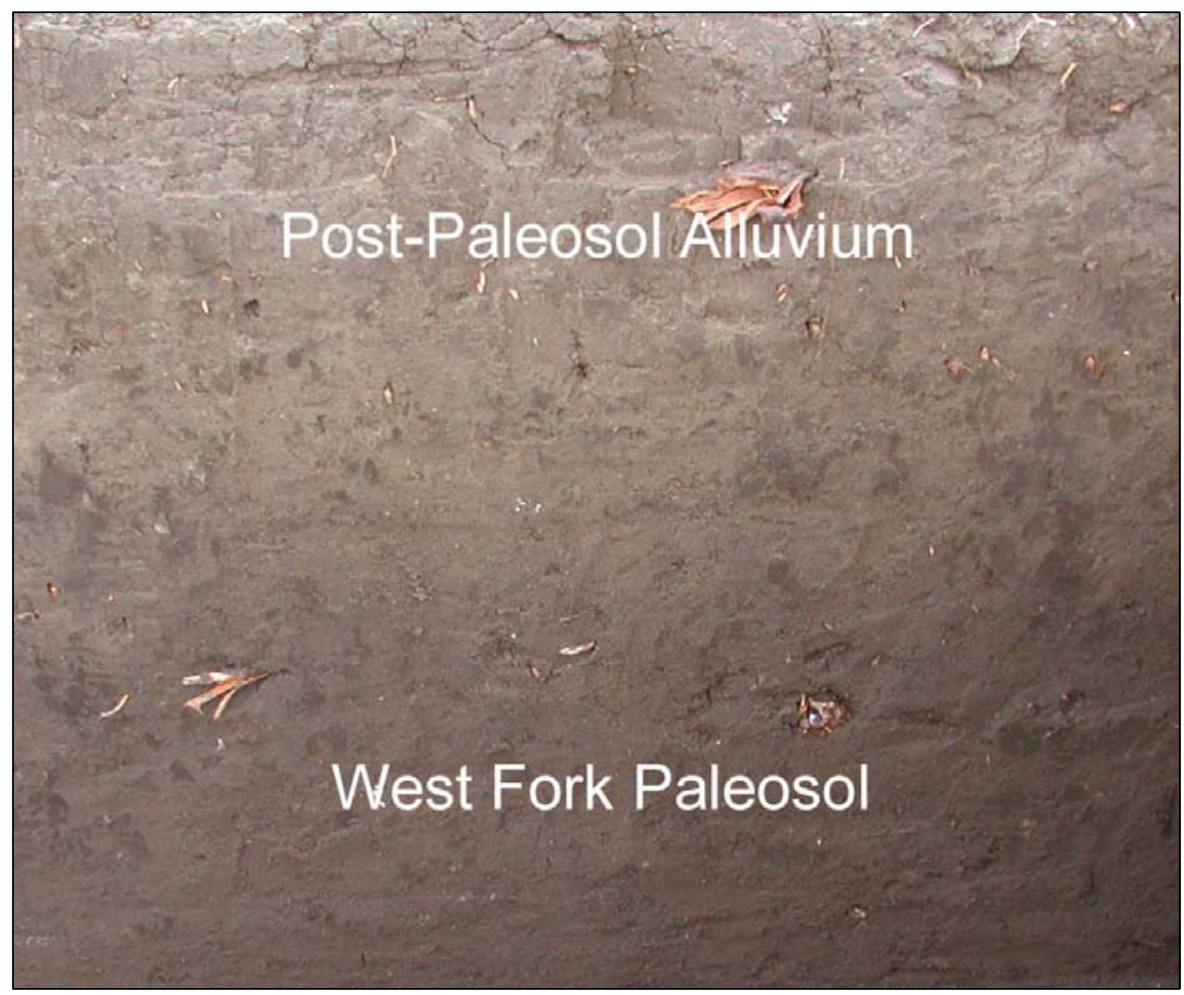

Figure 9. Gradational contact between West Fork paleosol and overlying post-paleosol alluvium; the contact is gradational because of bioturbation; numerous small burrow fills are visible as light fill in the paleosol sediment and dark fill in the overlying sediment; the view is about $1-\mathrm{x}-1 \mathrm{~m}$; Trench 1 locality; the upper part of the West Fork paleosol at this locality has a radiocarbon age of $1,240 \pm 40{ }^{14} \mathrm{C}$ years B.P.

\section{Post-Paleosol Alluvium}

The slow development of the cumulic West Fork paleosol ended upon its burial by recent alluvium. The post-paleosol alluvium caps the paleosol in every trench exposure at site 41TR170 except in those few cases where historic disturbance has resulted in sediment removal, exposing the top of the paleosol at the disturbed surface. The post-paleosol alluvium is uniformly a grayish brown $(10 \mathrm{YR} 5 / 2)$ clayey silt and fine sand, lighter in color than the dark gray paleosol. It averages $48 \mathrm{~cm}$ in thickness and ranges from $34 \mathrm{~cm}$ (Trench 8) to $68 \mathrm{~cm}$ (Trench 7) in thickness. It is massive without primary bedding structures preserved. The sediments are calcareous but lack visible carbonates such as filaments along root traces. A single radiocarbon age of $150 \pm 40$ ${ }^{14} \mathrm{C}$ years B.P. on charcoal (Trench 6) from a buried burned tree was obtained on the post-paleosol alluvium. The post-paleosol alluvium, if correlative with other post-paleosol alluvial units in the region, may have been deposited between about 800 and 100 years ago. If so, its sedimentation rate may be similar to that of the underlying paleosol. However, in contrast to the cumulic soil depositional environment, the post-paleosol alluvium likely accumulated during fewer flood events, but each flood produced a thicker layer of sandy sediment deposited on the wooded floodplain. A deeper channel may have been present in the Clear Fork valley during the past 800 years at the time of the deposition of the post-paleosol alluvium.

A historic A horizon soil sometimes occurs at the modern surface of late Holocene floodplain terraces in the region. A faint hint of a very weak A horizon was observed in the uppermost 5-10 $\mathrm{cm}$ at a few trench exposures (cf. Trenches 23 and 24) at site 41TR170. 


\section{Sediment Characteristics}

\section{Sand, Silt, Clay}

Alluvium, including the West Fork paleosol, from two trenches at site 41TR170 was analyzed for texture, organic carbon, and carbonates (see Table 4). As can be seen from the data, the alluvial sediments are predominantly fine-textured sandy, clayey silt. The sediments from Trench 6 are uniformly finer grained with larger amounts of silt than sediments from Trench 14. This relationship may be due to the presence of Trench 6 on the inside of the Clear Fork meander curve, resulting in less sand and more clayey silt deposited on the floodplain during flooding. Trench 14 is located on the outside of the meander curve. The sand fraction is dominated by very fine to fine quartz sand. Again, the sediment column from Trench 6 is finer textured than the sediments from Trench 14.

\section{Organic Carbon}

The sediments from the West Fork paleosol have a higher amount of organic carbon than does the underlying and overlying alluvium in Trench 14. However, in Trench 6, organic carbon is moderately high in both paleosol and nonpaleosol sediments alike.

\section{Carbonates}

All of the alluvium has a high amount of $\mathrm{CaCO}_{3}$ ranging from approximately 31 to 43 percent. There does not seem to be a pattern to the carbonate content in the alluvium. The carbonates may be largely detrital, derived from the local nearby Cretaceous limestone and marl bedrock. In Trench 6 , there is a slight increase in carbonates with depth, probably related to groundwater.

\section{Gravels}

\section{Gravels in the Late Holocene Alluvium}

The alluvium along the Clear Fork is generally fine-grained silty, fine sand, and clay, reflecting the Lower Cretaceous limestone bedrock in the Clear Fork drainage. Occasionally, the fine overbank alluvium will contain small, rounded, isolated limestone pebbles with occasional Cretaceous oyster shells and clam fragments. These isolated occurrences of small individual gravels are generally between $4 \mathrm{~mm}$ and $16 \mathrm{~mm}$ in diameter and are natural components of the alluvium. The isolated gravels occur in the grayish brown clay unit and in the West Fork paleosol. The small limestone pebbles all have a carbonate crust $(<0.5 \mathrm{~mm}$ thick) and a thin yellow weathering rind (ca. 1-4 mm thick); these properties indicate that the pebbles are reworked from older gravels in the Clear Fork river valley. The occurrence of larger stones in excess of 40 $\mathrm{mm}$ in diameter may indicate prehistoric cultural activity; stones of these sizes are too large to be transported in suspension and deposited with muds in overbank alluvium. 
Zones of gravels occur in basal West Fork paleosol sediments in Trenches 8, 9, 17, 18, 19, 20, 23, and 24. The gravel zones range from $10 \mathrm{~cm}$ (Trench 23) to $44 \mathrm{~cm}$ (Trench 9) in thickness. A single zone of gravel averaging $24 \mathrm{~cm}$ thick occurs at the base of the paleosol in Trenches 17, 18, 19, and 20. Two gravel zones, each averaging $13 \mathrm{~cm}$ thick, occur in Trenches 8, 9, 23, and 24 (the gravel zone in Trench 9 is a thick single layer of gravel that correlates with the two layers of gravel in adjacent Trench 8; in other words, the gravel in Trench 9 represents the same two episodes of deposition observed in Trench 8 but not separated by a clay, thus it appears to be a single layer of gravel instead of two).

In most cases, the base of the West Fork paleosol coincides with the top of the gravel zone. The gravels range in size from $2 \mathrm{~mm}$ in diameter (the lower limit of the definition of gravel) to 130 $\mathrm{mm}$ in diameter. Most of the gravels are in the 2-4-mm-diameter size class. The gravels are poorly sorted and may have been deposited by a single flood event with sufficient stream discharge to entrain, suspend, transport, and deposit them on the broad floodplain during the early stage of cumulic soil development.

As can be seen in Figure 10, size frequency of gravels (2,001 clasts) in the late Holocene alluvium can be compared with basal cemented gravels of possible Pleistocene age (1,191 clasts) but both groups of gravels are dominated by granules in the 2-4-mm category. Although some differences are apparent, the similarities in the size data suggest that either the sources of gravels during the Pleistocene and Holocene are the same or that the Holocene gravels are reworked from the Pleistocene gravel deposits. If the Holocene gravels are reworked from older deposits, it would account for the presence of gravels only in the earliest late Holocene floodplain alluvium. By the time the West Fork paleosol and post-paleosol alluvium were deposited, the Pleistocene gravels would be buried and not available for reworking. On the other hand, mean clast size of the Holocene gravels is larger than that of the Pleistocene gravels. It would be expected that, if the Holocene gravels are simply reworked Pleistocene gravels, the Holocene gravels should be generally smaller in size, not the other way around. The only explanation that seems reasonable is that the Pleistocene gravels observed and sampled in Trench 19 are not representative of the larger gravel population in the Clear Fork drainage basin and that the gravels elsewhere upstream are larger than the ones reported in this investigation.

\section{Pleistocene Gravels}

Carbonate-cemented gravels occur at the base of Trenches 18 and 19 and, although undated, may represent a buried edge of the late Pleistocene Carrollton alluvial gravels (Ferring 1990). The gravel deposit has a yellow clay matrix. The gravels are entirely rounded limestone and exhibit weak sorting. Clasts are generally $<20 \mathrm{~mm}$ in diameter, with large individual clasts, to $40 \mathrm{~mm}$ in diameter. The whitish limestone gravels have 2-mm-thick yellow weathering rinds as well as carbonate coats approximately $0.5 \mathrm{~mm}$ thick. Cemented masses of gravels occur in lenses instead of a single layer; secondary carbonates appear to be water-table-related rather than pedogenic. The degree of cementation and thickness of weathering rinds indicate that the gravel deposit in Trenches 18 and 19 may be Pleistocene in age. 


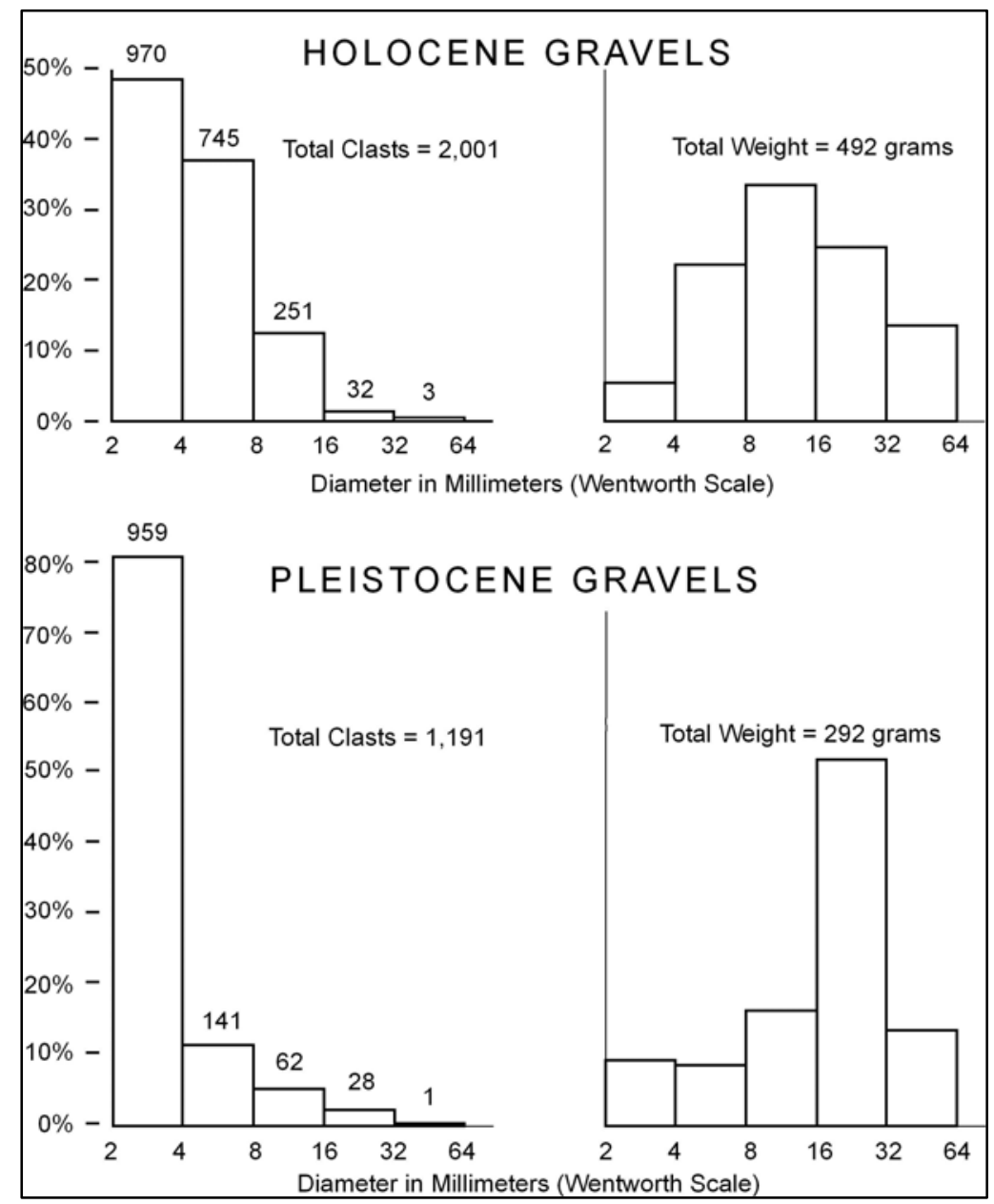

Figure 10. Gravels from Trench 19; Holocene gravels are from the 73-89-cm depth and Pleistocene gravels are at the base of the trench, $182-190+\mathrm{cm}$ in depth; clasts are 100 percent limestone, lacking chert or other lithology.

\section{Fossil Snail and Mussel Shells}

\section{Snails}

All of the late Holocene alluvium at site 41TR170 contains isolated shells of fossil snails of a variety of species. The larger, more conspicuous shells are of the land snail Rabdotus and the smaller Helicina. Aquatic species are rare in the alluvial deposits, occurring mainly at the base of Trench 14. Rabdotus is uncommon at the site today, having been replaced by a polygyrid as the dominant large land snail.

Also common on the modern wooded floodplain-terrace surface is Rumina decollata, a European import that is considered a garden pest today in Texas. It was first reported in the United States in South Carolina in 1822, and later in Brownsville, Texas, in 1913, and in Dallas, Texas, in 1933 (Pilsbry 1946:170). Although it burrows, shells of this species were not observed in the recent alluvium overlying the West Fork paleosol, indicating that the young post-paleosol alluvium may be predominantly older than the twentieth century. 


\section{Freshwater Mussel Shells}

Occasional mussel shells occur in the late Holocene alluvium, mostly in the clays of the West Fork paleosol. Many of the shells observed in trench walls are concave up. Because of the shape of curved shells and their dynamics with running water, the natural mode of deposition of these shells in a stream environment is concave down. Thus, it is reasonable to attribute these occurrences of mussels to human activity.

\section{Radiocarbon Dates}

Eight radiocarbon dates provide a good, internally consistent foundation for the alluvial chronology of the Clear Fork valley (Table 5). The entire alluvial sequence above the cemented gravels is less than 3,000 years old. The radiocarbon geochronology of the alluvium at 41TR170 is consistent with the regional late Holocene record.

Table 5

Radiocarbon Ages from Geomorphic Settings along the Clear Fork of the Trinity River, Site 41TR170, Tarrant County, Texas

\begin{tabular}{|c|c|c|c|c|c|c|}
\hline Trench \#: Depth $(\mathrm{cm})$ & Beta & $\begin{array}{c}\text { Material } \\
\text { Dated }\end{array}$ & $\begin{array}{l}\text { Measured } \\
\text { Radiocarbon Age }\end{array}$ & $\begin{array}{l}{ }^{13} \mathrm{C} /{ }^{12} \mathrm{C} \\
\text { Ratio (\%o) } \\
\end{array}$ & $\begin{array}{l}\text { Corrected } \\
\text { Radiocarbon Age }\end{array}$ & $\begin{array}{l}\text { Calibrated Age } \\
(2 \text {-sigma) } \\
\end{array}$ \\
\hline $\begin{array}{l}\text { Post-paleosol alluvium } \\
\text { 6: } 35-42\end{array}$ & 204912 & $\mathrm{C}$ & $160 \pm 40$ B.P. & -25.6 & $150 \pm 40$ B.P. & A.D. $1660-1950$ \\
\hline $\begin{array}{l}\text { West Fork paleosol } \\
\text { 14: } 48-53\end{array}$ & 205060 & $\mathrm{~S}$ & $740 \pm 70$ B.P. & -17.5 & $860 \pm 70$ B.P. & A.D. $1020-1280$ \\
\hline 1: $66-72$ & 205063 & $\mathrm{~S}$ & $1100 \pm 40$ B.P. & -16.2 & $1240 \pm 40$ в.Р. & A.D. $680-890$ \\
\hline 14: $99-105$ & 205059 & $\mathrm{~S}$ & $1410 \pm 70$ B.P. & -17.8 & $1530 \pm 70$ в.Р. & A.D. $400-650$ \\
\hline 23: $165-175$ & 205062 & $\mathrm{~S}$ & $2170 \pm 50$ B.P. & -16.9 & $2300 \pm 50$ в.Р. & $\begin{array}{l}\text { B.C. } 410-350 \& \\
\text { B.C. } 310-210\end{array}$ \\
\hline $\begin{array}{l}\text { Pre-paleosol alluvium, gray clay } \\
\text { 14: 205-215 }\end{array}$ & 204911 & $\mathrm{C}$ & $1650 \pm 40$ B.P. & -26.0 & $1630 \pm 40$ в.Р. & A.D. $350-530$ \\
\hline 6: $200-205$ & 204913 & $\mathrm{C}$ & N/A & - & $2360 \pm 40$ B.P. & B.C. $520-380$ \\
\hline $\begin{array}{l}\text { Pre-paleosol alluvium, yellow clay } \\
\quad \text { 18: } 186-198\end{array}$ & 205061 & $\mathrm{~S}$ & $2860 \pm 60$ B.P. & -22.3 & $2910 \pm 60$ B.P. & B.C. $1290-920$ \\
\hline
\end{tabular}

Data from Beta Analytic, Inc., Miami, Florida

Material Dated: $\mathrm{C}=$ charcoal; $\mathrm{S}=$ bulk sediment; all 3 charcoal samples were analyzed by the AMS method; all bulk sediment samples were pretreated for carbonates and analyzed by conventional method; samples collected by S. A. Hall; all dated charcoal fragments exhibit wood structure and sheen

Calibrations from Stuiver et al. 1998, Radiocarbon 40:1041-1083. Stratigraphic descriptions of the radiocarbon-dated samples are in Appendix I.

Three ages from Trench 14, however, seem to be at least 25 percent too young (bulk sediment and charcoal alike). The three ages are internally consistent, suggesting that the young ages are site-specific. The West Fork paleosol at Trench 14 is only $65 \mathrm{~cm}$ thick, one of the thinnest locations of the paleosol except at Trenches 18 and 19. If the paleotopography of the Clear Fork floodplain was slightly higher where Trench 14 was dug, the systematic youngness of the paleosol and other alluvium can be explained. Overbank sediments, including the cumulic 
paleosol, would accumulate earliest in topographically low areas on the floodplain and, accordingly, later on topographically high areas. Thus, differences of a few hundred years in the geochronology of the formation of the West Fork paleosol can be accounted for. Unfortunately, high-resolution GPS elevational data that would provide information on floodplain topography and paleotopography, thereby verifying the above explanation of age differences in the alluvium, were not taken during the study.

Additional radiocarbon dates on wood charcoal were obtained from buried cultural features and are presented elsewhere in this report. The ages of the features and the age of the associated alluvial stratigraphy appear to be discordant, the features generally younger than the correlated alluvium. Some of the differences may be related to paleotopography of the 2,000- to 1,000-yearold floodplain surface such as may account for the variability in radiocarbon ages of the alluvial sediment discussed above. Prehistoric cultural activity on the floodplain may have been concentrated on topographic high points, avoiding the lower wet places. If so, the radiocarbon ages, while correct, may seem too young when compared with ages from alluvium that represents both low and high points on the floodplain depositional surface.

\section{HOLOCENE LANDSCAPE AND ENVIRONMENT}

Earth science processes are not random across the landscape. Patterns exist due to variations in bedrock, vegetation, hydrology, and climate, producing unique records. As one variable shifts, others do as well, altering the consequences and producing a new record of events.

\section{Clear Fork}

The channel of the Clear Fork and other tributaries of the Trinity as well as the Trinity River itself exhibit moderately formed meander geometry, suggesting that the channel moves or meanders across its floodplain through time, continuously cutting and backfilling. If the streams in the Trinity River drainage were meandering back and forth across their floodplains, the stratigraphic as well as the archeological record would be obliterated with the passage of time. However, this does not appear to be the case. While the stream channels have a meander pattern geometry, the sediments do not indicate a history of meandering cut-and-fill valley process. Rather, the history of the Clear Fork as well as other regional streams is a pattern of basin-wide sedimentation and down-cutting that is in response to regional climate change, a pattern that occurs simultaneously throughout a drainage basin (Figure 11). The meander channel geometry either developed prior to overbank sedimentation 3,000 years ago, or it was a shallow meandering channel that down-cut and stabilized ca. 1,000 years ago when other channels became incised in the region or ca. 100土 years ago accompanying land clearance and introduction of livestock by American settlers.

\section{Paleoecology of West Fork Paleosol}

Over-thickened A horizon cumulic soils are not common in alluvial records. Some thinner A horizons may represent local floodplain stability for a century or two, long enough for organic matter to accumulate in a distinct zone. Cumulic soils a meter thick such as the Copan-West Fork, however, represent a major significant event in the fluvial history of stream valleys in the southcentral United States. 


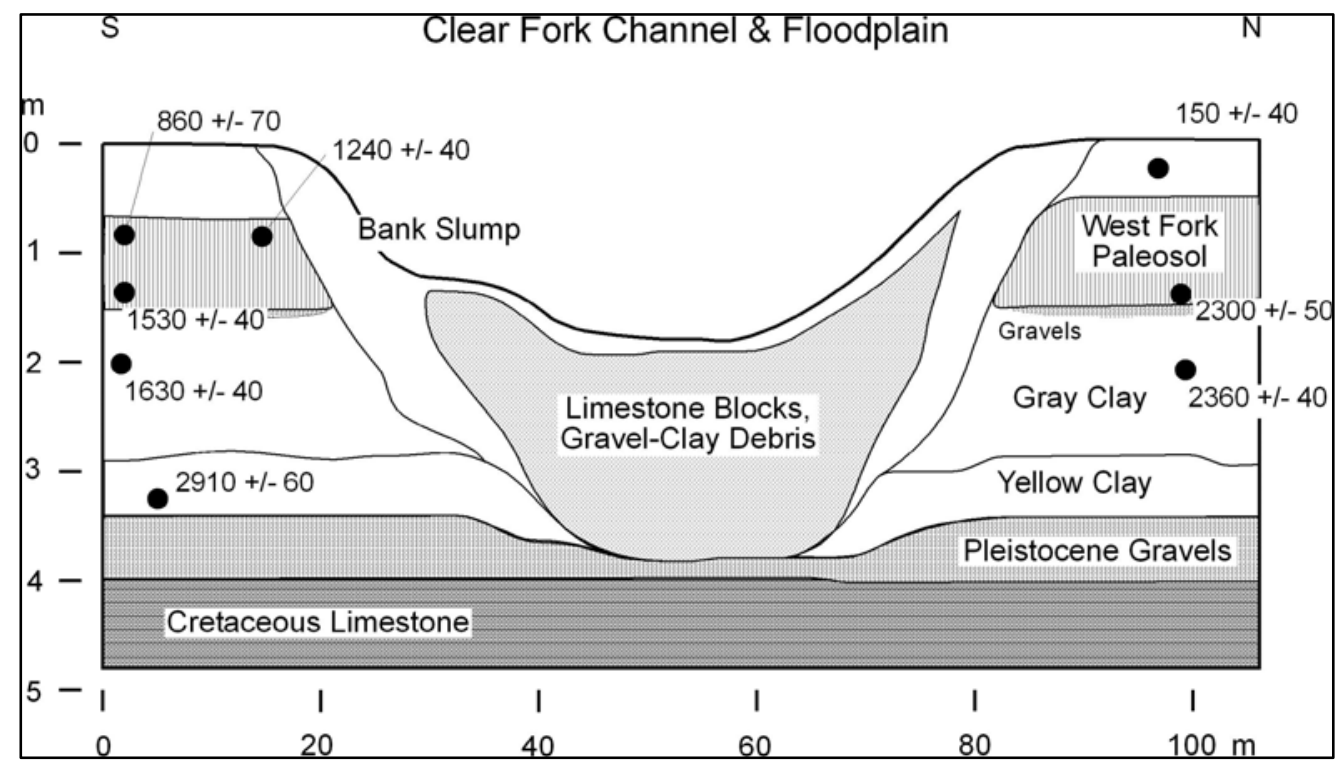

Figure 11. Cross section of the Clear Fork channel and floodplain at site 41TR170 prior to channelization; the natural channel has been partly filled in with construction debris; the base of the channel is not exposed; based on the USGS Benbrook 7.5 minute quadrangle (1981), the channel measured and illustrated above is the main and only channel of the Clear Fork in this area of the valley.

\section{Sedimentation}

The thick cumulic soil forms by slow aggradation on a broad flat alluvial valley. The valley may or may not have a channel. If a channel is present, it is shallow. If a channel is not present, runoff spreads over the valley floor. Sedimentation is by overbank or valley-wide spreading. The sediments deposited are fine textured: very fine sand, silt, and clay. The 1-m-thick West Fork paleosol accumulated over a period of about 1,000 to 1,500 years, resulting in a sedimentation rate of $0.7-1.0 \mathrm{~mm}$ per year. Because of the slow rate of sediment accumulation, primary sedimentologic structures such as laminations, cross-bedding, and clay drapes are obliterated by the bioturbation effects of burrowing animals.

\section{Paleoclimate}

Thick cumulic soils form in Great Plains stream valleys during periods of comparatively wet climate. The amount of moisture is uncertain, but the interaction of surface moisture and vegetation density is crucial. Increased precipitation increases plant density, whether prairie or woodland, thereby increasing water retention in local soils. Although surface water is more abundant, streams transport less sediment because the watersheds are more densely vegetated, and sediment supply by sheet erosion is largely diminished. Other effects are high water tables in alluvial valleys, abundant springs, and perennial stream flow. Valley floors are wet meadows where the plant communities are dominated by sedges and riparian grasses (as indicated below by carbon isotopes).

A review of the paleoenvironmental record from southcentral United States shows that plant communities (pollen), vertebrate faunas, and molluscan faunas reflect moister conditions about 2,000 to 1,000 years ago, the period of formation of the Copan-West Fork paleosol (Hall 1982, 
1988, 1990). An exhaustive faunal study at Hall's Cave also shows a comparatively wet period between about 2,000 and 1,000 years ago in Central Texas (Toomey 1993). Other studies show the corroboration of faunal, paleoclimatic, and fluvial evidence (Blum et al. 1994; Toomey et al. 1993). The paleolandscape record is clear and consistent.

The empirical paleoenvironmental record also shows that about 1,000 years ago the moist conditions that led to the development of the Copan-West Fork paleosol ended. Decreased precipitation led to a decrease in plant cover, an increase in runoff and a greater sediment load in streams, a lowering of the alluvial water table, and incision of valley floors. The Clear Fork channel may have deepened at this time, and occasional floods carried greater amounts of sediment onto the floodplain, burying the West Fork paleosol by $0.5 \mathrm{~m}$ of sandy clay.

\section{Carbon Isotopes and Late Holocene Vegetation}

$\mathrm{C}_{4}$ plants have isotope values ranging from -16 to $-9 \%$ with a mean value of $-13 \% . \mathrm{C}_{4}$ plants are few in number and on a continental scale are regarded as warm-season grasses and are generally absent from cooler regions. $\mathrm{C}_{3}$ plants have carbon isotope values ranging from -33 to 22 with a mean value of $-27 \%$. $\mathrm{C}_{3}$ species are cool-season grasses and are all of the woody plants in the vegetation. Because the vegetation is made up of both $\mathrm{C}_{3}$ and $\mathrm{C}_{4}$ species, the carbon isotopic composition of soils will be an amalgam of the two groups and will fall between -27 and $-13 \%$. When $\delta^{13} \mathrm{C}$ values fall above $-20 \%, \mathrm{C}_{4}$ plants dominate, and where $\delta^{13} \mathrm{C}$ values fall below $-20 \%, \mathrm{C}_{3}$ plants dominate the vegetation. The general abundance of $\mathrm{C}_{4}$ plants on a subcontinental scale across North America has been compared with various climatic variables and has been found to correlate positively with temperature, especially mean July minimum temperatures (Teeri and Stowe 1976).

The $\delta^{13} \mathrm{C}$ values from two separate sections in the late Holocene Clear Fork alluvium show a consistent pattern (Figure 12). In both sections, the pre-paleosol and West Fork paleosol alluvium have mean $\delta^{13} \mathrm{C}$ values of $-18.4 \pm 0.36$ and $-18.3 \pm 0.28 \%$, respectively. The postpaleosol alluvium has a mean $\delta^{13} \mathrm{C}$ value of $-20.8 \pm 1.07 \%$. The data are presented in Table 6 .

A literal interpretation of the carbon isotope data is that the proportion of $\mathrm{C}_{3}$ and $\mathrm{C}_{4}$ plants in the vegetation at TR170 has remained the same during the period ca. 2400 to 1000 years BP with $\mathrm{C}_{4}$ plants dominating the community. Subsequent to the end of the formation of the West Fork paleosol, after ca. 1000 years $\mathrm{BP}$, the vegetation shifted to a local community dominated by $\mathrm{C}_{3}$ plants (Figure 13).

\section{Stable Carbon Isotopes and Paleoclimate at Site 41TR170}

Given the positive relationship between the abundance of $\mathrm{C}_{4}$ plants and temperature (Boutton 1996), a literal interpretation of a shift from $C_{4}$ to $C_{3}$ plants represents a corresponding shift from warm-season to cool-season grasses and a general lowering of temperatures. Paleoclimatic reconstructions, using the modern analog, generally equate lower temperatures with increased moisture and higher temperatures with decreased moisture, a relationship that is observed in

many cases (Boutton et al. 1980). Thus, the alluvial isotope record can be interpreted literally as a late Holocene shift from comparatively warm-dry to cool-wet conditions in north-central Texas. 


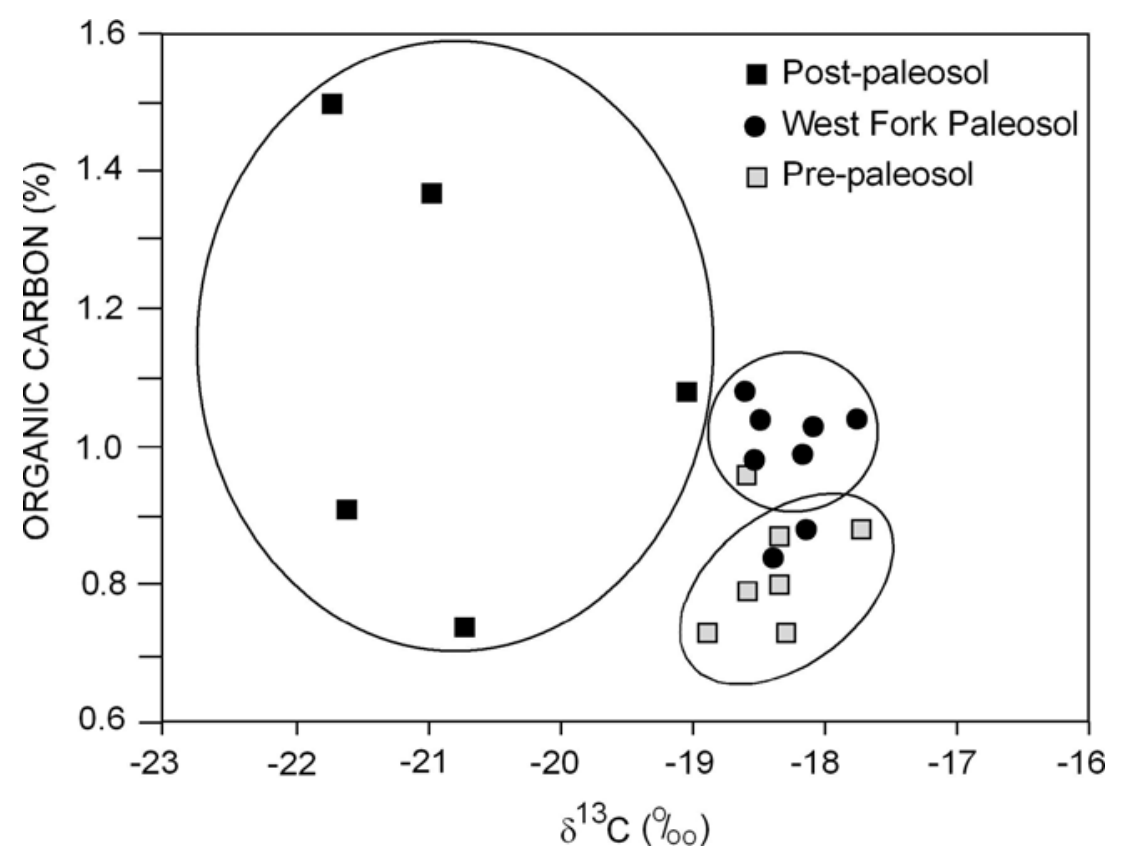

Figure 12. Distribution of $\delta^{13} \mathrm{C}$ values from late Holocene Clear Fork alluvium at site 41TR170; carbon isotope and organic carbon values from Table 4; West Fork paleosol has higher amounts of organic carbon than prepaleosol alluvium; however, the carbon isotope signature of the paleosol and pre-paleosol alluvium is the same; the post-paleosol alluvium has lower $\delta^{13} \mathrm{C}$ values (more negative) than the paleosol or pre-paleosol alluvium

The above paleoclimatic reconstruction, however, is at odds with other paleoecological records from the region. Indeed, the above interpretation of the $\delta^{13} \mathrm{C}$ record from late Holocene alluvium is entirely counter to the published information from regional alluvial stratigraphy, sedimentology, fossil vertebrates, and land snails (Hall 1982, 1988, 1990; Blum et al. 1994; Toomey 1993; Toomey et al. 1993).

The question remains: What does the $\delta^{13} \mathrm{C}$ record from late Holocene alluvium show if not a shift in $\mathrm{C}_{4}-\mathrm{C}_{3}$ plants and climate? First, it is important to point out that the modern $\mathrm{C}_{4}$-climate relationship was established from upland plant communities. Plant species from riparian habitats were not included in the analyses. This omission may be important when looking at $\delta^{13} \mathrm{C}$ values from alluvium. A number of $\mathrm{C}_{4}$ species are riparian plants: sedges (Carex), sacaton (Sporobolus), reed (Phragmites), and cane (Arundinaria), all with species that are found on wet meadows and floodplains of aggrading streams with a high alluvial water table. Thus, alluvial sediments of floodplains will have an organic carbon $\delta^{13} \mathrm{C}$ signature that reflects at least in part the riparian plant community. During floods, sediment that is derived from sheet erosion of upland top soils is deposited on floodplains. As a result, fine-textured overbank alluvium will contain a mix of organic carbon originating from both upland and riparian plant communities. If a floodplain is small, the input of organic carbon from riparian species may also be small compared with that derived from upland top soils. If a floodplain is wide, however, a riparian component of the organic carbon content of the alluvium may be substantial.

In the case of Clear Fork Trinity River at 41TR170, the floodplain is fairly wide, 0.6 to 1.0 miles across. The meandering channel was approx $60 \mathrm{~m}$ wide and approx. 3-4 $\mathrm{m}$ deep prior to it being filled with construction debris (see Figure 11). The sediments that make up the late Holocene 
Table 6

Carbon and Nitrogen Isotope Values from Late Holocene Alluvium Including the West Fork Paleosol at Site 41TR170, Clear Fork of the Trinity River, Tarrant County, Texas

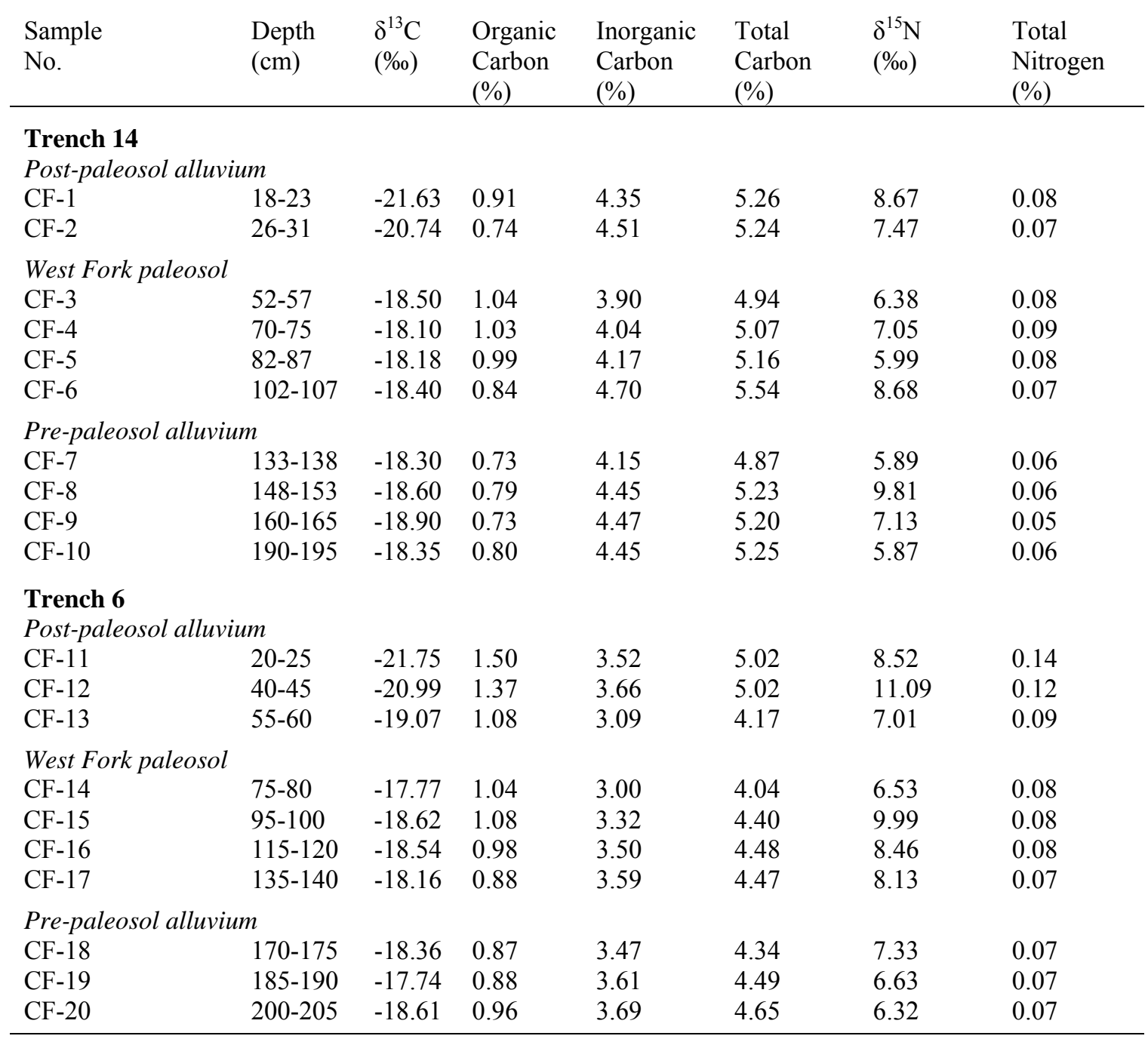

Note: Analyses by Dr. Thomas Boutton, Dept. of Range Management and Ecology, Texas A \& M University, College Station, Texas, USA

alluvium are fine-textured clayey and sandy silts; the sand fraction is generally very fine to fine quartz (see Table 4). The organic carbon content ranges from 0.73 to $1.50 \%$ (see Table 6 ). The fine-textured sediments are characteristic of overbank floodplain deposits. The West Fork paleosol is part of the sediment package. It is a cumulic over-thickened A horizon soil characterized by higher percentages of organic carbon than older or younger alluvium (see Figure 12). The higher amounts of organic carbon in the paleosol may reflect lower sedimentation rates. With a slower rate of alluviation, larger amounts of organic carbon from riparian plants will be incorporated into the floodplain deposits. 


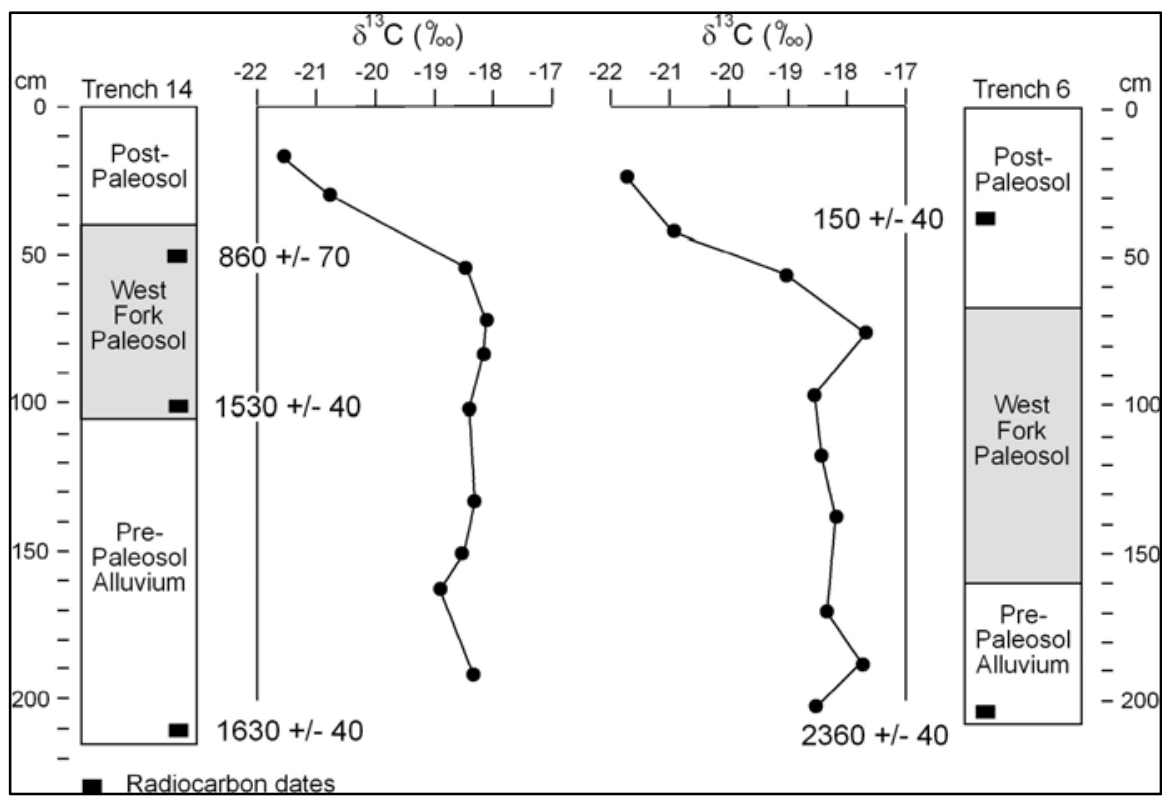

Figure 13. Stratigraphic sequence of carbon isotopes in late Holocene alluvium at site 41TR170; the radiocarbon ages from Trench 14 are consistently too young compared with the other dated sections as discussed in the text; carbon isotope data from Table 6.

The West Fork paleosol and alluvium underlying the paleosol collectively have a mean $\delta^{13} \mathrm{C}$ signature of $-18.3 \pm 0.32 \%$. These organic carbon isotope values are a result of a mix of riparian $\mathrm{C}_{4}$ and upland $\mathrm{C}_{3}$ sources. The enriched (less negative) $\delta^{13} \mathrm{C}$ signature is a result of the wetground floodplain environment and the presence of sedges and other riparian $\mathrm{C}_{4}$ species.

The end of the formation of the West Fork paleosol ca. 1000 years ago was caused by a regional climatic change to drier conditions and the deepening of the Clear Fork channel (discussed by Hall 1990). Channel erosion and lowering of the alluvial water table occurred together, resulting in a drying of the floodplain and a change in the riparian plant community. Wet meadow $\mathrm{C}_{4}$ plants were replaced by dry-habitat $\mathrm{C}_{3}$ species. Accordingly, the organic carbon contribution to the old floodplain surface experienced a shift in $\delta^{13} \mathrm{C}$ values reflecting the shift from $\mathrm{C}_{4}$ to $\mathrm{C}_{3}$ plants. As a consequence of the change in riparian and floodplain vegetation, post-paleosol alluvium incorporated greatly reduced amounts of organic carbon derived from $\mathrm{C} 4$ species, resulting in a depleted (more negative) $\delta^{13} \mathrm{C}$ values as documented in the alluvial sequence (see Figure 13).

The above scenario describes a case study where processes of sedimentation and geomorphology partially dictate the direction of the $\delta^{13} \mathrm{C}$ trends in alluvium. The organic carbon found in alluvial deposits is derived from both upland and riparian environments that can have differing $\mathrm{C}_{4}$ and $\mathrm{C}_{3}$ plant communities. Overbank sediments deposited on the wide floodplain of a moderate to large stream will have a $\delta^{13} \mathrm{C}$ signature that reflects the blend of organic carbon derived from the uplands in the watershed and from the stream's floodplain. A shift in the sedimentation or geomorphology of a stream valley may result in a shift in the proportion of organic carbon from $\mathrm{C}_{4}$ and $\mathrm{C}_{3}$ species that is incorporated in the alluvium, giving a false signal of vegetation and climatic change. 


\section{Other Stable Isotope Studies}

Fort Hood. A long sequence of carbon isotopes has been documented from Holocene alluvium in central Texas (Nordt et al. 1994). The sequence parallels that from Clear Fork with $\delta^{13} \mathrm{C}$ values indicating a dominance of $\mathrm{C}_{4}$ plants during the late Holocene and a shift to significantly lower amounts of $\mathrm{C}_{4}$ species in the past 400 years. The carbon isotope record is conservatively interpreted as representing 60-65\% warm-season grasses $\left(\mathrm{C}_{4}\right)$ from ca. 4000 to 2000 years $\mathrm{BP}$ and a shift to $65-70 \%$ warm-season grasses $\left(\mathrm{C}_{4}\right)$ ca. 2000 years $\mathrm{BP}$ to present with a short-duration warming episode ca. 2000 years BP.

The issue of upland versus a riparian origin of the organic carbon (and the resulting $\delta^{13} \mathrm{C}$ signature) in alluvium was recognized and addressed by Nordt et al. (1994:114):

Throughout most of the Holocene, the streams in Fort Hood had entrenched channels and low floodplain water tables. These factors, coupled with numerous flash-flood events, have prevented appreciable colonization of riparian plants on point bars and along the channel that may contribute spurious transported $\delta^{13} \mathrm{C}$ signatures to the alluvial sequence.

The above situation does not apply to Clear Fork where the wide floodplain and late Holocene sequence of slowly-accumulating overbank deposits in a floodplain environment differ from the smaller streams with flashy discharge at Fort Hood, central Texas.

Aubrey Clovis site. A 14,000-year section of alluvium from the Aubrey Clovis site on the Elm Fork Trinity River, Denton Co., has been investigated for a stable carbon and oxygen isotope record (Humphrey and Ferring 1994; Ferring 1990). Unfortunately for comparison with the Clear Fork record, the late Holocene alluvium dated between 3030 and 1730 years BP is documented by only six carbon isotope samples; younger isotope data were not reported (Humphrey and Ferring 1994:205).

Although the isotope data are sparse, a paleoclimatic sequence is presented by Humphrey and Ferring (1994:211) that first appeared in Ferring (1990:44). The climatic reconstruction shows a wet climate 5000-2000 and 1000 years BP to present and a dry climate from 2000 to 1000 years BP. The empirical basis that is cited for a generally wetter climate during the late Holocene is the pollen records from Ferndale (SE Oklahoma) and Boriack bogs (E Texas). While the pollen records show that the late Holocene climate was indeed recovering from a mid-Holocene dry period and becoming wetter, the pollen records do not show evidence for alternating wet-dry-wet episodes that correlate with the late Holocene alluvial sequences. Furthermore, the late Holocene climate reconstruction presented by Ferring (1990) and Humphrey and Ferring (1994) is at odds with the published paleoecological record from Texas and Oklahoma.

\section{GEOARCHEOLOGY}

As earth science processes are not random, the archeological record is likewise not random across the landscape. An understanding of their relationships provides insight to both. Portions of site 41 TR170 are buried by 1-2 $\mathrm{m}$ of alluvial clays. Multiple-stone features were found at the base (Trench 22) and below the base (Trench 19) of the West Fork paleosol. Why are the features at this depth and not at a more shallow depth? One explanation may be that at the time of occupation, the floodplain was not flooding as much and may have been wooded. Second, the location of the site at Trench 19 coincides with a topographic high on the pre-paleosol floodplain. The site was $139 \mathrm{~cm}$ above the low point in the floodplain about 2,300 years ago. 
Isolated burned stones and mussel shells occur at various depths within the West Fork paleosol sediments, as encountered in backhoe trenches. Their presence is likely cultural in origin; the stones and shells are too large to be easily transported by overbank or valley-spreading floodwater.

The fine-textured alluvial clays are strongly bioturbated by small burrowing animals such as earthworms, insects, and land snails. Consequently, sharp boundaries that distinguish primary sedimentologic structures such as lamellae and cross-beds are lost. Also lost are the sharp stratigraphic boundaries between alluvial units and erosional unconformities such as shown in Figure 8. The sharp borders of some prehistoric cultural features may become obscure as well. Theoretically and in practice, materials within the sediment column, such as pollen, soil chemistry and isotopes, magnetic particles, seeds, small bones, and snail shells, are also moved around, potentially masking direct stratigraphic relationships with cultural features.

Scale and degree of bioturbation are the prime issues to be addressed in relation to the archeological record preserved at a site. Of course, soil particles and small objects within the soil are still there; they have just been moved from their primary context. In the case of site 41TR170, the scale of movement is comparatively small because the burrowing animals are small. In an estimation of the degree of turbation that would take place at a single horizon, it is likely that 50 percent of the particles are moved less than $5 \mathrm{~cm}, 35$ percent have been moved 5-10 $\mathrm{cm}$, and 15 percent have been moved more than $10 \mathrm{~cm}$. This assumes 100 percent bioturbation, a number that may be too high as well as not possible to really know. The amount of movement can be estimated based on the degree of particle displacement seen in Figure 9 where the unconformity between the paleosol and post-paleosol sediment is obscured by small burrow fills.

The small scale and high degree of bioturbation accompanying cumulic A horizon soil accumulation (such as the West Fork paleosol) is probably universal (Courty et al. 1989:140-146; Retallack 2001:128-159). However, the fine clayey texture of these cumulic soils is a substrate generally avoided by burrowing rodents and other mammals. As a result, the severe bioturbation characteristic of sandy soils of West and East Texas has not occurred along the Clear Fork (Johnson 1989, 1990). In some sandy regions, such as seen at Fort Bliss, badgers literally churn up almost the entire upper meter of surficial sediment (Johnson and Johnson 2004). This extreme scale of bioturbation has not occurred at site 41TR170 where, instead, the scale of bioturbation is comparatively small and stratigraphic units maintain their overall integrity.

Because the burrowing animals along the Clear Fork valley are small, they have not disturbed small stones and rocks that make up cultural features. An earthworm will go around an obstacle such as a small stone ( $>20 \mathrm{~mm}$ in diameter), leaving the stone's position and orientation intact. Earthworm burrow fills are about $4 \mathrm{~mm}$ in diameter, insects produce burrow fills about $6 \mathrm{~mm}$ in diameter, and land snail burrow fills are generally no larger than about $8 \mathrm{~mm}$ in diameter (Johnson et al. 2005).

In conclusion, while bioturbation of clayey sediments and the West Fork paleosol at site 41TR170 is strong, the scale of turbation is comparatively small. Regions with sandy soils will be characterized by more severe bioturbation by rodents and larger mammals than present in Tarrant County. The scale and amount of bioturbation at this site is no more and no less than that occurring at similar sites along stream valleys in the Trinity River drainage basin. 


\section{SUMMARY AND CONCLUSIONS}

The Clear Fork alluvial record at site 41TR170 is less than 3,000 years old. About 3,000 to 2,500 years ago, yellow clayey alluvium was deposited on an old surface composed of cemented limestone gravels (Pleistocene?). About 2,500 years ago, these valley yellow clay deposits were eroded during a brief episode of incision. By about 2,400 years, the valley began to aggrade again, and gray clay and a thin layer of gravels were deposited on the eroded yellow clay. Soon afterwards, perhaps as early as 2,300 years ago, the climate changed to increased precipitation. The alluvial water table rose, stream flow became permanent, and the floodplain became a wet meadow. Silt and clay carried by occasional floodwaters spread over the valley floor. The slow accumulation of muds formed a 1-m-thick cumulic soil between about 2,300 and 1,000 years ago. Regional climate changed again about 1,000 years ago to drier conditions. The alluvial water table dropped. The Clear Fork channel down-cut through its floodplain. After down-cutting, the cumulic soil no longer formed, and floods deposited sediments on top of the old soil (now called the West Fork paleosol), burying it by $0.5 \mathrm{~m}$ of sandy clay. 


\section{CHAPTER 5 ARCHEOLOGICAL RESULTS}

This section presents the results of the 2005 GMI archeological investigations conducted at site 41TR170. The 19 features encountered during the project are described before the discussion of the material remains recovered from the project. A final section briefly summarizes the distribution of features and artifacts encountered in the 10 deep test units and the three excavation blocks.

\section{FEATURES}

A total of 19 features was identified across the site area of 41TR170 (Table 7). The features are numbered consecutively from $1-18$ and the final feature is number 20 . The number 19 was not assigned. These cultural anomalies occur both north (Features 3, 4, 5, 12, and 20) and south (the 14 other features) of the relic channel of the Clear Fork of the Trinity River. Based on the feature distribution, the area south of the relic channel appears to be the more intensively used, due to the prominent occurrence of features near the edge of the Pleistocene gravel bar, which represents an area with some relief near the river.

All features, except Feature 5, which is a charcoal-flecked stained area, consist of burned limestone or sandstone rocks that were transported to their current locations. The rocks tend to be larger than those found in the cemented gravel zone of the Pleistocene channel as exposed in Trenches 19 and 20 along the southern site area. Thus, the burned rocks are derived from either the incised paleochannels, which may coincide with the modern relic channel in the middle of the site, or the Duck Creek, Kiamichi, and Goodland geological exposures along the valley margins. Most of the rock features encountered during Stage 3 excavations were found in the southerly Blocks 1 and 3. The predominant limestones and sandstones in these features were probably carried south from the presumed location of the relic channel about $150 \mathrm{~m}$ away or from the base of the geological exposures more than $700 \mathrm{~m}$ away. Although there is strong evidence noted for the reuse of rock in burned features, the quantities of burned rock found along the southern margin of the site indicate a considerable labor expenditure involved in the initial rock procurement. 
Table 7

Features in Relation to Test Units, Trenches, and Blocks at Site 41TR170

\begin{tabular}{crcl} 
Feature \# & Test Unit \# & Backhoe Trench \# & Block \\
\hline 1 & 1 & 1 & Deep Test Unit \\
2 & 1 & 1 & Deep Test Unit \\
3 & 4 & 22 & Block 2 \\
4 & 3 & 23 & Deep Test Unit \\
5 & 3 & 23 & Deep Test Unit \\
6 & 18 & 19 & Block 1 \\
7 & 6 & 25 & Deep Test Unit \\
8 & 6 & 25 & Deep Test Unit \\
9 & $2 \& 13$ & 19 & Block 1 \\
10 & $12,15,19$ and 29 & 19 & Block 1 \\
11 & 16 & 19 & Block 1 \\
12 & 20 & 23 & Block 2 \\
13 & $11,12,16, \& 17$ & 19 & Block 1 \\
14 & 38 & 29 & Block 3 \\
15 & $33 \& 38$ & 29 & Block 3 \\
16 & $32,36, \& 37$ & 29 & Block 3 \\
17 & $30,31,34,35, \& 36$ & 29 & Block 3 \\
18 & 38 & 29 & Block 3 \\
19 & N/A & N/A & N/A \\
20 & $21,22,24, \& 25$ & 23 & Block 2
\end{tabular}

Based on the morphology of the 18 features with burned rock, six different kinds of named functions are postulated (Table 8). These include shallow rock-filled warming pits (Features 8, 9, 20 , and possibly 13), a formal deep hearth or roasting pit (Feature 12), a very large incipient earth oven (Feature 17) with a concentric series of low dump piles (Features 14, 15, 16), other small rake-off or rock dump features (Features 2, 3, possibly 4 and 11), possible recycled burned rock stock pile (Features 6 and possibly 11), a large fitted griddle area (Feature 10), and several features of unknown or undetermined function (Features 1, 7, and 18). Various artifacts and ecofacts (including flakes, projectile points, freshwater mussel shell, and bone) were recovered near several features, and an array of samples (including sediments for flotation, lipid, and radiocarbon assays) were collected from these features in hopes of identifying economic activities and determining absolute dates. The numbers, kinds, and diversity of materials associated with the features must be regarded as a minimal count due to the collection of sediment samples and the preliminary tally provided herein. Each feature is discussed below in order of its assigned number. 


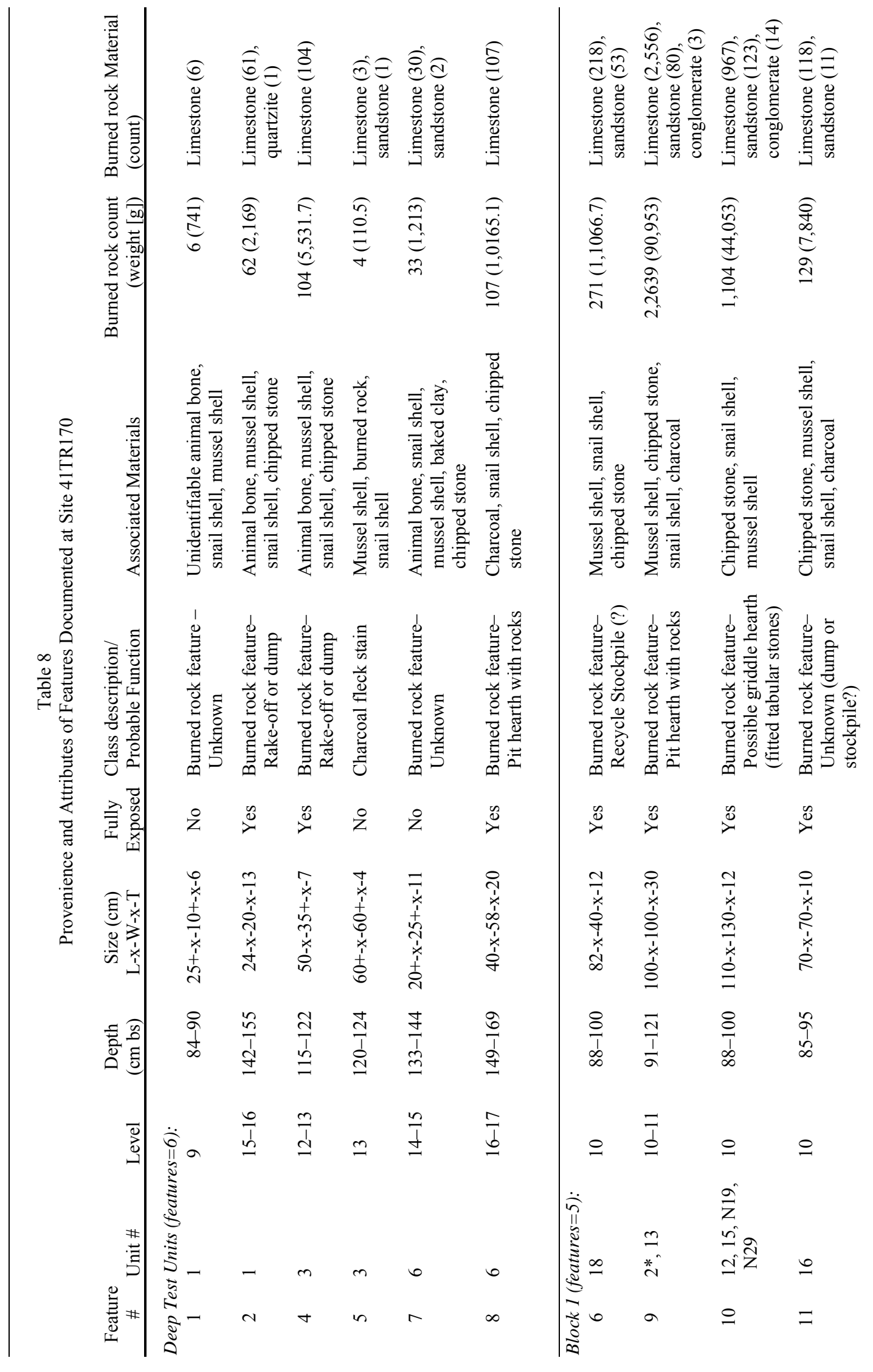




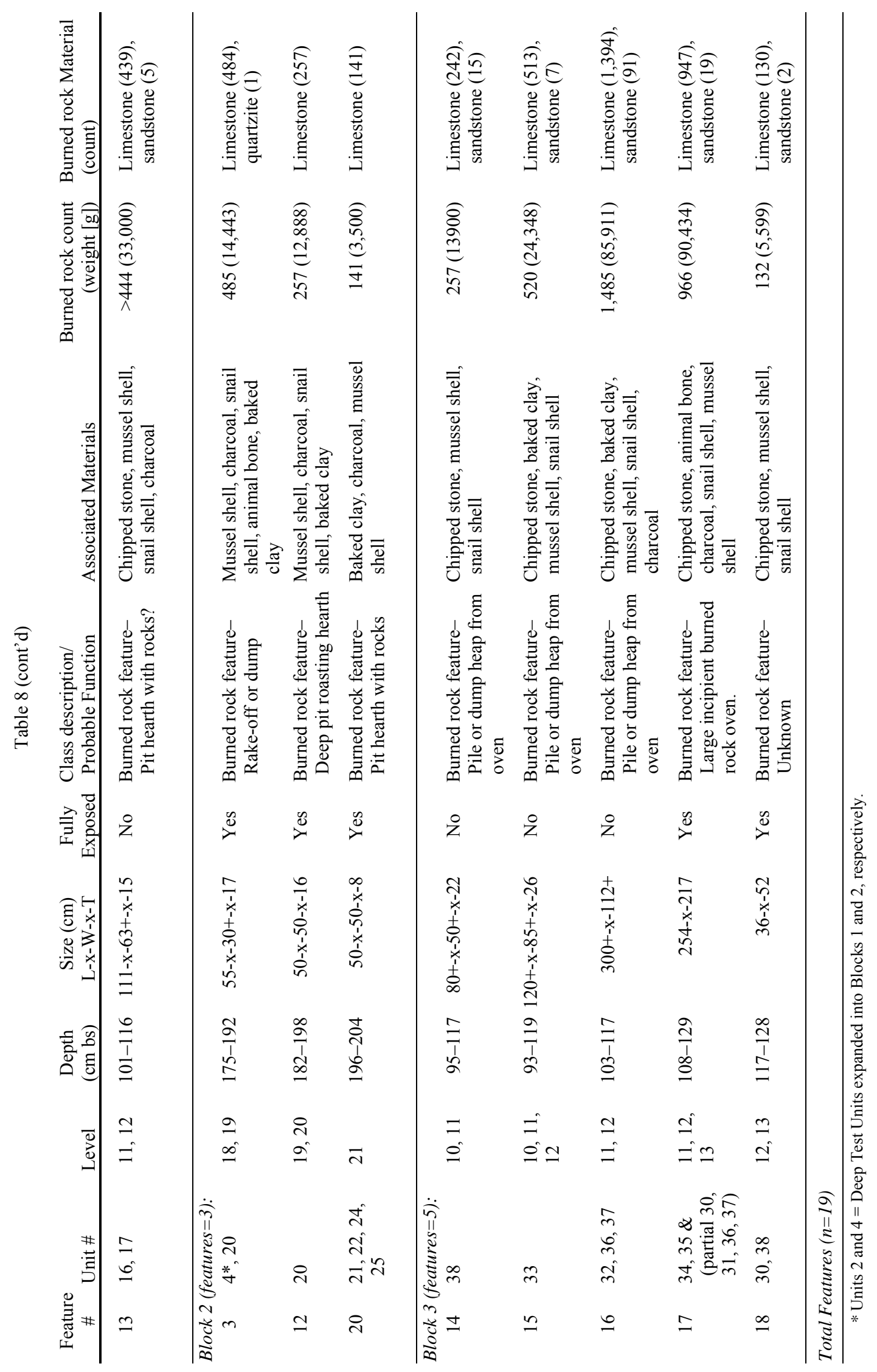




\section{Features from Deep Test Units}

\section{Feature 1 (Deep Test Unit 1; 84-90 cm bs)}

Feature 1 consisted of a tight cluster of six burned rocks protruding from the sidewall of the northwest corner of Test Unit 1, a deep test unit, located adjacent to Trench 1 just south of the relic river channel. No further units were excavated to open this area and fully expose the feature since the goal of excavations at the time was to dig Unit 1 to a depth of $2 \mathrm{~m}$. Thus, little information was gained about the nature of these rocks, their construction, or their function. Essentially six burned limestone rocks weighing $741 \mathrm{~g}$ were tightly clustered in an area measuring at least $25 \mathrm{~cm}$ (north-south) by $10 \mathrm{~cm}$ (east-west) in the upper portion of the West Fork paleosol. The upper portions of the burned rocks were at a depth of $84 \mathrm{~cm}$ and extended to $90 \mathrm{~cm}$ below surface. Stratigraphically, this 6-cm-thick burned rock cluster represented one of the youngest features within the site. The rocks might be the edge of a hearth, part of a dump, or a rake-off cluster, but mapping showed them to be confined to a very compact area. No charcoal was observed with these cobbles. A sample of sediments collected from the southeastern corner of the unit for flotation yielded only a rhabdotus snail shell and a $10-\mathrm{x}-4-\mathrm{x}-6 \mathrm{~cm}$ piece of concrete with one finished surface. The six burned rocks were collected. Other materials from the same level as the feature included 17 freshwater mussel shells, 16 of which were unidentifiable shell fragments, and one was classified as a Plectomerus dombeyanus. Two unidentifiable animal bones as well as 10 small fragments of possible baked clay were also recovered from this level.

\section{Feature 2 (Deep Test Unit 1; 142-155 cm bs)}

Feature 2 was a tight cluster of five burned rocks within a 24-cm (north-south) by 20 -cm (eastwest) area in the southwest corner of Test Unit 1 at a depth of $142-155 \mathrm{~cm}$ bs (Figure 14). This 13-cm-thick feature was east of and about $55 \mathrm{~cm}$ below Feature 1 and was obviously from a much earlier component. Due to the small area of the clustered rocks and the lack of associated occurrence of charcoal, this feature probably represented a discard pile or rake-off cluster of burned rock materials from a more formal feature that occurred beyond the present limits of the test unit. No further investigations were expanded in this area to ascertain the nature of this cluster of rocks. Sixty-two burned rocks totaling 2,169 g were collected from this feature context. The four mussel shell fragments consist of three unidentified specimens and one Quadrula pustulosa mortoni. One secondary flake and one possible spokeshave were recovered from this level; both are made from Brazos/Uvalde Gravel. One piece of animal bone recovered near the feature was identified as a medium-sized ungulate specimen exhibiting a green fracture.

\section{Feature 4 (Deep Test Unit 3; 115-122 cm bs)}

Feature 4 was a tight concentration of burned limestone and a few other outlying clasts exposed in the east wall of Trench 23 at a depth of $115-122 \mathrm{~cm}$ bs. Test Unit 3 was placed on the east side of Trench 23 to investigate these rocks. The rocks comprising Feature 4 were discrete from a dark charcoal-flecked stain and a few rocks noted in the southeast corner of the same test unit at the same depth, designated as Feature 5. 


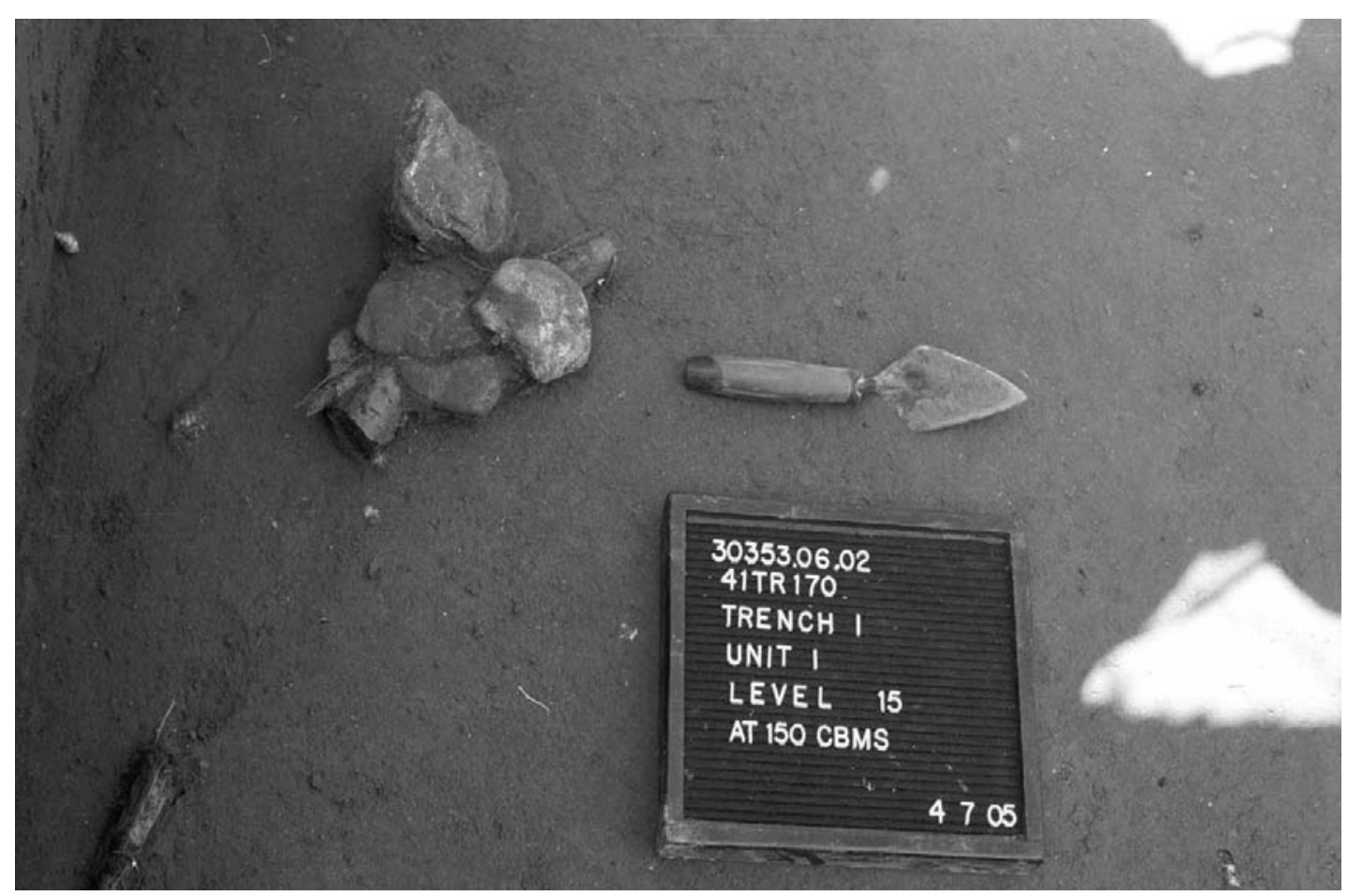

Figure 14. Photograph of Feature 2; photographer is facing west.

The rock cluster from Feature 4 consisted of about 20 rock clasts measuring $5-18 \mathrm{~cm}$ in diameter that were compacted in an area measuring $50 \mathrm{~cm}$ (north-south) by at least $35 \mathrm{~cm}$ (east-west) and about $7 \mathrm{~cm}$ thick (Figure 15). Ten other clasts were scattered up to $30 \mathrm{~cm}$ from this cluster in the upper part of the feature and were regarded as part of the rock concentration. Thus, the total extant feature was confined within a $98-\mathrm{cm}$ (north-south) by $72-\mathrm{cm}$ (east-west) area. The extent of disturbance to the feature from backhoe trenching is unknown. The cross-section observations indicated that the rocks were on an amorphous surface, but plan maps indicated that the rocks are at least two courses high with the lower level consisting of six rocks within a $50-\mathrm{x}-28-\mathrm{cm}$ area directly beneath the greatest concentration in the higher level. Several pieces of charcoal were directly associated with the burned rocks. The dark sediments of the West Fork paleosol prevented detection of any pit feature. The occurrence of confined rocks over two layers suggested that they might be in a pit or in a pile. The function of the burned rock cluster is uncertain. If a basin were present, then the rocks might reflect some primary stone-heating element, or perhaps a small roasting pit; alternatively, if they represent a pile, then the rocks may signify a rake-off, dump, or discard from hearth clearing or heating activities.

Materials recovered from Feature 4 include snails, three small ( $>19 \mathrm{~mm}$ ) chipped stone flakes (two are secondary and one is tertiary), three animal bones identified as turtle, and $104(5.5 \mathrm{~kg})$ of burned rock. 


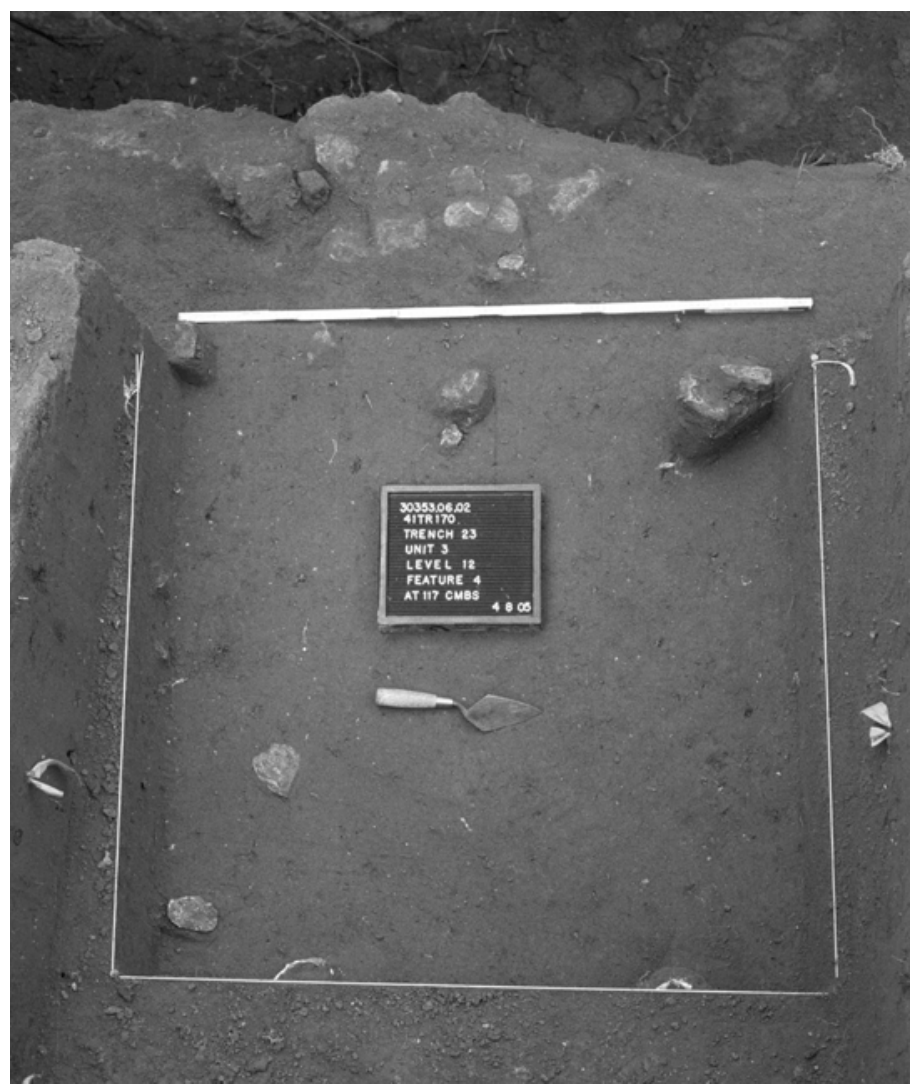

Figure 15. Photograph of Feature 4; photographer is facing west.

\section{Feature 5 (Deep Test Unit 3; 120-124 cm bs)}

Feature 5 consisted of an area of darker stained soil with concentrated charcoal flecking in the southeastern corner of Test Unit 3 at a depth of 120-124 cm bs (Figure 16). The 4-cm-thick charcoal-stained lens occurred in an area measuring at least $60 \mathrm{~cm}$ (north-south) by $60 \mathrm{~cm}$ (eastwest) and was not associated with an oxidized base. Four small (roughly 7-cm diameter) burned rocks, 11 unidentified mussel shell fragments, and seven snail shells were found with the feature. The dark staining and charcoal occurred $60 \mathrm{~cm}$ east of the clustered rocks and $24 \mathrm{~cm}$ to the east of the outlier rocks of Feature 4 within Test Unit 3. The dark charcoal-flecked area was relatively shallow and hence might be either a shallow heating basin in primary context that did not oxidize the basal soil, or the scraped-off cleaning matrix from some hearth feature that was buried by alluvial deposits soon after the cleaning event.

\section{Feature 7 (Deep Test Unit 6; 133-144 cm bs)}

Feature 7 represented a tight cluster and adjacent wide scatter of burned limestone rock in the extreme northwest corner of Test Unit 6 at a depth of 133-144 cm bs (Figure 17). The test unit was located next to Backhoe Trench 25, which was some $10 \mathrm{~m}$ south of the relic channel of the Clear Fork of the Trinity River. 


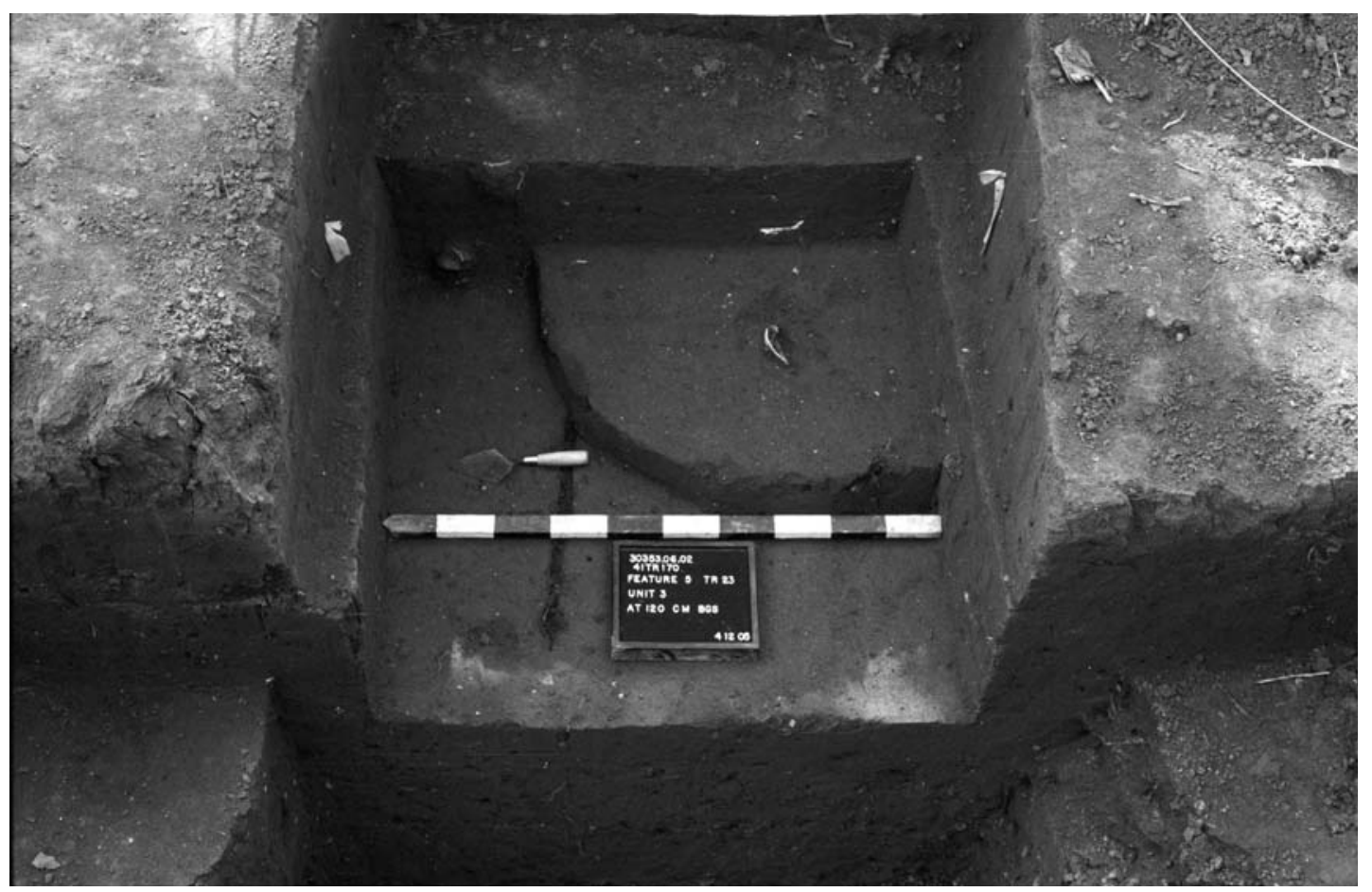

Figure 16. Photograph of Feature 5, Unit 3; photographer is facing east.

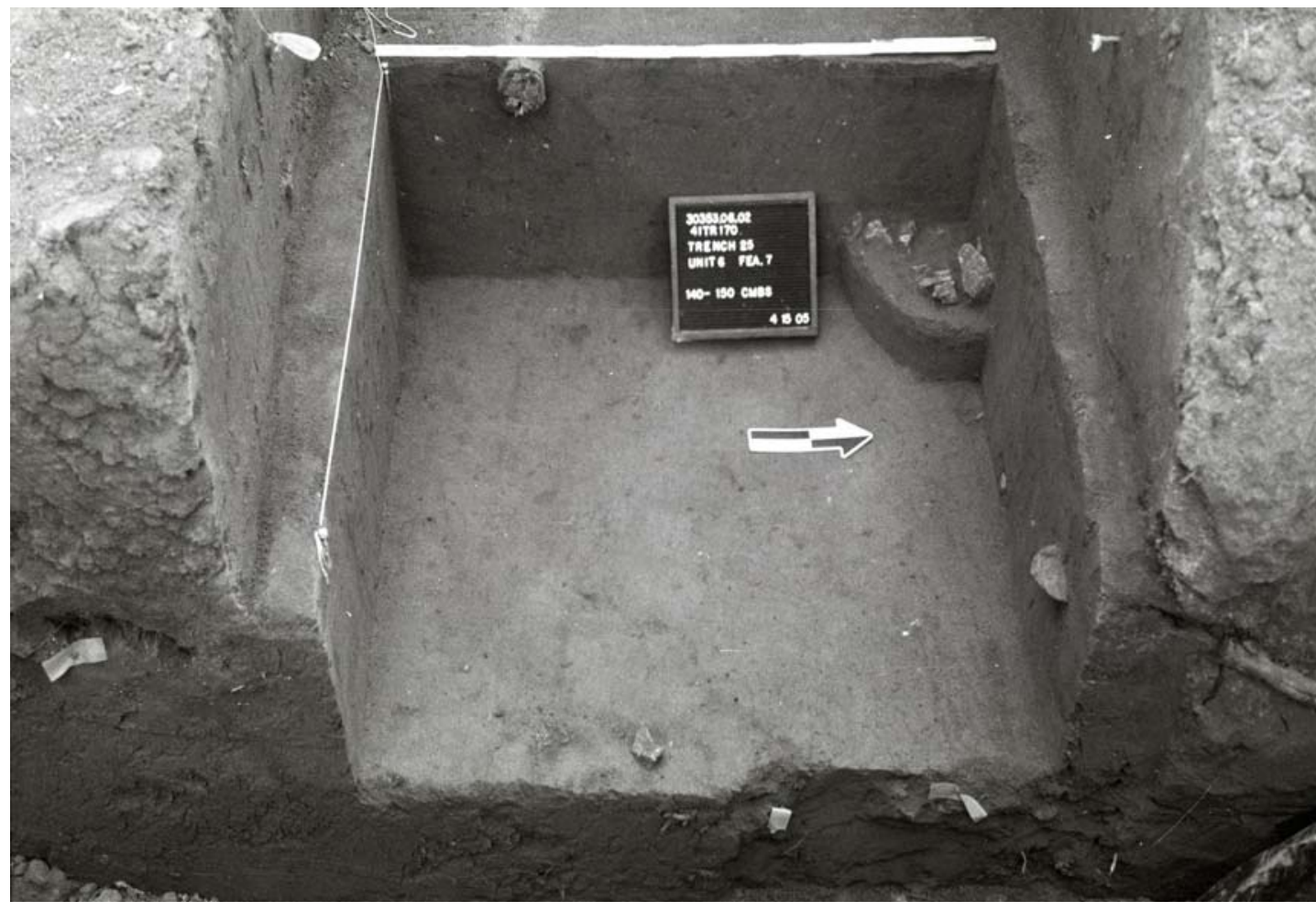

Figure 17. Photograph of Feature 7, Unit 6; photographer is facing west. 
The tight rock cluster was restricted to an 11-cm-thick area in the extreme corner of the test unit and measured $20 \mathrm{~cm}$ (north-south) by $25 \mathrm{~cm}$ (east-west); presumably parts of this cluster extended beyond the north and west walls of the unit. Other burned rocks occurred haphazardly and widely spaced across the floor of the test unit and appeared to be scattered by flooding events or foot traffic. These outlying stones demarcated an ephemeral occupation zone. The function of this rock feature is unknown due to the small area of exposure, but it might be related to Feature 8. No artifacts were identified during excavation of the feature, but one sediment sample was collected for waterscreening. Three pieces of baked clay were recovered as well as six flakes and one piece of shatter. Thirty-three $(1,213 \mathrm{~g})$ burned rocks were recovered from $130-140 \mathrm{~cm}$ bs. Charcoal, one piece of concrete, 18 unidentified mussel shell fragments, and eight snail shells were also identified. Only two pieces of bone were recovered from this level; one is a green fractured bone from a medium ungulate, the other is partially calcined but unidentifiable.

\section{Feature 8 (Deep Test Unit 6; 149-169 cm bs)}

Feature 8 occurred just below and to the east of Feature 7 within the northeast quadrant of Test Unit 6. Feature 8 was an oval, basin-shaped hearth in the northeast corner of Test Unit 6, adjacent to Backhoe Trench 25 (Figure 18). This feature measured $40 \mathrm{~cm}$ (north-south) by $58 \mathrm{~cm}$ (east-west) and extended from 149-169 cm bs for a total depth of $20 \mathrm{~cm}$. The upper $10 \mathrm{~cm}$ of this feature consisted of a nearly level layer of concentrated burned rock numbering about 33 clasts, and the lower $10 \mathrm{~cm}$ were composed of charcoal-flecked sediments lacking rocks confined to a straight-walled pit with relatively flat base. Possible pit feature fill occurred above the rock layer, but was not identified until the rocks were encountered. The profile indicated the lower sediments and the overall feature to be contained within a straight-walled basin. This was clearly a deep pit hearth or small oven feature, with a layer of rocks capping the fill matrix.

Two tertiary flakes and one piece of shatter were recovered from $145-150 \mathrm{~cm}$ bs, one small secondary flake was recovered from $150-160 \mathrm{~cm}$ bs, and one bone fragment was identified just south of this feature, but their association is uncertain. The 33 constituent burned rocks of the feature were collected for analysis of size, shape, and weight data. A total of 107 (approximately $10.2 \mathrm{~kg}$ ) burned rocks were recovered from $150-160 \mathrm{~cm}$ bs. One charcoal sample was collected. No further investigations were undertaken in this area.

\section{Features from Block 1}

\section{Feature 6 (Block 1, Unit 18; 88-100 cm bs)}

Feature 6 was designated as a dense concentration of large burned limestone and sandstone rocks located in the western half of Test Unit 18 of Block 1 (Figure 19). The rocks occurred in two-tothree tiers and consisted of mostly elongated limestone clasts measuring up to $20 \mathrm{~cm}$ long, which was larger than most rocks found with features in Block 1. The overall dimension of Feature 6 was $82 \mathrm{~cm}$ (north-south) by $40 \mathrm{~cm}$ (east-west), and it extended from $88-100 \mathrm{~cm}$ bs for a total thickness of $12 \mathrm{~cm}$. Although densely packed, the rocks were apparently not directly touching rocks in the adjacent layer. Due to the overall larger size of the clasts compared to those occurring in adjacent features, the elongated shape of the rock cluster, and the lack of inherent structure to the rock placement, it is possible that these rocks were culled from other features and 


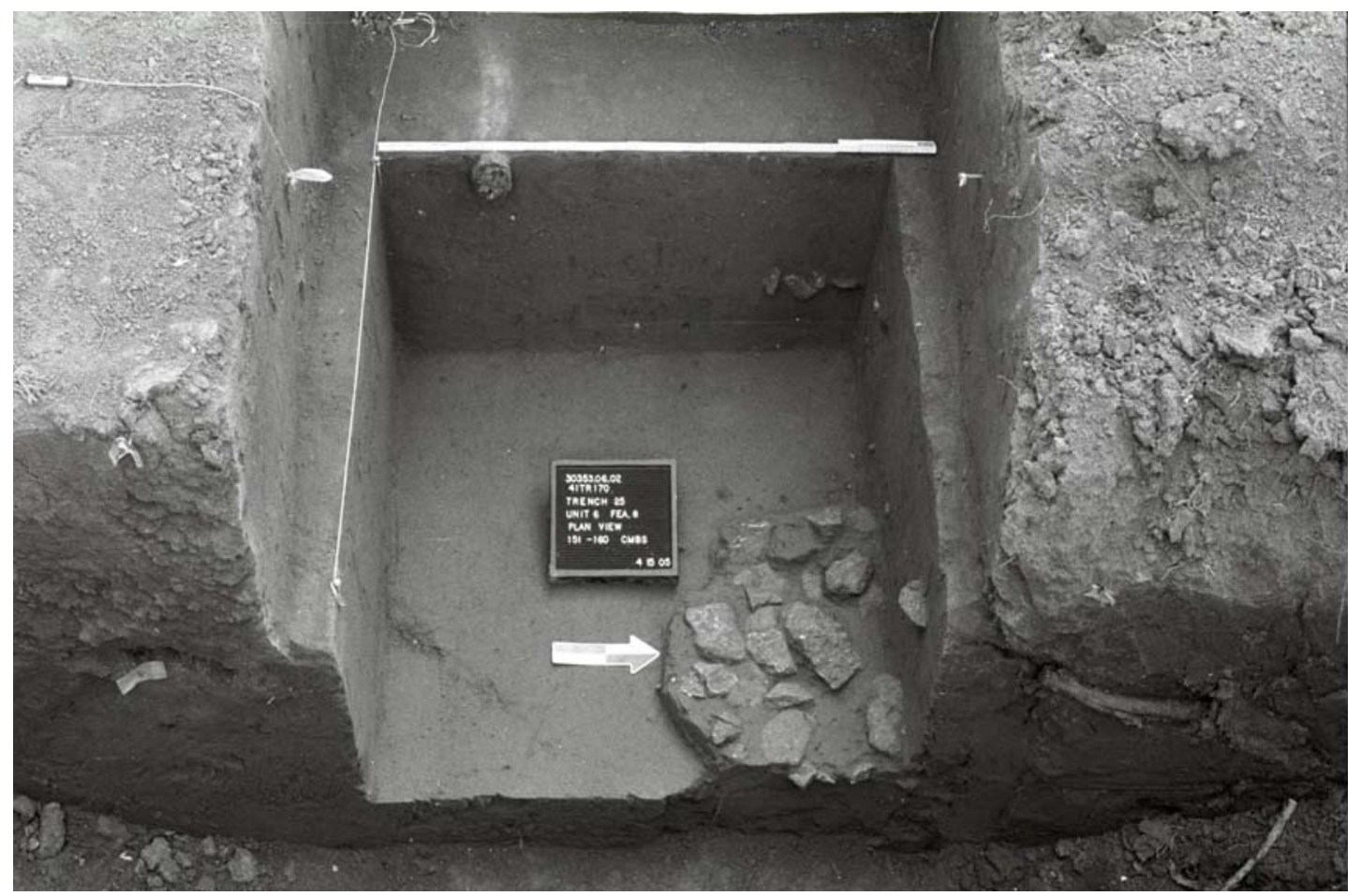

Figure 18. Photograph of Feature 8 in Unit 6; photographer is facing west.

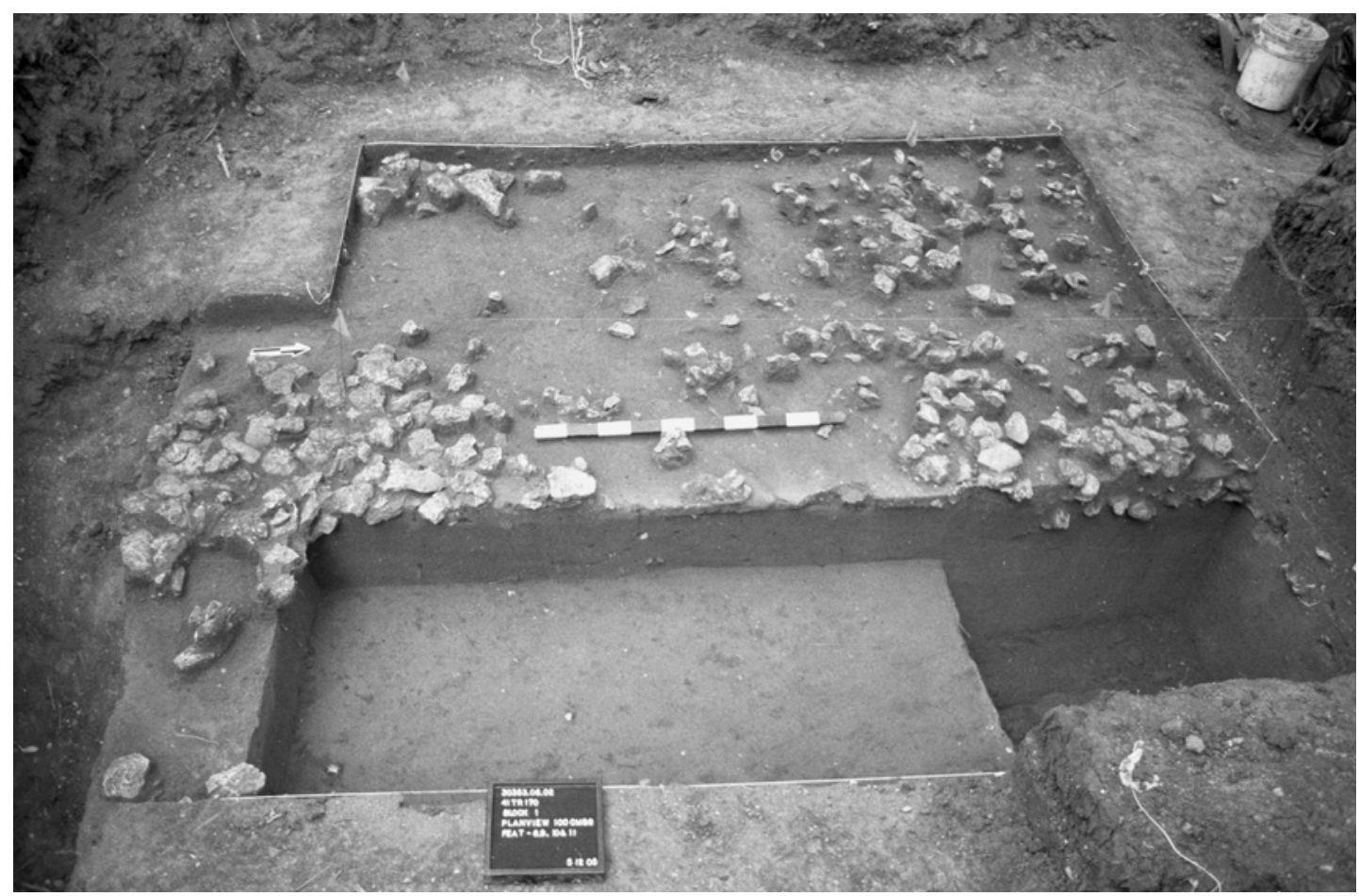

Figure 19. Photograph of Features 6, 9, and 10 in Block 1; photographer is facing west. Feature 6 is located in the southwest corner of Block 1, Feature 9 is located in the north half of Block 1, and Feature 10 is located in the southeastern corner of Block 1 . 
were piled as recycled lithic resources to be used in other rock-heating features. The structure, form, and composition of these rocks differed from those of nearby Features 9 and 10 (see Figure 19).

Materials associated with Feature 6 include a wide range of cultural remains, including nine small tertiary and secondary flakes, one edge-modified flake, 38 pieces of freshwater mussel shell including Plectomerus dombeyanus and Quadrula pustulosa mortoni, $0.2 \mathrm{~g}$ of charcoal, and 271 rocks weighing about $11.1 \mathrm{~kg}$. Six of the sandstone rocks from this cluster were collected for lipid residue analysis.

\section{Feature 9 (Block 1, Units 2 and 13; 91-121 cm bs)}

Feature 9 was initially assigned to the general massive series of clusters and scatters of burned rock in the southern portion of the site, about $148 \mathrm{~m}$ south of the relic river channel. Initial efforts to open Trench 19 encountered massive quantities of burned rock at approximately $90 \mathrm{~cm}$ bs. Accordingly, the trench was twice mechanically expanded south before an area of diminished burned rock was found and the trench could be placed without destroying much of the feature area. However, Deep Unit 2, which extended from the undisturbed ground surface through the burned rock zone designated as Feature 9 to cemented caliche at a depth of 175 , was placed $2.5 \mathrm{~m}$ north of Trench 19. The designation was initially retained during the excavation of Units 2,11 , and 12, which formed a north-south trench extending toward Trench 19. Nevertheless, the plan of these units showed differential densities in the clustering of burned rock, and the profile of these three units showed that burned rock extended into a shallow basin pit. At that point, the Feature 9 designation was applied to the massive layer of burned rock and the underlying pit feature with burned rock that was in the west half of Unit 2 and the east half of adjacent Unit 13 (see Figure 19). This concentration of rock first appeared at a depth of $91 \mathrm{~cm}$ bs and extended 30 $\mathrm{cm}$ in profile to a depth of $121 \mathrm{~cm}$ bs. Other scattered rocks, which were smaller and more diffuse the farther from the pit feature, occurred mostly at the occupation surface in adjacent units 11,13 , and 14 over an area measuring some $130 \mathrm{~cm}$ (north-south) by $145 \mathrm{~cm}$ (east-west).

Materials associated with Feature 9 in Units 2 and 13 include nine flakes, 61 pieces of freshwater mussel shell including Quadrula pustulosa mortoni, Amblema plicata, Fusconaia askewi, Lampsilis teres, two small samples of charcoal, and some snails. In addition, 14 sandstone cobbles were collected for possible lipid studies. About $58.6 \mathrm{~kg}$ of burned rock were collected, and an additional $32.3 \mathrm{~kg}$ of burned rock were analyzed and left in the field; nearly all of it was limestone.

Extraction of macrobotanical remains was undertaken on a single 5-liter sediment sample (Lot 342/FS 407) associated with Feature 9, 100-110 cm bs, in Unit 13 (see Appendix F). Light fraction obtained by flotation was composed of 32 milliliters $(\mathrm{ml} ; 6.1 \mathrm{~g})$ of mostly modern rootlets. Analysis of the residue noted the presence of moderate amounts of snails and two uncharred (modern) seeds, but no charcoal whatsoever. The occurrence of abundant rootlet and modern unburned seeds suggests that some displacement of recent remains has occurred at this feature. No useful subsistence, economic, or activity data were obtained from the macrobotanical analysis. 
A small piece of wood charcoal weighing $0.2 \mathrm{~g}$ was recovered by GMI technicians from sediment sample Lot 151/FS 286 using flotation methods. The charcoal came from Level $11(100-110 \mathrm{~cm}$ bs) of Test Unit 2 and was associated with Feature 9. This piece of charcoal was not sent for macrobotanical identification, but was submitted to Beta Analytic for radiocarbon dating. Despite the ability to extract the wood flecks from flotation, upon completion of radiocarbon pretreatment, insufficient carbon was recovered; however, a humin fraction of the charred material was recovered for dating. The resulting uncorrected radiocarbon date is $3630 \pm 40$ B.P. (Beta-213092) with a ${ }^{13} \mathrm{C} /{ }^{12} \mathrm{C}$ value of $-22.5 \%$ that yields a conventional radiocarbon date of $3670 \pm 40$ B.P. The 2-sigma calibration for this sample is cal B.C. 2140 to 1940 or cal B.P. 4100 to 3880. Note that the humin fraction has the potential to include older carbon from sediments or even reworked paleosols redeposited during flood events; as such, the radiocarbon date does not reliably reflect the age of the cultural occupation and is about 1,300 years earlier than the adjacent radiocarbon date from Feature 13 in the same excavation block. The importance of the date does provide insights into the degree of older carbon in the paleosols of the surrounding sediments.

Lipid analysis was conducted from a single rock from Feature 9. The specimen (Lot 341) came from the northeast quarter of Unit 13, bottom half of Level $11(105-110 \mathrm{~cm} \mathrm{bs})$. The lipid results (6GM 1) indicated an extremely high fat content, possibly indicative of residues from seeds, nuts, or rendered fats from non-large herbivore mammals. Based on the C18:1 isomers, the remains were more likely from plants, although the specific plant(s) were not identified.

\section{Feature 10 (Block 1, Units 12, 15, N19, N29; 88-100 cm bs)}

Feature 10 represented a large circular concentration of burned rock in Test Units 12, 15, the north half of 19, and the north half of 29, immediately north of Trench 19 and along the southern edge of Block 1 (see Figure 19). Other features associated with this occupation zone in Block 1 included Features 6, 9, 11, and 13.

The concentration of rock comprising Feature 10 measured $110 \mathrm{~cm}$ (north-south) by $130 \mathrm{~cm}$ (east-west) and ranged from $88-100 \mathrm{~cm}$ bs for a total depth $12 \mathrm{~cm}$. The rocks comprising the feature were relatively large (more than $10 \mathrm{~cm}$ in diameter) and unusually flat. Indeed, the upper surface of these rocks seemed to have the same elevations as if they were fitted together to create a single smooth surface. Some "heavy oxidation" of sediments was noted under some burned rocks, but charcoal and burned clay were sparse; the oxidation suggested that the heating occurred in situ. In light of the tight placement of the flat rocks that appeared to be fitted together to form a continuous surface with a similar upper elevation, it is possible that this feature might have served as a large griddle or some other kind of flat heating hearth surface.

Chipped stone materials associated with Feature 10 include 31 lithic flakes, four pieces of shatter, and one edge-modified flake. A total of 168 fragments of freshwater mussel shell was recovered, these included Lampsilis teres, Quadrula pustulosa mortoni, Amblema plicata, Lampsilis hydiana, Tritogonia verrucosa, Ligumia subrostrata. One possible ground stone (tool sharpening abrader?) and some snails were also collected. Fourteen rocks were collected specifically for lipid residue analysis. The amount of burned rock attributed to this feature is about 1,104 (approximately $44.1 \mathrm{~kg}$ ) pieces. 


\section{Feature 11 (Block 1, Unit 16; 85-95 cm bs)}

Located in Test Unit 16 in the northwest corner of Block 1, Feature 11 was a circular cluster of burned rock just west of Feature 9, and partially overlying Feature 13. The rocks consisted of medium to small pieces of angular limestone that were concentrated in an area about $70 \mathrm{~cm}$ in diameter, with a scatter of sparse rocks on the living surface covering a larger area (Figure 20). The rocks tended to be concentrated in a 10-cm-thick zone between 85 and $95 \mathrm{~cm}$ bs. About half of the rocks were flat, but unlike Feature 10, these rocks appeared to be jumbled and with less structure. The lack of a pit or depression suggested that these rocks were not part of a hearth or cooking feature. The function of this feature is unknown; perhaps the stones represent a stockpile of burned rock or a rake-off dump of rocks from adjacent Feature 9.

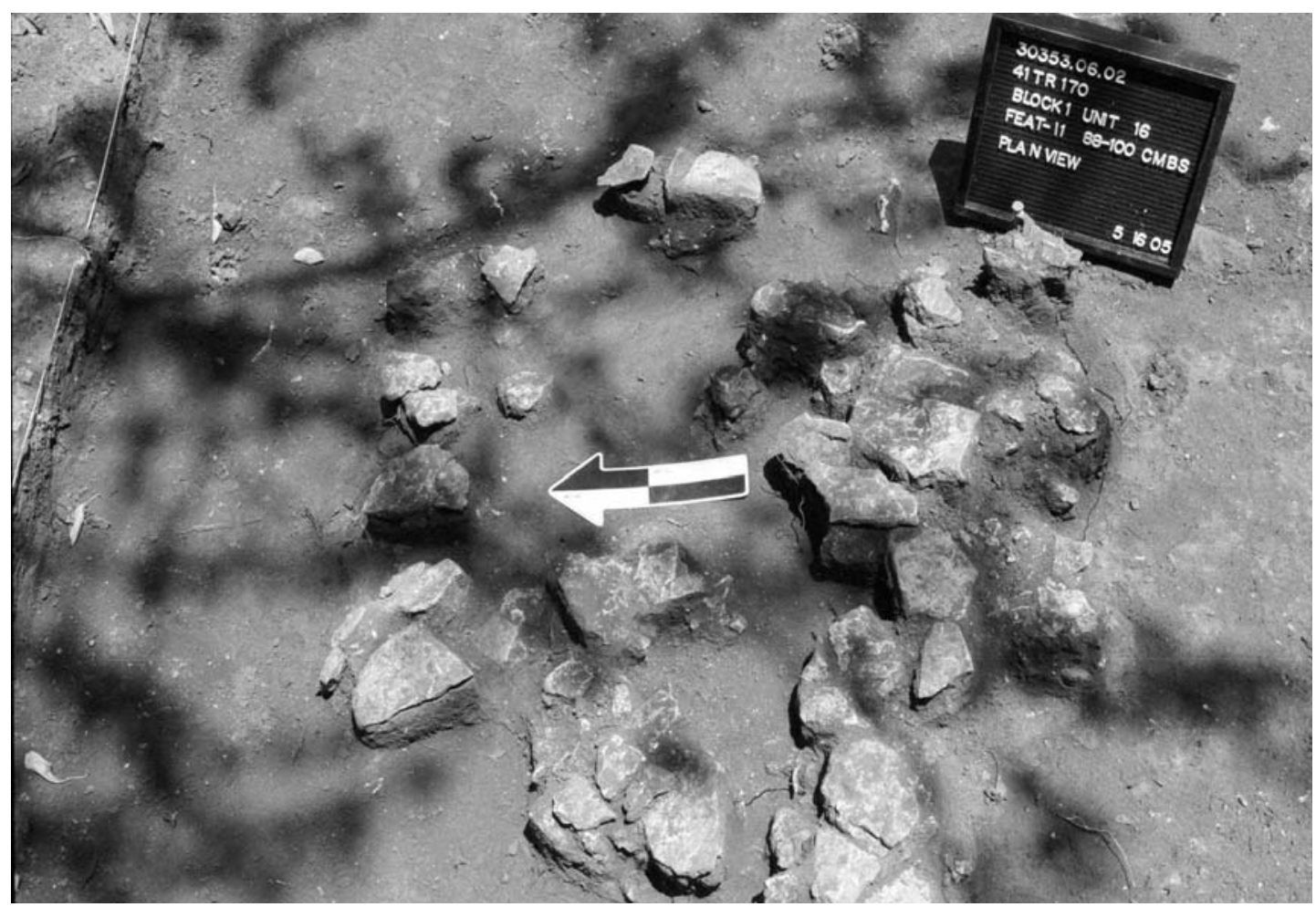

Figure 20. Photograph of Feature 11, Unit 16; photographer is facing east.

In the immediate vicinity of the feature, eight flakes, one piece of shatter, $6.6 \mathrm{~g}$ of charcoal, and a sample of nine Rabdotus snails were recovered. In addition, 67 fragments of freshwater mussel shell were collected, species identified included Ligumia subrostrata, Tritogonia cf. verrucosa, Quadrula sp., Lampsilis teres, and Fusconaia askewi. A 5-liter sample of collected material submitted for macrobotanical analysis revealed only insect parts and roots (see Appendix F). Three rocks were collected for possible lipid residue analyses and 25 other limestone rocks and seven sandstone rocks were collected as part of a sediment sample. The burned rocks associated with the feature were analyzed in the field and consisted of 129 specimens weighing a total of $7.8 \mathrm{~kg}$. 


\section{Feature 13 (Block 1, Units 16 and 17; 101-116 cm bs)}

Feature 13 was part of an oval-shaped pile of burned rocks that occurred in Test Units 16 and 17 within the northwest corner of Block 1 underneath Feature 11 (Figure 21). Despite its occurrence only $10 \mathrm{~cm}$ below Feature 11, Feature 13 was regarded as a distinctly different feature because of a 50-cm lateral shift to the west in the concentration of stones and the occurrence of a separate expansive scatter of rock documented in Level 11 that reflected an earlier occupation in this area. The rocks present in Levels 11 and 12 extended into the west sidewall of Block 1, which prevented complete delineation of the size of the feature.

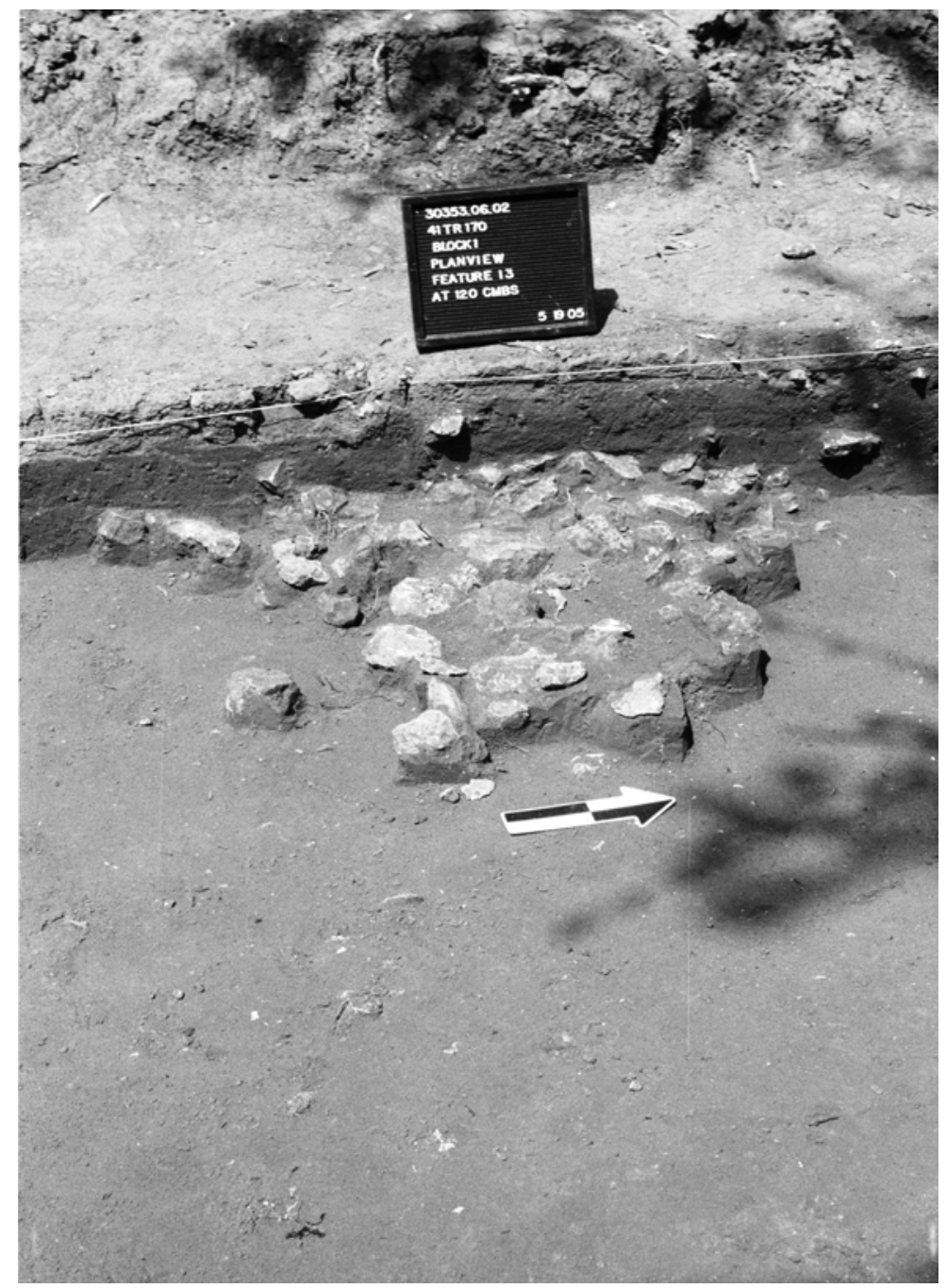

Figure 21. Photograph of Feature 13, Block 1; photographer is facing west.

No basin or pit was discerned during excavation or in the profile of this feature, but there was a distinct contraction in the horizontal distribution of rocks in the deeper level, so a pit might have been present. However, the surrounding matrix was not discolored, and rocks occurred throughout the matrix, which indicated that if a pit were present, the stones were in the fill and 
not lining the base. Alternatively, these may be piled discard rocks that were dumped into a depression. These burned limestone rocks occurred in an area measuring $111 \mathrm{~cm}$ (north-south) by at least $63 \mathrm{~cm}$ (east-west) and were recovered from 101-116 $\mathrm{cm}$ bs for a maximum thickness of $15 \mathrm{~cm}$. The rocks were noted in three to four layers or elevations, which also indicated some depth to the feature. For the most part, larger rocks occurred along the northern end of the feature in Level 11, which was directly over the concentration of rocks in Level 12; the smaller rocks to the south were believed to be a broadcast scatter of rocks on the occupation surface.

Artifacts associated with Feature 13 include eight flakes (one secondary, six tertiary, and one retaining cortex on the platform alone), $3.1 \mathrm{~g}$ of charcoal, and snail shell. Eighteen mussel shells and mussel shell fragments were also recovered; these included Amblema plicata, Tritogonia cf. verrucosa, Plectomerus dombeyanus. In addition, 12 sandstone cobbles were collected for possible lipid residue analysis and 221 pieces $(11,527 \mathrm{~g})$ of rock were collected as part of soil samples. Another $22.0 \mathrm{~kg}$ of burned rocks from the feature were analyzed and left in the field.

Two sediment samples (Lot 405/FS 464 and Lot 423/FS 484) from the east halves of Units 16 and 17, associated with Feature 13, were submitted for flotation to recover macrobotanical remains (see Appendix F). The combined prefloated samples measured $8.5 \mathrm{~g}$ and were from $110-120 \mathrm{~cm}$ bs of Block 1. They yielded moderate amounts $(40 \mathrm{ml} ; 6.5 \mathrm{~g})$ of plant remains, composed mostly of modern roots and some snails. A small amount $(0.5 \mathrm{~g})$ of charred plant remains obtained from Lot 423/FS 484 measured only 3.5 liters before processing; no charred remains came from the other 5.0-liter sample.

Three macrobotanical pieces were large enough to conduct charred wood cell structural analysis for species identification. One was determined to be Juglandaceae (hickory type; $<0.1 \mathrm{~g}$ ), another was Quercus (oak; $0.2 \mathrm{~g}$ ), and a third specimen was an unidentifiable species $(0.3 \mathrm{~g})$. The two recognized tree species are comparable to modern species in the region. None of the burned botanical pieces represented parts of plants from an annual. None of the charred plant parts from the 10 liters of sediments provided insights into the prehistoric subsistence economies or specific activities associated with this thermal feature.

The small piece of Quercus or oak wood charcoal weighing $0.1 \mathrm{~g}$ was recovered from the flotation sample (Lot 423/FS 484) from Level $12(110-120 \mathrm{~cm}$ bs) in the eastern half of Test Unit 17 and directly associated with Feature 13. The resulting uncorrected radiocarbon date is $1360 \pm$ 40 B.P. (Beta-213094) with a ${ }^{13} \mathrm{C} /{ }^{12} \mathrm{C}$ value of $-25.3 \%$ that yields a conventional radiocarbon date of $1360 \pm 40$ B.P. The 2-sigma calibration date for this sample is cal A.D. 630 to 710 or cal B.P. 1320 to 1240 . The date is relatively contemporaneous with the two radiocarbon dates from Features 16 and 17 in nearby Block 3 and is regarded as a reliable date for the cultural component associated with the rock features in Block 1.

Lipid analysis was conducted from a single rock from Feature 13. The specimen (Lot 421) came from the westcentral edge of Unit 17, Level $11(103-110 \mathrm{~cm} \mathrm{bs})$. The lipid results (6GM 2) indicated residues with an extremely high fat content, which possibly suggests oily remains from seeds, nuts, or rendered fats from non-large herbivore mammals. Based on the C18:1 isomers, the remains were more likely from plants, although the specific plant(s) were not identified. 


\section{Features from Block 2}

\section{Feature 3 (Block 2, Units 4 and 20; 175-192 cm bs)}

Feature 3 consisted of an occupation zone of scattered burned rock that initially appeared at the south end of Trench 22 within Unit 4 as an occupation zone located from 175-192 cm bs. Initially (at roughly $175 \mathrm{~cm} \mathrm{bs),} \mathrm{the} \mathrm{feature} \mathrm{was} \mathrm{a} \mathrm{widely} \mathrm{dispersed} \mathrm{scatter} \mathrm{of} \mathrm{burned} \mathrm{rock} \mathrm{with}$ ashy matrix and charcoal flecking throughout the unit and the floor of the adjacent trench; however, by $180-190 \mathrm{~cm}$ bs, the rocks became more organized and were tightly clustered in the southeastern corner of Unit 4 (Figure 22). Since the distribution of rocks on the upper level did not provide data on the compaction in the lower levels, and the ashy matrix occurred uniformly both within and outside the rock cluster, it is uncertain whether multiple occupation surfaces with different rock functions were present, or if the cluster of rocks occurred in a lower pit-like feature. Based on these materials and especially the presence of a thick ashy zone with charcoal flecking, Block 2 was established south and east of the occupation zone, and additional features were encountered in the expanded block.

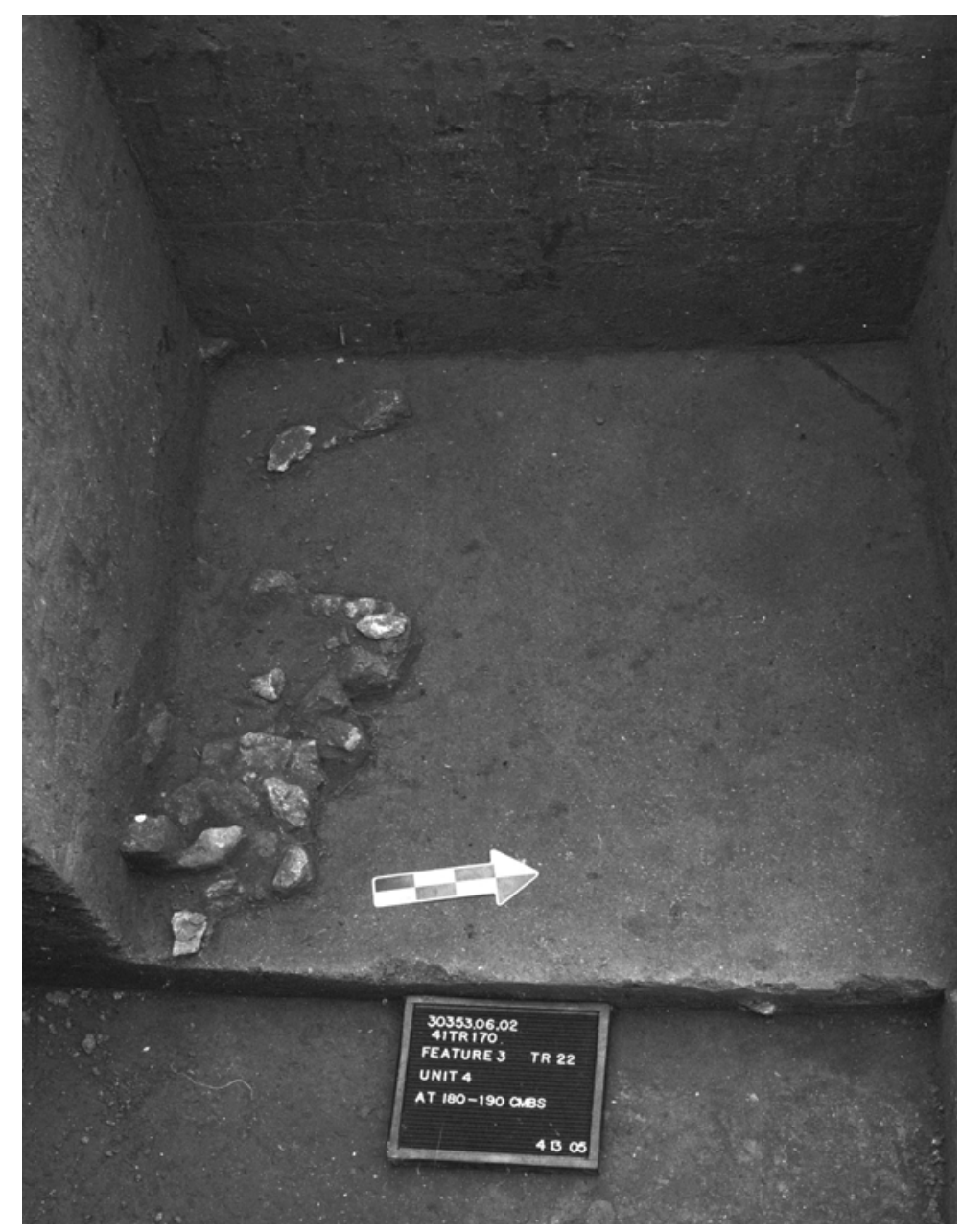

Figure 22. Photograph of Feature 3, Block 2; photographer is facing south. 
The initial large, amorphous scatter of burned rocks at $175-180 \mathrm{~cm}$ bs may represent the discard of rocks on a living surface; its dimensions were not fully ascertained since rocks clearly extended into the walls of the unit, and some of the scattered rocks exposed later in Block 2 may be from the same event. Based on the lack of a clear cluster, it appeared that the burned rocks had been kicked around and scattered. The source feature of this rock scatter is unknown.

Between 180-192 cm, the rocks became concentrated in the southeastern corner of Unit 4. At least 28 distinct cobbles were clustered in an area measuring $55 \mathrm{~cm}$ (east-west) by at least $30 \mathrm{~cm}$ (north-south) and $12 \mathrm{~cm}$ thick, with the feature extending into the southern edge of the unit. If the materials were not associated with an upper living surface scatter, then these rocks might be a small rake-off mound or concentration of burned stones derived from an adjacent rock-filled pit, Feature 12, located immediately to the south and occurring at depths of 190-200 cm bs.

Materials recovered from Feature 3 include 37 pieces $(8.6 \mathrm{~g})$ of bone (fish, turtle, and deer-sized mammal), $35 \mathrm{~g}$ of burned clay daub, and 485 pieces (approximately $14.4 \mathrm{~kg}$ ) of burned limestone. In addition, 140 fragments of freshwater mussel shell were recovered including Quadrula pustulosa mortoni, Amblema plicata, and Lampsilis hydiana. Seven sediment samples were collected and processed by GMI using waterscreen methods; a total of $3.7 \mathrm{~g}$ of charcoal and some of the burned clay were recovered.

\section{Feature 12 (Block 2, Unit 20; 182-198 cm bs)}

Feature 12 was a circular, basin-shaped, pit hearth or small roasting pit that contained a predominance of burned rock along the upper rim and occasional stone occurring inside the hearth feature matrix (Figure 23). It was immediately south of Feature 3 in Test Unit 20 of Block 2 , north of the relic channel of the Clear Fork of the Trinity River.

The burned rock associated with Feature 12 formed a circular outline and sloped toward the inner part of the hearth. It had a matrix of silty clay with a relatively high quantity of charcoal, although it occurred within the upper part of the thick, ashy, and daub-laden matrix found throughout Block 2. The pit orifice of Feature 12 measured $72 \mathrm{~cm}$ in diameter and the burned rock occurred from $182-198 \mathrm{~cm}$ bs for a total depth of $16 \mathrm{~cm}$. This feature was generally below the level of the burned rocks representing adjacent Feature 3, which may be the discard from this hearth or roasting pit.

No chipped stone was recovered during excavation of this feature. A number of chunks of charcoal totaling $9.6 \mathrm{~g}$ were piece-plotted and collected, and a charcoal-laden sediment sample weighing $321 \mathrm{~g}$ was specifically collected for extracting carbon for dating. A total of $22.6 \mathrm{~g}$ of baked clay was also collected. Four bags of sediment were collected for waterscreening. Five rocks were collected for lipid samples. The 257 burned rocks from the feature weighed roughly $12.9 \mathrm{~kg}$. This feature was completely excavated.

Two sediment samples (Lot 464/FS 470 and Lot 465/FS 471) from the east and west halves of Feature 12 were submitted for macrobotanical flotation to recover remains (see Appendix F). They came from depths of $190-200 \mathrm{~cm}$ bs in Block 2. The 10 liters of sediments yielded moderate amounts of remains, consisting of $38 \mathrm{ml}(5.8 \mathrm{~g})$ of plant remains. Analysis indicated that most was modern rootlets, although $2.5 \mathrm{~g}$ of charcoal wood was also recovered. Analysis of charred cell structure of wood on six of the larger specimens indicated that half the sample 


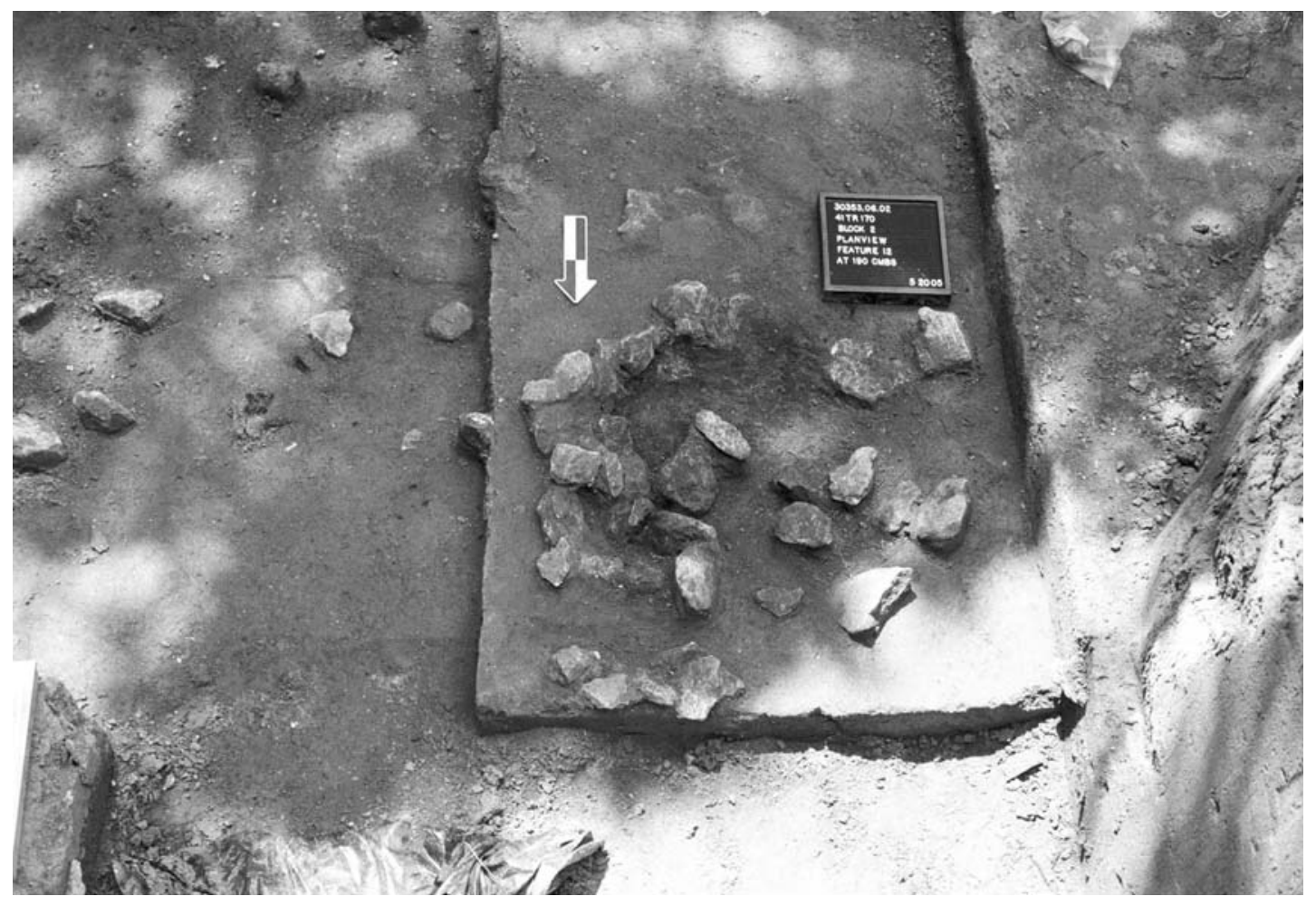

Figure 23. Photograph of Feature 12, Unit 20; photographer is facing south.

consisted of unidentified species of wood. Two pieces of Juglandaceae (hickory type) was present, as was a single specimen of Quercus (oak). Individual samples of wood charcoal ranged from $<0.1 \mathrm{~g}$ to $1.2 \mathrm{~g}$ in weight. The identified tree species were comparable to modern species in the region. None of the burned botanical pieces represented parts of plants from an annual, although one twig likely represented growth close to the age of wood procurement. The twig sample was submitted for radiocarbon dating. None of the charred plant parts provided insights into the prehistoric subsistence economies or specific activities associated with this thermal feature.

The small twig of unidentified wood charcoal, weighing $0.2 \mathrm{~g}$, was recovered from the flotation sample (Lot 464/FS 470) from the small basin-shaped rock-lined hearth, Feature 12. The sample was recovered from Level $20(190-198 \mathrm{~cm}$ bs $)$ in the eastern half of Test Unit 20. The resulting uncorrected radiocarbon date is $1420 \pm 40$ B.P. (Beta-213093) with a ${ }^{13} \mathrm{C} /{ }^{12} \mathrm{C}$ value of $-28.4 \%$ and yields a conventional radiocarbon date of $1360 \pm 40$ B.P. The 2-sigma calibration date for this sample is cal A.D. 630 to 710 or cal B.P. 1320 to 1240. The date is contemporaneous with all three other radiocarbon dates from Block 2. It is regarded as a reliable date for the cultural component associated with the rock features and thick ashy zone in Block 2.

Lipid analysis was conducted from a single rock from Feature 12. The specimen (Lot 468) came from the southeast quarter of Unit 20, Level 20 (196-198 cm bs). The lipid results (6GM 3) indicated a medium fat content, possibly signifying residues from mesquite beans, cholla cactus fruits, or perhaps fish. Based on the C18:1 isomers, the remains were more likely from plants, although the specific kinds of resources were not identified. 


\section{Feature 20 (Block 2, Units 21, 22, 24, and 25; 196-204 cm bs).}

Feature 20 was a small hearth associated with a small, tight cluster of burned rocks at the intersection of Units 21, 22, 24, and 25 in the northeast corner of Block 2 (Figure 24). This hearth was noted mostly for the concentration of seven limestone cobbles measuring about 8-15 $\mathrm{cm}$ in diameter that were tightly clustered in an area $50 \mathrm{~cm}$ in diameter, at a depth of 196-204 cm bs. Beneath the 8-cm-thick single layer of rock was a faint red oxidized layer under three of the rocks on the west side of the feature, which suggested that the rocks had been heated in place. Most likely, this was a small hearth used to heat stones for some unknown activity that might have involved stone cooking, plant or animal resource processing, or tasks involving prolonged heat radiation. A piece of freshwater mussel shell was found with the rocks.

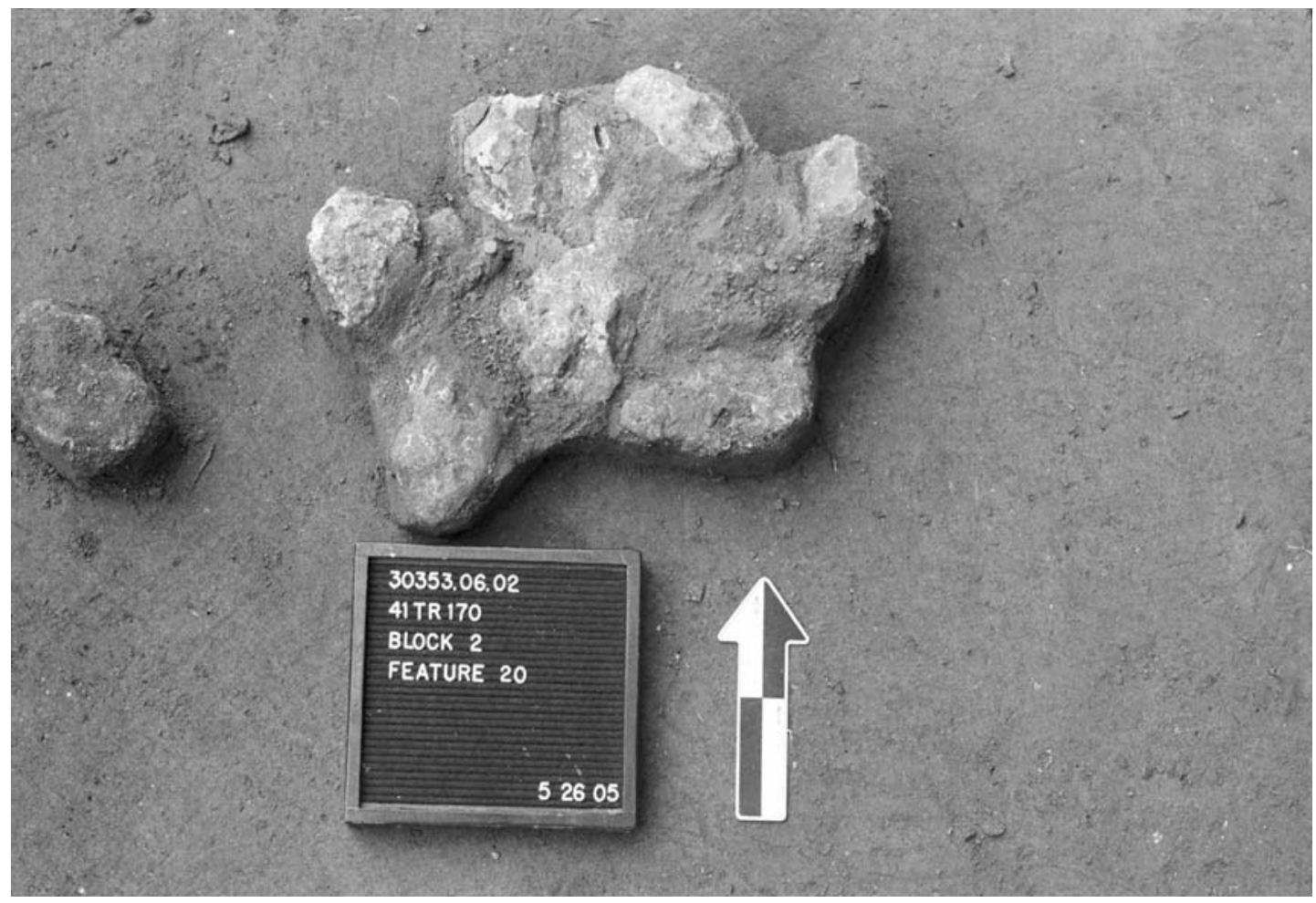

Figure 24. Photograph of Feature 20, Block 2; photographer is facing north.

No artifacts were directly associated with this feature. A small sample $(6.8 \mathrm{~g})$ of charcoal and sediments was collected for dating. Five of the rocks were collected for possible lipid analysis. An additional $0.2 \mathrm{~g}$ of charcoal and $4.4 \mathrm{~g}$ of baked clay were recovered from sediment samples screened in the laboratory. There was a total of 141 rocks from the feature weighing $3.5 \mathrm{~kg}$.

Two sediment samples (Lot 487/FS 618 and Lot 499/FS 619) retrieved from 200-210 cm bs in Test Unit 22 and directly from Feature 20 were submitted for macrobotanical flotation to recover remains (see Appendix F). The 10 liters of sediment yielded moderate amounts $(47 \mathrm{ml} ; 6.5 \mathrm{~g})$ of botanical remains, but most of it consisted of unburned rootlets and moderate to high quantities of land snails. Only about $0.3 \mathrm{~g}$ of charred wood was recovered from the 10 liters of sediment 
sample. Analysis of charred wood cell structure of four specimens indicated that two were unidentified species of wood, one was Juglandaceae (hickory type; $0.1 \mathrm{~g}$ ), and the other was Quercus (oak; $0.2 \mathrm{~g}$ ). Individual weights of wood charcoal ranged from $<0.1 \mathrm{~g}$ to $0.2 \mathrm{~g}$. The tree species are comparable to modern species in the region. The oak specimen was submitted for radiocarbon dating. None of the charred plant parts provided insights into the prehistoric subsistence economies or specific activities associated with this thermal feature.

The small piece of Quercus or oak wood charcoal weighing $0.2 \mathrm{~g}$ was recovered from the flotation sample (Lot 487/FS 618) associated with the small cluster designated as Feature 20. This flotation sample was recovered from Level $20(200-210 \mathrm{~cm} \mathrm{bs})$ of Test Unit 22 . The sample was submitted to Beta Analytic for radiocarbon dating. The resulting uncorrected radiocarbon date is $1600 \pm 40$ B.P. (Beta-213096) with a ${ }^{13} \mathrm{C} /{ }^{12} \mathrm{C}$ value of $-26.7 \%$ that yields a conventional radiocarbon date of $1570 \pm 40$ B.P. The 2-sigma calibration for this sample is cal A.D. 410 to 580 or B.P. 1540 to 1360 . The date is about 120 years earlier than the radiocarbon date collected from the base of the general ashy area and of Block 2 (Beta-213097), even though the feature is clearly within the ashy zone. Thus, this date is stratigraphically incongruent and slightly earlier than expected, based on three other dates from Block 2 area. Overall, the magnitude of the difference is not great relative to the known cultural sequences developed for the region.

Lipid analysis was conducted from a single rock from Feature 20. The specimen (Lot 557) came from the northwest quarter of Unit 25, Level 21 (198-203 cm bs). The lipid results (6GM 4) indicated similarities to residues derived from a large herbivore mixed with plant remains or, less likely, the bone marrow residues from a large herbivore. Although the specific species was uncertain, the results were compatible to residues derived from bison, deer, javelina, and perhaps sotol.

\section{Features from Block 3}

\section{Feature 14 (Block 3, Unit 38; 95-117 cm bs)}

Feature 14 was a dense burned rock feature partially exposed within the west half of Test Unit 38 in the extreme northwest corner of Block 3 (Figure 25). Feature 14 continued mostly into the west and perhaps into the north walls of this unit and beyond the limits of the block. The rocks of this feature were distinct from those in Feature 15, located some 50-60 cm to the east.

Feature 14 was a massive layer of burned rock, mostly lying flat in three to four noncontiguous tiers of sediments, that extended $80 \mathrm{~cm}$ (north-south) by at least $50 \mathrm{~cm}$ (east-west) at a depth between $95-117 \mathrm{~cm}$ bs. Based on the curvature of the dense rock cluster, slightly less than onehalf of this feature has been exposed. The entire feature may represent a circular concentration of stones that measured about $100 \mathrm{~cm}$ in diameter, and the three to four tiers of stone were at least $22 \mathrm{~cm}$ thick. The presence of sediments separating the clasts suggested that all may not have been deposited in a single instantaneous event, but might have accumulated at this spot. The profile did not indicate that the rocks were sloping into a pit feature, so the function of these burned stones is unknown. Possibly, they represented a pile or heap of sediments and burned rocks that might have been pulled from the deep pit Feature 17, located to the south, or perhaps represented a rake-off area or dump event, albeit a large one. 


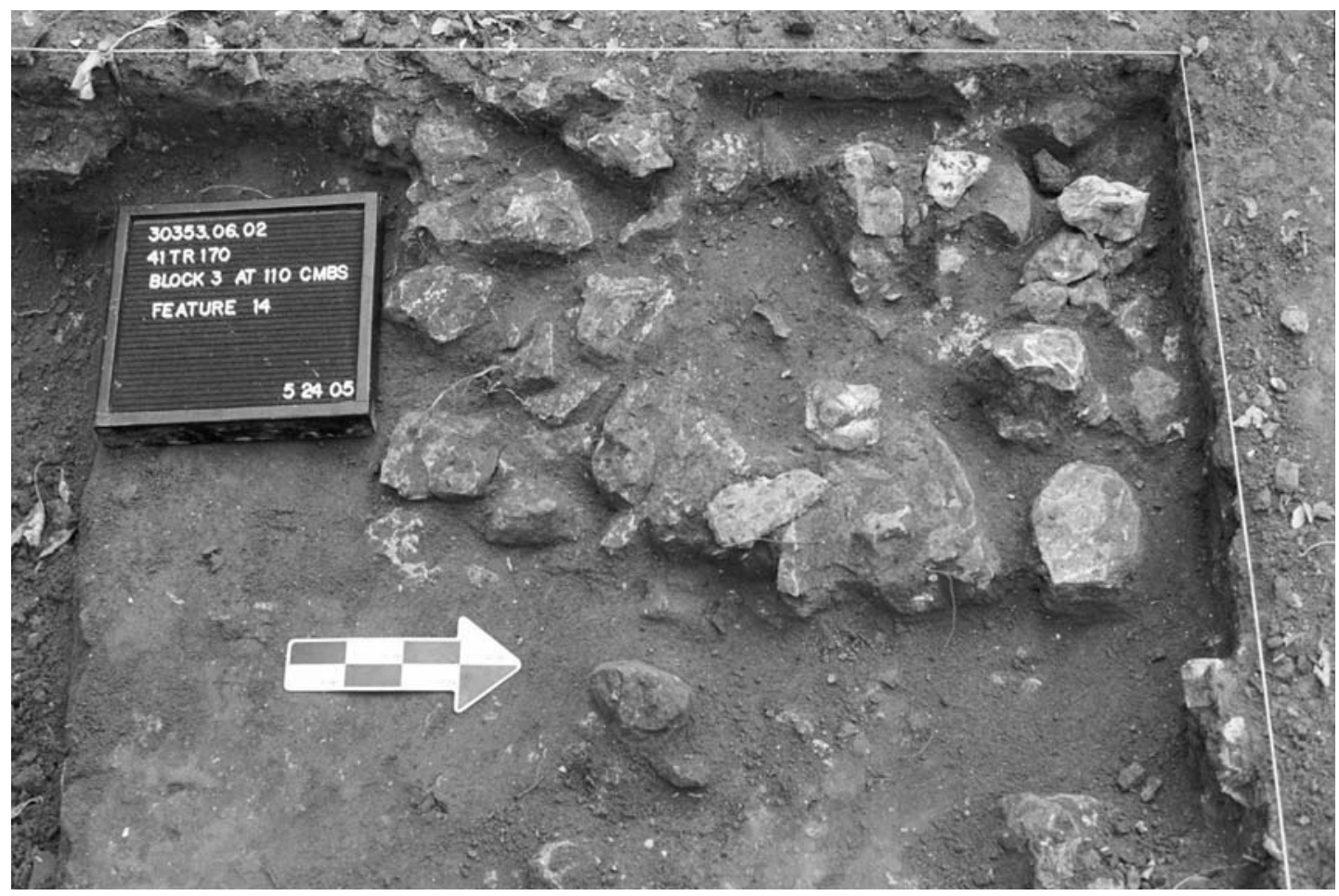

Figure 25. Photograph of Feature 14, Unit 38; photographer is facing west.

No artifacts were observed in association with this rock cluster during excavation. However, five sediment samples collected for waterscreening yielded one small secondary flake, and 21 mussel shell fragments. Five rocks were saved for lipid residue studies. Approximately 257 burned rocks $(13.9 \mathrm{~kg})$ were analyzed in the field or collected for analysis. All of the rock, with the exception of 15 pieces of sandstone, was recorded as limestone.

\section{Feature 15 (Block 3, Units 33 and 38; 93-119 cm bs)}

The burned rocks from Feature 15 completely covered the area of Test Unit 33 and the eastern quarter of Test Unit 38 to the west in the northern edge of Block 3; based on the density and limits of the feature, the rocks also extended beyond the excavation limits to the north and east (Figure 26). Feature 15 was a 26-cm-thick amorphous cluster of burned rock that measured at least $120 \mathrm{~cm}$ (east-west) by more than $85 \mathrm{~cm}$ (north-south). In profile, the rocks were on a relatively flat basal surface, two to three layers thick, and varied from stacked elements without intervening sediments to areas of the feature well separated by fine sediments. The presence of sediments between rocks suggested that they might represent a $26-\mathrm{cm}$-tall heap of burned rock and sediments, perhaps, like those present in adjacent Features 14 and 16, discard residues and dumps from a very large main rock pit, Feature 17, located along the south edge of Block 3.

Two small tertiary flakes and a possible Trinity dart point were recovered from this feature, along with 23 pieces of freshwater mussel shell including Quadrula sp., Tritogonia verrucosa, and Amblema plicata. No charcoal was recovered during the excavations. Eight rocks were originally collected for lipid analysis. Altogether, the rocks attributed to Feature 15 totaled 520 and weighed about $24.3 \mathrm{~kg}$. 


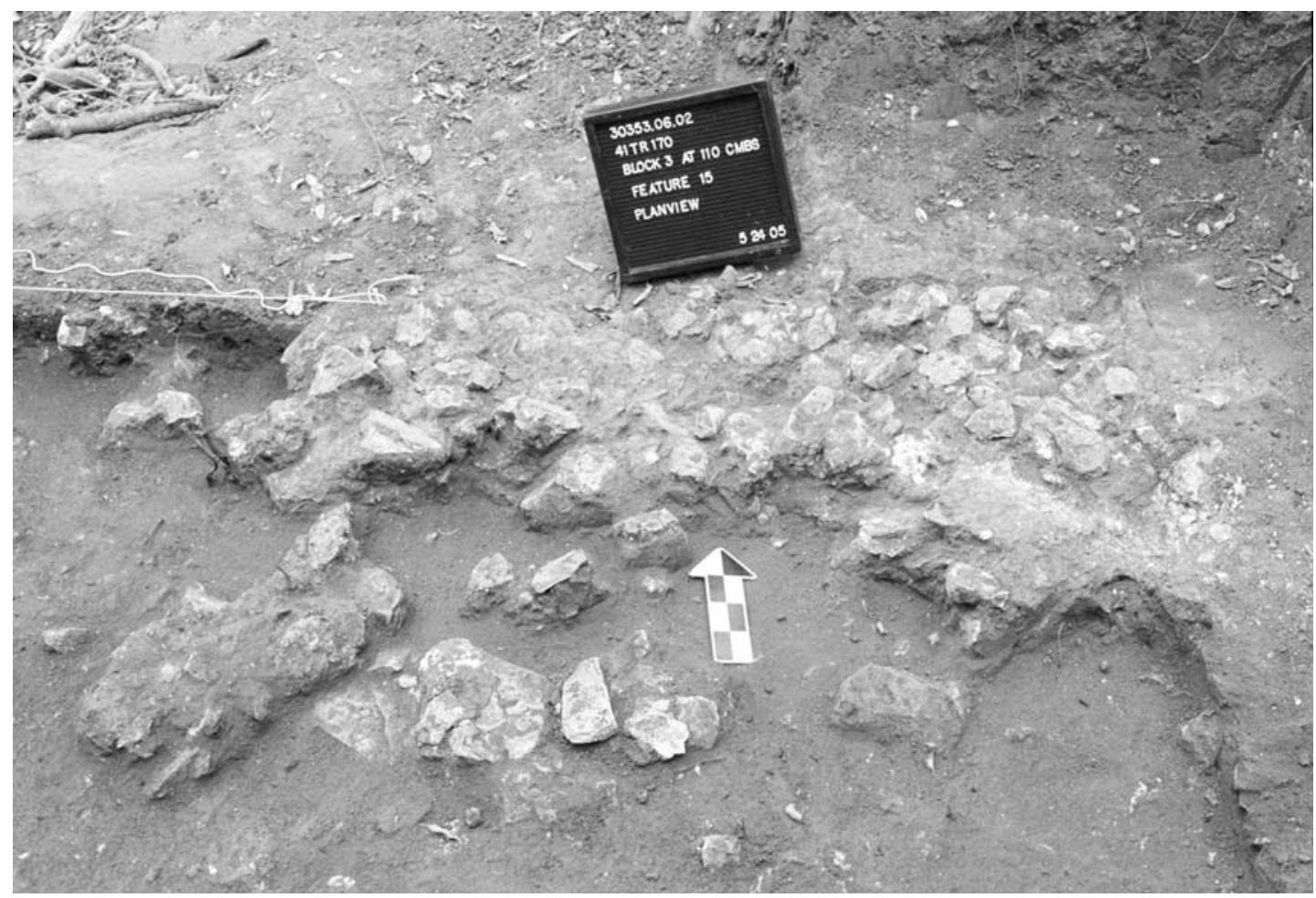

Figure 26. Photograph of Feature 15, Block 3; photographer is facing north.

\section{Feature 16 (Block 3, Units 32, 26, and 37; 103-117 cm bs)}

Feature 16 was a very large and complex accumulation of burned rock partially exposed in three test units $(32,36$, and 37) making up the eastern wall of Block 3 (Figure 27). Most of the rocks extended east of the block, so the actual configuration of the rocks was uncertain. In plan view, the rocks appeared to expand as lobes into the southeast corner of Unit 37 toward the south and covered almost all of the floor surface of Unit 32 in the north, but in intermediate Unit 36, they only extended some $20 \mathrm{~cm}$ from the edge of the block. Thus, in plan view, the rocks were concentrated in an area measuring more than $3 \mathrm{~m}$ (north-south) by more than 20 to $112 \mathrm{~cm}$ (eastwest). In profile, the rocks were jumbled in a 14-cm-thick zone that had sediments separating the rock clasts in some areas and rock-on-rock contact in other areas. Some of the relatively tabular rocks were sloping, but there was no consistency in the direction or steepness of angles. Overall, this feature appeared to be a long, linear dump heap of sediments and burned rock that surrounded a large pit oven, Feature 17.

Associated materials include three flakes, one edge-modified flake, $0.8 \mathrm{~g}$ of baked clay, charcoal, and 151 pieces of freshwater mussel shell including Amblema plicata, Fusconaia askewi, Tritogonia verrucosa, Quadrula pustulosa mortoni, Lampsilis teres, Plectomerus dombeyanus, and Quadrula apiculata.. Several sandstone rocks were plotted on maps and saved for possible lipid studies. A total of 1,485 burned rocks weighing $85.9 \mathrm{~kg}$ was recorded in association with Feature 16. 


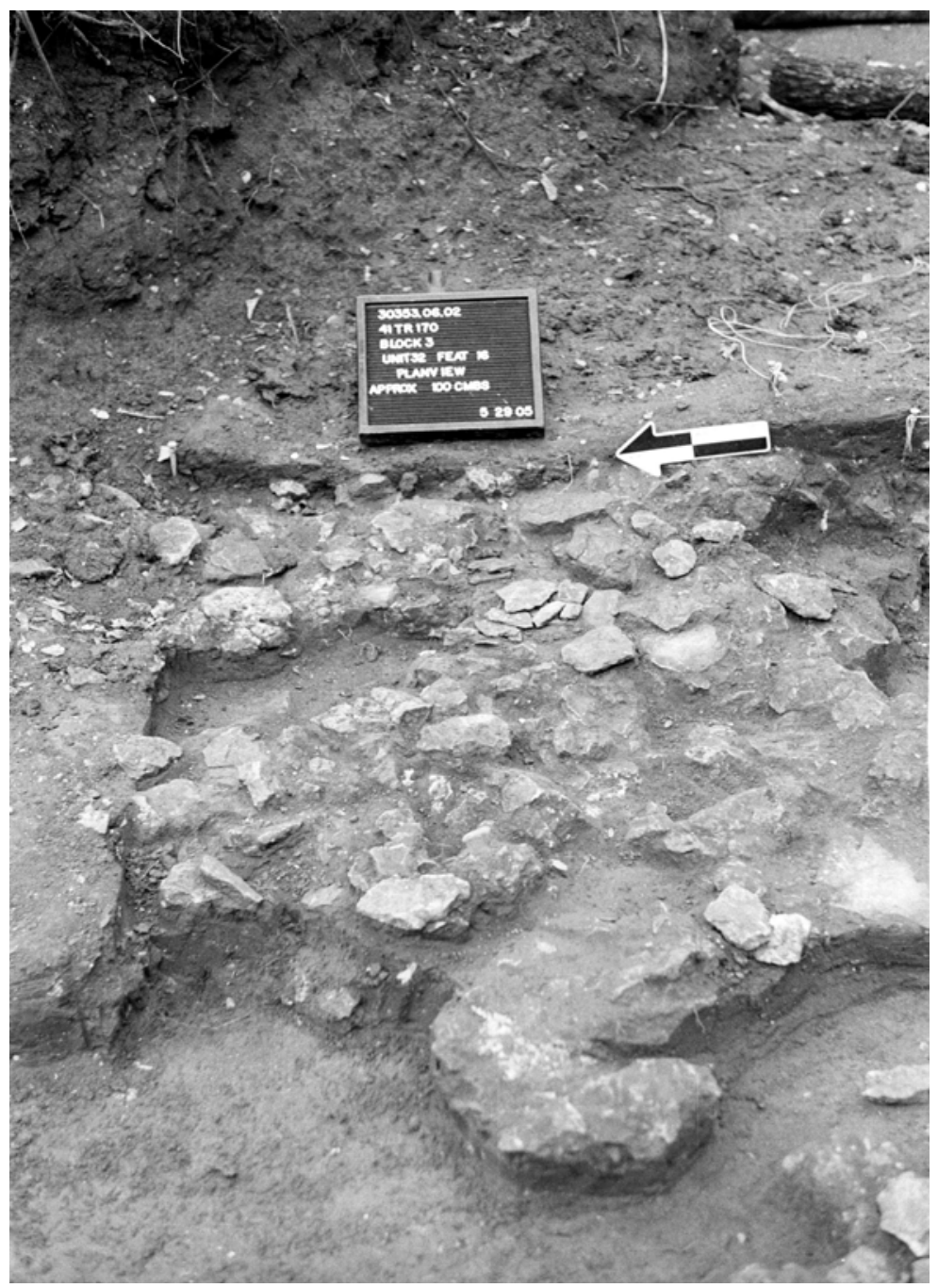

Figure 27. Photograph of Feature 16, Block 3; photographer is facing east.

Two sediment samples from $110-120 \mathrm{~cm}$ bs in Unit 36 and $100-110 \mathrm{~cm}$ bs in Unit 32 , were collected from the debris discard ring, Feature 16, and submitted for flotation to recover macrobotanical remains (see Appendix F). One 5-liter sediment sample yielded a small amount $(15 \mathrm{ml} ; 3.9 \mathrm{~g})$ of botanical remains, but all of it consisted of unburned rootlets and land snails. No burned wood, seeds, or other prehistoric macrobotanical remains were found. The second sample was from 100-110 cm bs in Unit 32. This 5-liter sediment sample also yielded small amounts $(22 \mathrm{ml} ; 2.3 \mathrm{~g})$ of organic remains. Most consisted of rootlets, insect parts, and $<0.1 \mathrm{~g}$ charred materials. The charred remains were composed of five pieces of unidentified wood and three twig fragments from unidentified tree species. The recovery of only charred wood species from these two samples indicated that no useful data on prehistoric subsistence economies or specific activities were derived from these sediment samples from the discard debris ring.

A small, unidentifiable twig of wood charcoal weighing $<0.1 \mathrm{~g}$ was recovered from the flotation sample (Lot 631/FS 662) from Level $11(100-110 \mathrm{~cm} \mathrm{bs)}$ of Test Unit 32 and was directly associated with the mounded heap of burned rock debris (Feature 16) removed from the adjacent 
large earth oven Feature 17. The small twig very likely represented the year's growth and should accurately date the cultural event that is unbiased by old wood or cross sectional problems. The sample was submitted to Beta Analytic for radiocarbon dating. The resulting uncorrected radiocarbon date is $1400 \pm 40$ B.P. (Beta-213098) with a ${ }^{13} \mathrm{C} /{ }^{12} \mathrm{C}$ value of $-22.2 \%$ that yields a conventional radiocarbon date of $1450 \pm 40$ B.P. The 2-sigma calibration for this sample is cal A.D. 540 to 660 or cal B.P. 1410 to 1290 . Even though the spatial relationship between archshaped debris ring (Feature 16) and the central pit (Feature-17) indicated that they are partially contemporaneous, the date from Feature 16 is some 140 years earlier than that from the adjacent central pit (Beta-213099). Assuming that either old wood or cross sectional factors have not adversely affected the ages of these two samples, the only way to interpret them is to suggest that the charcoal from the large earth oven pit may represent some different cooking event.

Lipid analysis was conducted from a single rock from the linear heap of rocks, Feature 16, surrounding the large oven feature, Feature 17. The specimen (Lot 711) came from the southwest quarter of Unit 37, Level $12(106.5-115 \mathrm{~cm} \mathrm{bs})$. The lipid results (6GM 6) indicated a high fat content, possibly suggesting residues from seeds or nuts. The specific plant(s) processed in the feature were not identified.

\section{Feature 17 (Block 3, Units 34, 35, S30, S31, SW36, and W37; 108-129 cm bs)}

Feature 17 was a very large and moderately deep basin-shaped pit with jumbles of burned rock present within $30 \mathrm{~cm}$ of the walls and floor, but only fine sediments without rocks in the middle or upper parts of the pit (Figure 28). Feature 17 was centered in Units 34 and 35, but part of the orifice extended into the south half of Units 30 and 31, the southwest edge of Unit 36, and the west edge of 37. Based on the distribution of rocks, the pit measured about $2.54 \mathrm{~m}$ (north-south) by $2.17 \mathrm{~m}$ (east-west) and extended from 108-129 cm below surface, for a total pit depth of $21 \mathrm{~cm}$.

The base of the pit was $10-15 \mathrm{~cm}$ deeper than the base of the rocks in surrounding Features 14 , 15 , or 16 , which tended to be concentric to the pit. Since the edge of these three features was some $80-110 \mathrm{~cm}$ from the edge of the Feature 17 pit, there appeared to be a modest "work area" between the pit and the clusters of burned rock that likely came from Feature 17. It was also interesting to note that whereas the tops of the dense rock of Features 14, 15, and 16 were clearly all evident by $110 \mathrm{~cm}$ bs, there was virtually no rock present in the area of the pit. By all accounts, this seemed to be an incipient earth oven feature with a modest discontinuous ring of rock and sediment dumps about $20 \mathrm{~cm}$ tall surrounding the oven pit. Assuming that the burned rock and sediments were derived from the large pit, then Feature 17 was an earth oven and not an open-air roasting pit.

Materials associated with the oven include two secondary flakes, snail shell, three unidentifiable bone fragments, and $0.5 \mathrm{~g}$ of charcoal. A total of 116 mussel shell fragments was recovered including Ligumia subrostrata, Quadrula sp., Lampsilis teres, Amblema plicata, Plectomerus dombeyanus, Quadrula pustulosa mortoni, and Quadrula apiculata. In addition, 10 burned sandstone rocks were removed for lipid analysis and 13 flotation samples were taken from the inside of the pit. The rocks from the pit analyzed in the field weighed $90.4 \mathrm{~kg}$. 


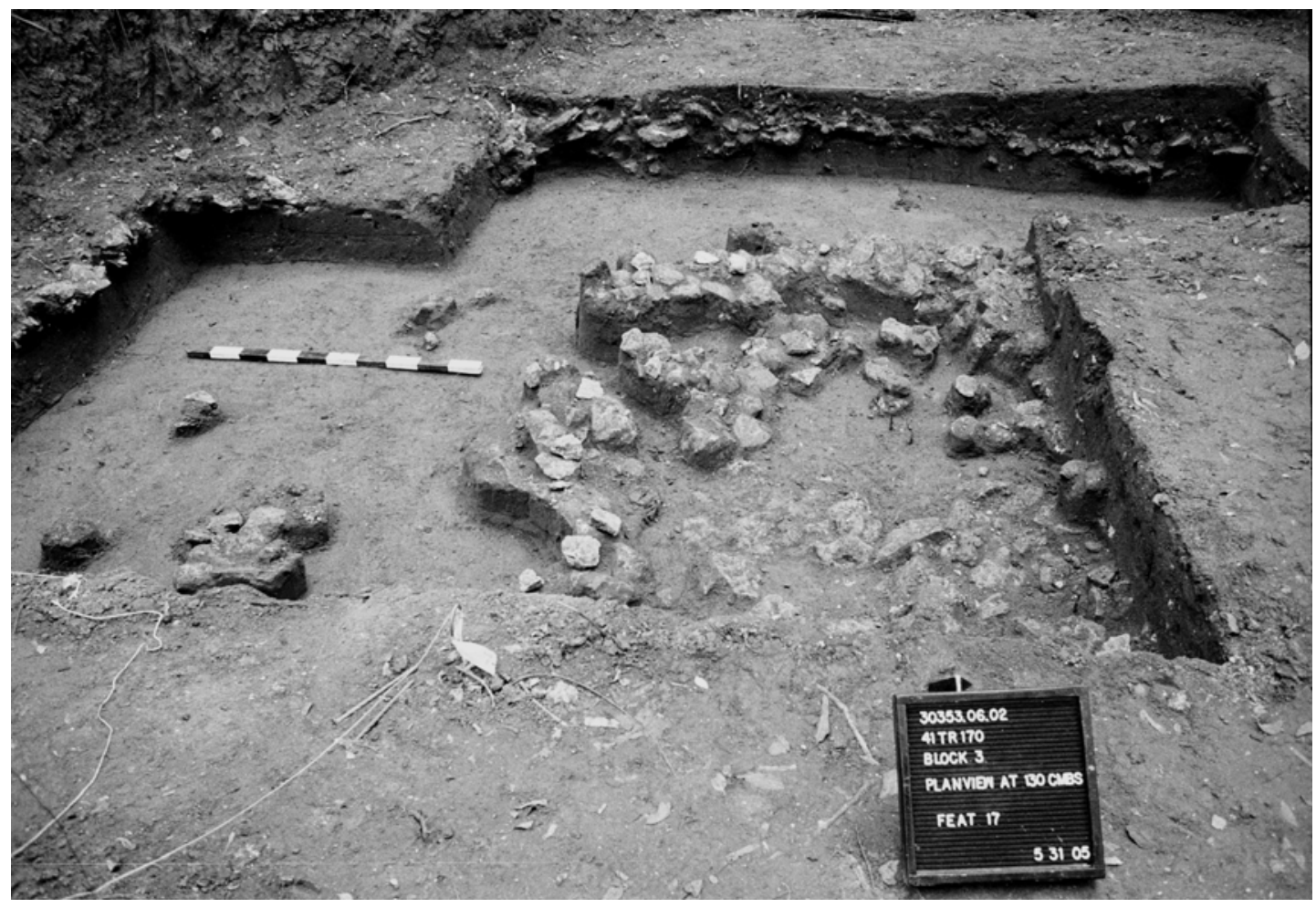

Figure 28. Photograph of Feature 17, Block 3; photographer is facing east.

Two sediment samples (Lot 662/FS 680, and Lots 613, 624/FS 706, 707) totaling 8 liters were submitted for macrobotanical flotation from the large pit oven, Feature 17 (see Appendix F). A 3-liter sample (Lot 662/FS 680) came from around rocks $110-130 \mathrm{~cm}$ bs from the south half of Unit 34; and a 5-liter sample (Lots 613, 624/FS 706, 707) came from 110-120 cm bs in Units 30 and 31. The single 3-liter sample (Lot 662/FS 680) yielded only $8 \mathrm{ml}$ of rootlets and $1.3 \mathrm{~g}$ of snail shell. No charred remains were recovered from such a small sample. The 5-liter sediment sample (Lots 613, 624/FS 706, 707) yielded $22 \mathrm{ml}(2.8 \mathrm{~g})$ of macrobotanical remains. The main macrobotanical component was composed of modern roots and two pieces of charred twigs $(<0.1 \mathrm{~g})$ of an indeterminate wood species. None of the charred plant parts provided insight into the prehistoric subsistence economies, past environmental conditions, or specific activities associated with this pit oven feature.

The small twigs of unidentified wood charcoal weighing $<0.1 \mathrm{~g}$ from the flotation samples (Lots 613, 624/FS 706 and 707) were submitted to Beta Analytic for radiocarbon dating. The resulting uncorrected radiocarbon date is $1340 \pm 40$ B.P. (Beta-213099) with a ${ }^{13} \mathrm{C} /{ }^{12} \mathrm{C}$ value of $-26.9 \%$ that yields a conventional radiocarbon date of $1310 \pm 40$ B.P. The 2-sigma calibration for this sample is cal A.D. 650 to 780 or cal B.P. 1300 to 1170 . This date is slightly more recent than the radiocarbon date from the debris ring on the northeast part of the oven feature. Quite likely, the date from the pit oven represents a use-episode separate from and more recent than the older discontinuous debris ring (Feature 16) deposited on the northeast side of the large pit. 
Lipid analysis was conducted from a single rock from the large pit feature oven, Feature 17. The specimen (Lot 626) came from the southcentral edge of Unit 31, bottom half of Level 12 (113 to $115 \mathrm{~cm} \mathrm{bs}$ ). The lipid results (6GM 5) indicated an extremely high fat content, possibly residues from seeds, nuts, or rendered fats from non-large herbivore mammals. Based on the C18:1 isomers, the remains were more likely from plants, although the specific plant(s) were not identified.

\section{Feature 18 (Block 3, Units 30 and 38; 117-128 cm bs)}

Located in Block 3, Feature 18 was a small oval-shaped cluster of burned rock that occurred in Test Unit 38 (northwest portion of Block 3) but at a depth below and distinct from burned rock dump Features 14, 15, 16, and the orifice of pit Feature 17 (Figure 29). Spatially, Feature 18 was in the "work zone area" rock void between the Feature 17 earth oven and Feature 14 dump pile to the north. The main portion of Feature 18 consisted of only 14 rocks confined to an area measuring $36 \mathrm{~cm}$ (north-south) by about $52 \mathrm{~cm}$ (east-west) and occurring at a depth from 117$128 \mathrm{~cm}$. Profile of this $11-\mathrm{cm}$-thick zone of burned rocks showed several rocks sloping at various angles, and in a few places, one rock resting on top of another. The sloping rocks might simply reflect some bioturbation or the settling of stones in old tree root cavities. Unless these rocks were in a small pit or depression, they likely represented different and earlier activities from those responsible for the incipient earth oven and surrounding dump piles. No sediment staining, oxidation, or charcoal flecking was observed near the rocks. Its function is unknown. Two small flakes, one tertiary and one secondary, were recovered in this area as well as 48 mussel shell fragments including Amblema plicata, Plectomerus dombeyanus, and Quadrula pustulosa mortoni. Two sediment samples were collected from the feature, and the total number of rock collected from Feature 18 was $137(5.6 \mathrm{~kg})$.

\section{MATERIAL OCCURRENCE AND ABUNDANCE}

\section{Lithic Materials}

Lithic analysis provides information about site function, technology and production, lithic source procurement (exchange/interaction), and cultural affiliation based on the presence of diagnostic stone tool types. In order to address these diverse issues, stone materials were initially separated into five main classes: (1) chipped stone tools, (2) chipped stone debitage, (3) cores, (4) ground, pecked, and battered stone artifacts, and (5) unworked lithics (fire-cracked/burned rock and manuports).

Acquisition of siliceous lithic materials generally comes from a primary geological source or from secondary alluvial sources in which the materials are available as water-worn cobbles of various sizes, degrees of weathering, and surface wear, and from geological sources within the drainage area. Quarried material as well as cobble usage from local alluvial deposits can be determined through examination of chipped decortication debris. Quarried material retains evidence of weathered cortex, while cobble and gravel-derived material shows stream wear on the exterior cortex. These distinctive surfaces are present on the dorsal faces of decortication debris and bifacial items on which least some of the original exterior surface of the source material remains. This evidence provides basic information on the nature of local extraction activities. 


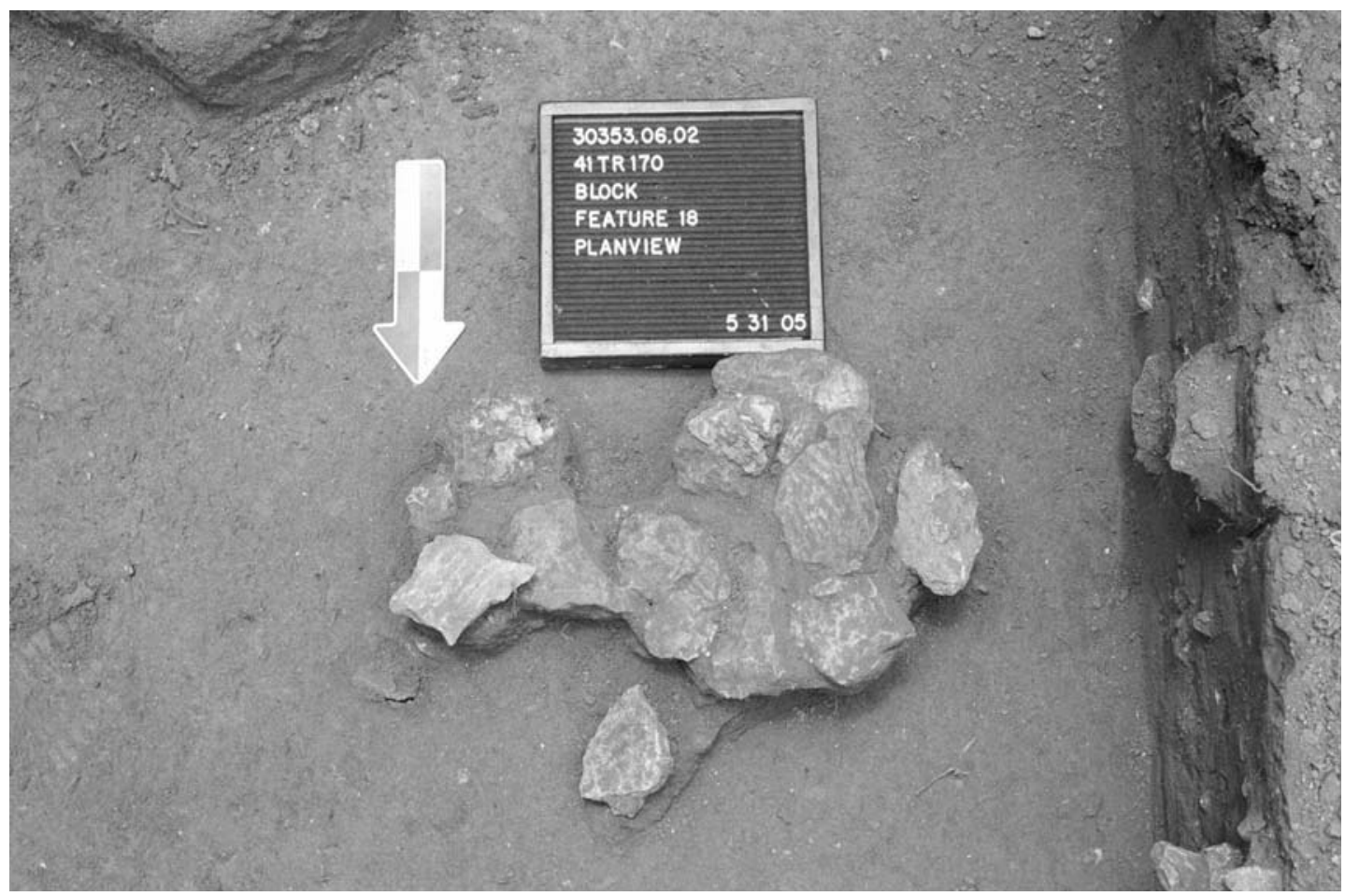

Figure 29. Photograph of Feature 18, Block 3; photographer is facing south.

Lithic materials are acquired, shaped into functional tools, used, and modified until final discard through a process of progressive reduction in bulk and form. This process normally proceeds through a series of definable stages that leave their own identifiable patterns. Use of cobbles from alluvial deposits does not ordinarily leave archeological evidence of its practice in the form of exploitation traces in streambeds, but is evident from the stream wear on the preserved cobble surface of chipping debris and other artifacts. Initial stage lithic reduction activity is thus indicated by the production of portable lithic items for later reduction as needed, leaving behind primarily decortication debitage, shattered stone from flaws or removal of chunks of cortex, and only a few more-finished items.

Further reduction into thinner bifaces and other usable items results in numerous interior flakes lacking cortex or stream wear as well as some biface thinning flakes and discarded cores. Some items are placed into use as simple unifacial or bifacial tools without more specialized flaking, for such activities as digging, chopping, and expedient scraping, while others are further refined into more specialized items such as projectile point/knives, drills, adzes, or formal scrapers. Production of these items results primarily in thinning flakes removed from thin bifaces or broken tools.

Debitage analysis obviously addresses the technological activities research domain. However, these data also apply to additional domains: the settlement pattern research domain is addressed by discriminating between special use sites (cobble assaying areas, economic resource procurement sites, loci where a single tool was used and sharpened, etc.) and general use or residential sites. In examining the patterning of special use and generalized sites on the landscape, the community pattern research domain is potentially addressed, and examination of 
lithic material types addresses the extra-regional trade research domain. In all cases other than the technological activities research domain, debitage data play a "supporting" role to additional lines of inquiry, which again underscores the importance of a holistic approach to the analysis and synthesis of artifact data.

A total of 233 chipped stone artifacts was recovered during test excavations at 41 TR170. Of this chipped stone material, at least 81 percent $(n=188)$ is composed of gravel cherts and 74.2 percent $(n=173)$ of the chipped stone material is composed of one specific type of gravel chert source. This most common raw material is a river-worn gravel chert that ranges in color from opaque cream to pale tan with occasional dark speckles and a smooth, yellowish tan to reddish brown cortex. This material is most likely Brazos/Uvalde Gravel from the Brazos River approximately $40 \mathrm{~km}$ to the west (Johnny Byers, Archeologist, University of North Texas, personal communication May 18, 2007). In addition, Cretaceous gravels are available on some of the upland ridges and major divides in the region. Other chipped stone raw materials documented in minor amounts include chalcedonic chert, Edwards chert, undifferentiated chert, and one piece of jasper.

\section{Lithic Debitage}

A total of 219 pieces of flintknapping debris was recovered during test excavations at 41TR170. Biface thinning flakes represent 33.7 percent $(n=74)$ of the debitage, and core flakes represent 17.8 percent $(n=39)$. Flake fragments comprise 33.8 percent $(n=74)$ of the debitage and shatter makes up 8.6 percent $(n=19)$. Rejuvenation flakes, blades, and potlids make up the remaining 5.2 percent of the debitage recovered from this site. No cores were identified in this assemblage. Seventy-three percent $(\mathrm{n}=160)$ of this debitage was produced as a by-product of the reduction of pale tan Brazos/Uvalde Gravel.

The distribution of debitage morphological categories indicates that a continuum of lithic reduction stages is represented. Only 17.8 percent of the debitage recovered from this site is made up of core flakes, though only four are primary flakes retaining cortex on the entire dorsal surface. Among the flake fragments, 26 percent $(\mathrm{n}=19)$ retain portions of the cortical surface, and again, only four are primary flakes. The moderate proportion of flakes retaining some cortex among the core flakes and flake fragments indicates that some relatively early stage biface reduction and preparation activities occurred onsite. As no chert raw material sources are available locally, occupants of 41TR170 appear to have brought in initially prepared raw materials as biface preforms and blanks, often retaining areas of cortical surface. This is supported by the lack of cores recovered from this site. At least 75 percent of the core flakes are composed of pale tan Brazos/Uvalde Gravel chert as are 77 percent of the flake fragments recovered onsite.

Later stage reduction activities are even more strongly represented by the lithic assemblage recovered during excavation at site 41TR170. Representation of biface thinning flakes surpasses that of core reduction flakes (74:39). Over 90 percent $(n=67)$ of the biface thinning flakes recovered are tertiary interior flakes. In addition, 90 percent $(n=66)$ of the biface thinning flakes measure less than $19 \mathrm{~mm}$ (.75 in). This strong representation of small, thin, tertiary biface thinning flakes is an indication that informal and formal tool production was the primary lithic reduction activity occurring onsite. As with the core flakes and flake fragments, a great majority of biface thinning flakes ( 78 percent; $n=53$ ) was made from pale tan Brazos/Uvalde Gravel chert. 
Initially prepared biface preforms were transported to 41TR170 from areas along the Brazos River. Further reduction of these bifaces onsite resulted in the creation of smaller discarded flake debitage and larger flakes that were employed for expedient utilization. Reduction of the biface blanks proceeded in this way until a bifacial tool (e.g., knife or dart point) was produced. The presence of nine rejuvenation flakes indicates that tool maintenance as well as production was occurring. Considering this sequence of biface reduction and the generally curatorial use of raw material, the absence of cores amongst this assemblage is not unexpected.

\section{Chipped Stone Tools}

Perhaps the most compelling argument for late stage reduction and final tool production onsite was revealed during analysis of the chipped stone tools. Thirteen of the 14 formal and informal tools recovered from this site are composed of the same Brazos/Uvalde Gravel chert that is represented among the earlier stage chipped stone materials. These tools include four projectile points, one biface, one possible spokeshave, and eight edge-modified flake implements.

The projectile points are all regarded as dart point forms and include one small, thick specimen classified as a probable Dallas point, one unidentifiable dart point blade, one Trinity point, and one Yarborough point (Figure 30). All identifiable dart points are regarded as Archaic types that were produced during the Middle and Late Archaic periods (Turner and Hester 1999:98, 190, 197). The single biface recovered during testing is a small fragment of a lateral side. The fragmentary portion of this biface is too small to derive meaningful measurements.

The single spokeshave and eight edge-modified flakes are all of pale tan Brazos/Uvalde Gravel chert material. The spokeshave was formed on the distal end of a large secondary flake; therefore, it does not exhibit a steep working edge. It is referred to as a spokeshave only in the sense that a pattern of use-wear is apparent along a concave segment of the flake edge. Five of the edge-modified flakes are formed on tertiary flakes; all but one is larger than $19 \mathrm{~mm}$ in size. Three of the edge-modified flakes were formed on secondary flakes and one on a primary flake; these flakes measure 19-38.1 mm. All of the thin, edge-modified flakes exhibit retouch flake scars or use wear along straight to convex edges. The working edges of these flakes are not steep, as would be expected for scraping and other heavy-use activities. Instead, these thin flakes were likely used as cutting and slicing tools. These kinds of implements are usually regarded as expedient tools, but in light of the scarcity of locally available lithic resources, these implements may have been saved and curated from one site and task to the next.

\section{Ground Stone Tools}

Two pieces of ground stone were collected from 41TR170. One of the ground stone specimens is an amorphous piece of sandstone with a slight carbonate encrustation from the perched water table. The evidence for use of this piece as a possible ground stone consists of a series of striations on one face that extends under the carbonate layer. Most likely, this is the kind of informal abrading implement used to sharpen bones or sticks. This possible ground stone tool came from Block 1 at the south end of the site and measures $57-x-84-x-14 \mathrm{~mm}$ in maximum dimension. The second ground stone fragment is a tabular sandstone piece that appears to be a fire-cracked griddle stone. This piece was recovered from Trench 21 and only one of the original smoothed surfaces is intact; the remainder has been broken off as a result of thermal fracturing. Black soot is evident on the remaining smooth surface. This fractured piece measures $74-\mathrm{x}-59-\mathrm{x}-$ $20 \mathrm{~mm}$ in maximum dimension. 


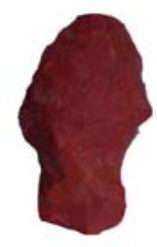

$\mathbf{a}$

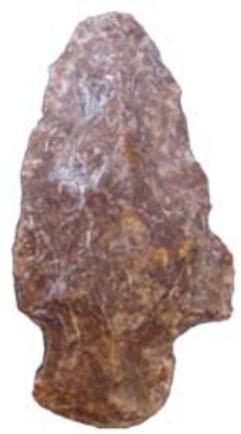

$\mathbf{C}$

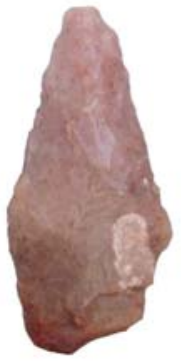

b

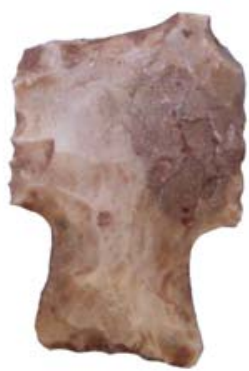

d

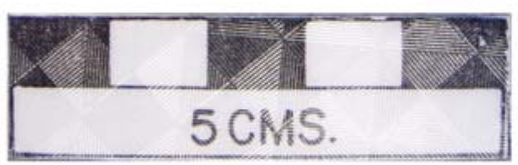

Figure 30. Projectile points from 41TR170 testing. (a) possible Dallas point (Test Unit 1, L 12); (b) unknown dart point (Block 2, Test Unit 22, $185 \mathrm{~cm}$ bs); (c) Trinity point (Block 3, Test Unit 33, L 12); (d) Yarborough point (Block 1, Test Unit 13).

\section{Burned Rock}

Considerable quantities of burned rock were encountered during excavations, indeed far more than expected for Trinity River basin sites. With an initial expectation of low frequencies of burned rocks, excavators were asked to collect samples to characterize size, material, and angularity, but later, much of these data were taken only in the field. Information on 8,303 pieces of burned rock weighing just under $451 \mathrm{~kg}$ was recorded during testing. Another 7,980 pieces of burned rock weighing just under $262 \mathrm{~kg}$ represent samples collected and weighed in the laboratory.

\section{Ochre}

The only piece of ochre recovered from the project is an amorphous piece of red hematite no larger than a small crumb that shows no evidence of striations, smoothing, or other forms of modifications. Whereas this small chunk might have been broken from a natural nodule carried to the site, there are no signs of cultural modification. Accordingly, this piece is regarded as a natural or noncultural inclusion, although naturally occurring hematite is very rare in these outwash sediments of Northcentral Texas. 


\section{Faunal Material}

\section{Bone}

A total of 268 bone fragments was recovered during the excavations of 41TR170. However, the frequencies of bone from two proveniences are artificially inflated. For example, a total of 16 fragments is listed from Test Unit 6, Level 7, but they represent a single element that was damaged during excavation; another 26 bone fragments from Test Unit 7, Level 5, represent excavation-damaged fragments of 10 elements from an apparently articulated deer fore leg, which shows no evidence of modification, although carnivore gnawing is evident. The 41TR170 archeofauna produced a sizeable amount of faunal material primarily consisting of fragmented artiodactyl remains and bivalve shell fragments. There is a signature of Bison bison at the site, and other taxa that are represented include white-tailed deer (Odocoileus virginianus), rabbits and hares (Lepus and Sylvilagus), turtles (terrestrial and aquatic), Canis (probably dog), fish, and hispid cotton rat (Sigmodon hispidus) (Table 9, Appendix H).

Table 9

Taxa Represented in the 41TR170 Fauna

Taxon

\section{Chordata \\ Reptilia}

Testudinata

cf. Pseudemys sp.

Terrepene sp.

2

Mammalia

Medium Ungulate

Bison bison (Linnaeus)

Odocoileus virginianus (Boddaert)

Deer size

Sylvilagus floridanus

Lepus californicus (Gray)

Sigmodon hispidus (Say and Ord)

Canis sp.

Pisces

Vertebrate NISP*

Total Vertebrate NSP* (w/unidentifiable)

$\mathrm{NISP}=$ Number of Identifiable Specimens

$\mathrm{NSP}=$ Number of Specimens

A high proportion of vertebrate remains from 41TR170 exhibits weathering, which may account for the low proportion that exhibits green fracturing because weathering tends to erode fracture morphology. The presence of weathering suggests that many of these remains were exposed on a relatively stable surface for an unknown period and were not rapidly buried. On the other hand, the ratio data between the numbers of vertebrate remains (Number of Specimens [NSP]) 
compared to the Number of Identifiable Specimens (NISP) indicate that remains from the site are not extremely fragmented compared to other sites from Texas (Figure 31, Table 10). As the NSP:NISP ratio increases, fragment size decreases. Low NSP:NISP suggests low intensity of fragmentation in a fauna in that the proportion of large, identifiable specimens is relatively high. The relative infrequency of cut marks and evidence of burning on the vertebrate remains and the fact that multiple white-tailed deer elements are relatively whole suggest that the ungulate remains are relatively unmodified by human butchering behavior. This, however, does not mean that the fauna are not archeological; the 41TR170 assemblage is taxonomically characteristic of an archeological rather than a paleontological fauna in that represented taxa, with the exception of Sigmodon hispidus, are commonly thought to have been prey for prehistoric human hunters.

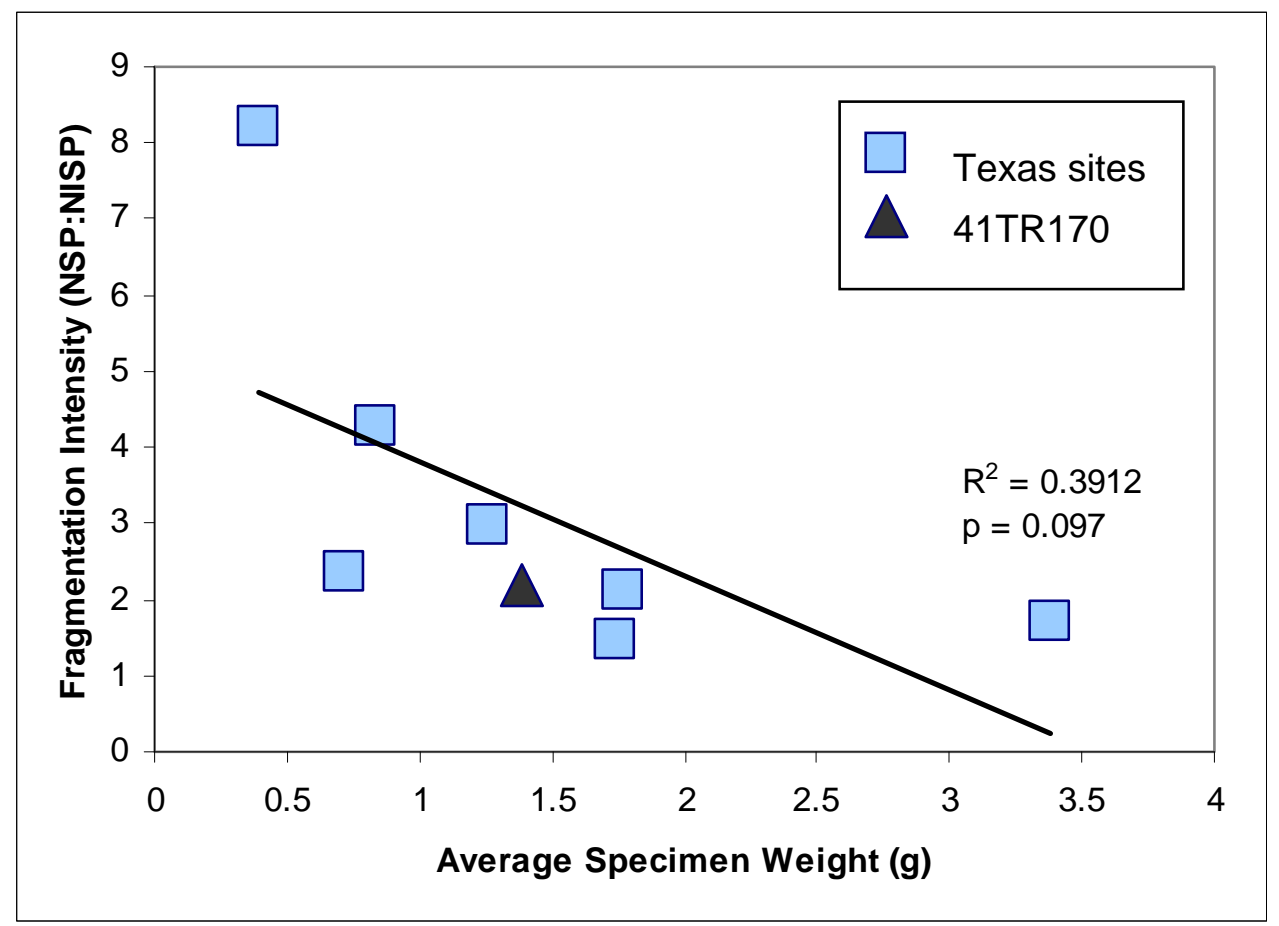

Figure 31. The relationship between fragment weight and NSP:NISP for sites in Texas (see Table 10). The sample of assemblages is small, but it demonstrates that as fragment size decreases, intensity of fragmentation (NSP:NISP) increases. The 41TR170 fauna is in the middle of the distribution at medium intensity of fragmentation.

\section{Freshwater Mussel Shell}

A total of 2,254 freshwater mussel shell fragments was recovered from the excavations. This count reflects the NSP of shell, and not the NISP; in most cases, the NSP counts are inflated due to excavation damage or postdepositional shell degradation. A reexamination of the shell assemblage was made to gather data on the frequency of hinge or umbo fragments by specific species of mussels as a closer examination of the NISP present in the various excavation areas. This study determined only 192 hinge elements were present, representing Amblema plicata ( $\mathrm{n}=65 ; 33.8$ percent), Lampsilis $s p .(\mathrm{n}=37 ; 19.2$ percent), Quadrula sp. ( $\mathrm{n}=31 ; 16.1$ percent), Plectomerus dombeyanus ( $\mathrm{n}=22 ; 11.4$ percent), Tritogonia verrucosa $(\mathrm{n}=16 ; 8.3$ percent), Ligumia subrostrata ( $\mathrm{n}=15 ; 7.8$ percent), Fusconaia askewi $(\mathrm{n}=3 ; 1.5$ percent), and Potamilus purpuratus ( $\mathrm{n}=3 ; 1.5$ percent). 
Table 10

Faunal Fragmentation Data for Texas Sites, Including 41TR170

\begin{tabular}{lcccc} 
Assemblage & NSP & NISP & NSP:NISP & Avg. Weight \\
\hline 41COL172 & 361 & 243 & 1.49 & 1.74 \\
41COL173 & 68 & 40 & 1.7 & 3.39 \\
41BX1623 & 154 & 73 & 2.11 & 1.77 \\
41BX1628 & 85 & 36 & 2.36 & 0.72 \\
41TR170 & 268 & $\mathbf{1 2 3}$ & 2.71 & $\mathbf{1 . 3 8}$ \\
16BO473 & 242 & 81 & 2.99 & 1.26 \\
41BX254/256 & 256 & 60 & 4.27 & 0.84 \\
41BX254 & 82 & 10 & 8.20 & 0.39 \\
\hline
\end{tabular}

Based on excavation results, no large discrete freshwater mussel shell dumps from single or multiple meals were present in the investigated areas. Only six unit/level proveniences contained more than four umbo fragments in excavation Blocks 1 and 3, and five unit/level proveniences from Block 2. The maximum hinge number from a single level consisted of eight specimens from Block 1, Unit 14, Level 10. Overall, the densities of freshwater mussel shell hinges per cubic meter of occupation zone fill from the intense cultural occupation zones in Blocks 1-3, were 14.8, 12.0, and 12.5, respectively. These low densities of umbo hinges stand in contrast to the often-frequent occurrence of shell features at sites within the Trinity River basin, especially along Denton Creek (Anthony and Brown 1994). The invertebrate fauna exhibit characteristics related to human use of the remains. Shell remains from Trench 9 are burned, and 11 fragments exhibit modification related to incision of the shells, presumably to remove portions for use in other contexts (e.g., bead-making or tool-making). Although only a small proportion of the remains exhibit evidence of burning and cutting $(<1 \%)$, this likely relates to the fact that the shellfish remains tend to be highly fragmented, in this case NSP:NISP is 11:74 (Appendix H).

\section{Snails}

Approximately 1,926 snails were obtained during the testing phase at 41TR170. Snails have potential to be proxies for reconstructing the paleoenvironmental conditions of the site and for providing an assessment of sediment integrity through the use of epimerization analysis or snails of a single species from single stratigraphic proveniences.

The sample of recovered snails taken from the screen during excavations represents a very small percentage of the snail number and diversity present in the Trinity River sediments at the site. Snails were present in virtually all proveniences of the site. Although very abundant, they were not systematically collected because their minute size makes them extremely susceptible to fluvial transport in alluvial settings. This uncertainty of cultural association and the loss of minute specimens (sometimes representing whole species) during the dry screening activities prevents systematic study of snails except from bulk sediment samples. Only some 10 specimens of Rabdotus snails were collected during dry screening from specific proveniences in the remote chance that new researchers may replace the investigative efforts of the late Dr. Glen Goodfriend in conducting sediment integrity studies using snail epimerization methods. 


\section{Ceramics}

No evidence of prehistoric pottery was found during the excavation of 41TR170. A few small pieces of burned clay had what appeared to be a finished, fiber-impressed surface and an irregular bumpy paste that resembled chunks of grog. Nevertheless, in lieu of clearer evidence for the unequivocal presence of grog temper, such as evidence of clay particles discolored from firing environments different from that used to fire the vessel, or finished (smoothed/decorated) surfaces on some grog particles, etc., there is no unequivocal evidence for the presence of pottery at the site. Accordingly, all of the pieces of burned clay from the site are regarded as burned clay daub.

\section{Burned Clay Daub}

A total of some 175 pieces of burned clay was collected during the testing phase, but the deep ashy zone in excavation Block 2 was also mottled with abundant bits of small brown chunks of daub that often broke up and passed through the $6.25-\mathrm{mm}$ screen. The recovered pieces of daub represent only a small portion of the daub present in this area of the site. Most of the recovered daub is plain, although some show impressions of grass on some surfaces, and a few pieces are large curved segments that encased sticks or poles up to a few centimeters in diameter. Preliminary examination of the daub failed to note any pieces that were porous with fiber inclusions, and none of the pieces appeared to have parallel alignments of twigs or other patterns of lashings. Burned clay pellets found in isolated contexts may be incidentally burned earth from either tree burns below surface or perhaps from isolated hearths, but in areas containing abundant ash and daub in zones several centimeters thick over a large area, the source of daub is apt to be from a structural feature.

\section{Sample Analyses}

\section{Sediment Samples}

A total of 148 sediment samples was collected from feature contexts and from specific quadrants in occupations zones usually associated with the block excavations on living surfaces. Approximately 64 bags are from direct feature context, 52 bags are from quadrant contexts, and 33 other samples are from contrasting feature contexts. Each sample constitutes one or more bags of sediment collected in a 12-liter galvanized bucket and bagged for later processing using a combination of flotation and waterscreening methods through fine mesh hardware cloth. Initial processing of 12 samples by GMI staff was started by floating 5 liters of sediment, with the volume of the remainder of the sediment samples being measured before being waterscreened.

These samples were to be used for the extraction of macrobotanical samples for economic plants and organic remains useful for radiocarbon dating. In addition, the heavy fraction component is apt to yield small resharpening flakes and smaller artifacts that might pass through the standard 6.25-mm mesh screens. 


\section{Charcoal and Macrobotanical Remains}

Charcoal was present in the alluvial sediments in contexts - usually above the West Fork paleosol - that reflected tree-burning events and as flecks and chunks of charcoal associated with features and occupation zones. When abundant chunks of charcoal were noted in near-surface contexts and the concentrations of charcoal chunks extended over several adjacent levels, those areas were regarded as noncultural episodes. Excavators were instructed not to sample those contexts for charcoal. In contrast, charcoal found with features or in layers containing artifacts was sought, and often these samples were point-plotted on maps and collected as discrete chunks, or gathered as a sediment matrix in a bag. In addition, some charred remains came from flotation and waterscreening activities.

A series of 15 sediment samples ranging from 3 to 5 liters each (71.5 liters total volume) was submitted to Dr. Phil Dering for flotation and macrobotanical identification (see Appendix F). These samples were directly associated with feature contexts from Blocks 1, 2, or 3, or were from the thick ashy zone found in Block 2. Five of the 15 samples yielded no charred remains whatsoever. The other 10 samples yielded very sparse quantities of charred remains, with only three samples yielding more than 0.2 g per 5-liter sample. Only one of the 10 samples weighed more than $0.6 \mathrm{~g}$, and this sample (Lot 465/FS 471) weighed $1.9 \mathrm{~g}$. This indicated that charcoal was very sparse, and cooking accidents, which might have left preserved tangible evidence of botanical remains indicative of economic activities, were not present among the sampled features. Analysis of the recovered charred remains document that most were charred pieces of wood or bark, but one piece resembled a fragment similar to the thin-walled nutshell from Carya/pecan. Although very small fragments, wood was identified as being from Celtis/hackberry (one provenience; $0.2 \mathrm{~g}$ ), Juglandaceae/hickory (seven proveniences; $<0.7 \mathrm{~g}$ ), Quercus/oak (three proveniences; $1.6 \mathrm{~g}$ ), and indeterminate charred wood (10 proveniences; $2.1 \mathrm{~g}$ ). Most of the wood probably served as fuel used in cooking operations. Based on the analyzed samples, macrobotanical remains have not yielded much informative data regarding the kinds of economic resources processed at the thermal features examined in the three excavation blocks. This is not to say that other features onsite may not have better preservation of macrobotanical remains from cooking accidents. However, based on the level of testing, the likelihood of preserved charred macrobotanical remains is regarded as poor. Even though 5-liter samples are adequate for the recovery of macrobotanical remains from activities involving semipermanent occupations, possibly larger volumes are needed to adequately sample macrobotanical remains from the relatively brief occupations in hunter-gatherer components, as represented at 41TR170.

\section{Radiocarbon Results from Cultural Contexts}

Eight macrobotanical samples recovered from the flotation of 5-liter samples associated with cultural feature contexts in Blocks 1-3 were submitted for AMS radiocarbon dating in order to understand the age of the cultural features in the three excavation blocks. Samples included wood fragments from Features 9 and 13 in Block 1, Features 16 and 17 in Block 3, and Features 12 and 20 as well as charcoal from the top and bottom of the ashy zone in Block 2. During pretreatment, insufficient charcoal was preserved from the sample obtained from Feature 9 (Block 1), but a humin fraction was obtained and dated; the results of the humin fraction do not reliably date the cultural components and its results are discussed separately below. 
Seven radiocarbon dates on solid carbon indicate that, despite the difference in depth of more than 1 meter between Block 2 and Blocks 1 and 3, all three targeted block areas were relatively contemporaneous (Table 11). Four AMS dates on carbon are available from Block 2. The treering calibrated ages (2 standard deviation; 95 percent confidence) range from A.D. 410-580 (Beta-213096) to A.D. 670-870 (Beta-213095). However, the earliest date from Block 2, associated with Feature 20 within the ashy zone, is stratigraphically inconsistent with the AMS radiocarbon date from the base of the same ashy layer at A.D. 540-660 (Beta-213097). No independent chronometric data exist to help resolve which date is in the correct stratigraphic context; so the age of the entire ashy zone between 190 and $220 \mathrm{~cm}$ bs in Block 2 could range between A.D. 540-660 (Beta-213097) and A.D. 670-870 (Beta-213095) and. These ages indicate that the ashy zone and both Features 12 and 20 date to the terminal Late Archaic period.

\begin{tabular}{|c|c|c|c|c|c|c|}
\hline \multirow[b]{2}{*}{ Block/Feature No. (Lot/FS \#) } & \multicolumn{5}{|c|}{$\begin{array}{l}\text { Table 11 } \\
\text { Ages from Feature Contexts at Site 41TR170, Tarrant County, Texas }\end{array}$} & \multirow[b]{2}{*}{$\begin{array}{c}\text { Calibrated Age } \\
(2 \text {-sigma })\end{array}$} \\
\hline & $\begin{array}{l}\text { Lab \# } \\
\text { Beta- }\end{array}$ & $\begin{array}{c}\text { Material } \\
\text { Dated }^{*}\end{array}$ & $\begin{array}{c}\text { Measured } \\
\text { Radiocarbon Age }\end{array}$ & $\begin{array}{c}{ }^{13} \mathrm{C} /{ }^{12} \mathrm{C} \\
\text { Ratio (\%o) }\end{array}$ & $\begin{array}{c}\text { Corrected } \\
\text { Radiocarbon Age }\end{array}$ & \\
\hline \multicolumn{7}{|l|}{ Block 1} \\
\hline Feature 9 (Lot 151/FS 286) & 213092 & $\mathrm{HF}$ & $3630 \pm 40$ B.P. & -22.5 & $3670 \pm 40$ в.Р. & 1940-2140 в.С. \\
\hline Feature 13 (Lot 423/FS 484) & 213094 & Cwq & $1360 \pm 40$ B.P. & -25.3 & $1360 \pm 40$ в.Р. & A.D. $630-710$ \\
\hline \multicolumn{7}{|l|}{ Block 2} \\
\hline Feature 12 (Lot 464/FS 470) & 213093 & Cwu & $1420 \pm 40$ B.P. & -28.4 & $1360 \pm 40$ в.Р. & A.D. $630-710$ \\
\hline Feature 20 (Lot 487/FS 618) & 213096 & Cwq & $1600 \pm 40$ B.P. & -26.7 & $1570 \pm 40$ в.P. & A.D. $410-580$ \\
\hline $\begin{array}{l}\text { Top of ashy zone (Lot 562/FS } \\
576 \text { ) }\end{array}$ & 213095 & $\mathrm{Cnc}$ & $1270 \pm 40$ в.Р. & -25.1 & $1270 \pm 40$ в.Р. & A.D. $670-870$ \\
\hline $\begin{array}{l}\text { Bottom of ashy zone (Lot } \\
\text { 569/FS 629) }\end{array}$ & 213097 & $\mathrm{Cwu}$ & $1480 \pm 40$ B.P. & -27.1 & $1450 \pm 40$ в.Р. & A.D. $540-660$ \\
\hline \multicolumn{7}{|l|}{ Block 3} \\
\hline Feature 16 (Lot 631/FS 662) & 213098 & $\mathrm{Cwu}$ & $1400 \pm 40$ B.P. & -22.2 & $1450 \pm 40$ в.Р. & A.D. $540-660$ \\
\hline $\begin{array}{l}\text { Feature } 17 \text { (Lot 613/FS } 706 \& \\
\text { Lot } 624 / \text { FS 707) }\end{array}$ & 213099 & Cwu & $1340 \pm 40$ в.Р. & -26.9 & $1310 \pm 40$ в.Р. & A.D. $650-780$ \\
\hline
\end{tabular}

*Material Dated: Cwq = charcoal, wood, Quercus/oak; Cwu = charcoal, wood, unidentifiable; Cnc = charcoal, nut, Carya/pecan; $\mathrm{HF}=$ humin acid fraction; macrobotanical identification conducted by Phil Dering

Radiocarbon data from Beta Analytic, Miami, Florida; calibrations from Stuiver et al. 1998, Radiocarbon 40:1041-1083.

Two AMS radiocarbon dates were derived from solid charcoal floated from sediments extracted from a large pit oven (Feature 17) and a mounded arc of burned rock debris (Feature 16) that encircled the pit oven in Block 3. The tree-ring calibrated ages ( 2 standard deviation; 95 percent confidence) range from A.D. 540-660 (Beta-213098) to A.D. 650-780 (Beta-213099). Since the more recent date is from the oven pit feature, it likely provides an age estimate of the terminal use of the oven feature. The earlier date from the adjacent encircling linear alignment of burned rock debris undoubtedly dates to an earlier use-event of the oven feature, since the date was derived from a burned twig that should reflect minimal chronometric error from cross-sectional and oldwood effects. Even though the two dates from Block 3 are not contemporaneous, they occur within the same time span as that attributed to the ashy zone found in Block 2 . 
Although two dates were processed from distinct feature contexts in Block 1, only one date was based on solid carbon, which should reliably reflect the age of the block. This single sample associated with Feature 13 provides a tree-ring calibrated age (2 standard deviation; 95 percent confidence) of A.D. 630-710 (Beta-213094). Since Block 1 is located about $4 \mathrm{~m}$ southeast of Block 3, and the one date falls within the temporal range ascribed to the features from Block 3, the features in both blocks are contemporaneous. Thus, Feature 13 (Block 1) and Features 16 and 17 (Block 3) are chronometrically contemporaneous. The main excavation focus of cultural activities encountered in Blocks 1, 2, and 3 represents cultural occupations from the terminal Archaic period and at a maximum represents a roughly 330-year range from A.D. 540-660 to A.D. $670-870$, provided that the earliest and stratigraphically inconsistent date of A.D. $410-580$ is discarded.

A single AMS radiocarbon date was based on the humin fraction of charred materials collected from a degraded piece of unidentified wood charcoal associated with Feature 9 in Block 1. This tree-ring calibrated (2 standard deviation; 95 percent confidence) AMS result provides an anomalously early age of B.C. 2140-1940; B.P. 4100-3800 (Beta-213092). Dates derived from the humin fraction are susceptible to contamination from organic acids resulting from ground waters or pedogenic or soil formation processes. Their results typically provide ages earlier than the target cultural event.

In this case, the resulting date on the humin fraction is some 2,470 to 3,020 years earlier than the span attributed to the cultural components based on the other seven AMS radiocarbon dates from cultural features. The date is also some 640 to 1,230 years earlier than the earliest geomorphic date based on the bulk humate sediments from the basal yellow clay (Beta-205061). The humin fraction date is some 1,520 to 1,940 years earlier than the bulk humate sediments from the base of the West Fork paleosol (Beta-205062: see Appendix J). Perhaps some of the anomalously early geomorphology dates obtained on bulk sediment samples from Trench 14 are related to the elevated amounts of early humin acids present in some of these deposits.

\section{Lipid Studies}

Studies conducted in South Texas have documented the retention of lipids or fatty acids bound inside the cores of porous burned rocks or on the surfaces of nonporous burned rocks. Extraction and analysis of lipids can contribute information to the activities and subsistence practices of prehistoric groups. A total of 93 pieces of burned sandstone and limestone, weighing about 61.8 $\mathrm{kg}$, was targeted in the field for collection as lipid residue samples. All or nearly all are directly from feature or excavation block contexts. During recovery, specific lipid samples were annotated on the block excavation feature maps with a sample number, point-plotted both horizontally and vertically, and collected so that the specific provenience for the context of specimens could be evaluated.

Single burned rocks from each of six features (two features per block) were submitted for lipid analysis as a trial test to determine whether fatty acids were preserved and to determine if meaningful information could be extracted from lipid studies of burned rocks (Appendix G). The results of this limited sample indicate that lipids are preserved on rock clasts in every burned rock feature examined. The residue signatures for two of six samples were deemed low but sufficient to obtain interpretable data. Three samples yielded extremely high C18:1 isomers and one yielded high amounts of $\mathrm{C} 18: 1$ isomers. The lipid results provide general fatty acid signature 
classes to general plants and/or animal resources, but not the same definitive identifications as obtained from macrobotanical remains. As such, their precision is not great for the identification of specific resources, as is often desirable for reconstructing prehistoric resources. Interestingly, the four samples with high (6GM 6) and extremely high (6GM 1, 2, and 5) forms of C18:1 isomers all came from features in adjacent Blocks 1 and 3 in the south end of the site. They all suggest decomposed foods with very high fat contents (such as seed and nuts), or rendered fats from animals other than large herbivores. However, the elevated C18:2 and long fatty acid chains suggest that burned rock Features 9 and 13 in Block 1 and the large oven (Feature 17) and dump ring (Feature 16) in Block 3 were likely used to cook plant remains with relatively high fat contents.

The two other samples (6GM 3 and 4) came from features in the ashy zone of Block 2 north of the relic channel. Recovery of lipids from these two samples was lower than the four samples from the south edge of the site, but any effect caused by the presence of the thick ashy zone is uncertain. The fatty acid signature from 6GM 3 (Feature 12) was indicative of mesquite, cholla, corn, or perhaps fish, but the long chain saturated fat component suggested the use or presence of the plant component. In light of the radiocarbon date from Feature 12 that is indicative of a Transitional Archaic age, the presence of corn is regarded as unlikely. The lipid signature from $6 \mathrm{GM} 4$ (Feature 20) was found to be consistent with that from the processing of large herbivore (bison, deer, javelina) marrow extraction, in combination with the presence of plants such as sotol hearts. The bones from the excavation block were predominantly of deer, and no sotol remains have been recovered from the few flotation samples processed from the ashy zone in Block 2.

\section{Column Samples}

Three series of sediment samples, each measuring $10-\mathrm{x}-10 \mathrm{~cm}$ by $5 \mathrm{~cm}$ thick, were collected as columns to provide fine scale resolution (thin levels) of materials from different parts of the site. The three columns were taken adjacent to Trench 1, Test Unit 1; Trench 19, Test Unit 4, Block 1; and Trench 22, Test Unit 2, Block 2. The purpose of these 120 discrete samples was to obtain a continuous column of sediments from surface to $2 \mathrm{~m}$ deep that might be used to systematically extract materials such as snails for environmental reconstruction, or phytoliths, or even magnetic susceptibility measurements that might be useful in determining occupation signatures. Only the column sample from Trench 19 will be curated; the remaining two were screened in the laboratory.

\section{Historic Remains}

Five historic artifacts and two pieces of concrete were recovered from four proveniences during the excavations of the 2-m-deep test units. The historic materials consist of two pieces of aqua glass, one piece of clear glass, one whiteware sauce rim, and one piece of corroded iron likely from a metal can. Due to their rare occurrence, it is not possible to determine whether they represent ephemeral activities on the floodplain or flotsam from periodic flood events. They are not regarded as important and will be discarded. 


\section{MATERIAL DISTRIBUTION AND RESULTS FROM TRENCH MONITORING AND DEEP TEST UNITS}

This section characterizes the information available for mechanical trench monitoring that occurred before the deep test unit excavations. Subsequent sections discuss the results of feature and material remains from the trenches and deep test pits.

\section{Trench Monitoring}

The results of monitoring mechanical excavations and the cultural materials recovered during this process are detailed in Table 12. Despite attempts to control monitoring of trenches and backdirt for signs of artifacts, the thickness of the mechanical excavated levels proved to be difficult to manage. Consequently, the general depth of materials from monitoring is less than precise.

Twelve of the 29 trenches were excavated north of the relic river channel (see Table 12). Four of these were void of cultural material, and in the remainder, cultural materials were recovered between 40 and $200 \mathrm{~cm}$ bs and consisted of burned rock, mussel shell, charcoal, one possible griddle stone, bone, and charcoal. Three backhoe trenches $(2,3$, and 4) were excavated in the location of the relic channel. The excavation of these trenches was halted when large limestone blocks were encountered. These blocks appear to have been placed within the old river channel as erosion prevention measures. No artifacts were found associated with these three trenches. Fourteen trenches were excavated south of the relic channel; three $(11,18$, and 29) were void of cultural material.

An examination of the data in Table 12 shows that cultural materials were observed during monitoring in all but ten of the 29 backhoe trenches excavated. Those with no artifacts present were Backhoe Trenches 2, 3, 4, 7, 11, 18, 26, 27, 28, and 29. Test Unit 9 was placed at Trench 28 specifically to evaluate the lack of artifacts noted during monitoring. However, six distinct classes of cultural material (lithics, bone, freshwater mussel shell, burned rock, charcoal, and historic glass) were recovered during excavation of this unit. Overall, manual excavation of the 10 deep test units recovered at least five or more classes of artifacts (lithic debris, burned clay daub, bone, freshwater mussel shell, charcoal, snail, historic artifacts, stone tools, and burned rock). Appendix A shows the comparison of artifacts observed during monitoring with the materials recovered during manual excavation of test units adjacent to the trenches. The least diverse range of materials came from Test Unit 8, which yielded only charcoal, snails, and one historic artifact during manual excavation.

Most remains observed while monitoring mechanical excavations consisted of burned rock, followed (in decreasing amounts) by freshwater mussel shell, charcoal flecks, and bone. About half of the burned rock clusters encountered during the manual excavations of the deep test units were found during mechanical monitoring (cf. Feature 3, Feature 4, Feature 9), and many other features were encountered during efforts to determine the origin of scattered rocks identified in backhoe dump piles. 


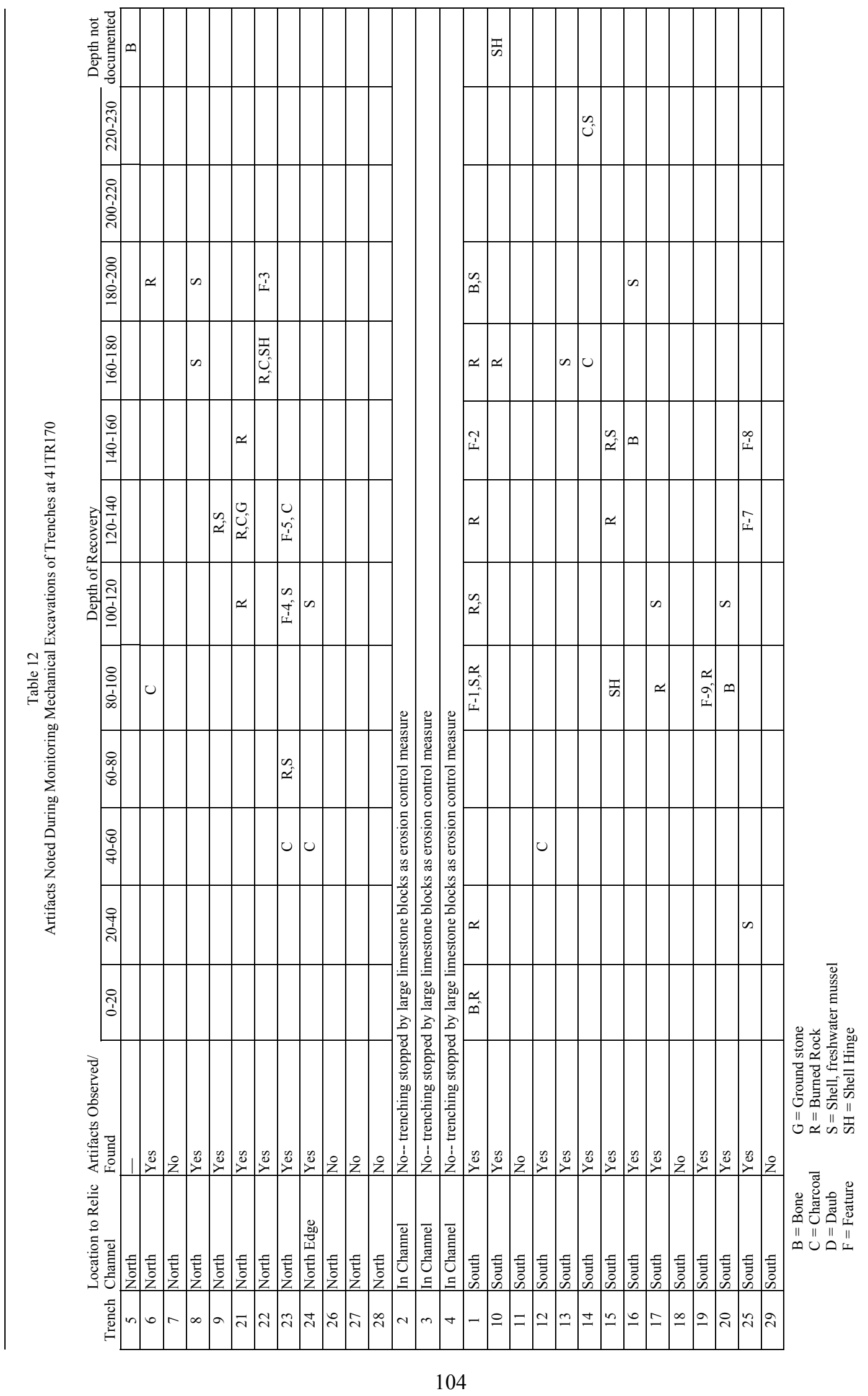




\section{Deep Test Units}

The 10 deep test units comprise about two-thirds $\left(20.0 \mathrm{~m}^{3}\right)$ of the total manually excavated volume of sediments (approximately $30.80 \mathrm{~m}^{3}$ ) examined during the testing phase. Five test units (Units 3, 4, 5, 9, and 10) were excavated north of the relic channel and five (Units 1, 2, 6, 7, and 8 ) were excavated south of the channel. Excavations in Unit 2 were terminated when cemented Pleistocene gravels were encountered about $180 \mathrm{~cm}$ bs; but Test Unit 4 was dug to $210 \mathrm{~cm}$ bs to capture the base of an ashy occupation zone. Test Units 2 and 4 were eventually expanded and incorporated into Blocks 1 and 2, respectively. The materials associated with these units will be discussed as a part of the appropriate block discussions. A summary of features recorded and artifacts collected from the deep test units is available in Appendix B.

The deep test units yielded eight (42.1 percent) of the 19 features. They also produced 15.9 percent $(n=35)$ of the lithic debris, 28 percent $(n=4)$ of the chipped stone tools, four percent $(12.3$ g) of the burned clay, 50 percent $(\mathrm{n}=107)$ of the bone, and 4 percent $(9.4 \mathrm{~g})$ charcoal samples. The deep units also yielded 24 percent $(n=542)$ of the total recovered freshwater mussel shell, seven percent $(\mathrm{n}=1,137)$ of the burned rock by count, and 5.1 percent $(36.8 \mathrm{~kg})$ of the burned rock by weight, as well as all seven of the historic artifacts from the project assemblage. Most of the historic artifacts came from the upper $30 \mathrm{~cm}$ of deposits. However, the one piece of corroded iron (can fragment?) from $90-100 \mathrm{~cm}$ bs in Unit 5 is believed to be intrusive - either from rodents or wall slump. No ground stone artifacts were recovered from the deep test units.

\section{Features}

Two of the eight features encountered during deep test unit excavations occurred in areas that were subsequently expanded into Blocks 1 and 2 and will be discussed in conjunction with the block. The other six features came from three of the 10 deep test units: Units 1, 3, and 6 located next to Trenches 1, 23, and 25, respectively. The two features from Test Unit 3 near Trench 23, at the extreme north end of the site, consist of a concentration of burned rocks within an approximately $50-\mathrm{cm}$-diameter buried $115-122 \mathrm{~cm}$ bs (Feature 4), and a concentration of charcoal flecks in a $60-\mathrm{cm}$ area at a depth of $120-124 \mathrm{~cm}$ bs (Feature 5). Due to the similarity of depths from this one unit and the proximity of the features, both might be associated with one occupation surface. However, the lack of features found in adjacent Test Unit 24, only some $7 \mathrm{~m}$ away, suggests that the features are localized. Limited information can be gained from the small area opened at the extreme north edge of the site.

The other four features occur in Trenches 1 and 25 located about $18 \mathrm{~m}$ apart along the south bank of the relic river channel. One feature, Feature 1, is a small cluster of rocks exposed in the corner of Test Unit 1 at a depth of $84-90 \mathrm{~cm}$ bs. Nothing is known about this fairly recent feature.

The other three features all occur at the same general depth (Feature 2, 142-155 cm bs, Test Unit 1; Feature 7, 133-144 cm bs, Test Unit 6; and Feature 8, 149-169 cm bs, Test Unit 6). All three features are small (roughly 22, 22, and $50 \mathrm{~cm}$ diameters) clusters of burned rock that are tentatively identified as residual remains of hearth rake-off or dump events, or in situ hearths with oxidized surfaces. Due to the paucity of associated remains, no further excavations were regarded as being warranted here. 


\section{Material Remains}

\section{Chipped Stone}

Four chipped stone tools were recovered from only one test unit; Unit 1 yielded one Dallas type dart point, one biface fragment, one edge-modified flake, and one spokeshave. One fragment of ground stone recovered from Unit 1 may represent a portion of a griddle stone. A total of 35 pieces (16 percent) of debitage was also recovered from Units 1, 3, 6, 9, and 10 (Table 13). In addition to the possible Dallas type dart point, Unit 1 yielded 10 pieces of debitage. Six pieces of debitage were recovered from Unit 3; 14 from Unit 6; one from Unit 9; and four from Unit 10.

Table 13

Distribution of Chipped Stone Debitage Classes Recovered from Test Units

\begin{tabular}{ccccccc}
$\begin{array}{c}\text { Unit } \\
\#\end{array}$ & $\begin{array}{c}\text { Biface thinning } \\
\text { flakes }\end{array}$ & Core flakes & $\begin{array}{c}\text { Flake } \\
\text { fragments }\end{array}$ & Shatter & $\begin{array}{c}\text { Rejuvenation } \\
\text { flake }\end{array}$ & Total \\
\hline 1 & 3 & 3 & 2 & 2 & - & 10 \\
3 & 1 & 3 & 2 & - & - & 6 \\
5 & - & - & - & - & - & 0 \\
6 & 5 & - & 7 & 2 & - & 14 \\
7 & - & - & - & - & - & 0 \\
8 & - & - & - & - & - & 0 \\
9 & - & 1 & - & - & - & 1 \\
10 & - & 1 & 2 & - & 1 & 3 \\
Total & 9 & 8 & 13 & 4 & 1 & 35 \\
\hline
\end{tabular}

The small possible Dallas point from Unit 1 is a nonbarbed dart point with broad side notches that appears to have been resharpened extensively. It was recovered from $110-120 \mathrm{~cm}$ bs and is of red jasper. The extreme distal tip is broken and missing. The blade edges are slightly convex and resharpened with an alternate bevel. The shoulders are asymmetrically placed relative to the midline axis and are "weak," rounded or unbarbed. The stem was made by the placement of wide side notches, which produces a slightly expanding stem, whose edges are crushed but not ground. The base is defined by rounded tangs and a convex base. The specimen is $231+\mathrm{mm}$ long, with a $138-\mathrm{mm}$ shoulder width, 84-mm stem width, 92-mm base width, 58-mm thickness, and 120-mm stem length. The overall morphology and size bear some resemblance to a Dallas point (Turner and Hester 2001:98), which is attributed to the Late Archaic period. Although this point is small enough to fall within the size range of many arrow points, this specimen is likely a dart point that has been extensively resharpened, based on the stem thickness.

The edge-modified flake, spokeshave, and biface fragment recovered from Unit 1 are all of Brazos/Uvalde Gravel. The biface appears to be a small lateral edge fragment from which little additional information can be determined. The spokeshave was formed on the distal end of a large secondary flake and does not exhibit a steep working edge. A pattern of use-wear is apparent along a concave segment of the flake edge. The edge-modified flake is a large secondary flake measuring in the $25.4-38.1 \mathrm{~mm}$ size range with minimal retouch along a lateral edge. 


\section{Vertebrate Fauna}

A total of 112 bones (41.7 percent) weighing $278.7 \mathrm{~g}$ came from the deep test units. Represented among these specimens are Bison bison, bison-sized mammal, Canis sp. (dog or wolf), Odocoileus virginianus (white-tailed deer), turtle, Pseudemys sp. (slider or cooter), deer-sized mammal, and medium-sized ungulate. Green fracturing was observed on deer-sized mammal and medium-sized ungulate specimens, but cut marks were observed on white-tailed deer and Pseudemys sp. specimens. Weathering was present on deer-sized mammal, medium-sized ungulate, medium-sized mammal, and white-tailed deer specimens. Partial calcining was observed on one turtle specimen and three unidentified specimens.

\section{Invertebrate Fauna}

Freshwater mussel shell fragments $(n=346 ; 15.4$ percent) were recovered from the deep test units and trenches. Seventeen of the fragments retained hinges or umbos to enable species level identification (Table 14). One of the unidentified mussel shell fragments from Trench 22 shows damage near the posterior ridge, and several of the unidentified fragments from Trench 9 are burned.

Table 14

Representation of Invertebrate Fauna Recovered from Trenches and Deep Test Units

\begin{tabular}{lc} 
Taxonomic Identification & Count \\
\hline Amblema plicata & 5 \\
Ligumia subrostrata & 2 \\
Plectomerus dombeyanus & 3 \\
Potamilus purpuratus & 1 \\
Quadrula pustulosa mortoni & 2 \\
Quadrula sp. & 2 \\
Tritogonia verrucosa & 2 \\
Unidentifiable fragments & $\underline{329}$ \\
Total & 346 \\
\hline
\end{tabular}

\section{Additional Materials and Samples}

Thirty-one pieces (33.1 percent of the site assemblage) of burned clay came from four of the units. A total of 31 samples of charcoal was collected from nine units. Burned rock recorded from Test Units 1-10, excluding Units 2 and 4, accounted for 6.3 percent $(n=1,040)$ of the total 41TR170 burned rock count and 3.9 percent $(28.2 \mathrm{~kg})$ by weight. Limestone was by far the most abundant rock type used; it accounted for 94.8 percent of the total burned rock by weight. Sandstone and quartzite were also present in minor amounts. 


\section{MATERIAL DISTRIBUTION AND RESULTS: BLOCK UNIT EXCAVATIONS}

The three block excavations comprised about $12.1 \mathrm{~m}^{3}$ or a little more than one-third of the total $32.2 \mathrm{~m}^{3}$ volume of sediments manually excavated during the testing phase. Blocks 1 and 3 were placed close to each other near Trench 19 about $140 \mathrm{~m}$ south of the relic channel next to the edge of the Pleistocene gravel bar at the south edge of the site to examine an large area of burned rock buried about $1 \mathrm{~m}$ deep. The features exposed in Blocks 1 and 3 occurred at the base of the West Fork paleosol, and the recovery a single Yarborough dart point in each of these blocks suggests that they are Late Archaic occupations. Block 2 was placed about $70 \mathrm{~m}$ north of the relic channel and was used to examine a zone of ash, daub, rocks, and artifacts that appeared nearly $2 \mathrm{~m}$ deep. Despite much greater depth, it too appeared beneath the West Fork paleosol, and the recovery of an unidentified dart point suggests that it is also an Archaic component. A series of seven AMS radiocarbon dates run on macrobotanical remains recovered by flotation methods from cultural feature contexts indicated that the cultural activities in all three excavation blocks were relatively contemporaneous and occurred within the period A.D. 540-870. Due to the proximity of Blocks 1 and 3 , they are discussed sequentially, followed by the results from Block 2 .

\section{Block 1}

Block 1 consisted of the placement of eight full 1-x-1-m blocks, and two 1-x-.5-m test units adjacent to Deep Test Unit 2 in order to examine a number of burned rock features in the south edge of the site. The following describes the features that occurred between 90 and $130 \mathrm{~cm}$ bs in this $10 \mathrm{~m}^{2}$ area. The volume of fill excavated from the new test units in Block 1 was $3.6 \mathrm{~m}^{3}$, which along with the fill examined from the deep unit testing brings the total volume for Block 1 to $4.0 \mathrm{~m}^{3}$. This represents about 12.4 percent of the manually excavated fill from this project.

\section{Features}

Five burned rock features in Block 1 represent a diversity of feature types (Figure 32). As discussed above, they include two shallow, rock-filled basin pit features, each about $1 \mathrm{~m}$ in diameter (Feature 9, Feature 13); an elongated cluster of large burned rocks believed to be a stock pile culled from earlier features and possibly intended for recycling into other features (Feature 6); a large area of stones fitted together to form a flat surface that might be a griddle-like feature (Feature 10); and a possible dump or rake-off pile (Feature 11). All are exterior cooking or small oven features that may likely have been used in baking or roasting forms of cooking. The occurrence of Feature 13 beneath the level of the other features suggests that multiple components are likely present. This interpretation is also hinted at by the vertical distribution of artifacts from this block (Appendix C).

Four sediment samples totaling 20 liters were processed for macrobotanical remains from Features 9, 11 and 13; however only one sample associated with Feature 13 yielded macrobotanical remains, which were only $<0.6 \mathrm{~g}$ of charred wood that was identified as Quercus, Juglandaceae, and indeterminate types. Part of this identified charcoal sample from Feature 13 was submitted for radiocarbon dating. It yielded an uncorrected date of $1360 \pm 40$ B.P. (Beta213094) and provided a 2-standard-deviation calibrated age of A.D. 630-710. A second sample not identified by a paleobotanist was selected from field samples collected by excavators from Feature 9. This sample did not survive pretreatment intact, but dating of the humin acid yielded 


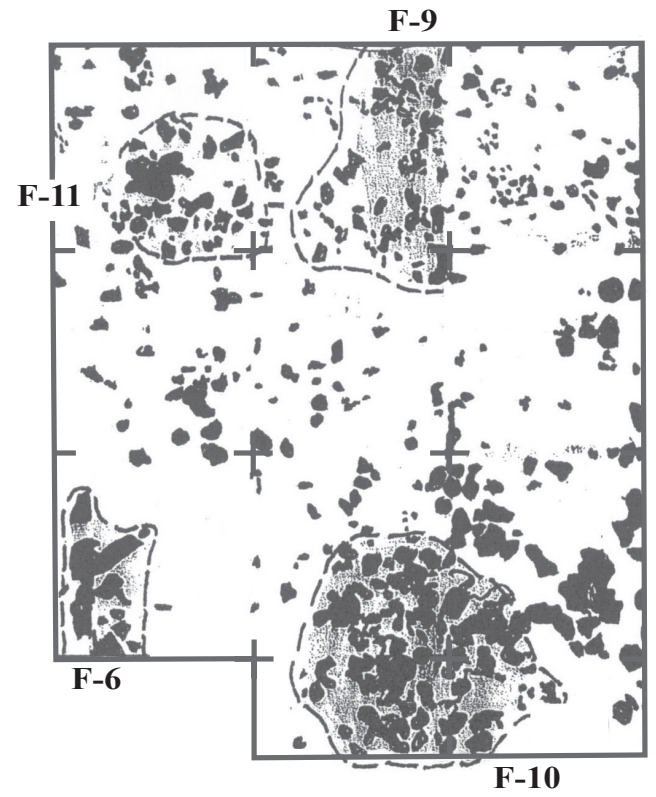

Level 10 (90-100 cm bs)

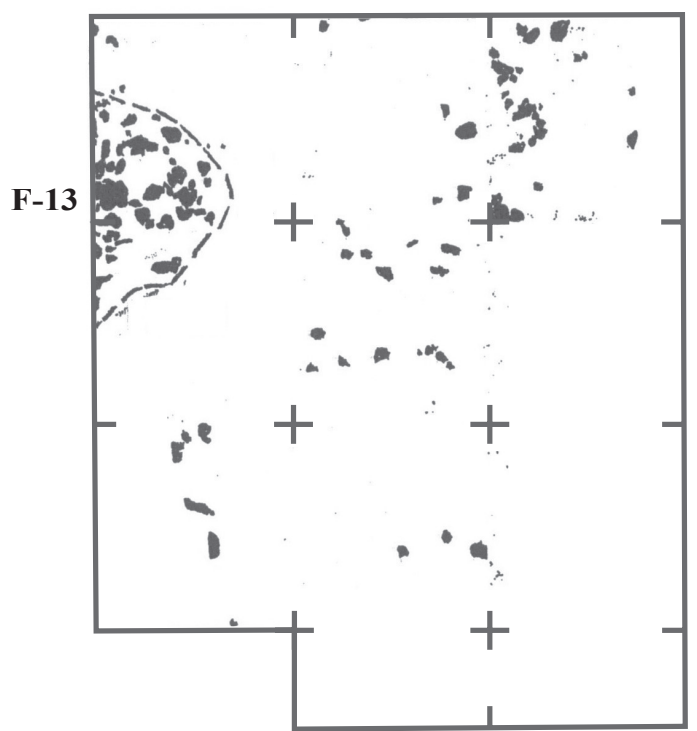

Level $12(110-120 \mathrm{~cm}$ bs $)$

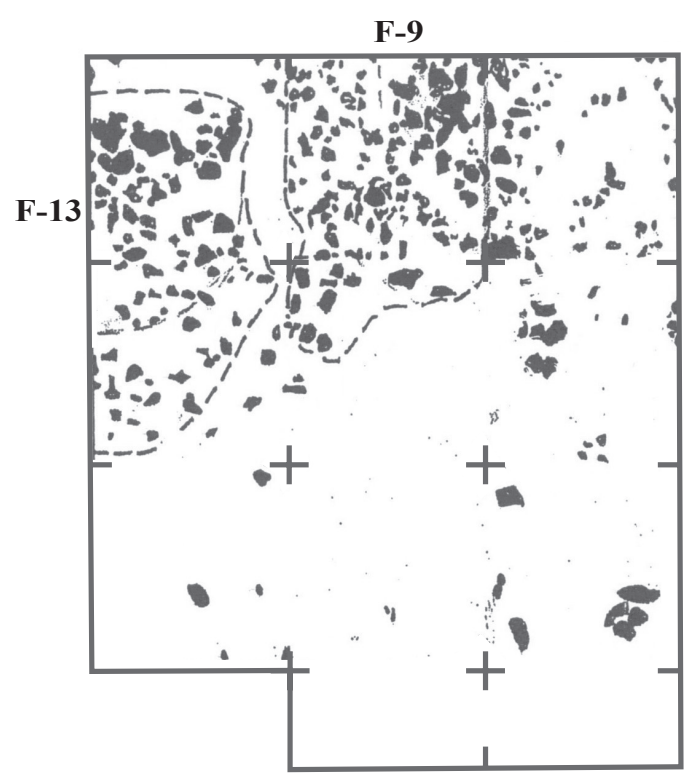

Level 11 (100-110 cm bs)

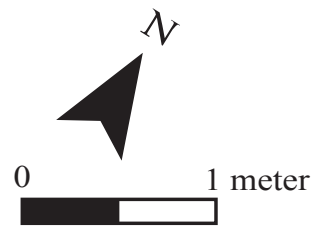

BLOCK 1 
an uncorrected date of 3,640 \pm 40 B.P. (Beta-213092) and provided a 2-standard-deviation calibrated age of B.C. 2140 to 1940. The latter date does not provide an accurate age for Feature 9 and is earlier than the radiocarbon date from the yellow clay basal deposits at the site. The date from Feature 13 is temporally consistent with the stratigraphic context and with dates from features in the adjacent Block 3 area.

\section{Material Remains}

The artifacts from Block 1 are moderately abundant for this and other sites in the Trinity River valley, although the assemblage is apt to be judged as meager in relation to the abundance of remains from Central Texas or other areas closer to chert resources. Although the volume of sediments examined in Block 1 constitutes about one-tenth of the total amount excavated, the area yielded over two-thirds of the flake debris, half of the stone tools, and a third of all freshwater mussel shell and burned rock documented during the testing phase. However, no animal bone and only five small pieces of burned clay were recovered, and organic remains were represented by one-twentieth of the amount from the entire testing phase.

\section{Chipped Stone}

Stone tools from Block 1 consist of six edge-modified flakes, one Yarborough dart point, and one possible ground stone abrading implement. Of the 219 total flakes, 158 (72.1 percent) were found in this area. All of the chipped stone tools and 75.4 percent of the chipped stone debitage from Block 1 are Brazos/Uvalde Gravel chert.

The dart point recovered from Unit 14, Level $13(120-130 \mathrm{~cm} \mathrm{bs})$, in Block 1 is a medium to large refined dart point base with prominent, unbarbed shoulders and a straight base (see Figure 30). It is of tan Brazos/Uvalde Gravel chert. The specimen is symmetrically biconvex, and the stem is aligned with the blade axis. The entire tip and distal blade are missing. The blade edges are convex, with one edge relatively uniform and the other undulating. The proximal blade edges are nearly parallel and straight. Shoulders are well defined, prominent, and unbarbed. The stem is slightly expanding and meets the straight base in sharply pointed tangs. The original unbroken specimen was much longer than the remaining $358+\mathrm{mm}$. It has a $238-\mathrm{mm}$ shoulder width, 139$\mathrm{mm}$ stem width, 171-mm base width, 81-mm blade thickness, and 159-mm stem length. The morphology compares favorably to the Yarborough type, which was made during the Archaic period and into the Late Archaic (Turner and Hester 1999:197).

The six edge-modified flakes recovered from Block 1 are all of pale tan Brazos/Uvalde Gravel chert. Four of the edge-modified flakes are tertiary flakes; one measures in the $6.4-12.7-\mathrm{mm}$ range, another in the 19-25.4- $\mathrm{mm}$ range, and two in the 25.4-38.1- $\mathrm{mm}$ range. The last two edgemodified flakes are a primary flake and a secondary flake, both measuring in the $25.4-38.1-\mathrm{mm}$ range. Considering the lack of a steep working edge, none of the six edge-modified flakes was selected for durability. These flakes were not intended for wood or bone working, nor for hide processing; it is more likely that these items were intended for use as cutting implements for meat or vegetation. 
The chipped stone debitage consists of 55 biface thinning flakes, 27 core flakes, 53 flake fragments, 14 pieces of shatter, one potlid, and eight rejuvenation flakes (Figure 33). Fifty of the biface thinning flakes are tertiary flakes, and only five are secondary (Table 15). Forty-nine of the biface thinning flakes are smaller than $19 \mathrm{~mm}$, and only six are between $19 \mathrm{~mm}$ and $38.1 \mathrm{~mm}$. Of the 27 core flakes, two are primary, 19 are secondary, and six have cortex on the platform only (see Table 15). Eighteen core flakes measure smaller than $19 \mathrm{~mm}$ and nine measure between $19 \mathrm{~mm}$ and $38.1 \mathrm{~mm}$. Of the 53 flake fragments, two are primary, eight are secondary, and 43 are tertiary. This distribution of chipped stone, particularly the dominance of biface thinning flakes and tertiary flake fragments, demonstrates that stone tool manufacture, use, and rejuvenation were the primary lithic technological activities represented in the Block 1 area.

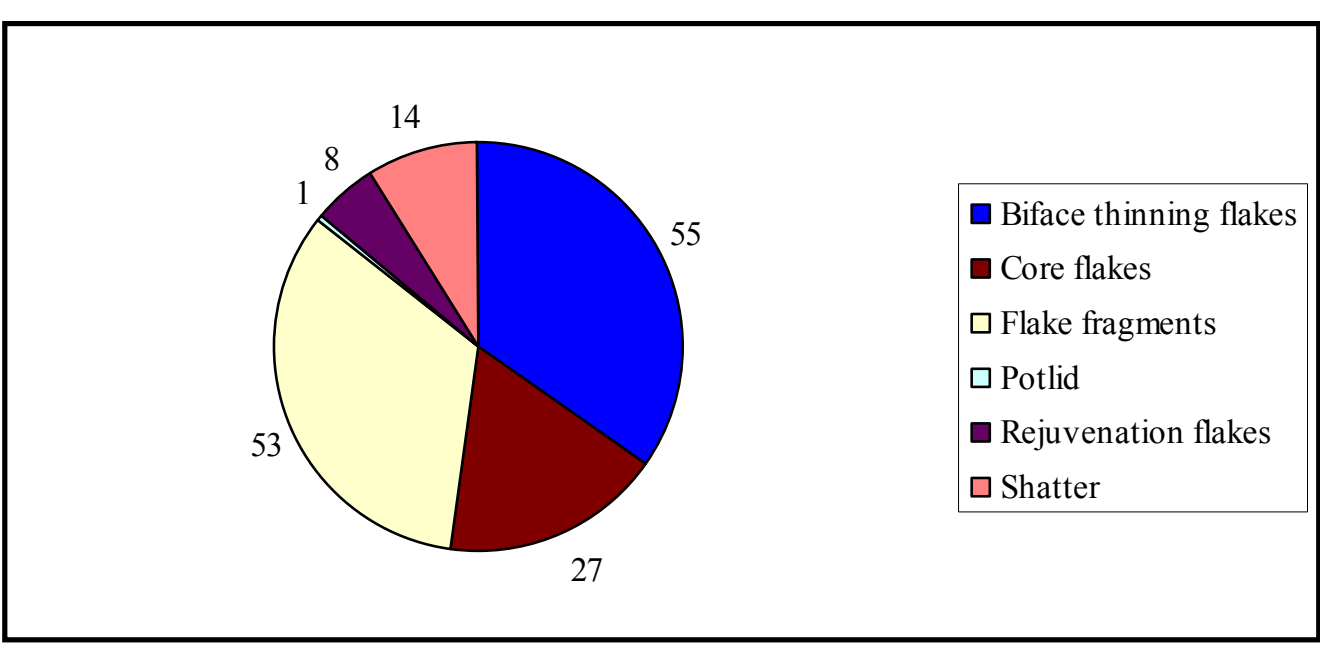

Figure 33. Pie chart depicting the proportion of chipped stone debitage classes identified in Block 1.

Table 15

Distribution of Size and Cortex Among Biface Thinning Flakes and Core Flakes in Block 1

\begin{tabular}{cccccccc}
$\begin{array}{c}\text { Debitage } \\
\text { Category }\end{array}$ & $<19 \mathrm{~mm}$ & $\begin{array}{c}19 \mathrm{~mm}- \\
38.1 \mathrm{~mm}\end{array}$ & Primary & Secondary & Tertiary & Only & Total \\
\hline $\begin{array}{c}\text { Biface thinning } \\
\text { flakes }\end{array}$ & 49 & 6 & 0 & 5 & 50 & 0 & 55 \\
Core flakes & 18 & 9 & 2 & 19 & 0 & 6 & 27 \\
\hline
\end{tabular}

\section{Invertebrate Fauna}

Among the site assemblage, a total of 771 (34 percent) freshwater mussel shell fragments was recovered from Block 1 excavation contexts. Sixty-three of these specimens retain hinges or umbos allowing for species-level identification; the remaining 708 fragments were unidentifiable (Table 16). One Lampsilis sp. specimen was modified by a rectilinear excision from near the posterior ridge. 
Table 16

Representation of Invertebrate Fauna Recovered from Block 1

Taxonomic Identification

Count

$\begin{array}{lc}\text { Amblema plicata } & 15 \\ \text { Fusconaia askewi } & 2 \\ \text { Lampsilis hydiana } & 3 \\ \text { Lampsilis teres } & 8 \\ \text { Lampsilis sp. } & 5 \\ \text { Ligumia subrostrata } & 3 \\ \text { Plectomerus dombeyanus } & 6 \\ \text { Quadrula pustulosa mortoni } & 9 \\ \text { Quadrula sp. } & 6 \\ \text { Tritogonia verrucosa } & 6 \\ \text { Unidentifiable fragments } & \underline{708} \\ \text { Total } & 771\end{array}$

\section{Additional Materials and Samples}

About 8,064 burned rocks weighing $297.2 \mathrm{~kg}$ were documented from this block. Limestone accounts for 86.8 percent of the rock from Block 1 by weight, sandstone accounts for 12.3 percent, and conglomerate 0.7 percent. A total of 49 rocks, mostly sandstone, was point-plotted and collected for possible lipid analysis. Single burned rocks from Features 9 and 13 were processed for the recovery of prehistoric lipid residues. Both results (6GM 1 and 6GM 2) yielded extremely high readings of C18:1 isomers, which are interpreted as perhaps being derived from fatty plants, such as seeds or nuts, or perhaps rendered fats from herbivores.

Block 1 also yielded five small pieces of unimpressed burned clay, six charcoal samples, and one very small piece of unmodified red hematite ocher.

\section{Block 3}

This block was placed next to exploratory Trench 29 dug to ascertain the extent of burned rock in the areas north of Trench 19 and Block 1. Block 3 is not contiguous with Block 1, but is located about $4 \mathrm{~m}$ to the northeast. A total of nine 1-x-1-m units was dug to explore the density and diversity of burned rock features along the south edge of the site. Altogether, about $4.0 \mathrm{~m}^{3}$ of sediments were excavated from this block and represent 12.4 percent of the total volume manually dug during this testing phase project.

\section{Features}

Five more feature numbers were assigned to discrete dump piles or rock-filled depressions (Figure 34). Overall, it seems that Features 14, 15, and 16 reflect relatively discrete low (15$20 \mathrm{~cm}$ tall) mounds or dumps of burned rock and sediments derived from the adjacent large burned-rock-filled pit. The Feature 17 rock pit is likely an incipient burned rock oven feature, but it is more than double the size and volume of the two possible pits found in Block 1. The 


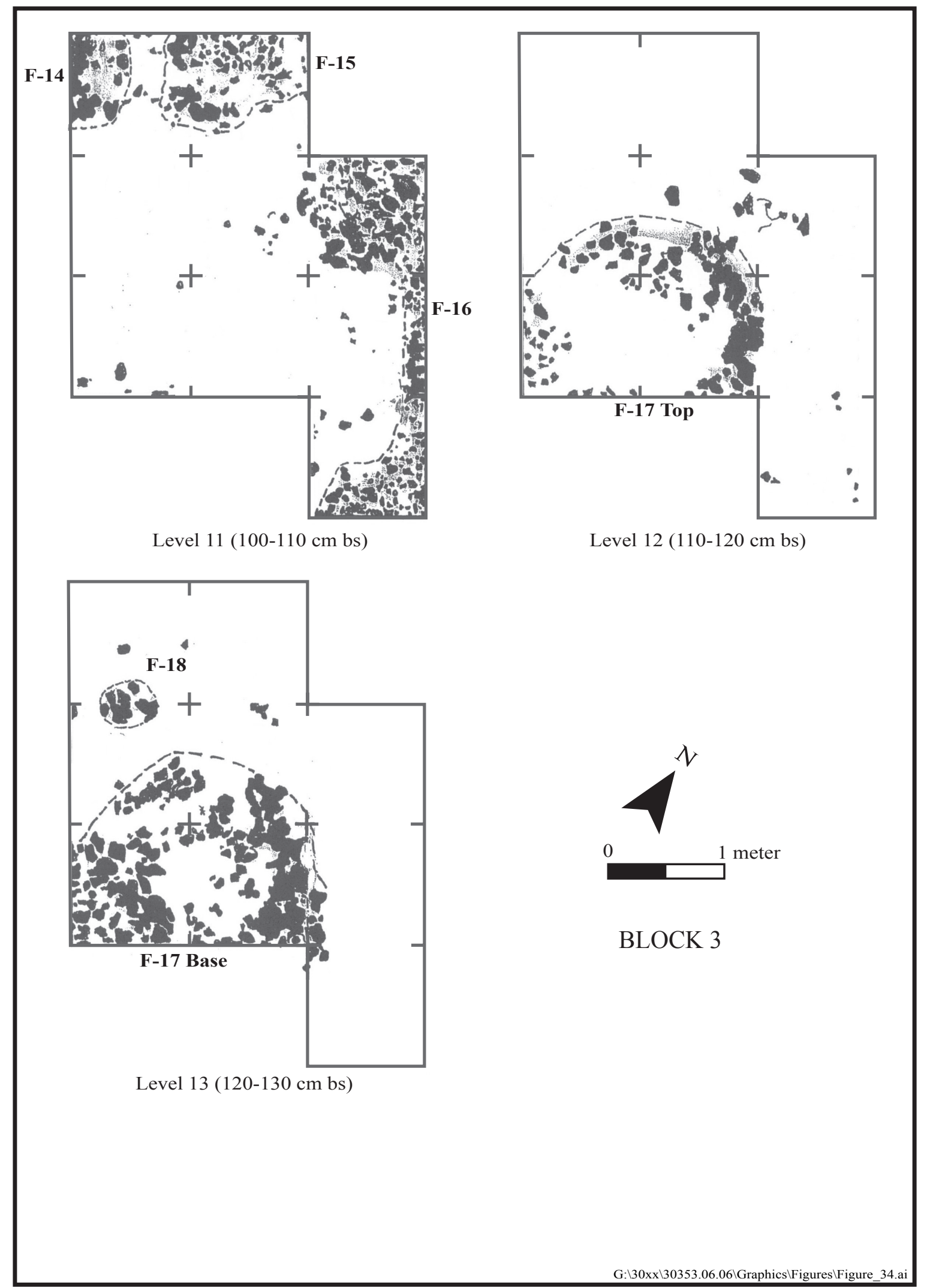

Figure 34. Distribution of features at Block 3. 
rock dump piles are concentric to the pit but are located about $80 \mathrm{~cm}$ away from the edge of the depression. This intervening area is an activity zone around the rim of the pit. The bases of the rock mounds are about the same elevation as the rim of the pit.

In contrast, Feature 18 is a small cluster of burned rock that occurred at a greater depth than the features comprising the burned rock mounds and incipient earth oven. Unless these rocks occurred in a pit, the feature elevation provides tantalizing evidence for multiple stratified occupations in this area.

Four sediment samples totaling 18 liters were processed for macrobotanical remains from Features 16 and 17; however only one sample associated with each feature yielded $<0.2 \mathrm{~g}$ of macrobotanical remains, identified as indeterminate wood type. Charcoal from Feature 16 was submitted for radiocarbon dating. It yielded an uncorrected date of $1400 \pm 40$ B.P. (Beta-213098) and provided a 2-standard-deviation calibrated age of A.D. 540-660. A second charcoal sample from Feature 17 yielded an uncorrected date of $1340 \pm 40$ B.P. (Beta-213099) and provided a 2standard-deviation calibrated age of A.D. 650-780. These dates are temporally consistent with the stratigraphic context and with dates from features in the adjacent Block 1 area.

\section{Material Remains}

The artifacts associated with Block 3 were very sparse and contrast markedly to the quantity of remains from Block 1, located only a few meters away. The low densities of remains are likely the result of excavations focusing on the features relating to a single activity and the presence of the exceptionally large oven feature and incipient dump ring with little sampling in peripheral areas where processing activities may have taken place. The most abundant class of materials is the burned rock. About half of all the burned rock from the entire testing phase came from this block. Other remains were rarely found. Only one-fifth of the recovered freshwater mussel shell came from here, but tools and debitage constitute about one-tenth of the assemblage; charcoal samples and snails are represented by only some five percent. Burned clay daub and bone are represented by about one percent of the total testing assemblage. No ground stone or historic artifacts were found.

\section{Chipped Stone}

The stone tools from Block 3 consist only of one Axtell or Trinity dart point and one edgemodified flake; these two artifacts represent about 14 percent of the 14 recognized tools from the site. Both tools are from the Brazos/Uvalde Gravel chert source.

The dart point recovered from Block 3, Unit 33, at a depth $113 \mathrm{~cm}$ bs is of tan gravel chert material that does not clearly exhibit heat treatment (see Figure 30). The projectile point is medium to large and crudely made. The specimen is biconvex but has stacked hinge fractures on one side that produce a thick, asymmetrical cross section, and the blade is skewed from the orientation of the stem. The tip shows a minimal amount of excavation damage. The blade edges are convex, with one edge relatively uniform and the other undulating. The shoulders are well defined, prominent, and unbarbed. The stem is slightly expanding with rounded tangs that meet the convex base. The stem seems to have been much better finished than the blade. The specimen is $429+\mathrm{mm}$ long, with a $222-\mathrm{mm}$ shoulder width, 127-mm stem width, $133-\mathrm{mm}$ base 
width, $92 \mathrm{~mm}$ blade thickness, and 122-mm stem length. The morphology compares favorably to the Axtell and Trinity types, which are both Middle to Late Archaic period points (Turner and Hester 2001:190).

The edge-modified flake recovered from Block 3 is a tertiary flake with a relatively small working edge. It appears that it may have served a limited expedient scraping function, though it is a utilized flake, with no apparent formal retouch. This piece measures between 19.4 and $25.4 \mathrm{~mm}$.

Only 22 (10 percent) of the 219 pieces of chipped stone debitage came from Block 3 (Figure 35). The debitage includes nine biface thinning flakes less than $19 \mathrm{~mm}$ in size; seven are tertiary and two are secondary. Chipped stone from Block 3 also includes three secondary core flakes less than $19 \mathrm{~mm}$ in size, seven flake fragments, one potlid, and two pieces of shatter (see Figure 35). Fifty percent $(\mathrm{n}=11)$ of the chipped stone debitage is composed of pale tan Brazos/Uvalde Gravel material. The remaining fifty-percent includes undifferentiated chert, chalcedonic chert, and Edwards chert.

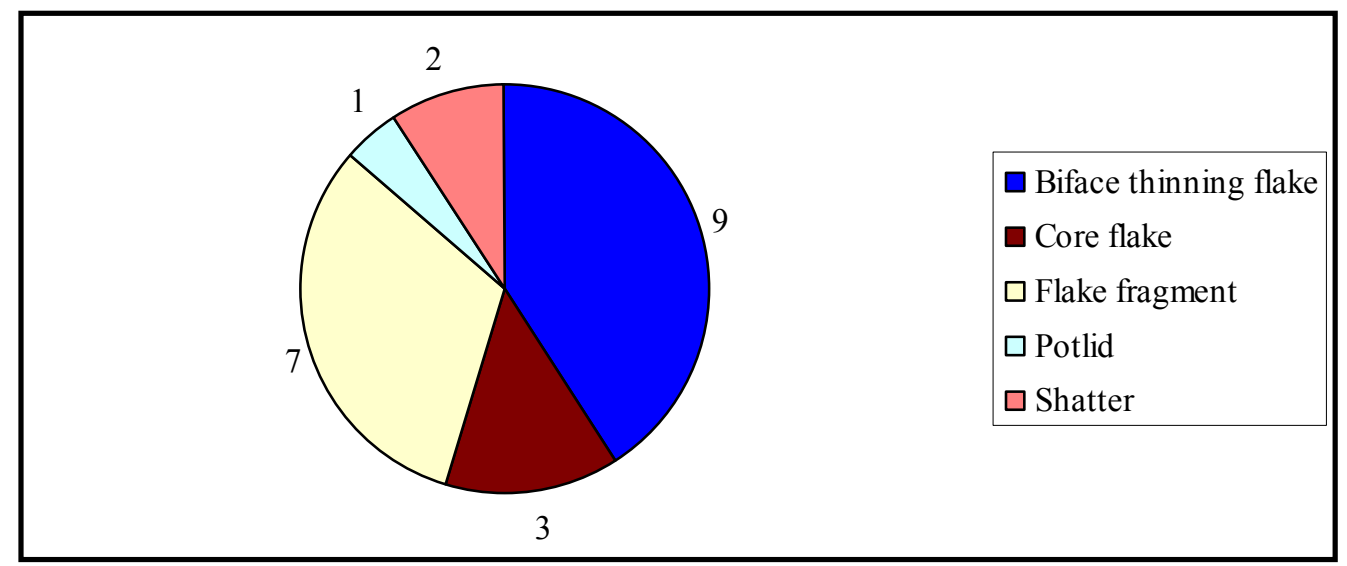

Figure 35. Pie chart depicting the proportion of chipped stone debitage classes identified in Block 3.

\section{Vertebrate Fauna}

Only four fragments of bone were recovered from Block 3 during testing. None of the faunal specimens was identifiable to species, although one fragment from 110-120 cm bs in Unit 35 was carbonized.

\section{Invertebrate Fauna}

Freshwater mussel shell is represented by some 466 fragments (20.6 percent of the site sample). Fifty-three of the fragments retain hinges or umbos to enable species-level identification (Table 17). Seven of the mussel shells from Block 3 show modification. Two Amblema plicata shells exhibit a rectilinear incision near the posterior ridge or ventral margin, and two others show damage near the posterior ridge. Two unidentified shell fragments and one Plectomerus dombeyanus specimen also show modification through a small rectilinear incision near the posterior ridge. 
Table 17

Representation of Invertebrate Fauna Recovered from Block 3

Taxonomic Identification

Count

$\begin{array}{lc}\text { Amblema plicata } & 23 \\ \text { Fusconaia askewi } & 1 \\ \text { Lampsilis teres } & 3 \\ \text { Lampsilis sp. } & 2 \\ \text { Plectomerus dombeyanus } & 8 \\ \text { Quadrula apiculata } & 2 \\ \text { Quadrula pustulosa mortoni } & 5 \\ \text { Quadrula sp. } & 3 \\ \text { Tritogonia verrucosa } & 4 \\ \text { Unidentifiable fragments } & \underline{413} \\ \text { Total } & 466\end{array}$

\section{Additional Materials and Samples}

Burned clay daub is represented by three pieces and may have been accidentally fired hunks of clay associated with the oven feature. Seven samples of charcoal were collected from the feature. A total of 5,592 pieces (34.3 percent of the site sample) of burned rock was documented from this area, and it represents about $312.2 \mathrm{~kg}$ (43.8 percent of the site sample) of the burned rock in the testing site assemblage. Ninety-four percent $(293.3 \mathrm{~kg})$ of the rock from Block 3 by weight is limestone, and the remainder is sandstone. Single burned rocks from Features 16 and 17 were processed for the recovery of prehistoric lipid resides. Similar to nearby Block 1, both results (6GM 6 and 6GM 5, respectively) yielded extremely high readings of C18:1 isomers, which are interpreted as perhaps being derived from fatty plants such as seeds or nuts, or perhaps rendered fats from herbivores.

\section{Block 2}

Block 2, north of the relic channel at the south end of Trench 22 and southeast of Deep Test Unit 4, was excavated in order to investigate an expansive occupation surface associated with a thick ashy zone located about $190-220 \mathrm{~cm}$ bs. Nine test units were placed south and east of deep Test Unit 4 , bringing the total surface area of the block to $10 \mathrm{~m}^{2}$ and a total volume of $4.1 \mathrm{~m}^{3}$. The manual excavations in Block 3 represent some 12.7 percent of the total controlled excavations conducting during this testing phase project. The characteristics of the features and artifacts from this small block contrast with those found in Blocks 1 and 3.

\section{Features}

Three burned rock features were documented in these excavations, but the entire ashy matrix in this area is also enigmatic and warrants further comment. Feature numbers were assigned to a small basin-shaped, rock-ringed pit hearth (Feature 12), an adjacent rake-off or dump area to the northwest (Feature 3), and a second ephemeral hearth represented by a small cluster of stones 
over an oxidized surface (Feature 20; Figure 36). The occurrence of the latter feature at a deeper depth suggests that multiple components are present in this part of the site. In addition to these formally defined features, relatively small burned rocks were widely scattered across the entire excavation block, but they formed no discernable pattern. As such, they roughly denote an occupation surface.

Four sediment samples were processed for macrobotanical remains from Features 12 and 20. These generally yielded small quantities of wood charcoal ranging from 0.2 to 1.9 grams. Identifications usually reflected Quercus, Juglandaceae, and indeterminate types. Two charcoal samples from feature contexts were submitted for radiocarbon dating. One sample from Feature 12 yielded an uncorrected date of $1420 \pm 40$ B.P. (Beta-213093) and provided a 2-standarddeviation calibrated age of A.D. 630-710. A second charcoal sample from Feature 20 yielded an uncorrected date of $1600 \pm 40$ B.P. (Beta-213096) and provided a 2-standard-deviation calibrated age of A.D. 410-580. The latter date is stratigraphically inconsistent with a radiocarbon date on charcoal from the base of the ashy zone.

Most intriguing was the thick ashy matrix that occurred completely across the entire $10-\mathrm{m}^{2}$ excavation block. In contrast to the overlying and underlying strata, this 40 -cm-thick zone was characterized by grayish ashy deposits with regular densities of charcoal flecking and small charred twig segments. No large posts were noticed. Pockets of the ashy matrix contained concentrated pea gravel, but it is uncertain whether this represents intrusive fill from rodent burrows or remnants of flood events near the base of the West Fork paleosol. Interestingly, some areas of the floor surface contained high densities of fine brown daub and poorly fired burned clay. Much of this was too friable and small to be saved, and so most was lost during screening. However, periodic chunks of larger daub were found. Other pieces of daub retained stick impressions, but never multiple parallel impressions in a series. One piece of daub is curved and retains a post or small branch impression. The volume of ashy deposits spanning $40 \mathrm{~cm}$ in thickness is remarkable. The fact that cultural remains and features occur throughout this zone leads to the conclusion that it likely had a cultural origin, rather than representing a natural fire along the creek bank. However, the basal contact of the ashy zone is abrupt without an oxidized surface. The basal contact of the ashy zone across the $10-\mathrm{m}^{2}$ area was scraped in an effort to locate postholes, fire pits, or other signs of architectural features, but nothing was found. The target occupation zone may represent a dense midden deposit and/or the remains of a very large structure or dwelling that greatly exceeds the size of the excavation block. None of the stray rocks in the block represents stone shims for posts or other forms of bracing for some superstructure.

Three sediment samples from the general ashy zone were collected and submitted for flotation analysis to extract macrobotanical remains (see Appendix F). Two of these samples (Lot 479/FS 469 and Lot 562/FS 576; 10 liters) came from the upper part of the ashy zone (190-200 cm bs); whereas one sample (Lot 569/FS 629; 5 liters) came from the base of the ashy zone $(210-220 \mathrm{~cm}$ bs). Altogether, the 15 liters of sediment yielded $66 \mathrm{ml}(12.3 \mathrm{~g})$ of plant remains, most of which were rootlets and small land snails. Also found were four uncharred (modern) seeds, along with five fragments of charred nuts, one piece of burned bark, and six chunks of wood charcoal. The total charred remains weighed about $0.6 \mathrm{~g}$. Analysis of charred wood cell structure and nuts identified the following. The upper sample yielded pieces of burned Carya (thick hickory/cf. pecan) nutshell, two pieces of Juglandaceae (hickory type; $0.2 \mathrm{~g}$ ), and indeterminate wood and bark species (total $0.1 \mathrm{~g}$ ). The sample from the lower deposits yielded about $0.3 \mathrm{~g}$ of wood charcoal representing Juglandaceae (hickory; $0.1 \mathrm{~g}$ ), Celtis sp. (hackberry; $0.2 \mathrm{~g}$ ), and a twig of 


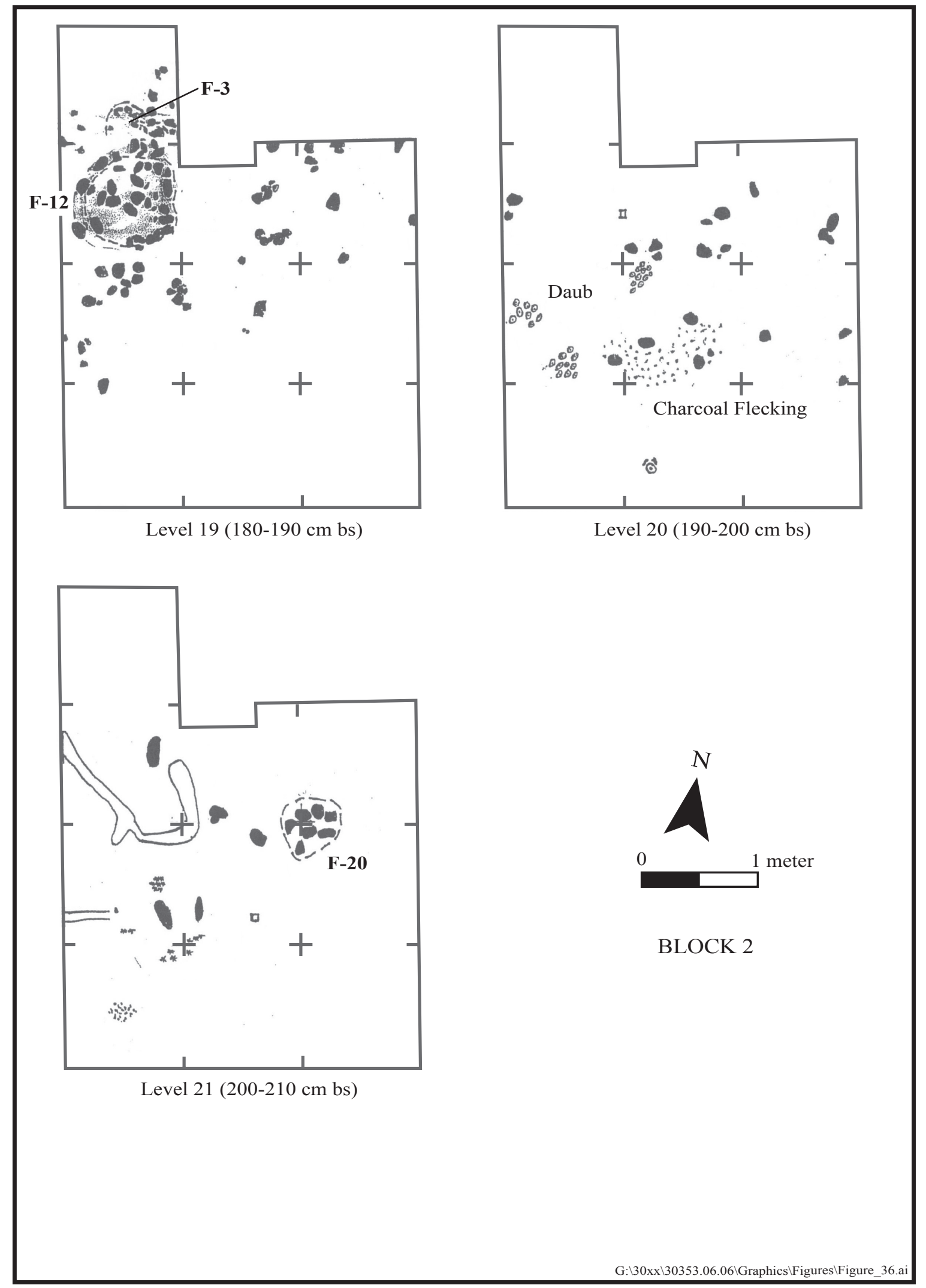

Figure 36. Distribution of features at Block 2. 
an indeterminate wood species $(<0.1 \mathrm{~g})$. The tree species are comparable to modern species in the region. The oak specimen was submitted for radiocarbon dating. Only the charred nutshells provide tentative evidence of economic activities and perhaps a fall to winter season of use. The nutshell does not provide convincing evidence that could account for the thick layer of ash buried at depth.

Two flotation samples were collected from the top and bottom of the general ashy zone recognized in Block 2, and should provide bracket ages for the stratigraphic zone and its associated features and cultural remains. One sample from near the top of the ashy zone consisted of a small piece $(<0.1 \mathrm{~g})$ of charred Carya (hickory or pecan) nut hull recovered from flotation sample Lot 562/FS 576 from Level 20 (190-200 cm bs) in the southwestern quarter of Test Unit 26. The sample was submitted to Beta Analytic for radiocarbon dating. The resulting uncorrected radiocarbon date is $1270 \pm 40$ B.P. (Beta-213095) with a ${ }^{13} \mathrm{C} /{ }^{12} \mathrm{C}$ value of $-25.1 \%$ that yields a conventional radiocarbon date of $1270 \pm 40$ B.P. The 2-sigma calibration for this sample is cal A.D. $670-870$ or cal B.P. $1280-1080$. The dating of a charred nut hull represents an annual growth, so the age should reflect no cross-sectional effect as commonly found in wood. The date is the most recent of four dates processed from Block 2 and is stratigraphically and temporally consistent. The sample probably represents an accurate terminal age for the ashy deposit in this part of the site.

The second sample from the general ashy fill comes from near the bottom of the fill. The sample is a small twig of unidentified wood charcoal weighing $<0.1 \mathrm{~g}$ recovered from flotation sample Lot 569/FS 629 from Level $22(210-220 \mathrm{~cm} \mathrm{bs})$ in the southwest quarter of Test Unit 26. The sample was submitted to Beta Analytic for radiocarbon dating. The resulting uncorrected radiocarbon date is $1480 \pm 40$ B.P. (Beta-213097) with a ${ }^{13} \mathrm{C} /{ }^{12} \mathrm{C}$ value of $-27.1 \%$ that yields a conventional radiocarbon date of $1450 \pm 40$ B.P. The 2-sigma calibration for this sample is cal A.D. 540-660 or cal B.P. 1410-1290. The date is believed to provide an age for the beginning of the general ashy deposit found in Block 2 and to bracket the ages of the dates associated with Features 12 and 20. However, radiocarbon date Beta-213096 from Feature 20 is younger by about 120 years than the date from the base of the ashy deposits. Insufficient information is available to determine which of these two dates is stratigraphically inconsistent.

\section{Material Remains}

Block 2 is situated across the relic channel from Blocks 1 and 3 and appears to exhibit a very different occupation signature. The ashy matrix of the block enhanced the preservation of bone and other organic remains, but the overall quantities of burned rock, chipped stone tools, and debris are meager.

\section{Chipped Stone}

Block 2 only yielded four (1.8 percent) of the 219 pieces of debitage and only one chipped stone tool. The four chipped stone flakes include one small tertiary biface thinning flake, one primary core flake, one small tertiary blade flake, and one secondary flake fragment, all of pale tan Brazos/Uvalde Gravel material. 
The single stone implement from Block 2 is an unidentified dart point fragment recovered from Unit 22 at a depth of $185 \mathrm{~cm}$ bs (see Figure 30). This is a medium-sized dart point fragment of tan gravel chert with some pink tinges indicative of heat treatment. The extreme distal tip shows a minor impact spall. The blade edges are straight, symmetrical, and biconvex. The shoulders are weak, rounded, and unbarbed. The stem contracts slightly and has a convex base. One side of the base is broken, perhaps by the same event that caused the loss of the distal tip. The specimen is $352+\mathrm{mm}$ in length, with a $66-\mathrm{mm}$ blade thickness, $166-\mathrm{mm}$ shoulder width, $126-\mathrm{mm}$ stem width, 108-mm stem length, and a base width of $97+\mathrm{mm}$. The morphology does not clearly compare to any defined dart point type.

Undoubtedly, stone tool manufacturing and resharpening are not activities represented in this area. In contrast, about two-thirds of all burned clay, bone, and charcoal were recovered from this block. Freshwater mussel shell from this block constitutes 29.6 percent $(n=669)$ of the testing assemblage. Burned rock from Block 2 represents 12.9 percent of this class of material by weight recovered during testing.

\section{Vertebrate Fauna}

Faunal remains represented among the 153 specimens collected from Block 2 include Odocoileus virginianus (white-tailed deer), Testudinata (turtle), Terrepene sp. (box turtle), Pseudemys sp. (slider or cooter), Sylvilagus floridanus (eastern cottontail rabbit), Lepus californicus (jackrabbit), Sigmodon hispidus (hispid cotton rat), Pisces (fish), deer-sized mammal, and medium-sized ungulate. Green fracturing was observed on deer-sized mammal and medium-sized ungulate specimens. Carbonization or calcination was observed on two unidentified specimens and two medium-sized ungulate specimens. Weathering was present on deer-sized mammal, mediumsized ungulate, white-tailed deer specimens, Pseudemys sp., and unidentified specimens.

\section{Invertebrate Fauna}

Of the site assemblage, freshwater mussel shell is represented by some 669 fragments $(29.6$ percent). Fifty-eight of the fragments retain hinges or umbos to enable species-level identification (Table 18). No modifications were observed on the invertebrate fauna from Block 2 .

\section{Additional Materials and Samples}

Only 1,490 pieces (9.1 percent of the site sample) of burned rock by count and $66.1 \mathrm{~kg}(9.2$ percent of the site sample) by weight were documented for this block. Ninety-eight percent $(64.7 \mathrm{~kg})$ of the burned rock from Block 2 is limestone. Single burned rocks from Features 12 and 20 were processed for the recovery of prehistoric lipid resides. Both results (6GM 3 and $6 \mathrm{GM} 4$ ) returned lower levels of fatty residues than the four samples from the southern edge of the site. The residue signature from Feature 12 resembles the lipids from mesquite, cholla cactus, fish, or corn, although the corn identification is remote in regard of the early age of the occupation. The signature from Feature 20 resembles that derived from large herbivores, perhaps bison, deer, or javelina, or sotol. 
Table 18

Representation of Invertebrate Fauna Recovered from Block 2

Taxonomic Identification

Count

$\begin{array}{lc}\text { Amblema plicata } & 22 \\ \text { Lampsilis hydiana } & 4 \\ \text { Lampsilis teres } & 7 \\ \text { Lampsilis sp. } & 4 \\ \text { Ligumia subrostrata } & 9 \\ \text { Plectomerus dombeyanus } & 3 \\ \text { Potamilus purpuratus } & 3 \\ \text { Quadrula pustulosa mortoni } & 1 \\ \text { Quadrula sp. } & 1 \\ \text { Tritogonia verrucosa } & 4 \\ \text { Unidentifiable fragments } & \underline{611} \\ \text { Total } & 669\end{array}$

The density of baked clay (200 pieces, $196.1 \mathrm{~g}$ ) and daub (32 pieces, $83.6 \mathrm{~g}$ ) was greater in Block 2 than any other area of the site. Thirty-five grams of charcoal samples were obtained from Block 2. The abundance of charcoal flecking observed in the ashy matrix during fieldwork indicated the potential for obtaining macrobotanical remains from this site. Nonetheless, the processing of some 35 liters of sediment from the ashy zone and associated features in Block 2 only yielded some $3.3 \mathrm{~g}$ of macrobotanical remains, which consisted mostly of charred wood. The interpretive returns after analysis for this effort seem to be low. 



\section{CHAPTER 6 SUMMARY, COMPARISONS, AND CONCLUSIONS}

This chapter accomplishes two goals. First, it summarizes the results of the current work-the methods, geomorphic studies, and the archeological discoveries - conducted at site 41TR170. Second, it presents a review of the regional literature to ascertain how common or uncommon such burned rock features are in the upper Trinity River and middle Brazos River basins. Efforts are made to document the horizontal and temporal occurrence of similar sites in the region.

\section{SUMMARY OF THE TESTING RESULTS AT SITE $41 T R 170$}

The archeological testing of the alluvial sediments at 41TR170 involved a three-stage approach that included (1) monitoring mechanical backhoe trenches, with geomorphological studies; (2) manual excavation of 10 test units that, with the exception of Unit 2 that encountered cemented gravels $175 \mathrm{~cm} \mathrm{bs}$, reached to depths of 200 or $210 \mathrm{~cm} \mathrm{bs}$; and (3) manual excavation of $9 \mathrm{~m}^{2}$ more at each of three target occupation zones identified during deep testing. The trenches were placed north and south of a relic meander of the Clear Fork of the Trinity River, which was in use until historically channelized and straightened about 40 years ago. The backhoe trenching focused on examining all areas that had previously reported features or artifacts recorded during the archeological survey by Seibel et al. (2000).

The geomorphic study indicates that the upper $2 \mathrm{~m}$ of the site generally contain deposits dating to the last 2,900 years. The prominent geomorphic feature in most trenches was the presence of the buried West Fork paleosol, which was capped by more-recent sediments. The underlying basal sediments consisted of either grayish clay or yellowish clay (see Appendix I). At the extreme southern end of the site, the trenching and manual excavations encountered cemented gravels that likely represent a Pleistocene-age gravel bar that rises above the more modern deposits in the Clear Fork floodplain, just south of the site. The lack of an abrupt boundary in the soil strata suggests that the deposits have been subjected to some bioturbation by roots, earthworms, and rodents; but the damage and deposit mixing have not been as severe as found in many other parts of the Southern Plains. 
The manual excavations at site 41TR170 documented, with few exceptions, a general low density of archeological remains but extreme clarity of deposits. This pattern suggests that, by and large, prehistoric human use of the Clear Fork floodplain during the past 2,900 years involved mostly short-term, probably specialized extractive or processing activities, but camps near the river were rare and of brief duration. Reasons for this pattern are uncertain, but such issues as dense vegetation near the river, irritating insects, and/or uncertainty about flooding events were likely contributing factors. Indeed, some of the regional settlement trends along the Clear Fork of the Trinity suggest that camps tend to be located on the low hills or floodplain terraces at the margins of the valley (cf. Ferring and Byers 2004). Accordingly, a concentration of burned rock features identified in the southern portion of 41TR170 occurs near the edge of a slightly elevated Pleistocene gravel terrace. Although the sizes of the rock clasts of the terrace are too small to have contributed to the numerous thermal features, the elevated setting is apt to have been a factor in the occupation settlement strategy so that people could escape muddy standing water during periodic episodes on the floodplain.

Importantly, the archeological remains that were periodically left on the lower alluvial settings tended to enter the archeological record quickly. The coarser sediment texture of the Clear Fork alluvium is not prone to excessive shrink-swell fluctuations or the formation of cracks in clays that allow archeological materials to accelerate the diffusion of occupation zones. The alluvial sediments offer great potential for finding discrete, unmixed, archeological remains. The overall assessment is that the site has a high degree of integrity, with low bioturbation of major clasts.

The third phase of excavations focused on three blocks, each measuring about $9 \mathrm{~m}^{2}$ each. Blocks 1 and 3 were along the south edge of the site and contained a multitude of burned rock features within a 40-cm-thick zone buried about $90 \mathrm{~cm}$ bs. In contrast, investigations of Block 2, located north of the relic river channel, about $275 \mathrm{~m}$ away, found a thick, ashy zone containing small burned rock features at a depth of about $200 \mathrm{~cm}$ bs. Eight radiocarbon dates derived from cultural feature contexts yielded seven reliable dates based on wood charcoal and one anomalously early date based on humin acid, probably derived from translocation of substances coming from reworked older sediments in the river.

Despite the large horizontal and vertical separation of the three excavation blocks, the features in all three are essentially contemporaneous. The one acceptable date from Block 1 provides a 2 standard-deviation calibrated span of A.D. 630 to 700. Two dates from the features in adjacent Block 3 provide a 2-standard-deviation calibrated span of A.D. 540 to 780 (with a 10-year overlap between the two dates ca. A.D. 650 to 660). Four dates from the thick ashy lens in Block 2 range from A.D. 540 to 870 , although the date from Feature 20 in the middle of the ashy zone yielded a slightly older date of A.D. 410 to 580 . Based on the range of dates and minor elevation and perhaps stratigraphic differences, it seems that at least two portions of the valley at 41TR170 were intermittently used for a range of purposes by Transitional Archaic people between ca. A.D. 540 and 870 . The intensity of these occupations far outweighs evidence for any other period in this part of the Clear Fork valley.

Despite the significant integrity of features, the abundance of artifacts must be judged as low. Indeed, the recovery of fewer than 230 pieces of flake debris, four dart points, one small biface fragment, and nine edge-modified flakes from the about $30 \mathrm{~m}^{3}$ of manually dug and screened deposits is a very sparse artifact assemblage relative to Central Texas standards. Nonetheless, most sites in the Trinity River basin have yielded sparse assemblages (Yates and Ferring 1986). 
Although small, the chipped stone assemblage does reveal some interesting patterns. As at other sites along the Clear Fork, all of the chipped stone is composed of chert; no quartzite was present. Of this, at least 81 percent $(\mathrm{n}=188)$ is composed of chert that is obviously gravel-derived and 74.2 percent $(n=173)$ of that is composed of one specific type of gravel chert source. This material appears to represent Brazos/Uvalde Gravel from the Brazos River (Johnny Byers, Archeologist, University of North Texas, personal communication May 18, 2007). As no chert raw material sources are available locally, occupants of 41TR170 appear to have brought in initially prepared raw materials as biface preforms and blanks, often retaining small areas of cortical surface. This is supported by the lack of cores recovered from this site. In addition, the edge-modified flakes from this site all are thin and exhibit retouch flake scars or use wear along straight to convex edges. The working edges of these flakes are not steep, as would be expected for scraping and other heavy-use activities. Instead, these thin flakes were likely used as cutting and slicing tools. These kinds of implements are usually regarded as expedient tools, but in light of the scarcity of locally available lithic resources, these implements may have been saved and curated from one site and task to the next.

The feature diversity, as well as the presence and absence of select feature types, is the most outstanding attribute of 41TR170. Unlike many sites in the Trinity River basin, discrete freshwater mussel shell piles are scarce at 41TR170 (cf. Anthony and Brown 1994; Lintz et al. 2004; Yates and Ferring 1986). Also the size, density, and diversity of the rock features found at the south edge of 41TR170 are rarely observed among the Trinity River basin sites, and this issue will be dealt with in greater detail below. Whereas most burned rock features in the Trinity River tend to be small clusters of burned rock weighing only a few kilograms, the quantity of rock found in Blocks 1 and 3 is large and diverse. These two blocks represent a minimum of 20 percent of the horizontal extent of burned rock features in the south part of the site, and they yielded 12,781 of the 16,283 burned rock clasts weighing about $578.2 \mathrm{~kg}$ of the total $712.5 \mathrm{~kg}$ collected from the project. Results from testing, trenching, and probing indicate that a zone of burned rock features, perhaps $20-30 \mathrm{~m}$ wide, is apt to occur along the margin of the elevated Pleistocene terrace. Based on the differences in the sizes of stone clasts in the burned rock features relative to the size of gravel in the Pleistocene gravels, nearly all of the feature rocks were hauled from valley margin exposures more than a kilometer away.

The discovery of 10 discrete burned rock features buried about 90-120 cm deep in adjacent Blocks 1 and 3, which together encompass a total of $19 \mathrm{~m}^{2}$, is remarkable, both in terms of the density of features, the sizes of features, and the diversity of postulated forms. The large burned rock features at 41 TR 170 are quite varied. They include an exceptionally large $(2.54 \mathrm{~m})$ incipient pit oven encircled by a series of low $(20-\mathrm{cm}$ tall) mounds of discard burned rock and sediments in Block 3. In nearby Block 1, two much smaller (roughly 1-m diameter) pits with burned rock lack the encircling discarded rocks. However, other burned rock features are interpreted as cull piles of rocks awaiting recycling into other features, or rake-off or dumps from the smaller oven/pits; an unusual fitted layer of burned rock is interpreted as a large griddle. In other words, the rock features in the southern part of the site seem to relate to preparations for cooking (cull pile), cooking activities (pit features, griddle) or postcooking rake-off/discard piles (encircling ring about Feature 17 in Block 3). These include features that are situated both above the paleosurface (piles and dumps) as well features excavated below the paleosurface (pits). This range of features above and below the prehistoric surface accounts for the $30-\mathrm{cm}$ range in elevations where features are recorded in this area. 
The diversity of rock features in Blocks 1 and 3 is mirrored in the variety of material remains in the south edge of the site. The recovery of Yarborough and Trinity type dart points in combination with the radiocarbon dates from Blocks 1 and 3 supports the use of both areas by a late Transitional Archaic people over a relatively brief time. These points and the radiocarbon dates suggest that the occupations were relatively contemporaneous. Whereas Block 1 yielded 158 flakes and six tools, including a ground stone abrader, a series of edge-modified implements, and the Yarborough point, Block 3 with the large oven feature yielded only 22 flakes, one Trinity point, and one edge-modified tool. Bone, burned clay daub, and charcoal are relatively rare in Blocks 1 and 3. Although 771 and 461 fragments of freshwater mussel shell fragments were recovered as nonclustered scatters from the two blocks, the count of identifiable hinge or umbo fragments is 63 and 50, respectively. Thus, freshwater mussel procurement and processing seems to have been a low-level activity relative to the amount of burned rock present along the southern edge of the site. Attempts to derive information about the resources cooked at these features were not entirely successful, based on the macrobotanical and lipid residue analyses. Even though the recovery of useful information was not profitable in the areas examined, probing has shown that considerable areas of burned rock remain near the Pleistocene terrace.

In contrast, the excavations conducted in Block 2, north of the relic channel, encountered a deeply buried ashy zone associated with two discrete burned rock pit features and one burned rock rakeoff dump. These also represent Transitional Archaic period features. Although not identical in form, the recovery of one nondiagnostic large dart point and radiocarbon dates suggests that the features and ash zone (190-230 cm bs) are generally contemporaneous with the large rock features and activities farther south.

One of the most outstanding attributes of Block 2 is the ashy matrix, which includes a fair degree of bone preservation, abundant charcoal, and quantities of daub or burned clay, some of which have impressions of sticks and twigs. A total of 153 pieces of animal bone was recovered from Block 2, a substantial amount compared to the four pieces recovered from Blocks 1 and 3 combined. Nevertheless, lithic remains are all but absent from this area; only one point and four flakes were found in the 3.6- $\mathrm{m}^{3}$ excavation on this occupation zone. Despite careful attention to the abrupt basal contact of the ashy zone, no postholes, hearth features, or other architectural attributes were observed. The presence of burned rock features within the ash zone and the bone indicate that the ash may have been derived from cultural activities. The nature of those activities that created the ashy matrix is presently unknown. The attribution of the ashy zone to a simple midden function belies the abundance of charcoal and fired daub with stick impressions. If these lines of evidence reflect a burned structure, then the lack of architectural features found at the basal contact would suggest that the house must be very large and very different from those found at Lake Granbury (Skinner 1971). In light of the age of the ashy deposits dating to the middle of the first millennium A.D., the prospects of the ash representing a structure is remote. Nevertheless, ashy "middens" have been occasionally found at 41TR174 and other sites in the Trinity River basin (Burson et al. 2000). Unfortunately, no excavations have examined a sufficiently large area to precisely determine what caused these middens or how they were formed. Clarification on the nature of these features is not discernable without further fieldwork.

Excavations on both the north and the south sides of the relic channel of the Clear Fork River revealed the presence of terminal Archaic occupations. However, there are substantial differences in the material expression of the occupations on each side of the river. Excavations north of the relic channel in Block 2 revealed an ashy site matrix not observed south of the channel and recovered a greater density of animal bone $(n=153)$ compared to that recovered in 
Blocks 1 and $3(\mathrm{n}=4)$. Only five chipped stone artifacts were recovered from Block 2 compared to the 190 chipped stone artifacts from Blocks 1 and 3. Only 1,490 pieces of burned rock comprising three features, one small pile of burned rock, and two small hearths $(<50 \mathrm{~cm}$ in diameter) were recorded in Block 2. These findings are in contrast to 10 features in Blocks 1 and 3 including a substantial incipient burned rock oven, two large pit hearths/ovens, one possible griddle feature, one unknown burned rock feature, and five rake-off/dump piles. This is a strong indication that, while roughly contemporaneous, activities occurring on each side of the river were distinct enough to produce very different signatures on the archeological record. Although these two laterally separate portions of site 41 TR 170 were both occupied between ca. A.D. 540 and 870 and cannot be distinguished from one another temporally, their substantial dissimilarity suggests that they may be treated as separate components of this site. Table 19 summarizes the data obtained during testing from each cultural component identified at site 41TR170; two laterally defined components are listed - one north of the relict channel and one south of the relict channel.

The contrast in feature morphology between Block 2 and Blocks 1 and 3 indicate that very different subsistence resources were likely being processed in these activity areas. It is suspected that, as in Central Texas and indeed the Brazos River valley, the more intensively used ovens and dump piles in the southern portion of the site accumulated as a result of baking and steaming plant resources that require longer roasting times. The minimal amount of bone recovered from this southern portion of the site seems to support this emphasis on plant resources, though differential preservation may also be a factor. In addition, analysis of the chipped stone debitage and flake tools from the southern portion of the site indicates that these materials served as cutting and slicing implements. None of the tools recovered exhibited the kind of steep working edge that is typically required for hide processing or other heavy-use activities associated with game processing.

In both the north and the south portions of this site, separate occupations are suggested by slight differences in depth of features and by overlapping and laterally shifted features. Attempts to differentiate distinct occupation surfaces were complicated by the presence of features of two types: those that were situated on and above the terminal Archaic surface (i.e., piles of rock and dumps), and those that were prehistorically excavated below the terminal Archaic surface (i.e., earth oven basins and pit hearths). Therefore, stratigraphically distinct components could not be identified within Blocks 1, 2, or 3.

\section{THERMAL FEATURES IN THE TRINITY AND BRAZOS RIVER DRAINAGES}

\section{Distribution of Burned-Rock-Feature Sites in Northcentral Texas}

Initial perceptions among several practicing professional archeologists in the Dallas/Fort Worth area who observed the burned rock features at 41TR170 indicated that the number and sizes of such features were relatively unique for the Trinity River basin. Many of the burned rock features reported for sites along the Trinity River consist of small (50-72-cm diameter) clusters of burned/fire-cracked rock, comparable to Features 12 and 20 found in Block 2 at 41TR170. However, the large burned rock areas in Blocks 1 and 3 at 41 TR170 are unusual in their individual sizes, density, structure, and clarity in feature discreteness. The common rock features in Block 1 seem to be concentrations of burned rocks, several clasts thick, in large, shallow (15- 
Table 19

Site 41TR170 Terminal Archaic Component Table

\begin{tabular}{|c|c|c|}
\hline Characteristic & Terminal Archaic South (Blocks 1, 3) & Terminal Archaic North (Block 2) \\
\hline Test units considered & $1,2,6-8,11-19,29,30-38$ & $3-5,9,10,20-28$ \\
\hline Total $\mathrm{m}^{3}$ excavated & 9.2 & 7 \\
\hline Vertical extent excavated $(\mathrm{cm})$ & 40 & 50 \\
\hline Horizontal extent excavated $\left(\mathrm{m}^{2}\right)$ & 23 & 14 \\
\hline Features recorded & 14 & 5 \\
\hline Feature types represented & $\begin{array}{l}\text { Burned rock rake-off or dump (4), } \\
\text { Large incipient oven (1), } \\
\text { Pit hearth with burned rock (3), } \\
\text { Poss. griddle hearth (1), } \\
\text { Recycle stockpile (1), } \\
\text { Unknown burned rock feature (4) }\end{array}$ & $\begin{array}{l}\text { Burned rock rake-off or dump (2), } \\
\text { Charcoal stain (1), } \\
\text { Deep roasting pit (1), } \\
\text { Pit hearth with burned rock (1) }\end{array}$ \\
\hline Projectile point frequency & $\begin{array}{l}3 \text { (Dallas, Trinity, and Yarborough } \\
\text { types) }\end{array}$ & 1 (unknown type) \\
\hline Edge-modified flake frequency & 8 & 0 \\
\hline Biface frequency & 1 fragment & 0 \\
\hline Spoke shave frequency & 1 & 0 \\
\hline Ground stone frequency & 1 (possible abrader) & 0 \\
\hline Floral species recovered & Oak, hickory & $\begin{array}{l}\text { Oak, hickory, hackberry, poss. } \\
\text { pecan }\end{array}$ \\
\hline Faunal species recovered & Unidentifiable & $\begin{array}{l}\text { White-tailed deer, rabbit, turtle, } \\
\text { dog, fish, cotton rat }\end{array}$ \\
\hline Aquatic species recovered & $\begin{array}{l}\text { Amblema plicata, } \\
\text { Fusconaia askewi, } \\
\text { Lampsilis sp., } \\
\text { Ligumia subrostrata, } \\
\text { Plectomerus dombeyanus, } \\
\text { Potamilus purpuratus } \\
\text { Quadrula sp., } \\
\text { Tritogonia verrucosa }\end{array}$ & $\begin{array}{l}\text { Amblema plicata, } \\
\text { Lampsilis sp., } \\
\text { Ligumia subrostrata, } \\
\text { Plectomerus dombeyanus, } \\
\text { Potamilus purpuratus } \\
\text { Quadrula sp., } \\
\text { Tritogonia verrucosa }\end{array}$ \\
\hline
\end{tabular}

30-cm thick) basins measuring up to $1.5 \mathrm{~m}$ in diameter with lighter scatters of rock covering larger areas (Features 9 and 13). However, another feature seems to be stockpiles of rocks for thermal use, based on differences in the sizes of individual rock elements, their degree of concentration in an amorphous $40-\mathrm{x}-80-\mathrm{cm}$ area, and the heaped appearance on the living surface (Feature 6). Still another feature (Feature 10) appeared as a pavement of heated rocks that, due to the uniformity of the upper surface, seemed to be a multirock griddle apparatus measuring about $1.3 \mathrm{~m}$ in diameter. In nearby Block 3 was found a large (2.1-2.5-m diameter), 21-cm-deep basin pit with scattered burned rock (Feature 17) surrounded by discontinuous linear heaps of concentrated burned rock (Features 14, 15, and 16). All four features were interpreted as a large earth oven with discarded piles of hot stones that were removed to extract unknown baked foodstuff. Radiocarbon dates suggest that the rock features in all three areas were relatively 
contemporaneous (Transitional Archaic ages) with a minor degree of stratification, indicative of intermittent, multi-occupational usage spanning a few hundred years. The dates on the pit oven feature and the surrounding dump heaps clearly document feature reuse.

The subjective impressions for the uniqueness of these kinds of features in the Trinity River basin needed to be supported by an examination of the regional archeological record to determine how common they are. The following discussion presents first the literature survey of Trinity River basin archeology to see how frequently thermal features have been reported and, if possible, the kinds of inferred uses for such thermal features. Next are the summaries of burned rock mounds, ovens, and rock middens in Central Texas, and a review of the distributional extent northward toward the Trinity River basin. Some of the literature on rock ovens found north of the Red River is also reviewed to show that, although rare, ovens do occur in Oklahoma and southwestern Kansas. Most of these studies are fraught with problems due to the lack of adequate excavations necessary to understand these kinds of features, the lack of rigorous observations that result in unreliable descriptions/interpretations, and the nomenclature limitations that mask the true variation of the these classes of features. Finally, a new summary of burned rock features is presented, compiled from the Texas Archeological Sites Atlas database for the 15-county region within 50 miles $(80 \mathrm{~km})$ of site 41TR170. Special emphasis is placed on the differential densities of sites containing burned rock scatters, hearth features, and oven features that occur within the upper Trinity River and middle Brazos River basins. These data form the basis for supporting or refuting claims for the uniqueness of the rock features at 41TR170. The issues over the information available from such kinds of sites are distinct from these surveys.

\section{A Review of Trinity River Archeology Overview Studies}

A few regional archeological syntheses have been prepared for the Trinity River basin, but most provide precious little information about the type, kind, or class of burned rocks observed on sites in the region (Biesaart et al. 1985; Lynott 1977; Prikryl 1990; Skinner et al. 1978; Yates and Ferring 1986). Avocational archeologists or hobbyists reported many of the earliest archeological discoveries in the region; however, the quality of their records is sometimes poor. Brief site reports in the Dallas Archeological Society journal, The Record, indicate that, based on the diversity of projectile point styles in private artifact collections, many sites were reoccupied over thousands of years (see Lynott 1977 and Prikryl 1990). Thermal features from such sites are difficult to interpret, unless they have been directly dated, since the stratigraphic and cultural context is often lacking. The problem is further compounded by the common use of generalized functional terminology such as "hearth" for describing the size, extent, and composition of features. In the Trinity River basin, many "hearths" consist of burned clay layers, but some have small clusters of thermally altered rock. Some may be haphazard burned rock dumps, while others are well-formed basins inside prehistoric structures.

Burned rock features are apparently so rare that one relatively early synthesis of the Trinity River basin does not even list burned rock as a class of artifact, feature, or type of site (Skinner et al. 1978). A contemporaneous study mentions the occurrence of "hearths," but fails to differentiate among the various kinds of heating elements (Lynott 1977:Appendices D-G). Although Lynott (1977:Appendices D-G) does use such terms as cooking "ashpits" (sic), baking pits, or cooking pits in his data compilation, he fails to clarify whether or not these pits contain thermal rock elements. Lynott (1977:Appendices D, E) does mention that 10 of 25 sites (40 percent) in the East Fork and Elm Fork regions have "hearths" (types unknown), but only four (16 percent) are 
reported to have more than three hearth features; a maximum number of 21 hearths is reported for one site along the Elm Fork of the Trinity. In contrast, his summary of 29 excavated sites in the central Brazos River basin noted that 19 (66 percent) contain reported hearths (types unknown), and 10 (34 percent) of these sites have more than three hearths, with the maximum number of hearths reported to be 135 features (Lynott 1977:Appendix G). Thus, Lynott's early compilation of data supports the notion that hearths are more common in the Brazos River basin than in the Trinity River basin.

In the early 1980s, the Office of the State Archeologist at the Texas Historical Commission compiled summary statistics of regions and counties throughout Texas (Biessart et al. 1985). The database compiled general feature types, but the information was presented in a format that does not permit sorting by multiple attributes such as cultural affiliations or specific site numbers. The data collection cut-off was established as May 1981. Four classes of burned features were recorded: (1) hearths in subsistence setting, (2) hearths in social/ceremonial settings (inside house structures?), (3) burned rock middens, and (4) burned rock features of unspecified type. The specific kinds of hearths are not specified, so any hearth association with heated rocks is not known.

The data on these four classes of features from the 15-county region encompassing the 50-mile $(80 \mathrm{~km})$ area around 41TR170 are presented by drainage basin in Table 20. Thermal features are present at 182 of the 940 sites. As of 1981 , most reported sites ( $n=548 ; 58.3$ percent) occurred in the Brazos River basin as opposed the number of sites $(n=392 ; 41.7$ percent $)$ in the Trinity River basin. The combined number of sites with subsistence and social/ceremonial hearths occurs in percentages comparable to total site occurrences for the two drainage basin regions $(n=38 ; 55.9$ percent, Brazos River; $\mathrm{n}=30$; 44.1 percent Trinity River basin). Nevertheless, burned rock middens occur 8.5 times more often in the Brazos River basin $(n=34 ; 89.5$ percent $)$ than they do in the Trinity River basin ( $\mathrm{n}=4 ; 10.5$ percent). Even though the information is 25 years out of date, a strong pattern is evident in the scarcity of burned rock middens in the Trinity River basin region.

Another synthesis used a geoarcheological approach for modeling the distribution of sites on the Trinity River terraces (Yates and Ferring 1986). A survey of 148 archeological reports prepared between 1923 and 1985 found that, overall, slightly more than half (51.4 percent) were prepared by avocational archeologists, slightly more than a quarter ( 26.4 percent) were developed by archeologists under federal contract, and more than one-fifth (22.3 percent) were reports on academic work conducted for degree theses or research grants (Yates and Ferring 1986:Table5.1). Upon closer examination, however, 75.6 percent of the reports written before 1970 were prepared by avocationalists. After that date, the hobbyists contributed a scant 16.9 percent of the archeological reports included in the literature survey. These figures support the perception that avocationalists have made important early contributions to the archeological literature of the region.

The summary by Yates and Ferring (1986:Table 5.3) of 81 sites recorded prior to 1985 on eight 7.5 topographic quadrangles (approximately 506.64 square miles; 1,323.41 square kilometers) discerns that only 15 sites (18.5 percent) reportedly contained hearths, although the frequency and kinds of hearths were unspecified. The cultural affiliations attributed to these hearth-bearing sites consisted of Late Archaic $(n=1)$, Late Prehistoric $(n=1)$, multiple component $(n=6)$, and unknown prehistoric $(n=7)$. Not much was known about the cultural affiliation of burned rock features in 1986, and unfortunately, things have not improved appreciably in the subsequent years. 
Table 20

Frequency of Thermal Features for 15 Counties in Northcentral Texas Based on 1981 Data

(after Biesaart et al. 1985)

\begin{tabular}{|c|c|c|c|c|c|c|}
\hline County & $\begin{array}{c}\text { Hearth } \\
\text { (Subsistence) }\end{array}$ & $\begin{array}{l}\text { Hearth (Social/ } \\
\text { Ceremonial) }\end{array}$ & $\begin{array}{c}\text { Burned Rock } \\
\text { Midden }\end{array}$ & $\begin{array}{c}\text { Burned Rock } \\
\text { Feature (unspecified } \\
\text { type) }\end{array}$ & $\begin{array}{l}\text { Total Sites with } \\
\text { Poss. Rock } \\
\text { Features } \\
\end{array}$ & $\begin{array}{c}\text { Total Reported } \\
\text { Sites } \\
\end{array}$ \\
\hline \multicolumn{7}{|c|}{ All in Trinity River Basin } \\
\hline Wise & 0 & 0 & 1 & 0 & 1 & 13 \\
\hline Denton & 8 & 0 & 3 & 2 & 13 & 80 \\
\hline Collin & 2 & 1 & 0 & 0 & 3 & 60 \\
\hline Dallas & 12 & 0 & 0 & 0 & 12 & 204 \\
\hline Ellis & 5 & 0 & 0 & 7 & 12 & 35 \\
\hline Sum & 27 & 1 & 4 & 9 & 41 & 392 \\
\hline \multicolumn{7}{|c|}{ Mostly in Trinity River Basin } \\
\hline Jack & 1 & 0 & 0 & 0 & 1 & 2 \\
\hline Tarrant & 1 & 0 & 0 & 0 & 1 & 26 \\
\hline Sum & 2 & 0 & 0 & 0 & 2 & 28 \\
\hline \multicolumn{7}{|c|}{ Mostly in Brazos River Basin } \\
\hline Parker & 0 & 0 & 0 & 0 & 0 & 3 \\
\hline Johnson & 0 & 0 & 2 & 0 & 2 & 4 \\
\hline Sum & 0 & 0 & 2 & 0 & 2 & 7 \\
\hline \multicolumn{7}{|c|}{ All in Brazos River Basin } \\
\hline Palo Pinto & 13 & 0 & 25 & 34 & 72 & 98 \\
\hline Erath & 1 & 0 & 0 & 0 & 1 & 11 \\
\hline Hood & 8 & 0 & 1 & 7 & 16 & 58 \\
\hline Somervell & 1 & 0 & 1 & 11 & 13 & 47 \\
\hline Bosque & 4 & 0 & 4 & 4 & 12 & 85 \\
\hline Hill & 10 & 1 & 1 & 13 & 25 & 242 \\
\hline Sum & 37 & 1 & 32 & 69 & 139 & 541 \\
\hline Total Trinity & 29 & 1 & 4 & 9 & 41 & 392 \\
\hline Total Brazos & 37 & 1 & 34 & 69 & 141 & 548 \\
\hline Grand Total & 66 & 2 & 38 & 78 & 182 & 940 \\
\hline
\end{tabular}

Prikryl (1990) prepared an archeological synthesis of the Elm Fork drainage of the Trinity River. His overview of a $300-\mathrm{mi}^{2}\left(777 \mathrm{~km}^{2}\right)$ area was supplemented by field visits to many of these sites and documentation of many avocational collections. He compiled information on 238 archeological sites, but most of his data relate to the kinds of tool forms, especially projectile point types, and the kinds of raw lithic materials used during various cultural periods, with little discussion regarding features at these sites. Prikryl's site data appendix lists only nine sites (3.8 percent) with hearths: one site has burned clay hearths, three have rock-lined hearths, but in the five other instances, hearth types are unspecified. Cultural affiliations for the eight sites with rock-lined or unspecified hearths consist of Late Archaic $(n=1)$, multiple component $(n=4)$, and unknown prehistoric $(n=3)$. Prikryl (1990:83) mentions that Archaic component sites occur at depth and are underrepresented in his summary; however, with his emphasis on artifacts held in private collections, feature documentation are also underreported. 
Thus, even though a number of archeological regional summaries have dealt with sites in the Trinity River basin, the nature of thermal features in Northcentral Texas is still poorly known. The quality of reported information is of questionable reliability, and the data from most sites are too poor to ascertain whether most hearths are associated with heated stones. One tentative trend developed from these studies is that burned rock ovens with large central pits are very rare in the Trinity River basin relative to those found in the Brazos River valley.

\section{A Review of Texas Burned-Rock-Midden Distribution Overviews}

Despite the seemingly rare occurrence of large burned rock features in Northcentral Texas, they are very common across the Edwards Plateau and especially in counties along the Balcones Escarpment and the Lower Pecos regions. Over 150 midden sites in greater Central Texas have been dug by archeologists over the past 90 years (Black et al. 1997:269). The general lack of new information derived from most of these excavations prompted the Texas State Historic Preservation Officer to declare in the mid-1980s that his office would no longer support recommendations for mitigation of such features until explicit new advances in approaches were developed. This led to considerable debate and data syntheses leading to reformulation of research designs and field and analytical tactics to be used on burned rock midden features (cf. Black et al. 1997; Hester 1991). These studies resulted in vast improvements in documenting the structure of rock clasts and the fine sediment component of features, their ages, and their association with artifacts and macrobotanical remains.

Regional distributional studies of excavated burned rock features documented for Central Texas mostly cover a 30-county region extending north and west of the Balcones Escarpment, west to the Pecos River, and north to the Colorado River in Tom Green, Coleman, and Runnels counties (Creel 1991, 1997; Howard 1991:55). The farthest occurrences of excavated burned rock middens toward Fort Worth are in Bosque and Johnson counties, within the Brazos River basin and within 50 miles of 41TR170. Howard's tabulation of excavated sites includes 224 features from 142 sites, which closely agrees with the more recent tabulation by Black et al. (1997).

Considerably more known sites contain unexcavated burned rock middens. One study of an 18county region (extending from Coleman and Brown counties on the north to Medina, Uvalde, and Kinney counties on the south) indicates 3,341 site records, but reliable records exist for only some 2,975 sites (Black et al. 1997). Of these, 760 sites contain a minimum of 1,271 burned rock midden features in a variety of shapes ranging from domed (77 percent), to annular mound (17 percent), and sheet midden (6 percent; Taylor 1997:751). These data compilations suggest that large ovens and middens may be uncommon in the Trinity River basin.

The scarcity of rock oven features north of the Central Texas region denotes some degree of decrease in the use of hot stone technological features that form rock middens and oven mounds. Nonetheless, a number of burned rock mounds and rock ovens have been recorded in southcentral Oklahoma (cf. sites 34Jn-32, 34At-81, 34At-90, 34Mi-68, 34Mi-253; Lintz and Vehik 1986; Wyckoff 1984; Wyckoff and Brooks 1983:Table 14). Although no systematic study has been conducted in Oklahoma and Kansas, many burned rock features may occur along the eastern edge of the Cross Timbers woodland region and near the tall grass prairies. Insufficient studies have been conducted on the Oklahoma features to clarify the kinds of resources cooked in these ovens. Probably, similar resources occur in the Trinity River basin, since the same post oak woodlands extend south into Northcentral Texas. Reasons for the scarcity of these features in the Trinity River basin remain unclear. 
Most archeologists have suggested that the large burned rock features and rock middens represent predominantly Archaic-age cooking features, since many are associated with various Archaicstyle dart points. However, extensive excavations conducted in large annular rock oven middens at four sites in the O. H. Ivie Reservoir along the Colorado River found that despite the recovery of many Archaic projectile points, charcoal recovered from stratified midden deposits yielded internally-consistent Late Prehistoric dates. The incongruity of early period dart points in a late period midden was attributed to the use of Archaic-age sediments with incidental artifacts dug from off-mound for use as an earthen buffer or to protect the foodstuff from excessive heating in the core element of the oven. Upon retrieval of the cooked food, the fine sediments and older dart points were tossed out of the central oven pit and subsequently buried by the addition of later cooking episodes; the radiocarbon dating of these features readily points out the age incongruity indicated by the dart points and the carbon dates (Treece 1992:Table 52). Clearly, low confidence in age or cultural affiliation assignation should apply to burned rock features based only on "associated artifacts" (Black et al. 1997:280). A compilation of 141 radiocarbon dates from 35 Central Texas middens discerned that 81 percent dated to after A.D. 800 and were Late Prehistoric in age. The earliest date on a midden was nearly 6,700 years old. Black and colleagues caution that the ages are skewed against the earlier dates due to various charcoal preservation factors and the tendency for archeologists to choose better preserved and morerecent features. Nevertheless, the results clearly indicate that earth ovens and mounds in Central Texas have a long history of use and that many date to the Late Prehistoric period.

\section{A Review of Thermal Features in the Texas Archeological Sites Atlas Database}

The foregoing reviews of the regional archeological literature of the Trinity River basin and the burned rock literature for Central Texas suggest that large burned rock features are uncommon. However, many of these syntheses are quite old and do not incorporate the most recent site file data. The following discussion updates the distribution of burned rock features by using the sites atlas electronic database maintained by the Texas Historical Commission. The data reflect conditions of the site records as of April 2006.

Insofar as site 41TR170 is located only some 5 miles $(8 \mathrm{~km})$ from the drainage divide between the Trinity and Brazos river basins, any regional survey of site databases should include portions of the adjacent river valley. In order to assess the uniqueness of sites with burned rock close to 41TR170, a series of steps was implemented in compiling and analyzing data from the electronic site files. Initially, the target region for consideration involved all counties within an $80-\mathrm{km}(50-$ mi) radius of site $41 \mathrm{TR} 170$ in total or in part. This target region consisted of some 15 counties. Table 21 lists for each of the 15 counties the percentage of the county within the 50-mile radius search area, the nearest and farthest points of the county from site 41TR170, the occurrence and estimated percent of the county within the Trinity and Brazos river basins, and the total number of archeological sites recorded in the Texas Archeological Sites Atlas database.

The number of sites recorded for any county merely reflects the intensity of previous archeological investigations conducted in response to proposed development. Some counties, such as Dallas, Denton, and Tarrant, have many recorded sites due to urban development and the incidence of many archeological studies. A large number of sites in other counties, including Bosque, Hill, and Palo Pinto, relate to studies conducted at proposed reservoir projects. Other

counties with few reported sites, such as Jack, Erath, and Johnson, merely reflect the scarcity of archeological projects rather than a genuine absence of archeological remains. 
Table 21

Sites within 80-km Target Search Area, Their Drainage Basin, and Number of Recorded Sites

\begin{tabular}{|c|c|c|c|c|c|c|c|c|c|c|}
\hline $\begin{array}{l}\text { County } \\
\text { Name }\end{array}$ & $\begin{array}{c}\text { Est. \% of } \\
\text { County inside } \\
\text { Search Radius }\end{array}$ & $\begin{array}{l}\text { Near } \\
\text { to } \\
\text { mi }\end{array}$ & $\begin{array}{l}\text { est Point } \\
\text { County } \\
\text { km }\end{array}$ & $\begin{array}{r}\text { Farthe } \\
\text { to C } \\
\text { mi }\end{array}$ & $\begin{array}{l}\text { st Point } \\
\text { ounty } \\
\mathrm{km}\end{array}$ & $\begin{array}{c}\text { Mostly in } \\
\text { Trinity } \\
\text { Drainage } \\
\text { Basin }\end{array}$ & $\begin{array}{c}\text { Est. \% Area in } \\
\text { Trinity } \\
\text { Drainage Basin }\end{array}$ & $\begin{array}{c}\text { Mostly in } \\
\text { Brazos } \\
\text { Drainage } \\
\text { Basin }\end{array}$ & $\begin{array}{c}\text { Est. \% Area in } \\
\text { Brazos } \\
\text { Drainage Basin }\end{array}$ & $\begin{array}{l}\text { Total No. of } \\
\text { Known Sites }\end{array}$ \\
\hline Jack & 20 & 40 & 64 & 80 & 128 & Yes & 60 & No & 40 & 18 \\
\hline Wise & 80 & 20 & 32 & 60 & 96 & Yes & 100 & No & 0 & 69 \\
\hline Denton & 80 & 20 & 32 & 60 & 96 & Yes & 100 & No & 0 & 526 \\
\hline Collin & 35 & 38 & 60 & 78 & 125 & Yes & 100 & No & 0 & 168 \\
\hline Palo Pinto & 30 & 42 & 67 & 75 & 120 & No & 0 & Yes & 100 & 319 \\
\hline Parker & 100 & 12 & 19 & 42 & 67 & No & 40 & Yes & 60 & 103 \\
\hline Tarrant & 100 & 0 & 0 & 30 & 48 & Yes & 85 & No & 15 & 205 \\
\hline Dallas & 100 & 20 & 32 & 50 & 80 & Yes & 100 & No & 0 & 427 \\
\hline Erath & 15 & 45 & 102 & 88 & 141 & No & 0 & Yes & 100 & 44 \\
\hline Hood & 100 & 20 & 32 & 50 & 80 & No & 0 & Yes & 100 & 78 \\
\hline Johnson & 100 & 10 & 16 & 38 & 61 & No & 15 & Yes & 85 & 56 \\
\hline Ellis & 80 & 20 & 32 & 62 & 99 & Yes & 100 & No & 0 & 226 \\
\hline Somervell & 90 & 32 & 51 & 55 & 88 & No & 0 & Yes & 100 & 145 \\
\hline Bosque & 20 & 40 & 64 & 80 & 128 & No & 0 & Yes & 100 & 285 \\
\hline \multirow[t]{2}{*}{ Hill } & 30 & 35 & 56 & 78 & 125 & No & 0 & Yes & 100 & 294 \\
\hline & & & & & & & & & & 2,963 \\
\hline
\end{tabular}

Subsequent to the delineation of the target sample, data on the Texas Archeological Sites Atlas was queried using the advanced keyword search function to find those sites with recorded thermal features. Three general classes of burned rock were postulated. "Class 1 burned rock" refers to sites with widely dispersed scatters of burned rock recorded on the site; these may be various kinds of thermal features destroyed/scattered by either natural erosion or cultural activities such as plowing. "Class 2 burned rock" refers to "hearths" that might reflect relatively small areas of clustered burned rock; unfortunately, due to taxonomic vagaries and poor descriptions, some classes of hearths might not contain burned rocks. "Class 3 burned rock" refers to large burned rock features such as ovens or rock mounds. Due to the high potential for multitudes of archeologists to use nonstandardized terms in recording burned rock, 13 different terms were searched on the electronic database to capture most thermal features recorded in the target region. The words used in the initial search in the Texas Archeological Sites Atlas database for Class 1 burned rock include "fire cracked rock"/“fire-cracked rock," "burned rock," "FCR," and "burnt rock." A total of 329 records (11.1 percent) of probable scatters was identified using these terms. The initial search for Class 2 types of small, discrete features was conducted on the words "hearth," "rock filled hearth," "rock lined hearth," and "rock hearth." A total of 64 sites (2.2 percent) with small hearths was initially identified. The search for Class 3 features was conducted on "rock oven," "oven," "burned rock mound," "burned rock midden," and "BRM." A total of 28 records ( 0.9 percent) lists these kinds of large rock features.

The total number of sites containing records for the three classes of burned rock is about 422 records. This is a misleading number, since it includes duplicate listing for each time a site was revisited during different phases of investigations. Eliminating these multiple listings for specific kinds of features at the same site drops the number to 367 sites. However, this number is still too 
high, since the sites are listed each time a different class of burned rock feature is used in the site form. Thus, for example, if the field records indicate that a discrete hearth is present on a site with an oven, the site will be counted twice. When these duplicate records are eliminated by manually checking for redundancy among site numbers, the list of unique sites with reported burned rock dropped to only 322 of the total 2,963 sites (10.87 percent) in the 15 -county target region.

However, further inspection of the Texas Archeological Sites Atlas database using the keyword function still over-inflated the count of sites due to vagaries in the terminologies used by the recording archeologists completing the site forms. For example, the word "ovens" elicited positive responses for sites with historic baked enamel stoves/ovens and with historic cookware pottery marked as being "oven-safe." Other errors occurred when archeologists stated negative occurrences on the electronic site forms; for example, a few sites report that "no oven features" are present. Similarly, searches conducted on the general term "hearth" yielded positive responses for sites with just oxidized clay layers observed in backhoe trenches without associated burned rock or, in some cases, even any artifacts or ecofacts. Such oxidized soils might just be naturally burned tree events that became buried and may have no cultural genesis whatsoever. In some cases, archeologists noted that a few scattered rocks (a Class 1 descriptor) indicated the eroded presence of "hearths" (a Class 2 descriptor). Sites identified with the problems listed above were deleted or manually changed to fit the circumstance in the initial file search. All electronic site forms for Classes 2 or 3 (features with integrity and substance) were thoroughly reviewed, but no time was spent reviewing site forms with scattered rock. In lieu of standardized archeological terminology and nomenclature, such problems will likely persist within the Texas sites atlas database. These kinds of errors limit the usefulness of the electronic site atlas, and the resulting site counts should be regarded as approximately correct. Following revisions, the adjusted count of Class 1 sites with scattered burned rock is 283 (9.5 percent of all recorded sites), Class 2 sites with discrete hearths is 52 (1.8 percent), and Class 3 sites with ovens/middens is 26 ( 0.9 percent). Considering just the subset of sites with thermal features, sites found in both drainages with Class I isolated or scattered remains is 283 ( 88.2 percent), Class 2 sites with small hearth features occur at 52 places (16.2 percent), and Class 3 ovens/mound/middens occur at only 26 sites ( 8.1 percent) with thermal features within the entire study region.

When the site/feature class data from specific counties are grouped by river drainage basin, an interesting pattern emerges (Table 22). Only 321 of the 2,963 recorded sites (10.8 percent) in the entire region report the occurrence of burned rock as scatters or features. Although the greater number of sites occurs in counties completely or mostly within the Trinity River basin (1,639 of 2,$963 ; 55.3$ percent), the greater number of sites with any kind of reported thermal/burned rock features ( 211 of $321 ; 65.7$ percent) is in counties wholly or mostly within the Brazos River basin. Sites with thermal features are nearly twice as common in the Brazos River basin $(211 ; 65.7$ percent) than they are in the Trinity River Basin (110; 34.3 percent).

Striking differences are evident when the distribution of the specific kinds of discrete features is compiled. Figure 37 shows the percentage of a specific feature class to the total number of sites reported for each county in the study area. The percentage of counties with reported Class 1scattered burned or fire-cracked rock-in the Trinity River basin ranges from 0.00 to 14.63 percent, with only two of seven counties containing more than 6.0 percent. In contrast, the percentages for counties in the Brazos River basin range from 6.41 to 22.45 percent, with all eight counties containing more than 6.0 percent of sites with burned or fire-cracked rock. 
Table 22

Distribution of Thermal Feature Types by Drainage Basin

\begin{tabular}{|c|c|c|c|}
\hline Burned Rock Feature Class: & $\begin{array}{c}\text { Class 1: Possible Isolated and } \\
\text { Scattered Burned Rock }\end{array}$ & $\begin{array}{l}\text { Class 2: Small Hearth } \\
\text { Features }\end{array}$ & $\begin{array}{l}\text { Class 3: Rock Ovens and } \\
\text { Middens }\end{array}$ \\
\hline Keyword Search Terms: & $\begin{array}{l}\text { "FCR, fire cracked rock, fire- } \\
\text { cracked rock, burned rock, } \\
\text { burnt rock" }\end{array}$ & $\begin{array}{l}\text { "Hearth, rock filled hearth, } \\
\text { rock lined hearth, rock } \\
\text { hearth" }\end{array}$ & $\begin{array}{l}\text { "Ovens, rock ovens, burned } \\
\text { rock mounds, burned rock } \\
\text { midden, BRM" }\end{array}$ \\
\hline
\end{tabular}

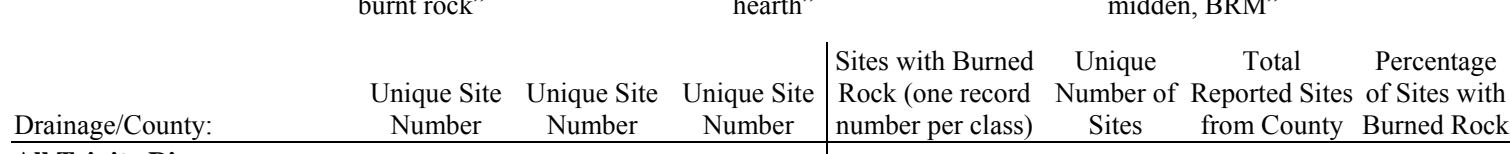

\begin{tabular}{|c|c|c|c|c|c|c|c|}
\hline \multicolumn{8}{|l|}{ All Trinity River } \\
\hline Wise & 4 & 3 & 0 & 7 & 6 & 69 & 8.70 \\
\hline Denton & 27 & 6 & 1 & 34 & 33 & 526 & 6.27 \\
\hline Collin & 12 & 0 & 0 & 12 & 12 & 168 & 7.14 \\
\hline Dallas & 19 & 0 & 0 & 19 & 19 & 427 & 4.45 \\
\hline Ellis & 6 & 0 & 0 & 6 & 6 & 226 & 2.65 \\
\hline Sites Per River Segment Sum & 68 & 9 & 1 & 78 & 76 & 1416 & 5.37 \\
\hline \multicolumn{8}{|l|}{ Mostly Trinity } \\
\hline Jack & 0 & 0 & 0 & 0 & 0 & 18 & 0.00 \\
\hline Tarrant & 30 & 9 & 1 & 40 & 34 & 205 & 16.59 \\
\hline Sites Per River Segment Sum & 30 & 9 & 1 & 40 & 34 & 223 & 15.25 \\
\hline \multicolumn{8}{|l|}{ Mostly Brazos } \\
\hline Parker & 9 & 5 & 0 & 14 & 12 & 103 & 11.65 \\
\hline Johnson & 7 & 1 & 2 & 10 & 8 & 56 & 14.29 \\
\hline Sites Per River Segment Sum & 16 & 6 & 2 & 24 & 20 & 159 & 12.58 \\
\hline \multicolumn{8}{|l|}{ All Brazos } \\
\hline Palo Pinto & 42 & 2 & 13 & 57 & 44 & 319 & 13.79 \\
\hline Erath & 4 & 3 & 1 & 8 & 7 & 44 & 15.91 \\
\hline Hood & 5 & 3 & 0 & 8 & 8 & 78 & 10.26 \\
\hline Somervell & 26 & 5 & 1 & 32 & 29 & 145 & 20.00 \\
\hline Bosque & 26 & 5 & 6 & 37 & 29 & 285 & 10.18 \\
\hline Hill & 66 & 10 & 1 & 77 & 74 & 294 & 25.17 \\
\hline Sites Per River Segment Sum & 169 & 28 & 22 & 219 & 191 & 1165 & 16.39 \\
\hline Trinity River Total & 98 & 18 & 2 & 118 & 110 & 1639 & 6.71 \\
\hline Brazos River Total & 185 & 34 & 24 & 243 & 211 & 1324 & 15.94 \\
\hline Project Total & 283 & 52 & 26 & 361 & 321 & 2963 & 10.83 \\
\hline
\end{tabular}




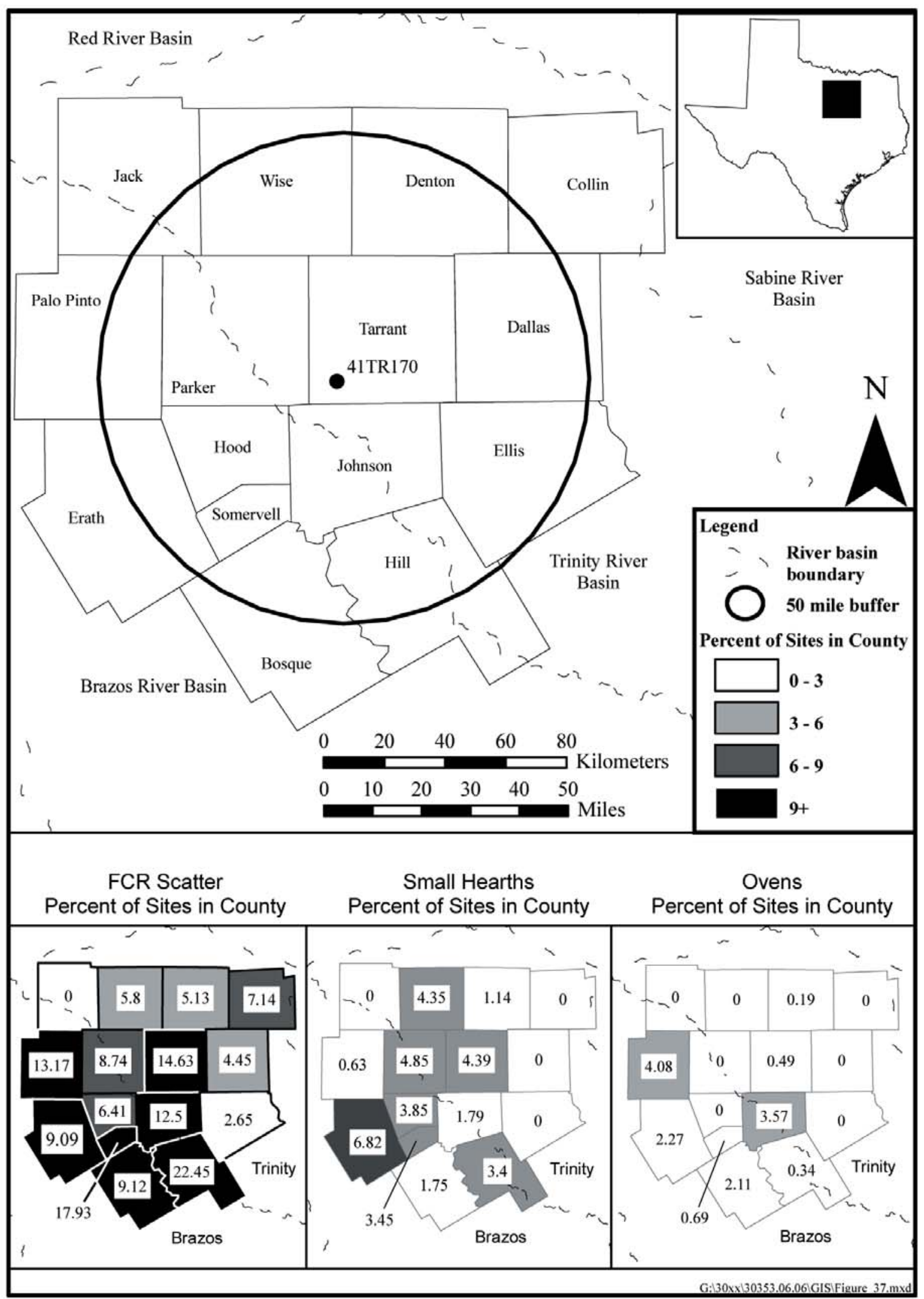

Figure 37. The distribution of scatter, small hearths, and ovens in counties near site 41TR170. 
When the same approach is used for Class 2-small hearth features-similar patterns are apparent. The percentage of counties with discrete features ranges from 0.00 to 4.39 percent in the Trinity River basin, and four of the counties report no occurrence of discrete hearths; five of seven counties have less than 3 percent small, discrete features. In contrast, the percentage of small features in the Brazos River basin ranges from 0.63 to 6.82 percent; small hearths occur in all counties; and five of eight counties report between 3 percent and 9 percent.

The situation is most pronounced for counties with Class 3 - oven features. The percentage of counties with oven features ranges from 0.00 to 0.49 percent, with only two of seven counties reporting oven features in the Trinity River basin. However, in the Brazos River basin, the percentage of ovens ranges from 0.00 to 4.08 percent, with rock ovens occurring in six of eight counties.

Restated another way, for counties that are wholly or partly in the Trinity River basin, Class 1 scatters occur at 98 of the 110 (89.1 percent) sites with thermal features; whereas Class 2 sites with discrete features are represented by 18 of 110 (16.4 percent) sites with features. Class 3 oven sites are present on only 2 of 110 (1.8 percent) sites with features in the Trinity River basin. The previously recorded sites with ovens are 41DN197 and 41TR147.

Turning to the Brazos River basin, the instances of Classes 1 and 2 sites occur in percentages nearly comparable to those reported above for the Trinity River basin (87.6 percent, 185 of 211 sites with scatters; 16.1 percent, 34 of 211 sites with discrete hearths). The biggest difference is in the reported sites with earth ovens. The 24 of 211 sites with ovens (11.37 percent) in the Brazos River basin represent a ten-fold increase over the percentage of sites with ovens in the Trinity River basin.

Efforts to use the Texas sites atlas to delineate temporal affiliations of hot rock features were completely thwarted. Very few sites with thermal features were assigned to a single component, or to any component at all. Indeed, 19 of the 26 Class 3 sites with oven features were attributed to undefined prehistoric period. Of the seven other sites with oven features, four were attributed to Archaic affiliations and three were mixed Archaic and Late Prehistoric affiliations. Detailed chronometric studies for oven sites in Central Texas have documented that archeologists historically have shown a temporal bias by ascribing oven features to the Archaic period, when most radiocarbon dates are Late Prehistoric (Black et al. 1997). At this time, insufficient data are available to judge the age of oven features in the region. Comparable trends are evident in the Class 2 sites with discrete hearths. Two factors underlie the lack of chronometric data: (1) few large-scale excavations have been conducted at sites with rock features, and (2) the practice of submitting site forms to TARL for site numbers usually precedes the availability of chronometric results or sometimes even a clear understanding of the components represented.

\section{Summary of Burned Rock Feature Distributions}

The regional literature review clearly denotes strong differences exist in the distribution of oven features between the Trinity River and Central Texas. Without doubt, these patterns suggest very different resource procurement and processing activities in the Trinity River basin from those commonly found in the middle Brazos River region and across the Edwards Plateau. Since limestone is abundant across the Trinity River region, the differences are not related to source of heating elements. Most likely, the patterns are due to some differences found in the economically 
important tubers, bulbs, or sotol heads or cactus pads in post oak or savannah regions of the Trinity River basin. Identification of the specific kinds of resources may require the discovery of accidental cooking events, because the simple charring of cellular plant remains is not necessarily indicative of cooking. Thus, greater intensity of investigating burned rock features in the Trinity River basin is needed in order to provide the opportunity of finding such cooking mistakes. Although the Texas Archeological Sites Atlas database reaffirms that the thermal feature differences are authentic, further studies are needed to deduce the environmental constraints that restricted the resources in the region. Clearly, the prehistoric activities in regard to hot rock features in the Trinity River basin are not at all similar to those found in Central Texas. 



\section{CHAPTER 7 RECOMMENDATIONS}

This chapter presents an assessment of the eligibility of site 41TR170 for inclusion in the National Register of Historic Places and for designation as a Texas State Archeological Landmark (SAL). The following provides discussions about the criteria for eligibility in these two programs and the potential of the site to yield data that would address the range of research topics.

\section{SIGNIFICANCE OF SITE 41TR170}

The purpose for conducting archeological testing at site 41TR170 was to assess the significance of the site regarding its integrity and information potential to determine if the proposed construction of SH 121 would adversely affect a significant site. Site significance is defined on the federal level by the National Historic Preservation Act (NHPA) of 1966, as amended through 2000 [16 U.S.C. $\S 470$ et seq.; P.L. 89-665; 80 Stat. 915] and through Section 106 of that act. A testing phase is integral to evaluating whether properties are eligible for inclusion in the National Register. The qualification for a property to be considered eligible for listing in the NRHP is based on four criteria of evaluation defined by 36 CFR Part 60. These four criteria are applied following the identification of relevant historical themes and related research questions.

The quality of significance in American history, architecture, archeological, and culture is present in districts, sites, buildings, structures, and objects that possess integrity of location, design, setting, materials, workmanship, feeling, and association, and:

A. That are associated with events that have made a significant contribution to the broad patterns of our history; or

B. That are associated with the lives of persons significant in our past; or

C. That embody the distinctive characteristics of a type, period, or method of construction, or that represent the work of a master, or that possess high artistic values, or that represent a significant and distinguishable entity whose components may lack individual distinction; or

D. That have yielded, or may be likely to yield, information important in prehistory or history [36 CFR $\S 60.4]$. 
Criterion $\mathrm{D}$ is most often applicable to prehistoric, and to many historic, sites. Important information is generally recognized to refer to scientific importance (Butler 1987). However, scientific importance is partially driven by the research perspectives of the time and in part by the state of available information regarding a particular research topic in a specific research area. The purpose for conducting archeology should not be to fill museum drawers with relics, but rather to fill information gaps in knowledge about specific research domains. As research progresses within a region, well-excavated sites contribute information to some research domains. Through time, data needs for some research questions may be addressed to various degrees, even though complementary data are often needed from different periods, seasons, settings, and site types to fully understand the diversity of activities. As data required to address specific questions approach redundancy, such information may diminish the priority of that kind of repetitive information needed from nearby sites. This suggests that the identification criteria of important historic properties (i.e., sites considered eligible for or listed on the National Register) are tied to both a specific geographical area reflecting a cultural adaptation or region and a state of accumulated knowledge about a research domain. Archeological sites with integrity that contain artifacts and features that can contribute information toward addressing research issues are regarded as significant and are eligible for inclusion in the NRHP.

Archeological sites that exist on static landforms, such as bedrock surfaces or ancient upland hilltops that lack aeolian sands, can contain concentrated densities of artifacts and feature remains. Such palimpsest remains of occupations are generally regarded as worthless for unraveling or contributing useful information toward the understanding of prehistory because the artifact assemblages are mixed and uninterpretable. In such cases, the sites are not regarded as scientifically important, and in general, these kinds of sites are not eligible for inclusion in the NRHP.

The most ideal kinds of archeological remains are those left in rapidly aggrading settings, where there is a chance for noncultural sediments to separate a series of materials and residues representing brief, short-term activities. Usually, alluvial terraces (during general building periods), wind-blown or aeolian sand sheets and dunes, and sometimes colluvial slope wash are the kinds of settings and events that are apt to quickly bury archeological remains and preserve the discreteness of activities. The evaluation of the depositional potential is one of the key characteristics for distinguishing the integrity of deposits. As discussed in preceding chapters, site 41TR170 retains integrity and may have stratigraphically isolatable deposits.

However, while the existence of prehistoric remains in clear or unmixed archeological context is one key variable for distinguishing important sites, other variables include issues of preservation and the robustness of the archeological record. In some cases, the activities are simply too ephemeral to have left evidence, or the evidence is too sparse for interpretation and contribution to the regional information base. In such cases, despite exceptional depositional segregation of occupations, the sites cannot be regarded as scientifically important, for the information is simply uninterpretable. In general, these kinds of sites are also not eligible for inclusion in the NRHP.

In regard to this latter concept, the artifact assemblage from 41TR170 is regarded as paltry or sparse relative to the quantities of artifacts common on sites in the Brazos or Colorado river basins, but the abundance is comparable to many Late and Transitional Archaic sites in the Trinity River basin (cf. Yates and Ferring 1986). If there is to be any progress in understanding the prehistory of vast regions of Northcentral Texas, archeologists must shift their thinking to the comparability of assemblages present in chert-poor and feature-poor regions such as Northcentral Texas and not focus on artifact materials from chert-rich regions such as found in Central Texas. 
At the state level, archeological sites may be considered significant and be recognized or designated as an SAL, provided that at least one of the following conditions is met:

(1) The archeological site is situated on lands owned or controlled by the State of Texas or one of its political subdivisions; or

(2) The archeological site is situated on private lands that have been specifically designated as an SAL ... and fits at least one of the following criteria:

(A) Preservation of materials must be sufficient to allow application of standard archeological techniques to advantage;

(B) The majority of artifacts are in place so that a significant portion of the site's original characteristics can be defined through investigation;

(C) The site has the potential to contribute to cumulative culture history by the addition of new information;

(D) The site offers evidence of unique or rare attributes; and/or

(E) The site offers a unique and rare opportunity to test techniques, theory, or methods or preservation, thereby contributing to scientific knowledge [Texas Natural Resources Code 1977; Title 9, Chapter 191, Texas Antiquities Committee, Section 191.094 and Chapter 41.7, Antiquities Code of Texas].

Since site 41TR170 is on property to be purchased by the city of Fort Worth and/or TxDOT, it technically meets SAL Condition 1, regarding political subentities of Texas. At issue, however, is whether a site meeting that criterion is significant and eligible for designation as an SAL or for inclusion in the NRHP. In considering the five criteria specifically listed for SAL Condition 2, it seems that the testing phase at site $41 \mathrm{TR} 170$ has demonstrated that within the investigated area most criteria do not apply. The application of standard archeological techniques (SAL Condition 2A) did not yield significant quantities, abundance, or robustness of information from the tested area of site 41TR170. The potential of the investigated portion of the site to contribute significant or new information to the cumulative culture history (SAL Condition $2 \mathrm{C}$ ) is not encouraging, based on the information returns obtained so far. The relatively small size of the artifact assemblage is common for sites in such chert-poor regions as Northcentral Texas. However, the quantity of burned rock features and documentation that the heated stones were used in nearly a half dozen feature types is something quite rare in the Trinity River basin. The regional overview above suggests that such features tend to be more common in the Brazos River basin, a mere 5 miles to the west. The information potential about the nature, diversity, and function of the features in the areas of Blocks 1,2, and 3 may not have been exhausted, especially in regard to the overall diversity and spatial relationships. However, various studies have shown that the meager returns are frustratingly difficult to use.

\section{POTENTIAL FOR SITE 41TR170 TO ADDRESS REGIONAL RESEARCH DOMAINS}

Several research domains were formulated in the research design chapter above. Detailed studies of the recovered assemblages of artifacts and processing of select samples for macrobotanical analysis, lipid identification, and radiocarbon dating all provide insights into the kind of preservation present at site 41TR170. The results are summarized in Table 23. 
Table 23

Data Sets Available to Address Research Design Issues

\begin{tabular}{|c|c|c|c|c|}
\hline \multirow{2}{*}{$\begin{array}{l}\text { Research Issue } \\
\text { Required Data Sets } \\
\end{array}$} & \multirow{2}{*}{$\begin{array}{l}\text { Additional } \\
\text { Fieldwork }\end{array}$} & \multicolumn{3}{|c|}{ Research Potential } \\
\hline & & Block 1 & Block 3 & Block 2 \\
\hline \multicolumn{5}{|l|}{ 1. Cultural and absolute chronology indicators } \\
\hline Diagnostic points & Perhaps & Low & Low & Low \\
\hline Radiocarbon dates (cultural deposits) & No & Low & Medium & Medium \\
\hline \multicolumn{5}{|l|}{ 2. Paleoenvironmental conditions indicator } \\
\hline Sediment texture and chemistry & No & Medium & High & Medium \\
\hline Pollen potential & No & Low & Low & Low \\
\hline Phytolith potential & No & Low (?) & Low (?) & Low (?) \\
\hline Snail species diversity (from column samples) & No & Low (?) & Low (?) & Low (?) \\
\hline Macrobotanical remains (from sediment flotation) & No & Low & Low & Med-Low \\
\hline Faunal remains potential & No & No & Low & Med-Low \\
\hline \multicolumn{5}{|l|}{ 3. Community structure indicators } \\
\hline Spatial pattern of features & Yes & High & High & Medium \\
\hline Diversity of feature forms & Yes & High & High & Med-Low \\
\hline \multicolumn{5}{|l|}{ 4. Settlement pattern structure indicators } \\
\hline Landscape setting & No & Done & Done & Unknown \\
\hline Magnetic susceptibility (column samples) & No & Medium & Medium & Medium \\
\hline \multicolumn{5}{|l|}{ 5. Subsistence pattern indicators } \\
\hline Macrobotanical (sedimentation flotation) & No & Low & Low & Medium \\
\hline Faunal/bone studies & No & Low & Low & Medium \\
\hline Lipid residue studies (porous burned rock) & No & Medium & Medium & Medium \\
\hline \multicolumn{5}{|l|}{ 6. Technological pattern indicators } \\
\hline Stone tool manufacture & No & Med-Low & Low & Low \\
\hline Butchering/animal processing & No & Low & Low & Med-Low \\
\hline Hot rock technology & Yes & High & High & Low \\
\hline \multicolumn{5}{|l|}{ 7. Regional exchange and interaction indicators } \\
\hline Trade goods & No & Low (?) & Low (?) & Low (?) \\
\hline Distant lithic resource utilization & No & Low (?) & Low (?) & Low (?) \\
\hline
\end{tabular}

The radiocarbon dating studies have provided adequate results so that the processing of further samples would contribute little new meaning or information. In other instances, such as lipid and macrobotanical recovery, the test samples returned positive results, but either the diversity of recovered remains was limited and failed to turn up economically useful macrobotanical remains or the lipids only provided insights into general food classes that provide little interpretative refinement. Other avenues of investigations, such as exploring hot rock technology through thermal breakage patterns and clasts size, are certainly possible, but it is unlikely that the necessary time and efforts expended would provide deeper insights into the nature of the features. For most research issues, unsettling questions remain about whether further excavations of 41TR170 materials would add to knowledge regarding Transitional Archaic lifestyles in Northcentral Texas. Based on the results from a rather robust testing phase, the meager material returns from the site seem to signal that further work would not be very productive. 
There is no doubt that further excavations along the south edge of the site would provide potentially important data about the distribution of other rock features adjacent to the Pleistocene gravel bar. As yet, no satisfactory explanation exists for the cause of the thick ashy deposits encountered in Block 2. In light of the overlapping and potentially stratified features, it seems that the ash is likely a cultural midden. Perhaps sediment chemistry and/or magnetic susceptibility could provide new kinds of information that could shed light on the accumulation of this midden-like deposit. With the exception of community patterning issues, it seems that recovered remains may return redundant kinds of information at an expenditure of considerable effort.

The testing phase at 41TR170-especially work along the south edge of the site-has documented considerable variability in feature forms during the Transitional Archaic period for the Trinity River basin. Test probes also strongly suggest that many more burned rock features occur parallel to the Pleistocene gravel terrace. In this regard, the testing has not exhausted the information potential related to the community structure or the spatial patterning of activities by these people. However, the associated stone, shell, and bone artifact assemblages are meager. Flotation of more then 70 liters of sediments from feature contexts has failed to find economically useful macrobotanical remains other than a single nutshell and small amounts of wood charcoal. Efforts to retrieve lipids samples from the burned rock features proved to be successful, but the results indicate general classes of plants and animals; analysis was not very helpful in isolating the resources processed in these hot rock features. Although examination of more burned rock features may stumble onto examples of cooking accidents that preserve ancient foodstuff, the current robust level of testing suggests that the information content from the site is relatively limited.

The literature review of the surrounding 15-county region indicates that 41TR170 is unusual for sites in the Trinity River basin due to the abundance of large burned rock features. However, it is located only some 5 miles from the Trinity-Brazos river drainage divide, where such features in the Brazos River basin are far more common. The scarcity of comparable kinds of sites in the Trinity River basin might be due to the particular setting of 41TR170. The potential that this site represents an aberrational northeastern expression of an otherwise Brazos River tradition is suggested not only by the prevalence and density of burned rock features but also by the lithic assemblage. The chipped stone assemblage from this site appears to reflect curatorial behavior and exhibits an extremely high proportion of Brazos/Uvalde Gravel cherts. High quality gravel and cobble cherts were likely obtained from the Brazos River - the shortest distance to the river from $41 \mathrm{TR} 170$ is $40 \mathrm{~km}(24.8 \mathrm{mi})$ to the west.

Most survey and testing phases in this portion of the Trinity River valley examine areas near modern and relic channels, and little attention has been paid to valley margins near Pleistocene terraces. Such distal terrace settings have not been rigorously examined to adequately characterize the prehistoric encampments that are primarily located in these settings. Previous research suggests that archeological sites found within the valleys of the West and Clear Forks of the Trinity River fall within three general patterns (Ellis 1998). The first includes sites that are located on the uplands and exhibit a wide range of artifact classes and diagnostics artifacts; often these sites are the result of multiple occupations creating a palimpsest due to the lack of rapid sedimentation. Second, are sites that occur on the floodplains or low terraces away from the river; these sites exhibit narrower occupations spans and a broad array of artifacts. These sites are the result alluvial stratification of the same occupation and activity patterns that contributed to the formation of the upland sites. Finally, sites located near the channel of the river are those with a narrow range of artifacts found in low density. 
Site 41TR170 most appropriately falls within the second archeological site pattern observed within the Trinity River valley. This is particularly true for the southern site component located near the edge of the river valley where flooding would have been less frequent. Although the range of artifacts and artifact classes may not be broad compared to Central Texas standards, it is within the expected range for the upper Trinity River valley. More telling perhaps than the range of artifacts is the diversity and density of the features recorded at this site. The archeological features at 41TR170 tell a story of repeated occupation and use of this site between A.D. 540 and 870. In both the northern and southern portions of the site, the pattern of site-use and activities appears to have remained relatively consistent during each episode of occupation, creating a dense record of subsistence activity separated by minimal alluvial sedimentation.

The low artifact density at 41TR170 is commonly considered to be a function of the lack of accessible quality chert resources in the Trinity River basin. Still, based on the intensity of testing conducted at 41TR170, the artifact returns seem somewhat sparse even for a site in alluvial settings in the Trinity River basin. If this site represents intermittent use by people accustomed to traditions and cooking technologies more commonly associated with the Brazos River valley, the low density may instead be a function of the distance of the occupants from their residential base and their resulting curatorial behavior with regard to chipped stone resources. Alternatively, the scant nature of the artifact assemblage may have been a function of the minimal needs associated with the specific activities occurring on site during the Transitional Archaic. For instance, perhaps the particular plants or other foods that were cooked in the burned rock ovens and pit hearths at this site required little processing with stone tools, thus resulting in minimal discard.

\section{RECOMMENDATIONS}

Even though site 41TR170 and its features are interesting from a regional perspective, the site has very limited potential of making further contributions to the archeological knowledge of the region beyond what has been gathered from this intensive testing phase. For the reasons outlined above, the site does not meet the standards of Criterion D or any other significance standard required for assessing National Register eligibility. Similarly, for reasons stated above, the site is not worthy of SAL designation because it fails to meet the criteria listed under Condition 2 . Thus, site 41TR170 is considered not eligible for NRHP inclusion and no further archeological fieldwork is recommended. 


\section{REFERENCES CITED}

Anthony, D., and D. O. Brown

1994 Archaeological Investigations in the Denton Creek Floodplain. Data Recovery Excavations at 41DL270, Denton and Dallas Counties. Hicks and Company Archaeology Series 37, Austin.

Barnes, V.

1988 Geological Atlas of Texas, Dallas Sheet (Revised). Bureau of Economic Geology, University of Texas, Austin.

Bell, R. E., E. B. Jelks, and W. W. Newcomb (assemblers)

1967 A Pilot Study of Wichita Indian Archaeology and Ethnohistory. Submitted to the National Science Foundation.

Biessart, L., W. Roberson, and L. Spotts

1985 Prehistoric Archaeological Sites in Texas: A Statistical Overview. Special Report 28. Office of the State Archaeologist, Texas Historical Commission, Austin.

Black, S., L. Ellis, D. Creel, and G. T. Goode

1997 Hot Rock Cooking on the Greater Edwards Plateau: Four Burned Rock Midden Sites in West-Central Texas, Volume 2. Texas Archeological Research Laboratory Studies in Archeology 22, pp. 45-70. The University of Texas at Austin.

Blum, M. D., R. S. Toomey III, and S. Valastro, Jr.

1994 Fluvial Response to Late Quaternary Climatic and Environmental Change, Edwards Plateau, Texas. Palaeogeography, Palaeoclimatology, Palaeoecology 108:1-21.

Blum, M. D., and S. Valastro, Jr.

1994 Late Quaternary Sedimentation, Lower Colorado River, Gulf Coastal Plain of Texas: Geological Society of America Bulletin 106:1002-1016.

Boutton, T. W.

1996 Stable carbon isotope rations of soil organic matter and their use as indicators of vegetation and climate, in Boutton, T. W., and Yamasaki, S., eds., Mass Spectrometry of Soils: Marcel Dekker, Inc., New York, p. 47-82. 
Boutton, T. W., Harrison, A. T., and Smith, B. N.

1980 Distribution of biomass of species differing in photosynthetic pathway along an altitudinal transect in southeastern Wyoming grassland: Oecologia, v. 45, p. 287-298.

Brune, G.

1977 Springs of Texas, Volume I. Branch-Smith, Inc., Fort Worth.

Bruseth, J. E., and N. A. Kenmotsu

1991 Soldiers of Misfortune: The de Soto Expedition Through Texas. Heritage 9(4):1217.

Bruseth, J. E., L. M. Raab, and D. E. McGregor

1987 Late Holocene Paleoecology of the Prairie Region of Texas. In Introduction to the Richland Creek Archaeological Project: Environmental Background and Cultural Setting. Richland Creek Technical Series, Vol. 1, edited by J. E. Bruseth and R. W., Moir, pp. 29-47. Southern Methodist University, Dallas.

Bureau of Economic Geology

1972 Geologic Atlas of Texas, Dallas Sheet, 1 sheet, scale 1:250,000. Bureau of Economic Geology, Austin.

Burson, E., S. Hunt, D. Peter, and D. Shanabrook

2000 Cultural Resources Survey of the Proposed West Fork Interceptor, WF-11B, Original and Alternative Routes, Tarrant and Dallas Counties, Texas. Miscellaneous Reports of Investigations No 213. Geo-Marine, Inc. Plano.

Butler, W. B.

1987 Significance in Archaeology and Other Frustrations in the CRM Process. American Antiquity 52(4):820-829.

Caran, S. C.

2000 Geomorphology, Stratigraphy, and Implications for Cultural Resource Assessment. In Archeological Investigations along the Clear Fork of the Trinity River: Intensive Survey of the SH 121 Project; Tarrant County, Texas, by S. Seibel, J. W. Karbula, S. Dial, and R. Feit, pp. A1-A19. Archeology Series No. 74. Hicks \& Company, Inc., Austin, Texas.

Cerling, T. E., J.Quade, Y. Wang, and R. Bowman

1989 Carbon Isotopes in Soils and Palaeosols as Ecology and Palaeoecology Indicators. Nature 341:138-139.

Chipman, D. E.

1992 Spanish Texas 1519-1821. University of Texas Press, Austin.

Cliff, M. B., D. E. Peter, S. M. Hunt, D. Shanabrook, T. Carter, and V. Green

1996 Archeological Evaluation of the Harbor Pointe Site (41DL369) Dallas County, Texas. Miscellaneous Reports of Investigations Number 120. Geo-Marine, Inc., Plano, Texas. 
Cliff, M. B., D. Shanabrook, S. Hunt, W. Autin, and M.Prior

1999 Buried Archeological Site Potential in the Dallas Floodway Project Area. Miscellaneous Reports of Investigations No. 187. Geo-Marine, Inc., Plano, Texas.

Courty, M. A., P. Goldberg, and R. Macphail

1989 Soils and Micromorphology in Archaeology. Cambridge University Press, Cambridge.

Creel, D.

1991 Assessing the Relationship Between Burned Rock Midden Distribution and Archaic Subsistence in West-Central Texas. In The Burned Rock Middens of Texas: An Archeological Symposium, edited by T. R. Hester, pp. 33-44. Studies in Archeology 13. Texas Archeological Research Laboratory, The University of Texas at Austin.

1997 Chapter 5: Analysis of the Distribution of Burned Rock Midden Sites in the Study Area. In Hot Rock Cooking on the Greater Edwards Plateau: Four Burned Rock Midden Sites in West-Central Texas, Volume 1, by S. Black, L. Ellis, D. Creel, and G. T. Goode, pp. 89-99. Studies in Archeology 22. Texas Archeological Research Laboratory, The University of Texas at Austin.

Crook, W. W., Jr., and R. K. Harris

1952 Trinity Aspect of the Archaic Horizon: Carrollton and Elam Foci. Bulletin of the Texas Archeological Society 23:7-38.

Dawson, T. E., S. Mambelli, A. H. Plamboeck, P. H. Templer, and K. P. Tu

2002 Stable Isotopes in Plant Ecology. Annual Review of Ecology and Systematics 33:507-559.

Ehleringer, J. R., Cerling, T. E., Helliker, B. R.

$1997 \mathrm{C}_{4}$ Photosynthesis, Atmospheric $\mathrm{CO}_{2}$, and Climate. Oecologia 112:285-299.

Ellis, L. G.

1998 Archeological Survey Report of River Legacy Trail from near FM157 to near Loop 360, Tarrant County, Texas. Texas Department of Transportation, Environmental Affairs Division.

Fenneman, N. M.

1931 Physiography of Western United States. McGraw-Hill, New York.

1938 Physiography of Eastern United States. McGraw-Hill, New York.

Ferring, C. R.

1986 Late Quaternary Geology and Environments of the Upper Trinity Basin. In An Assessment of the Cultural Resources in the Trinity River Basin, Dallas, Tarrant, and Denton Counties, Texas, edited by B. C. Yates and C. R. Ferring, pp. 32-112. Institute of Applied Sciences, North Texas State University, Denton. 
1987 Geoarchaeology of Site 41CO141, A Late Holocene Locality in the Upper Trinity Basin, Cooke County, Texas. In Test Excavations at 41CO141, Ray Roberts Reservoir, Cooke County, Texas, edited by D. J. Prikryl and B. C. Yates, p. 19-52. Institute of Applied Sciences, North Texas State University, Denton,

1990 Late Quaternary Geology and Geoarchaeology of the Upper Trinity River Drainage Basin, Texas. Guidebook, Field Trip \#11. Geological Society of America.

Ferring, C. R., and J. A. Byers

2004 Report on an Archaeological Survey of the Eagle Mountain Connection Pipeline, Lake Benbrook Segment, Tarrant County Texas. Geoarch Consultants, Denton.

Ferring, C. R., and B. C. Yates (with contributions by H. Gill-King and K. Brown)

1997 Holocene Geoarcheology and Prehistory of the Ray Roberts Lake Area, North Central Texas. Institute of Applied Sciences, University of North Texas, Denton.

Hall, S. A.

1977 Geology and Palynology of Archaeological Sites and Associated Sediments. In The Prehistory of the Little Caney River (1976 Field Season), edited by D. O. Henry, pp. 13-41. Contributions in Archaeology 1. University of Tulsa.

1978 Late Holocene Alluvial Chronology from Northeastern Oklahoma. American Quaternary Association (AMQUA) $5^{\text {th }}$ Biennial Meeting, Abstracts p. 207. Reprinted 1978 in Oklahoma Geology Notes 38:245.

19791000 Years of Paleoclimatic History from Northeastern Oklahoma. Geological Society of America, South-Central Section, $13^{\text {th }}$ Annual Meeting, Abstracts with Programs 11(2):148. Reprinted 1979 in Oklahoma Geology Notes 39:73.

1982 Late Holocene Paleoecology of the Southern Plains. Quaternary Research 17:391407.

1988 Environment and Archaeology of the Central Osage Plains. Plains Anthropologist $33: 203-218$.

1990 Channel Trenching and Climatic Change in the Southern U.S. Great Plains. Geology 18:342-345.

Hall, S. A., and C. Lintz

1984 Buried Trees, Water Table Fluctuations, and 3000 Years of Changing Climate in West-central Oklahoma. Quaternary Research 22:129-133.

Hester, T. R. (editor)

1991 The Burned Rock Middens of Texas: An Archeological Symposium. Studies in Archeology 13. Texas Archaeological Research Laboratory, The University of Texas at Austin. 
Hill, R. T.

1901 Geography and Geology of the Black and Grand Prairies, Texas. Twenty-First Annual Report of the United States Geological Survey to the Secretary of the Interior 1899-1900. United States Geological Survey, Washington, D.C.

Hofman, J. L.

1989 Protohistoric Culture History on the Southern Great Plains. In From Clovis to Comanchero: Archeological Overview of the Southern Great Plains, by J. L. Hofman, R. L. Brooks, J. S. Hays, D. W. Owsley, R. L. Jantz, M. K. Marks, and M. H. Manhein, pp. 91-100. Research Series No. 35. Arkansas Archeological Survey, Fayetteville.

Howard, M.

1991 Burned Rock Midden Excavations, Hearths and Botanical Remains. In The Burned Rock Middens of Texas: An Archeological Symposium, edited by T. R. Hester, pp. 45-70. Studies in Archeology 13. Texas Archeological Research Laboratory, The University of Texas at Austin.

Humphrey, J. D., and C. R. Ferring

1994 Stable Isotopic Evidence for Latest Pleistocene and Holocene Climatic Change in North-central Texas. Quaternary Research 41:200-213.

Huhnke, M. H., and M. D. Wurtz

2004 Cultural Resources Assessment of Riverside Oxbow Environmental Restoration, Fort Worth, Tarrant County, Texas. Miscellaneous Reports of Investigations No. 267. Geo-Marine, Inc., Plano, Texas.

Hunt, S. M., and D. E. Peter

1997 Cultural Resources Survey of the Proposed Randol Mill Road Extension, Phase 2, City of Fort Worth, Tarrant County, Texas. Miscellaneous Reports of Investigations No. 146. Geo-Marine, Inc., Plano, Texas.

Johnson, D. L.

1989 Subsurface Stone Lines, Stone Zones, Artifact-Manuport Layers, and Biomantles Produced by Bioturbation Via Pocket Gophers (Thomomys bottae). American Antiquity 54:370-389.

1990 Biomantle Evolution and the Redistribution of Earth Materials and Artifacts. Soil Science 149:84-102.

Johnson, D. L., J. E. J. Domier, and D. N. Johnson

2005 Reflections on the Nature of Soil and its Biomantle. Annals of the Association of American Geographers 95:11-31.

Johnson, D. L., and D. N. Johnson

2004 Bioturbation by Badgers and Rodents in Producing Polygenetic and Polytemporal Desert Soil Biomantles; Soil Formation, or Soil Evolution? Geological Society of America, Annual Meeting, Abstracts with Programs 36(5):97. 
Jones, C. A.

$1985 C_{4}$ Grasses and Cereals; Growth, Development, and Stress Response. John Wiley \& Sons, New York.

Kier, R. S., L. E. Garner, and L. F. Brown

1977 Land Resources of Texas. Bureau of Economic Geology. University of Texas at Austin.

Leavitt, S. W., R. F. Follett, J. M. Kimble, and E. G. Pruessner

2007 Radiocarbon and $\delta^{13} \mathrm{C}$ Depth Profiles of Soil Organic Carbon in the U.S. Great Plains: A Possible Spatial Record of Paleoenvironment and Paleovegetation. Quaternary International 162-163:21-34.

Lebo, S. A., and K. L. Brown

1990 Archaeological Survey of the Lewisville Lake Shoreline, Denton County, Texas. Institute of Applied Sciences, University of North Texas, Denton.

Lintz, C., F. Largent, E. Burson, M. Huhnke, and S. Hunt

2004 Geomorphology and Archaeological Testing at Site 41TR174, along the Proposed West Fork Relief Interceptor WF-11B Sewer Line, Tarrant County, Texas. Miscellaneous Reports of Investigations No. 300. Geo-Marine, Inc., Plano

Lintz, C., and R. Vehik

1986 The Archaeology of Impoundment 16, Lower Clear Boggy Creek Watershed, Johnson County, Oklahoma. Archaeological Research Report No. 13. Oklahoma Conservation Commission, Oklahoma City.

Lynott, M. J.

1977 A Regional Model for Archaeological Research in North Central Texas. Ph.D. dissertation, Department of Anthropology, Southern Methodist University, Dallas.

Newcomb, Jr., W. W.

1993 Historic Indians of Central Texas. Bulletin of the Texas Archeological Society 64:163.

Nordt, L. C., T. W. Boutton, C. T. Hallmark, and M. R. Waters

1994 Late Quaternary Vegetation and Climate Changes in Central Texas Based on the Isotopic Composition of Organic Carbon. Quaternary Research 41:109-120.

Peter, D. E., and D. E. McGregor (editors)

1988 Late Holocene Prehistory of the Mountain Creek Drainage. Joe Pool Lake Archaeological Project, Volume I. Archaeology Research Program, Southern Methodist University, Dallas.

Peter, D. E., B. Ellwood, J. Schieber, and B. Yates

1987 Test Excavations of the River Bend Site (41TR68). Center for Geoarcheological Studies, University of Texas at Arlington. 
Peter, D. E., S. M. Hunt, and M. M. Green

1994 Intensive Survey of a Portion of Zoo Creek, Tarrant County, Texas. Miscellaneous Reports of Investigations No. 68. Geo-Marine, Inc., Plano, Texas.

Peter, D. E., and V. G. Clow (editors)

1999 An Archeological and Osteological Investigation of 41DL373, Spring Creek Park Preserve, Dallas County, Texas. Miscellaneous Report of Investigations No. 186. Geo-Marine, Inc., Plano, Texas.

Petermann, A.

1872 Map of Texas, Indian Territory, Louisiana, Arkansas, Missouri, Kansas. Gotha.

Pilsbry, H. A.

1946 Land Mollusca of North America (North of Mexico). Volume 2, Part 1. Academy of Natural Sciences, Philadelphia.

Prikryl, D. J.

1987 A Synthesis of Prehistory on the Lower Elm Fork of the Trinity River. Unpublished Master's thesis, University of Texas, Austin.

1990 Lower Elm Fork Prehistory: A Redefinition of Cultural Concepts and Chronologies along the Trinity River, North Central Texas. Report 37. Office of the State Archeologist, Texas Historical Commission, Austin.

Ressel, D.

1981 Soil Survey of Tarrant County, Texas. United States Department of Agriculture, Soil Conservation Service, Washington, D. C.

Retallack, G. J.

2001 Soils of the Past, an Introduction to Paleopedology. Blackwell Science, Oxford, UK.

Seibel, S., J. W. Karbula, S. Dial, and R. Feit

2000 Archaeological Investigations along the Clear Fork of the Trinity River: Intensive Survey of the SH 121 Project; Tarrant County, Texas. Archaeology Series No. 74. Hicks \& Company, Inc., Austin.

Skinner, S. A.

1971 Prehistoric Settlement of the De Cordova Bend Reservoir, Central Texas. Bulletin of the Texas Archeological Society 42:149-270.

Skinner, S. A., J. Richner, and M. Johnston

1978 Dallas Archaeological Potential: Procedures for Locating and Evaluating Prehistoric Resources. Archaeological Research Program Research Report 11. Institute for the Study of Earth and Man, Southern Methodist University, Dallas. 
Story, D. A.

1985 Adaptive Strategies of Archaic Cultures of the West Gulf Coastal Plain. In Prehistoric Food Production in North America, edited by R. I. Ford, pp. 19-56. Anthropological Papers No. 75. Museum of Anthropology, University of Michigan, Ann Arbor.

1990a Environmental Setting. In The Archeology and Bioarcheology of the Gulf Coastal Plain, vol. I., by D. A. Story, J. A. Guy, B. A. Burnett, M. D. Freeman, J. C. Rose, D. G. Steele, B. W. Olive, and K. J. Reinhard, pp. 1:5-1:26. Research Series No. 38. Arkansas Archeological Survey, Fayetteville.

$1990 \mathrm{~b}$ Cultural History of the Native Americans. In The Archeology and Bioarcheology of the Gulf Coastal Plain, vol. I, by D. A. Story, J. A. Guy, B. A. Burnett, M. D. Freeman, J. C. Rose, D. G. Steele, B. W. Olive, and K. J. Reinhard, pp. 1:163-1:366. Research Series No. 38. Arkansas Archeological Survey, Fayetteville.

Taylor, A. J.

1997 18-County Burned Rock Midden Site Distribution Study. In Hot Rock Cooking on the Greater Edwards Plateau: Four Burned Rock Midden Sites in West-Central Texas, vol. 2, by S. Black, L. Ellis, D. Creel, and G. T. Goode, pp. 45-70. Studies in Archeology 22. Texas Archeological Research Laboratory, The University of Texas at Austin.

Teeri, J. A., and Stowe, L. G.

1976 Climatic patterns and the distribution of C4 grasses in North America: Oecologia, v. 23 , p. $1-12$.

Treece, A. C.

1992 A Study of Five Annular Burned Rock Middens from the O.H. Ivie Reservoir, West Central Texas. Master's thesis, Department of Anthropology, University of Texas at Austin.

Toomey, R. S., III

1993 Late Pleistocene and Holocene Faunal and Environmental Changes at Hall's Cave, Kerr County, Texas. 2 vols. PhD. dissertation, Department of Geological Sciences, University of Texas at Austin.

Toomey, R. S., III, M. D. Blum, and S. Valastro, Jr.

1993 Late Quaternary Climate and Environments of the Edwards Plateau, Texas. Global and Planetary Change 7:299-320.

Turner E. S., and T. R. Hester

1999 A Field Guide to Stone Artifacts of Texas Indians. Gulf Publishing, Houston.

Waller, S. S., and J. K. Lewis

1979 Occurrence of $\mathrm{C}_{3}$ and $\mathrm{C}_{4}$ Photosynthetic Pathways in North American Grasses: Journal of Range Management 32:12-28. 
Waters, M. R., and L. C. Nordt

1995 Late Quaternary Floodplain History of the Brazos River in East-central Texas: Quaternary Research 43:311-319.

Werdman, C.

1969 Arlington, Texas . . . Youngest City-Oldest History. Werdman Publications, Arlington, Texas.

Yates, B. C., and C. R. Ferring (editors)

1986 An Assessment of the Cultural Resources in the Trinity River Basin, Dallas, Tarrant, and Denton Counties, Texas. Institute of Applied Sciences, North Texas State University, Denton. Submitted to the U.S. Army Corps of Engineers, Fort Worth District.

Wyckoff, D. G.

1984 The Foragers: Eastern Oklahoma. In Prehistory of Oklahoma, edited by R. Bell. Academic Press, Inc., Orlando.

Wyckoff, D. G., and R. Brooks

1983 Oklahoma Archaeology: A 1981 Perspective. Archaeological Resource Survey Report 16. Oklahoma Archaeological Survey, Norman. 

APPENDIX A

ARTIFACTS NOTED FROM MONITORING MECHANICALLY DUG TRENCHES 



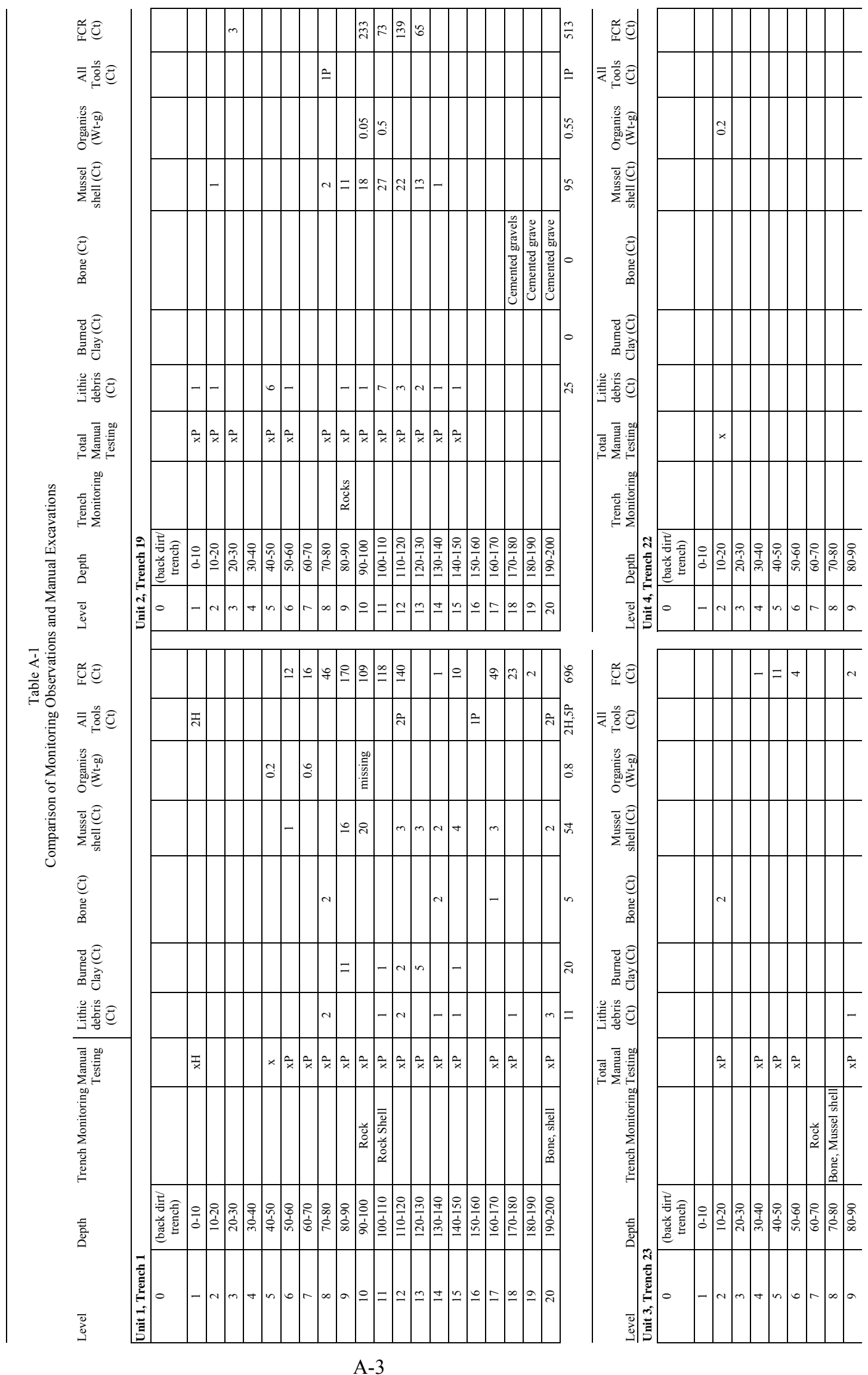




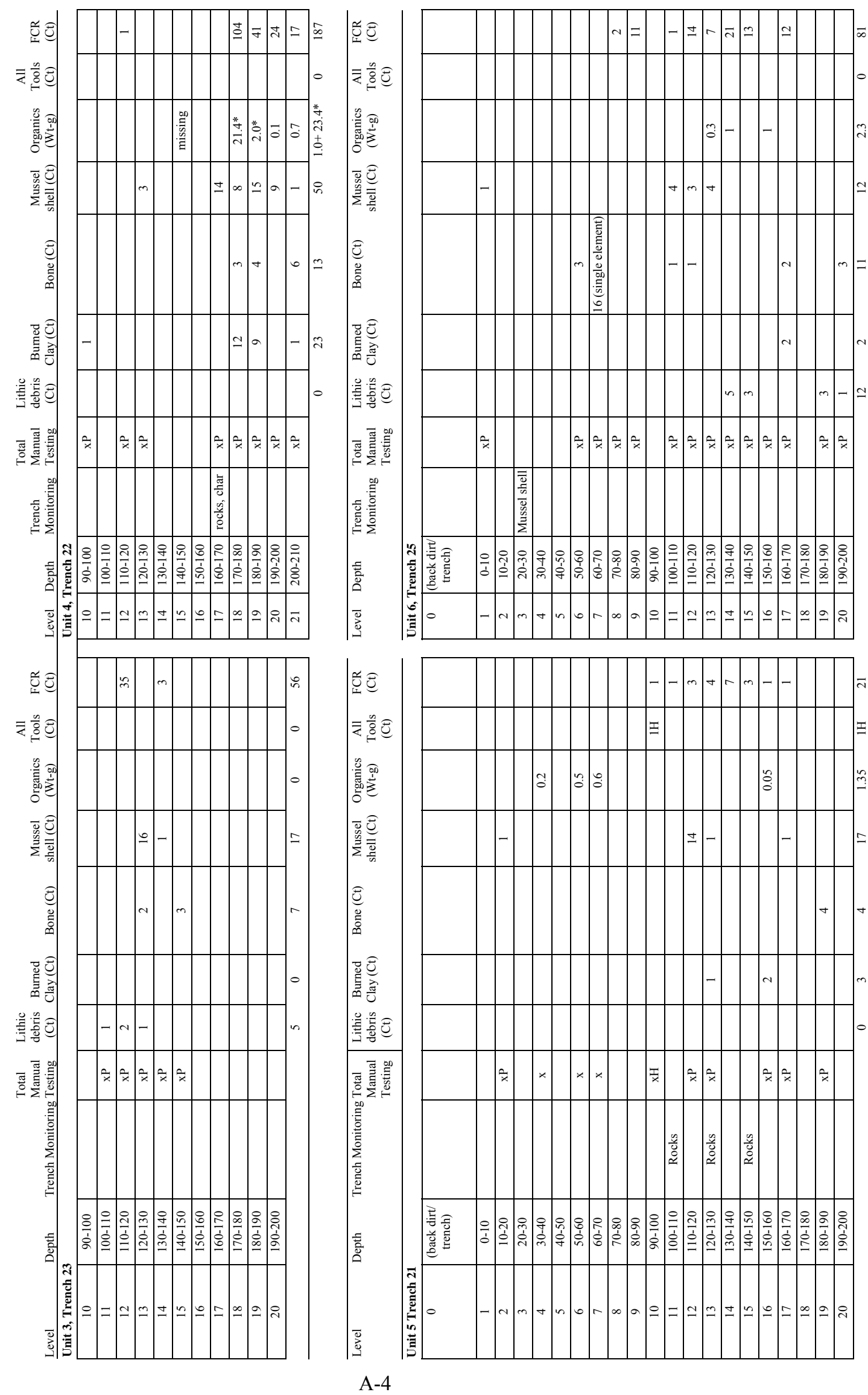




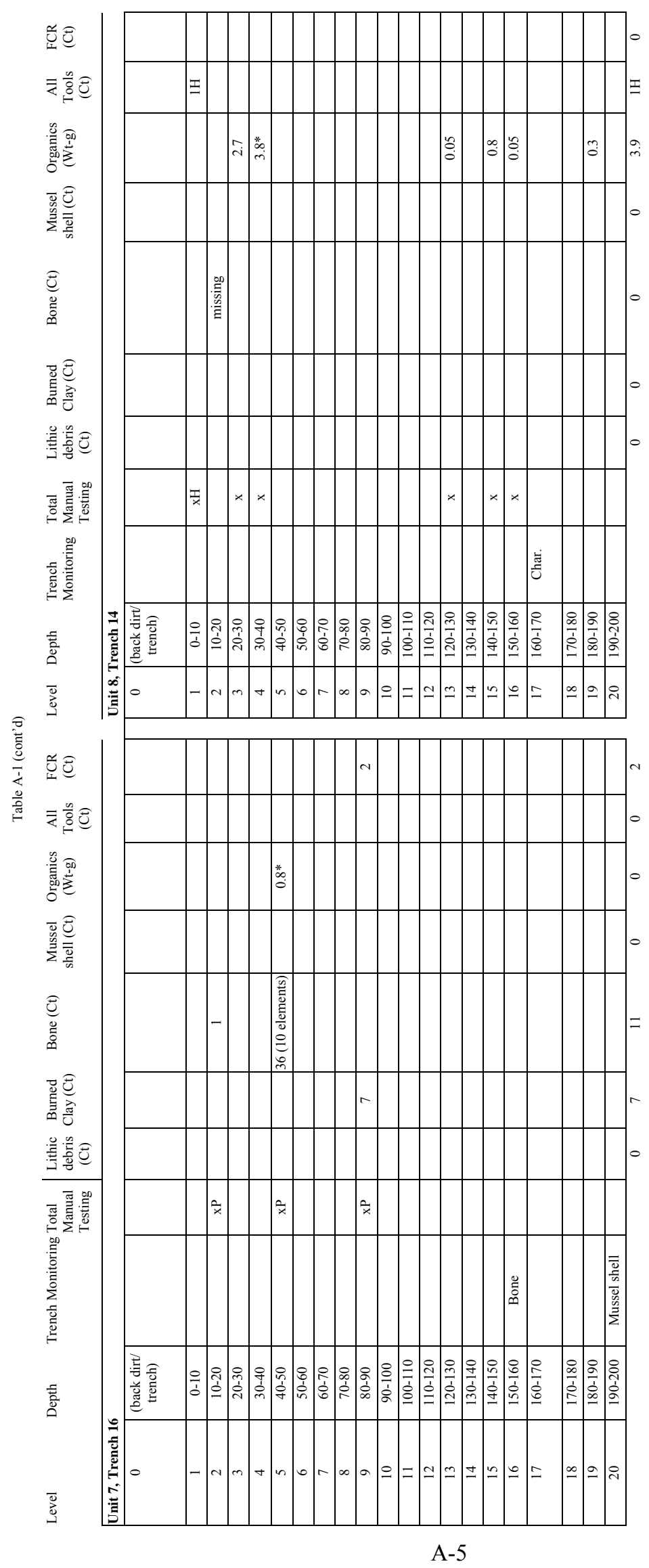



APPENDIX B

ARTIFACT COUNTS FROM DEEP MANUALLY DUG TEST UNITS 



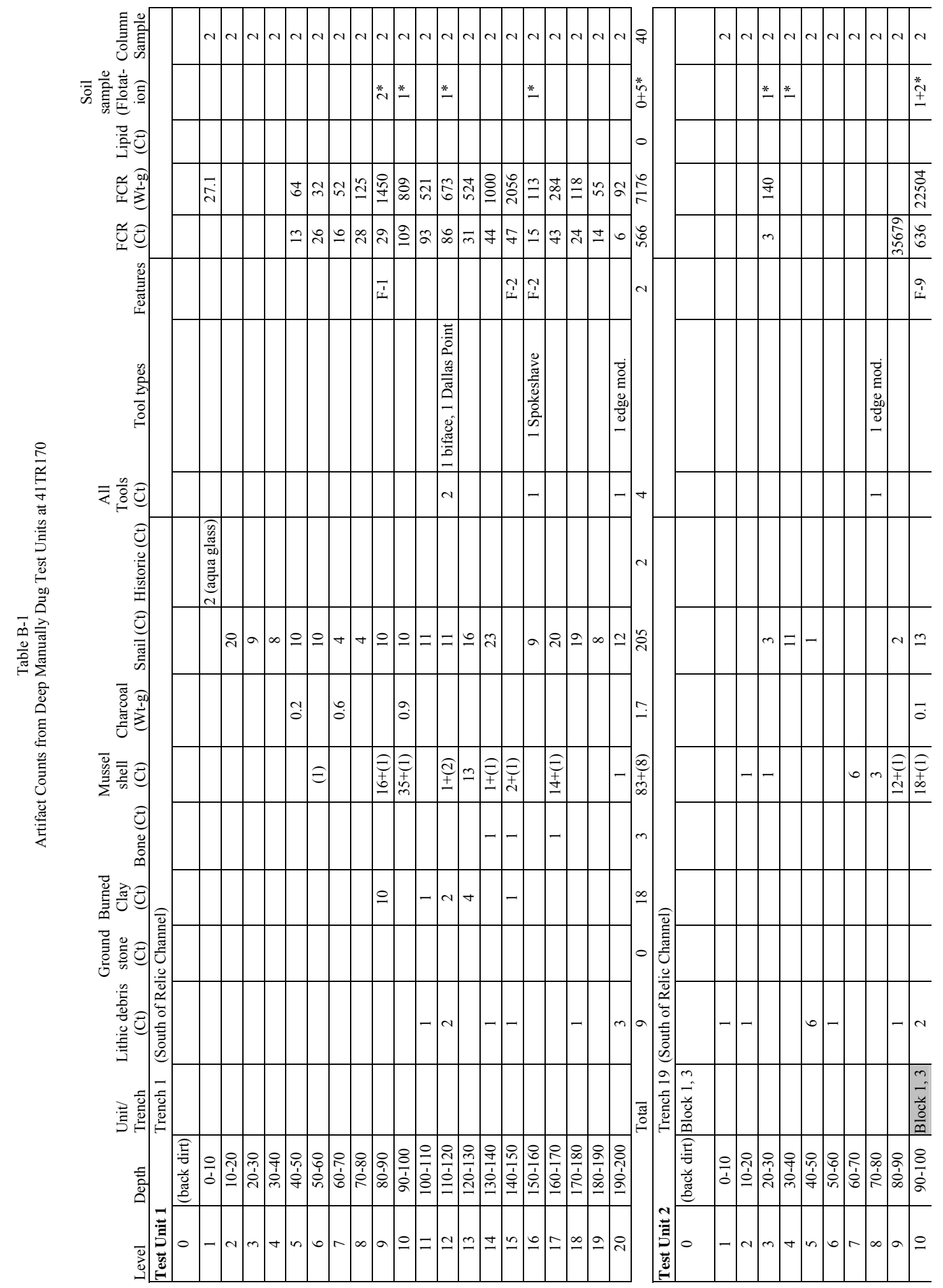

B-3 


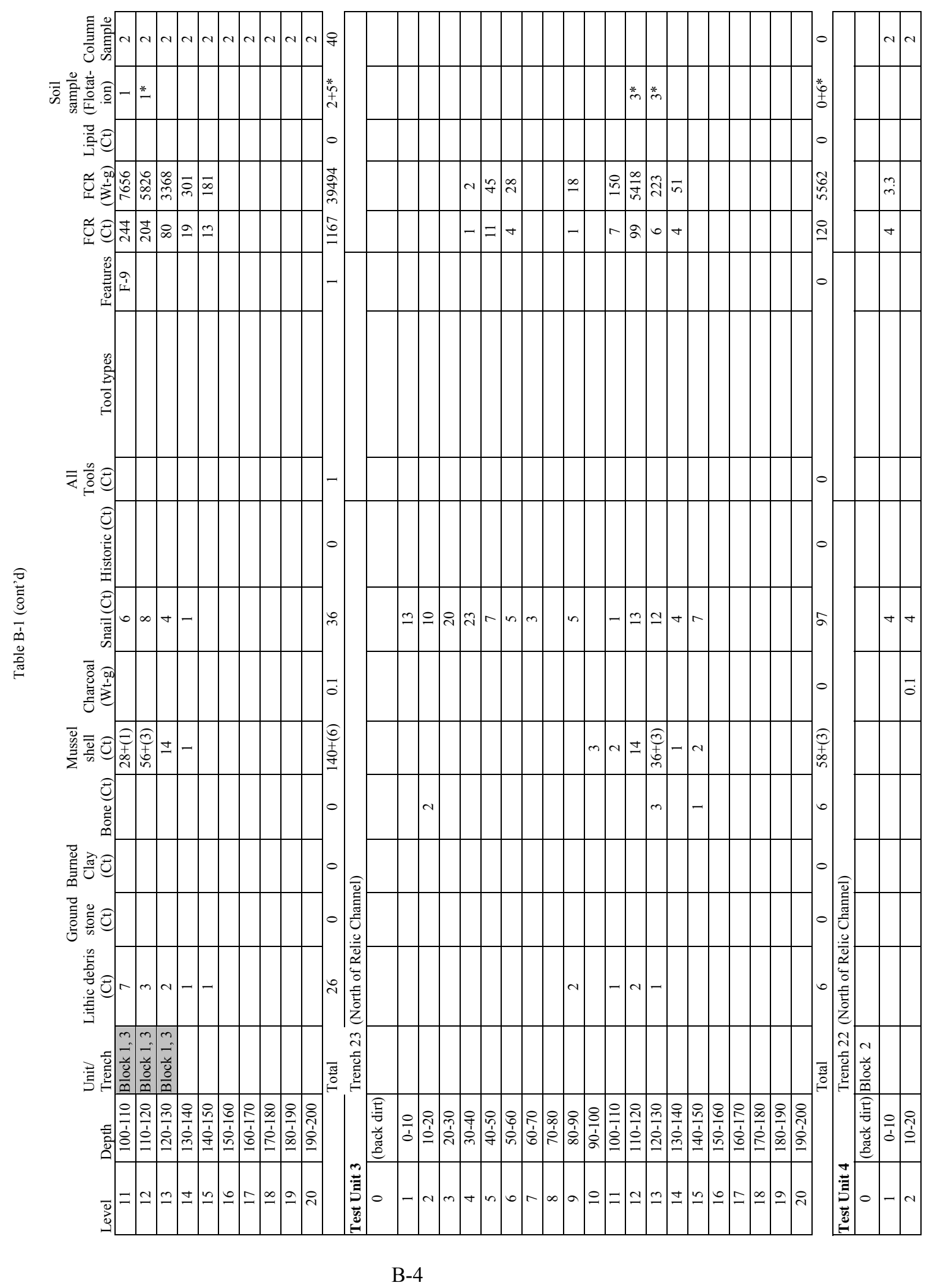




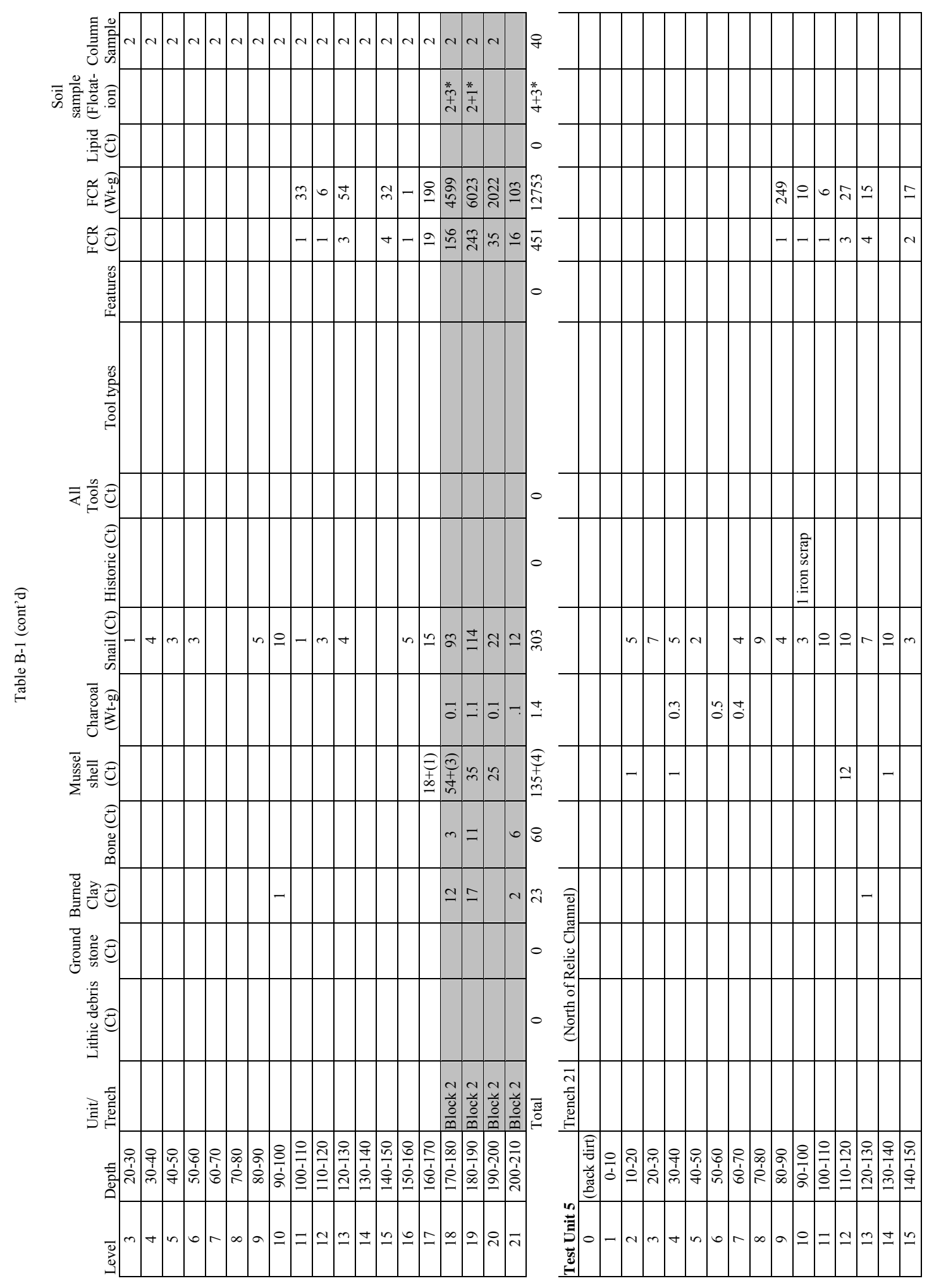

B-5 


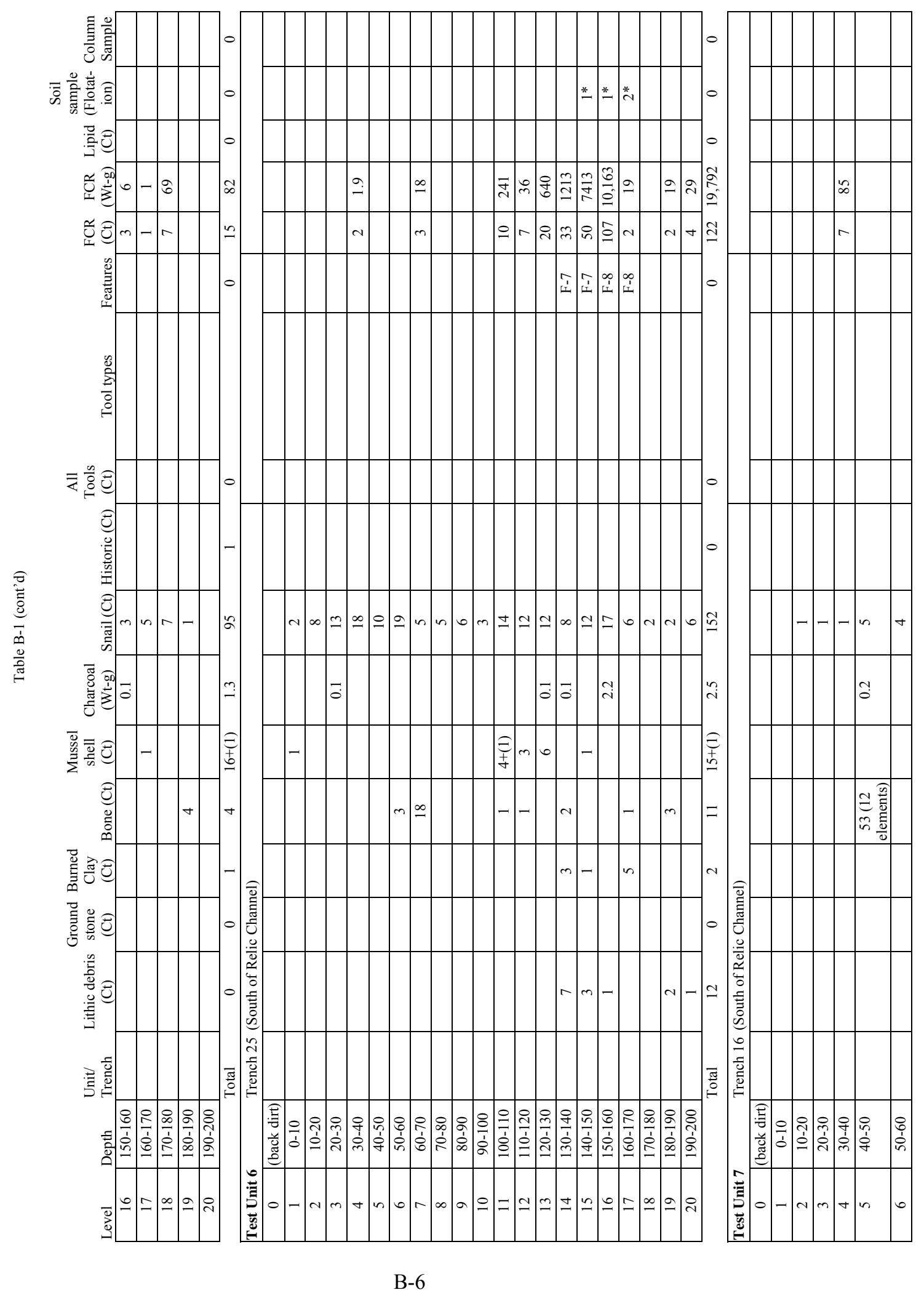




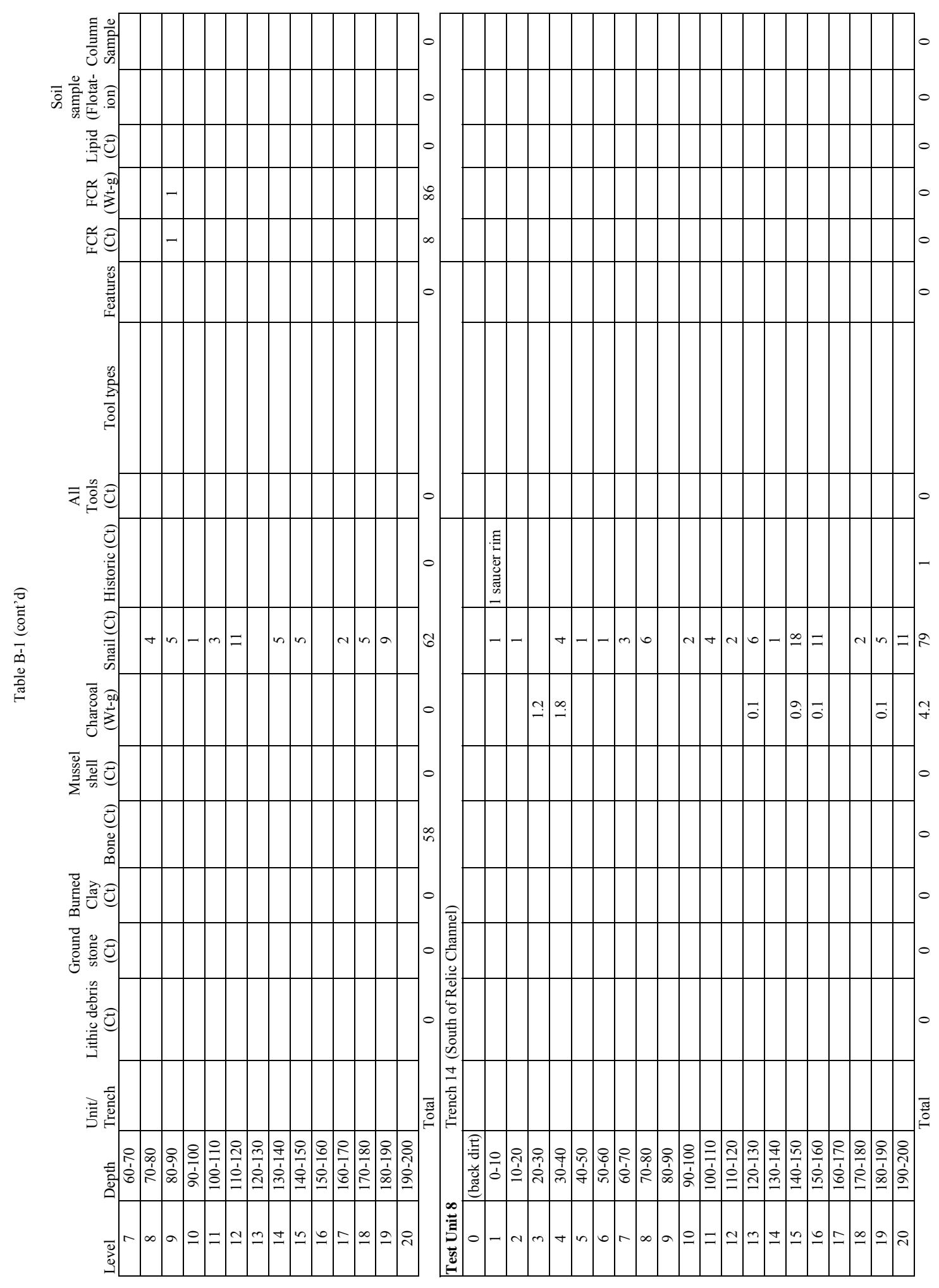

B-7 


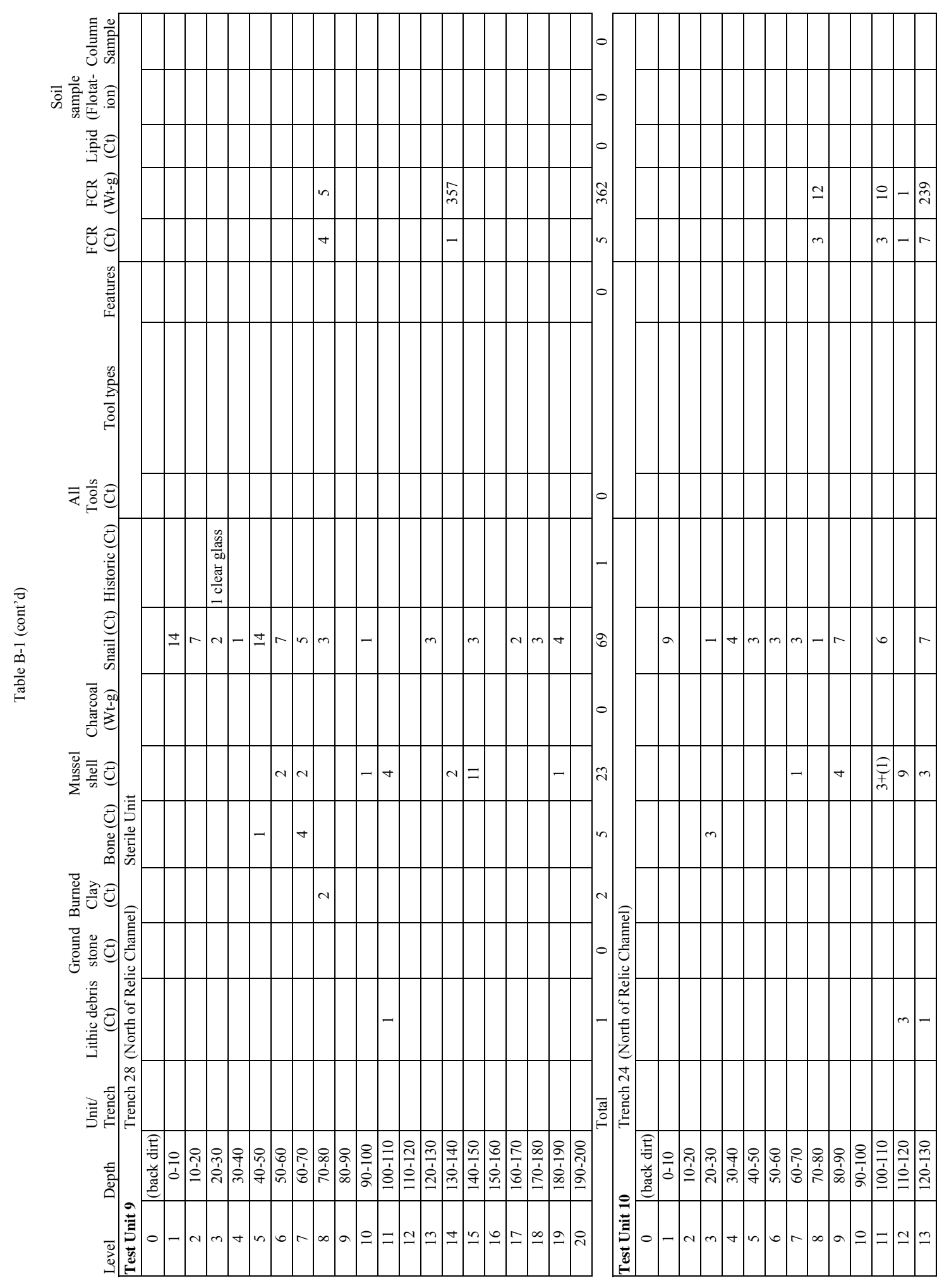

B-8 


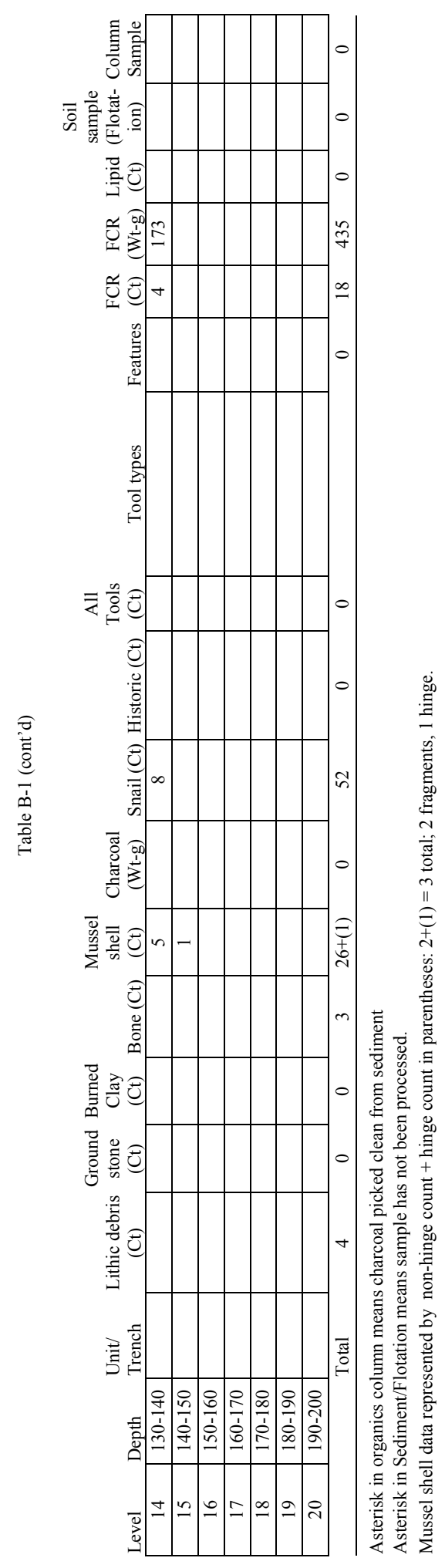

B-9 

APPENDIX C

ARTIFACTS FROM BLOCK 1 



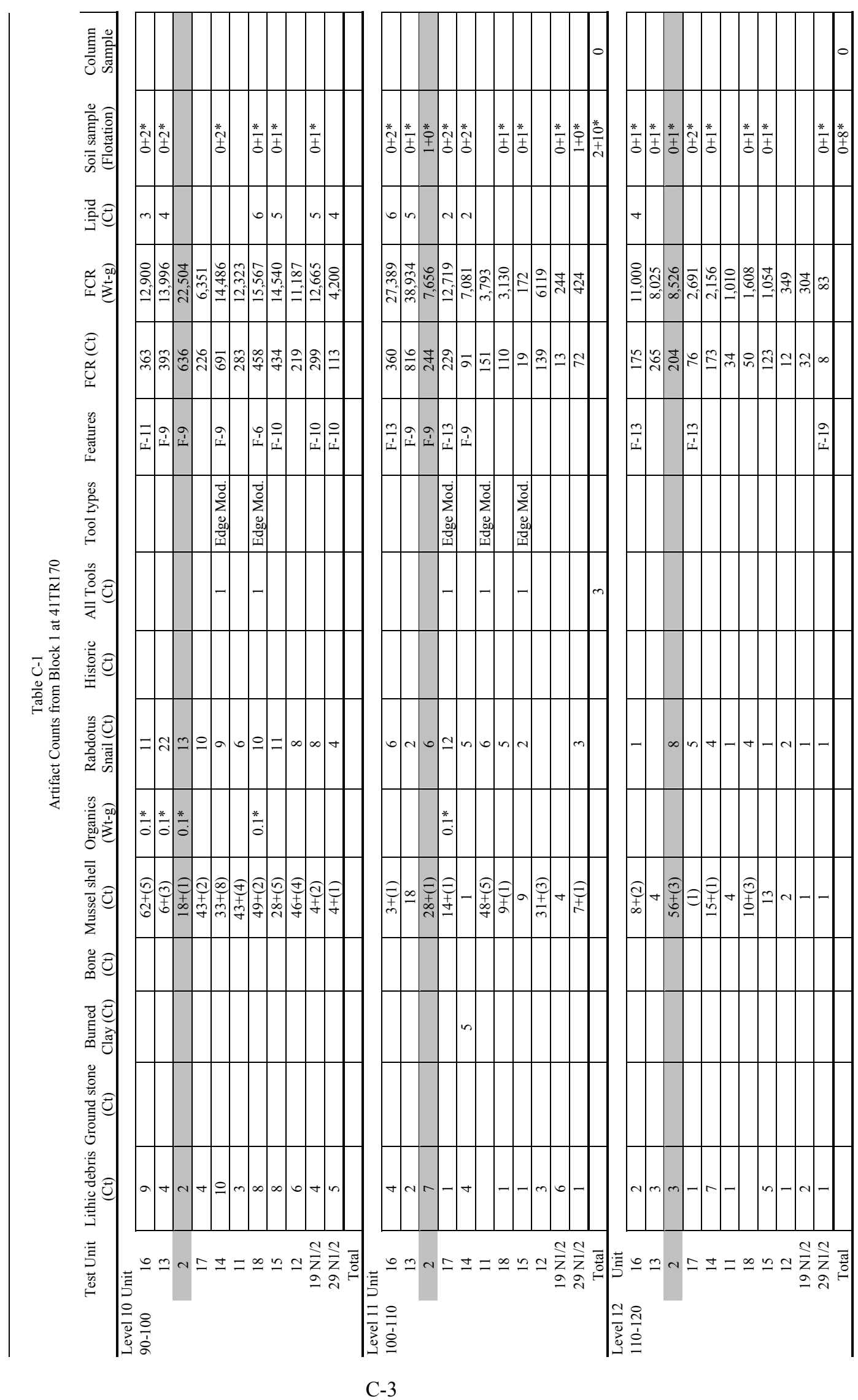




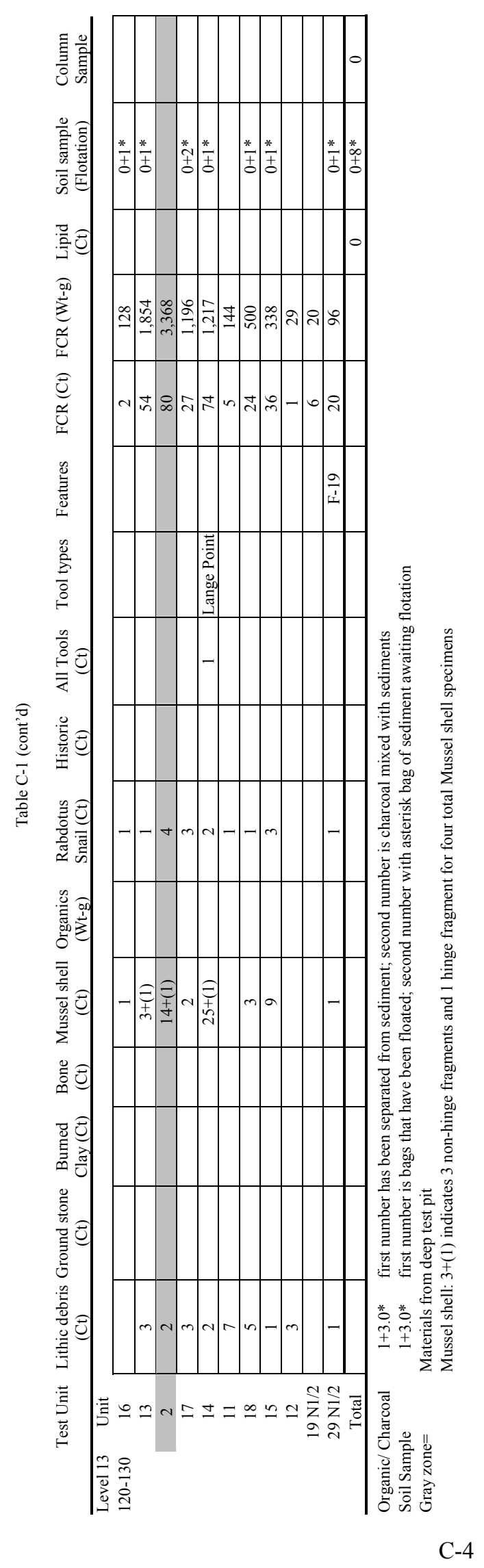


APPENDIX D

ARTIFACTS FROM BLOCK 2 



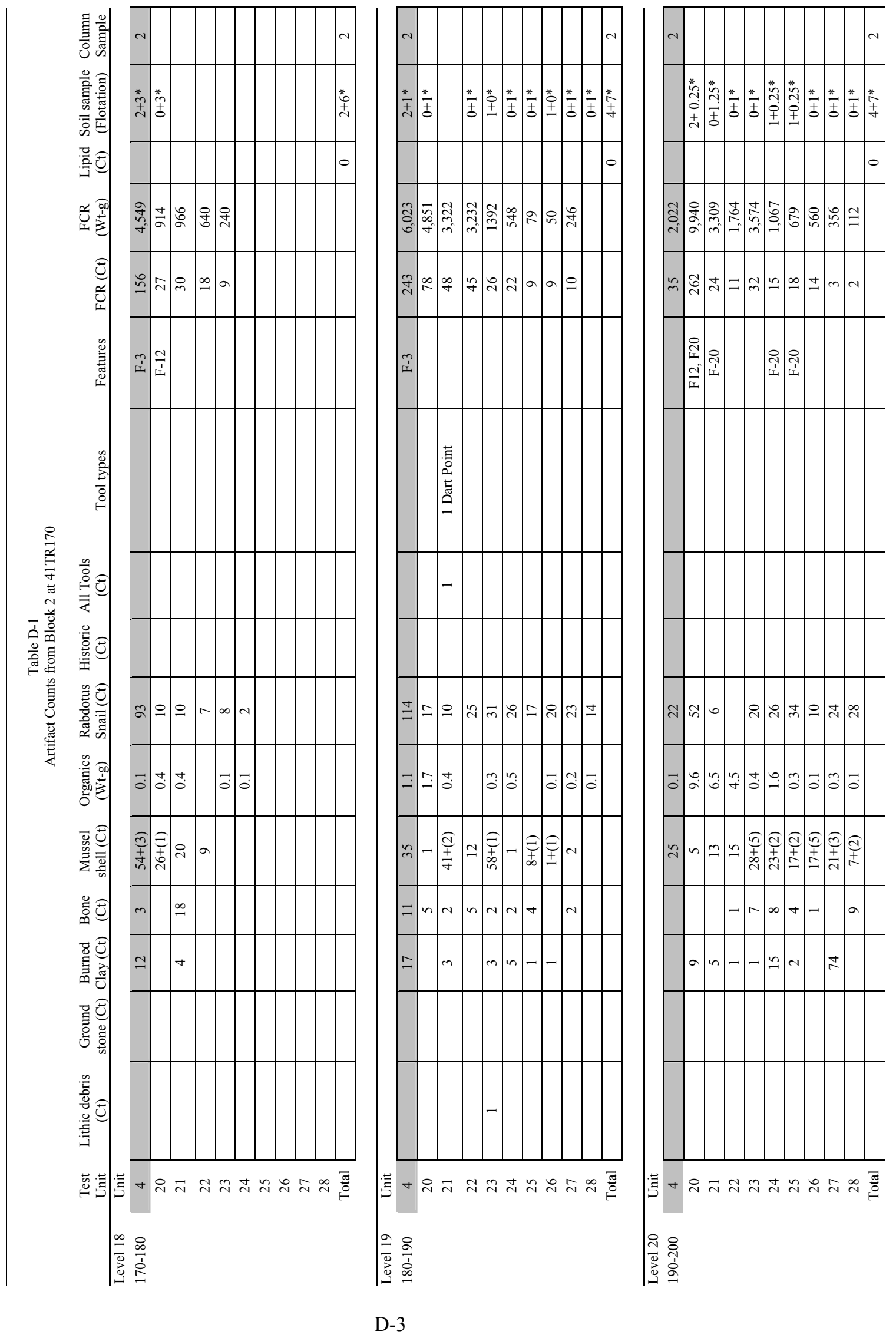




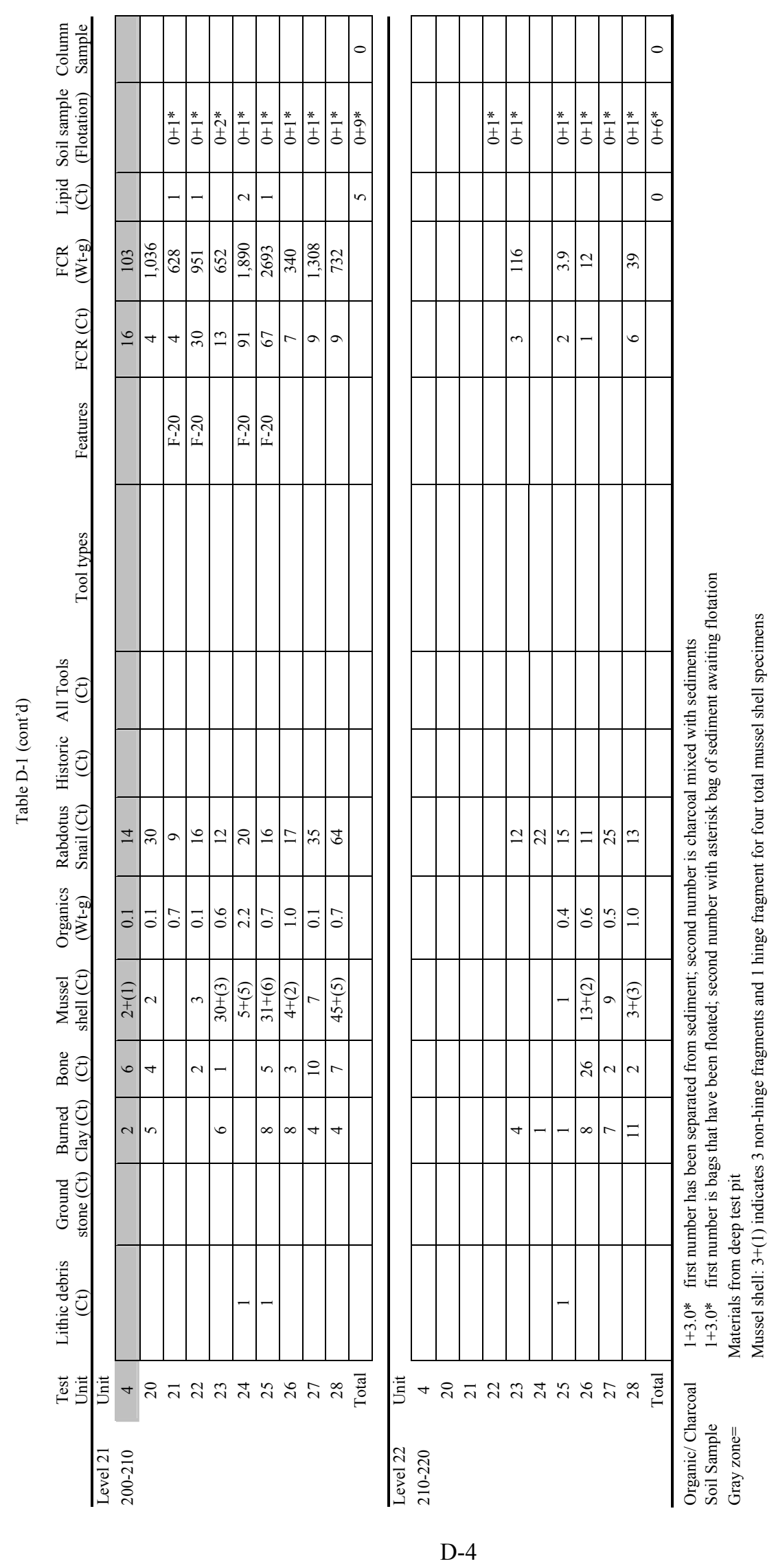


APPENDIX E

ARTIFACTS FROM BLOCK 3 



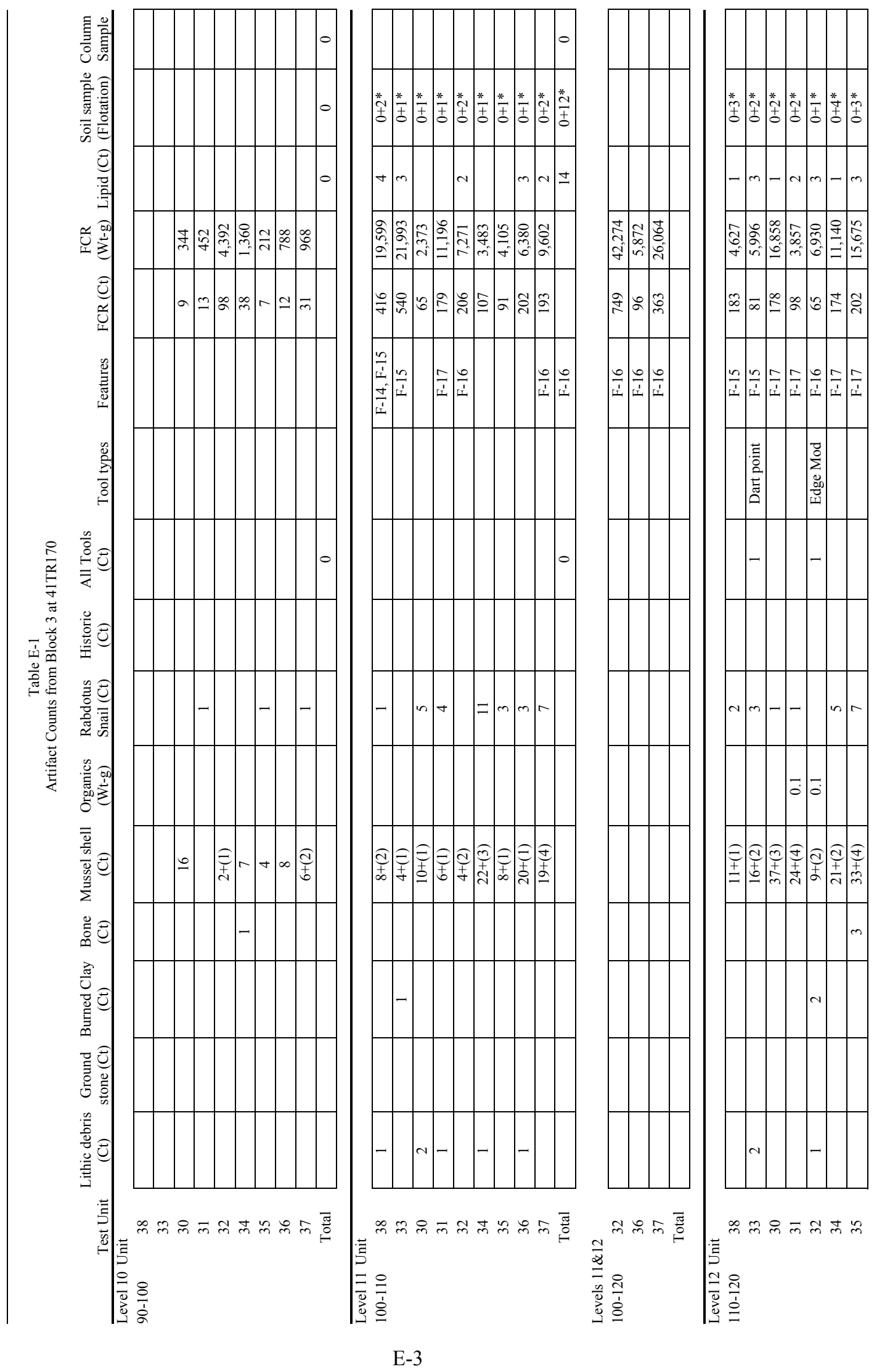




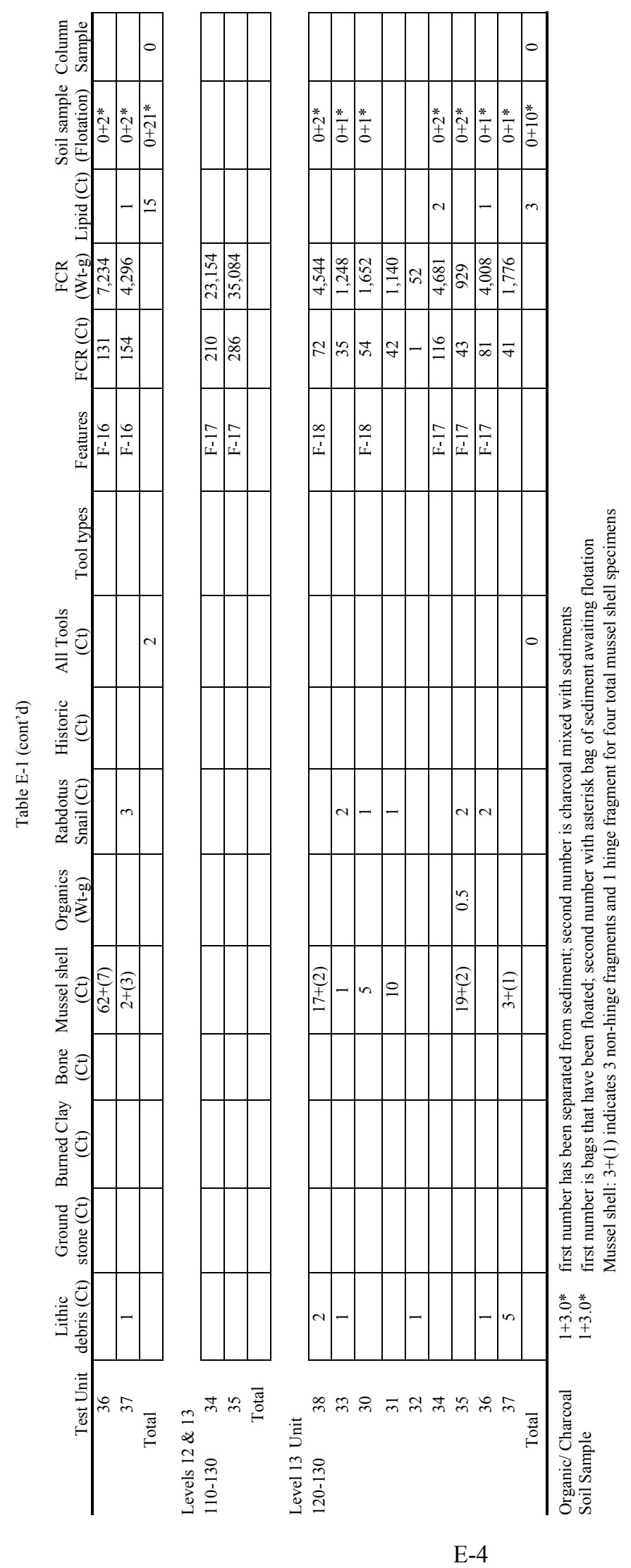




\section{APPENDIX F \\ FEASIBILITY STUDY OF MACROBOTANICAL PRESERVATION AND IDENTIFICATION FROM SITE $41 T R 170$ \\ by \\ Dr. Phil Dering \\ Shumla Archeobotanical Services}



Fifteen flotation samples totaling 71.5-liters were examined in this study. The flotation effort averaged 4.8 liters-per-sample. The samples were recovered from seven features and an ashy occupation zone located in two excavation blocks.

\section{LABORATORY METHODS}

Flotation. Flotation is the process by which organic remains, primarily charred plant fragments, are recovered from archeological sediments using water as the separating agent. The samples from 41TR170 were processed using a simple continuous flow device and a $0.0375 \mathrm{~mm}$ mesh collection screen. The heavy material, consisting of large clasts, some bone, and occasionally heartwood charcoal or nut charcoal, falls to the bottom of the bucket, and the lighter material, including most of the plant material, both carbonized and uncarbonized, floats to the surface and flows into the collection screen. This floating material is called the light fraction. The material that sinks to the bottom, termed the heavy fraction, is rinsed into a 1-mm stainless steel screen. Both fractions are tagged and slowly dried before they are examined in the laboratory. Flotation recovery was tested in two samples using 50 poppy seeds, and 96 percent of the poppy seeds were recovered.

Laboratory Procedures. The analysis follows standard archeobotanical laboratory procedures. The light fraction of each flotation sample is passed through a nested set of screens of 4-mm, 2$\mathrm{mm}, 1-\mathrm{mm}$, and $0.450-\mathrm{mm}$ mesh and examined for charred material that is separated for identification. Carbonized wood from the $4 \mathrm{~mm}$ and $2 \mathrm{~mm}$ screens (smaller pieces are seldom identifiable) is separated in a 25-piece grab sample and identified. Care is taken to select representative materials from both levels (cf. Diehl 2003:213; Huckell 2002:645; Miksicek 1994:243). If the sample contains more than 25 fragments, instead of providing counts, I scan the material, separate it into categories, and record the volume and weight of each taxon or type.

Charred material caught on all of the sieve levels, including the bottom pan, is scanned for floral parts, fruits, seeds, and other potentially edible plant parts such as nut or maize fragments, and these plant parts are counted and examined for identification.

Disturbance Indicators. Sample content may be affected by various physical and biological disturbance factors, including insect or small mammal activity, and plant root growth. In an effort to assess this impact, the amount of roots, insect parts, termite pellets, gastropods, rodent fecal pellets, and other biological material is estimated. These amounts are reported on a scale of 1-25 (+), 25-50 (++), and over $50(+++)$.

Identification. Due to the rapid decomposition of plant material in soils, only carbonized seeds and wood fragments are considered to be a part of the archeological sample. Identification of carbonized wood is accomplished by using the snap technique, examining the transverse, radial, and tangential surfaces at 8 to 45 power with a binocular dissecting microscope, and comparing the material to reference specimens in the Shumla Archeobotanical Services herbarium. The anatomy of some woods is so similar that identification to species or even genus is not possible. For this reason I combine some taxa into wood types. All identifications in the "type" category represent identifications to the taxon level indicated by the name of the type. For example, small walnut (Juglans sp.) or hickory/pecan (Carya spp.) wood fragments may be indistinguishable. These are placed in a more general category, walnut family-type (Juglandaceae). 
Generally speaking, there are three types of nuts that grow in Trinity River valley, hickory nuts (Carya spp.), pecans (Carya illinoiensis), and walnuts (Juglans nigra). Many of the charred nut fragments found in archeological samples consist of the hardened pericarp, commonly called the nut-shell. These small fragments are often difficult to separate into species, and instead are placed in a type, usually designated thin-nut and thick-nut. Thin nuts resemble pecan pericarps, and thick nuts resemble either hickory or walnut pericarps. Although the identification is not as precise as a species-level identification, thin nut fragments are most likely pecan fragments.

\section{RESULTS AND DISCUSSION}

The analysis is summarized in Tables F-1 and F-2. The overview in Table F-1 presents flotation sample volume, seed density, seed taxa abundance, and disturbance indicators. Table F-2 presents the identifications and counts of charred plant material recovered from the flotation samples.

As noted in Table F-1, modern contaminants, primarily roots, were found in abundant quantities in all of the flotation samples. Roots were present in all of the samples, and gastropods occurred in eight of the samples. Uncarbonized seeds were observed in three of the samples. The abundance of roots and uncarbonized seeds indicates that the deposits were affected by plant growth and animal burrowing activity.

Charcoal weights were low, varying from a maximum of 1.9-g in FS 471 from the western half of Feature 12, to six samples that had no charcoal. Charcoal weight totaled approximately $3.8 \mathrm{~g}$ for all samples. The majority of the charred material was wood charcoal. All of the identified material was recovered from the $2 \mathrm{~mm}$ and $1 \mathrm{~mm}$ screens, an indication that the assemblage was greatly reduced in size as well as quantity. Although overall charcoal recovery was low, carbonized nut fragments were recovered from FS 576.

Wood. Three wood types and the indeterminate category were noted in the samples. Identified wood types were the walnut/hickory type (Juglandaceae), oak (Quercus sp.), and hackberry (Celtis sp.). Walnut/hickory-type wood charcoal may be walnut, hickory, or pecan wood. The walnut/hickory type fragments from the flotation samples were too small to identify to the genus level. Walnuts, hickories, hackberries and oaks are trees that would have been growing in the Trinity River valley during the occupation of site 41TR170.

Nuts. Nut fragments were recovered from FS 576 in the ashy occupation zone in Block 2, between 190-200 cm below the surface and 2-meters from Feature 12, which was located in the same level. The recovery of pecan fragments from an occupation zone with a significant quantity of ash and daub suggests that pecan was harvested and processed during the occupation, and some shells were incidentally introduced into hearths nearby. The fragments were part of a thin pericarp or nut shell fragment discarded during processing. Repeated use and cleaning of hearths spread the ashy zone across the occupation surface.

Nuts were probably harvested, consumed, and stores in large quantities along the Trinity River bottoms. However, unlike hickory, pecan is not recovered in very large quantities from archeological sites, probably because pecan does not need to be boiled to extract the oils and nut meat from the shell. The processes that are involved in pecan harvesting and consumption do not encourage charring, one of the factors that may contribute to the under-representation of pecan in the archeological record (Hall 2003:108). 
Table F-1

Summary of Preserved Plant Remains from 15 Flotation Samples at 41TR170

\begin{tabular}{|c|c|c|c|c|c|c|c|c|c|c|c|}
\hline Lot \#/ FS \# & Feature & Unit & $\begin{array}{c}\text { Depth } \\
\text { (cm bs) } \\
\text { Level }\end{array}$ & 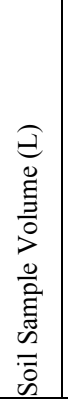 & 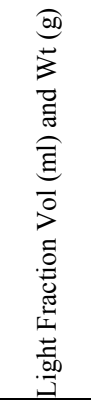 & 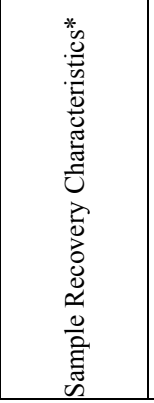 & 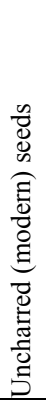 & 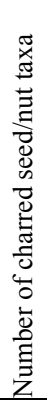 & 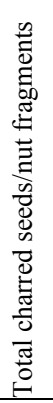 & 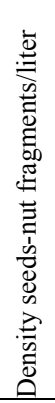 & 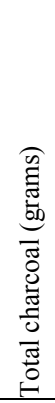 \\
\hline \multicolumn{12}{|c|}{ Block 1 Flotation Summary } \\
\hline Lot 342/ FS 407 & Feature 9 & Unit 13 & $100-110$ & 5.0 & $32 / 6.1$ & $\mathrm{r}+++, \mathrm{g}++$ & 2 & 0 & 0 & 0 & -- \\
\hline Lot 393/ FS 356 & Feature 11 & Unit $16, \mathrm{~N} 1 / 2$ & $90-100$ & 5.0 & $3 / .2$ & $\mathrm{r}++, \mathrm{ip}+$ & 0 & 0 & 0 & 0 & -- \\
\hline Lot 405/ FS 464 & Feature 13 & Unit $16, \mathrm{E} 1 / 2$ & $110-120$ & 5.0 & $24 / 4.2$ & $\mathrm{r}+++, \mathrm{g}++$ & 0 & 0 & 0 & 0 & -- \\
\hline Lot 423 / FS 484 & Feature 13 & Unit $17, \mathrm{E} 1 / 2$ & $110-120$ & 3.5 & $16 / 2.3$ & $\mathrm{r}+++$ & 0 & 0 & 0 & 0 & 0.5 \\
\hline \multicolumn{12}{|c|}{ Block 2 Flotation Summary } \\
\hline Lot 464/ FS 470 & Feature $12, \mathrm{E} 1 / 2$ & Unit 20, E1/2 & $190-200$ & 5.0 & $15 / 2.6$ & $\mathrm{R}++$ & 0 & 0 & 0 & 0 & 0.6 \\
\hline Lot 465/ FS 471 & Feature 12, W 1/2 & Unit $20, \mathrm{~W} 1 / 2$ & $190-200$ & 5.0 & $23 / 3.2$ & $\mathrm{R}++$ & 0 & 0 & 0 & 0 & 1.9 \\
\hline Lot $487 /$ FS 618 & Feature $20, \mathrm{~W} 1 / 2$ & Units 21, 24, & $200-210$ & 5.0 & $18 / 1.7$ & $\mathrm{r}+++, \mathrm{g}+++$ & 0 & 0 & 0 & 0 & 0.2 \\
\hline Lot 499/ FS 619 & Feature $20, \mathrm{E} 1 / 2$ & Units 22,25 & $200-210$ & 5.0 & $29 / 4.8$ & $\mathrm{r}++, \mathrm{g}+++$ & 0 & 0 & 0 & 0 & 0.1 \\
\hline Lot 479/ FS 469 & General Ashy Zone & Unit 21, SW 1/4 & $190-200$ & 5.0 & $45 / 7.7$ & $\mathrm{r}+++, \mathrm{g}+++$ & 3 & 0 & 0 & 0 & 0.2 \\
\hline Lot 562/ FS 576 & General Ashy Zone & Unit $26, \mathrm{SW} 1 / 4$ & $190-200$ & 5.0 & $5 / 0.8$ & $\mathrm{r}+++, \mathrm{g}++$ & 0 & 1 & 4 & 0.8 & 0.1 \\
\hline Lot 569/ FS 629 & General Ashy Zone & Unit 26, SW 1/4 & $210-220$ & 5.0 & $16 / 3.8$ & $\mathrm{r}+++, \mathrm{g}+++$ & 1 & 0 & 0 & 0 & 0.2 \\
\hline \multicolumn{12}{|c|}{ Block 3 Flotation Summary } \\
\hline Lot 694/ FS 654 & $\begin{array}{l}\text { Feature } 16 \text { (discard } \\
\text { ring) }\end{array}$ & Unit 36 & $110-120$ & 5.0 & $15 / 3.9$ & $\mathrm{r}+++, \mathrm{g}++$ & 0 & 0 & 0 & 0 & -- \\
\hline Lot 631/ FS 662 & $\begin{array}{l}\text { Feature } 16 \text { (discard } \\
\text { ring) }\end{array}$ & Unit 32 & $100-110$ & 5.0 & $22 / 2.3$ & $\mathrm{r}+++, \mathrm{ip}+$ & 0 & 0 & 0 & 0 & $<.1$ \\
\hline Lot 662/ FS 680 & Feature 17 (oven) & Unit $34 \mathrm{~S} 1 / 2$ & $110-120$ & 3.0 & $8 / 1.3$ & $\mathrm{r}+++, \mathrm{g}++$ & 0 & 0 & 0 & 0 & -- \\
\hline $\begin{array}{l}\text { Lot } 613 / \text { FS } 706 \\
\& \text { Lot } 624 / \text { FS } \\
707\end{array}$ & Feature 17 (oven) & Unit 30,31 & $110-120$ & 5.0 & $22 / 2.8$ & $\mathrm{r}+++$ & 0 & 0 & 0 & 0 & $<.1$ \\
\hline \multicolumn{4}{|c|}{ Total Volume } & 71.5 & & & & & & & \\
\hline
\end{tabular}

* Key to Sample Recovery Characteristics

$\mathrm{g}=$ gastropods; $\mathrm{r}=$ roots; ip $=$ insect parts

Frequency as Disturbance indicators $(+=1-25, \quad++=26-50, \quad+++=$ over 50$)$

Consequently, despite its remarkable potential as a food resource, the use of pecan is not documented at many sites in Texas. Pecan fragments have been recovered from sites in Central Texas from the Kyle site in Hill County and from Bird Point Island in north-central Texas (Fritz 1987; Jelks 1962). Additionally, pecan has been noted in a few Woodland and Caddo sites in northeast Texas (Dering 1992; 1993; 1995).

There are only scattered ethnohistoric references to pecan, primarily because the Spanish writers did not often distinguish the types of nuts they were observing. Hall (2003:106-108) has assembled most of these observations, and he reiterates the difficulty in distinguishing nut types from accounts related in the journals kept by the Spanish observers. Cabeza de Vaca noted the collection of nuts along rivers of the Texas coastal plain. These can be identified as pecan 
Table F-2

Identified Charred Plant Contents from Flotation Samples from Site 41TR170

\begin{tabular}{|c|c|c|c|c|c|c|c|c|c|}
\hline $\begin{array}{c}\text { Catalog Lot and } \\
\text { FS \# }\end{array}$ & Feature & Excavation Unit & $\begin{array}{c}\text { Depth } \\
\text { (cm bs) } \\
\text { Level }\end{array}$ & Plant Taxon & $\begin{array}{l}\text { Common } \\
\text { Name }\end{array}$ & $\begin{array}{c}\text { Plant } \\
\text { Part }\end{array}$ & Count & $\begin{array}{l}\text { Vol } \\
(\mathrm{ml})\end{array}$ & $\begin{array}{c}\text { Weight } \\
(\mathrm{g})\end{array}$ \\
\hline \multicolumn{10}{|c|}{ Block 1 Macrobotanical Samples } \\
\hline Lot 342/ FS 407 & F-9 & Unit 13 & $100-110$ & \multicolumn{3}{|c|}{ No identifiable plant remains } & -- & -- & -- \\
\hline Lot 393/ FS 356 & F-11 & Unit $16, \mathrm{~N} 1 / 2$ & $90-100$ & \multicolumn{3}{|c|}{ No identifiable plant remains } & -- & -- & -- \\
\hline Lot 405/ FS 464 & F- 13 & Unit $16 \mathrm{E} 1 / 2$ & $110-120$ & \multicolumn{3}{|c|}{ No identifiable plant remains } & -- & -- & -- \\
\hline Lot $423 /$ FS 484 & F- 13 & Unit $17 \mathrm{E} 1 / 2$ & $110-120$ & Quercus sp. & Oak & Wood & 19 & -- & 0.2 \\
\hline Lot 423/ FS 484 & F- 13 & Unit $17 \mathrm{E} 1 / 2$ & $110-120$ & Juglandaceae & Hickory-type & Wood & 4 & -- & $<0.1$ \\
\hline Lot 423 / FS 484 & F- 13 & Unit $17 \mathrm{E} 1 / 2$ & $110-120$ & Indeterminate & NA & Wood & 25 & -- & 0.3 \\
\hline \multicolumn{10}{|c|}{ Block 2 Macrobotanical Samples } \\
\hline Lot 464/FS 470 & F-12 & Unit 20, E1/2 & $190-200$ & Indeterminate & NA & Wood & $25+$ & 2 & 0.5 \\
\hline Lot 464/FS 470 & F-12 & Unit 20, E1/2 & $190-200$ & Juglandaceae & Hickory-type & Wood & 4 & - & $<0.1$ \\
\hline Lot 464/ FS 470 & F-12 & Unit 20, E1/2 & $190-200$ & Indeterminate & $\mathrm{NA}$ & Twig & 1 & - & $<0.1$ \\
\hline Lot 465/ FS 471 & F-12 & Unit $20, \mathrm{~W} 1 / 2$ & $190-200$ & Juglandaceae & Hickory-type & Wood & 12 & -- & 0.3 \\
\hline Lot 465/ FS 471 & F-12 & Unit 20, W1/2 & $190-200$ & Quercus sp. & Oak & Wood & 25 & -- & 1.2 \\
\hline Lot 465/ FS 471 & F-12 & Unit 20, W1/2 & $190-200$ & Indeterminate & $\mathrm{NA}$ & Wood & $25+$ & 2 & 0.4 \\
\hline Lot 487/ FS 618 & $\mathrm{~F}-20 \mathrm{~W} 1 / 2$ & Units 21,24 , & $200-210$ & Indeterminate & NA & Wood & 5 & -- & $<0.1$ \\
\hline Lot 487/ FS 618 & F-20 W1/2 & Units 21, 24, & $200-210$ & Quercus sp. & Oak & Wood & 12 & -- & 0.2 \\
\hline Lot 499/ FS 619 & F-20 E1/2 & Units 22,25 & $200-210$ & Indeterminate & $\mathrm{NA}$ & Wood & 16 & -- & $<0.1$ \\
\hline Lot 499/ FS 619 & F-20 E1/2 & Units 22,25 & $200-210$ & Juglandaceae & Hickory-type & Wood & 15 & -- & 0.1 \\
\hline Lot 479/ FS 469 & Ashy zone & Unit $21 \mathrm{SW} 1 / 4$ & $190-200$ & Indeterminate & NA & Bark & 4 & -- & 0.1 \\
\hline Lot 479/ FS 469 & Ashy zone & Unit $21 \mathrm{SW} 1 / 4$ & $190-200$ & Juglandaceae & Hickory-type & Wood & $25+$ & 2 & 0.1 \\
\hline Lot 562/ FS 576 & Ashy zone & Unit $26 \mathrm{SW} 1 / 4$ & $190-200$ & Indeterminate & NA & Wood & 25 & -- & $<0.1$ \\
\hline Lot $562 /$ FS 576 & Ashy zone & Unit $26 \mathrm{SW} 1 / 4$ & $190-200$ & Juglandaceae & Hickory-type & Wood & 15 & -- & 0.1 \\
\hline Lot 562/ FS 576 & Ashy zone & Unit $26 \mathrm{SW} 1 / 4$ & $190-200$ & Carya sp. & $\begin{array}{l}\text { Thin Hickory } \\
\text { (cf. pecan) }\end{array}$ & Nut & 4 & -- & $<0.1$ \\
\hline Lot 569/ FS 629 & Ashy zone & Unit $26 \mathrm{SW} 1 / 4$ & $210-220$ & Juglandaceae & Hickory-type & Wood & 4 & -- & 0.1 \\
\hline Lot 569/ FS 629 & Ashy zone & Unit $26 \mathrm{SW} 1 / 4$ & $210-220$ & Celtis sp. & Hackberry & Wood & 22 & -- & 0.2 \\
\hline Lot 569/ FS 629 & Ashy zone & Unit $26 \mathrm{SW} 1 / 4$ & $210-220$ & Indeterminate & $\mathrm{NA}$ & Twig & 1 & -- & $<0.1$ \\
\hline \multicolumn{10}{|c|}{ Block 3 Macrobotanical Samples } \\
\hline Lot 694/ FS 654 & F-16 & Unit $36 \mathrm{~W} 1 / 2$ & $110-120$ & \multicolumn{3}{|c|}{ No identifiable plant remains } & -- & -- & -- \\
\hline Lot 631/ FS 662 & F-16 & Unit 32 & $100-110$ & Indeterminate & NA & Wood & 5 & -- & $<0.1$ \\
\hline Lot $631 /$ FS 662 & F-16 & Unit 32 & $100-110$ & Indeterminate & NA & Twig & 3 & -- & $<0.1$ \\
\hline Lot 662/ FS 680 & F-17 & Unit $34 \mathrm{~S} 1 / 2$ & $110-120$ & \multicolumn{3}{|c|}{ No identifiable plant remains } & -- & - & -- \\
\hline \begin{tabular}{|c|} 
Lot $613 /$ FS $706 \&$ \\
Lot $624 /$ FS 707
\end{tabular} & F-17 & Units 30,31 & $110-120$ & Indeterminate & NA & Twig & 2 & -- & $<.1$ \\
\hline
\end{tabular}

because pecan trees dominate the overstory of the rivers on the central and upper Texas coast, and because Cabeza de Vaca states that they produce only every other year (Covey 1983 [1961]:69). The Mendoza-Lopez expedition of 1683-4 also encountered pecans at the western edge of their distribution, probably on the Middle Concho River and to the east near the Tom Green and Concho County line (Wade 2003:106-7; 113). Along the Middle Concho River, the Spaniards were accompanied by Jumanos or Piros who presumably shared in the pecan feast, although the account of pecan utilization is not very clear. In 1709 Fray Isidro Espinosa encountered Native Americans with pecans in April, noting that they collected them, shelled them, and kept them throughout the year for consumption (Tous 1930:10-11). Both Hall (2003:107) and Campbell (1975:18) note that these were Payaya, and the area was most likely the Medina River south of San Antonio. Most significant is Espinosa's description of processing; they simply shelled the 
pecans and kept the nutmeat in bags, or on strings. This is clearly not a process that involves the use of fire or the rendering of fat from the nut. Pecan cotyledons (the nut meat) are so large that they are easily separated from the shell and consumed outright or mixed into other foods. During a later expedition around 1720, Espinosa noted that the Caddo in northeastern Texas collected a small, thick-shelled hickory nut and also a thin-shelled nut, clearly a reference to pecan (Hatcher 1927:153).

\section{CONCLUSIONS}

The 15 flotation samples examined in this study contained three wood charcoal types and pecan nut fragments. Charred plant remains from all samples weighed just $3.8 \mathrm{~g}$, a rather low total weight. Wood types, including walnut family (Juglandaceae), hackberry, and oak, are typical elements of riparian vegetation in northern Texas. Pecan fragments were recovered from FS 571, one of the few examples from an archeological site in northern Texas. The fragments were recovered about 2-meters from the nearest heating feature, from an occupation zone with ash and daub. This may indicate that pecan was harvested at the site and introduced into the deposits as background refuse not associated specifically with any feature described during the excavations.

The energy potential for pecan in the prehistoric economy has been demonstrated by Hall (2003) who also noted that dense pecan along many rivers in Texas may have had a profound effect on social and subsistence organization in prehistory. Despite this recognized potential, the use of pecan is not documented very well in the archeological record. Part of the problem may be under-representation due to the lack of burning associated with pecan processing, but it also may be due to the lack of research and recovery in the areas where pecan groves are dominant. Examples from the Kyle Site (Jelks 1962) and Baker Cave (Chadderdon 1983) indicate that uncarbonized pecans are recovered in substantial quantities from sheltered sites near stands of pecan. Continued excavation and recovery of botanical materials from open sites should help to fill the gap in our understanding of prehistoric subsistence resources and organization. 



\section{REFERENCES CITED}

Adams, K

1994 Macrobotanical Analyses. In, The Roosevelt Rural Sites Study: Changing Land Use in the Tonto Basin, Volume 3, edited by Richard Ciolek-Torello and John R. Welch, pp. 167-188. Statistical Research Technical Series No. 28. Tucson, Arizona.

Covey, C. (translator)

1983 Adventures in the Unknown Interior of America, translated and edited by Cyclone. University of New Mexico Press. [reprint of 1961 edition published by CrowellCollier Publishing].

Campbell, T. N.

1975 The Payaya Indians of Southern Texas. Special Publication No. 1, Southern Texas Archaeological Association. San Antonio, Texas.

Chadderdon, $\mathrm{M}$.

1983 Baker Cave, Val Verde County, Texas: The 1976 Excavations. Special Report 13, The Center for Archaeological Research, The University of Texas at San Antonio. San Antonio, Texas.

1992 Analysis of Macrobotanical Remains from 41DT11, 41DT21, 41DT63. In: Archeological Investigations at 41DT11, 41DT21, 41DT50, 41DT54, and 41DT63, at Cooper Lake, Delta County, Texas, by E. Gadus, R.C. Fields, and C. B. Bousman, pp. 115-119. Reports of Investigations 86, Prewitt and Associates, Inc. Austin, Texas.

1993 Macrobotanical Analysis of Samples from Four Woodland and Caddoan Period Sites in the Cooper Late Area of the Upper Sulfur River. In Excavations at the Tick, Spike, Johns Creek, and Peerless Bottoms Sites, Cooper Lake Project, Delta and Hopkins Counties, Texas, by R.C. Fields, E. F. Gadus, L. W. Klement, C. B. Bousman, and J. B. McLerran, pp. 337-355. Reports of Investigations 91, Prewitt and Associates, Inc. Consulting Archeologists. 
1995 Analysis of Archaeobotanical Remains. In Archaeology of 41MX5: A Late Prehistoric Caddoan Hamlet in Morris County, Texas, by R. L. Brewington, J. Dockall, and H. J. Shafer, pp. 147-154. Reports of Investigations 1, Center for Environmental Archaeology. Texas A\&M University. College Station, Texas.

Diehl, M.

2003 Prehistoric Subsistence Strategies and the Macrobotanical Assemblage. In Hohokam Farming on the Salt River Floodplain, edited by T. Kathleen Henderson, pp. 211-230. Anthropological Papers No. 42, Center for Desert Archaeology. Tucson, Arizona. Anthropological Papers No. 9. Pueblo Grande Museum. Phoenix, Arizona.

Fritz, G.

1987 Analysis of Carbonized Macrobotanical Remains. In The Bird Point Island and Adams Ranch Sites. Richland Creek Technical Series, Volume II, Archaeology Research Program, Institute for the Study of Earth and Man, Southern Methodist University. Dallas, Texas.

1993 Archeobotanical Evidence from the Cobb-Pool Site, A Late Prehistoric Farmstead in Dallas County, Texas. Bulletin of the Texas Archeological Society 64:227-245.

Hall, G.

2003 Pecan Food Potential in Prehistoric North America. Economic Botany 54:103-112.

Hatcher, M. A. (translator)

1927 Descriptions of the Tejas or Asinai Indians, 1691-1722. Translated from Spanish by Mattie Austin. Southwestern Historical Quarterly 31: pp.150-180.

Huckell, L.

2002 Paleoethnobotany. In Tonto Creek Archaeological Project Artifact and Environmental Analyses. Volume 2: Stone Tool and Subsistence Studies, ed. Jeffery J. Clark, pp. 643-709. Anthropological Papers No. 23. Center for Desert Archaeology. Tucson, Arizona.

Jelks, E. B.

1962 The Kyle Site: A Stratified Central Texas Aspect Site in Hill County, Texas. Archaeology Series 5. Department of Anthropology, The University of Texas at Austin.

Kwiatkowski, S.

1992 The Rye Creek Flotation and Macrobotanical Analyses. In The Rye Creek Project: Archaeology in the Upper Tonto Basin. Volume 2: Artifact and Specific Analyses, pp. 325-375. Anthropological Papers No. 11. Center for Desert Archaeology, Tucson, Arizona. 
Miksicek, C.

1994 Deceptive Barrenness: Archaeobotanical Material from the Schuk Toak Project Area. In Archaeological Studies of the Avra Valley, Arizona: Excavations in the Schuk Toak District. Vol 2. Scientific Studies and Interpretations, ed. by Allen Dart, pp. 243-266. Anthropological Papers No. 16. Center for Desert Archaeology. Tucson.

Tous, G. C. (translator)

1930 The Espinosa-Olivares-Aguirre Expedition of 1709: Espinosa's Diary. Preliminary Studies of the Texas Catholic Historical Society I (3):1-14.

Wade, $\mathrm{M}$.

2003 The Native Americans of the Texas Edwards Plateau. University of Texas Press. Austin, Texas. 



\section{APPENDIX G}

\section{FEASIBILITY STUDY OF LIPID RESIDUES ON BURNED ROCK FROM SITE 41TR170}

by

M. E. Malainey. Ph.D.

11 Mager Drive West

Winnipeg, MB

Canada R2M 0R9 



\section{INTRODUCTION}

A total of six burned rock samples were submitted for analysis. Subsamples were taken, then exterior surfaces were ground off to remove any contaminants. Samples were powdered and absorbed lipids were extracted with organic solvents. Fatty acid components of the lipid extracts were analyzed using gas chromatography. Residues were identified using criteria developed from the decomposition patterns of experimental residues. The first section of this report outlines the development of the identification criteria. Following this, analytical procedures and results are presented.

\section{FATTY ACIDS AND DEVELOPMENT OF THE IDENTIFICATION CRITERIA}

\section{Introduction and Previous Research}

Fatty acids are the major constituents of fats and oils (lipids) and occur in nature as triglycerides, consisting of three fatty acids attached to a glycerol molecule by ester-linkages. The shorthand convention for designating fatty acids, $\mathrm{Cx}$ : $\mathrm{y \omega z}$, contains three components. The " $\mathrm{Cx}$ " refers to a fatty acid with a carbon chain length of $x$ number of atoms. The " $y$ " represents the number of double bonds or points of unsaturation, and the " $\omega z$ " indicates the location of the most distal double bond on the carbon chain, i.e. closest to the methyl end. Thus, the fatty acid expressed as C18:1 $\omega 9$, refers to a mono-unsaturated isomer with a chain length of 18 carbon atoms with a single double bond located nine carbons from the methyl end of the chain. Similarly, the shorthand designation, C16:0, refers to a saturated fatty acid with a chain length of 16 carbons.

Their insolubility in water and relative abundance compared to other classes of lipids, such as sterols and waxes, make fatty acids suitable for residue analysis. Since employed by Condamin et al. (1976), gas chromatography has been used extensively to analyze the fatty acid component of absorbed archaeological residues. The composition of uncooked plants and animals provides important baseline information, but it is not possible to directly compare modern uncooked plants and animals with highly degraded archaeological residues. Unsaturated fatty acids, which are found widely in fish and plants, decompose more readily than saturated fatty acids, sterols or waxes. In the course of decomposition, simple addition reactions might occur at points of unsaturation (Solomons 1980) or peroxidation might lead to the formation of a variety of volatile and nonvolatile products which continue to degrade (Frankel 1991). Peroxidation occurs most readily in fatty acids with more than one point of unsaturation.

Attempts have been made to identify archaeological residues using criteria that discriminate uncooked foods (Marchbanks 1989; Skibo 1992; Loy 1994). Marchbanks' (1989) percent of saturated fatty acids $(\% \mathrm{~S})$ criteria has been applied to residues from a variety of materials including pottery, stone tools and burned rocks (Marchbanks 1989; Marchbanks and Quigg 1990; Collins et al. 1990). Skibo (1992:89) could not apply the \%S technique and instead used two ratios of fatty acids, $\mathrm{C} 18: 0 / \mathrm{C} 16: 0$ and $\mathrm{C} 18: 1 / \mathrm{C} 16: 0$. He (1992) reported that it was possible to link the uncooked foods with residues extracted from modern cooking pots actively used to prepare one type of food; however, the ratios could not identify food mixtures. The utility of these ratios did not extend to residues extracted from archaeological potsherds because the ratios of the major fatty acids in the residue changed with decomposition (Skibo 1992:97). Loy (1994) proposed the use of a Saturation Index (SI), determined by the ratio: $\mathrm{SI}=1$ - 
[(C18:1+C18:2)/C12:0+C14:0+C16:0+C18:0)]. He (1994) admitted, however, that poorly understood decompositional changes to the original suite of fatty acids make it difficult to develop criteria for distinguishing animal and plant fatty acid profiles in archaeological residues.

The major drawback of the distinguishing ratios proposed by Marchbanks (1989), Skibo (1992) and Loy (1994) is they have never been empirically tested. The proposed ratios are based on criteria that discriminate food classes on the basis of their original fatty acid composition. The resistance of these criteria to the effects of decompositional changes has not been demonstrated. Rather, Skibo (1992) found his fatty acid ratio criteria could not be used to identify highly decomposed archaeological samples.

In order to identify a fatty acid ratio unaffected by degradation processes, Patrick et al. (1985) simulated the long-term decomposition of one sample and monitored the resulting changes. An experimental cooking residue of seal was prepared and degraded in order to identify a stable fatty acid ratio. Patrick et al. (1985) found that the ratio of two C18:1 isomers, oleic and vaccenic, did not change with decomposition; this fatty acid ratio was then used to identify an archaeological vessel residue as seal. While the fatty acid composition of uncooked foods must be known, Patrick et al. (1985) showed that the effects of cooking and decomposition over long periods of time on the fatty acids must also be understood.

\section{Development of the Identification Criteria}

As the first stage in developing the identification criteria used herein, the fatty acid compositions of more than 130 uncooked Native food plants and animals from Western Canada were determined using gas chromatography (Malainey 1997; Malainey et al. 1999a). When the fatty acid compositions of modern food plants and animals were subject to cluster and principal component analyses, the resultant groupings generally corresponded to divisions that exist in nature (Table G-1). Clear differences in the fatty acid composition of large mammal fat, large herbivore meat, fish, plant roots, greens and berries/seeds/nuts were detected, but the fatty acid composition of meat from medium-sized mammals resembles berries/seeds/nuts.

Samples in cluster A, the large mammal and fish cluster had elevated levels of C16:0 and C18:1 (see Table G-1). Divisions within this cluster stemmed from the very high level of C18:1 isomers in fat, high levels of C18:0 in bison and deer meat and high levels of very long chain unsaturated fatty acids (VLCU) in fish. Differences in the fatty acid composition of plant roots, greens and berries/seeds/nuts reflect the amounts of $\mathrm{C} 18: 2$ and $\mathrm{C} 18: 3 \omega 3$ present. The berry, seed, nut and small mammal meat samples appearing in cluster B have very high levels of C18:2, ranging from 35 percent to 64 percent (see Table G-1). Samples in subclusters V, VI and VII have levels of C18:1 isomers from 29 percent to 51 percent, as well. Plant roots, plant greens and some berries appear in cluster $\mathrm{C}$. All cluster $\mathrm{C}$ samples have moderately high levels of C18:2; except for the berries in subcluster XII, levels of C16:0 are also elevated. Higher levels of C18:3 103 and/or very long chain saturated fatty acids (VLCS) are also common except in the roots, which form subcluster XV.

Secondly, the effects of cooking and degradation over time on fatty acid compositions were examined. Originally, 19 modern residues of plants and animals from the plains, parkland and forests of Western Canada were prepared by cooking samples of meats, fish and plants, alone or combined, in replica vessels over an open fire (Malainey 1997; Malainey et al. 1999b). After four days at room temperature, the vessels were broken and a set of sherds analysed to determine 


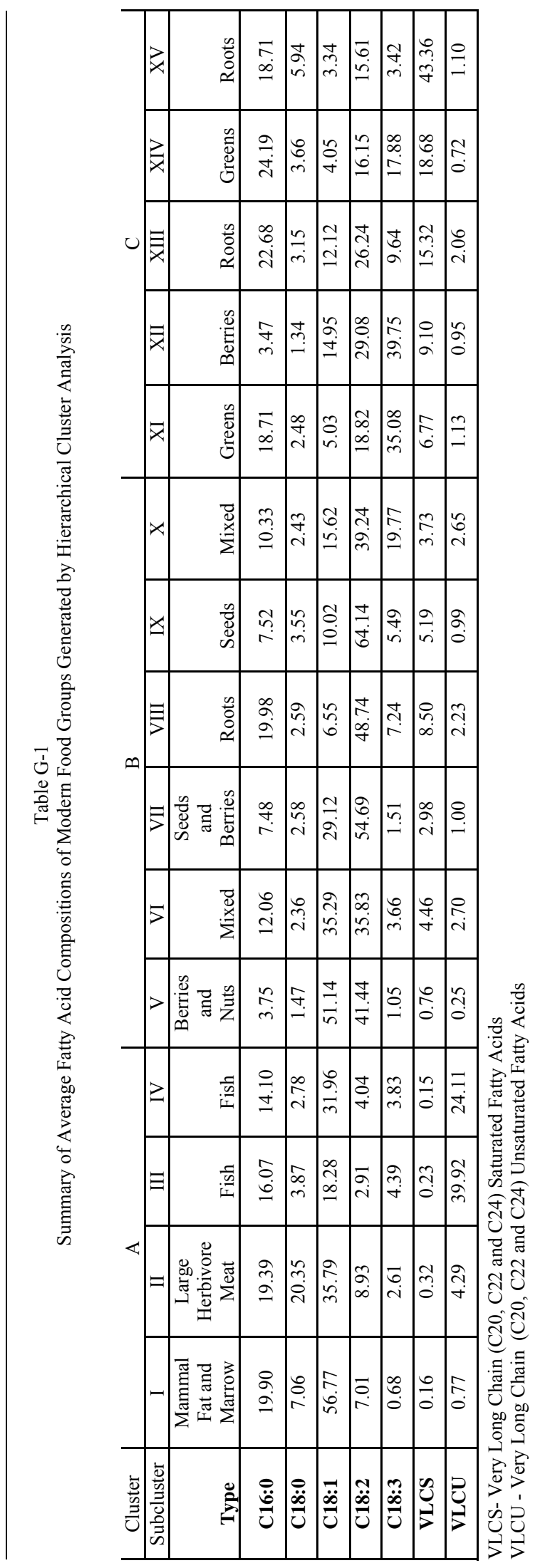


changes after a short term of decomposition. A second set of sherds remained at room temperature for 80 days, then placed in an oven at $75^{\circ} \mathrm{C}$ for a period of 30 days in order to simulate the processes of long-term decomposition. The relative percentages were calculated on the basis of the ten fatty acids (C12:0, C14:0, C15:0, C16:0, C16:1, C17:0, C18:0, C18:1w9, C18:1w11, C18:2) that regularly appeared in Precontact Period vessel residues from Western Canada. Observed changes in fatty acid composition of the experimental cooking residues enabled the development of a method for identifying the archaeological residues (Table G-2).

Table G-2

Criteria for the Identification of Archaeological Residues Based on the Decomposition Patterns of Experimental Cooking Residues Prepared in Pottery Vessels

\begin{tabular}{lccc} 
Identification & Medium Chain & C18:0 & C18:1 isomers \\
\hline Large herbivore & $\leq 15 \%$ & $\geq 27.5 \%$ & $\leq 15 \%$ \\
Large herbivore with plant & Low & $\geq 25 \%$ & $15 \% \leq X \leq 25 \%$ \\
OR Bone marrow & & & \\
Plant with large herbivore & $\geq 15 \%$ & $\geq 25 \%$ & no data \\
Beaver & Low & Low & $\geq 25 \%$ \\
Fish or Corn & Low & $\leq 25 \%$ & $15 \% \leq X \leq 27.5 \%$ \\
Fish or Corn with Plant & $\geq 15 \%$ & $\leq 25 \%$ & $15 \% \leq X \leq 27.5 \%$ \\
Plant (except corn) & $\geq 10 \%$ & $\leq 27.5 \%$ & $\leq 15 \%$ \\
\hline
\end{tabular}

It was determined that levels of medium chain fatty acids (C12:0, C14:0 and C15:0), C18:0 and C18:1 isomers in the sample could be used to distinguish degraded experimental cooking residues (Malainey 1997; Malainey et al. 1999b). These fatty acids are suitable for the identification criteria because saturated fatty acids are stable and the mono-unsaturated fatty acid degrades very slowly, as compared to polyunsaturated fatty acids (deMan 1992). Higher levels of medium chain fatty acids, combined with low levels of C18:0 and C18:1 isomers, were detected in the decomposed experimental residues of plants, such as roots, greens and most berries. High levels of C18:0 indicated the presence of large herbivores. Moderate levels of C18:1 isomers, with low levels of C18:0, indicated the presence of either fish or foods similar in composition to corn. High levels of C18:1 isomers with low levels of C18:0, were found in residues of beaver or foods of similar fatty acid composition. The criteria for identifying six types of residues were established experimentally; the seventh type, plant with large herbivore, was inferred (see Table G-2). These criteria were applied to residues extracted from more than 200 pottery cooking vessels from 18 Western Canadian sites (Malainey 1997; Malainey et al. 1999c; 2001b). The identifications were found to be consistent with the evidence from faunal and tool assemblages for each site.

Work has continued to understand the decomposition patterns of various foods and food combinations (Malainey et al. 2000a, 2000b, 2000c, 2001a; Quigg et al. 2001). The collection of modern foods has expanded to include plants from the Southern Plains. The fatty acid compositions of mesquite beans (Prosopis glandulosa), Texas ebony seeds (Pithecellobium ebano Berlandier), tasajillo berry (Opuntia leptocaulis), prickly pear fruit and pads (Opuntia engelmannii), Spanish dagger pods (Yucca treculeana), cooked sotol (Dasylirion wheeler), agave 
(Agave lechuguilla), cholla (Opuntia imbricata), piñon (Pinus edulis) and Texas mountain laurel (or mescal) seed (Sophora secundiflora) have been determined. Experimental residues of many of these plants, alone or in combination with deer meat, have been prepared by boiling foods in clay cylinders or using sandstone for either stone boiling (Quigg et al. 2000) or as a griddle. In order to accelerate the processes of oxidative degradation that naturally occur at a slow rate with the passage of time, the rock or clay tile containing the experimental residue was placed in an oven at $75^{\circ} \mathrm{C}$. After either 30 or 68 days, residues were extracted and analysed using gas chromatography. The results of these decomposition studies enabled refinement of the identification criteria.

\section{Methodology}

Descriptions of the samples are presented in Table G-3. Possible contaminants were removed by grinding off exterior surfaces with a Dremel ${ }^{\circledR}$ tool fitted with a silicon carbide bit. Immediately thereafter, the sample was crushed with a hammer mortar and pestle and the powder transferred to an Erlenmeyer flask. Lipids were extracted using a variation of the method developed by Folch et al. (1957). The powdered sample was mixed with a 2:1 mixture, by volume, of chloroform and methanol ( 2 X $30 \mathrm{~mL})$ using ultrasonication $(2 \times 10 \mathrm{~min})$. Solids were removed by filtering the solvent mixture into a separatory funnel. The lipid/solvent filtrate was washed with $16 \mathrm{~mL}$ of ultrapure water. Once separation into two phases was complete, the lower chloroform-lipid phase was transferred to a round-bottomed flask and the chloroform removed by rotary evaporation. Any remaining water was removed by evaporation with benzene $(1.5 \mathrm{~mL}) ; 1.5 \mathrm{~mL}$ of chloroformmethanol $(2: 1, \mathrm{v} / \mathrm{v})$ was used to transfer the dry total lipid extract to a screw-top glass vial with a Teflon ${ }^{\circledR}$-lined cap. The sample was flushed with nitrogen and stored in a $-20^{\circ} \mathrm{C}$ freezer.

Table G-3

List of Burned Rock Samples Analyzed from Site 41TR170

\begin{tabular}{cccccccc} 
Lab No. & Block & Feature & Unit & Level & $\begin{array}{c}\text { Lot/Bag } \\
\text { Number }\end{array}$ & $\begin{array}{c}\text { Rock } \\
\text { Number }\end{array}$ & $\begin{array}{c}\text { Sample } \\
\text { Size (g) }\end{array}$ \\
\hline 6GM 1 & 1 & 9 & 13 & L-11 & $341 / 410 \mathrm{~A}$ & 6 & 38.141 \\
6GM 2 & 1 & 13 & 17 & L-11 & $421 / 438 \mathrm{~A}$ & 22 & 35.059 \\
6GM 3 & 2 & 12 & 20 & L-20 & $468 / 578 \mathrm{~A}$ & 30 & 35.670 \\
6GM 4 & 2 & 20 & 25 & L-21 & $557 / 625 \mathrm{~A}$ & 5 & 36.173 \\
6GM 5 & 3 & 17 & 31 & L-12 & $626 / 708 \mathrm{~A}$ & 7 & 40.477 \\
6GM 6 & 3 & 16 & 37 & L-12 & $711 / 673 \mathrm{~A}$ & 4 & 40.720 \\
\hline
\end{tabular}

A $400 \mu \mathrm{L}$ sample of the total lipid extract solution was placed in a screw-top test tube and dried in a heating block under nitrogen. Fatty acid methyl esters (FAMES) were prepared by treating the dry lipid with $5 \mathrm{~mL}$ of $0.5 \mathrm{~N}$ anhydrous hydrochloric acid in methanol $\left(68^{\circ} \mathrm{C} ; 60 \mathrm{~min}\right)$. Fatty acids that occur in the sample as di- or triglycerides are detached from the glycerol molecule and converted to methyl esters. After cooling to room temperature, $3.4 \mathrm{~mL}$ of ultrapure water was added. FAMES were recovered with petroleum ether $(2.5 \mathrm{~mL})$ and transferred to a vial. The solvent was removed by heat under a gentle stream of nitrogen; the FAMES were dissolved in 75 $\mu \mathrm{L}$ of iso-octane then transferred to a GC vial with a conical glass insert. 
Solvents and chemicals were checked for purity by running a sample blank. The entire lipid extraction and methyl esterification process was performed and FAMES were dissolved in $75 \mu \mathrm{L}$ of iso-octane. Traces of contamination were subtracted from sample chromatograms. The relative percentage composition was calculated by dividing the integrated peak area of each fatty acid by the total area of fatty acids present in the sample.

The step in the extraction procedure where the chloroform, methanol and lipid mixture is washed with water is standard procedure for the extraction of lipids from modern samples. Following Evershed et al. (1990), who reported that this step was unnecessary for the analysis of archaeological residues, previously the solvent-lipid mixture was not washed. This step was recently adopted to remove impurities so that clearer chromatograms could be obtained in the region where very long chain fatty acids (C20:0, C20:1, C22:0 and C24:0) occur. It was anticipated that the detection and accurate assessment of these fatty acids could be instrumental in separating residues of animal origin from those of plant (Malainey et al. 2000a, 2000b, 2000c, 2001a).

In order to identify the residue, the relative percentage composition was determined first with respect to all fatty acids present in the sample (including very long chain fatty acids) (see Table 4) and secondly with respect to the ten fatty acids utilized in the development of the identification criteria (C12:0, C14:0, C15:0, C16:0, C16:1, C17:0, C18:0, C18:1w9, C18:1w11 and C18:2) (not shown). The second step is necessary for the application of the identification criteria presented in Table G-2.

It must be understood that the identifications given do not necessarily mean that those particular foods were actually prepared because different foods of similar fatty acid composition and lipid content would produce similar residues. It is possible only to say that the material of origin for the residue was similar in composition to the food(s) indicated.

\section{Gas Chromatography Analysis Parameters}

The Gas Chromatography (GC) analysis was performed on a Varian 3800 gas chromatograph fitted with a flame ionization detector connected to a personal computer. Samples were separated using a DB-23 fused silica capillary column (30 m X $0.25 \mathrm{~mm}$ I.D.; J\&W Scientific; Folsom, CA). An autosampler injected a $1 \mu \mathrm{L}$ sample using a split/splitless injection system. Hydrogen was used as the carrier gas with a column flow of $1.0 \mathrm{~mL} / \mathrm{min}$. Column temperature was held at $80^{\circ} \mathrm{C}$ for 1 minute then increased to $140^{\circ} \mathrm{C}$ at a rate of $20^{\circ} \mathrm{C}$ per minute. It was then programmed from 140 to $230^{\circ} \mathrm{C}$ at $4^{\circ} \mathrm{C}$ per minute. The upper temperature was held for 15 minutes. Chromatogram peaks were integrated using Varian MS Workstation ${ }^{\circledR}$ software and identified through comparisons with external qualitative standards (NuCheck Prep; Elysian, MN).

\section{Results of Archaeological Data Analysis}

The fatty acid compositions of residues extracted from the burned rocks are presented in Table G4. The term, Area, represents the area under the chromatographic peak of a given fatty acid, as calculated by the Varian MS Workstation ${ }^{\circledR}$ software minus the solvent blank. The term, Rel\%, represents the relative percentage of the fatty acid with respect to the total fatty acids in the sample. Hydroxide or peroxide degradation products can interfere with the integration of the C22:0 and C22:1 peaks; these fatty acids were excluded from the analysis. 
Table G-4

Fatty Acid Composition and Identification of Burned Rock Residues from Site 41 TR170

\begin{tabular}{|c|c|c|c|c|c|c|}
\hline \multirow{3}{*}{ Fatty acid } & \multicolumn{2}{|c|}{ 6GM 1} & \multicolumn{2}{|c|}{ 6GM 2} & \multicolumn{2}{|c|}{ 6GM 3} \\
\hline & \multicolumn{2}{|c|}{ Block 1, Feature 9} & \multicolumn{2}{|c|}{ Block 1, Feature 13} & \multicolumn{2}{|c|}{ Block 2, Feature 12} \\
\hline & Area & Rel\% & Area & Rel\% & Area & Rel\% \\
\hline C12:0 & 0 & 0.00 & 812 & 0.25 & 0 & 0.00 \\
\hline C14:0 & 2934 & 0.35 & 3648 & 1.11 & 2717 & 3.97 \\
\hline C14:1 & 0 & 0.00 & 1195 & 0.36 & 0 & 0.00 \\
\hline C15:0 & 2052 & 0.24 & 2085 & 0.64 & 2811 & 4.10 \\
\hline C16:0 & 97262 & 11.44 & 43578 & 13.30 & 18326 & 26.75 \\
\hline C16:1 & 24422 & 2.87 & 5646 & 1.72 & 6661 & 9.72 \\
\hline C17:0 & 955 & 0.11 & 1197 & 0.37 & 3913 & 5.71 \\
\hline C17:1 & 1377 & 0.16 & 0 & 0.00 & 0 & 0.00 \\
\hline C18:0 & 12117 & 1.43 & 20928 & 6.39 & 5555 & 8.11 \\
\hline C18:1s & 649115 & 76.37 & 226884 & 69.25 & 17167 & 25.06 \\
\hline C18:2 & 50678 & 5.96 & 12368 & 3.78 & 7137 & 10.42 \\
\hline C18:3w3 & 1235 & 0.15 & 0 & 0.00 & 0 & 0.00 \\
\hline C20:0 & 2734 & 0.32 & 3409 & 1.04 & 552 & 0.81 \\
\hline C20:1 & 2608 & 0.31 & 2318 & 0.71 & 1747 & 2.55 \\
\hline C24:0 & 2476 & 0.29 & 3540 & 1.08 & 1922 & 2.81 \\
\hline Total & 849965 & 100.00 & 327608 & 100.00 & 68508 & 100.00 \\
\hline Identification & \multicolumn{2}{|c|}{$\begin{array}{c}\text { Extremely high fat } \\
\text { content }\end{array}$} & \multicolumn{2}{|c|}{ Extremely high fat content } & \multicolumn{2}{|c|}{ Medium fat content } \\
\hline \multirow{3}{*}{ Fatty acid } & \multicolumn{2}{|c|}{ 6GM 4} & \multicolumn{2}{|c|}{ 6GM 5} & \multicolumn{2}{|c|}{ 6GM 6} \\
\hline & \multicolumn{2}{|c|}{ Block 2, Feature 20} & \multicolumn{2}{|c|}{ Block 3, Feature 17} & \multicolumn{2}{|c|}{ Block 3, Feature 16} \\
\hline & Area & Rel\% & Area & Rel\% & Area & Rel\% \\
\hline C12:0 & 0 & 0.00 & 0 & 0.00 & 587 & 0.64 \\
\hline C14:0 & 3869 & 6.80 & 2498 & 0.39 & 4176 & 4.56 \\
\hline C14:1 & 0 & 0.00 & 0 & 0.00 & 0 & 0.00 \\
\hline C15:0 & 1861 & 3.27 & 1784 & 0.28 & 3324 & 3.63 \\
\hline C16:0 & 10987 & 19.32 & 88762 & 13.71 & 14740 & 16.09 \\
\hline C16:1 & 2472 & 4.35 & 8034 & 1.24 & 4915 & 5.37 \\
\hline C17:0 & 912 & 1.60 & 651 & 0.10 & 529 & 0.58 \\
\hline C17:1 & 0 & 0.00 & 0 & 0.00 & 0 & 0.00 \\
\hline C18:0 & 14567 & 25.61 & 14962 & 2.31 & 12918 & 14.10 \\
\hline C18:1s & 12328 & 21.67 & 466576 & 72.09 & 36335 & 39.67 \\
\hline C18:2 & 2142 & 3.77 & 54731 & 8.46 & 4570 & 4.99 \\
\hline C18:3w3 & 1084 & 1.91 & 1299 & 0.20 & 1380 & 1.51 \\
\hline C20:0 & 1970 & 3.46 & 3591 & 0.55 & 3778 & 4.12 \\
\hline C20:1 & 2062 & 3.63 & 2131 & 0.33 & 1774 & 1.94 \\
\hline C24:0 & 2627 & 4.62 & 2212 & 0.34 & 2575 & 2.81 \\
\hline Total & 56881 & 100.00 & 647231 & 100.00 & 91601 & 100.00 \\
\hline Identification & \multicolumn{2}{|c|}{ Large herbivore + Plant } & \multicolumn{2}{|c|}{ Extremely high fat content } & \multicolumn{2}{|c|}{ High fat content } \\
\hline
\end{tabular}


While all samples contained sufficient fatty acids to attempt identification, recoveries from 6GM 3 and 6GM 4 were quite low; somewhat more lipid was recovered from 6GM 6. In comparison, recoveries from the other three samples, 6GM 1, 6GM 2 and 6GM 5, were significantly higher.

Three burned rock residues have significantly elevated levels of C18:1 isomers, which indicates the presence of fat or oil in the residue. Levels of C18:1 isomers in 6GM 1, 6GM 2 and 6GM 5 are extremely high, ranging from 69.25 percent to 76.37 percent. These levels are observed in the decomposed residues of foods of very high fat content seeds or nuts, such as piñon. Rendered fats of certain mammals (other than large herbivores) exhibit similarly very high levels of fat content when fresh. Given that these represent partially decomposed archaeological burned rock residues, a plant origin is more likely.

One residue, $6 \mathrm{GM} 6$, is characterized by high levels of $\mathrm{C} 18: 1$ isomers. The most probable source of this residue is locally available high fat content seeds and nuts. Given the elevated levels of C18:2, medium chain fatty acids and very long chain fatty acids in this residue, it is more likely to be of plant origin.

One residue, 6GM 3, appears to result from the preparation of medium fat content foods, such as mesquite, corn and cholla. This residue has elevated levels of C18:1 isomers and relatively lower levels of C18:0. Fish produces similar residues; but the elevated levels of C18:2 and medium and very long chain saturated fatty acids are indicative of a plant origin.

One residue, $6 \mathrm{GM} 4$, is consistent with the preparation of large herbivore in combination with plants or large herbivore bone marrow. These residues are characterized by elevated levels of C18:0 and C18:1 isomers. The elevated levels of medium and very long chain saturated fatty acids in this residue support a large herbivore meat and plant combination, rather than large herbivore bone marrow. In the Great Plains, bison and deer are the most likely source of residues with elevated levels of C18:0; however, javelina and the seeds of certain cacti are known to produce similar residues. It is possible that this residue represents a combination of javelina or cacti seeds, such as sotol, with plant. 


\section{REFERENCES CITED}

Collins M. B., B. Ellis and C. Dodt-Ellis

1990 Excavations at the Camp Pearl Wheat Site (41KR243): An Early Archaic Campsite on Town Creek, Kerr County, Texas. Studies in Archaeology 6. Texas Archeological Research Laboratory, The University of Texas at Austin.

Condamin, J., F. Formenti, M. O. Metais, M. Michel, and P. Blond

1976 The Application of Gas Chromatography to the Tracing of Oil in Ancient Amphorae. Archaeometry 18(2): 195-201.

deMan, J. M.

1992 Chemical and Physical Properties of Fatty Acids. In: Fatty Acids in Foods and their Health Implications, edited by C. K. Chow, pp. 17-39. Marcel Dekker, New York.

Evershed, R. P., C. Heron and L. J. Goad

1990 Analysis of Organic Residues of Archaeological Origin by High Temperature Gas Chromatography and Gas Chromatography-Mass Spectroscopy. Analyst 115:13391342.

Folch, J., M. Lees and G. H. Sloane-Stanley

1957 A simple method for the isolation and purification of lipid extracts from brain tissue. Journal of Biological Chemistry 191:833.

Frankel, E. N.

1991 Recent Advances in Lipid Oxidation. Journal of the Science of Food and Agriculture 54:465-511.

Loy, T.

1994 Residue Analysis of Artifacts and Burned Rock from the Mustang Branch and Barton Sites (41HY209 and 41HY202). In: Archaic and Late Prehistoric Human Ecology in the Middle Onion Creek Valley, Hays County, Texas. Volume 2: Topical Studies, by R. A. Ricklis and M. B. Collins, pp. 607- 627. Studies in Archeology 19, Texas Archeological Research Laboratory, The University of Texas at Austin. 
Malainey, M. E.

1997 The Reconstruction and Testing of Subsistence and Settlement Strategies for the Plains, Parkland and Southern boreal forest. Unpublished Ph.D. thesis, University of Manitoba.

Malainey, M. E., K. L. Malisza, R. Przybylski and G. Monks

2001a The Key to Identifying Archaeological Fatty Acid Residues. Paper presented at the $34^{\text {th }}$ Annual Meeting of the Canadian Archaeological Association, Banff, Alberta, May 2001.

Malainey, M. E., R. Przybylski and B. L. Sherriff

1999a The Fatty Acid Composition of Native Food Plants and Animals of Western Canada. Journal of Archaeological Science 26:83-94.

1999b The Effects of Thermal and Oxidative Decomposition on the Fatty Acid Composition of Food Plants and Animals of Western Canada: Implications for the Identification of archaeological vessel residues. Journal of Archaeological Science 26:95-103.

1999c Identifying the former contents of Late Precontact Period pottery vessels from Western Canada using gas chromatography. Journal of Archaeological Science 26(4): 425-438.

2001b One Person's Food: How and Why Fish Avoidance May Affect the Settlement and Subsistence Patterns of Hunter-Gatherers. American Antiquity 66(1): 141-161.

Malainey, M. E., R. Przybylski and G. Monks

2000a The identification of archaeological residues using gas chromatography and applications to archaeological problems in Canada, United States and Africa. Paper presented at The $11^{\text {th }}$ Annual Workshops in Archaeometry, State University of New York at Buffalo, February 2000.

2000b Refining and testing the criteria for identifying archaeological lipid residues using gas chromatography. Paper presented at the $33^{\text {rd }}$ Annual Meeting of the Canadian Archaeological Association, Ottawa, May 2000.

2000c Developing a General Method for Identifying Archaeological Lipid Residues on the Basis of Fatty Acid Composition. Paper presented at the Joint Midwest Archaeological \& Plains Anthropological Conference, Minneapolis, Minnesota, November 2000.

Marchbanks, M. L.

1989 Lipid Analysis in Archaeology: An Initial Study of Ceramics and Subsistence at the George C. Davis Site. Unpublished M.A. thesis, The University of Texas at Austin.

Marchbanks, M. L., and J. M. Quigg

1990 Appendix G: Organic Residue and Phytolith Analysis. In: Phase II Investigations at Prehistoric and Rock Art Sites, Justiceburg Reservoir, Garza and Kent Counties, Texas, Volume II, by D. K. Boyd, J. T. Abbott, W. A.Bryan, C. M. Garvey, S. A. Tomka and R. C. Fields. pp. 496-519. Reports of Investigations No. 71. Prewitt and Associates, Inc, Austin. 
Patrick, M., A. J. de Konig and A. B. Smith

1985 Gas Liquid Chromatographic Analysis of Fatty Acids in Food Residues from Ceramics Found in the Southwestern Cape, South Africa. Archaeometry 27(2): 231236.

Quigg, J. M., C. Lintz, S. Smith and S. Wilcox

2000 The Lino Site: A Stratified Late Archaic Campsite in a Terrace of the San Idelfonzo Creek, Webb County, Southern Texas. Technical Report No. 23765, TRC Mariah Associates Inc., Austin. Texas Department of Transportation, Environmental Affairs Division, Archaeological Studies Program Report 20, Austin.

Quigg, J. M., M. E. Malainey, R. Przybylski and G. Monks

2001 No bones about it: using lipid analysis of burned rock and groundstone residues to examine Late Archaic subsistence practices in South Texas. Plains Anthropologist 46(177): 283-303.

Skibo, J. M.

1992 Pottery Function: A Use-Alteration Perspective. Plenum Press, New York.

Solomons, T. W. G.

1980 Organic Chemistry. John Wiley \& Sons, Toronto. 


\section{Characteristics of Limestone Rocks Submitted for Lipid Analysis}

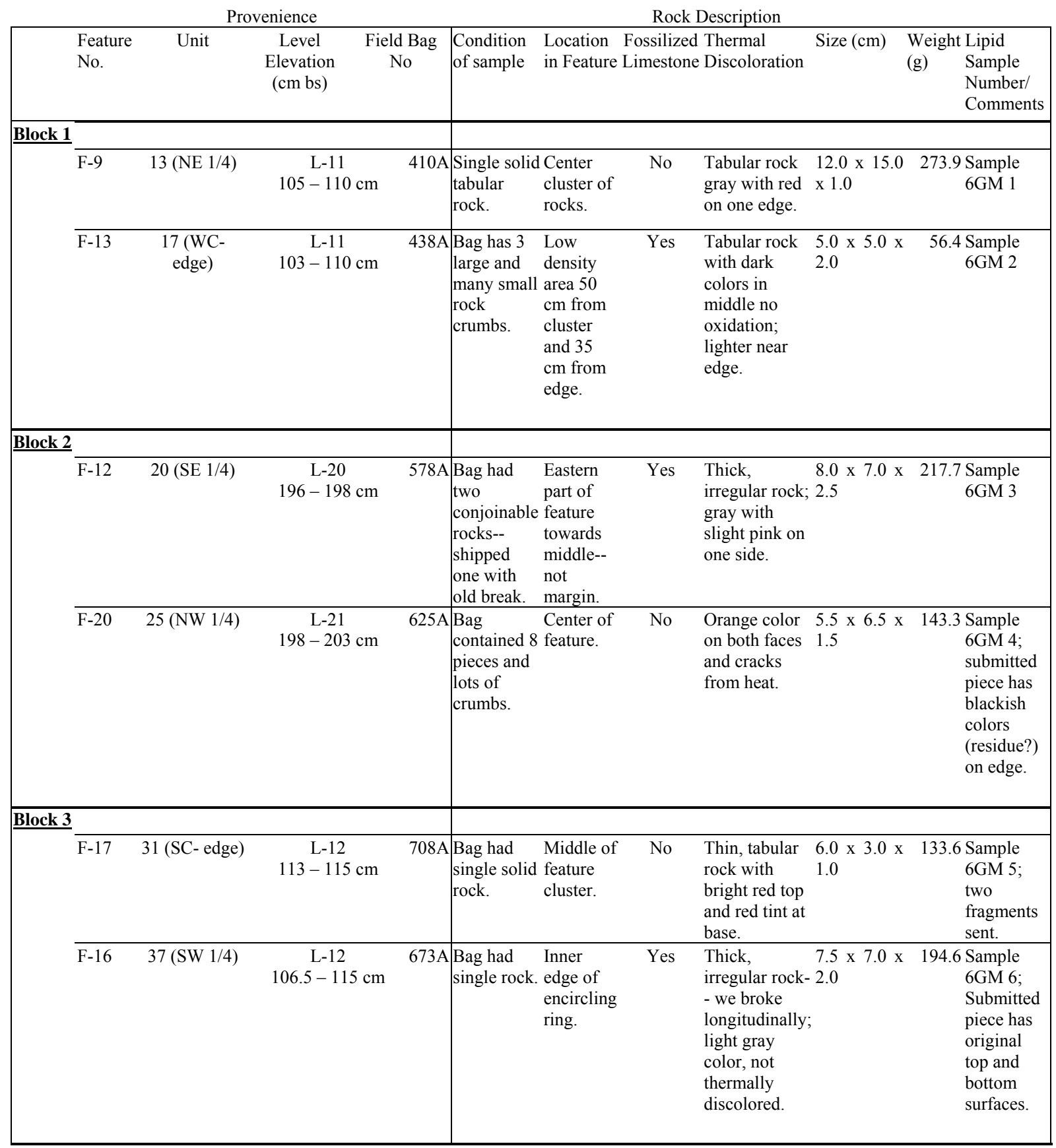




\section{APPENDIX H}

\section{ZOOARCHAEOLOGICAL ANALYSIS OF THE SITE $41 T R 170$ FAUNA: TARRANT COUNTY, TEXAS}

by

Steve Wolverton, Ph.D. \& Charles Randklev

Department of Geography

Institute of Applied Sciences

University of North Texas 



\section{INTRODUCTION}

The site 41TR170 archaeofauna produced a sizeable amount of faunal material primarily consisting of fragmented artiodactyl remains and bivalve shell fragments. There is a signature of Bison bison at the site, and other taxa that are represented include white-tailed deer (Odocoileus virginianus), leporids (Lepus and Sylvilagus), turtles (terrestrial and aquatic), Canis (probably dog), fish, the hispid cotton rat (Sigmodon hispidus), and several shellfish taxa (Table H-1). This report summarizes basic criteria for identification of the specimens followed by a brief statement on taphomony. The number of identifified specimens (NISP) is reported in Table H-1. Burning, weathering, and green fracturing are recorded in the appendix, but they are discussed only briefly in the report. Biological nomenclature throughout this report follows Hall (1981) with updates from Schmidly (1994) for vertebrates and Howells et al. (1996) for invertebrates.

Table H-1

Taxa Represented in the Site 41TR170 Fauna

\begin{tabular}{|c|c|}
\hline Taxon & NISP \\
\hline \multicolumn{2}{|l|}{$\begin{array}{c}\text { CHORDATA } \\
\text { Reptilia }\end{array}$} \\
\hline Testudinata & 32 \\
\hline cf. Pseudemys sp. & 27 \\
\hline Terrepene sp. & 2 \\
\hline \multicolumn{2}{|l|}{ Mammalia } \\
\hline Medium Ungulate & 21 \\
\hline Bison bison (Linnaeus) & 3 \\
\hline Bison size & 1 \\
\hline Odocoileus virgianus (Boddaert) & 27 \\
\hline Deer size & 4 \\
\hline Sylvilagus floridanus & 1 \\
\hline Lepus californicus (Gray) & 1 \\
\hline Sigmodon hispidus (Say and Ord) & 1 \\
\hline Canis sp. & 1 \\
\hline Pisces & 2 \\
\hline Vertebrate NISP & 123 \\
\hline Total Vertebrate NSP (w/ unidentifiable) & 268 \\
\hline \multicolumn{2}{|l|}{ Mollusca } \\
\hline \multicolumn{2}{|l|}{ Bivalvia: Unionoida: Unionidae } \\
\hline Amblema plicata (Say) & 65 \\
\hline Fusconaia askewi (Marsh) & 3 \\
\hline Lampsilis sp. & 11 \\
\hline Lampsilis teres (Rafinesque) & 18 \\
\hline Lampsilis cf. teres & 1 \\
\hline Lampsilis hydiana (Lea) & 7 \\
\hline Ligumia subrostrata (Say) & 15 \\
\hline
\end{tabular}


Table H-1 (cont'd)

\begin{tabular}{l|c}
\multicolumn{1}{c|}{ Taxon } & NISP \\
\hline Plectomerus dombeyanus (Valenciennes) & 19 \\
Plectomerus cf. dombeyanus & 3 \\
Potamilus purpuratus (Lamarck) & 2 \\
Potamilus cf. purpuratus & 1 \\
Quadrula sp. & 12 \\
Quadrula apiculata (Say) & 2 \\
Quadrula mortoni (Simpson) & 17 \\
Tritogonia verrucosa (Rafinesque) & 13 \\
Tritogonia cf. verrucosa & 3 \\
Invertebrate NISP & 192 \\
Total invertebrate NSP (w/ unidentifiable) & 2254 \\
Total NISP & 315 \\
Total Specimens & 2522 \\
\hline
\end{tabular}

\title{
SYSTEMATIC PALEONTOLOGY
}

Specimens are assigned to class, order, suborder, family, genus, and species according to their identifiability. Size classes (e.g., "medium ungulate" and "deer size") are used to describe remains that bear no diagnostic features but are similar in size and shape to portions from a particular element from a species; the class "medium ungulate" is less diagnostic than "deer size" and tends to comprise long-bone midshaft fragments. Specimens assigned to medium ungulate are not included in the systematic paleontology. Given the low density of elements from the axial skeleton and the taxonomic overlap in morphological characteristics of rib fragments in particular, several fragments are considered "unidentified." When identifications of such elements are possible (including long-bone shaft fragments), they are offered in terms of size class, which is a conservative approach. Two specimens are referred to Pisces and are not given further attention in the report. Freshwater bivalve remains are identified through comparison to modern specimens from the region and through use of published criteria discussed in more detail below.

$\underline{\text { Vertebrate Fauna }}$

\author{
Class Mammalia (mammals) \\ Order Artiodactyla (even-hooved animals) \\ Family Cervidae (deer, elk, and moose) \\ Deer size (compares in size to Odocoileus virginianus)
}

NISP: 1 left mandibular ascending ramus, 1 left anterior lumbar vertebral zygapophysis, 1 right medial femur shaft fragment, 1 metapodial shaft fragment.

$$
\text { Total NISP }=4
$$

Odocoileus virginianus (white-tailed deer)

NISP: 7 right humerus fragments (refit), 1 right distal humerus fragment, 3 left radius fragments (refit), 1 right radius (complete), 2 right ulna fragments (refit), 1 right ulna shaft fragment, 1 left ulna shaft fragment, 1 left cuneiform, 1 left lunar, 1 left scaphoid, 1 left trapezoid magnum, 1 left unciform, 1 left astragalus, 1 right astragalus, 1 first phalanx, 3 third phalanx fragments (refit).

$$
\text { Total NISP }=27
$$


Remarks: These specimens were identified in comparison to modern specimens and according to criteria outlined by Lawrence (1951). Long-bone midshafts are not diagnostic and were assigned to "medium ungulate" as a result (Appendix 1A). Remains of white-tailed deer are common in archaeological sites that date to the Holocene in Texas (see references in Perttula 2004), and though mule deer (Odocoileus hemionus) have occurred in the state, their historic distribution is farther west (Schmidly 1994). Further, white-tailed deer tend to be slightly smaller than mule deer (though there is overlap). The specimens from 41TR170 compare in size quite favorably to small white-tailed deer. White-tailed deer represents the largest-bodied, consistently available prey to humans in eastern North America during most of the Holocene-ranging between 22.5 and $180 \mathrm{~kg}$ (Schmidly 1994; Smith 1991). Elk (Cervus elaphus) and bison (Bison bison) were also available in areas of the eastern woodlands, the mid-south, and the Midwest (e.g., Wolverton 2002). However, white-tailed deer were extremely important prey because their range extends across all of eastern North America and they thrive in many kinds of habitat (Hall 1981; Hamilton and Whitaker 1979; Smith 1991). Further, it is well documented that deer were heavily hunted by prehistoric humans and that this taxon was an extremely important source of protein during much of the Holocene, especially during the late Holocene (e.g., Wolverton 2005).

Several specimens appear to have come from the front limbs of the same individual in that limb elements are for the most part paired from similar horizontal and vertical contexts. Only the first phalanx appears to have been fractured when fresh, though one radius exhibits a potential cutmark at its distal end. Along similar lines there is a nearly complete set of left carpals that anatomically refit with one another. That one of the radii is complete is almost unheard of in archaeological contexts in that marrow-bearing limb bones are ubiquitously fragmented to retrieve within-bone nutrients. There is little to no evidence that these white-tailed deer front limbs were processed for within-bone nutrients; however, the absence of cutmarks does not indicate that the limbs were not butchered for meat in that cutmarks are epiphenomena, i.e., they are accidental marks left not in attempts to butcher bone but in attempts to remove meat (Lyman 1994).

There is a poor record of prehistoric white-tailed deer body size in north Texas compared to other portions of the state. Two astragali from 41 TR170 add to the small database in that the astragalus is a useful indicator of body size in ungulates (Purdue 1987, 1989; Wolverton et al. 2007). Southeast Texas deer are extremely small as observed in the large late Holocene sample from the Eagle's Ridge site (41CH252). During the Holocene deer from central Texas were relatively large in comparison to those from southeast Texas. Size of north Texas white-tailed deer during the late Holocene appears to fall between the southeast and central Texas distributions (Figure H1). As the database grows it will be possible to determine whether or not the four astragali sampled represent body size or sexual dimorphism, i.e., they might be from does.

Family Bovidae (antelopes, cattle, gazelles, goats, sheep, and relatives)

Bison bison (bison)

NISP: 1 left upper molar, 2 left astragali (refit).

Total NISP $=2$

Remarks: The Bison bison specimens exhibit diagnostic features that allow them to be distinguished from domestic cattle using modern comparative materials and published criteria. The astragalus was identified using criteria described by Olsen (1960). The main criterion used in this identification is the position of the medial tubercle in relation to the distal trochlea on the anterior surface of the astragalus; the tubercle is relatively distal in Bos taurus. Further 


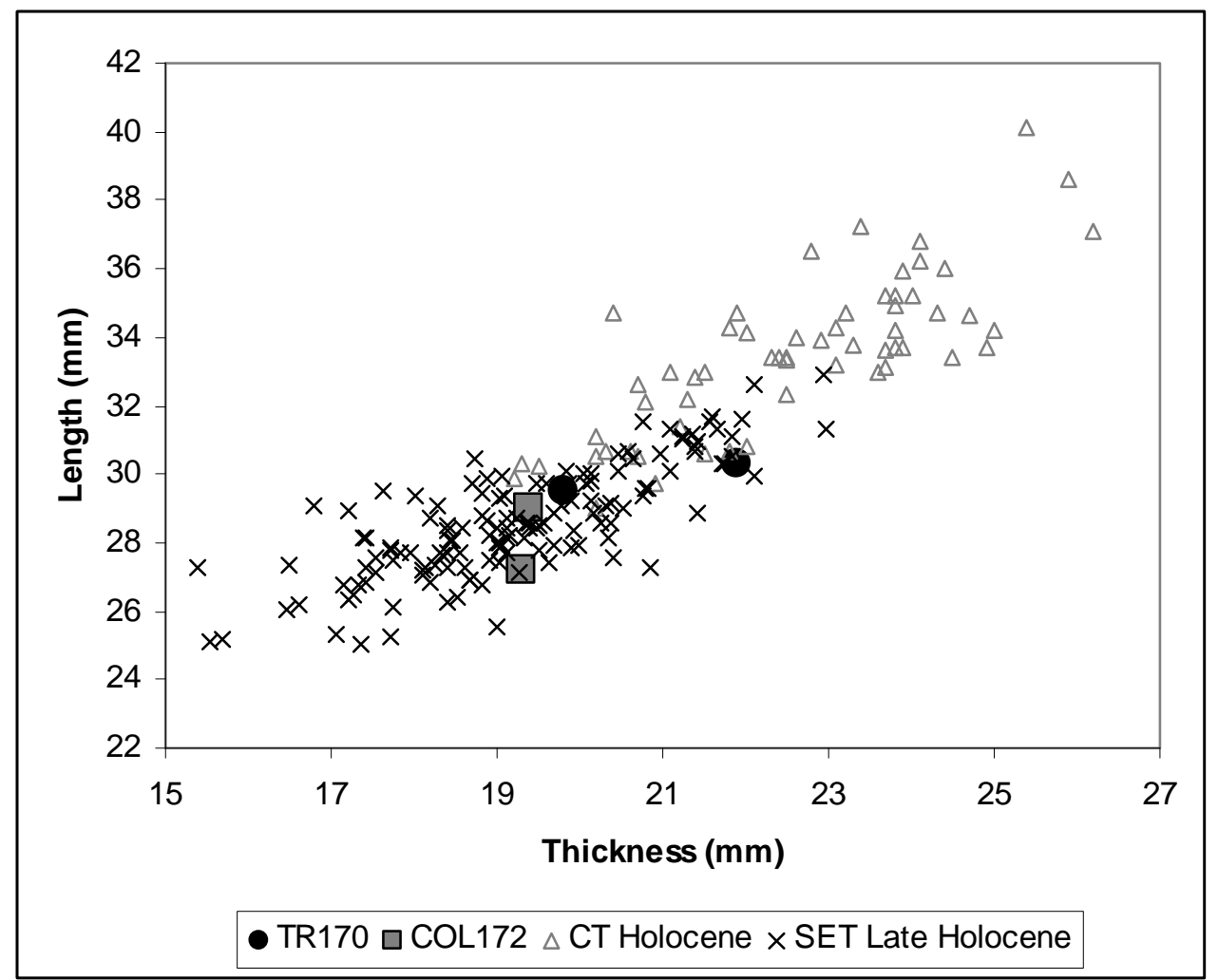

Figure H-1. Astragalus size for WTD from three regions of Texas: COL172 and TR171 are both in north Texas, the central Texas specimens are from the Holocene in the Edwards Plateau, and the southeast Texas specimens are from the Eagle's Ridge site in Chambers County, which dates to the late Holocene.

distinction is possible using the shape of the posterior articular surface of the astragalus (Lawrence 1951). The left upper molar is either an $\mathrm{M}^{1}$ or $\mathrm{M}^{2}$, which cannot be easily distinguished when isolated from the maxilla. From a biogeographic perspective, this site is important because it offers additional evidence as to the Holocene distribution of Bison bison in Texas.

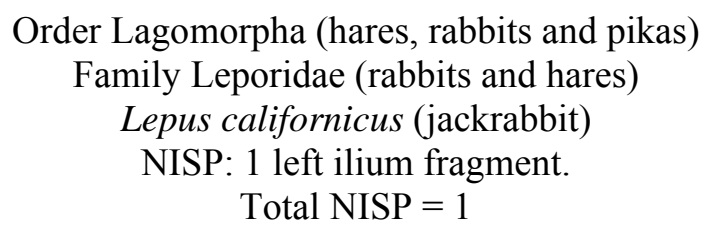

Remarks: The ilium fragment is too large to be from cottontail and is thus assigned to Lepus. Postcranial elements of Lepus are difficult to separate to species; only the black-tailed jackrabbit (Lepus californicus) occurs in Texas historically (Schmidly 1994). Other members of Lepus tend to occur to the west and north of Texas (Dunn et al. 1982).

Sylvilagus floridanus (eastern cottontail rabbit) NISP: 1 right anterior mandible fragment with $\mathrm{P}_{4}$. Total NISP $=1$ 
Remarks: This specimen was identified through comparison to modern specimens. Although diagnostic characteristics of jackrabbits (Lepus sp.) and swamp rabbits (Sylvilagus aquaticus) are similar to those of the eastern cottontail (S. floridanus) and the marsh rabbit (S. palustris), the latter two species tend to be much smaller in body size. The range of $S$. palustris includes the southeastern United States, but its range during the historic period is east of Louisiana (Hall 1981). In contrast, the range of the eastern cottontail extends through much of eastern North America. Based on size and modern ranges, the mandible specimen is assigned to S. floridanus. The eastern cottontail tolerates a diverse array of habitats but generally prefers brushy areas along timbered edges, which includes river and stream corridors (Jones et al. 1985). Relative to many other prey taxa (e.g., white tailed deer and turkey [Meleagris gallopavo]) the cottontail would have offered relatively low returns in that their body size is small. However, trapping and/or netting technologies substantially decrease the cost of acquiring rabbits, which increases their net caloric return rate to humans.

Order Rodentia (rodents)

Family Muridae (mice and rats)

Sigmodon hispidus (hispid cotton rat)

NISP: 1 right proximal femur.

Total NISP $=1$

Remarks: The hispid cotton rat is common in most areas of Texas including Tarrant County. This specimen compares closely in size and morphology to Sigmodon hispidus using modern comparative materials in our collection. This burrowing rodent is likely to be intrusive to the cultural deposit at 41TR170.

\author{
Order Carnivora (carnivores) \\ Family Canidae (dogs, foxes, and relatives) \\ Canis sp. \\ NISP: 1 right proximal humerus \\ Total NISP $=1$
}

Remarks: This specimen compares favorably to domestic dog (C. familiaris) or wolf (C. lupus). The designation as Canis sp. reflects that it is difficult to distinguish domestic dog post-cranial remains from those of wolves and large coyote (C. latrans) (Kranz 1959; Nowak 1979). Proximal breadth $(33.1 \mathrm{~mm})$ and proximal depth $(47.1 \mathrm{~mm})$ were taken following Von den Driesch (1976), but no morphometric comparisons to other canids are made here.

$$
\begin{gathered}
\text { Class Reptilia (reptiles) } \\
\text { Order Testudinata (turtles and tortoises) } \\
\text { NISP: } 1 \text { peripheral carapace fragment, } 7 \text { carapace fragments, } 6 \text { carapace/plastron fragments, } 18 \\
\text { plastron fragments. } \\
\text { Total NISP }=32
\end{gathered}
$$

Remarks: Specimens in Testudinata are clearly turtle but are too fragmentary to assign to a more specific taxon.

cf. Pseudemys sp. (compares favorably with cooters and sliders)

NISP: 17 carapace fragments, 7 carapace/plastron fragments, 1 costal carapace fragment, 1 peripheral carapace fragment, 1 left proximal humerus.

Total NISP $=27$ 
Remarks: No member of Pseudemys is common in the Upper Trinity River drainage today, though P. texana's (Texas cooter) modern range is just to the south in central Texas and several species of the genus occur in east Texas (Garrett and Barker 1987). The fragmentary nature of the remains makes it difficult to assign them to a particular species with confidence, hence the designation as cf. Pseudemys sp. The peripheral carapace fragment exhibits a potential cutmark.

Terrepene sp. (box turtle)

NISP: 1 costal carapace fragment, 1 vertebral carapace fragment.

Total NISP $=2$

Remarks: These specimens are identified to Terrepene sp. through comparison to modern materials. The costal fragment is too curved to be assigned to any other turtle taxon, and the vertebral carapace fragment is an exact morphological match with modern members of the genus. Two species of box turtle in the genus Terrepene occur within Texas today, the ornate box turtle (Terrepene ornata) and the three-toed box turtle (Terrepene carolina). The ornate box turtle is the western form, though the species are capable of hybridization where their ranges overlap (Ernst et al. 1994). The ranges of T. ornata and T. carolina converge in central Texas, though $T$. ornata is more common across Texas (Dixon 1987; Garrett and Barker 1987). It is likely that turtle remains at 41TR170 are from prey hunted by humans (Wolverton 2005).

$\underline{\text { Invertebrate Fauna }}$

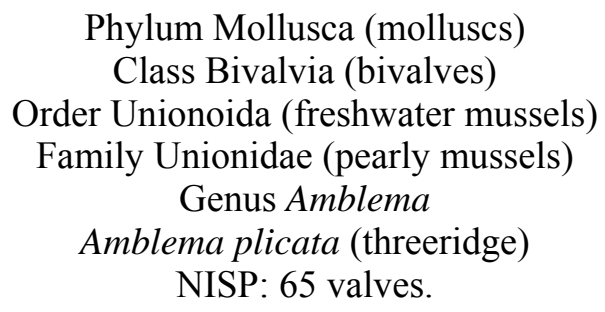

Remarks: Specimens identified as A. plicata are heavy shelled, and characterized by the presence of 3 to 7 ridges, which run diagonal to the ventral margin. The pseudocardinal teeth for these specimens are also diagnostic: the left valve contains two large, divergent, grooved, triangular pseudocardinal teeth. The right valve has one elevated, grooved, triangular pseudocardinal tooth. Threeridge is a robust species, tolerant of drought and low water quality, and potentially inhabits both lakes and streams (Howells et al. 1996). The species examined are elongated and relatively compressed, which is indicative of species found in lotic systems. Three of the 65 valves examined have probable cutmarks near the posterior most ridge; these valves contain rectangular excisions, which appear physically different than wearing of the shell due to hydrological or taphonomic processes. The excisions are a probable byproduct of human exploitation for food and tool or jewelry use (Howells et al. 1996; Peacock 2000).

\section{Genus Fusconaia \\ Fusconaia askewi (Texas pigtoe) \\ NISP: 3 valves.}

Remarks: Texas pigtoes are small rhomboidal to elliptical shaped with moderately thick shells. The main criteria used in identification are posterior truncation and ventral indentation near the posterior ridge. F. askewi is often confused with freshwater mussels from the genus Quadrula. 
The three specimens examined were compared to modern samples from the Upper Trinity River Drainage. Texas Pigtoe is a lotic species found inhabiting various substrates and tolerates flowing to standing water (Howells et al. 1996). F. askewi is intolerant to changes in environmental conditions, and thus a reasonable indicator of stream health. The presence of Texas Pigtoe at 41TR170 is unique, in that it exceeds the known modern range for this species.

\author{
Genus Lampsilis \\ NISP: 11 \\ Lampsilis teres (yellow sandshell) \\ NISP: 18 valves. \\ Lampsilis cf. teres (compares favorably with yellow sandshell)
}

NISP: 1 valve.

Remarks: Specimens identified to the genus Lampsilis, possess pseudocardinal teeth synonymous with this genus. The right valve contains two pseudocardinal teeth; the anterior tooth is low and compressed, the posterior tooth is triangular, striated and raised above the hinge line. The left valve is characterized by two divergent, compressed pseudocardinal teeth, which are elevated above the hinge line and may be emarginated in some species. Yellow sandshell is elongate in outline, with thick shells that taper to a point at the posterior margin. The pseudocardinal teeth are typical of species from this genus. The specimens examined were identified to the species level, using modern comparative specimens. The main characteristic used in distinguishing this species from others in the Lampsilis or Ligumia genus is the presence of moderately raised beaks lacking shell ornamentation. Similar to the Texas pigtoe, yellow sandshell is intolerant of environmental perturbations, and is found only in lotic habitats.

\title{
Lampsilis hydiana (Louisiana fatmucket) \\ NISP: 7 valves.
}

Remarks: Specimens identified as Lampsilis hydiana are characterized by being large, swollen and rhomboidal in shape. The umbo is used as the main diagnostic feature to distinguish $L$. hydiana from similar species. The beak cavity for the Louisiana fatmucket is moderately deep; the umbo is raised well above the hinge line and lacks ornamentation such as v-shaped ridges. $L$. hydiana is relatively tolerant of environmental disturbances and can adapt to both lentic and lotic systems. This species can also tolerate low flow and backwater areas (Howells et al. 1996).

\section{Genus Ligumia \\ Ligumia subrostrata (pondmussel) \\ NISP: 15 valves.}

Remarks: Ligumia subrostrata is identified by the presence of wide v-shaped ridges radiating out from the umbo. The use of shell ornamentation for identification is due to similarities in general shell morphology among species in the genus Lampsilis, Toxolasma and Ligumia. Pondmussel, unlike the other species recovered at 41TR170, is unique in that it can tolerate a variety of lotic habitats, but adapts well to small streams, ponds and backwater areas (Howells et al., 1996). The presence of Ligumia subrostrata is also significant, in that it exceeds the known range for this species. 


\section{Genus Plectomerus \\ Plectomerus dombeyanus (bankclimber) \\ NISP: 19 valves. \\ Plectomerus cf. dombeyanus (compares favorably with bankclimber)}

NISP: 3 valves.

Remarks: Specimens identified as $P$. dombeyanus have a pronounced posterior ridge, which extends from the ventral margin and terminates near the umbo. The surface of bankclimber is also used in differentiating this species from Tritogonia verrucosa. Specifically, shell ornamentation in the form of pustules and tubercles is restricted to the beak area, while in $T$. verrucosa shell ornamentation is found throughout the shell surface. The pseudocardinal teeth for these specimens are diagnostic as well: the left valve contains two large, divergent, grooved pseudocardinal teeth separated by a shallow notch. The right valve has one elevated, grooved, pseudocardinal tooth with an anterior and posterior denticle. Bankclimber is often found near the banks or shallow areas of large, slow flowing rivers (Howells et al. 1996). The presence of $P$. dombeyanus is significant because it is found only in these prehistoric assemblages in the north Texas region.

Potamilus purpuratus (bleufer)

NISP: 2 valves.

Potamilus cf. purpuratus (compares favorably with bleufer)

NISP: 1 valve.

Remarks: Bleufer is characterized by having a large oblong, compressed shell that is subrhomboidal to subellipitcal in appearance. None of the specimens from 41TR170 are completely intact, but the thickness of the shell and lack of ornamentation or ridges is useful in identification. The main criterion used in identifying P. purpuratus is the morphology of the pseudocardinal teeth: the left valve contains two large, striated, erect, pseudocardinal teeth separated by a shallow notch. The posterior tooth is square to subrectangular in shape, while the anterior tooth is pointed and always forward of the umbo. The right valve has one slightly compressed pointed pseudocardinal tooth and a thin compressed anterior denticle. Bleufer is found in both lentic and lotic systems, preferring deep bodies of water with muddy to sandy bottoms (Howells et al. 1996).

\section{Genus Quadrula \\ NISP: 12 valves. \\ Quadrula apiculata (southern mapleleaf) \\ NISP: 2 valves.}

Remarks: Specimens identified to the genus Quadrula are classified based on the pseudocardinal teeth, which are fairly conserved throughout this genus. The right valve for quadrulids contains one pseudocardinal tooth, which is rectangular or columnar in shape, heavily striated, and elevated above the hinge line. In some specimens an anterior denticle may be present. The left valve for this genus contains two pseudocardinal teeth, which are rectangular to subtriangular in shape, striated and elevated above the hinge line. The left pseudocardinal teeth tend not to be widely separated, and the anterior tooth is much larger than the posterior pseudocardinal tooth. Southern mapleaf is identified primarily based on shell ornamentation and comparison with contemporary specimens. Both of the valves examined have small pimples anterior to the sulcus. One valve examined is covered entirely with pimples, suggesting that it may have been a juvenile 
(less than two years of age). Q. apiculata is a ubiquitous species able to inhabit both lakes and streams and that tends to establish large populations (Howells et al. 1996). It is interesting to note that only 2 valves were recovered.

\title{
Quadrula mortoni (western pimpleback) \\ NISP: 17 valves.
}

Remarks: Specimens identified as Western Pimpleback have pseudocardinal teeth typical of quadrulids. One important difference is the teeth found in the left valve. The pseudocardinal teeth in the left valve are similar to other members of this genus, except that the anterior tooth is more massive, and tends to be greater in stature than the posterior tooth. The external morphology of the Western pimpleback is another criterion used in differentiating this species. Q. mortoni possesses a heavy, thick shell with little or no ornamentation that may range from globular to subrhombodial in shape. This species may at times be confused with the pigtoe, but can be differentiated based on a more inflated, globular appearance and a posterior ridge that is rounded rather than defined. Western Pimpleback occurs in both lentic and lotic habitats, and appears to be ecophenotypically plastic. The specimens from 41TR170 are more round-shaped, which is indicative of a lotic habitat. The presence of Western Pimpleback at 41TR170 is unique, in that it exceeds the known range for this species. Finally, it is important to note that Quadrula pustulosa morton is used interchangeably with Quadrula mortoni, but should be referred to as $Q$. mortoni based on recent molecular findings (Serb et al. 2003).

\author{
Genus Tritogonia \\ Tritogonia verrucosa (pistolgrip) \\ NISP: 13 valves. \\ Tritogonia $c f$. verrucosa (compares favorably with pistolgrip) \\ NISP: 3 valves.
}

Remarks: Pistolgrip is identified using shell morphology and by comparing pseudocardinal teeth with contemporary specimens. The surface of pistolgrip is covered with pimples, pustules and small tubercles. The overall shape of the valve is elongated and rhomboid in appearance. The valves are thick, and squarely or obliquely truncated near the interface between the posterior and ventral margin. The beaks are slightly elevated above the hinge line and are helpful in differentiating T. verrucosa from bankclimber. The pseudocardinal teeth for these specimens are diagnostic as well: the left valve contains two large, divergent, serrated, triangular pseudocardinal teeth, which may be oblique to one another. The right valve has one elevated, grooved, triangular pseudocardinal tooth with only an anterior denticle. Pistolgrip is a lotic species found often in riffles, but may also tolerate slow flowing rivers (Howells et al., 1996). Like other lotic species, the pistolgrip is intolerant to environmental disturbance.

\section{TAPHONOMY}

A high proportion of vertebrate remains from 41TR170 exhibits weathering (Table H-2), which may account for the low proportion that exhibit green fracturing in that weathering tends to erode fracture morphology. The presence of weathering suggests that many of these remains were exposed on a relatively stable surface for an unknown period; many of these remains were not rapidly buried. On the other hand, NSP:NISP data indicate that remains from the site are not extremely fragmented compared to other sites from Texas (Table H-3; Figure H-2). NSP:NISP is 
Table H-2

Frequencies of Taphonomic Characteristics for the Vertebrate Fauna

\begin{tabular}{llcc} 
Characteristic & NSP & \%NSP \\
\hline a. & weathering & 22 & 8.2 \\
b. burning & 12 & 4.4 \\
c. green fracture & 11 & 4.1 \\
d. carnivore damage & 2 & 0.7 \\
e. & potential cutmarks & 2 & 0.7 \\
\hline
\end{tabular}

Table H-3

Fragmentation Data for Texas Sites Including 41TR170

\begin{tabular}{lcccc} 
Assemblage & NSP & NISP & NSP:NISP & Avg. Weight \\
\hline 41COL172 & 361 & 243 & 1.49 & 1.74 \\
41COL173 & 68 & 40 & 1.7 & 3.39 \\
41BX1623 & 154 & 73 & 2.11 & 1.77 \\
41BX1628 & 85 & 36 & 2.36 & 0.72 \\
41TR170 & $\mathbf{2 6 8}$ & $\mathbf{1 2 3}$ & 2.71 & $\mathbf{1 . 3 8}$ \\
16BO473 & 242 & 81 & 2.99 & 1.26 \\
41BX254/256 & 256 & 60 & 4.27 & 0.84 \\
41BX254 & 82 & 10 & 8.20 & 0.39 \\
\hline
\end{tabular}

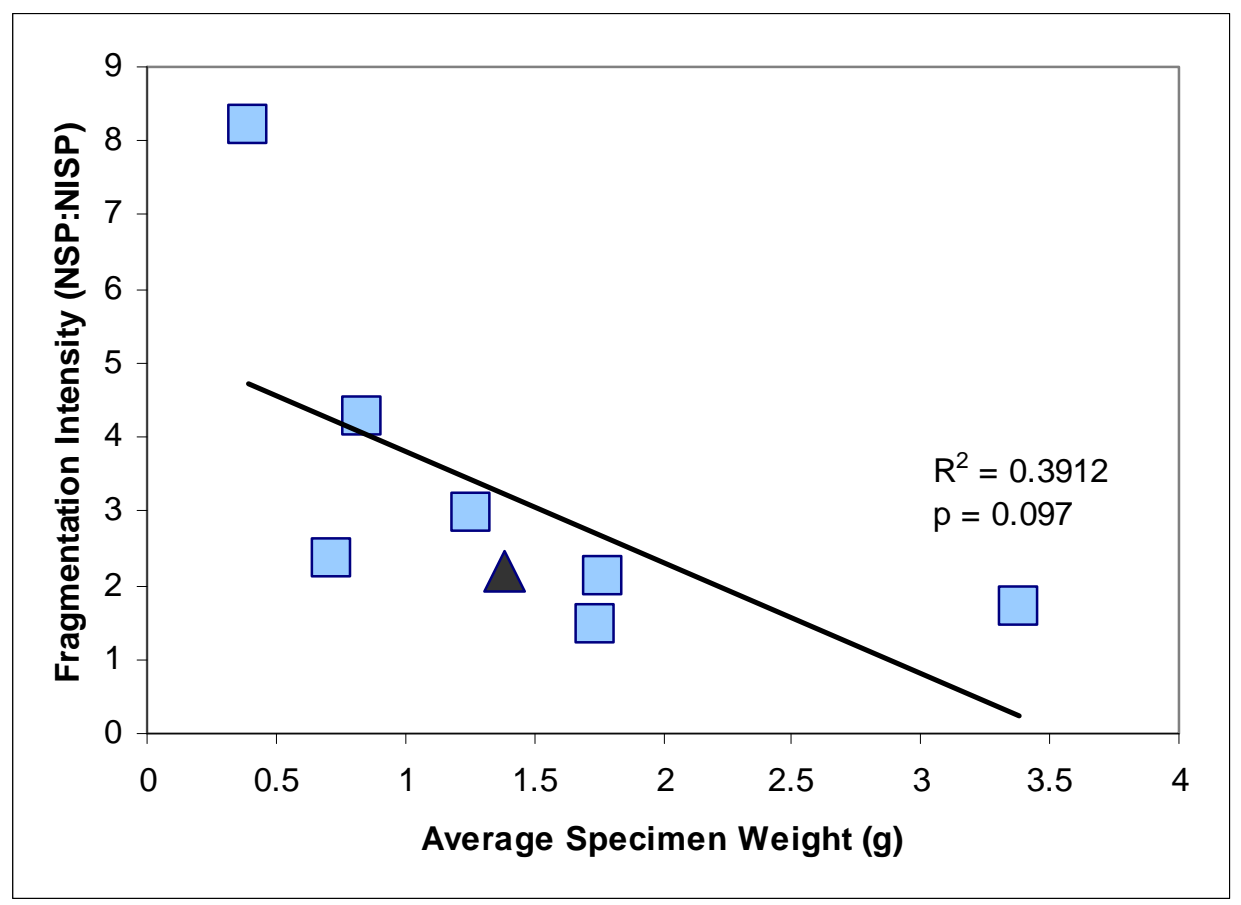

Figure H-2. The relationship between fragment weight and NSP:NISP for sites in Texas (see Table H-3). The sample of assemblages is small, but it demonstrates that as fragment size decreases intensity of fragmentation (NSP:NISP) increases. The 41TR170 fauna is in the middle of the distribution at medium intensity of fragmentation. 
a ratio between the number of vertebrate remains (Number of Specimens [NSP]) in a fauna compared to the Number of Identifiable Specimens (NISP); as the ratio increases a fragment size decreases. Low NSP:NISP suggests low intensity of fragmentation in a fauna in that the proportion of large, identifiable specimens is relatively high. That cutmarks and evidence of burning are infrequent on the vertebrate remains(see Table H-2) and that multiple white-tailed deer elements are relatively whole suggest that the ungulate remains are relatively unmodified by human butchery behaviors. This, however, does not mean that the fauna is not archaeological; the 41TR170 assemblage is taxonomically characteristic of an archaeological rather than a paleontological fauna in that represented taxa, with the exception of Sigmodon hispidus, are commonly thought to have been prey for prehistoric human hunters.

The invertebrate fauna exhibits characteristics related to human use of the remains. Shell remains from Trench 9 are burned, and 11 fragments exhibit modification related incision of the shells presumably to remove portions for use in other contexts (e.g., bead-making or tool-making). Although only a small proportion of the remains exhibit evidence of burning and cutting $(<1 \%)$ this likely relates to the fact shellfish remains tend to be highly fragmented, in this case NSP:NISP is 11.74.

\section{SUMMARY}

This report offers criteria for element and taxonomic identifications. Many of the specimens are too fragmented to provide diagnostic criteria for identification. As a result, only brief discussion of taphonomy is possible (see above). The fauna contains remains of a taxa that are important in terms of biogeography-Bison bison, Plectomerus dombeyanus, Fusconaia askewi, Ligumia subrostrata, and Quadrula mortoni. Further, the invertebrate fauna is important in terms of environmental science in that it reflects prehistoric hydrological conditions in the Upper Trinity River that are less common today (e.g., ubiquitous, perennial, deep-flowing streams). Whitetailed deer are commonly represented as remains of prehistoric diet throughout much of the Midwest and Texas. The cotton rat femur was likely to have been naturally deposited. The fauna is fairly uniform in its taphonomy in that many remains exhibit weathering, which suggests that parts of the fauna were exposed on the surface for some period. 


\begin{tabular}{|c|c|c|c|c|c|c|c|c|}
\hline \multirow[b]{2}{*}{ FS } & \multirow[b]{2}{*}{ Unit } & \multirow[b]{2}{*}{ Level } & \multicolumn{5}{|c|}{$\begin{array}{l}\text { Table H-4 } \\
\text { Vertebrate Remains from Site 41TR170 }\end{array}$} & \multirow[b]{2}{*}{ Comment } \\
\hline & & & Taxon & Element & Side & Number & Weight & \\
\hline 126 & $\mathrm{~T} 24-10$ & 3 & Bison bison & upper molar & $\mathrm{L}$ & 1 & 4.6 & \\
\hline 338 & BHT19E & $100 \mathrm{cmbs}$ & Bison bison & Astragalus & $\mathrm{L}$ & 2 & 32.9 & 2 refit \\
\hline 338 & BHT19E & $100 \mathrm{cmbs}$ & Bison size & Unid & $\mathrm{U}$ & 1 & 3.9 & \\
\hline 54 & $\mathrm{~T} 5$ & Backdirt & Canis sp. & proximal humerus \& shaft & $\mathrm{R}$ & 1 & 32.7 & $\begin{array}{l}\text { Proximal Depth = 47.1; } \\
\text { Proximal breadth = } 33.1\end{array}$ \\
\hline 630 & Blk2-26 & 22 & cf Pseudemys sp. & carapace/plastron & $\mathrm{U}$ & 7 & 0.9 & \\
\hline 630 & Blk2-26 & 22 & cf Pseudemys sp. & carapace fragments & $\mathrm{U}$ & 10 & 4.7 & \\
\hline 630 & Blk2-26 & 22 & cf Pseudemys sp. & proximal humerus \& shaft & $\mathrm{L}$ & 1 & 0.1 & weathered \\
\hline 631 & Blk2-26 & 22 & cf Pseudemys sp. & carapace fragments & $\mathrm{U}$ & 2 & 0.9 & рp\#1 \\
\hline 633 & Blk2-26 & 22 & cf Pseudemys sp. & carapace fragments & $\mathrm{U}$ & 4 & 1.5 & рp\#3 \\
\hline 634 & Blk2-26 & 22 & cf Pseudemys sp. & costal carapace & $\mathrm{R}$ & 1 & 2.4 & pp\#4 \\
\hline 110 & T16-7 & 2 & cf Pseudemys sp. & peripheral carapace & $\mathrm{U}$ & 1 & 1.5 & cutmark \\
\hline 421 & Т22-25 & 19 & cf Pseudemys sp. & carapace & $\mathrm{U}$ & 1 & 2.5 & pp\#12 \\
\hline 148 & T1-1 & 14 & Deer size & metapodial SF & $\mathrm{U}$ & 1 & 3.6 & Weathered; GF \\
\hline 178 & $\mathrm{~T} 22-4$ & F3 & Deer size & ascending ramus & $\mathrm{L}$ & 1 & 0.5 & artifact 37 \\
\hline 568 & Blk2-23 & 20 & Deer size & $\begin{array}{l}\text { medial femur SF } \\
\text { anterior lumbar }\end{array}$ & $\mathrm{R}$ & 1 & 10.8 & GF \\
\hline 627 & Blk2-28 & 22 & Deer size & zygapophysis & $\mathrm{L}$ & 1 & 0.7 & Weathered \\
\hline 593 & Blk2-28 & 20 & Lepus sp. & Illium & $\mathrm{L}$ & 1 & 0.1 & \\
\hline 102 & $\mathrm{~T} 25-6$ & 7 & Mmamm & SF & $\mathrm{U}$ & 3 & 7.2 & 3 refit; weathered \\
\hline 100 & $\mathrm{~T} 25-6$ & 6 & MU & $\mathrm{SF}$ & $\mathrm{U}$ & 2 & 10.8 & Weathered \\
\hline 113 & T16-7 & 5 & MU & SF & $\mathrm{U}$ & 1 & 1.3 & \\
\hline 170 & T1-1 & 17 & MU & $\mathrm{SF}$ & $\mathrm{U}$ & 1 & 0.5 & Weathered \\
\hline 174 & $\mathrm{~T} 23-3$ & 15 & MU & $\mathrm{SF}$ & $\mathrm{U}$ & 1 & 2.8 & Weathered/GF \\
\hline 182 & T1-1 & 15 & MU & $\mathrm{SF}$ & $\mathrm{U}$ & 1 & 0.4 & GF \\
\hline 192 & $\mathrm{~T} 25-6$ & 14 & MU & $\mathrm{SF}$ & $\mathrm{U}$ & 1 & 0.6 & GF \\
\hline 203 & $\mathrm{~T} 22-4$ & 21 & MU & $\mathrm{SF}$ & $\mathrm{U}$ & 1 & 0.4 & Weathered \\
\hline 210 & T25-6 & 12 & MU & SF & $\mathrm{U}$ & 1 & 0.4 & Splinter \\
\hline 245 & T25-6 & 19 & MU & $\mathrm{SF}$ & $\mathrm{U}$ & 3 & 0.9 & Weathered \\
\hline 338 & BHT19E & $100 \mathrm{cmbs}$ & MU & $\mathrm{SF}$ & $\mathrm{U}$ & 1 & 1.1 & GF \\
\hline 591 & Blk2-28 & 21 & MU & SF & $\mathrm{U}$ & 1 & 6.4 & GF \\
\hline 604 & Blk2-27 & 21 & MU & $\mathrm{SF}$ & $\mathrm{U}$ & 1 & 1 & CARB \\
\hline 610 & Blk2-25 & 21 & MU & $\mathrm{SF}$ & $\mathrm{U}$ & 1 & 0.3 & PCARB \\
\hline 610 & Blk2-25 & 21 & MU & SF & $\mathrm{U}$ & 1 & 0.6 & Weathered \\
\hline 635 & Blk2-26 & 21 & MU & $\mathrm{SF}$ & $\mathrm{U}$ & 1 & 2.4 & $\mathrm{pp \# 12;} \mathrm{GF}$ \\
\hline 6 & T16 & $155 \mathrm{cmbs}$ & Odocoileus virginianus & distal humerus & $\mathrm{R}$ & 1 & 10.6 & \\
\hline 113 & T16-5 & 5 & Odocoileus virginianus & Ulna & $\mathrm{R}$ & 2 & 12.7 & $\begin{array}{l}2 \text { fragments (refit) light } \\
\text { carnivore damage }\end{array}$ \\
\hline 113 & T16-5 & 5 & Odocoileus virginianus & Radius & $\mathrm{L}$ & 3 & 22.7 & $\begin{array}{l}3 \text { fragments (refit)/ } 1 \\
\text { possible cutmark distal end/ } \\
\text { partially GF }\end{array}$ \\
\hline 113 & T16-5 & 5 & Odocoileus virginianus & Radius & $\mathrm{R}$ & 1 & 51.1 & complete \\
\hline 113 & T16-5 & 5 & Odocoileus virginianus & Humerus & $\mathrm{R}$ & 7 & 47 & $\begin{array}{l}7 \text { fragments (refit); nearly } \\
\text { complete element }\end{array}$ \\
\hline 113 & T16-5 & 5 & Odocoileus virginianus & Lunar carpal & $\mathrm{L}$ & 1 & 1.9 & \\
\hline 113 & T16-5 & $7 ?$ & Odocoileus virginianus & Scaphoid carpal & $\mathrm{L}$ & 1 & 2.3 & \\
\hline
\end{tabular}

H-14 
Table H-4 (cont'd)

\begin{tabular}{|c|c|c|c|c|c|c|c|c|}
\hline FS & Unit & Level & Taxon & Element & Side & Number & Weight & Comment \\
\hline 113 & T16-5 & 5 & Odocoileus virginianus & Unciform carpal & $\mathrm{L}$ & 1 & 1.2 & \\
\hline 113 & T16-5 & 5 & Odocoileus virginianus & Trapezoid magnum carpal & $\mathrm{L}$ & 1 & 2.1 & \\
\hline 113 & T16-5 & 5 & Odocoileus virginianus & Cunieform carpal & $\mathrm{L}$ & 1 & 1.4 & \\
\hline 113 & T16-7 & 5 & Odocoileus virginianus & Ulna SF & $\mathrm{L}$ & 1 & 6.4 & Weathered \\
\hline 113 & T16-7 & 5 & Odocoileus virginianus & Ulna SF & $\mathrm{R}$ & 1 & 1.2 & \\
\hline & & & & & & & & $\begin{array}{l}\text { Weathered: A1 19.8, A2 } \\
\text { 33.14, A3 29.51, A4 23.92, }\end{array}$ \\
\hline 536 & Blk2-22 & 20 & Odocoileus virginianus & Astragalus & $\mathrm{L}$ & 1 & 12.1 & A5 35.77, A6 20.12 \\
\hline 590 & Blk2-28 & 21 & Odocoileus virginianus & 3rd phalanx & $\mathrm{U}$ & 1 & 2 & \\
\hline 600 & Blk2-20 & 21 & Odocoileus virginianus & 1st phalanx & $\mathrm{U}$ & 3 & 4 & pp\#1; 3 refit \\
\hline & & & & & & & & $\begin{array}{l}\text { Carnivore damage: A1 21.9, } \\
\text { A2 34.5, A3 30.31, A4 }\end{array}$ \\
\hline 612 & Blk2-25 & 21 & Odocoileus virginianus & Astragalus & $\mathrm{R}$ & 1 & 11.2 & 24.29, A5 37.63, A6 21.07 \\
\hline 178 & $\mathrm{~T} 22-4$ & F3 & Pisces & Unid & $\mathrm{U}$ & 1 & 0.6 & artifact 38 \\
\hline 590 & Blk2-28 & 21 & Pisces (large) & vertebrae & $\mathrm{U}$ & 1 & 1.3 & \\
\hline 334 & BHT22-21 & 19 & Sigmodon hispidus & proximal femur \& shaft & $\mathrm{R}$ & 1 & 0.1 & \\
\hline 630 & Blk2-26 & 22 & Sylvilagus floridanus & Anterior mandible w/ P4 & $\mathrm{R}$ & 1 & 0.1 & \\
\hline 546 & Blk2-25 & 20 & Terrepene sp. & costal carapace & $\mathrm{U}$ & 1 & 0.5 & \\
\hline 610 & Blk2-25 & 21 & Terrepene sp. & vertebral carapace & $\mathrm{U}$ & 1 & 0.6 & \\
\hline 110 & $\mathrm{~T} 16-7$ & 2 & Testudinata & plastron fragments & $\mathrm{U}$ & 3 & 0.1 & PCAL \\
\hline 145 & T21-5 & 19 & Testudinata & plastron fragments & $\mathrm{U}$ & 4 & 1.4 & \\
\hline 324 & Т22-21 & F3 & Testudinata & carapace/plastron & $\mathrm{U}$ & 3 & 0.8 & \\
\hline 334 & ВНТ22-21 & 19 & Testudinata & peripheral carapace & $\mathrm{U}$ & 1 & 0.4 & \\
\hline 337 & Т22-20 & 19 & Testudinata & plastron fragments & $\mathrm{U}$ & 2 & 0.1 & \\
\hline 398 & ВНT22-22 & 19 & Testudinata & carapace & $\mathrm{U}$ & 3 & 1.1 & \\
\hline 418 & Т22-24 & 19 & Testudinata & plastron/carapace & $\mathrm{U}$ & 2 & 0.7 & \\
\hline 421 & Т22-25 & 19 & Testudinata & plastron fragment & $\mathrm{U}$ & 1 & 1.7 & \\
\hline 560 & Blk2-23 & 20 & Testudinata & carapace fragment & $\mathrm{U}$ & 1 & 0.3 & \\
\hline 563 & 23 & 20 & Testudinata & plastron fragments & $\mathrm{U}$ & 4 & 1.2 & \\
\hline 589 & Blk2-22 & 21 & Testudinata & plastron fragments & $\mathrm{U}$ & 2 & 0.7 & \\
\hline 592 & Blk2-28 & 21 & Testudinata & carapace fragment & $\mathrm{U}$ & 1 & 0.1 & \\
\hline 604 & Blk2-27 & 21 & Testudinata & plastron fragments & $\mathrm{U}$ & 2 & 0.5 & \\
\hline 607 & Blk2-26 & 21 & Testudinata & carapace fragments & $\mathrm{U}$ & 2 & 0.8 & \\
\hline 610 & Blk2-25 & 21 & Testudinata & carapace/plastron & $\mathrm{U}$ & 1 & 0.2 & \\
\hline 21 & $\mathrm{~T} 1-1$ & 9 & Unid & Unid & $\mathrm{U}$ & 2 & 0.7 & 2 refit \\
\hline 47 & T23-3 & 2 & Unid & Unid & $\mathrm{U}$ & 2 & 1.2 & \\
\hline 100 & T25-6 & 6 & Unid & Unid & $\mathrm{U}$ & 1 & 0.1 & \\
\hline 102 & T25-6 & 7 & Unid & Unid & $\mathrm{U}$ & 14 & 1.7 & \\
\hline 102 & T25-6 & $\&$ & Unid & Unid & $\mathrm{U}$ & 1 & 0.1 & CAL \\
\hline 108 & Т28-9 & 5 & Unid & Unid & $\mathrm{U}$ & 1 & 0.9 & \\
\hline 113 & T16-5 & 5 & Unid & Unid & $\mathrm{U}$ & 3 & 0.3 & \\
\hline 113 & T16-5 & 5 & Unid & Unid & $\mathrm{U}$ & 6 & 0.8 & \\
\hline 113 & T16-5 & 5 & Unid & Unid & $\mathrm{U}$ & 23 & 4.1 & \\
\hline 124 & Т28-19 & 7 & Unid & Unid & $\mathrm{U}$ & 4 & 0.2 & \\
\hline 126 & T24-10 & 3 & Unid & Unid & $\mathrm{U}$ & 2 & 0.4 & \\
\hline 133 & T22-4 & F3 180-183 & Unid & Unid & $\mathrm{U}$ & 3 & 0.1 & \\
\hline 146 & T22-4 & 18 & Unid & Unid & $\mathrm{U}$ & 1 & 0.1 & \\
\hline
\end{tabular}


Table H-4 (cont'd)

\begin{tabular}{|c|c|c|c|c|c|c|c|c|}
\hline FS & Unit & Level & Taxon & Element & Side & Number & Weight & Comment \\
\hline$\overline{192}$ & Т25-6 & 14 & Unid & Unid & $\mathrm{U}$ & 1 & 0.1 & PCAL \\
\hline 195 & Т26-6 & 11 & Unid & Unid & $\mathrm{U}$ & 1 & 0.2 & PCAL \\
\hline 203 & T22-4 & 21 & Unid & Unid & $\mathrm{U}$ & 3 & 0.6 & Weathered \\
\hline 219 & T22-4 & F3 & Unid & Unid & $\mathrm{U}$ & 6 & 0.9 & \\
\hline 232 & T22-4 & 19 & Unid & Unid & $\mathrm{U}$ & 2 & 0.4 & \\
\hline 234 & T22-4 & 21 & Unid & Unid & $\mathrm{U}$ & 2 & 0.6 & Weathered \\
\hline 242 & T25-6 & 17 & Unid & Unid & $\mathrm{U}$ & 1 & 0.6 & 2 splinters (refit) \\
\hline 324 & $\mathrm{~T} 22-21$ & F3 & Unid & Unid & $\mathrm{U}$ & 5 & 4.2 & \\
\hline 324 & $\mathrm{~T} 22-21$ & F3 & Unid & Unid & $\mathrm{U}$ & 10 & 0.8 & \\
\hline 337 & ВНТ22-20 & $19 \mathrm{~F} 12$ & Unid & Unid & $\mathrm{U}$ & 3 & 0.1 & \\
\hline 342 & $\mathrm{~T} 22-23$ & $19 \mathrm{~F} 12$ & Unid & Unid & $\mathrm{U}$ & 1 & 0.1 & \\
\hline 398 & ВНT22-22 & 19 & Unid & Unid & $\mathrm{U}$ & 2 & 0.2 & \\
\hline 400 & Blk2-23 & 19 & Unid & Unid & $\mathrm{U}$ & 1 & 0.2 & \\
\hline 420 & T22-25 & & Unid & Unid & $\mathrm{U}$ & 1 & 0.1 & $\mathrm{pp} \# 11$ \\
\hline 424 & T22-27 & 19 & Unid & Unid & $\mathrm{U}$ & 2 & 1 & \\
\hline 451 & Blk3-33 & 10 & Unid & Unid & $\mathrm{U}$ & 1 & 0.2 & \\
\hline 486 & Blk3-35 & $11 \& 12$ F17 & Unid & Unid & $\mathrm{U}$ & 1 & 0.1 & \\
\hline 509 & Blk3-35 & 12 & Unid & Unid & $\mathrm{U}$ & 2 & 0.3 & CARB \\
\hline 540 & Blk2-24 & 20 & Unid & Unid & $\mathrm{U}$ & 8 & 0.4 & \\
\hline 558 & Blk2-25 & 20 & Unid & Unid & $\mathrm{U}$ & 3 & 0.1 & \\
\hline 559 & Blk2-28 & 20 & Unid & Unid & $\mathrm{U}$ & 2 & 0.2 & \\
\hline 563 & 23 & 20 & Unid & Unid & $\mathrm{U}$ & 1 & 0.1 & CAL \\
\hline 589 & Blk2-22 & 21 & Unid & Unid & $\mathrm{U}$ & 1 & 0.1 & \\
\hline 590 & Blk2-28 & 21 & Unid & Unid & $\mathrm{U}$ & 3 & 0.2 & \\
\hline 593 & Blk2-28 & 20 & Unid & Unid & $\mathrm{U}$ & 6 & 0.3 & \\
\hline 601 & Blk2-20 & 21 & Unid & Unid & $\mathrm{U}$ & 1 & 1 & pp\#2 \\
\hline 604 & Blk2-27 & 21 & Unid & Unid & $\mathrm{U}$ & 7 & 1.3 & \\
\hline 616 & Blk2-23 & 21 & Unid & Unid & $\mathrm{U}$ & 1 & 0.1 & CARB \\
\hline 627 & Blk2-28 & 22 & Unid & Unid & $\mathrm{U}$ & 1 & 0.5 & \\
\hline 638 & Blk2-27 & 22 & Unid & Unid & $\mathrm{U}$ & 1 & 0.1 & \\
\hline 720 & Blk2-26 & 20 & Unid & Unid & $\mathrm{U}$ & 1 & 0.3 & \\
\hline 639/637? & Blk2-27 & 22 & Unid & Unid & $\mathrm{U}$ & 1 & 0.1 & \\
\hline
\end{tabular}




\section{REFERENCES CITED}

Dixon, J. R.

1987 Amphibians and Reptiles of Texas. Texas A \& M University Press, College Station.

Dunn, J. P., J. A. Chapman, et al.

1982 Jackrabbits (Lepus californicus and Allies). Wild Mammals of North America: Biology, Management, Economics. J. A. Chapman and G. A. Feldhamer. Johns Hopkins Press, Baltimore.

Ernst, C. H., R. W. Barbour, et al.

1994 Turtles of the United States and Canada. Smithsonian Institution Press, Washington, D.C.

Garrett, J. M., and D. G. Barker

1987 A Field Guide to Reptiles and Amphibians of Texas. Gulf Publishing Company, Houston.

Hall, E. R.

1981 The Mammals of North America, Second Edition. Wiley, New York.

Hamilton, W. J., and J. O. J. Whitaker

1979 Mammals of the Eastern United States. Cornell University Press, Ithaca.

Howells, R. G., R. W. Neck, et al.

1996 Freshwater Mussels of Texas. Texas Parks and Wildlife Department, Austin.

Jones, J. K. J., D. M. Armstrong, et al.

1985 Guide to Mammals of the Plains States. University of Nebraska Press, Lincoln.

Krantz, G. S.

1959 "Distinctions between the skulls of coyotes and dogs. ." Kroeber Anthropological Society Papers 21: 40-45. 
Lawrence, B.

1951 "Post-cranial skeletal characteristics of deer, pronghorn, and sheep-goat with notes on Bos and Bison." Papers of the Peabody Museum of American Archaeology and Ethnology, Harvard University 35(3)(3).

Lyman, R. L.

1994 Vertebrate Taphonomy. Cambridge University Press, New York.

Nowak, R. M.

1979 "North American Quaternary Canis." Monographs of the Museum of Natural History, University of Kansas 6.

Olsen, S. J.

1960 "Post-cranial skeletal characters of Bison and Bos." Papers of the Peabody Museum of American Archaeology and Ethnology, Harvard University, 35(4).

Peacock, E.

2000 "Assessing bias in archaeological shell assemblages." Journal of Field Archaeology 27:183-196.

Perttula, T. K. (editor)

2004 The Prehistory of Texas. Texas A \& M University Press, College Station.

Purdue, J. R.

1987 "Estimation of body weight of white-tailed deer (Odocoileus virginianus) from central Illinois." Journal of Ethnobiology 7:1-12.

1989 "Changes during the Holocene in the size of white-tailed deer (Odocoileus virginianus) from central Illinois." Quaternary Research 32:307-316.

Schmidly, D. J.

1994 The Mammals of Texas, Revised Edition. University of Texas Press, Austin.

Serb, J. M., J. E. Buhay, et al.

2003 "Molecular systematics of the North American freshwater genus Quadrula (Unionidae: Ambleminae) based on mitochondrial ND1 sequences." Molecular Phylogenetics and Evolution 28:1-11.

Smith, W. P.

1991 “Odocoileus virginianus.” Mammalian Species 388:1-13.

Von den Driesch, A.

1976 "A guide to the measurement of animal bones from archaeological sites." Bulletin of the Peabody Museum of Archaeology and Ethnology 1.

Wolverton, S.

2002 "Zooarchaeological evidence of prairie taxa in central Missouri during the midHolocene.” Quaternary Research 58:200-204. 
2005 "The effects of the Hypsithermal on prehistoric foraging efficiency in Missouri." American Antiquity 70:91-106.

Wolverton, S., J. H. Kennedy, et al.

2007 "A paleozoological perspective on white-tailed deer (Odocoileus virginianus texana) population density and body size in central Texas." Environmental Management 39:545-552. 



\title{
APPENDIX I
}

\section{STRATIGRAPHIC DESCRIPTIONS OF 28 TRENCHES AT SITE 41TR170, TARRANT COUNTY, TEXAS}

\author{
by \\ Stephen A. Hall, Ph.D. \\ Red Rock Geological Enterprises
}



Stratigraphy of 28 trenches, site 41TR170, Tarrant County, Texas; texture follows Wentworth scale; dry sediment color from Munsell Soil Color Charts where indicated; numbers are centimeters depth from modern [2005] surface; radiocarbon dates are summarized in Table 4.

Trench 1 (South), located perpendicular to south-side bend in old Clear Fork channel; photograph of West Fork paleosol and post-paleosol contact shown in Figure 7

0-53 cm Post-paleosol alluvium, grayish brown (10YR 5/2), silt, clayey, sandy, massive with no visible bedding, calcareous but no visible carbonates, occas. land snail shell (Rabdotus) and shell fragments, no pebbles, soft when damp, hard when dry, earth worm and burrowing insect traces, A horizon soil absent at upper surface; lower boundary with paleosol indistinct and gradational due to bioturbation across boundary

53-182 West Fork paleosol, dark grayish brown (10YR 4/2), silt, clayey, sandy, massive without visible bedding or microstratigraphy, absence of slickensides, soft when damp, hard when dry, calcareous but no visible carbonates, occas. land snail shells (Rabdotus, Helicina), earth worm traces throughout; lower boundary grades to underlying silt within a few centimeters; lower boundary of paleosol is not at same depth and is $23 \mathrm{~cm}$ more shallow elsewhere in trench exposure; some carbonate filaments occur in lower $14 \mathrm{~cm}$ of paleosol at measured section (fewer in upper and more in lower part of this zone); isolated mussel shell at $95 \mathrm{~cm}$ depth; isolated in situ stones at 92 and $112 \mathrm{~cm}$ depth and 2 stones, one on top of the other, at $133 \mathrm{~cm}$ depth; conventional radiocarbon age on bulk sediment from $66-72 \mathrm{~cm}$ depth is 1240 $\pm 40{ }^{14} \mathrm{C}$ yrs B.P. (Beta-205063); age represents near last stage of paleosol development

182-194+ Pre-paleosol alluvium, grayish brown to brown (10YR 5/2-3), silt, clayey, sandy, occas. pebbles $(<8 \mathrm{~mm}$ dia.), massive with no visible bedding, calcareous with abundant carbonate filaments; isolated mussel shell at $188 \mathrm{~cm}$ depth

Trench 1 (North), south edge of old Clear Fork channel; trench dissects the old floodplain containing the paleosol sequence (described below) and adjacent slumped sediment along right bank of old channel

0-47 cm Post-paleosol alluvium, grayish brown, silt, clayey, sandy, massive with no visible bedding, soft, earth worm traces, calcareous with no visible carbonates

47-165 West Fork paleosol, dark grayish brown, silt, clayey, sandy, massive, calcareous, occas. faint carbonate filaments throughout (filaments absent in trench 1 south section), soft when damp, occas. land snail shells (Rabdotus); lower $16 \mathrm{~cm}$ of paleosol has low to moderate number of carbonate filaments; isolated in situ stone at $88 \mathrm{~cm}$ depth

165-186+ Pre-paleosol alluvium, grayish brown, silt, clayey, sandy, occas. pebble $(<10 \mathrm{~mm}$ dia.), massive, hard, calcareous with large number of carbonate filaments

Within 2 meters north of the above section, the sediment exposed in the trench is a deposit of unstratified grayish brown clayey silt that slumped into the old Clear Fork channel. 
Trench 2, located just north of trench 1 in the south edge of the old Clear Fork channel

0-115+cm Mixed and pseudo-stratified deposit of limestone blocks, yellowish brown clay with rounded gravels, grayish brown silt and clay with gravels, decaying wood; this material represents artificial fill that was dumped in the old channel sometime within the past 50 years

Trench 3, located in middle of old channel of Clear Fork

0-180+ cm Mixture of limestone blocks, yellowish clay with rounded gravels, brown sandy clay with gravels; this material represent artificial fill in the old channel

Trench 4, located at lowest point in old Clear Fork channel

$0-175+\mathrm{cm}$ Mixture of limestone blocks and brown sandy clay with gravels; this material is artificial fill in the old channel and means that the original channel floor (if still intact) occurs below 2 meters or more below the present surface of the artificial fill deposit

Trench 5, located on the slope of the north bank (inside bend) of the old Clear Fork channel; sandy deposits (rare in the study area) may represent weak point-bar development on the inside curve of the old channel

0-52 cm Limestone blocks, resting on old slope of channel bank deposits; pieces of undecomposed wood at base of rubble; this debris layer at the top of the trench exposure thickens from 15 to $75 \mathrm{~cm}$ north-to-south towards channel, sharp basal contact with underlying deposits

52-172+ Medium light brown, sand, fine to very fine, lenses of sand 5-6 cm thick, calcareous but no visible carbonates, occas. pebble, land snail shells (Rabdotus), sand bedding discontinuous due to severe bioturbation by rodent-sized burrows; a massive block of grayish brown clayey silt at north end of trench exposure may represent a slumped mass of the West Fork paleosol and associated flood-terrace alluvium

Trench 6, located on the floodplain north of the old Clear Fork channel

0-65 cm Post-paleosol alluvium, grayish brown, silt, clayey, fine sand, massive with lack of distinct bedding, soft when damp, calcareous but with no visible carbonates, occas. land snail shell (Rabdotus, Helicina), earthworm traces, bone fragment at $36 \mathrm{~cm}$ depth; A horizon soil absent from top of sequence; AMS radiocarbon age on charcoal from $35-42 \mathrm{~cm}$ depth is $150 \pm 40{ }^{14} \mathrm{C}$ yrs B.P. (Beta-204912)

65-160 West Fork paleosol, dark grayish brown, silt, clayey, fine-very fine sand, massive with absence of bedding features, soft when damp, hard when dry, calcareous but no visible carbonates, earthworm traces, lower $12 \mathrm{~cm}$ of paleosol has small number of weak carbonate filaments, basal contact transitional with underlying lighter-colored silt 
160-205+ Pre-paleosol alluvium, grayish brown silt, clayey, sandy, massive with absence of bedding, hard, calcareous with carbonate filaments in pockets, more filaments that in lower part of paleosol; AMS radiocarbon age on charcoal from 200-205 cm depth is $2360 \pm 40{ }^{14}$ C yrs B.P. (Beta-204913)

Trench 7, located north of and adjacent old Clear Fork channel just north of Trench 5

0-68 cm Post-paleosol alluvium, grayish brown, silt, clayey, fine-very fine sand, massive with lack of bedding features, soft when damp, calcareous but without visible carbonates, occas. land snail shell (Rabdotus), earthworm traces

68-204 West Fork paleosol, dark grayish brown, silt, clayey, fine-very fine sand, massive, occas. land snail shell, calcareous but no visible carbonates, base of paleosol grades to underlying lighter colored silt within $10 \mathrm{~cm}$

204-222+ Pre-paleosol alluvium, grayish brown silt, clayey, massive with no bedding features, occas. land snail shell (Rabdotus), calcareous with carbonate filaments, no carbonate nodules

Trench 8, located just north of old Clear Fork channel along with Trenches 9 and 28

0-34 cm Post-paleosol alluvium; grayish brown clay, silty, very fine sand, massive with no bedding, soft, occas. land snails, earthworm traces, calcareous but no visible carbonates, numerous rootlets

34-120 West Fork paleosol; dark grayish brown, clay, silty and sandy, very fine sand, massive with no bedding structures, occas. isolated land snails (Rabdotus, Helicina), calcareous but with no visible carbonates even at base, occas. isolated rounded limestone pebbles $(<25 \mathrm{~mm}$ diameter) in lower $25 \mathrm{~cm}$ of paleosol; paleosol developed on gravels with gradational contact with underlying gravels

120-135 Gravels, limestone, unbedded, rounded, matrix is grayish brown clay, clasts $<80 \mathrm{~mm}$ long axis, rounded gravels have yellow weathering rinds $(<2.0 \mathrm{~mm})$ and are coated with secondary carbonates $(<1.0 \mathrm{~mm})$ suggesting these gravels are recycled from older deposit; larger clasts $(>80 \mathrm{~mm})$ are angular and lack weathering rinds and carbonate coats indicating short-distance fluvial transport and contemporaneous origin with time of deposition and not recycled from older deposits

135-146 Grayish brown clay, silty, sandy, massive, hard, occas. isolated rounded limestone pebble, calcareous but no visible carbonates

146-158 Gravels, limestone, unbedded, rounded, matrix is grayish brown sandy silty clay; same properties as gravels at $120-135 \mathrm{~cm}$ depth

158-194+ Grayish brown clay, silty, sandy, massive, hard, occas. isolated rounded limestone pebble, moderate development of carbonate filaments below $160 \mathrm{~cm}$ depth 
Trench 9, located just north of old Clear Fork channel

0-54 cm Post-paleosol alluvium; grayish brown clay, silty, sandy, massive with no bedding structures, soft, no pebbles, occas. isolated land snails (Rabdotus), calcareous but no visible carbonates

54-119 West Fork paleosol; dark grayish brown clay, sandy, silty, soft, occas. land snails, line of pebbles (limestone, rounded, $<20 \mathrm{~mm}$ dia.) at $74 \mathrm{~cm}$ depth $(20 \mathrm{~cm}$ below top of paleosol), occas. isolated pebbles to base of paleosol

119-163 Gravels, limestone, unbedded, rounded, weathering rind, carbonate coats, class generally $<50 \mathrm{~mm}$ dia. (1 limestone clast $130 \mathrm{~mm}$ dia.); matrix is a grayish brown silty sandy clay; this gravel bed may correspond to the 2 gravel beds in adjacent Trench 8

163-190+ Grayish brown clay, silty, sandy, massive, hard, moderate development of carbonate filaments, no gravels visible

Trench 10, located on south (right) bank of old Clear Fork channel immediately adjacent to Trench 11

0-46 cm Post-paleosol alluvium; grayish brown clay, silty, very sandy, massive, soft, calcareous, no visible carbonates, numerous land snail shells including broken shell fragments

46-96 West Fork paleosol; dark grayish brown, clay, silty, sandy, massive, soft when wet, calcareous but no carbonate filaments, occas. isolation land snails (Rabdotus), grades into underlying gray clay

96-180 Grayish brown clay, silty, sandy, massive without bedding structures, soft when damp, calcareous but without filaments; 2 large isolated stones + mussel shell at 101$106 \mathrm{~cm}$ depth and another isolated stone at $159 \mathrm{~cm}$ depth, stones are rounded limestone pebbles 40 to $50 \mathrm{~mm}$ dia.

180-228+ Dark grayish brown clay, silty, sandy, massive without bedding, calcareous but without carbonate filaments except lower $8 \mathrm{~cm}$ of paleosol that has low concentration of carbonate; this lower dark gray zone (not observed in other trenches) may represent an early stage of cumulic (paleosol) soil development that was interrupted by a brief period of more rapid sedimentation resulting in a local zone of lightercolored clay (96-180 cm depth)

Trench 11, located at south edge of old Clear Fork channel, cutting into slump deposits and rubble (mixture of yellow clay and rounded limestone gravels from sewer line excavation) along channel cut bank

0-52 cm Post-paleosol alluvium; grayish brown clay, very sandy, silty, soft, massive with no bedding structures, calcareous but no visible carbonates, rare land snails and common fragments of land snail shells, earthworm traces 
52-110+ West Fork paleosol; dark grayish brown clay, very sandy, silty, soft when wet, massive, calcareous but no filaments, land snails, sand increases with depth; base of paleosol not exposed in this trench

Trench 12, located south side of old Clear Fork channel, just south of Trenches 10 and 11; West Fork paleosol is thinner in this area

0-51 cm Post-paleosol alluvium; grayish brown clay, sandy, silty, massive without bedding structures, soft, common land snail shells; burned tree stump partially buried at base of this unit overlying paleosol and possibly into upper-most level of paleosol (charcoal collected for radiocarbon dating)

51-110 West Fork paleosol; dark grayish brown, clay, silty, sandy, massive without bedding structures, soft when damp, calcareous with weak carbonate filaments throughout paleosol (unusual occurrence) except upper $10 \mathrm{~cm}$, occas. land snail shells

110-198+ Pre-paleosol alluvium; grayish brown clay, silty, sandy, massive without bedding, soft, occas. land snail shells (Rabdotus, Helicina) + aquatic snail shells (Helisoma); lower $20 \mathrm{~cm}$ hard and with dense carbonate filaments

Trench 13, located on south edge of old Clear Fork channel between two gullies that have cut into the bank; the gullies are likely modern and the large west-most gully may have been artificially cut and widened; a linear mound or berm is located just southwest of Trench 13 along the east edge of the wide gully; the absence of post-paleosol alluvium at this locality is evidence that earth-moving activity has altered the surface here recently

0-180 cm West Fork paleosol; dark grayish brown clay, silty, sandy, massive without bedding or pedogenic structures, occas. land snail shells, soft, calcareous but no filaments except very weak filaments below $80 \mathrm{~cm}$ depth

180-205+ Pre-paleosol alluvium; grayish brown, silty, sandy, massive, moderately hard, calcareous with numerous carbonate filaments

Trench 14, located south of old Clear Fork channel; location of 3 radiocarbon ages in stratigraphic succession

0-40 cm Post-paleosol alluvium; grayish brown clay, silty, massive without bedding, soft, occas. land snail shells (Rabdotus, Helicina), numerous rootlets, earthworm traces, calcareous without carbonate filaments except in basal $4-5 \mathrm{~cm}$ above gradational contact with underlying paleosol (unusual occurrence of carbonate filaments in postpaleosol sediments)

40-105 West Fork paleosol; dark grayish brown clay, silty, sandy, soft, massive with bedding, occas. land snail shells (Rabdotus), calcareous with moderate density carbonate filaments (unusual occurrence of any carbonate filaments) although less dense than in underlying sediment; conventional radiocarbon age on bulk sediment from $48-53 \mathrm{~cm}$ depth near top of paleosol is $860 \pm 70{ }^{14} \mathrm{C}$ yrs B.P. (Beta-205060); conventional radiocarbon age on bulk sediment from 99-105 cm depth near base of paleosol is $1530 \pm 40{ }^{14} \mathrm{C}$ yrs B.P. (Beta-205059) 
105-215+ Pre-paleosol alluvium; grayish brown clay, silty, very fine sand, massive, hard, calcareous with weak carbonate filaments throughout; occas. land snail shells (Rabdotus); zone of detritus at 205-215 cm depth at base of trench, includes numerous land snails (Rabdotus, Helicina), aquatic snails (Helisoma, Physa), charcoal; AMS radiocarbon age on charcoal from $205-215 \mathrm{~cm}$ depth is $1630 \pm 40{ }^{14} \mathrm{C}$ yrs B.P. (Beta-204911)

Trench 15, located south of Trench 14, farther south from the old Clear Fork channel; the surface in this area is disturbed and the material overlying the West Fork paleosol is rubble from a former gravel quarry operation; the top of the paleosol is probably missing as well

0-17 cm Rubble; grayish and yellowish brown clay with rounded limestone gravels, massive deposit without bedding; sharp basal contact with underlying paleosol

17-85 West Fork paleosol; dark grayish brown clay, silty, massive without bedding structures, soft, calcareous, gradational contact with underlying clay

85-236+ Grayish brown clay, silty, massive with no bedding structures, occas. land snails (Rabdotus), calcareous with weak carbonate filaments, lighter sediment color with increasing depth, lower $20 \mathrm{~cm}$ is zone of scattered rounded limestone gravels in gray clay, gravels have thin carbonate coats

Trench 16, located between Trenches 14 and 15

0-49 cm Post-paleosol alluvium, grayish brown clay, silty, sandy, very fine sand, massive without bedding structures, soft, calcareous, occas. weak carbonate filaments, earthworm traces, deer leg bone in situ at $41 \mathrm{~cm}$ depth

49-142 West Fork paleosol; dark grayish brown clay, silty, massive without bedding, absence of ped structures, soft, calcareous with moderate density of carbonate filaments on inside of root casts, earthworm traces, narrow lens of land snail shells (Helicina) at 70-72 $\mathrm{cm}$ below top of paleosol

142-180+ Grayish brown clay, silty, very fine sand, massive, no pebbles, hard, calcareous, weak carbonate filaments

Trench 17, located on south side of old Clear Fork channel; top of West Fork paleosol and overlying deposits were removed sometime ago by local quarrying operations

0-66 West Fork paleosol; dark grayish brown clay, silty, sandy, massive with no bedding, occas. land snails and land snail shell fragments (Rabdotus), earthworm traces, numerous rootlets, calcareous but without carbonate filaments, lower boundary gradational with underlying clay

66-127 Grayish brown clay, silty, sandy, massive without bedding, moderately hard, no pebbles, calcareous, very weak carbonate filaments lower $15 \mathrm{~cm}$ of this unit

127-165 Gravels, limestone, rounded, generally $<30 \mathrm{~mm}$ dia., gray clay matrix, weak carbonate filaments in clay 
165-191+ Grayish brown clay, silty, sandy, massive, hard, calcareous, moderate amount of carbonate filaments; no pebbles; land snail fragments

Trench 18, located in south-most area of project in a group of 3 Trenches $(18,19,20)$; upper deposits are disturbed and the upper part of the paleosol may be missing

0-18 cm Disturbed material; yellowish brown clay, silty, massive, soft, calcareous, no carbonate filaments, sharp basal contact with underlying paleosol; a few small $(4 \mathrm{~mm}$ dia.) burrow fills across yellow clay-paleosol boundary

18-74 West Fork paleosol; dark grayish brown clay, silty, sandy, massive with absence of bedding, calcareous without carbonate filaments, numerous roots and rootlets, occas. land snails (Rabdotus), earthworm traces; exceptionally thin paleosol at this trench may be due to loss of its upper section during nearby gravel quarrying activity

74-100 Gravels, gravel-to-gravel contact, dark grayish brown silty clay matrix (lithology of paleosol), gravels lack sorting or internal bedding structure, gravels well rounded, generally $<40 \mathrm{~mm}$ dia., largest individual clast $120 \mathrm{~mm}$ dia., gravels include Cretaceous oyster fossils, gravels and matrix have carbonate filaments, whitish limestone gravels have ca. $1 \mathrm{~mm}$-thick yellow weathering rinds (some gravels do not have weathering rinds), gravels generally lack carbonate coats (lost during transport?); gravels appear to have accumulated in a single flood event and may have been recycled from an upstream Pleistocene terrace; sharp irregular basal contact with underlying yellow clay, a few large flat stones at contact

100-198 Pre-paleosol alluvium, yellowish brown clay, silty, massive without bedding, occas. isolated rounded limestone pebble (no lenses, only isolated individuals), weak carbonate filaments in lower $30 \mathrm{~cm}$ of yellow clay unit; conventional radiocarbon age from 186-198 cm depth is $2910 \pm 60{ }^{14} \mathrm{C}$ yrs B.P. (Beta-205061); age is oldest alluvium from post-dating the cemented gravels

198-228+ Cemented gravels, gravel-to-gravel contact, yellow clay matrix, gravels exhibit weak sorting, rounded, limestone, clasts generally $<20 \mathrm{~mm}$ dia., large individual clast to 40 $\mathrm{mm}$ dia., carbonate coats ca. $0.5 \mathrm{~mm}$ thick, whitish limestone gravels have $2 \mathrm{~mm}$ thick yellow weathering rinds, cemented masses of gravels occur in lenses instead of single layer (although this is the upper weathered $30 \mathrm{~cm}$ surface of what may be a much larger deposit and the gravel exposure in this and adjacent trenches may not be representative); secondary carbonates appear water table related rather than pedogenic; degree of cementation and thickness of weathering rinds indicate that this gravel deposit may be Pleistocene

Trench 19, south-most group of trenches $(18,19,20)$ farthest from old channel of Clear Fork; the ground surface has been disturbed in this area; the uppermost material is not an in situ deposit and the upper section of the West Fork paleosol may be missing

0-32 cm Disturbed material; yellowish brown sand, clayey, massive, sharp basal contact with underlying paleosol 
32-73 West Fork paleosol, dark grayish brown clay, silty, massive with no bedding, soft when wet, calcareous but no visible carbonates, occas. land snail shells (Rabdotus), absence of pebbles, paleosol grades into underlying gravels

73-89 Gravels, limestone, rounded, generally $<50 \mathrm{~mm}$ dia., largest size class 4-16 mm dia., includes Cretaceous oyster fossils, gravel-to-gravel contact, dark grayish brown silty clay matrix, gravel layer thins toward the east in trench exposure

89-182 Pre-paleosol yellow clay alluvial unit; yellowish brown clayey sand, massive without bedding, occas. isolated rounded limestone pebbles $(<50 \mathrm{~mm}$ dia.), calcareous with weak carbonate filaments; gradational color shift with increasing depth from grayish to yellowish brown in upper $30 \mathrm{~cm}$ of unit; sharp irregular basal contact with underlying cemented gravels

182-190+ Cemented gravels, limestone, rounded, generally $<40 \mathrm{~mm}$ dia., gravel-to-gravel contact, yellowish brown clay matrix, gravels with yellow weathering rinds and carbonate coats; hard masses of cemented gravels (not a single layer); same cemented gravels exposed at the base of trench 18; probably Pleistocene in age

Trench 20, located in south-most area of project; upper deposits have been removed during local gravel quarrying activity and the upper section of the West Fork paleosol may be missing

0-68 cm West Fork paleosol; dark grayish brown clay, silty, massive without bedding, calcareous without visible carbonates, occas. isolated limestone pebble $(<20 \mathrm{~mm}$ dia., $0.5 \mathrm{~mm}$ carbonate coats, $4.0 \mathrm{~mm}$ yellow weathering rinds; may be recycled from nearby Pleistocene gravel deposit), paleosol developed on underlying gravels, irregular sharp basal contact with underlying gravels

68-85 Gravels, limestone, unsorted without bedding, gravel-to-gravel contact, dark grayish brown silty clay matrix, gravels with carbonate coats and yellow weathering rinds, absence of carbonate filaments, lower boundary sharp contact with underlying gray clay

85-205+ Pre-paleosol gray clay alluvial unit; grayish brown silty clay, massive, calcareous with weak carbonate filaments throughout and increasing in abundance in lower 50 $\mathrm{cm}$, occas. isolated small rounded limestone pebble, occas. isolated land snail shell (Rabdotus)

Trench 21, located north side of old Clear Fork channel west of Trenches 6 and 22; adjacent sewer line; upper sediments are disturbed

0-12 cm Disturbed material; brown clay mixed with small limestone pebbles and a sandstone pebble; sharp basal contact with underlying grayish brown clay

12-39 Post-paleosol alluvium; grayish brown clay, silty, massive without bedding, calcareous but no visible carbonate filaments, isolated land snail shells (Helicina), gradational basal contact with underlying paleosol 
39-191+ West Fork paleosol; dark grayish brown clay, silty, massive without bedding, calcareous, weak discontinuous carbonate filaments below $100 \mathrm{~cm}$ depth, carbonate filaments increase in abundance below $170 \mathrm{~cm}$ depth; numerous rootlets, earthworm traces, occas. isolated small ( $<20 \mathrm{~mm}$ dia.) rounded limestone pebbles; pre-paleosol sediments are not exposed in this trench

Trench 22, located between Trench 21 and 6 north of Clear Fork channel along sewer line; upper surficial material is disturbed

0-7 cm Disturbed material; light brown clay, massive with isolate small limestone pebbles, occas. land snail shell, sharp contact with underlying brown clay

7-39 Post-paleosol alluvium; grayish brown clay, silty, massive, calcareous but without carbonate filaments, occas. isolated land snail, no pebbles, gradational contact with underlying paleosol

39-185+ West Fork paleosol; dark grayish brown clay, silty, massive without bedding, calcareous, rare faint carbonate filaments below $60 \mathrm{~cm}$ depth and denser more common filaments below $110 \mathrm{~cm}$ depth, numerous rootlets, earthworm traces, occas. isolated land snail (Rabdotus), absence of pebbles throughout paleosol; prehistoric stone feature at base of exposure in lower part of paleosol $(185 \mathrm{~cm} \mathrm{depth})$; base of paleosol not exposed; pre-paleosol deposits not exposed in trench

Trench 23, located in northwest corner and farthest north from the old Clear Fork channel in the project area

0-39 cm Post-paleosol alluvium; grayish brown clay, silty, massive without bedding, calcareous but without carbonate filaments, absence of pebbles, soft, gradational basal contact with underlying paleosol; possible presence of very weak A horizon at present-day surface in upper $5-10 \mathrm{~cm}$ of this alluvial unit

39-179 West Fork paleosol; dark grayish brown clay, silty, massive without bedding, calcareous, weak carbonate filaments below $115 \mathrm{~cm}$ depth; earthworm traces throughout, isolated land snail shells (Rabdotus), occas. isolated small rounded limestone pebbles, line of small pebbles at $108 \mathrm{~cm}$ depth; dark color of paleosol becomes less dark (from dark grayish brown to grayish brown) below about $100 \mathrm{~cm}$ depth; paleosol extends to top of underlying gravels; cultural stone feature at $121 \mathrm{~cm}$ depth within the middle of the paleosol; conventional radiocarbon age on bulk sediment from $165-175 \mathrm{~cm}$ depth is $2300 \pm 50{ }^{14} \mathrm{C}$ yrs B.P. (Beta-205062); age represent earliest development of West Fork paleosol

179-189 Gravels, limestone, rounded, generally small ( $<30 \mathrm{~mm} \mathrm{dia.),} \mathrm{gravel-to-gravel}$ contacts, grayish brown clay matrix, upper and lower boundary irregular

189-204 Grayish brown clay, silty, very fine sand, massive, hard, dense carbonate filaments, absence of pebbles 
204-214 Gravels, limestone, rounded, generally small $(<30 \mathrm{~mm}$ dia.), gravel-to-gravel contacts, grayish brown clay matrix, upper and lower boundary irregular (properties similar to those of upper gravels at $179-189 \mathrm{~cm}$ depth); upper and lower gravels may each represent deposition from a single flood event

214-267+ Grayish brown clay, silty, very fine sand, massive, hard, dense carbonate filaments, occas. isolated land snail (Rabdotus), rare isolated pebbles

Trench 24, located in northwest corner of project area north of old Clear Fork channel adjacent Trench 23; photograph of Trench 24 stratigraphy in Figure 8

0-40 cm Post-paleosol alluvium; grayish brown clay, silty, massive without bedding, earthworm traces, numerous rootlets, calcareous but without visible carbonates, occas. land snail shell (Rabdotus), gradational basal contact with underlying paleosol; possible presence of very weak A horizon at present-day surface in upper $5-10 \mathrm{~cm}$ of this alluvial unit

40-168 West Fork paleosol; dark grayish brown clay, silty, massive without bedding, occas. isolated land snail shell (Rabdotus), soft when damp, numerous earthworm casts, occas. isolated rounded limestone pebbles $<40 \mathrm{~mm}$ dia.; large isolated stone of possible cultural origin at $118 \mathrm{~cm}$ depth (likely the same cultural horizon as observed in adjacent trench 23 at $121 \mathrm{~cm}$ depth)

168-180 Gravels, limestone, clasts are within a gray clay matrix and not clast supported, generally $<40 \mathrm{~mm}$ dia., with yellow weathering rind ca. $1.0 \mathrm{~mm}$ thick and a carbonate coat $<0.5 \mathrm{~mm}$ thick that is abraded on the surface indicating fluvial transport; the isolated pebbles are recycled from an older gravel deposit; weak carbonate filaments in the $168-180 \mathrm{~cm}$ gravel-clay zone

180-198 Grayish brown clay, silty, massive without bedding, calcareous with some carbonate filaments, sharp irregular contact with underlying gravels

198-216+ Gravels, rounded, limestone, gravel-to-gravel contact, grayish clay matrix, not sorted and unbedded as far as can been seen in the limited exposure; gravels $<40 \mathrm{~mm}$ dia., gravel surfaces with carbonate filaments (filaments follow traces of rootlets that grew around pebbles), gravels with laminated carbonate coats $<0.5 \mathrm{~mm}$ thick, coats are abraded, yellow weathering rinds to $1.5 \mathrm{~mm}$ thick; gravels probably derived from older gravel deposit (Pleistocene) upstream in Clear Fork valley

Trench 25, located just west of Trench 1 near the south bank of the old channel of Clear Fork

0-57 cm Post-paleosol alluvium; grayish brown silty clay, numerous burrow fills, rootlets, lens of land snail shell debris at $12-16 \mathrm{~cm}$ depth, slightly darker zone at $25-34 \mathrm{~cm}$ depth that may indicate a local A horizon soil within the post-paleosol alluvium (this is the only case of a possible buried soil within this unit in the project area); calcareous but without visible carbonates, occas. land snails (Rabdotus), no pebbles 
57-155 West Fork paleosol; dark grayish brown clay, silty, massive without bedding, soft, calcareous and with weak carbonate filaments below $100 \mathrm{~cm}$ depth, occas. isolated land snail shell (Rabdotus) and snail shell fragments, mussel at $117 \mathrm{~cm}$ depth, several angular limestone rocks in a line at $155 \mathrm{~cm}$ depth; paleosol forms gradational contact with underlying clay

155-198+ Pre-paleosol alluvium; grayish brown clay, silty, massive without bedding, calcareous with some carbonate filaments, no pebbles

Trench 26, located northeast corner of project area

0-43 cm Post-paleosol alluvium; grayish brown silty clay, massive without bedding, numerous rootlets, earthworm traces, calcareous but without visible carbonates, land snail shell fragments, no pebbles

43-135 West Fork paleosol; dark grayish brown silty clay, massive without bedding, calcareous and with weak carbonate filaments below $80 \mathrm{~cm}$ depth; occas. isolated land snail shell (Rabdotus), no pebbles, increased carbonate filaments with depth, wide gradational contact with underlying clay; shift from paleosol to pre-paleosol difficult to discern (not a lithologic boundary, rather based on shift from dark to less dark color)

135-195+ Pre-paleosol alluvium; grayish brown silty clay, massive without bedding, calcareous and with carbonate filaments, fewer filaments below $150 \mathrm{~cm}$ depth, no pebbles

Trench 27, located just west of Trench 26 at the north edge of the project area

0-39 cm Post-paleosol alluvium; grayish brown clay, silty, massive, soft, numerous rootlets, pores, earthworm traces, calcareous but without visible carbonates, no pebbles, isolated land snail shells (Rabdotus), gradational lower contact with paleosol

39-118 West Fork paleosol; dark grayish brown clay, silty, massive with no bedding structures preserved, soft, calcareous, rare occas. weak carbonate filaments in lower $30 \mathrm{~cm}$ of paleosol, occas. land snail shell (Rabdotus), gradational contact with underlying clay

118-196+ Pre-paleosol alluvium; grayish brown clay, silty, massive, hard, calcareous, moderate amount of carbonate filaments (more than above in paleosol), occas. land snail shells (Rabdotus), no pebbles

Trench 28, located along the north bank of the old Clear Fork channel southeast of Trenches 8 and 9

0-45 cm Post-paleosol alluvium; grayish brown silty clay, massive without bedding structures, calcareous but without visible carbonates, soft, earthworm traces, grades into underlying paleosol 
45-171 West Fork paleosol, dark grayish brown clay, silty, massive and without bedding, soft when wet, earthworm traces, occas. land snail shells (Rabdotus), calcareous but without carbonate filaments, although low numbers of weak filaments occur in the lower $25 \mathrm{~cm}$ of the paleosol; isolated small limestone pebbles occur below $95 \mathrm{~cm}$ depth, gradational contact with underlying clay

171-192+ Pre-paleosol alluvium, grayish brown clay, silty, massive without bedding, hard, dense carbonate filaments, no pebbles observed 


\section{REFERENCES}

Cerling, T. E., Quade, J., Wang, Y., and Bowman, R.

1989 Carbon isotopes in soils and palaeosols as ecology and palaeoecology indicators: Nature, v. 341, p. 138-139.

Courty, M. A., Goldberg, P., and Macphail, R.

1989 Soils and micromorphology in archaeology: Cambridge University Press, Cambridge, $344 \mathrm{p}$.

Dawson, T. E., Mambelli, S., Plamboeck, A. H., Templer, P. H., and Tu, K. P.

2002 Stable isotopes in plant ecology: Annual Review of Ecology and Systematics, v. 33, p. 507-559.

Ehleringer, J. R., Cerling, T. E., Helliker, B. R.

$1997 \mathrm{C}_{4}$ photosynthesis, atmospheric $\mathrm{CO}_{2}$, and climate: Oecologia, v. 112, p. 285-299.

Johnson, Donald L.

1989 Subsurface stone lines, stone zones, artifact-manuport layers, and biomantles produced by bioturbation via pocket gophers (Thomomys bottae): American Antiquity, v. 54, p. 370-389.

Johnson, Donald L.

1990 Biomantle evolution and the redistribution of earth materials and artifacts: Soil Science, v. 149, p. 84-102.

Johnson, D. L., Domier, J. E. J., and Johnson, D. N.

2005 Reflections on the nature of soil and its biomantle: Annals of the Association of American Geographers, v. 95, p. 11-31.

Johnson, D. L. and Johnson, D. N.

2004 Bioturbation by badgers and rodents in producing polygenetic and polytemporal desert soil biomantles; soil formation, or soil evolution?: Geological Society of America, annual meeting, Abstracts with Programs, v. 36, issue 5, p. 97. 
Jones, C. A.

$1985 \mathrm{C}_{4}$ Grasses and Cereals; Growth, Development, and Stress Response. John Wiley \& Sons, New York, 419 p.

Leavitt, S. W., Follett, R. F., Kimble, J. M., and Pruessner, E. G.

2007 Radiocarbon and $\delta^{13} \mathrm{C}$ depth profiles of soil organic carbon in the U.S. Great Plains: A possible spatial record of paleoenvironment and paleovegetation: Quaternary International, v. 162-163, p. 21-34.

Retallack, G. J.

2001 Soils of the past, An introduction to paleopedology: Blackwell Science, Oxford, UK, $404 \mathrm{p}$.

Waller, S. S., and Lewis, J. K.

1979 Occurrence of C3 and C4 photosynthetic pathways in North American grasses: Journal of Range Management, v. 32, p. 12-28. 
APPENDIX $\mathbf{J}$

RADIOCARBON DATES FROM TESTING CONDUCTED AT SITE 41TR170 

Radiocarbon Dates from Cultural Features 



\begin{tabular}{|c|c|c|c|}
\hline Sample Data & $\begin{array}{c}\text { Measured } \\
\text { Radiocarbon Age }\end{array}$ & $\begin{array}{c}13 \mathrm{C} / 12 \mathrm{C} \\
\text { Ratio }\end{array}$ & $\begin{array}{c}\text { Conventional } \\
\text { Radiocarbon Age }\left(^{*}\right)\end{array}$ \\
\hline $\begin{array}{l}\text { Beta - } 213092 \\
\text { SAMPLE : } 41 \text { TR } 170 F S 286 \\
\text { ANALYSIS : AMS-Standard deliver } \\
\text { MATERIAL/PRETREATMENT : } \\
2 \text { SIGMA CALIBRATION : }\end{array}$ & $\begin{array}{l}\qquad 3630+/-40 \mathrm{BP} \\
\text { (charred material): acid washes } \\
\text { Cal BC } 2140 \text { to } 1940 \text { (Cal BP }\end{array}$ & $-22.5 \mathrm{o} / 00$ & $3670+/-40 \mathrm{BP}$ \\
\hline
\end{tabular}


(Variables: $\mathrm{C} 13 / \mathrm{C} 12=-22.5: \mathrm{lab}$. mult $=1$ )

La borato ry num ber: Beta-213092

Conventional radiocarbon age: $3670 \pm 40 \mathrm{BP}$

2 Sigma calib rated result: Cal BC 2140 to 1940 (Cal BP 4100 to 3880) ( $95 \%$ probability)

In tercept data

Intercept of radiocarbon age

with calibration curve: Cal BC 2030 (Cal BP 3980 )

1 Sigma calibrated results: Cal BC 2130 to 2080 (Cal BP 4080 to 4030 ) and (68\% probability) Cal BC 2060 to 1970 (Cal BP 4010 to 3920 )

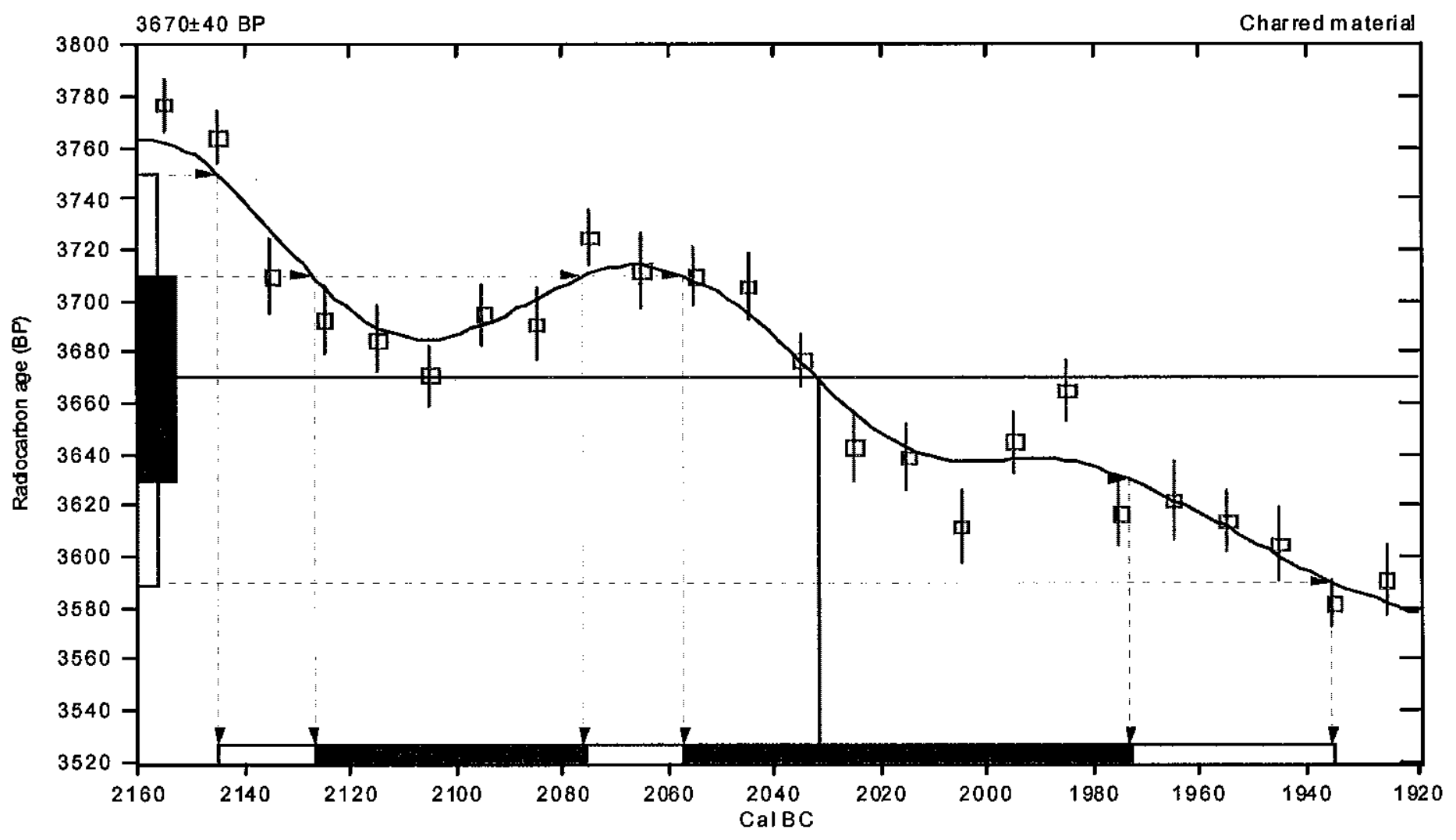

References:

Database used INTC AL 98

Calibration Database

Editorial Comm ent

Stuiver, M., van der Plicht, $H, 1998$, Radiocarbon 40(3), pxii-xiii

INTCAL98 Radiocarbon Age Calibration

Mathe matics

Stuiver, M., et. al., 1998, Radiocarbon 40(3), p1041-1083

A Simplified Approach to Calibrating C14 Dates

Talma, A. S., Vogel, J. C., 1993 , Radiocarbon 35(2), p317-322 


\begin{tabular}{|c|c|c|}
\hline Sample Data & $\begin{array}{l}\text { Measured } \\
\text { Radiocarbon Age }\end{array}$ & $\begin{array}{c}13 \mathrm{C} / 12 \mathrm{C} \\
\text { Ratio }\end{array}$ \\
\hline $\begin{array}{l}\text { Beta - } 213093 \\
\text { SAMPLE : 41TR170FS470 } \\
\text { ANALYSIS : AMS-Standard delivery } \\
\text { MATERIAL/PRETREATMENT : (c } \\
\text { 2 SIGMA CALIBRATION : } \mathrm{C}\end{array}$ & $\begin{array}{l}\qquad 1420+/-40 \mathrm{BP} \\
\text { ary } \\
\text { (charred material): acid/alkali/acid } \\
\text { Cal AD } 630 \text { to } 710 \text { (Cal BP } 1320 \text { to } 1240)\end{array}$ & $-28.4 \mathrm{o} / \mathrm{oo}$ \\
\hline $\begin{array}{l}\text { Beta - } 213094 \\
\text { SAMPLE : 41TR170FS484 } \\
\text { ANALYSIS : AMS-Standard delivery } \\
\text { MATERIAL/PRETREATMENT : (c } \\
\text { 2 SIGMA CALIBRATION : } \mathrm{C}\end{array}$ & $\begin{array}{l}\qquad 1360+/-40 \mathrm{BP} \\
\text { ery } \\
\text { (charred material): acid/alkali/acid } \\
\text { Cal AD } 630 \text { to } 710 \text { (Cal BP } 1320 \text { to } 1240 \text { ) }\end{array}$ & $-25.3 \mathrm{o} / \mathrm{oo}$ \\
\hline
\end{tabular}

Beta - 213095

$1270+/ .40 \mathrm{BP}$

$-25.10 / 00$

Conventional

Radiocarbon Age(*)

SAMPLE : 41TR170FS576

ANALYSIS : AMS-Standard delivery

MATERIAL/PRETREATMENT : (charred material): acid/alkali/acid

2 SIGMA CALIBRATION : $\quad$ Cal AD 670 to 870 (Cal BP 1280 to 1080)

Beta -213096

$1600+/-40 \mathrm{BP}$

$-26.7 \mathrm{o} / \mathrm{oo}$

$1570+/-40 \mathrm{BP}$

SAMPLE : 41TR170FS618

ANALYSIS : AMS-Standard delivery

MATERIAL/PRETREATMENT : (charred material): acid/alkali/acid

2 SIGMA CALIBRATION : $\quad$ Cal AD 410 to 580 (Cal BP 1540 to 1360)

Beta -213097

$1480+/-40$ BP

$-27.1 \mathrm{o} / 00$

$1450+/-40 \mathrm{BP}$

SAMPLE : 41TR170FS629

ANALYSIS : AMS-Standard delivery

MATERIAL/PRETREATMENT : (charred material): acid/alkali/acid

2 SIGMA CALIBRATION : $\quad$ Cal AD 540 to 660 (Cal BP 1410 to 1290) 


\begin{tabular}{|c|c|c|c|}
\hline Sample Data & $\begin{array}{c}\text { Measured } \\
\text { Radiocarbon Age }\end{array}$ & $\begin{array}{c}13 \mathrm{C} / 12 \mathrm{C} \\
\text { Ratio }\end{array}$ & $\begin{array}{c}\text { Conventional } \\
\left.\text { Radiocarbon Age }{ }^{*}\right)\end{array}$ \\
\hline $\begin{array}{l}\text { Beta - } 213098 \\
\text { SAMPLE : } 41 \text { TR170FS662 } \\
\text { ANALYSIS : AMS-Standard deliver } \\
\text { MATERIAL/PRETREATMENT : } \\
\text { 2 SIGMA CALIBRATION : }\end{array}$ & $\begin{array}{l}\qquad 1400+/ \sim 40 \mathrm{BP} \\
\text { ry } \\
\text { (charred material): acid/alkali/acid } \\
\text { Cal AD } 540 \text { to } 660(\text { Cal BP } 1410 \text { to } 1290)\end{array}$ & $-22.2 \mathrm{o} / \mathrm{oo}$ & $1450+/-40 \mathrm{BP}$ \\
\hline $\begin{array}{l}\text { Beta - } 213099 \\
\text { SAMPLE : 41TR170FS706\&707 } \\
\text { ANALYSIS : AMS-Standard deliver } \\
\text { MATERIAL/PRETREATMENT : } \\
\text { 2 SIGMA CALIBRATION : }\end{array}$ & $\begin{array}{l}\qquad 1340+/-40 \mathrm{BP} \\
\text { (charred material): acid/alkali/acid } \\
\text { Cal AD } 650 \text { to } 780(\text { Cal BP } 1300 \text { to } 1170)\end{array}$ & -26.9 o/oo & $1310+/-40 \mathrm{BP}$ \\
\hline
\end{tabular}




\section{CALIBRATION OF RADIOCARBON AGE TO CALENDAR YEARS}

(Variables: $\mathrm{C} 13 / \mathrm{C} 12=-28.4: 1 \mathrm{ab}$. mult $=1$ )

La borato ry num ber: Beta-213093

Conventional radiocarbon age: $\quad 1360 \pm 40 \mathrm{BP}$

2 Sigma calibrated result: Cal AD 630 to 710 (Cal BP 1320 to 1240)

(95\% probability)

In tercept data

Intercept of radiocarbon age

with calibration curve: Cal AD 660 (Cal BP 1280)

1 Sigma calibrated result: Cal AD 650 to 680 (Cal BP 1300 to 1270)

(68\% probability)

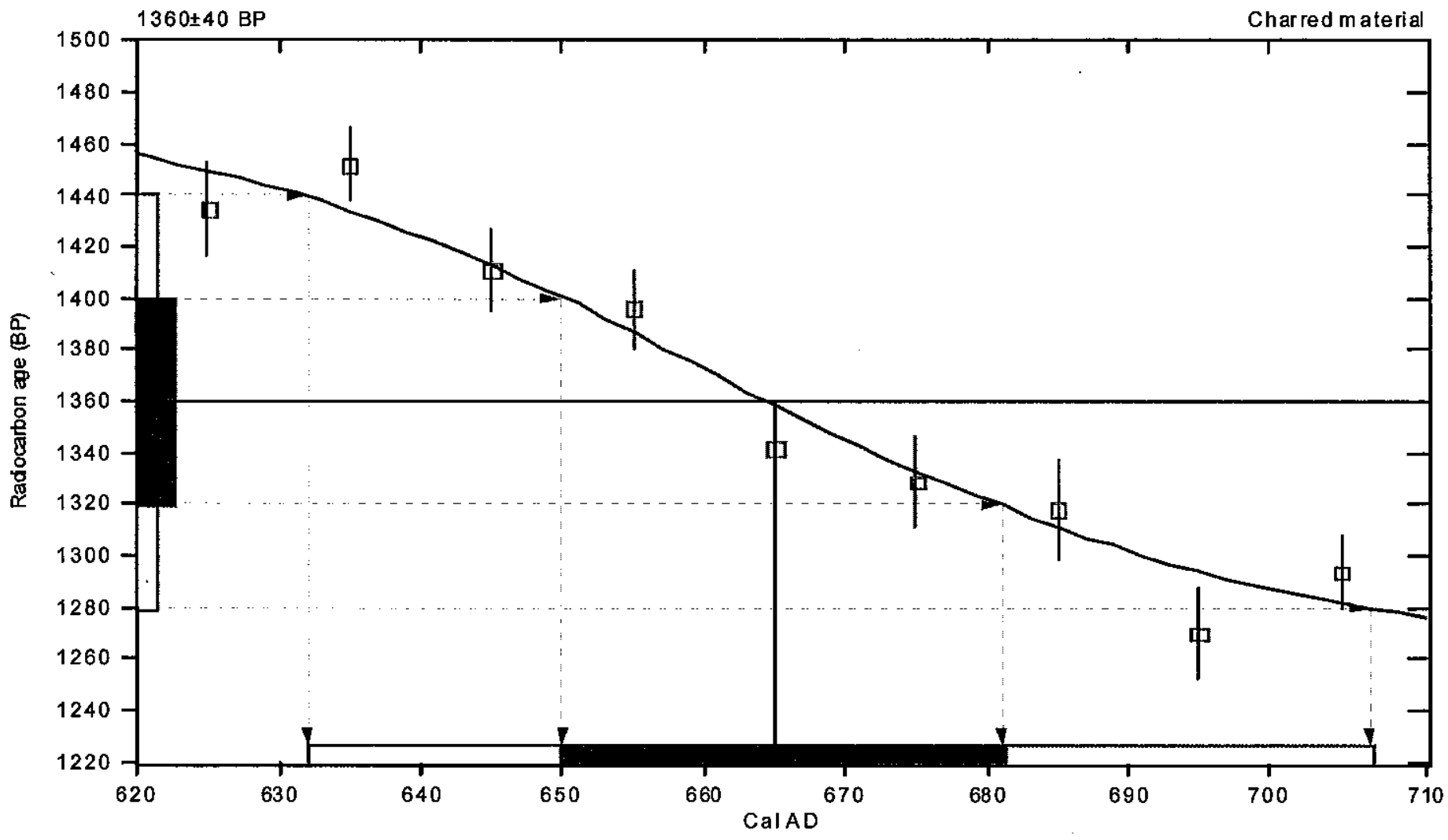

References:

Database used INTC AL 98

Calibration Database

Editorial Comm ent

Stui ver, M., van der Plicht, $H ., 1998$, Radiocarbon 40(3), pxii-xiii

INTCAL98 Radiocarbon Age Calibration

Stuiver, M., et. al., 1998, Radiocarbon 40(3), p1041-1083

Mathe matics

A Simplified Approach to Calibrating C14 Dates

Talma, A. S., Vogel, J. C., 1993, Radiocarbon 35(2), p317-322

\section{Beta Analytic Radiocarbon Dating Laboratory}

4985 S.W.74th Court, Miami, Florida $33155 \cdot$ Tel: (305)667-5167•F ax: (3 05)663-0964・E-Mail: beta@radiocarbon.com 


\section{CALIBRATION OF RADIOCARBON AGE TO CALENDAR YEARS}

(Variables: $\mathrm{C} 13 / \mathrm{C} 12=-25 \cdot 3: 1 \mathrm{ab}$. mult $=1$ )

Laborato ry number: Beta-213094

Conventional radiocarbon age: $1360 \pm 40 \mathrm{BP}$

2 Sigma calibrated result: Cal AD 630 to 710 (Cal BP 1320 to 1240) (95\% probability)

In tercept data

Intercept of radiocarbon age

with calibration curve: Cal AD 660 (Cal BP 1280)

1 Sigma calibrated result: Cal AD 650 to 680 (Cal BP 1300 to 1270)

(68\% probability)

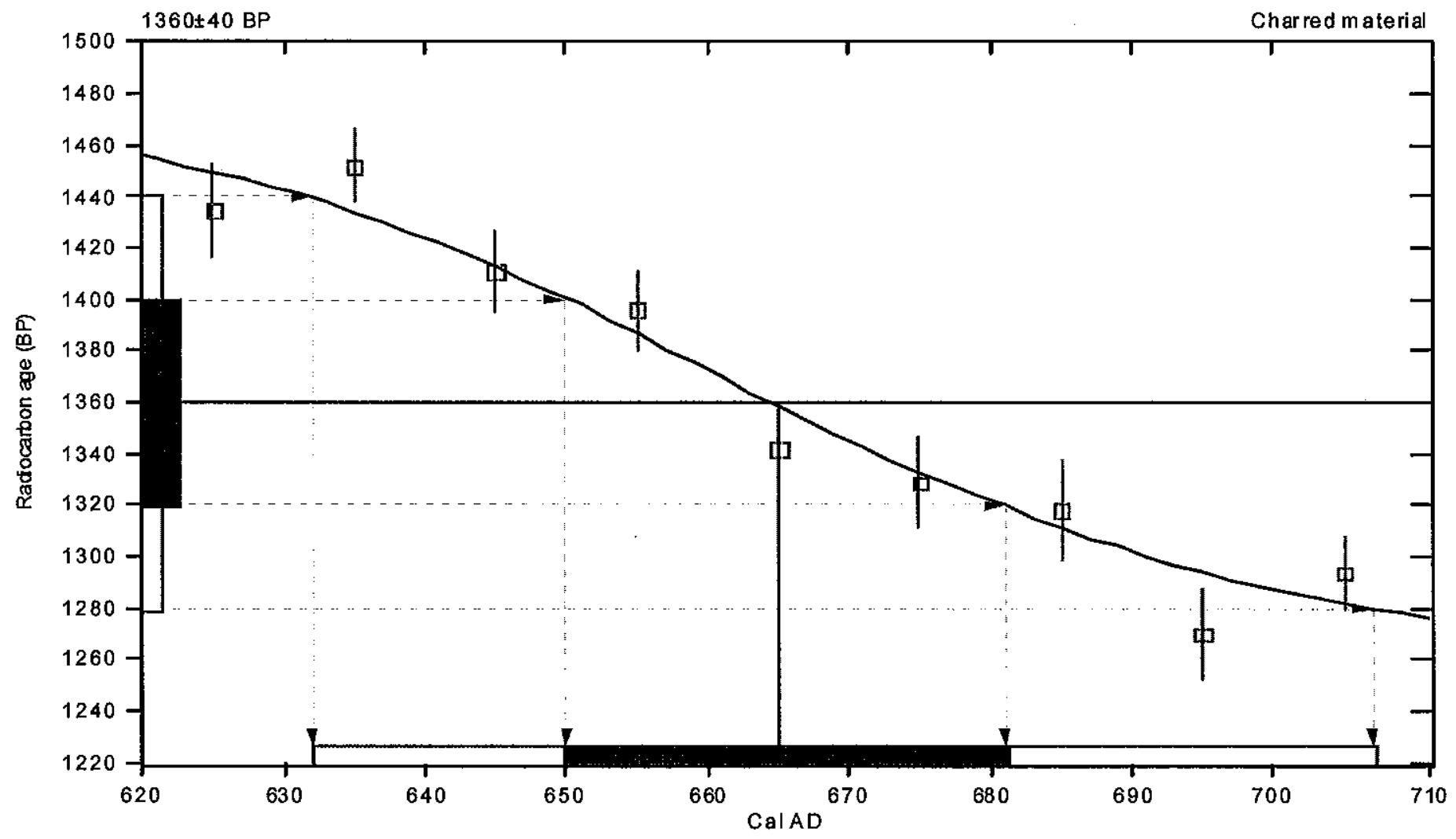

References:

Database used INTC AL 98

Calibration Database

Editorial Comm ent

Stuiver, M., vander Plicht, $H, 1998$, Radiocarbon 40(3), pxii-xi $i i$

INTCAL 98 Radiocarbon Age Calibration

Stuiver, M., et. al., 1998, Radiocarbon 40(3), p1041-1083

Mathe matics

A Simplified Approach to Calibrating C14 Dates

Talma, A. S., Vogel, J. C., 1993, Radiocarbon 35(2), p317-322 


\section{CALIBRATION OF RADIOCARBON AGE TO CALENDAR YEARS}

(Variables: C 13/C 12 $=-25.1$ :lab. mult $=1$ )

Laborato ry number: Beta-213095

Conventio nal radiocarbon age: $1270 \pm 40 \mathrm{BP}$

2 Sigma calibrated result: Cal AD 670 to 870 (Cal BP 1280 to 1080 )

(95\% probability)

In te rcept data

Intercepts of radiocarbon age

with calibration curve: Cal AD 720 (Cal BP 1230) and

Cal AD 740 (Cal BP 1210) and

Cal AD 760 (Cal BP 1190)

1 Sigma calibrated result: Cal AD 690 to 780 (Cal BP 1260 to 1170 )

(68\% probability)

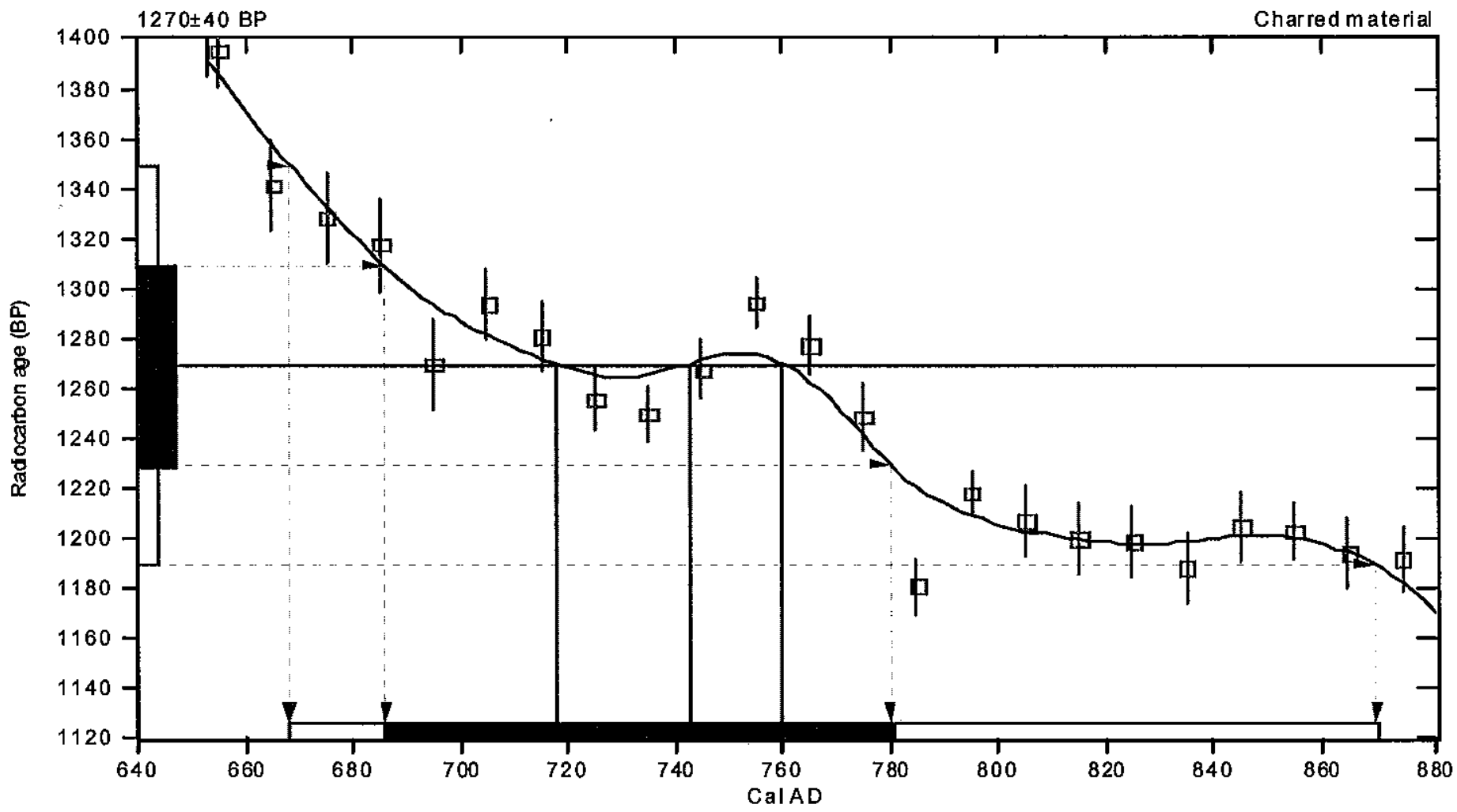

References:

Database used INTC AL 98

Calibration Database

Editorial Comm ent

Stuiver, $M$, vander Plicht, $H .1998$, Radiocarbon 40(3), pxii-xiii

INTCAL 98 Radiocarbon Age Calibration

Stui ver, M., et. al., 1998, Radiocarbon 40(3), p1041-1083

Mathematics

A Simplified Approach to Calibrating C14 Dates

Talma, A. S., Vogel, J. C., 1993, Radiocarbon 35(2), p317-322

\section{Beta Analytic Radiocarbon Dating Laboratory}

4985 S.W.74th Court, Miami, Florida 33155 -Tel: (305)667-5167• Fax: (305)663-0964· E-Mail: beta@radiocarbon.com 


\section{CALIBRATION OF RADIOCARBON AGE TO CALENDAR YEARS}

(Variables: $\mathrm{C} 13 / \mathrm{C} 12=-26.7: 1 \mathrm{ab}$. mult $=1$ )

La borato ry number: Beta-213096

Conventio nal radiocarbon age: $1570 \pm 40 \mathrm{BP}$

2 Sigma calibrated result: Cal AD 410 to 580 (Cal BP 1540 to 1360)

(95\% probability)

In te rcept data

Intercepts of radiocarbon age

with calibration curve: $\quad \mathrm{Cal}$ AD 460 (Cal BP 1480) and

Cal AD 480 (Cal BP 1470) and

Cal AD 520 (Cal BP 1430)

1 Sigma calibrated result: Cal AD 430 to 540 (Cal BP 1520 to 1410 )

(68\% probability)

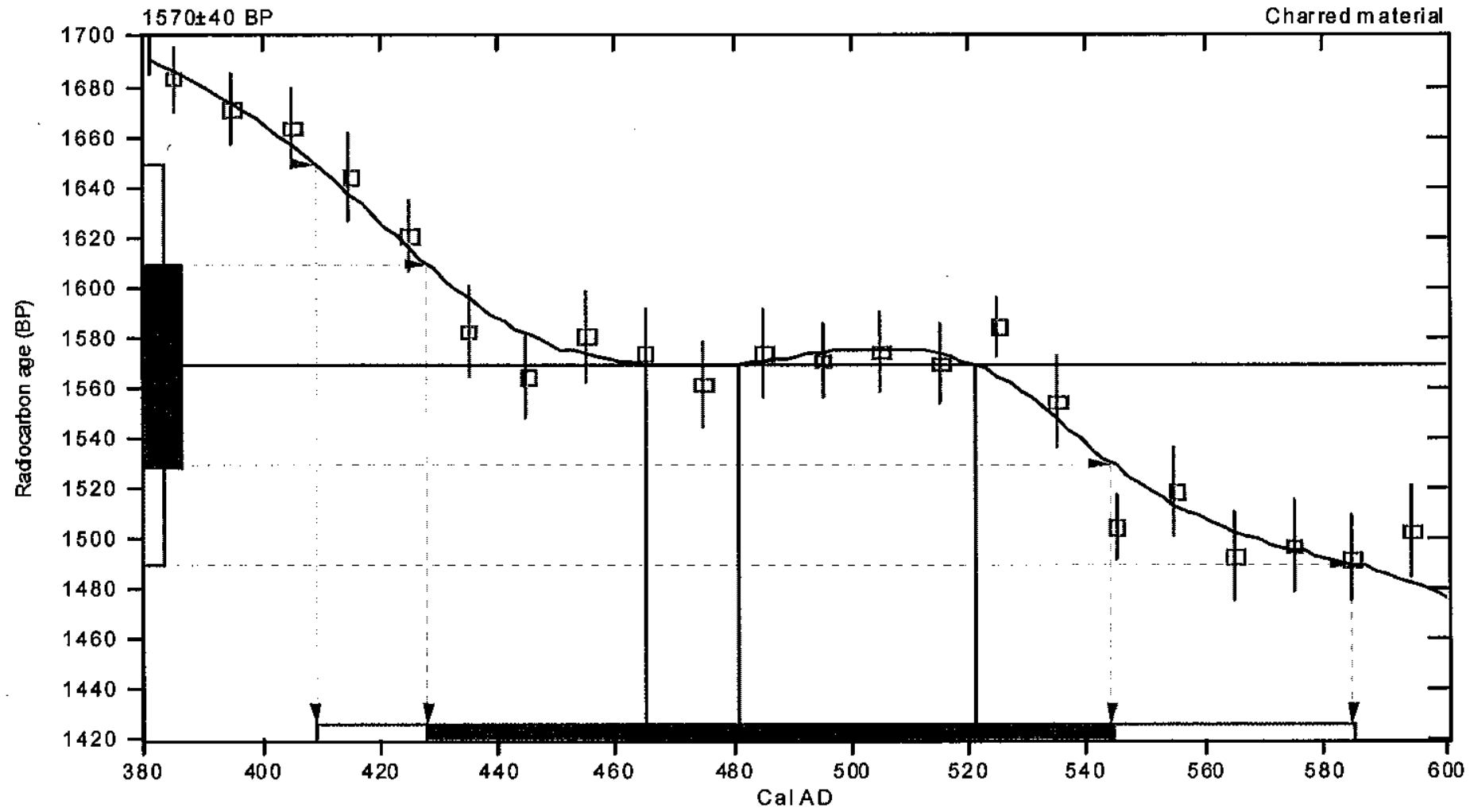

References:

Database used INTC AL 98

Calibration Database

Editorial Comm ent

Stui ver, M., van der Plicht, H, 1998, Radiocarbon 40(3), pxii-xi ii

INTCAL98 Radiocarbon Age Calibration

Stuiver, M., et. al., 1998, Radiocarbon 40(3), p1041-1083

Mathe matics

A Simplified Approach to Calibrating C14 Dates

Talma, A. S., Vogel, J. C., 1993, Radiocarbon 35(2), p317-322

\section{Beta Analytic Radiocarbon Dating Laboratory}

4985 S.W.74th Court, Miami, Florida 33155 - Tel: (305)667-5167·Fax: (305)663-0964 E-Mail: beta@radiocarbon.com 


\section{CALIBRATION OF RADIOCARBON AGE TO CALENDAR YEARS}

(Variables: $\mathrm{C} 13 / \mathrm{C} 12=-27.1:$ lab. mult $=1$ )

Laborato ry number: Beta-213097

Conventional radiocarbon age: $1450 \pm 40 \mathrm{BP}$

2 Sigma calibrated result: Cal AD 540 to 660 (Cal BP 1410 to 1290)

(95\% probability)

In te rcept data

Intercept of radiocarbon age

with calibration curve: Cal AD 620 (Cal BP 1320)

1 Sigma calibrated result: Cal AD 580 to 650 (Cal BP 1360 to 1300 )

(68\% probability)

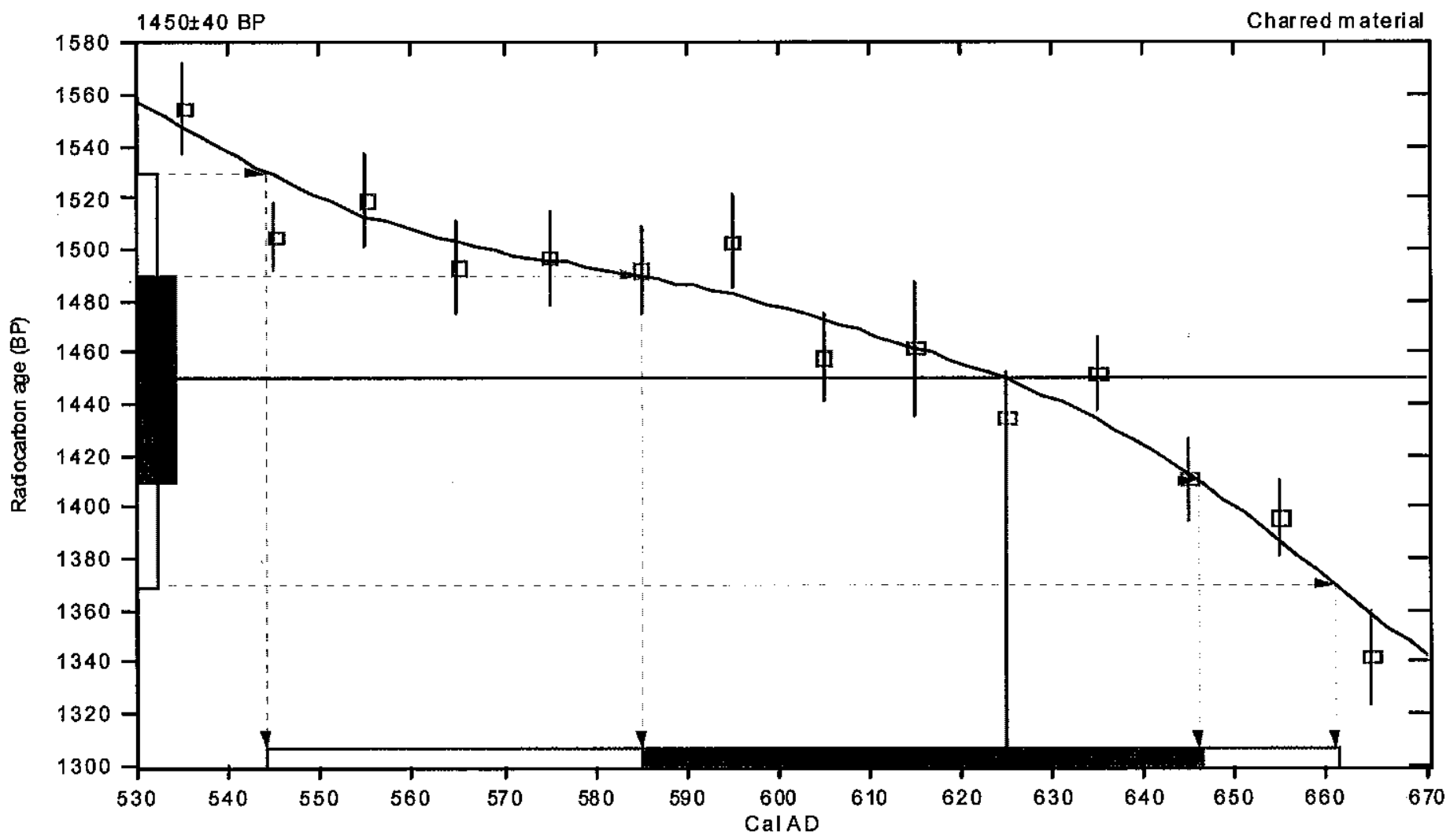

References:

Database used INTC AL 98

Calibration Database

Editorial Comm ent

Stuiver, M., van der Plicht, H., 1998, Radiocarbon 40(3), pxii-xi ii

INTCAL 98 Radiocarbon Age Calibration

Stuiver, $M_{.}$, et. al., 1998, Radiocarbon 40(3), p1041-1083

Mathe matics

A Simplified Approach to Calibrating C14 Dates

Talma, A.S., Vogel, J. C., 1993, Radiocarbon 35(2), p317-322 


\section{CALIBRATION OF RADIOCARBON AGE TO CALENDAR YEARS}

(Variables: $\mathrm{C} 13 / \mathrm{C} 12=-22.2$ :lab. $\mathrm{mult}=1$ )

La borato ry num ber: Beta-213098

Conventional radiocarbon age: $\quad 1450 \pm 40 \mathrm{BP}$

2 Sigma calibrated result: Cal AD 540 to 660 (Cal BP 1410 to 1290)

( $95 \%$ probability)

In tercept data

Intercept of radiocarbon age

with calibration curve: Cal AD 620 (Cal BP 1320)

1 Sigma calibrated result: Cal AD 580 to 650 (Cal BP 1360 to 1300)

(68\% probability)

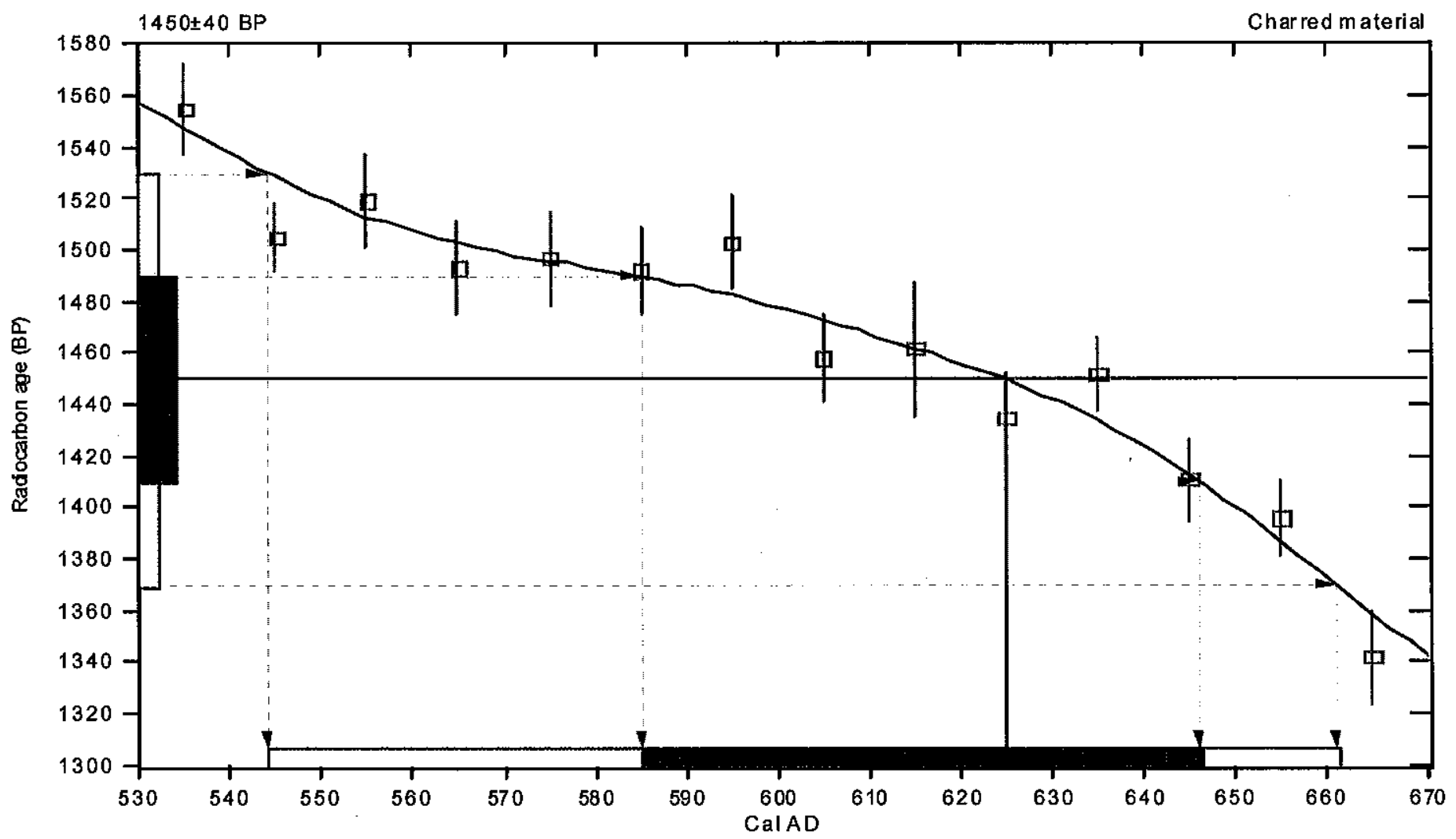

References:

Database used INTC AL 98

Calibration Database

Editorial Comm ent

Stuiver, M., van der Plicht, H., 1998, Radiocarbon 40(3), pxii-xiii

INTCAL 98 Radiocarbon Age Calibration

Stuiver, M., et. al., 1998, Radiocarbon 40(3), p1041-1083

Mathe matics

A Simplified Approach to Calibrating C14 Dates

Talma, A. S., Vogel, J. C., 1993, Radiocarbon 35(2), p317-322

\section{Beta Analytic Radiocarbon Dating Laboratory}

4985 S.W.74th Court, Miami, Florida 33155・Tel: (305)667-5167・Fax: (305)663-0964 E-Mail: beta@radiocarbon.com 


\section{CALIBRATION OF RADIOCARBON AGE TO CALENDAR YEARS}

(Variables: C13/C12=-26.9:lab. mult $=1$ )

La borato ry num ber: Beta-213099

Conventional radiocarbon age: $1310 \pm 40 \mathrm{BP}$

2 Sigma calibrated result: Cal AD 650 to 780 (Cal BP 1300 to 1170)

(95\% probability)

In tercept data

Intercept of radiocarbon age

with calibration curve: Cal AD 690 (Cal BP 1260)

1 Sigma calibrated results: Cal AD 670 to 720 (Cal BP 1280 to 1230) and

(68\% probability) Cal AD 740 to 760 (Cal BP 1210 to 1190 )

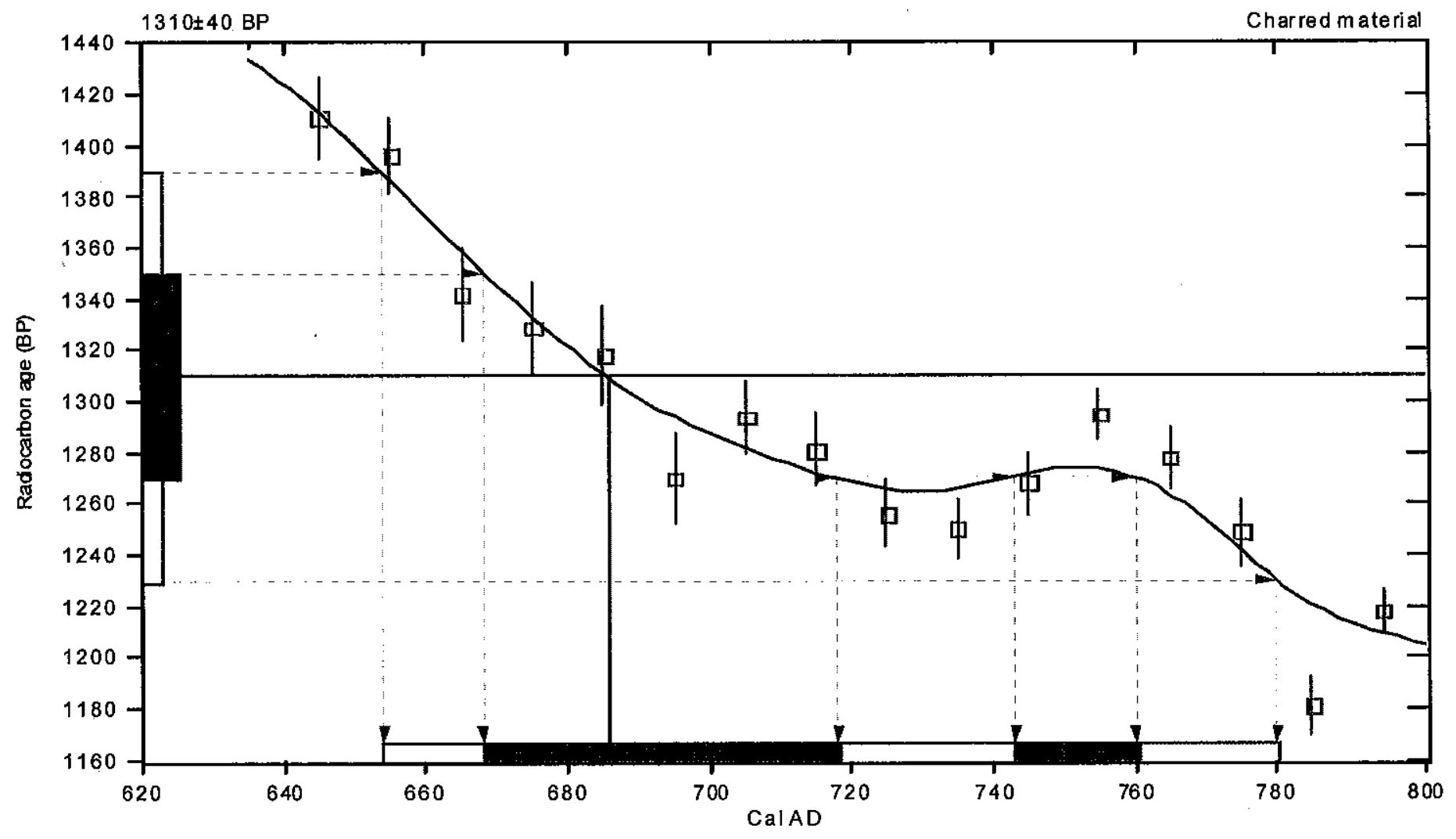

References:

Database u sed

INTC AL 98

Calibration Database

Editorial Comm ent

Stui ver, M., van der Plicht, $H ., 1998$, Radiocarbon 40(3), pxii-xiii

INTCAL 98 Radiocarbon Age Calibration

Stui ver, M., et. al., 1998, Radiocarbon 40(3), p1041-1083

Mathe matics

A Simplified Approach to Calibrating C14 Dates

Talma, A.S., Vogel, J. C., 1993, Radiocarbon 35(2), p317-322 

Radiocarbon Dates from Geomorphic Deposition Units 



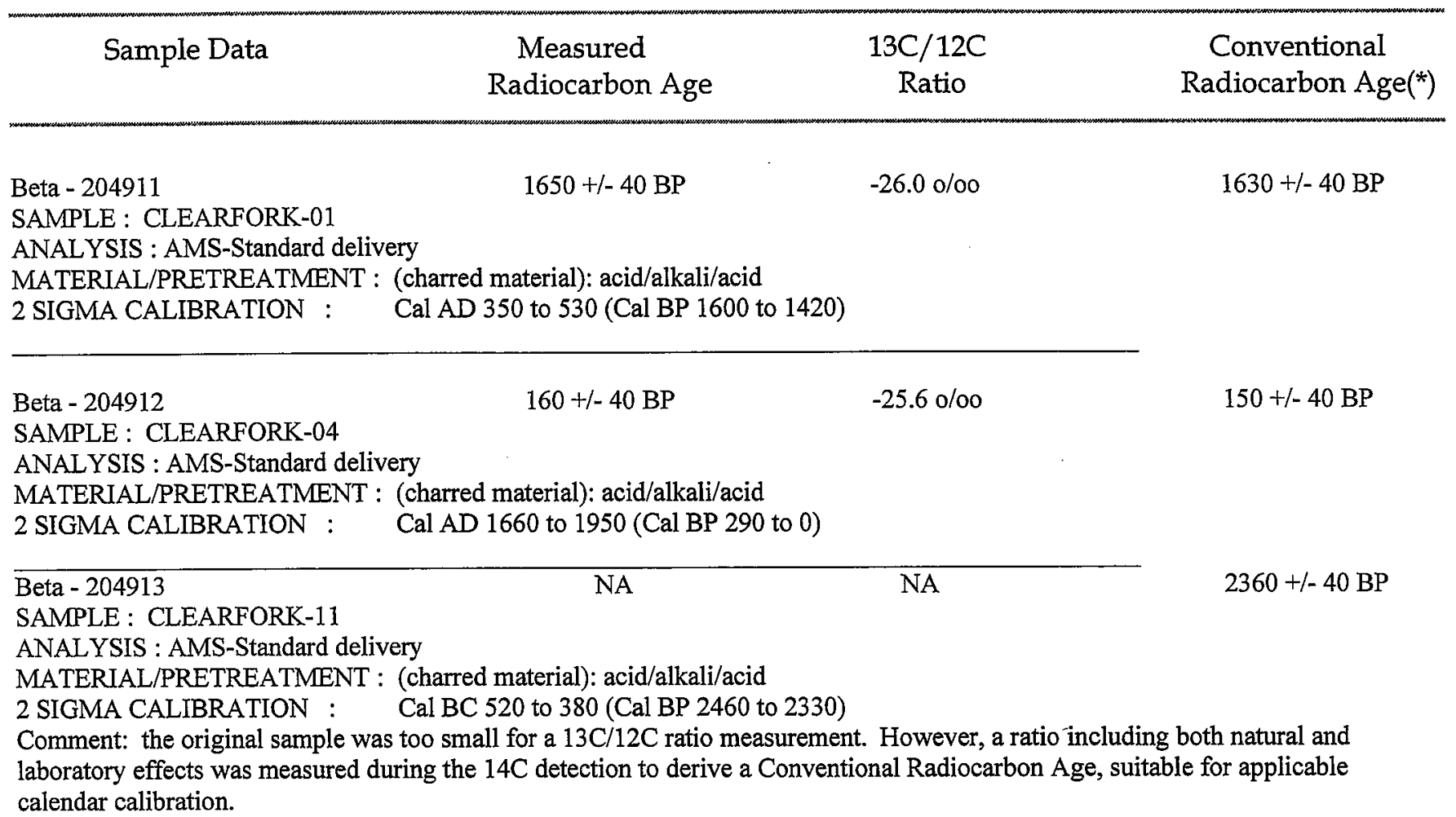

Beta - 205059

$1410+/-70 \mathrm{BP}$

$-17.8 \% / 00$

$1530+/-70 \mathrm{BP}$

SAMPLE : CLEAR FORK 02

ANALYSIS : Radiometric-Standard delivery (bulk low carbon analysis on sediment)

MATERIAL/PRETREATMENT : (organic sediment): acid washes

2 SIGMA CALIBRATION : $\quad \mathrm{Cal} \mathrm{AD} 400$ to 650 (Cal BP 1550 to 1300 )

Beta - 205060

$740+/-70 \mathrm{BP}$

$-17.5 \mathrm{o} / 00$

$860+/-70 \mathrm{BP}$

SAMPLE : CLEAR FORK 03

ANALYSIS : Radiometric-Standard delivery (bulk low carbon analysis on sediment)

MATERIAL/PRETREATMENT : (organic sediment): acid washes

2 SIGMA CALIBRATION : $\quad \mathrm{Cal} \mathrm{AD} 1020$ to 1280 (Cal BP 930 to 670) 


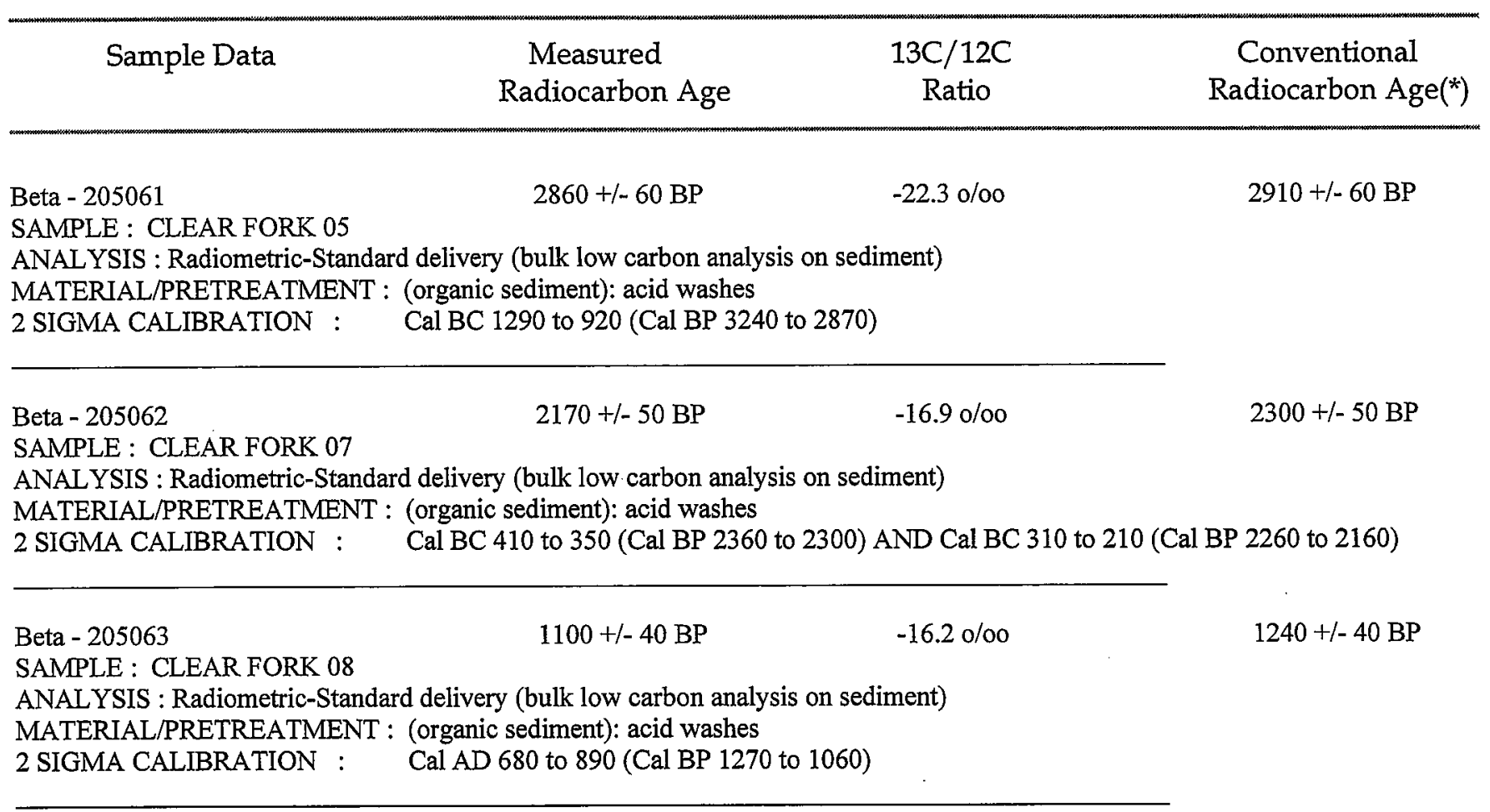




\section{CALIBRATION OF RADIOCARBON AGE TO CALENDAR YEARS}

(Variables: C13/C12=-26:lab. mult $=1$ )

Laborato ry number: Beta-204911

Conventio nal radiocarbon age: $1630 \pm 40 \mathrm{BP}$

2 Sigma calibrated result: Cal AD 350 to 530 (C al BP 1600 to 1420)

(95\% probability)

In tercept data

Intercept of radiocarbon age

with calibration curve: Cal AD 420 (Cal BP 1530)

1 Sigma calibrated result: $\mathrm{Cal} A \mathrm{AD} 400$ to 440 (Cal BP 1550 to 1510 )

(68\% probability)

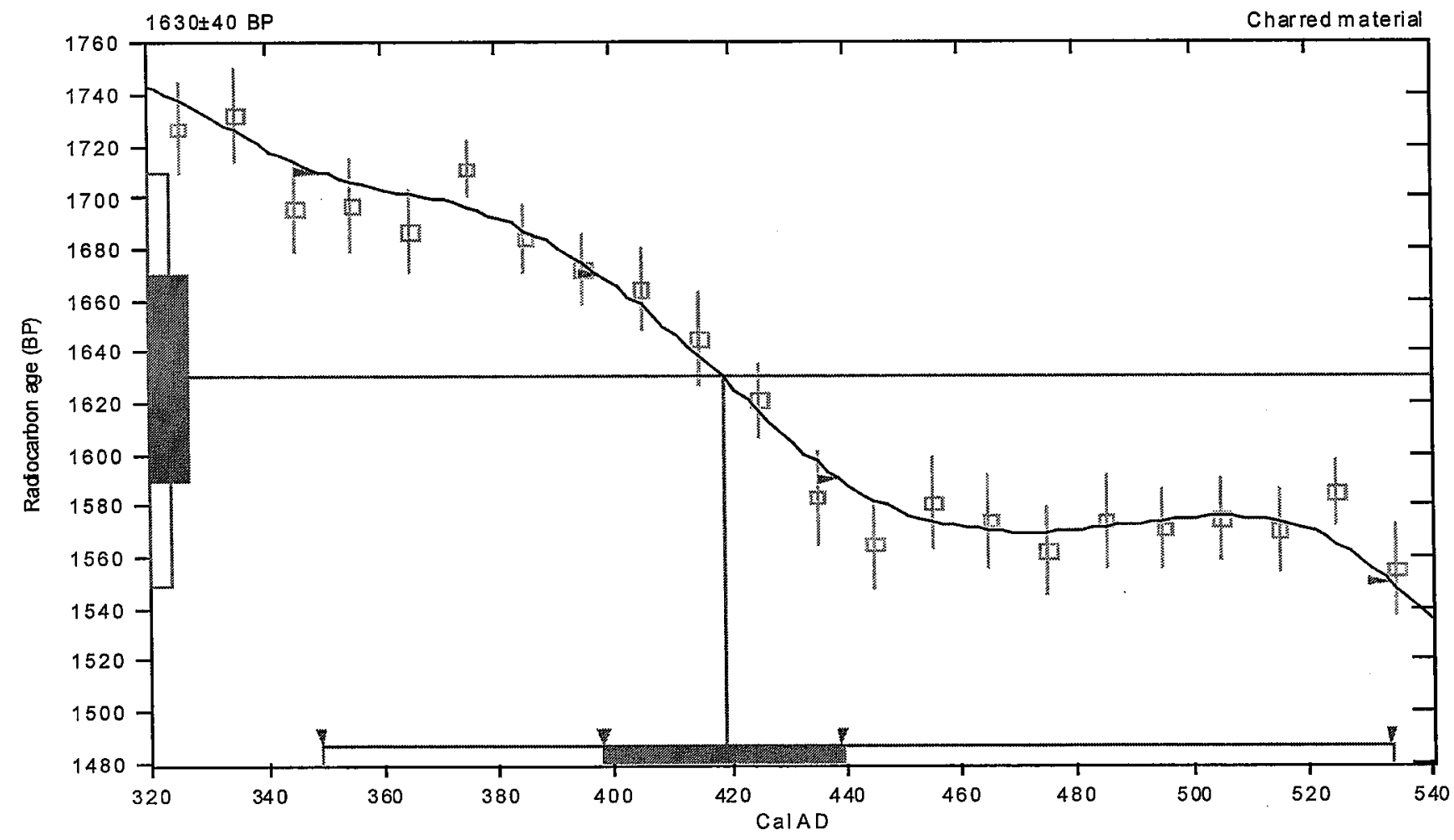

References:

Database used

INTC AL 98

Calibration Database

Editorial Comm ent

Stuiver, $M$., van der Plicht, $H$., 1998, Radiocarbon 40(3), pxii-xi ii

INTCAL 98 Radiocarbon Age Cal ibration

Stuiver, M., et. al., 1998, Radiocarbon 40(3), p1041-1083

Mathe matics

A Simplified Approach to Calibrating C14 Dates

Talma, A. S., Vogel, J. C., 1993, Radiocarbon 35(2), p317-322

\section{Beta Analytic Radiocarbon Dating Laboratory}

4985 S.W.74th Court, Miami, Florida 33155・Tel: (305)667-5167•Fax: (305)663-0964 -E-Mail: beta@radiocarbon.com 


\section{CALIBRATION OF RADIOCARBON AGE TO CALENDAR YEARS}

(Variables: C13/C12=-25.6:lab. mult $=1$ )

Laborato ry num ber: Beta-204912

Conventional radiocarbon age: $150 \pm 40 \mathrm{BP}$

2 Sigma calibrated result: Cal AD 1660 to 1950 (Cal BP 290 to 0)

( $95 \%$ p robability)

In terc ep t data

Intercepts of radiocarbon age

with calibration curve:

Cal AD 1680 (Cal BP 270) and

Cal AD 1740 (CalBP 210) and

Cal AD 1810 (Ca1 BP 140) and

$\mathrm{Cal}$ AD 1930 (Cal BP 20) and

Cal AD 1950 (Ca1BP 0)

1 Sigma calibrated results: $\mathrm{Cal} A \mathrm{AD} 1670$ to 1700 (Cal BP 280 to 250) and

(68\% probability) Cal AD 1720 to 1780 (Cal BP 230 to 170 ) and

Cal AD 1800 to 1820 (Cal BP 150 to 130$)$ and

Cal AD 1840 to 1880 (Cal BP 110 to 70 ) and

$\mathrm{Cal}$ AD 1920 to 1950 (Cal BP 30 to 0 )

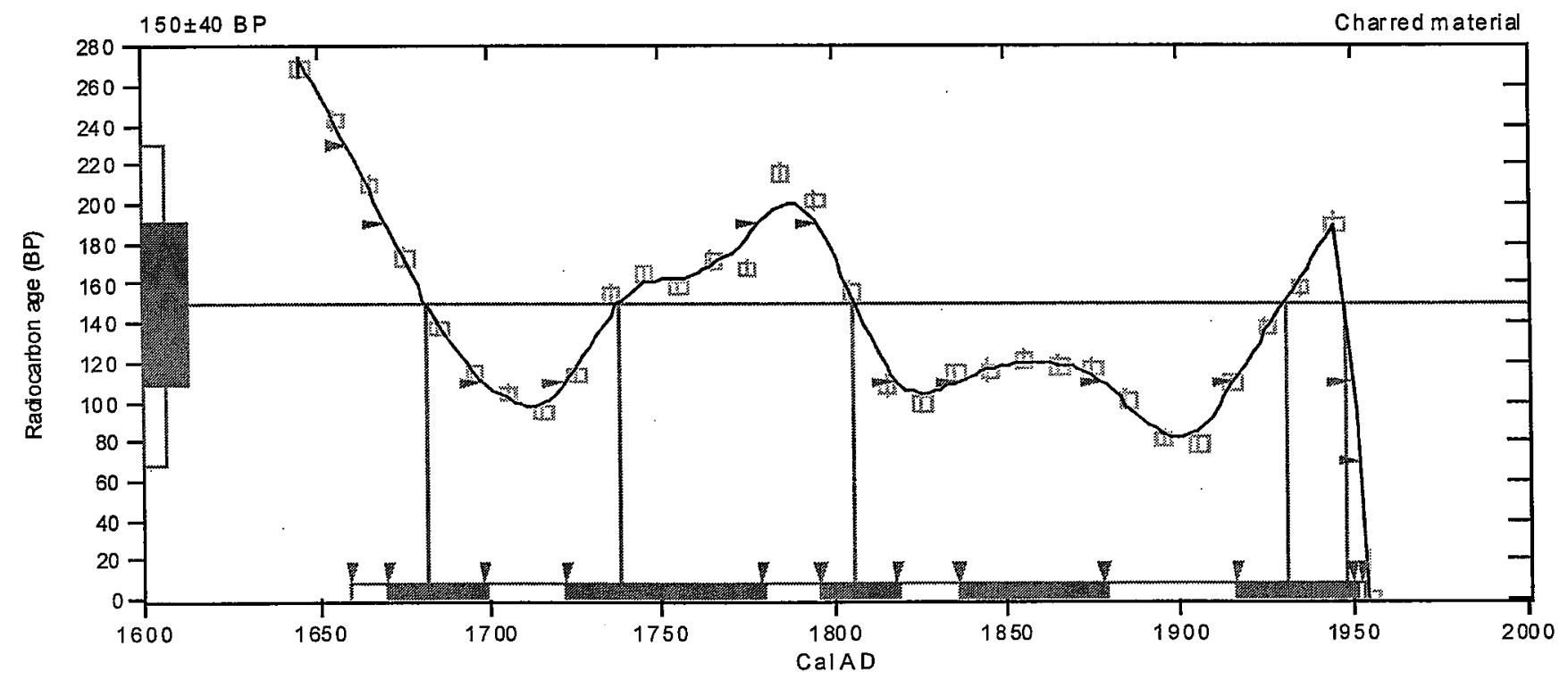

References:

Database u sed

INTC AL 98

Calibration Database

Editorial Comm ent

Stuiver, $M_{.,}$van der Plicht, $H ., 1998$, Radi ocarbon 40(3), pxii-xi ii

INTCAL 98 Radiocarbon Age Calibration

Stuiver, M., et. al., 1998, Radiocarbon 40(3), p1041-1083

Mathe matics

A Sim plified Approach to Calibrating C14 Dates

T alma, A. S., Vogel, J. C., I993, Radiocarbon 35(2), p317-322 


\section{CALIBRATION OF RADIOCARBON AGE TO CALENDAR YEARS}

(Variables: C13/C12=-26:lab. mult $=1$ )

Laborato ry number: Beta-204913

\section{Conventio nal radiocarbon age: $2360 \pm 40 \mathrm{BP}$}

2 Sigma calib rated result: Cal BC 520 to 380 (Cal BP 2460 to 2330) (95\% probability)

\section{In tercept data}

Intercept of radiocarbon age with calibration curve:

Cal BC 400 (Cal BP 2350)

1 Sigma calibrated result: Cal BC 410 to 390 (Cal BP 2360 to 2340)

(68\% probability)

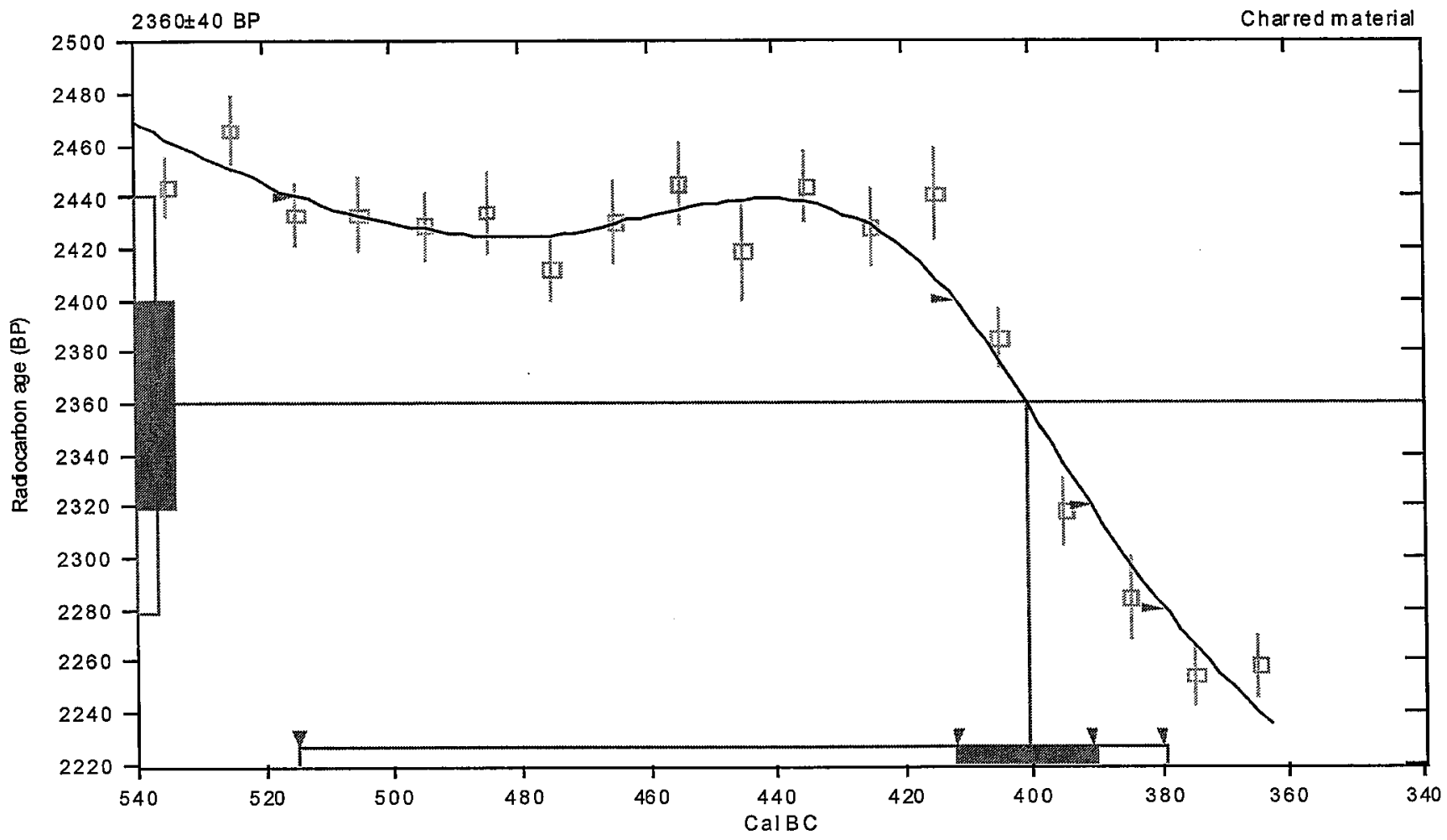

References:

Database used

INTC AL 98

Calibration Database

Editorial Comm ent

Stuiver, M., vander Plicht, $H ., 1998$, Radiocarbon 40(3), pxii-xi ii

INTCAL 98 Radiocarbon Age Cal ibration

Stuiver, M., et. al., 1998, Radiocarbon 40(3), p1041-1083

Mathe matics

A Simplified Approach to Calibrating C14 Dates

Talma, A.S., Vogel, J. C., 1993, Radiocarbon 35(2), p317-322 


\section{CALIBRATION OF RADIOCARBON AGE TO CALENDAR YEARS}

(Variables: C13/C12=-17.8:1ab. mult=1)

La borato ry num ber: Beta-205059

Conventional radiocarbon age: $1530 \pm 70 \mathrm{BP}$

2 Sigma calib rated result: Cal AD 400 to 650 (C al BP 1550 to 1300) ( $95 \%$ probability)

In tercept data

Intercept of radioc arbon age

with calibration curve: Cal AD 540 (Cal BP 1410)

1 Sigma calibrated result: Cal AD 430 to 620 (Cal BP 1520 to 1330 )

(68\% probability)

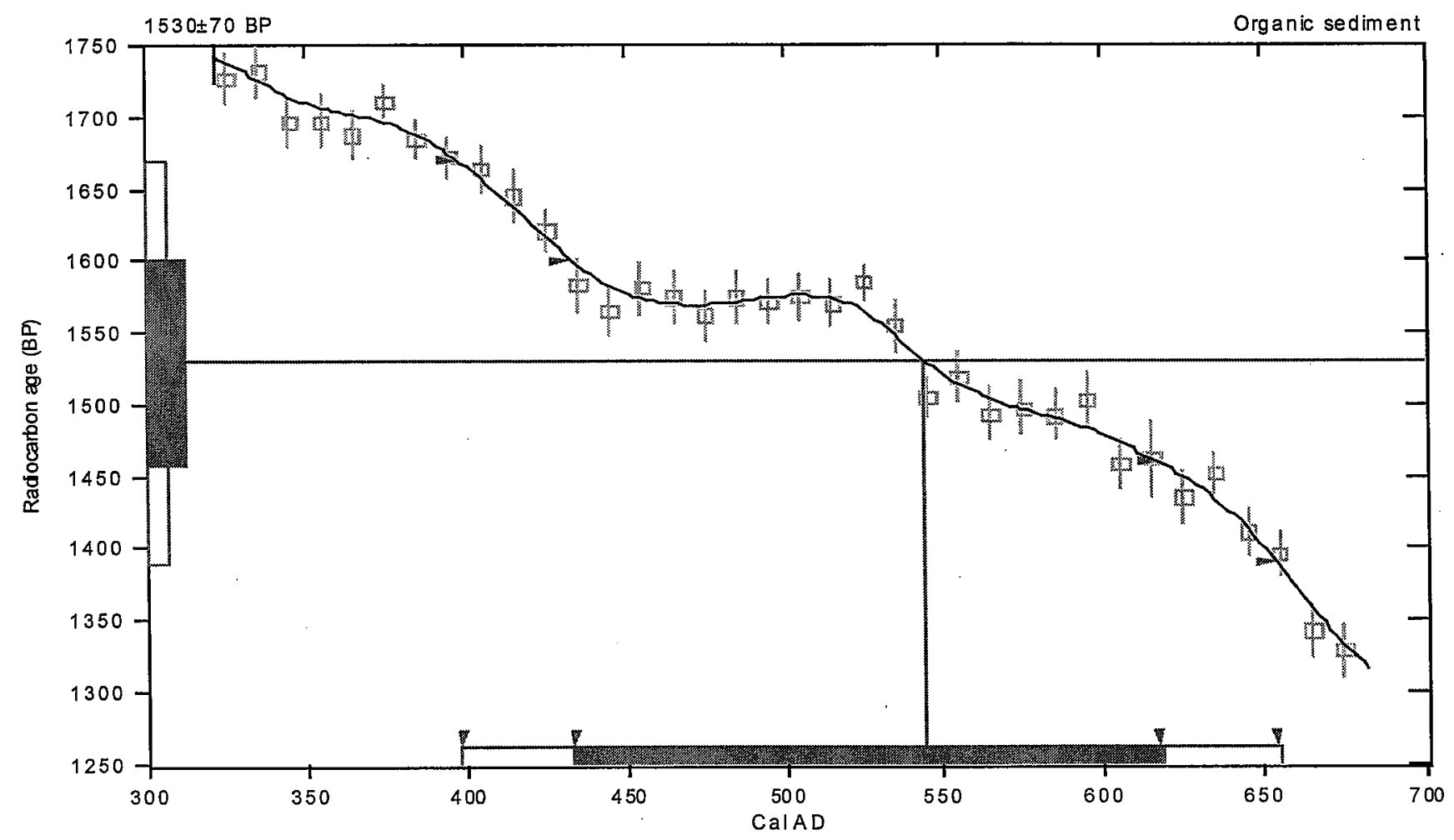

References:

Database used

INTC AL 98

Calibration Database

Editorial Comm ent

Stui ver, M., van der Plicht, $H ., 1998$, Radi oc arb on 40(3), pxii-xi ii

INTCAL98 Radiocarbon Age Calibration

Stuiver, M., et. al., 1998, Radiocarbon 40(3), p1041-1083

Mathe matics

A Simpl ified Approach to Calibrating C14 Dates

Talma, A.S., Vogel, J. C., 1993, Radiocarbon 35(2), p317-322

\section{Beta Analytic Radiocarbon Dating Laboratory}

4985 S.W.74th Court, Miami, Florida $33155 \cdot$ Tel: (305)667-5167 - Fax: (305)663-0964 - E-Mail: beta@radio carbon.com 


\section{CALIBRATION OF RADIOCARBON AGE TO CALENDAR YEARS}

\section{(Variables: C 13/C12 $=-17.5:$ lab. mult $=1$ )}

Laborato ry number: Beta-205060

\section{Conventio nal radiocarbon age: $860 \pm 70 \mathrm{BP}$}

2 Sigma calib rated result: Cal AD 1020 to 1280 (Cal BP 930 to 670) (95\% probability)

In tercept data

Intercept of radiocarbon age

with calibration curve: Cal AD 1190 (Cal BP 760)

1 Sigma calibrated results: Cal AD 1050 to 1100 (Cal BP 900 to 850 ) and (68\% probability) Cal AD 1140 to 1260 (Cal BP 810 to 690 )

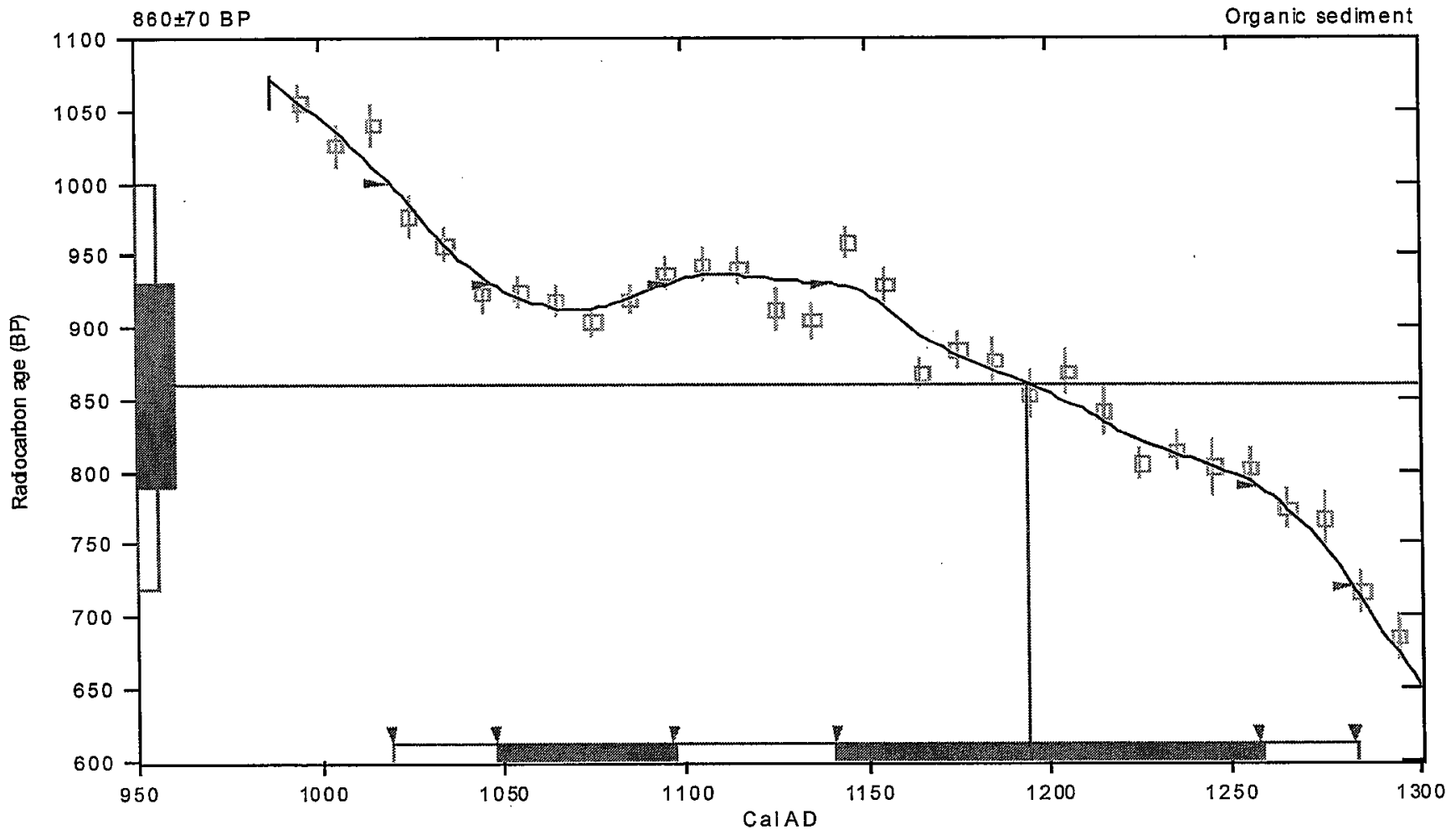

References:

Database u sed INTC AL 98

Calibration Database

Editorial Comm ent

Stuiver, M., vander Plicht, H., 1998, Radiocarbon 40(3), pxii-xi ii

INTCAL 98 Radiocarbon Age Calibration

Stuiver, M., et. al., 1998, Radiocarbon 40(3), p1041-1083

Mathe matics

A Simplified Approach to Calibrating C14 Dates

Talma, A. S., Vogel, J. C., 1993, Radiocarbon 35(2), p317-322

\section{Beta Analytic Radiocarbon Dating Laboratory}




\section{CALIBRATION OF RADIOCARBON AGE TO CALENDAR YEARS}

(Variables: C 13/C12=-22.3:lab. mult=1)

Laborato ry num ber: Beta-205061

Conventional radiocarbon age: $2910 \pm 60 \mathrm{BP}$

2 Sigma calib rated result: Cal BC 1290 to 920 (Ca I BP 3240 to 2870)

(95\% probability)

$$
\text { In terc ep } t \text { data }
$$

Intercept of radiocarbon age

with calibration curve:

1 Sigma calibrated result: Cal BC 1200 to 1000 (Cal BP 3150 to 2950)

(68\% probability)

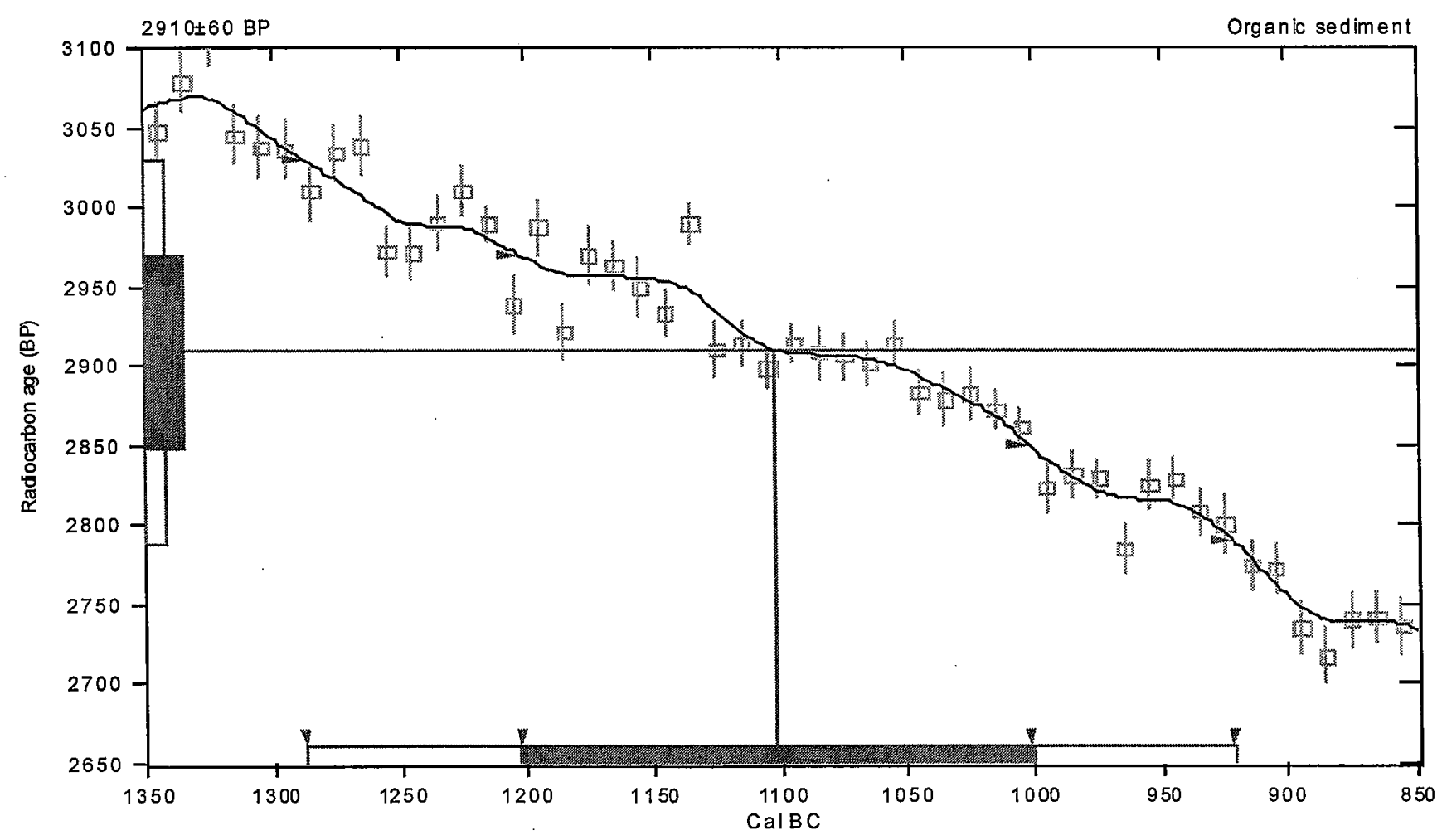

References:

Database used

INTC AL 98

Calibration Database

Editorial Comm ent

Stuiver, $M .$, vander Plicht, $H ., 1998$, Radiocarbon 40(3), pxii-xi ii

INTCAL 98 Radiocarbon Age Calibration

Stuiver, M., et. al., 1998, Radiocarbon 40(3), p1041-1083

Mathe matics

A Simplified Approach to Calibrating C14 Dates

Talma, A. S., Vogel, J. C., 1993, Radiocarbon 35(2), p317-322

\section{Beta Analytic Radiocarbon Dating Laboratory}

4985 S.W.74th Court, Miami, Florida $33155 \cdot$ Tel: (305)667-5167·Fax: (305)663-0964 - E-Mail: beta@radiocarbon.com 


\section{CALIBRATION OF RADIOCARBON AGE TO CALENDAR YEARS}

(Variables: C13/C12=-16.9:1ab. mult=1)

Laborato ry number: Beta-205062

Conventio nal radiocarbon age: $2300 \pm 50 \mathrm{BP}$

2 Sigma calibrated results: Cal BC 410 to 350 (Cal BP 2360 to 2300) and (95\% probability) Cal BC 310 to 210 (Cal BP 2260 to 2160)

In tercept data

Intercept of radiocarbon age

with calibration curve: Cal BC 390 (Cal BP 2340)

1 Sigma calibrated result: Cal BC 400 to 370 (Cal BP 2350 to 2320)

(68\% probability)

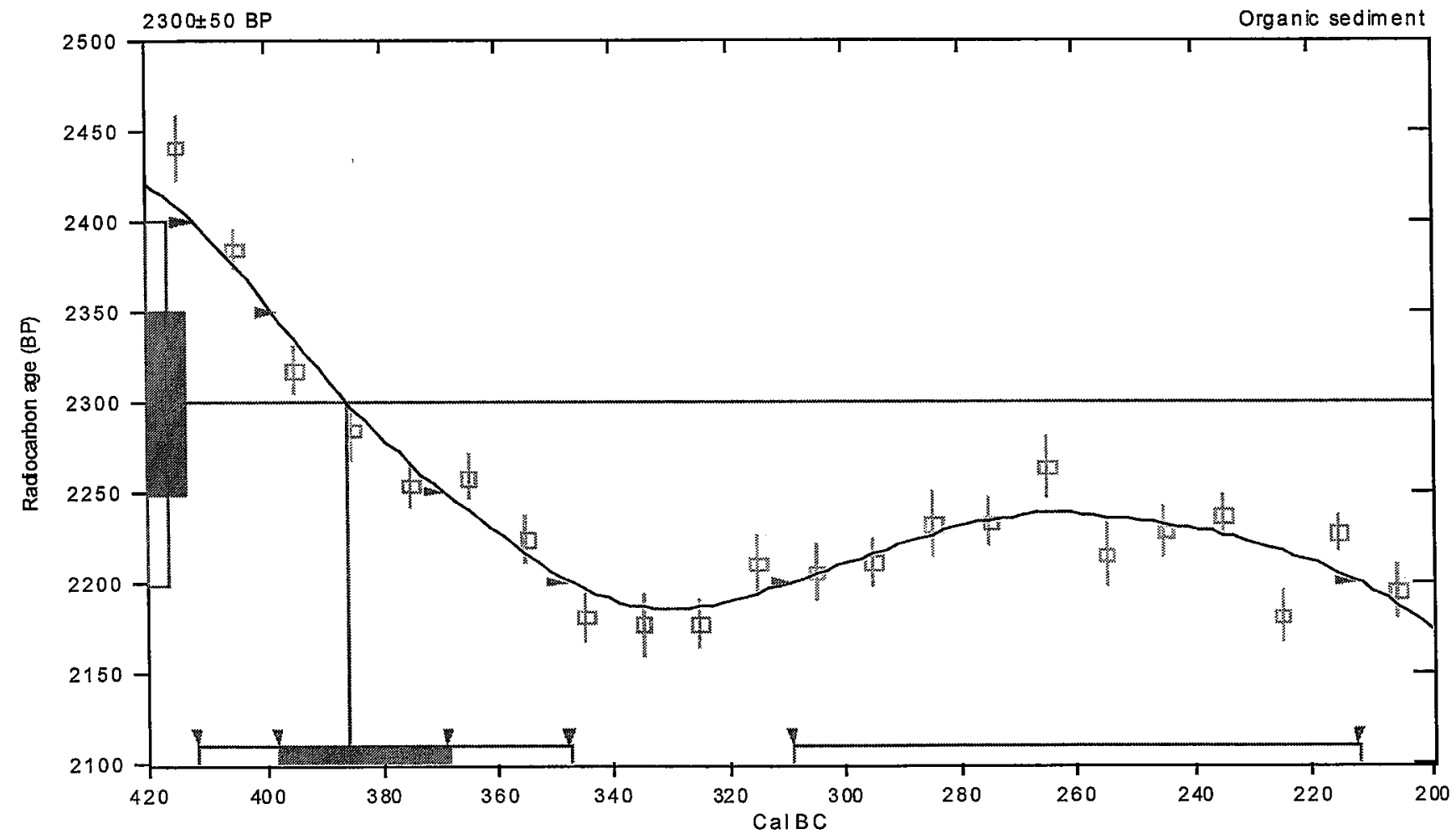

References:

Database used

INTC AL 98

Calibration Database

Editorial Comm ent

Stuiver, $M .$, vander Plicht, $H ., 1998$, Radiocarbon 40(3), pxii-xi ii

INTCAL98 Radiocarbon Age Cal ibration

Stuiver, M., et. al., 1998, Radiocarbon 40(3), p1041-1083

Mathe matics

A Simplified Approach to Calibrating C14 Dates

Talma, A.S., Vogel, J. C., 1993, Radiocarbon 35(2), p317-322

\section{Beta Analytic Radiocarbon Dating Laboratory}

4985 S.W.74th Court, Miami, Florida 33155・Tel: (305)667-5167・Fax:(305)663-0964・E-Mail: beta@radiocarbon.com 


\section{CALIBRATION OF RADIOCARBON AGE TO CALENDAR YEARS}

(Variables: C13/C12 $=-16.2:$ lab. mult $=1$ )

La borato ry num ber: Beta-205063

Conventio nal radiocarbon age: $1240 \pm 40 \mathrm{BP}$

2 Sigma calib rated result: Cal AD 680 to 890 (Cal BP 1270 to 1060) (95\% probability)

In tercept data

Intercept of radioc arbon age with calibration curve: Cal AD 780 (Cal BP 1170)

1 Sigma calibrated results: Cal AD 710 to 810 (Cal BP 1240 to 1140 ) and (68\% probability) Cal AD 840 to 860 (Cal BP 1110 to 1100 )

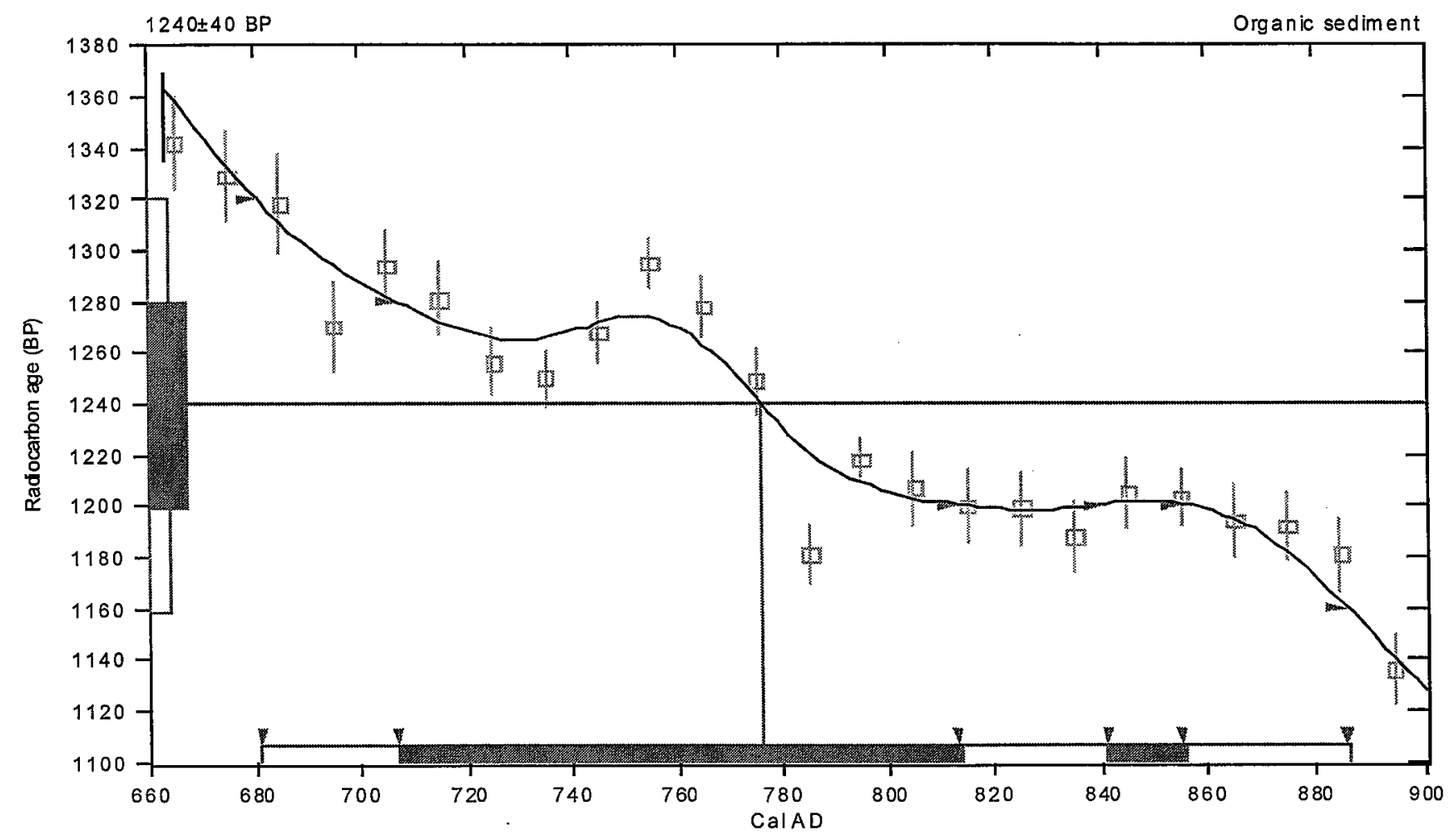

References:

Database u sed INTC AL 98

Calibration Database

Editorial Comm ent

Stuiver, M., vander Plicht, $H ., 1998$, Radiocarbon 40(3), pxii-xi ii

INTCAL 98 Radiocarbon Age Cal ibration

Stuiver, M., et. al., 1998, Radiocarbon 40(3), p1041-1083

Mathe matics

A Simplified Approach to Calibrating C14 Dates

Talma, A.S., Vogel, J. C., 1993, Radiocarbon 35(2), p317-322

\section{Beta Analytic Radiocarbon Dating Laboratory}

4985 S.W.74th Court, Miami, Florida $33155 \cdot$ Tel: (305)667-5167 F ax: (305)663-0964 - E-Mail: beta@radiocarbon.com 